\title{
Pilot Residential Deep Energy Retrofits and the PNNL Lab Homes
}
S Chandra
D Stroer
$S$ Widder
J Mcllvaine
G Parker
D Chasar
S Sande
D Beal
J Blanchard
K Sutherland

January 2012

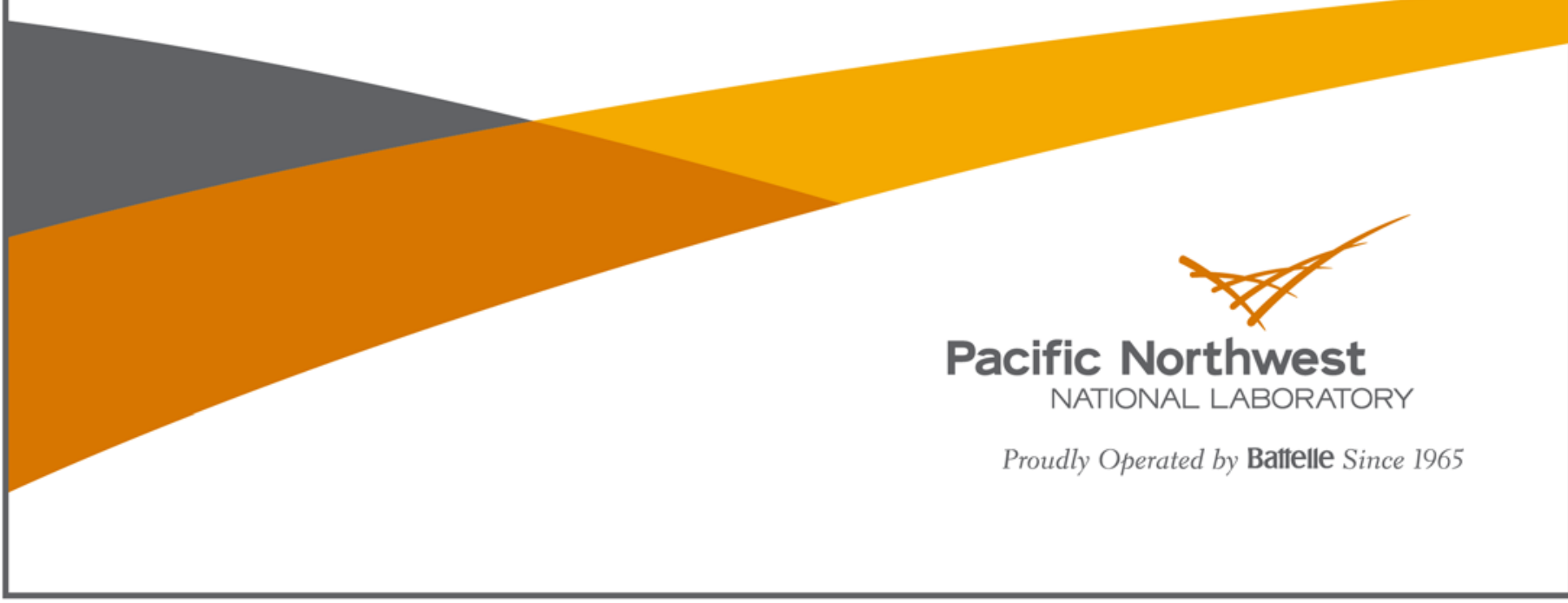




\title{
DISCLAIMER
}

This report was prepared as an account of work sponsored by an agency of the United States Government. Neither the United States Government nor any agency thereof, nor Battelle Memorial Institute, nor any of their employees, makes any warranty, express or implied, or assumes any legal liability or responsibility for the accuracy, completeness, or usefulness of any information, apparatus, product, or process disclosed, or represents that its use would not infringe privately owned rights. Reference herein to any specific commercial product, process, or service by trade name, trademark, manufacturer, or otherwise does not necessarily constitute or imply its endorsement, recommendation, or favoring by the United States Government or any agency thereof, or Battelle Memorial Institute. The views and opinions of authors expressed herein do not necessarily state or reflect those of the United States Government or any agency thereof.

\author{
PACIFIC NORTHWEST NATIONAL LABORATORY \\ operated by \\ BATTELLE \\ for the \\ UNITED STATES DEPARTMENT OF ENERGY \\ under Contract DE-AC05-76RL01830
}

Printed in the United States of America

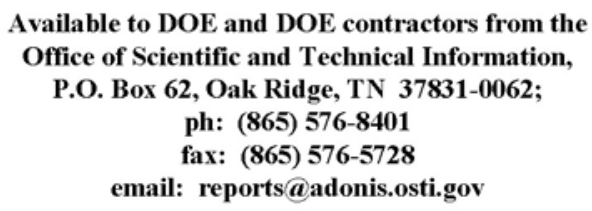

Available to the public from the National Technical Information Service 5301 Shawnee Rd., Alexandria, VA 22312 ph: (800) 553-NTIS (6847) email: orders@ntis.gov <http://www.ntis.gov/about/form.aspx> Online ordering: http://www.ntis.gov 


\title{
Pilot Residential Deep Energy Retrofits and the PNNL Lab Homes
}

\author{
S Chandra $^{1} \quad$ D Stroer $^{2}$ \\ S Widder $^{1} \quad$ J Mcllvaine $^{3}$ \\ G Parker ${ }^{1} \quad$ D Chasar ${ }^{3}$ \\ S Sande $^{1} \quad$ D Beal $^{3}$ \\ J Blanchard $^{1} \quad$ K Sutherland ${ }^{3}$
}

January 2012

Prepared for

the U.S. Department of Energy

under Contract DE-AC05-76RL01830

Pacific Northwest National Laboratory

Richland, Washington 99352

\footnotetext{
${ }^{1}$ Pacific Northwest National Laboratory, Richland, Washington

${ }^{2}$ Calcs Plus, Venice, FL

${ }^{3}$ FSEC, a research institute of the University of Central Florida, Cocoa, FL
} 



\section{Summary}

This report summarizes research investigating the technical and economic feasibility of several pilot deep energy retrofits, or retrofits that save $30 \%$ to $50 \%$ or more on a whole-house basis while increasing comfort, durability, combustion safety, and indoor air quality. The work is being conducted for the U.S. Department of Energy Building Technologies Program as part of the Building America Program.

As part of the overall program, Pacific Northwest National Laboratory (PNNL) researchers are collecting and analyzing a comprehensive dataset that describes pre- and post-retrofit energy consumption, retrofit measure cost, health and comfort impacts, and other pertinent information for each home participating in the study. The research and data collection protocol includes recruitment of candidate residences, a thorough test-in audit, home energy modeling, and generation of retrofit measure recommendations, implementation of the measures, test-out, and continued evaluation. On some homes, more detailed data will be collected to disaggregate energy-consumption information.

This multi-year effort began in October 2010. To date, the PNNL team has performed test-in audits on 51 homes in the marine, cold, and hot-humid climate zones, and completed 3 retrofits in Texas, 10 in Florida, and 2 in the Pacific Northwest. Two of the retrofits are anticipated to save $50 \%$ or more in energy bills and the others' savings are in the $30 \%$ to $40 \%$ range. Fourteen other retrofits are under way in the three climate zones. Metering equipment has been installed in seven of these retrofits - three in Texas, three in Florida, and one in the Pacific Northwest.

This report provides information on the research protocol and status of the PNNL deep energy retrofit project as of December, 2011. The report also presents key findings and lessons learned, based on the body of work to date.

In addition, the report summarizes the status of the PNNL Lab Homes that are new manufactured homes procured with minimal energy-efficiency specifications typical of existing homes in the region, and sited on the PNNL campus. The Lab Homes serve as a flexible test facility (the first of its kind in the

Pacific Northwest) to rapidly evaluate energy-efficient and grid-smart technologies that are applicable to residential construction. 



\section{Acknowledgments}

The authors acknowledge the guidance and support of David Lee, Terry Logee, Eric Werling, Sam Rashkin, and Chris Early of the U.S. Department of Energy Building Technologies Program in sponsoring this work and providing helpful feedback.

The team is most appreciative of the homeowners who are choosing to invest in the energy performance and comfort of their homes and decided to participate in this study. This work would not be possible without these motivated individuals who have opened up their homes to the research team, answered numerous questions, and shown incredible patience in participating in the research study.

The team appreciates the encouragement and support from Michael Baechler, senior program manager at PNNL, who received the initial funding for this work. Thanks also to our line managers Sean McDonald and Todd Samuel for helping us whenever we asked.

The PNNL research team was assisted by Lori Sanders of Energy Incentives, Inc., Jonathan Cohen of Imagine Energy, Greg Sullivan of Efficiency Solutions, Brady Peeks and Tom Hewes of Northwest Energy Works, Paul Kriescher of Lightly Treading, and Steve Peebles of All Good Energy. We thank Roderick Jackson of the Oak Ridge National Laboratory who led the ORNL work in the Metro Atlanta, Georgia, and provided helpful data and feedback; Lieko Earle, National Renewable Energy Laboratory, who contributed on a home in Denver; Brent Singer, Lawrence Berkeley National Laboratory, who provided input on the indoor air-quality monitoring approach; and researchers from the Florida Solar Energy Center who shared the occupancy simulation protocols being used at the Lab Homes there.

The authors are also grateful to the capable team of PNNL researchers who assisted in data collection, retrofit coordination, modeling, and data analysis efforts, including James Hand, Nathan Bauman, JJ Jenks, and Vrushali Mendon. Thanks also to Susan Ennor and Mike Parker with PNNL Communications Services, who provided editorial expertise.

Finally, this report is compiled in honor and memory of Subrato Chandra. This research would not have been possible without his vision, motivation, guidance, and individual effort. Subrato devoted most of his professional life to the pursuit of energy efficient residential housing and this report summarizes some of his final work. 



\section{Acronyms and Abbreviations}

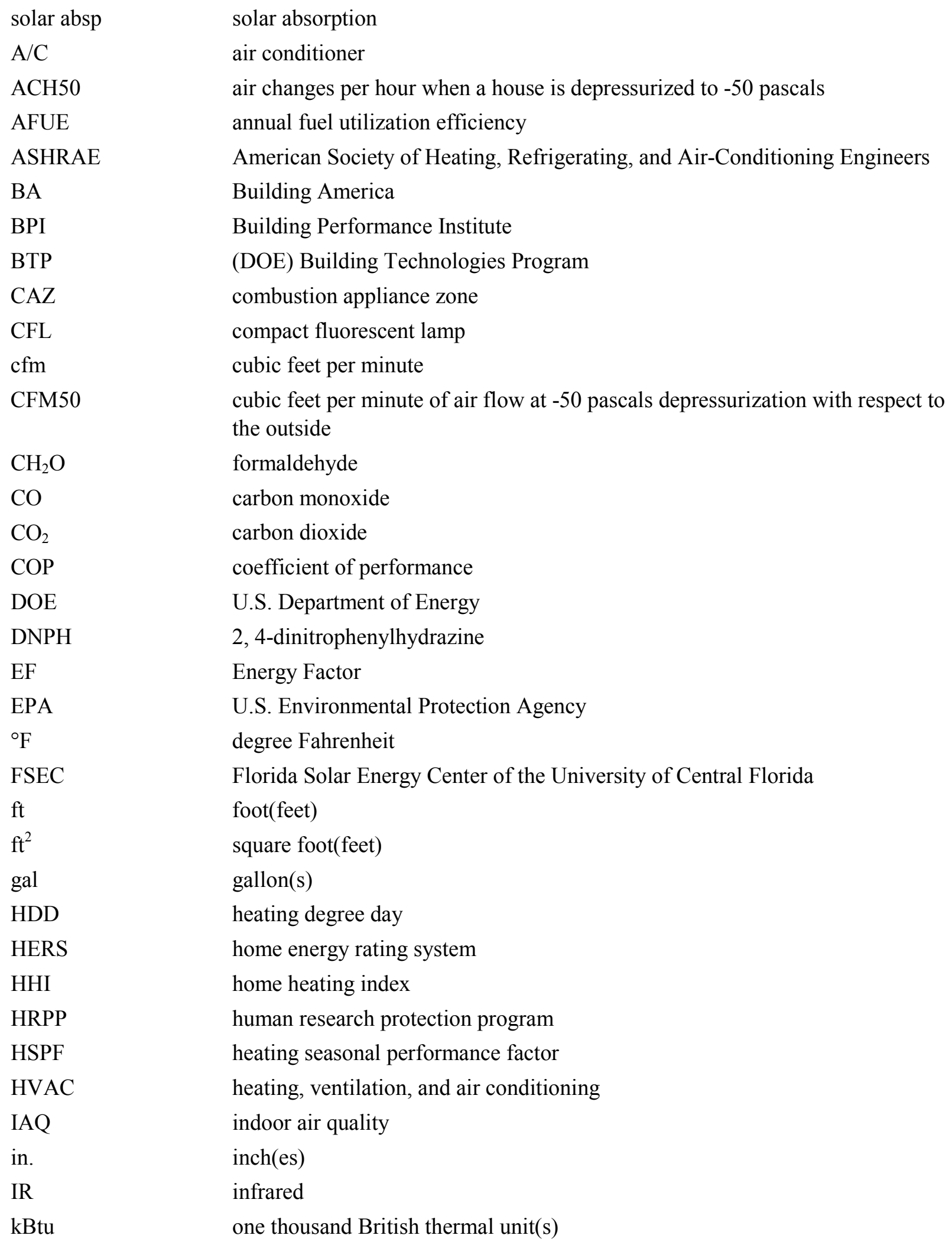

kBtu

air changes per hour when a house is depressurized to -50 pascals annual fuel utilization efficiency

American Society of Heating, Refrigerating, and Air-Conditioning Engineers

Building America

Building Performance Institute

(DOE) Building Technologies Program

combustion appliance zone

compact fluorescent lamp

cubic feet per minute

cubic feet per minute of air flow at -50 pascals depressurization with respect to the outside

formaldehyde

carbon monoxide

carbon dioxide

coefficient of performance

U.S. Department of Energy

2, 4-dinitrophenylhydrazine

Energy Factor

U.S. Environmental Protection Agency

degree Fahrenheit

Florida Solar Energy Center of the University of Central Florida

foot(feet)

square foot(feet)

gallon(s)

heating degree day

home energy rating system

home heating index

human research protection program

heating seasonal performance factor

heating, ventilation, and air conditioning

indoor air quality

inch(es)

infrared

one thousand British thermal unit(s) 


\begin{tabular}{|c|c|}
\hline $\mathrm{kW}$ & kilowatt(s) \\
\hline $\mathrm{kWh}$ & kilowatt-hour(s) \\
\hline LBNL & Lawrence Berkeley National Laboratory \\
\hline $\mathrm{m}$ & meter(s) \\
\hline $\mathrm{m}^{2}$ & square meters \\
\hline MBtu & Million British thermal units \\
\hline NA & not available or not applicable \\
\hline $\mathrm{NO}_{\mathrm{x}}$ & nitrogen oxides \\
\hline ORNL & Oak Ridge National Laboratory \\
\hline $\mathrm{Pa}$ & $\operatorname{pascal}(\mathrm{s})$ \\
\hline PID & photo-ionization detector \\
\hline PM & particulate matter \\
\hline $\mathrm{PM}_{2.5}$ & particulate matter with an aerodynamic diameter of 2.5 microns or less \\
\hline PNNL & Pacific Northwest National Laboratory \\
\hline POC & point of contact \\
\hline ppm & parts per million \\
\hline $\mathrm{QA} / \mathrm{QC}$ & Quality Assurance/Quality Control \\
\hline $\mathrm{R}^{2}$ & coefficient of determination of a linear regression \\
\hline RESNET & Residential Energy Services Network \\
\hline RH & relative humidity \\
\hline SEER & Seasonal Energy Efficiency Ratio \\
\hline SHGC & Solar Heat Gain Coefficient \\
\hline $\mathrm{T}$ & temperature $\left({ }^{\circ} \mathrm{F}\right)$ \\
\hline TED & The Energy Detective \\
\hline $\mathrm{TF}$ & TrueFlow \\
\hline TVOC & total volatile organic compound \\
\hline $\mathrm{U}$ & thermal transmittance, Btu $/ \mathrm{hr} / \mathrm{sq} . \mathrm{ft} /{ }^{\circ} \mathrm{F}$ \\
\hline WCD & worst-case depressurization \\
\hline WRT & with respect to \\
\hline $\mathrm{ZEH}$ & zero-energy home \\
\hline
\end{tabular}




\section{Contents}

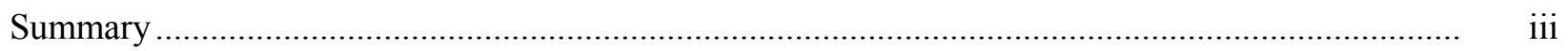

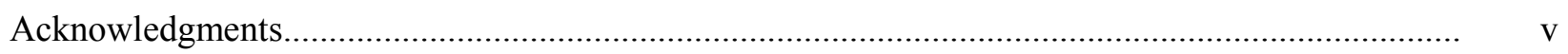

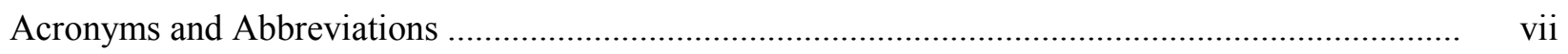

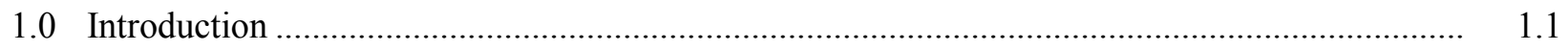

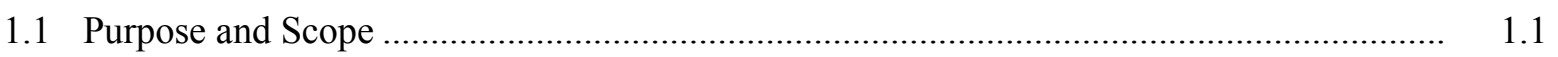

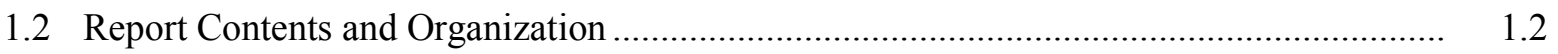

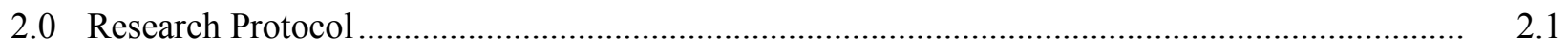

2.1 Recruitment and Home Selection .................................................................................. 2.2

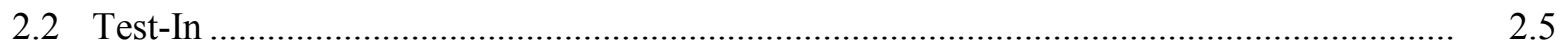

2.2.1 Home Energy Assessment ............................................................................ 2.5

2.2.2 Combustion Safety Testing …........................................................................ 2.7

2.2.3 Indoor Air-Quality Assessment..................................................................... 2.8

2.3 Modeling and Recommending Retrofit Measures............................................................ 2.9

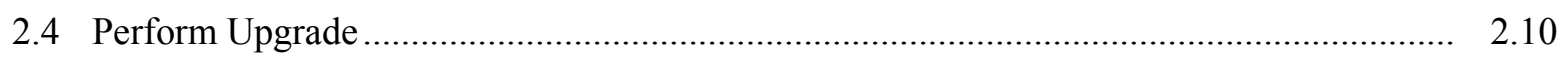

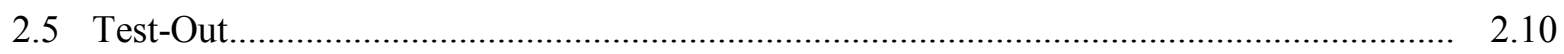

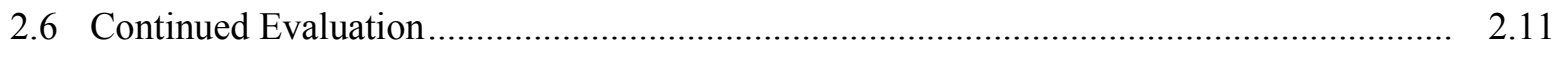

3.0 Current Status and Future Work ..................................................................................

4.0 Key Findings and Lessons Learned ............................................................................

4.1 Difficulty in Achieving Deep Energy Retrofits and Engaging With Homeowners ............ 4.1

4.2 Common Retrofit Measures Implemented in the Pacific Northwest Study Homes ............ 4.2

4.3 Energy Savings and Cost-Effectiveness in the Pacific Northwest .................................... 4.3

4.4 Initial Energy-Savings Data from Metered Homes in the Southeast ............................... 4.4

4.4.1 Atlanta Retrofit Homes .................................................................................. 4.5

4.4.2 San Antonio Retrofit Homes ......................................................................... 4.6

4.4.3 Florida Retrofit Homes............................................................................... 4.8

$5.0 \quad$ PNNL Lab Homes .................................................................................................. 5.1

5.1 Lab Homes Procurement Process, Characteristics, and Status Through December 2011... 5.2

5.2 Instrumentation and Control Systems ..................................................................... 5.3

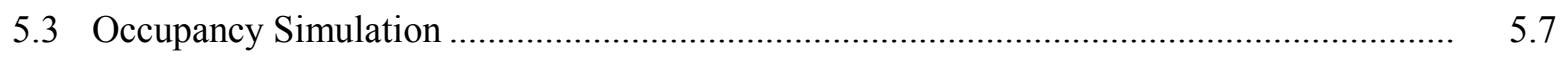

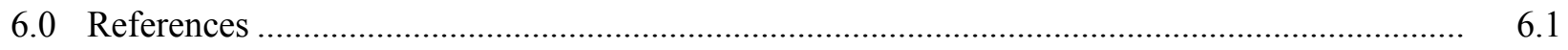

Appendix A - PNNL Research Protocol for Conducting Pilot Deep Energy Retrofits in Residences. A.1

Appendix B - Tri-Fold Brochure ................................................................................... B. 1

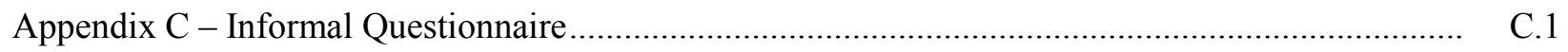

Appendix D - Legal Agreements...................................................................................... D.1

Appendix E - Homeowner Questionnaire …........................................................................... E.1

Appendix F - Home Audit Data Collection Form ..................................................................... F.1

Appendix G - Indoor Air-Quality Procedure …................................................................. G.1 
Appendix H - Calibration Instructions ......................................................................... H.1

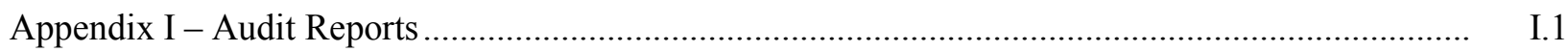

Appendix J - Case Studies of Retrofit Projects ............................................................................. J.1

Appendix K - Completed Retrofits in Florida ....................................................................... K.1 


\section{Figures}

1.1 The PNNL Lab Homes ................................................................................................. 1.2

2.1 Home Page of the Deep Energy Retrofit Website .................................................................. 2.2

2.2 First Page of the Onsite Energy Audit Data Collection Form, Authored by PNNL ................... 2.6

2.3 PNNL Research Staff Conducting a Blower Door Test and Duct Blaster Test......................... 2.7

2.4 Comparison of Monthly Electricity Consumption for Utility Bills and Energy Gauge Model .... 2.10

2.5 Comparison of Existing Home Energy Consumption, Post-Retrofit Estimated or Modeled Energy Consumption, and Actual Energy Consumption and Disaggregated Energy Consumption Data Obtained from Actual Metering.

3.1 Status of Deep Energy Retrofit Homes as of December 15, 2011 ........................................ 3.1

4.1 Dependence of Capital Cost of Retrofit Measures, Normalized Based on the Estimated Energy Cost Savings and Relative Building Envelope Leakage ............................................. 4.3

4.2 Dependence of Payback Period, Including Incentives, of Retrofit Measures with Respect to HHI and Relative Building Envelope Leakage.

4.3 San Antonio Retrofit Cooling Performance Comparison ...................................................... 4.6

4.4 Florida Retrofit Cooling Performance Comparison............................................................ 4.8

5.1 The Lab Homes During Setup in Late September 2011 ..................................................... 5.1

5.2 The Experimental Home in November 2011 Undergoing a Blower Door Test.......................... 5.1

5.3 Experimental Home Exterior IR Scan of West Wall and Sliding Glass Door........................... 5.3

5.4 Baseline Home Exterior IR Scan of West Wall and Sliding Glass Door................................... 5.3

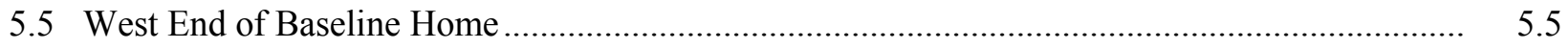

5.6 Window on West End of Experimental Home............................................................... 5.5

5.7 Weather Station on East End of the Experimental Home ....................................................... 5.5

5.8 Conduit Running Parallel to the House Marriage Line.......................................................... 5.5

5.9 Fully Instrumented Electrical Panel with Current Transformers on All 42 Circuits .................. 5.6

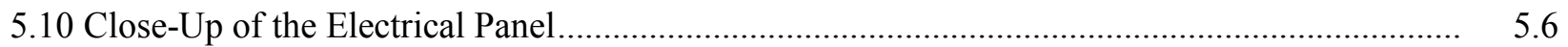

5.11 The Campbell Scientific Data Logger and Termination Panels Used to Measure Electrical Power via Circuit Transducers

5.12 The Second Data Logger Used to Measure Temperature, Humidity, and Other Parameters as Well as Control Functions. .............................................................................................. 5.6

5.13 Internal Loads Imposed at the FSEC Lab Homes Facility for Each Hour of the Day ................. 5.7 


\section{Tables}

2.1 Summary of PNNL Deep Energy Retrofit Research Protocol............................................... 2.1

2.2 Selection Criteria Developed to Determine Home Eligibility and Select Desirable Candidate

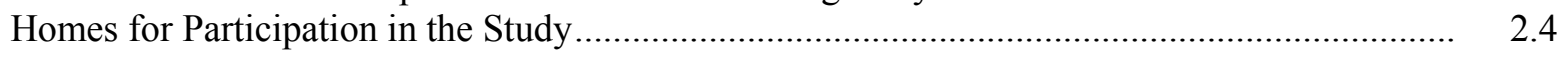

2.3 Combustion Appliance Zone Depressurization Limits ........................................................ 2.8

3.1 Key Characteristics of the 15 PNNL-Led Completed Retrofits................................................. 3.1

4.1 San Antonio Measured Cooling Performance Comparison ..................................................... 4.7

4.2 Florida Measured Cooling Performance Comparison ........................................................... 4.9

5.1 Measured Characteristics of the Lab Homes on November 15, 2011 ...................................... 5.2

5.2 Electrical Metering for Each Home ................................................................................ 5.4

5.3 Temperature, Humidity, and Other Metered Parameters ......................................................... 5.4 


\subsection{Introduction}

Energy use in residential homes has increased over the past several decades and now accounts for $22 \%$ of total energy use in the United States (EIA 2010). Because public desire to decrease overall energy demand is growing (Akerlof et al. 2010), attention is being focused on making the residential sector more energy efficient. During the current downswing in new residential construction (U.S. Census Bureau 2011), retrofitting existing homes to save energy has become the focus of new energy-efficiency programs for the built environment (American Recovery and Reinvestment Act of 2009).

Historically, energy retrofits have occurred on a large scale through state-level weatherization programs and various programs sponsored by electric and gas utilities. These programs have reduced the average annual natural-gas consumption by $20 \%$ to $25 \%$ and whole-house electrical energy by $10 \%$ (Schweitzer 2005; Blasnik 2006, 2007). To advance the state of the art, the U.S. Department of Energy (DOE) Building America (BA) Program has established a goal to achieve even more savings through more aggressive "deep energy retrofits" that reduce energy consumption by $30 \%$ to $50 \%$ or more on a whole-house basis. With more than 115 million existing households in the United States (BEDB 2011), residential energy retrofitting represents a large potential for energy savings. This large potential has led to the formation of numerous incentive programs and rebates by federal, state, and local governments and utilities.

\subsection{Purpose and Scope}

To advance the science and understanding of deep energy retrofits, a team of researchers from the Pacific Northwest National Laboratory (PNNL) partnered with Oak Ridge National Laboratory (ORNL) to demonstrate and provide technical assistance on approximately 50 selected pilot residences in a variety of climate zones. The research team, funded by DOE's BA Program, applied integrated building science and systems engineering principles to determine "what it takes" to achieve energy savings of $30 \%$ to $50 \%$ or more and simultaneously increase the comfort, combustion safety, durability, and indoor air quality (IAQ) of a home. Analysis of the data obtained through this research program will provide powerful information with which to accomplish the following:

- Identify effective strategies to achieve cost-effective deep energy upgrades in different climate zones.

- Understand and quantify the relationship between energy savings and health and safety impacts.

- Characterize the cost of deep energy upgrades as a function of existing home performance.

- Analyze differences between estimated (modeled) and realized energy savings.

- Measure the impact of behavioral components on energy reduction.

- Recognize homeowner motivations and feedback in performing deep energy upgrades.

To achieve these objectives, PNNL researchers are collecting and analyzing a comprehensive dataset that describes pre- and post-retrofit energy consumption, energy-efficiency measure cost, health and comfort impacts, and other pertinent information for each home participating in the study. The research and data collection protocol includes recruitment of candidate residences, a thorough test-in audit, home energy modeling, generation of retrofit measure recommendations, implementation of the measures, testout, and continued evaluation. On some homes, more detailed data will be collected to disaggregate energy-consumption information. Implementation of this research protocol to effectively characterize the pre- and post-retrofit condition of each home is expected to be a multi-year effort, which began in October 2010. 
In addition to the pilot deep energy retrofits effort described above, another major activity undertaken by the PNNL researchers was the procurement of a matched pair of laboratory homes on the PNNL campus in Richland, Washington. The homes arrived in September 2011 (Figure 1.1).

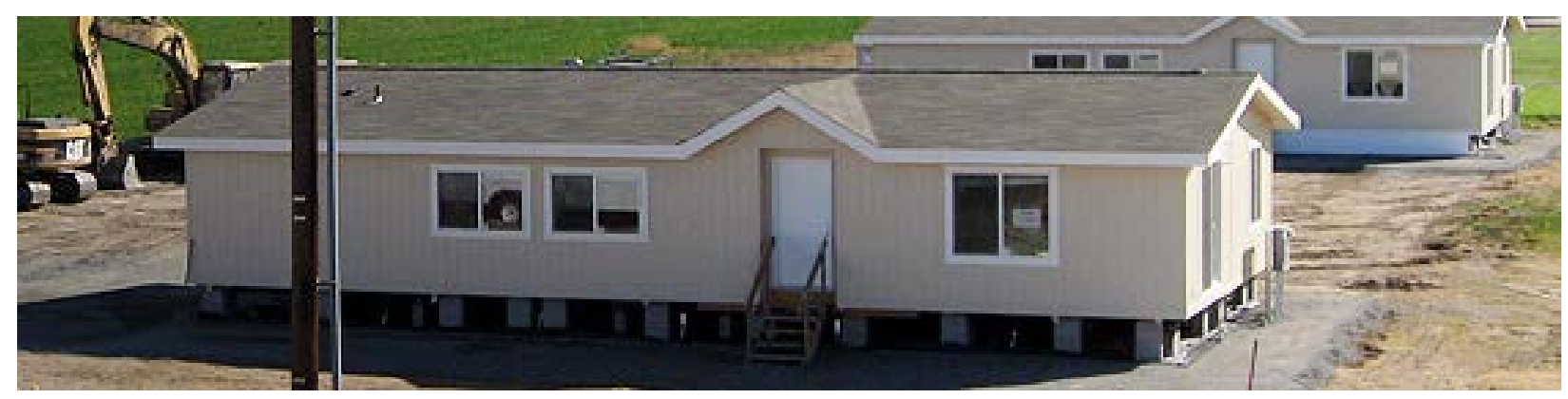

Figure 1.1. The PNNL Lab Homes

The Lab Homes (http://labhomes.pnnl.gov/) are new manufactured homes procured with minimal energy-efficiency specifications typical of existing homes in the region. The Lab Homes are intended to serve as a flexible test facility (the first of its kind in the Pacific Northwest) to rapidly evaluate energyefficient and grid-smart technologies that are applicable to retrofit and new construction. In addition to BA funding, the Lab Homes received funding from DOE Office of Building Technologies Fenestrations R\&D, DOE Office of Electricity and Energy Reliability, the Bonneville Power Administration, and others.

\subsection{Report Contents and Organization}

This report summarizes the status and findings of the research conducted through December 2011. The ensuing sections present a detailed discussion of the PNNL team's research protocol, the current status of residential retrofits participating in the program, key findings based on the research conducted to date, and lessons learned. This interim report is designed to provide a research update to DOE Building Technologies Program (BTP) staff, program managers, and other interested parties. The report focuses primarily on the efforts of the PNNL team in the marine, cold, and hot-humid climates and does not discuss the research conducted by ORNL researchers. The ORNL research and results are summarized in a separate report (Jackson et al. 2011). The Lab Homes activities through December 2011 are described in Section 5.0 of this report. Additional research-related material, including PNNL's research protocol, deep energy retrofit information, homeowner questionnaires, homeowner and research agreements, building measurements and testing, the procedure for air sampling in retrofit homes, instructions for calibrating models, audit reports, case studies of retrofit projects, and completed retrofits in Florida are provided in Appendixes A through K. 


\subsection{Research Protocol}

To address the pilot deep energy retrofit research objectives, the PNNL team drafted a detailed research protocol in the fall of 2010, which was reviewed and approved by the PNNL Institutional Review Board in January 2011. The research protocol consists of five phases and describes the specific methods and data to be collected during each phase, as summarized in Table 2.1. The complete protocol is included in Appendix A. Please note that this protocol was developed for owner-occupied homes. It turned out that for a significant number of homes in this study (primarily in Florida) the homes were foreclosed before retrofits were accomplished. In some other homes (primarily the Texas homes) the scope was generally established before the PNNL BA team became involved. For those homes, PNNL partners bought and retrofitted them with non-BA funds. The PNNL team performed only a part of the protocol for these homes.

Table 2.1. Summary of PNNL Deep Energy Retrofit Research Protocol

\begin{tabular}{|c|c|}
\hline Activity & Data Collected \\
\hline \multicolumn{2}{|l|}{ Phase I: Recruitment and Home Selection } \\
\hline $\begin{array}{l}\text { - Determine home selection criteria and } \\
\text { recruitment methods. }\end{array}$ & Not applicable \\
\hline $\begin{array}{l}\text { - Respond to, interview, and confirm } \\
\text { candidate homeowners. }\end{array}$ & $\begin{array}{l}\text { Homeowner informational questionnaire communicating } \\
\text { participant interest, confirmation of homeowner commitment via } \\
\text { metering and homeowner agreements. }\end{array}$ \\
\hline \multicolumn{2}{|l|}{ Phase II: Test-In } \\
\hline $\begin{array}{l}\text { - Conduct preliminary home performance } \\
\text { assessment and homeowner interview. }\end{array}$ & $\begin{array}{l}\text { Age and condition of home, blower door depressurization test } \\
\text { results, duct leakage test results, combustion test results, air } \\
\text { handler flow and pressure test results, indoor air-quality test } \\
\text { results, homeowner schedule and other behavioral data, and } \\
\text { historical utility data. }\end{array}$ \\
\hline $\begin{array}{l}\text { - Generate model based on home audit } \\
\text { information in one or more software } \\
\text { programs (Energy Gauge, REMRate, and } \\
\text { BEopt) and develop recommendations. }\end{array}$ & $\begin{array}{l}\text { Modeled energy savings of each recommended upgrade measure } \\
\text { and total savings of upgrade package. Approximate costs and } \\
\text { paybacks for upgrades. }\end{array}$ \\
\hline \multicolumn{2}{|l|}{ Phase III: Perform Upgrade } \\
\hline $\begin{array}{l}\text { - Work with subcontractor(s) to verify } \\
\text { quality assurance/quality control of } \\
\text { installed upgrade measures. }\end{array}$ & $\begin{array}{l}\text { Document measure installation, scope of work, cost for each } \\
\text { measure or measure package. This information can contribute to } \\
\text { the BTP Resource Tool and National Measures Database. }\end{array}$ \\
\hline \multicolumn{2}{|l|}{ Phase IV: Test-out } \\
\hline $\begin{array}{l}\text { - Perform post-upgrade home performance } \\
\text { assessment to measure level of savings } \\
\text { achieved. }\end{array}$ & Same as for test-in audit \\
\hline \multicolumn{2}{|l|}{ Phase V: Continued Evaluation } \\
\hline $\begin{array}{l}\text { - Perform continued energy and IAQ } \\
\text { monitoring and/or bill analysis }\end{array}$ & $\begin{array}{l}\text { Actual realized energy savings, changes in indoor comfort and } \\
\text { health parameters, changes in the relative contribution to total } \\
\text { energy consumption of different components. Some of the homes } \\
\text { are metered to measure the electrical energy use of the whole } \\
\text { house and between } 3 \text { to } 11 \text { other major end-use circuits. Interior } \\
\text { temperature and relative humidity (RH) also are measured. }\end{array}$ \\
\hline $\begin{array}{l}\text { - Issue follow-up questionnaire regarding } \\
\text { outcome. }\end{array}$ & Homeowner opinion regarding upgrade outcome \\
\hline
\end{tabular}


Each of these research phases, the data collection methods, data gathered during the phase, and outcomes are discussed in the following sections.

\subsection{Recruitment and Home Selection}

The first step in implementing a deep energy retrofit research program is recruiting homeowners or institutions interested in pursuing a deep energy retrofit. In the Pacific Northwest, a number of recruitment strategies were pursued, including newsletter postings, emails to colleagues, and creation of informational and marketing material. All of these recruitment strategies were focused on contacting independent homeowners. Although working with many private homeowners has challenges with regard to funding, schedules, and coordination, the research team believes the lessons learned from this strategy are necessary to informing a successful large-scale deep energy retrofit program. In hot-humid climates, in addition to homeowners, existing program partners such as Habitat for Humanity affiliates in Florida or Build San Antonio Green (a non-profit organization in San Antonio, Texas) worked with PNNL researchers to accomplish deep energy retrofits, where construction and energy retrofit funding came from non-BA sources but not from the homeowners.

The key central coordination point of this grassroots recruitment campaign is an informational website, http://deepenergyretrofits.pnnl.gov, created by the research team. The home page of this website is shown in Figure 2.1. As the research proceeds, the website will be updated to provide information about the status of the retrofits, reports, and best practices developed as a result of this study, and other resources for homeowners interested in a comprehensive retrofit approach.

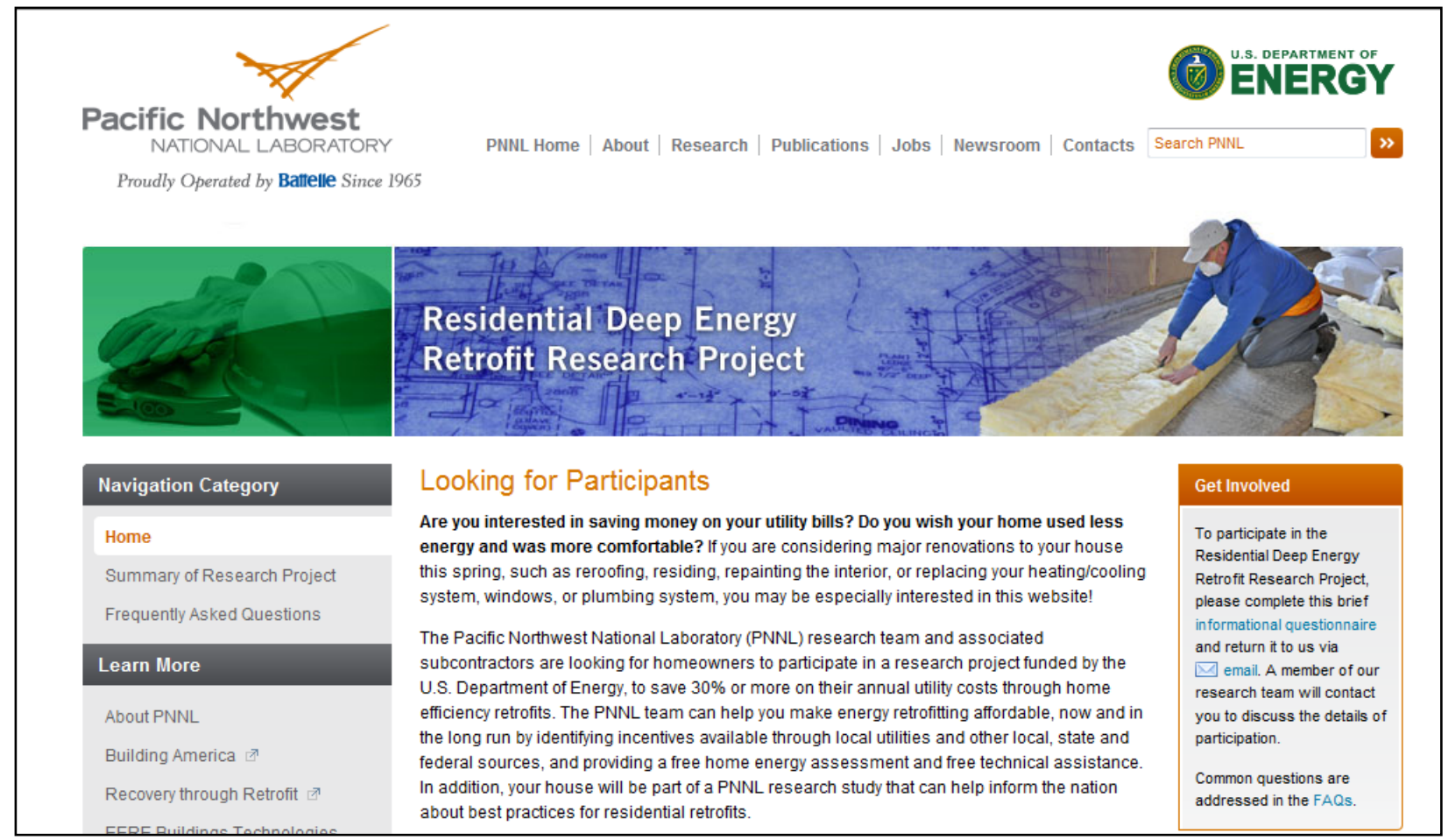

Figure 2.1. Home Page of the Deep Energy Retrofit Website. The PNNL team created the site to serve as a central coordination point for receiving inquiries from interested parties and to provide information about research program status. 
Another example of marketing material, a brochure, is included in Appendix B. This type of informational material was very successful at generating interest in the study and directing interested parties to the website for more information.

The recruitment and home selection process typically proceeds as follows. After visiting the website, participants first communicate their interest in the study by completing and submitting an informational questionnaire (included in Appendix C). The questionnaire provides the researchers with preliminary information about the home - its age, square footage, type of heating and cooling system, average and maximum utility bills, and other home eligibility criteria - and the homeowner's retrofit goals. The questionnaire is part of a streamlined process, making it easy to track and document inquiries received through the website. In conjunction with the questionnaire, the research team applies a set of criteria (Table 2.2) to determine home eligibility and select homes for participation in the study.

After a good candidate home is identified, a telephone meeting is conducted with the homeowner to discuss the specifics of participating in the program, obtain more details about the existing home characteristics, and outline a timeline for moving forward. To ensure homeowners are serious about moving forward, they are asked to complete a legal agreement that clarifies the allocation of liability and risk, communicates clearly what participation in the study entails, and ensures the homeowners meet the selection criteria. The agreement also certifies that homeowners are serious about moving forward with retrofits, although this aspect is not legally binding - meaning the homeowners can choose not to move forward with retrofits at any point if circumstances change or they decide it is not the right time for any reason. A related document, the metering agreement, which affords research staff access to a participating home under certain conditions in the event the home is selected for more extensive metering, is also signed by homeowners and PNNL contracting staff. Signing these agreements signifies homeowner commitment to saving $30 \%$ to $50 \%$ on utility bills through the program. The homeowner and metering agreements are included in Appendix D. Minor variants of these agreements were used in Florida and San Antonio, Texas. Subcontractors Calcs-Plus and the Florida Solar Energy Center (FSEC) led the work in Florida and Texas and handled agreements between themselves and the homeowners.

After these agreements are signed, the homeowners are sent a homeowner questionnaire and the test-in audit is scheduled. The homeowner questionnaire is used to collect information regarding occupant behavior and energy-use patterns to be used as inputs in modeling the home's energy consumption. Specific information about the occupants' habits, such as thermostat setpoints, washing machine and dryer use, dishwasher use, and shower duration and frequency, helps researchers create an accurate model that approximates the home's actual energy-consumption profile. The modeling and calibration procedure are described in more detail in Section 2.3. The homeowner questionnaire also elicits information about homeowner energy consumption, health, and comfort concerns that may be incentivizing retrofit decisions. This information can help the research team diagnose existing home problems and recommend thoughtful retrofit solutions. The complete homeowner questionnaire is included as Appendix E. 
Table 2.2. Selection Criteria Developed to Determine Home Eligibility and Select Desirable Candidate Homes for Participation in the Study

\begin{tabular}{|c|c|c|}
\hline Variable & Criteria for Selection & Justification \\
\hline Remodeling scope & $\begin{array}{l}\text { Owners will be making or will } \\
\text { consider improvements to a } \\
\text { combination of heating/cooling } \\
\text { system, water heater, appliances, } \\
\text { windows, insulation, lighting, fans, } \\
\text { air-sealing, etc. }\end{array}$ & $\begin{array}{l}\text { Ensures that homeowners are open to the } \\
\text { potential scope of a deep energy retrofit }\end{array}$ \\
\hline Age of home & At least 5 years old & $\begin{array}{l}\text { Older homes generally more } \\
\text { cost-effective to retrofit }\end{array}$ \\
\hline Size of home & Prefer less than $3,000 \mathrm{ft}^{2}$ & $\begin{array}{l}\text { Aims to serve middle class and } \\
\text { affordable homes }\end{array}$ \\
\hline Typical utility bill amount & $\begin{array}{l}\text { Prefer higher than average usage } \\
\text { and utility rate (to be quantified } \\
\text { based on region) and significant } \\
\text { difference between peak and low } \\
\text { month }\end{array}$ & $\begin{array}{l}\text { Shorter payback for retrofit measures in } \\
\text { homes with greater initial energy use, } \\
\text { thus owners likely to be more motivated } \\
\text { to do deep energy retrofits. High } \\
\text { difference between peak and low month } \\
\text { indicates greater opportunities for } \\
\text { envelope and equipment improvements }\end{array}$ \\
\hline $\begin{array}{l}\text { Business use (e.g., catering, } \\
\text { daycare) or unusual energy- } \\
\text { intensive equipment in homes }\end{array}$ & $\begin{array}{l}\text { No extreme energy-using } \\
\text { businesses (small home office is } \\
\text { okay) }\end{array}$ & Higher energy usage (confounder) \\
\hline Period of time house is occupied & $\begin{array}{l}\text { Year-round (not vacation home or } \\
\text { second home) }\end{array}$ & Not representative energy-use pattern \\
\hline Home is occupied by & Owner & Authority to perform retrofit activities \\
\hline Number of occupants & & $\begin{array}{l}\text { Large number of occupants could } \\
\text { confound energy-savings data }\end{array}$ \\
\hline $\begin{array}{l}\text { Reported severe mold, asbestos, } \\
\text { lead paint, or other issues that } \\
\text { would prevent safe retrofits }\end{array}$ & None & $\begin{array}{l}\text { Lawsuit, expert testimony, etc. Bad } \\
\text { exposure }\end{array}$ \\
\hline Planned sale or move & No & $\begin{array}{l}\text { No opportunity to retest post-retrofit } \\
\text { and/or different pre- and post-energy-use } \\
\text { information }\end{array}$ \\
\hline Planned addition & Undesirable & $\begin{array}{l}\text { Difficult to compare pre- and post- } \\
\text { retrofit energy use }\end{array}$ \\
\hline Smoking allowed in the home & No & $\begin{array}{l}\text { Greater opening of windows } \\
\text { (confounder), non-representative IAQ }\end{array}$ \\
\hline $\begin{array}{l}\text { Windows are routinely left open } \\
\text { in summer or winter when } \\
\text { heating, ventilation, and air } \\
\text { conditioning (HVAC) system is } \\
\text { operating }\end{array}$ & No (spring or fall is okay) & Confounder \\
\hline Heating and cooling method & $\begin{array}{l}\text { Must have central, forced-air } \\
\text { heating or cooling system. } \\
\text { Evaporative coolers, large whole- } \\
\text { house fans, wood stoves, or wood } \\
\text { fireplaces cannot serve as the } \\
\text { primary heating or cooling system. } \\
\text { Gas or electric fireplaces are okay. }\end{array}$ & $\begin{array}{l}\text { Other systems would be non- } \\
\text { representative }\end{array}$ \\
\hline
\end{tabular}




\subsection{Test-In}

A thorough test-in audit was conducted in each participating home to document pre-retrofit conditions and characterize energy performance. The test-in audit included a home energy assessment, combustion safety testing in homes with combustion appliances in conditioned space, and a preliminary indoor airquality assessment in some homes. The specific tests conducted as part of the test-in audit and data collected are described in greater detail in the following sections.

To gather test-in data and make retrofit recommendations, the researchers collaborated with local contractors, energy raters, and auditors on potential challenges and retrofit implementation. This was helpful in gaining local knowledge on typical building styles and construction techniques, as well as determining the serviceability of newer technology options. If no local trades were familiar with, or willing to install and service, a particular technology, the technologies available as retrofit options were affected.

\subsubsection{Home Energy Assessment}

To characterize and collect data about each home's existing energy performance, researchers devised an audit template, included in this report as Appendix F, which describes the significant factors that could affect energy use. This audit template drew from guidelines for home energy professionals, currently under development by $\mathrm{DOE}^{1}$, and the Building Performance Institute (BPI) Technical Standards for Certified Building Analyst 1 (BPI 2005). Recorded information includes home dimensions, geometry, location, insulation levels, number and type of appliances, building material characteristics, weather information, and other pertinent items. An example of the first page of the audit form is shown in Figure 2.2.

In addition to defining building and appliance characteristics, the research team characterized building and duct leakage using a blower door test and duct blaster test, respectively. The building leakage test is conducted with all doors and windows closed to determine only inadvertent leakage pathways. The blower door pulls a measured volume of air through a fan installed in the doorway. A manometer then measures the pressure differential between the indoors and outdoors. Researchers used TecTite software to determine the fan flow and relative pressure differential at multiple points. The multipoint test gives a more accurate measurement of required fan flow in cubic feet per minute (cfm) to reach -50 pascals $(\mathrm{Pa})$ with respect to the outside (referred to as CFM50). The duct blaster test uses a similar mechanism to measure the amount of air the duct blaster fan must supply to bring the ducts to a specific pressurization (or depressurization) with respect to the house. The greater the fan flow, the leakier the ducts.

For selected homes, room-to-room pressure differentials with the air handler running were determined to ensure good mixing of air throughout the home and to diagnose potential air distribution problems.

Other pressure diagnostic tests were used to identify the home's primary air boundary. Figure 2.3 depicts PNNL staff conducting air leakage testing during an audit.

\footnotetext{
${ }^{1}$ DOE has drafted Workforce Guidelines for Home Energy Upgrades; the current draft is available from http://www1.eere.energy.gov/wip/development_review.html. Final publication is targeted for 2012.
} 


\section{A. Onsite Energy Audit Data Collection Form}

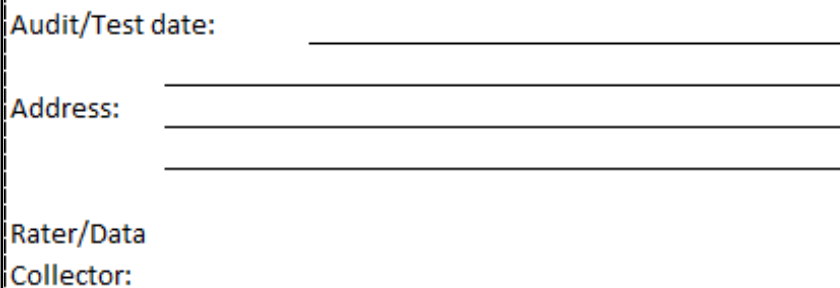

Notes:

Collector:

Combustion Appliances

Yes or No

If Yes, describe the Location of Combustion Appliance Zone (CAZ)

If there is a CAZ inside or adjacent to the conditioned space fill out CAZ TAB

\begin{tabular}{|c|c|c|c|c|}
\hline General & \multicolumn{2}{|c|}{ Data } & \multicolumn{2}{|c|}{ Notes } \\
\hline \multicolumn{5}{|l|}{ Total Floor Area: } \\
\hline Conditioned Floor Area: & & & \multicolumn{2}{|c|}{ If different than above } \\
\hline Average Ceiling Height & & & \multicolumn{2}{|c|}{ If variable, see bldg sketch } \\
\hline Conditioned Volume & \multicolumn{2}{|c|}{0} & & \\
\hline \multicolumn{5}{|l|}{ Year Built } \\
\hline \multicolumn{5}{|l|}{ Orientation (Front Door Faces): } \\
\hline \multirow[t]{2}{*}{$\begin{array}{l}\text { Shading (indicate location of } \\
\text { trees/buildings in sketch) }\end{array}$} & $\begin{array}{l}\text { Distance and } \\
\text { direction to } \\
\text { neighboring house }\end{array}$ & & $\begin{array}{l}\text { Height of } \\
\text { neighboring } \\
\text { house }\end{array}$ & \\
\hline & $\begin{array}{l}\text { Number of large } \\
\text { trees near house }\end{array}$ & & $\begin{array}{l}\text { Side }(\mathrm{s}) \text { of house } \\
\text { with trees }\end{array}$ & \\
\hline \multicolumn{5}{|l|}{ Number of Stories: } \\
\hline \multicolumn{5}{|l|}{ Number of Bedrooms: } \\
\hline \multicolumn{5}{|l|}{ Number of Bathrooms: } \\
\hline Garage: Yes / No & \multirow{2}{*}{\multicolumn{2}{|c|}{ Attached Garage?: Yes / No }} & Total SF $=$ & \\
\hline Room Over Garage?: Yes / No & & & Conditioned SF = & \\
\hline \multicolumn{5}{|c|}{ Assessment of Potential Hazards- Take pictures of any potential hazards } \\
\hline Is there vermiculite insulation?: Yes / No & & $\begin{array}{l}\text { If yes, DO NO } \\
\text { blower door } t\end{array}$ & ouse under negative & pressure with \\
\hline
\end{tabular}

Figure 2.2. First Page of the Onsite Energy Audit Data Collection Form, Authored by PNNL. For the complete form, see Appendix F. 


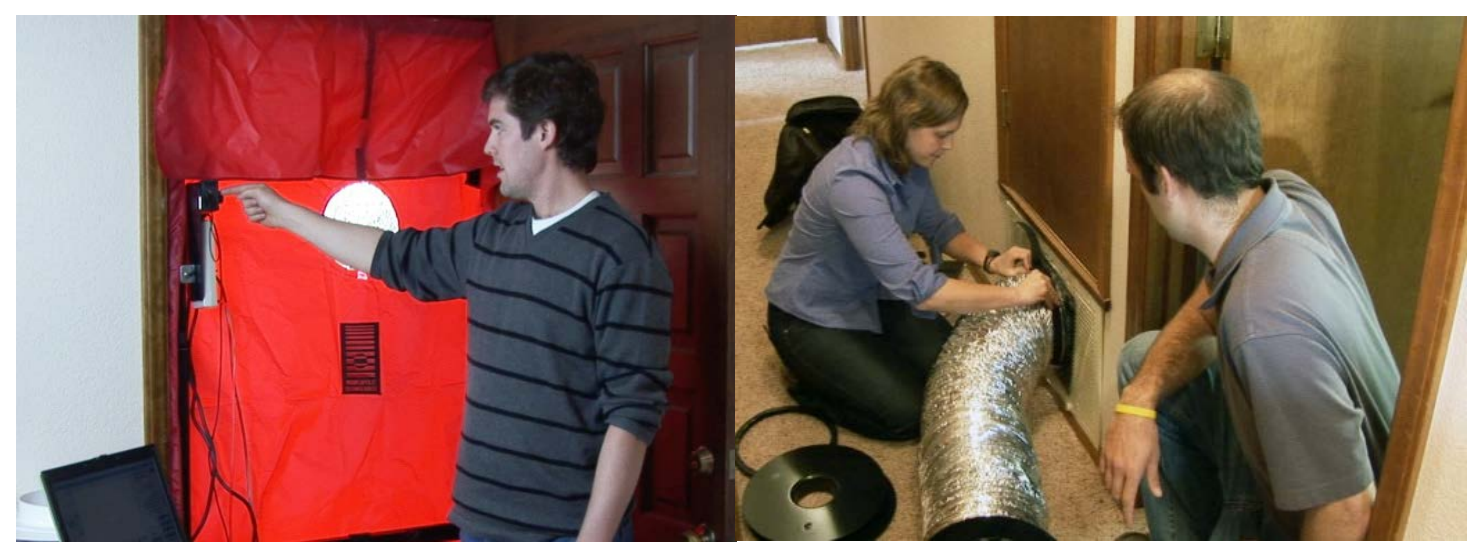

Figure 2.3. PNNL Research Staff Conducting a Blower Door Test (left) and Duct Blaster Test (right)

The research team used an infrared camera to pinpoint specific leakage areas and to identify thermal breaks and areas of compressed or nonexistent insulation. Using building tightness information, the team determined the necessary amount of ventilation. Supplied ventilation was assessed by measuring the effectiveness of the air handler and any exhaust fans and determining their usage patterns. This allowed researchers to determine if adequate ventilation was being supplied to the existing house and estimate when supplemental ventilation would be required in the retrofit homes. Ventilation system performance was assessed by measuring the flow rates of the air handler and any exhaust fans in the home, as applicable. The flow rate of the air handler was determined using a manometer and a TrueFlow plate to measure the pressure differential between the air handler and the house. The measured pressure differential allows the user to calculate an adjusted flow rate through the duct system. Exhaust fan flow is determined using a similar manometer and an exhaust fan box. The manometer measures the pressure differential in the box relative to the ambient room with the exhaust fan running to determine the flow rate (in $\mathrm{cfm}$ ).

\subsubsection{Combustion Safety Testing}

To ensure the health and safety of homeowners, each audit also included combustion testing in homes that had atmospherically vented or natural-draft gas appliances. This test consists of checking for gas leaks at all exposed gas pipes, visually inspecting for serious combustion problems (e.g., flame rollout), determining worst-case depressurization (WCD) of the combustion appliance zone (CAZ), measuring for sufficient draft in the flue, and analyzing the flue-gas composition to determine combustion efficiency.

Gas leaks are identified using a semiconductor type of sensor for positive identification of methane or other volatile hydrocarbons.

Depressurization of the CAZ is determined by operating all exhausting appliances, including the air handler, dryer, and any exhaust fans, to generate the greatest negative pressure in the area near an atmospherically vented combustion appliance. If the CAZ WCD exceeds a level determined safe for that appliance, listed in Table 2.3, the significant depressurization in the CAZ may pull combustion gases into the house rather than exhausting them up the flue, which creates a significant health hazard. If the WCD CAZ is exceeded, the appliance should be replaced with a sealed combustion unit that separates combustion air from conditioned air. 
Table 2.3. Combustion Appliance Zone Depressurization Limits (BPI 2005; DHW = domestic hot water)

\begin{tabular}{|l|c|}
\hline \multicolumn{1}{|c|}{ Venting Condition } & Limit (Pa) \\
\hline $\begin{array}{l}\text { Orphan natural draft water heater } \\
\text { Natural draft boiler or furnace commonly vented } \\
\text { with water heater }\end{array}$ & -3 \\
\hline $\begin{array}{l}\text { Natural draft boiler or furnace with vent damper } \\
\text { commonly vented with water heater }\end{array}$ & -5 \\
\hline $\begin{array}{l}\text { Individual natural draft boiler or furnace } \\
\text { Mechanically assisted draft boiler or furnace } \\
\text { commonly vented with water heater }\end{array}$ & -5 \\
\hline $\begin{array}{l}\text { Mechanically assisted draft boiler or furnace alone; } \\
\text { or fan assisted DHW alone }\end{array}$ & -15 \\
\hline $\begin{array}{l}\text { Exhaust to chimney - top draft inducer; } \\
\text { High static pressure flame retention head oil burner; } \\
\text { Sealed combustion appliance }\end{array}$ & -50 \\
\hline
\end{tabular}

The likelihood of back-drafting is based on the strength of the draft removing combustion gases from the home through the flue. The research team determined the strength of the draft, measured as a pressure differential between the flue and the house, while the combustion appliance was operating.

Back-drafting is most dangerous when a combustion appliance is not operating correctly, as this can lead to increased carbon monoxide (CO) formation, a significant health hazard. The combustion efficiency is also indicative of an appliance's emissions. The research team measured the combustion efficiency of combustion appliances in conditioned space using a combustion gas analyzer to determine $\mathrm{CO}$ concentration, combustion temperature, oxygen concentration, and amount of excess air.

Combustion testing includes determination of safe combustion and combustion gas exhaust for gas ranges and ovens (if those appliances are present). Appendix F describes the gas oven and range testing protocol.

\subsubsection{Indoor Air-Quality Assessment}

In addition to characterizing home energy performance and consumption safety, the PNNL research team evaluated IAQ in some Pacific Northwest homes. The purpose of the evaluation is to explore the relationship between IAQ in homes and home tightness or the installation of energy-related retrofit measures in homes. Of concern is that fact that air-sealing, installing additional insulation, and other home improvement measures can increase the concentration of hazardous air contaminants in homes, thereby increasing exposure rates for occupants and causing unhealthy living situations (Widder and Baechler 2011). 
To determine the pre-retrofit IAQ in homes, individual samples of particulate matter, nitrogen oxides $\left(\mathrm{NO}_{\mathrm{x}}\right), \mathrm{CO}$, carbon dioxide $\left(\mathrm{CO}_{2}\right)$, total volatile organic compounds (TVOCs), formaldehyde $\left(\mathrm{CH}_{2} \mathrm{O}\right)$, and radon were collected. The particulates, TVOCs, $\mathrm{CO}_{2}$, temperature, and relative humidity $(\mathrm{RH})$ were sampled using the EVM 7 environmental monitor to collect real-time samples for anywhere from 1 to 7 days. The particulate matter sampling train includes an impactor, an optical engine, a gravimetric filter cassette, a pump, and an orifice-controlled flow sensor. The TVOC sensor is a photo-ionization detector with parts-per-million ( $\mathrm{ppm}$ ) sensitivity, and the $\mathrm{CO}_{2}$ sensor is a non-dispersive infrared sensor. Both sensors operate with a small fan to pull air across the sensors and exhaust it. To test for $\mathrm{NO}_{\mathrm{x}}$ and $\mathrm{CH}_{2} \mathrm{O}$, samples were collected with a chemical-specific sample collection tube and a hand-operated pump. For CO sampling, a real-time handheld $\mathrm{CO}$ detector was used to determine ambient $\mathrm{CO}$ concentrations. The research team determined radon concentrations in existing homes using the RadStar R300 radon meter.

The standard operating protocol for indoor air-quality testing, including a description of the equipment, is included as Appendix G.

\subsection{Modeling and Recommending Retrofit Measures}

Appliance information, occupant behavior information, building and duct leakage test data, and other information are entered into a residential energy modeling software program to model the existing building energy consumption and determine energy savings from specific retrofit measures. Each home is modeled in one or more software programs, including Energy Gauge, BeOpt, and/or REMRate (FSEC 2011; NREL 2010; AEC 2010). The model is then calibrated to the homeowner's utility bills (when analyzing owner-occupied homes). This is done using the utility bill analysis spreadsheet, which compares the homeowner's actual monthly utility bills to the generated model output. Figure 2.4 illustrates a comparison of the modeled versus actual utility bills for one home in the Pacific Northwest generated by the utility bill analysis spreadsheet.

The base load, heating load, and cooling load are then simultaneously optimized to create a model that accurately reflects homeowner usage patterns. A systemic way of optimizing the model was developed and is included as Appendix $\mathrm{H}$.

After a calibrated model of the pre-retrofit condition is generated, each retrofit option is modeled individually to determine the incremental capital cost, energy savings, and payback period of each measure. The individual savings, along with estimated costs for each measure, are analyzed to develop the most cost-effective retrofit approach for that specific home and that meets the homeowner's agenda and budget. Cost estimates are generated from the National Renewable Energy Laboratory national measures database, price quotes from local contractors, and manufacturer literature. The capital cost and payback period for each measure is calculated using the gross cost of the measure and any available incentives and rebates. The team works with local utilities and the Database of State Incentives for Renewable Energy website to identify all available incentives and rebates. 


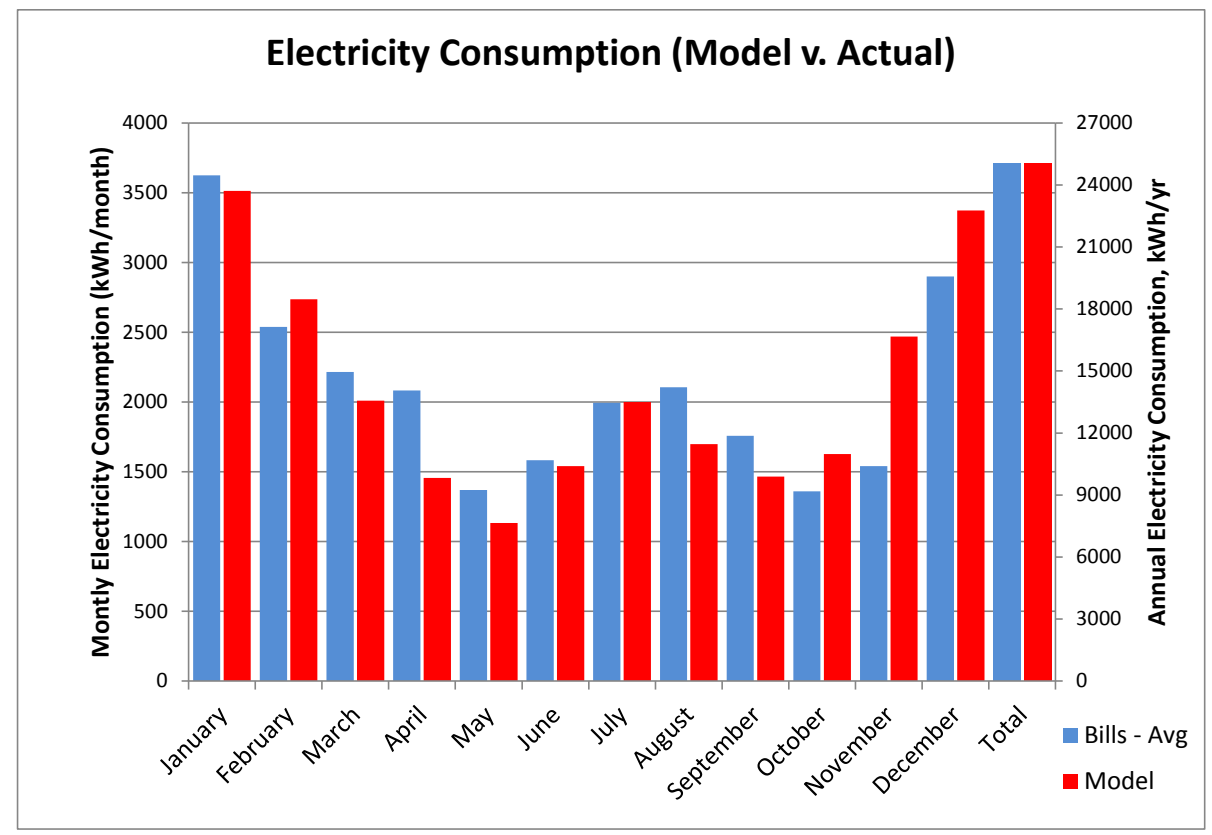

Figure 2.4. Comparison of Monthly Electricity Consumption for Utility Bills and Energy Gauge Model. The annual comparison is also included on the secondary (right) vertical axis.

The most cost-effective measures are selected to determine a final recommended retrofit package that achieves savings of $30 \%$ to $50 \%$ or more. The final recommended series of measures is modeled as a package to account for synergistic effects on energy savings and payback period. These results are presented in an audit report that is provided to the homeowner after the home energy audit. The team then meets with the homeowner to talk through the report, answer any questions he/she may have, and plan for their retrofits. Audit reports for eight candidate homes in the Pacific Northwest are included as Appendix I.

\subsection{Perform Upgrade}

After the retrofit recommendations have been presented to the homeowner, the homeowner is responsible for contracting with a qualified technician or contractor to complete the agreed-upon retrofits. In many cases, the PNNL team helped homeowners select qualified trades personnel and communicated the scope of work. This was seen as very beneficial for homeowners who viewed contractor selection as a large hurdle, and, in some cases, delayed the start of retrofit work.

\subsection{Test-Out}

As retrofit measures are implemented, PNNL collects cost and measure data. Changes in the scope of work are identified during the test-out audit prior to final savings calculations. The test-out involves the same tests, conducted in the same manner, as the test-in audit — home energy assessment, combustion safety testing as applicable, and indoor air-quality testing. The goal of the test-out audit is to quantify post-retrofit changes in home energy performance and IAQ. These data informs an as-retrofit model. This final test-out model is compared to realized savings assessed based on utility bill data, as exemplified in Figure 2.5. 

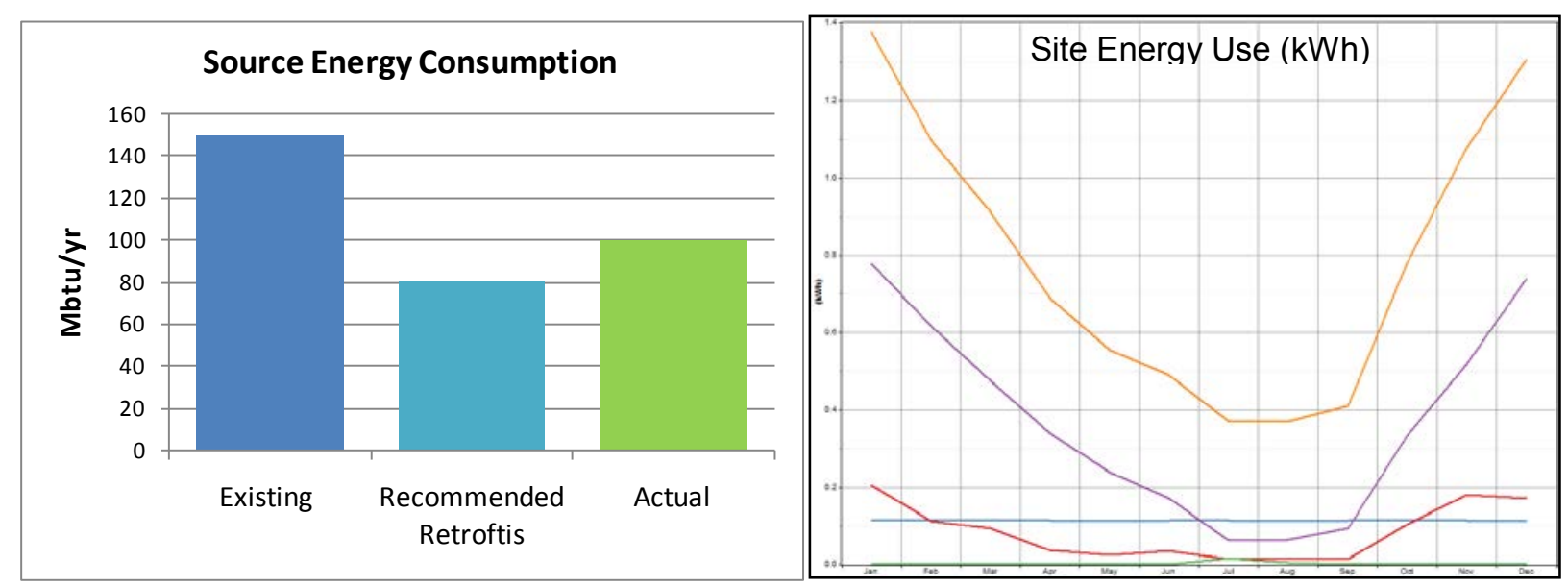

Figure 2.5. Comparison of Existing Home Energy Consumption, Post-Retrofit Estimated or Modeled Energy Consumption, and Actual Energy Consumption (left) and Disaggregated Energy Consumption Data Obtained from Actual Metering (right)

\subsection{Continued Evaluation}

Some homes have been instrumented to collect long-term data about a whole-house and sub-metered level. The data will enable the research team to do the following:

- Compare metered data to anticipated savings.

- Understand how the retrofit has changed energy usage patterns (e.g., decrease in heating energy consumption versus just decrease in total energy consumption).

- Obtain hard data about deep energy retrofits and innovative systems.

Components that are monitored include HVAC; water heating; major appliances (i.e., dryer, refrigerator, and range); and, to the extent possible, three categories of miscellaneous electricity use: home entertainment, small appliances, and lighting (hardwired and plug-in). Both electricity and naturalgas usage are monitored, along with interior temperature and $\mathrm{RH}$, to quantify the impacts of retrofits on comfort. Where feasible, PNNL researchers also collected a few weeks or months of pre-retrofit data. This will provide a robust comparison between pre- and post-retrofit energy consumption. 



\subsection{Current Status and Future Work}

Figure 3.1 illustrates the status of all deep energy retrofits being considered in this research program. The ORNL team has completed deep energy retrofits in 9 homes in the metropolitan area of Atlanta, Georgia. The PNNL team is leading retrofits in the other locations. A total of 51 pre-retrofit test-in audits have been completed by the PNNL team, primarily in hot-humid, marine, and cold climates, as seen on the map. Of the 51 test-in audits, 15 PNNL-led retrofits are completed. The PNNL team has completed 3 retrofits in San Antonio, Texas, 10 in Florida, 1 in Portland, Oregon, and 1 in Dayton, Washington. Metering equipment has been installed in seven of these completed retrofits - three in Texas, three in Florida, and one in Washington State. Fourteen additional retrofits are in progress, with 5 additional good candidates identified.

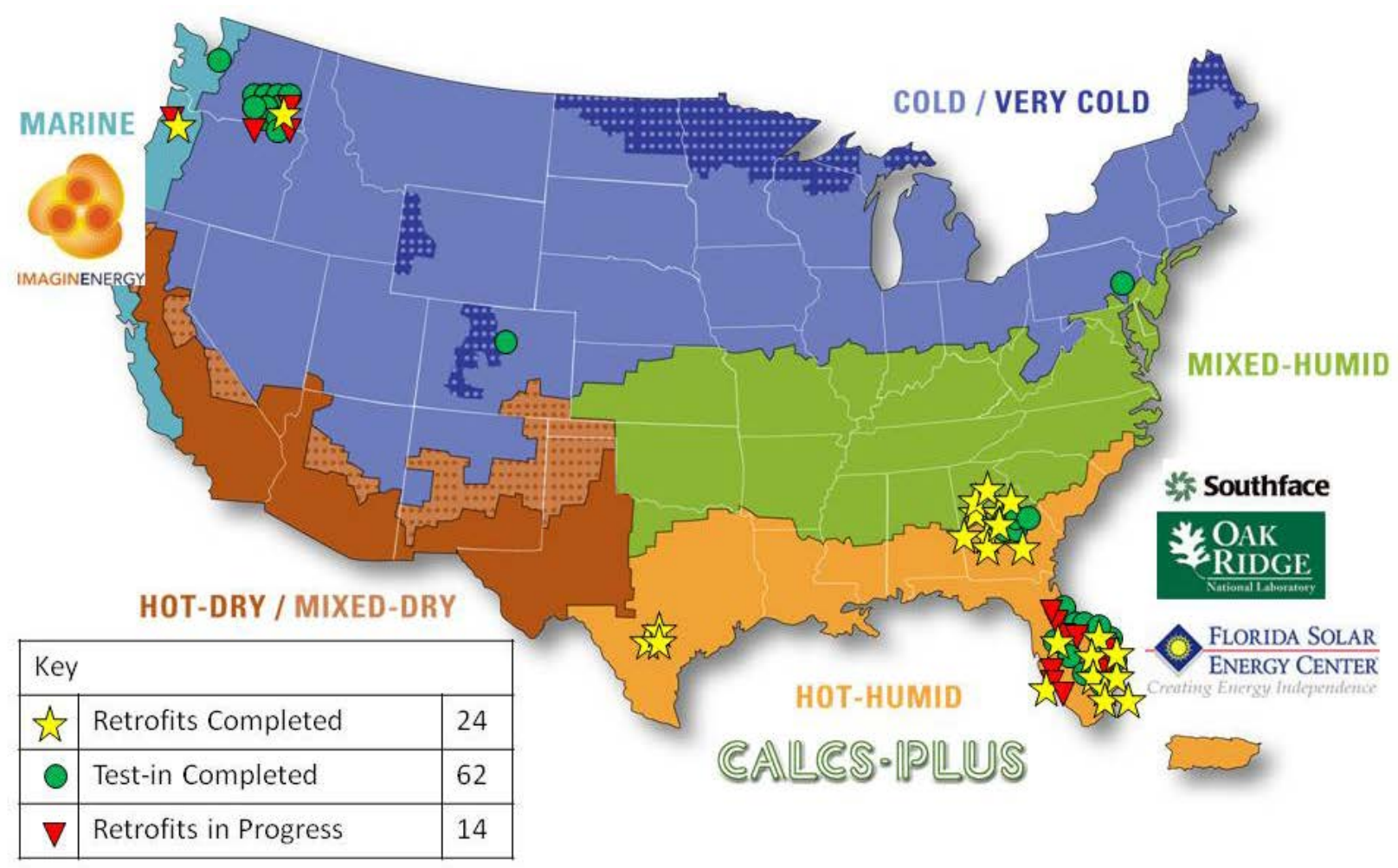

Figure 3.1. Status of Deep Energy Retrofit Homes as of December 15, 2011

Table 3.1. Key Characteristics of the 15 PNNL-Led Completed Retrofits

\begin{tabular}{|c|c|c|c|c|c|c|c|}
\hline Retrofit & Location & $\begin{array}{c}\text { Floor } \\
\text { Area } \\
\left(\mathrm{ft}^{2}\right)\end{array}$ & $\begin{array}{c}\text { HERS } \\
\text { Pre- }\end{array}$ & $\begin{array}{c}\text { HERS } \\
\text { Post- }\end{array}$ & $\begin{array}{l}\text { Estimated } \\
\text { Energy } \\
\text { Savings } \\
(\$)\end{array}$ & $\begin{array}{c}\text { Estimated } \\
\text { Energy } \\
\text { Savings } \\
(\%)\end{array}$ & Date Occupied \\
\hline FL-1 & Lakeland, FL & 1,250 & 177 & 85 & 962 & 40 & May 2011 \\
\hline FL-2 & Green Acres, FL & 1,373 & 97 & 75 & 431 & 26 & June 2011 \\
\hline FL-3 & Eustis, $\mathrm{FL}^{(\mathrm{a})}$ & 1,040 & 132 & 78 & 724 & 42 & September 2011 \\
\hline FL-4 & Melbourne, FL & 1,583 & 117 & 76 & 731 & 35 & August 2011 \\
\hline
\end{tabular}


Table 3.1. (contd)

\begin{tabular}{|c|c|c|c|c|c|c|c|}
\hline Retrofit & Location & $\begin{array}{c}\text { Floor } \\
\text { Area } \\
\left(\mathrm{ft}^{2}\right)\end{array}$ & $\begin{array}{c}\text { HERS } \\
\text { Pre- }\end{array}$ & $\begin{array}{c}\text { HERS } \\
\text { Post- }\end{array}$ & $\begin{array}{c}\text { Estimated } \\
\text { Energy } \\
\text { Savings } \\
(\$)\end{array}$ & $\begin{array}{c}\text { Estimated } \\
\text { Energy } \\
\text { Savings } \\
(\%)\end{array}$ & Date Occupied \\
\hline FL-5 & Melbourne, FL & 1,608 & 136 & 85 & 749 & 33 & August 2011 \\
\hline FL-6 & Indian Harbor Beach, FL & 1,962 & 122 & 70 & 1,076 & 35 & November 2011 \\
\hline FL-7 & West Palm Beach, FL & 1,176 & 109 & 70 & 676 & 40 & October 2011 \\
\hline FL-8 & Lake Worth, FL & 1,573 & 120 & 78 & 872 & 39 & November 2011 \\
\hline FL-9 & Lake Worth, FL & 1,334 & 119 & 64 & 960 & 48 & November 2011 \\
\hline FL-10 & Venice, FL $^{(a)}$ & 1,814 & 189 & 57 & 1,642 & 63 & July 2011 \\
\hline TX-1 & San Antonio, $\mathrm{TX}^{(\mathrm{a})}$ & 1,047 & 161 & 93 & 545 & 33 & May 2011 \\
\hline $\mathrm{TX}-2$ & San Antonio, $\mathrm{TX}^{(\mathrm{a})}$ & 845 & 150 & 88 & 435 & 38 & April 2011 \\
\hline $\mathrm{TX}-3$ & San Antonio, $\mathrm{TX}^{(\mathrm{a})}$ & 675 & 156 & 93 & 371 & 35 & June 2011 \\
\hline PNW-1 & Dayton, WA ${ }^{(\mathrm{a})}$ & 2,600 & 125 & 90 & 2,375 & 66 & July 2011 \\
\hline PNW-2 & Portland, $\mathrm{OR}^{(\mathrm{a})}$ & 2,430 & NA & 68 & NA & NA & November 2011 \\
\hline
\end{tabular}

(a) Home is metered to measure performance

Notes:

Estimated Energy Savings computed with BA benchmark setpoints: cooling $=76^{\circ} \mathrm{F}$; heating $=71^{\circ} \mathrm{F}$

(except for PNW-1)

HERS $=$ home energy rating system

$\mathrm{NA}=$ not available

Of all the homes in Table 3.1, only one (PNW-1) was habitable and occupied while the retrofits were being done. The other 14 homes were vacant and in very poor shape when the renovations started and remained vacant throughout the gut rehab process. The owners paid for the renovations and energy upgrades in only 3 (PNW-1, PNW-2, and FL-6) of the 15 homes. Four homes (FL-1, TX-1, TX-2, and TX-3) were financed by funding secured by the local city. Owners of the three Texas homes were relocated for a few months while the renovations were being done. The remaining homes were funded by Habitat for Humanity affiliates in Florida. All Florida homes and PNW-2 were foreclosed or vacant properties bought by the owners and then renovated.

In 2012, PNNL researchers plan to identify a few additional deep energy retrofit homes to add to the study. These new homes will be targeted at the 50\% savings benchmark or beyond and may include renewable systems. In addition to more traditional upgrade measures, the research team will explore passive solar strategies in the Pacific Northwest, as well as home automation technologies and other behavioral components, to increase savings and the cost-effectiveness of savings.

PNNL plans to complete retrofits, test-outs, and utility data collection and analysis for all of the PNNL-led deep energy retrofits. The data will be compared to model predictions, and further analysis will be performed to understand the differences between realized and projected savings. For some homes, retrofit impact on IAQ, health, and comfort will be tracked and quantified. Specifically, the pre- and post-retrofit concentrations of TVOCs, particulates, $\mathrm{CO}_{2}, \mathrm{CO}$, radon, and various other indoor air pollutants will be monitored and recorded. In addition, occupant satisfaction with upgrades and other behavioral data will be collected and analyzed. 
Of the retrofits in progress or completed, at least two are expected to save $50 \%$ or more on a whole-house basis, while others are expected to achieve savings in the $30 \%$ to $40 \%$ range (see Table 3.1 ). Technical case studies have been prepared for a less aggressive $30 \%$-level retrofit in Texas (TX-1) and a more aggressive retrofit in Florida (FL-10), which is expected to save 50\% on a whole-house basis. Case studies of four homes in the Pacific Northwest, designed for a more general audience and covering the initial test-in and analysis procedures, have also been completed. These six case studies are included as Appendix J.

Appendix K provides details about eight completed retrofits (FL-1 through FL-8 in Table 3.1)

In addition, the PNNL team (through subcontractor Calcs-Plus) assisted in diagnosing four ORNL-led deep energy retrofits in Tennessee. Detailed trip reports were prepared after conducting thorough diagnostic tests on these homes. This report does not provide any further details about that specific effort because it is expected to be included in a future ORNL report. 



\subsection{Key Findings and Lessons Learned}

Although this multi-year project has completed only its first year, some key findings and lessons learned have been identified. Insights regarding the categorization or definition of deep energy retrofits, common measures and best practices, trends in modeled or projected energy savings and cost-

effectiveness, and working with homeowners are discussed in this section. The research team expects to have many additional findings when all retrofits, post-retrofit metering, and data analysis are completed. Those findings will be presented in a follow-up report that will build on this interim report.

\subsection{Difficulty in Achieving Deep Energy Retrofits and Engaging With Homeowners}

The goal of the research program was to demonstrate the feasibility and characteristics of residential deep energy retrofits. In this research project, consistent with the definitions of the BA Program, a deep energy retrofit was defined as achieving $30 \%$ to $50 \%$ energy savings or more on a whole-house basis, while also improving the comfort, durability, and IAQ of the home. It is noteworthy that the PNNL home-recruitment website generated significant interest in the project. In spring and summer of 2011, nearly 100 homeowners in Florida and nearly 50 in the Richland, Washington area completed the initial questionnaire, which required them to acknowledge that the deep energy retrofits could cost them between $\$ 7,000$ and $\$ 20,000$ - and they were prepared to invest such amounts. However, very few homeowners followed through, despite considerable advice from, and interactions with, the PNNL research team. Many test-in audits were conducted and detailed reports were prepared. However, for one reason or another, homeowners did not continue to engage the PNNL team and only two owner-financed retrofits were completed. This reinforces a Lawrence Berkeley National Laboratory (LBNL) finding (Fuller et al. 2010) based on a comprehensive review of large-scale retrofit efforts over the past 30 years. One statement in the LBNL report points to the key challenge of motivating homeowners: “... there is no proven formula - and only limited success to date with reliably motivating large numbers of Americans to invest in comprehensive home energy improvements, especially if they are being asked to pay for a majority of the improvement costs...."

A key lesson learned from the Pacific Northwest research study is the difficulty of working with homeowners. In the Pacific Northwest, the PNNL team successfully generated a great deal of interest in the program from independent homeowners and conducted many test-in audits. However, in contrast to the situation in the Southeast, retrofits in the Pacific Northwest are almost exclusively homeownerfunded. In the Southeast, most of the retrofit homes are owned and funded by institutions or organizations. This significantly alters the research model for the Pacific Northwest, because homeowners require much more engagement and follow-up on each home. In addition, because most retrofits in the Pacific Northwest are homeowner-funded, the scope and timeline for retrofits are affected. For example, in homeowner retrofits, short-term cost-effectiveness and capital cost seemed more important for each measure and were ultimately determined by homeowner priorities. An institution may have the overarching goal of reducing energy consumption and can be more flexible regarding budgets and longer payback periods. The Pacific Northwest also has very low electricity rates, which prolongs payback periods on most measures. 
Privately financed deep energy retrofits are indeed very rare, and many of the homeowners have elected not to pursue the deep energy retrofits despite receiving detailed analysis and feedback from PNNL. Discussions with homeowners established that many believed the deep energy retrofit could provide a comprehensive, simple, "silver bullet" solution that would save $50 \%$ and require very little upfront investment. Many also seemed to believe that it would involve new, innovative technologies. Unfortunately, the inclusion of new technologies often increases the cost of a retrofit because of the capital cost of first-of-a-kind equipment and the lack of local trades' familiarity and service/installation support. In addition, the capital cost associated with a deep energy retrofit, although participants were informed initially, was often more than that to which homeowners were ready to commit.

The homeowners who have moved forward with retrofits often do so under a limited scope or a long timeline of improvement. For example, it is more common for homeowners to replace HVAC in the first year, consider adding insulation and air-sealing in the second year, replace the hot water heater in the third year, and so on. This approach is due partially to funding availability and partially to the inconvenience of taking on extensive retrofits on multiple areas of a house all at once. Perhaps these retrofits are not deep, once deep is properly defined, but they are what the majority of motivated, informed homeowners were willing and able to undertake. For deeper savings, methods to improve financing or increase homeowner buy-in are needed.

One successful method the team has identified for encouraging homeowners to pursue retrofits is identifying and contacting qualified contractors on their behalf, communicating the scope of work to the contractors, and providing the homeowner with an estimate. For individuals interested in deep energy retrofits, the two main hurdles seemed to be identifying the best package of retrofit options (which the PNNL audit report identified), and finding qualified and experienced contractors to complete the work. This suggests that an auditor/general contractor partnership or business model would work well for the deep energy retrofit business model, because the audit results could serve as a preliminary contract for the work. This model is being used successfully by one of the subcontractors on this project, Imagine Energy in Portland, Oregon. A similar model was used by ORNL in conducting the deep energy retrofits in the metropolitan Atlanta, Georgia area (Jackson et al. 2011)

\subsection{Common Retrofit Measures Implemented in the Pacific Northwest Study Homes}

In the Pacific Northwest, the study homes included a wide variety of existing housing stock. The building stock characteristics varied significantly between homes in the Tri-Cities, Washington, and homes in the marine climates of Seattle and Portland.

In the Tri-Cities, the building stock represented in our study reflects the history of the area, which developed significantly beginning in the 1940s in connection with the Hanford Site nuclear efforts. Housing styles and sizes range from a 700- $\mathrm{ft}^{2}, 1940$ s-era, B1-style government house to a 2,100- $\mathrm{ft}^{2} 1970$ s tri-level home, both of which use primarily electric heat. Gas appliances are found only in newer homes. Because of this, HVAC replacement was the most common and effective measure for homes in the Tri-Cities. Homeowners often installed high-efficiency heat pumps to replace the aging electric furnaces or baseboard heaters. Many homes received some insulation during a weatherization effort funded by the City of Richland in the 1980s, which improved the thermal performance of homes and prevented most egregious air leaks and bypasses. 
In other, more historic Washington State locations (e.g., Seattle, Portland, and Dayton), the situation and building styles were much different. Participating homes from these cities are almost exclusively turn-of-the-century, 1.5-story homes. Although many had received some wall and attic insulation as part of a previous weatherization effort, they often had original or only marginally improved heating systems and duct work. Also, in these balloon-framed houses, the insulation was not as effective at air-sealing; much of the infiltration was a result of the uninsulated and leaky basement walls and rim joists. In this type of home, HVAC replacement was still a common and effective measure, although the recommended systems varied based on fuel availability, the familiarity of local trades, and other unique constraints. The realized savings of these measures as they are installed and operated during the heating and cooling season will be evaluated in the next phase of this research program - and will be the true measure of success.

\subsection{Energy Savings and Cost-Effectiveness in the Pacific Northwest}

All homes participating in the study were presented with retrofit packages that saved between $30 \%$ and $50 \%$, as modeled. However, the cost and payback period of these measures varied, based on the condition of the existing house. Obviously, better-performing homes allow less opportunity for costeffective savings. Although strong correlations cannot be made based on the existing data, it seems that the cost of the retrofit is more strongly dependent on the existing house building envelope leakage than on the home's energy intensity, quantified in this case as home heating index (HHI), with units of kiloBritish thermal units per square foot per heating degree day $\left(\mathrm{kBtu} / \mathrm{ft}^{2} / \mathrm{HDD}\right)$. This is probably because the HHI is dependent on occupant behavior (e.g., setpoints, number and type of household appliances), while building envelope leakage is a physical property of the house that is completely affected by any airsealing retrofit measures. In contrast, some aspects of home energy use, especially those related to occupant habits, will not be affected by the retrofit. The trend lines shown in Figure 4.1 are least squares regressions, with all points weighted equally.
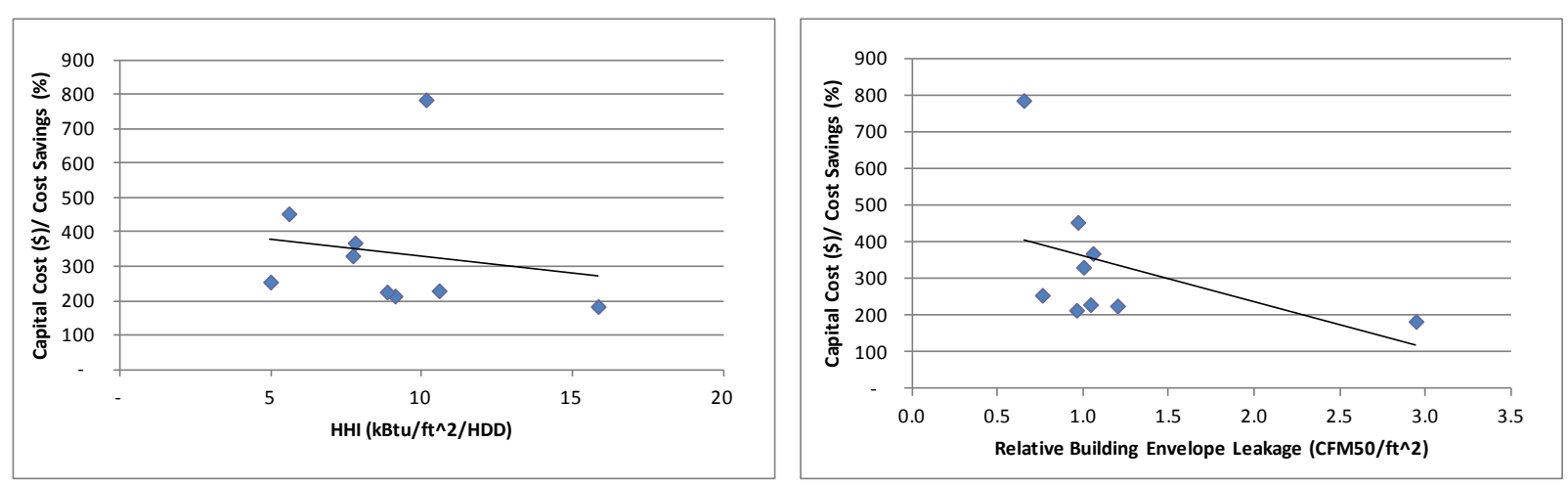

Figure 4.1. Dependence of Capital Cost of Retrofit Measures, Normalized Based on the Estimated Energy Cost Savings (capital cost (\$)/ Cost Savings (\%)) with Respect to HHI $\left(\mathrm{kBtu} / \mathrm{ft}^{2} / \mathrm{HDD}\right)$ and Relative Building Envelope Leakage $\left(\mathrm{CFM} 50 / \mathrm{ft}^{2}\right)$. Trend lines are a least square regression.

Because electricity rates in the Pacific Northwest are very low, recommended deep energy retrofit packages were not very cost-effective. Although the research team recommended the most cost-effective measures, based on the simple payback period of the measure, the average payback period for the study was 17 years, with a range of 6 to 39 years. Only one home had a payback period less than 10 years. 
Contrary to the capital cost of the retrofit, the payback period did not appear to be dependent on the HHI and was only mildly dependent on the relative building leakage, as shown in Figure 4.2. Although the slope of the least squares trend line is not flat, the cluster of low payback period data points near a relative building leakage of $1.0 \mathrm{CFM} 50 / \mathrm{ft}^{2}$ indicates that relative building leakage may not be the only contributing factor.
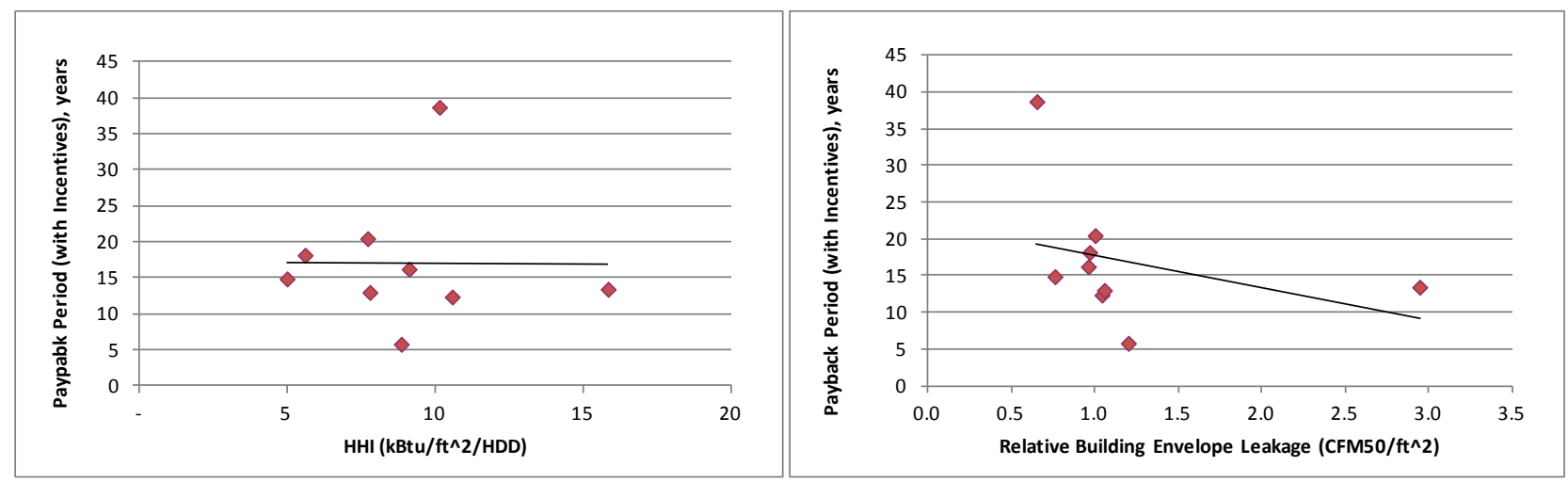

Figure 4.2. Dependence of Payback Period, Including Incentives, of Retrofit Measures (years) with Respect to HHI (kBtu/ $\left.\mathrm{ft}^{2} / \mathrm{HDD}\right)$ and Relative Building Envelope Leakage (CFM50/ $\mathrm{ft}^{2}$ ). Trend lines are a least square regression.

The research team will expand on this preliminary analysis in the final report, including additional dependent variable, actual costs, and realized savings values. However, these initial results indicate that the value of deep energy retrofits must be based on non-energy criteria, like comfort. The research team is characterizing some health and comfort impacts as part of this research study and will include the additional metrics as part of the quantification of value in future analyses.

\subsection{Initial Energy-Savings Data from Metered Homes in the Southeast}

Electrical energy and interior temperature and RH were monitored in 12 deep energy retrofit homes in the Southeast - 6 in the Atlanta, Georgia metropolitan area, 3 in San Antonio, Texas, and 3 in Florida. This monitoring was done by the FSEC under subcontract to PNNL and all metering inside the panel boxes was performed by licensed electricians. Two home energy feedback devices (The Energy Detective (TED) and eMonitor) were used to collect total and sub-metered electrical end uses. Many homes had natural-gas appliances; however, gas monitoring was not performed. Larger electrical end uses, such as space heating and cooling as well as water heating, were sub-metered. Smaller electrical branch circuits were also monitored, including refrigerator, dishwasher, and various plug loads. Two eMonitor models, eMonitor-12 and eMonitor-24, were chosen for these homes in Georgia and Florida. The eMonitor system ${ }^{1}$ includes an online interface with graphical display of all monitored circuits (in near-real-time) and stored historical data. Due to space constraints in the electrical panel boxes in the San Antonio homes, the TED-5000 system was used. The TED energy monitor, which uses power-line carrier technology, was an ideal choice because circuit monitors can be placed in separate panels. Although limited to four circuits, this device provided the mandatory house and space conditioning measurements

\footnotetext{
${ }^{1}$ http://www.powerhousedynamics.com/
} 
needed for the study. The TED 5004C ${ }^{2}$ was purchased with a countertop liquid crystal display to provide energy feedback to occupants. Data are stored in the TED "gateway" device at the home.

In addition to monitoring electric energy, interior temperature and $\mathrm{RH}$ are recorded using Hobo data loggers manufactured by Onset Computer Corporation. These standalone loggers record average hourly interior conditions, which are downloaded on 1- to 2-month intervals. These data, along with ambient data collected from local National Weather Service stations, provide a means of determining cooling (and/or heating) performance when integrated with energy data collected via the energy feedback devices (TED or eMonitor).

As part of this project, hourly and cumulative outputs over several days from TED and eMonitor devices were compared to established reference devices. A Fluke 435 Power Analyzer provided the primary reference readings for whole-house energy use. A Wattnode WNB-3D-240-P power meter, manufactured by Continental Control Systems, was used as a reference point for end-use measurements (air-conditioner condenser, air handler, and water heater). TED total home energy readings were generally very close to reference values, except during one period when interference over the home power lines caused a high error level. The cause of this error was addressed by relocating the TED gateway to a location directly adjacent to the main breaker panel. Errors were higher in end-use energy readings with the TED device ranging from $-2 \%$ to $+1 \%$ for domestic hot water and from $-4 \%$ to $+8 \%$ for the airconditioning equipment.

Total home energy reading errors with the eMonitor device consistently ranged from $-9 \%$ to $-11 \%$. End-use energy reading errors ranged more widely from $-8 \%$ to $+8 \%$ for water heater and airconditioning equipment.

Measured energy data were collected from the two feedback devices in different ways. TED data were collected on a weekly basis by directly contacting the internet-connected device through a browser interface. Collected data were reviewed on a monthly basis to verify data quality and review home performance. Problems with two TED devices prevented data collection during the first month (June 2011) but were corrected by early July 2011. Uninterrupted data have been collected since July 9, 2011. Data collection from the eMonitors proved less troublesome and less labor-intensive than with TED device. The eMonitor feedback device is also internet-connected, but in contrast to TED device the data are not stored locally (except for a 1-day buffer) and are continually pushed to a remote site where they can be accessed and downloaded periodically. A server at FSEC retrieved the eMonitor data on a daily basis and stored them locally. These data were reviewed periodically for overall quality and brief analysis. Interior temperature and RH readings were recorded in all homes by Hobo data loggers on an hourly basis to match the hourly energy data. The loggers were downloaded on 1- to 2-month intervals. Outdoor temperature and dewpoint were collected and stored on FSEC servers from National Weather Service stations located at airports in cities near the monitored homes.

\subsubsection{Atlanta Retrofit Homes}

Six retrofit homes located in metropolitan Atlanta, Georgia, were the first to receive monitoring equipment, beginning in early May 2011. ORNL recruited these homes and provided retrofit assistance (under a separate DOE contract from this project). The original ORNL project plan did not include

\footnotetext{
${ }^{2}$ http://www.theenergydetective.com
} 
monitoring, but it was added through a partnership with FSEC under the PNNL contract. Measured energy data have been continuously collected and stored at FSEC since April 2011. The data have been periodically reviewed for gross errors but have otherwise only been stored for ready access by ORNL.

\subsubsection{San Antonio Retrofit Homes}

Three retrofit homes in San Antonio, Texas, have been monitored since July 9, 2011. FSEC provided only monitoring assistance for these homes with retrofit support provided by Build San Antonio Green and home performance measurements performed by Calcs-Plus. These small homes (675 to 1,047 square feet) received extensive envelope and moderate equipment improvements, greatly increasing comfort and overall livability. Some of the homes were upgraded from window-unit air conditioners to central air and heat.

Figure 4.3 shows the area-adjusted cooling performance of the three homes in comparison to two new homes constructed in 2009. The new homes, built by Woodside Homes in San Antonio, had identical $1,979 \mathrm{ft}^{2}$ floor plans and were evaluated recently by Chasar et al. (2010). The two dashed regression lines represent measured data from the new homes collected during the summer of 2009. The standard practice new home (control) was constructed with a few components above the minimum building code requirements including a Seasonal Energy Efficiency Ratio (SEER) 14 air conditioner (similar to that used in the retrofits).

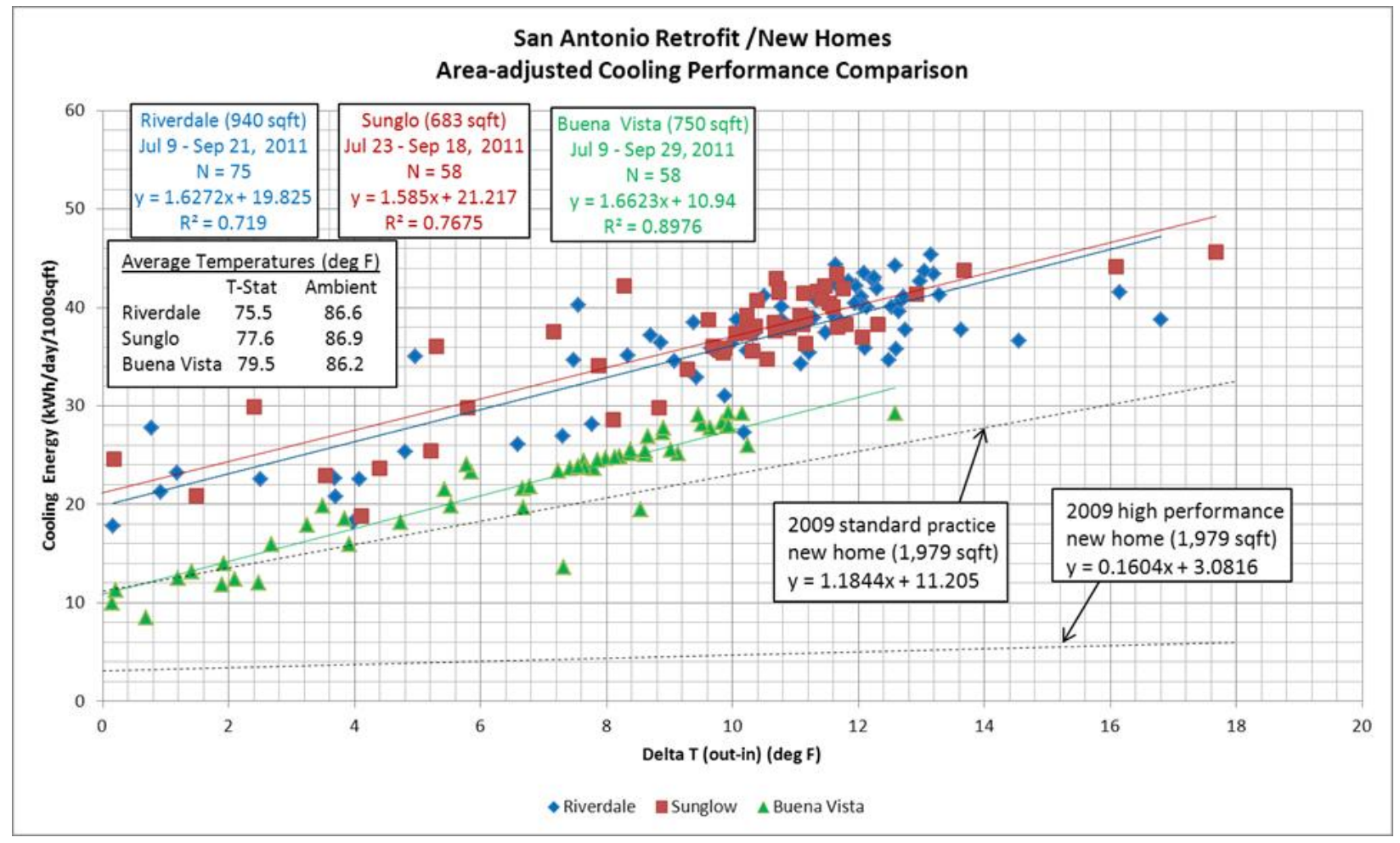

Figure 4.3. San Antonio Retrofit Cooling Performance Comparison 
The level of cooling performance in the retrofit homes, while not on par with the standard practice new home, exhibited a considerable degree of efficiency. The new homes are two to three times larger than the retrofits, making direct comparisons of cooling performance difficult. The smaller retrofit homes tend toward a higher level of interior loads from appliances and occupant activity common in homes of all sizes. This leads to higher cooling energy use on a square-foot basis. Table 4.1 compares retrofit cooling performance to the Woodside standard practice (control) home and includes Woodside's highest performing (improved) home as a best-case reference. Savings are derived from comparing areas under the linear regression lines over the Delta $\mathrm{T}$ (x-axis) values in Figure 4.3 from $0^{\circ} \mathrm{F}$ to $18^{\circ} \mathrm{F}$. One retrofit home (Buena Vista) used $18.5 \%$ more area-adjusted cooling energy than the control home. The other retrofits used roughly $60 \%$ more energy.

Table 4.1. San Antonio Measured Cooling Performance Comparison

\begin{tabular}{lccccc}
\hline \multicolumn{1}{c}{ Home } & $\begin{array}{c}\text { Year } \\
\text { Built }\end{array}$ & $\begin{array}{c}\text { HERS Index } \\
\text { Pre-Post }\end{array}$ & $\begin{array}{c}\text { Area/ } \\
\text { Size Factor }\end{array}$ & $\begin{array}{c}\text { Area Under } \\
\text { Regression Line }\end{array}$ & $\begin{array}{c}\text { Savings Relative } \\
\text { to Control (\%) }\end{array}$ \\
\hline Woodside control & 2009 & $\mathrm{n} / \mathrm{a}-86$ & $1,979 / 1 \mathrm{x}$ & 394 & NA \\
Woodside improved & 2009 & $\mathrm{n} / \mathrm{a}-37$ & $1,979 / 1 \mathrm{x}$ & 81 & 79.3 \\
Sunglo retrofit & $19 ? ?$ & $156-93$ & $675 /-2.9 \mathrm{x}$ & 639 & -62.3 \\
Riverdale retrofit & 1949 & $161-93$ & $1,047 /-1.9 \mathrm{x}$ & 620 & -57.7 \\
Buena Vista retrofit & 1950 & $150-88$ & $845 /-2.3 \mathrm{x}$ & 466 & -18.5 \\
\hline $\begin{array}{l}\text { HERS = home energy rating system } \\
\text { NA = not applicable }\end{array}$
\end{tabular}

Please note that the names Sunglo, Riverdale, and Buena Vista refer to homes TX-3, TX-1, and TX-2 in the summary Figure 3.1, respectively.

Utility bills were acquired for the San Antonio homes from both pre- and post-retrofit periods. The collected TED data and utility electric readings were compared over the same post-retrofit billing periods to validate the home-energy monitor against utility data. The comparison results were good, showing that the TED whole-house readings matched the billed kilowatt-hours ( $\mathrm{kWh}$ ) to $-2 \%$ to $+6 \%$ for two billing periods from each home with an average difference of $3 \%$.

Electric billing data were also used to assess post-retrofit cooling performance improvements. Cooling energy was estimated by averaging the electricity use from the three lowest bills and subtracting that value from each of the June through September bills. This method assumes that the lowest bills over the year approximate the non-cooling electricity use, and further assuming this level to be constant throughout the year yields estimated cooling energy when subtracted from the total monthly energy use during the cooling months. In addition, cooling degree days were obtained for the equivalent billing cycle and plotted against estimated cooling energy for each month. Linear regression analysis (not included in this report) showed reasonably well-fit data on two homes (Riverdale and Buena Vista) with $\mathrm{R}^{2}$ values between 0.78 and 0.99 and cooling energy-savings estimates of $41 \%$ and $54 \%$ when comparing the postcooling $\mathrm{kWh}$ with the pre-cooling $\mathrm{kWh}$. Pre-retrofit billing data from the third home (Sunglo) were far more scattered $\left(\mathrm{R}^{2}=0.22\right)$ and did not yield a meaningful comparison. 


\subsubsection{Florida Retrofit Homes}

Three retrofit homes in Venice, Eustis, and Sarasota, Florida, have been monitored since late summer 2011. Retrofit design assistance and performance testing was provided by FSEC on one home (Eustis) and by Calcs-Plus on the others.

Limited summer data were collected from two Florida retrofit homes (Venice [47 days] and Eustis [12 days]). Figure 4.4 shows a cooling performance comparison of these homes with data from two 1998, Central Florida homes used as benchmarks by Chasar et al. (2006). The benchmark homes have identical 2,400 $\mathrm{ft}^{2}$ floor plans, one built to 1998 standard practice with a SEER 10 cooling system, and the other a near-net-zero-energy home (ZEH) with a SEER 14.4 system. These homes were originally detailed by Parker et al. (1998).

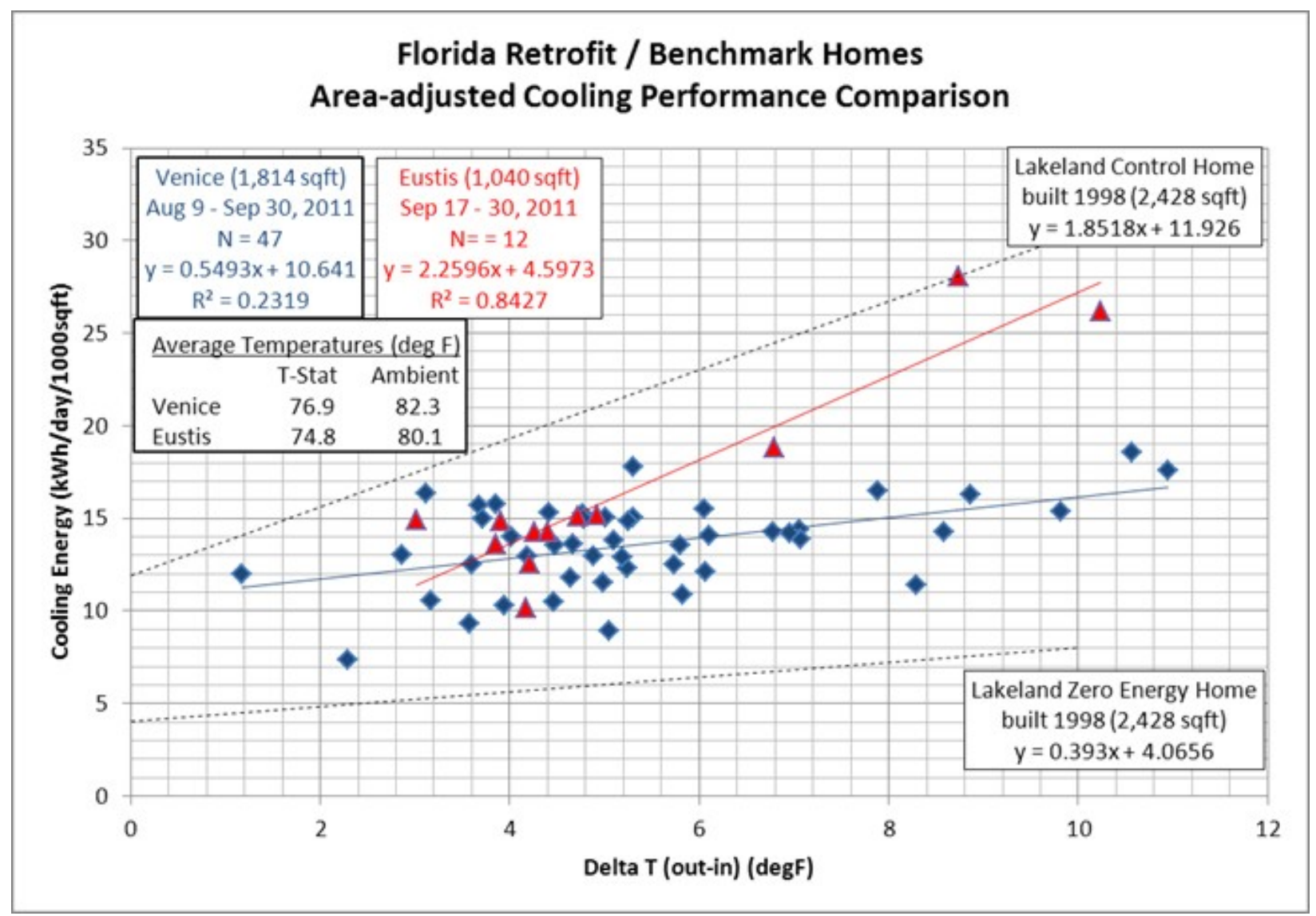

Figure 4.4. Florida Retrofit Cooling Performance Comparison

The Venice home provided nearly 7 weeks of cooling data, showing a trend of cooling energy savings over the 1998 control home (37\%) with significant scatter. The small sample size of the Eustis home (12 days) provided a limited assessment, showing cooling energy savings of $25 \%$ over the 1998 control home. Data from the 1998 near-ZEH home continues to set the bar for area-adjusted cooling performance efficiency, even when compared to more recent vintage homes with higher-efficiency equipment (Chasar et al. 2006). Additional retrofit data collection is planned for summer 2012 to enhance the cooling performance evaluation. 
Table 4.2. Florida Measured Cooling Performance Comparison

\begin{tabular}{llccccc}
\hline \multicolumn{1}{c}{ Home } & $\begin{array}{c}\text { Year } \\
\text { Built }\end{array}$ & $\begin{array}{c}\text { HERS Index } \\
\text { Pre-Post }\end{array}$ & Area & $\begin{array}{c}\text { A/C } \\
\text { SEER }\end{array}$ & $\begin{array}{c}\text { Area Under } \\
\text { Regression Line }\end{array}$ & $\begin{array}{c}\text { Savings Relative } \\
\text { to Control (\%) }\end{array}$ \\
\hline Lakeland Control & 1998 & NA & 2,428 & 10 & 212 & NA \\
Lakeland Near-ZEH & 1998 & NA & 2,428 & 14.4 & 60 & 71.5 \\
Venice Retrofit & 1978 & $185-57$ & 1,800 & 16.3 & 135 & 36.8 \\
Eustis Retrofit & $19 ? ?$ & $131-77$ & 1,040 & 13 & 159 & 25.0 \\
\hline A/C = air conditioner & & & & & \\
HERS = home energy rating system & & & & & \\
NA = not applicable & & & & & \\
ZEH = zero-energy home & &
\end{tabular}





\subsection{PNNL Lab Homes}

PNNL Lab Homes (http://labhomes.pnnl.gov/) is a first of its kind facility in the Pacific Northwest. PNNL has purchased two identical custom factory-built doublewide homes and set them up, side by side, on the PNNL campus to conduct energy research (Figures 5.1 and 5.2).

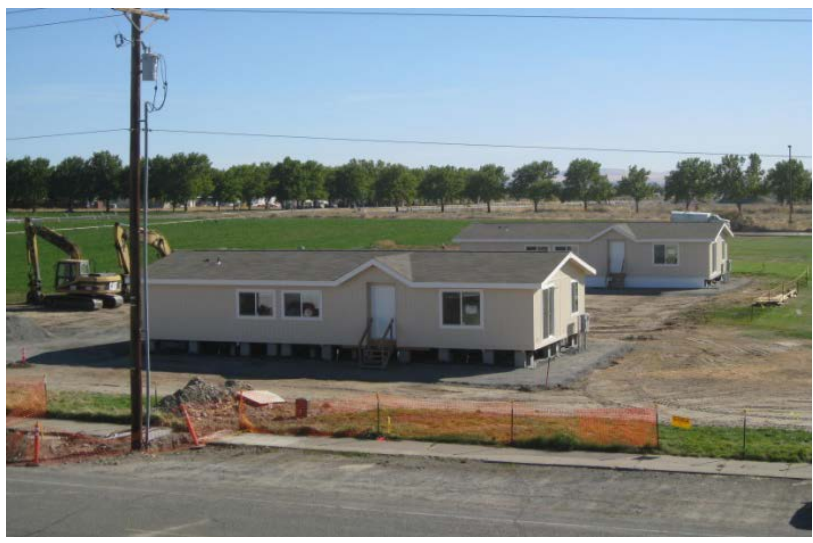

Figure 5.1. The Lab Homes During Setup in Late September 2011. The home in the foreground is the experimental home and the other is the baseline home.

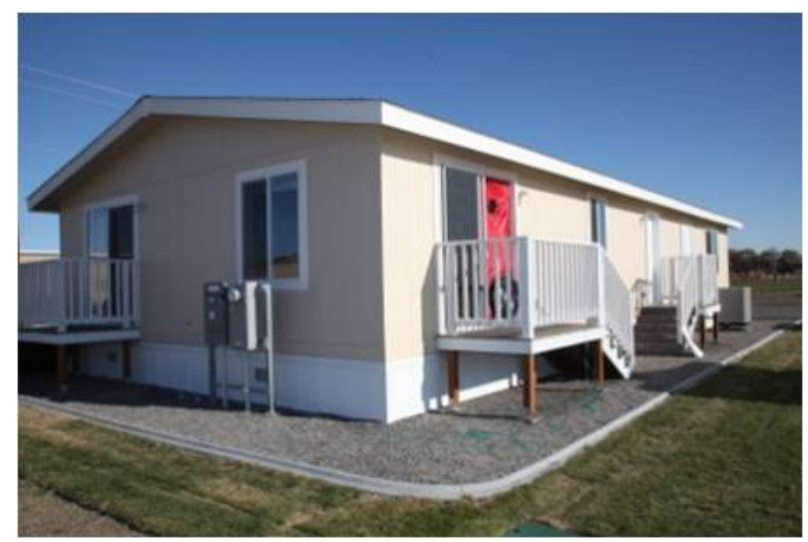

Figure 5.2. The Experimental Home in November 2011 Undergoing a Blower Door Test

PNNL, working with multiple sponsors, will use the identical 1,494 $\mathrm{ft}^{2} 3 \mathrm{BR} / 2 \mathrm{BA}$ Lab Homes for experiments focused on reducing energy use and peak demand. In each study, one home, the baseline home, will remain a control typifying an average, existing home in the Pacific Northwest, and the other, the experimental home, will test a new technology. Occupancy in each home will be simulated to account for human activity. The homes have been certified for occupancy by the City of Richland.

Lab Homes is a flexible research facility for PNNL and its research partners who aim to achieve highly energy-efficient homes. Homes are fully instrumented with controllable circuits, dual heating systems (a SEER 13 heat pump and in wall "Cadet" electric resistance fan-driven heaters), environmental sensors, and a weather station.

The first experiment will explore the performance of highly insulating (R-5) windows during the winter and summer of 2012 as compared to typical double-pane aluminum-framed windows. Additional research is planned to evaluate grid-friendly appliances and home energy automation systems and protocols funded by the DOE Office of Electricity and Energy Reliability.

The homes were procured by pooling multiple funding sources:

- DOE/Energy Efficiency and Renewable Energy (BA and Emerging Technology programs)

- DOE/Office of Electricity Delivery and Energy Reliability

- Bonneville Power Administration

- PNNL Facilities

- Tri-Cities Research District (signs)

- City of Richland (smart meters/upsized transformer) 
- Battelle Memorial Institute (made land available)

- GE Appliances (grid-friendly appliances).

\subsection{Lab Homes Procurement Process, Characteristics, and Status Through December 2011}

The Lab Homes effort began in fall 2010 after Battelle made the land available on the PNNL campus near the Battelle 6th Street warehouse. Initially the thought was to procure the homes manufactured in the factory with the different windows, dual heating systems, and additional electrical wiring (so that more circuits could be individually measured). In addition, a sophisticated commercial-grade 42-breaker electrical panel with 24 programmable and controllable breakers was specified to simulate human occupancy. Specifications were prepared and the homes were solicited via a competitive bid. Unfortunately, PNNL did not receive a single bid. The end date was extended for another month and in March 2011 one bid was received - over the allocated budget. The decision was made to start over with a new approach.

The new approach was to procure the services of a general contractor who would purchase two identical, standard double-wide homes which meet the U.S. Department of Housing and Urban Development code for manufactured housing from a factory builder (Marlette Homes) near PNNL, transport and set up the homes, and undertake the structural, electrical, and window modifications to both homes. The revised specifications, which included additional site preparation work required by the City of Richland, were issued in June. PNNL received four bids in July. The low bid was from Total Site Services for slightly less than $\$ 400,000$. That bid was accepted.

The homes arrived on campus in September 2011 and setup was nearly completed by early November when PNNL engineers and a consultant (Efficiency Solutions) began the instrumentation effort. A ribbon-cutting ceremony was held on November 15. Attendance was over 100 and included funding partners, regional energy-efficiency organizations, and PNNL staff and management. At that time airtightness and infrared (IR) camera tests were performed by consultants (Northwest Energy Works and Washington State University-Extension Energy) and PNNL staff. Table 5.1 shows results of the measured airtightness and airflow tests. Figures 5.3 and 5.4 provide the initial IR scans of the Lab Homes.

Table 5.1. Measured Characteristics of the Lab Homes on November 15, 2011

\begin{tabular}{lcc}
\hline & Experimental & Baseline \\
\hline House airtightness at -50 Pa, CFM50 & 718 & 676 \\
House airtightness at -50 Pa, ACH50 & 3.5 & 3.3 \\
Duct airtightness to outside at -25 Pa, (cfm/floor area) & 0.038 & 0.048 \\
Air handler flow (cfm) & 875 & 927 \\
Whole-house ventilation fan flow (cfm) & 50 & 49 \\
\hline
\end{tabular}




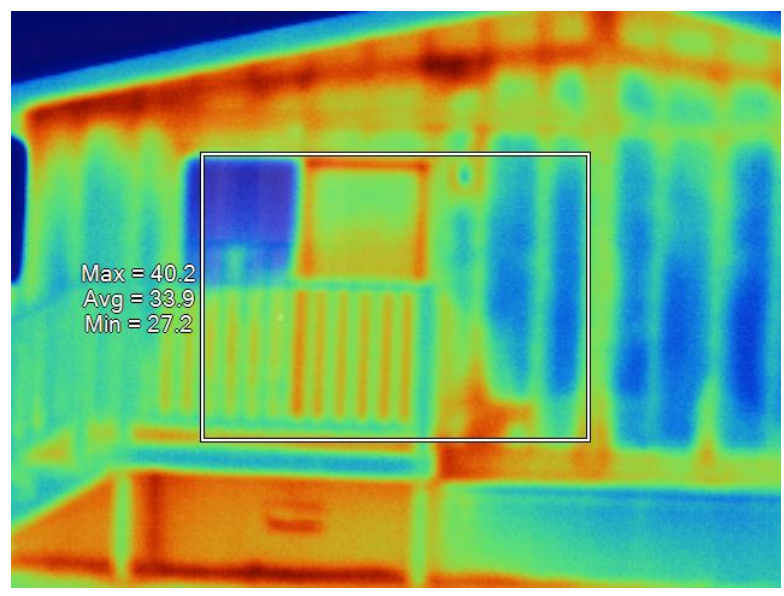

Figure 5.3. Experimental Home Exterior IR Scan of West Wall and Sliding Glass Door

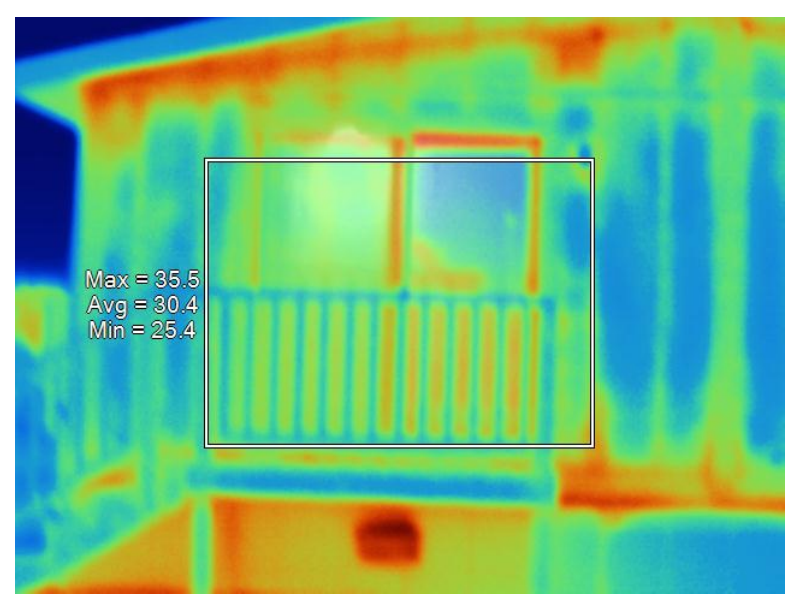

Figure 5.4. Baseline Home Exterior IR Scan of West Wall and Sliding Glass Door

As of the end of December, the instrumentation on both homes was nearly complete and targeted to be $100 \%$ complete by early January 2012 . Then, null tests will be conducted to quantify the difference in airtightness and heating energy performance in these identical homes. Next, the windows and sliding glass doors in both homes will be replaced. The experimental home will receive the R-5 triple-pane vinyl product (U-factor $=0.18$ to 0.20 ; Solar Heat Gain Coefficient $[\mathrm{SHGC}]=0.28$ ) and the baseline home will receive the standard double-pane metal product (U-factor $=0.54$ to 0.68 ; $\mathrm{SHGC}=0.58)$. After the experimental home is retrofitted with the R-5 windows and the baseline home with the aluminum-framed windows, the flows and airtightness will be re-measured. House and duct sealing will be done and fan flows adjusted to make the airtightness and airflow characteristics of the two homes as close to identical as possible. That way, the window experiment will be evaluating only the impact of the highly insulating windows. The windows experiments are slated to begin in late January 2012.

The homes have two sliding glass doors and windows to have a total fenestration area of about 191 $\mathrm{ft}^{2}$, which is $12.8 \%$ of the conditioned floor area of $1,494 \mathrm{ft}^{2}$. This is more glass than typical manufactured homes have but closer to glazing amounts found in site-built homes. The ceiling, wall, and floor insulation levels are R22 blown fiberglass, R11 fiberglass batts, and R22 fiberglass (R11 batts +R11 blankets), respectively. The homes have a perimeter duct system with through-the-floor perimeter crossover ducts. The ceiling in the interior is sloped, the interior wall height at the perimeter is $7.5 \mathrm{ft}$, and at the ceiling peak the height is $9.17 \mathrm{ft}$. The total house volume is $12,452 \mathrm{ft}^{3}$.

The walls are $2 \times 6$ frame walls and were intentionally procured with R-11 wall insulation typical of existing homes. IR scans on a cold evening (November 15, 2011) when the outdoor temperature was in the low 20s and indoor temperatures were in the low 70s showed (Figures 5.3 and 5.4) non-uniform wall temperatures - as are typically found in existing homes.

\subsection{Instrumentation and Control Systems}

Each home is being instrumented identically and extensively. All metering will be done using research-grade Campbell Scientific data loggers and sensors or equivalent. Two Campbell data loggers will be used per home, one allocated to electrical measurements and one to temperature and other data collection. All data will be collected on a regular interval and processed. 
Tables 5.2 and 5.3 below describe the planned instrumentation channels. Not all channels will necessarily be measured for all experiments.

Table 5.2. Electrical Metering for Each Home

\begin{tabular}{lll}
\hline \multicolumn{1}{c}{ Performance Metric } & \multicolumn{1}{c}{ Monitoring Method/Points } & \multicolumn{1}{c}{ Monitored Variables } \\
\hline Whole Building Energy Use & $\begin{array}{l}\text { Panel mains } \\
\text { Utility smart meter }\end{array}$ & $\mathrm{kW}$, amps, volts, PF \\
HVAC Energy Use (heat pumps) & $\begin{array}{l}\text { Panel metering compressor } \\
\text { Panel metering AHU/back-up resistance } \\
\text { elements } \\
\end{array}$ & $\mathrm{k}$ Panel/end-use metering condensing unit fan and \\
& $\begin{array}{l}\text { controls } \\
\text { Panel metering each unit heater }\end{array}$ & $\mathrm{kW}$, amps, volts, PF \\
& $\begin{array}{l}\text { Panel metering of } 3 \text { ventilation breakers } \\
\text { (2 bathrooms and whole house) }\end{array}$ & $\mathrm{kW}$, amps, volts, PF \\
HVAC Energy Use (wall unit & $\mathrm{kW}$, amps, volts, PF \\
HVAC Energy Use (ventilation) & $\begin{array}{l}\text { Panel metering of water heater breakers } \\
\text { Panel metering of all appliance and lighting } \\
\text { Water Heating }\end{array}$ & $\mathrm{kW}$, amps, volts, PF \\
Appliances and Lighting & $\mathrm{kW}$, amps, volts, PF \\
\hline AHU = air handling unit; PF = power factor & \\
\hline
\end{tabular}

Table 5.3. Temperature, Humidity, and Other Metered Parameters

\begin{tabular}{lll}
\hline \multicolumn{1}{c}{ Performance Metric } & \multicolumn{1}{c}{ Monitoring Method/Points } & Monitored Variables \\
\hline Space Temperatures & $\begin{array}{l}\text { Dry bulb/at least 11 sensors per home (3 bedrooms, } \\
\text { living room, dining room, kitchen, bathrooms, utility } \\
\text { rooms, water heater closet, entry, and hallway) } \\
\text { Mean radiant/2 sensor per home; plan for one in living } \\
\text { room and one in master bedroom. }\end{array}$ & Temperature, Deg. F \\
& $\begin{array}{l}\text { Percent relative humidity/2 sensors per home (hallway } \\
- \text { near bathrooms and living room) }\end{array}$ & \% RH \\
Space Relative Humidity & $\begin{array}{l}\text { Thermocouple/2 sensors per window (center of glass, } \\
\text { interior and exterior); one window instrumented with }\end{array}$ & Temperature, Deg. F \\
Glass Surface Temperatures & 6 sensors (3 interior and 3 exterior) & \\
& Pyranometer /1 sensor per home & Watts/m ${ }^{2}$ \\
Through-Glass Solar & Package station outputs & Outside temperature \\
Radiation & & Outside humidity \\
Meteorological Station & & Wind speed \\
& & Wind direction \\
& & Barometric pressure \\
& & Rainfall \\
Total water and hot water & Gallons per interval \\
\hline
\end{tabular}


Exterior and interior surface-mounted conduits are used to enclose the instrumentation and control wiring as well as the additional electrical wiring done for individual control of circuits. Figures 5.5 through 5.12 show some of the details of the Lab Homes. Pictures used in Figures 5.5 through 5.12 were taken on December 22, 2011.

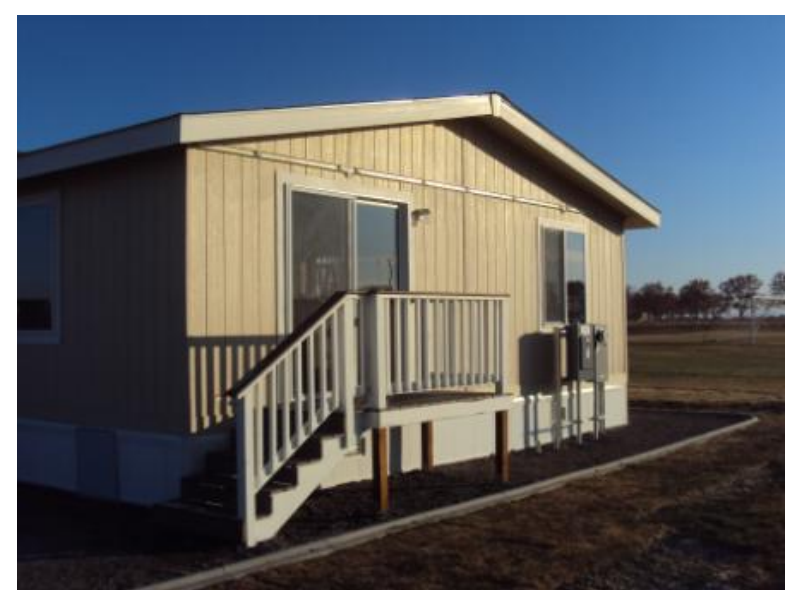

Figure 5.5. West End of Baseline Home. Note conduit tray (above slider and window) to hold exterior thermocouple wiring.

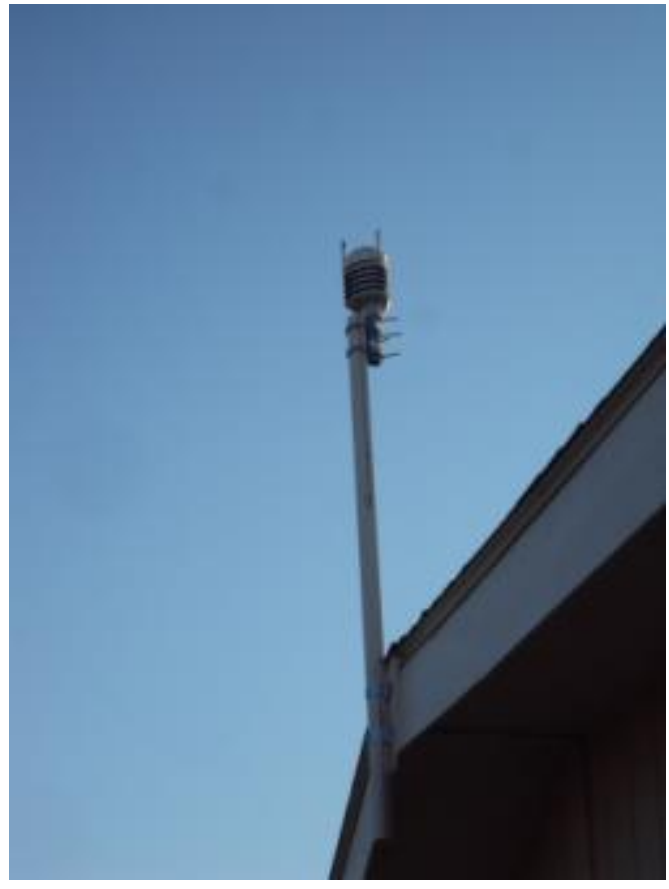

Figure 5.7. Weather Station on East End of the Experimental Home

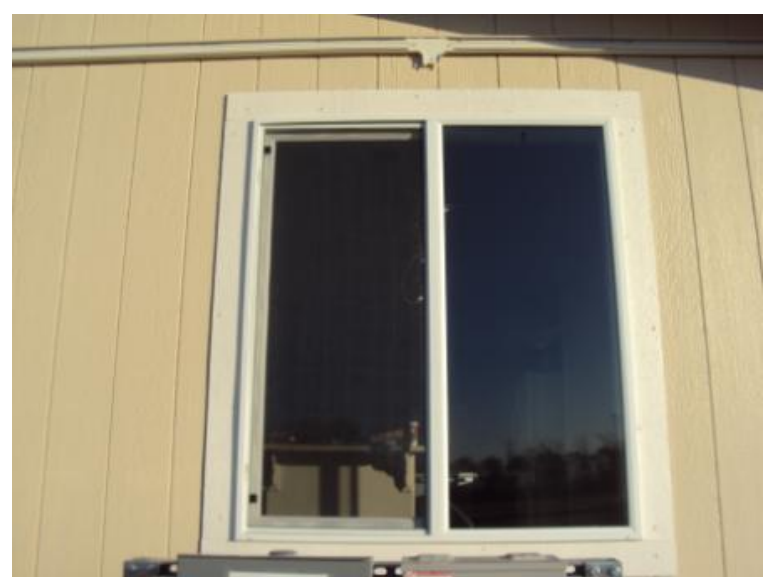

Figure 5.6. Window on West End of Experimental Home. Note conduit and " $T$ " above window ready for thermocouple installation.

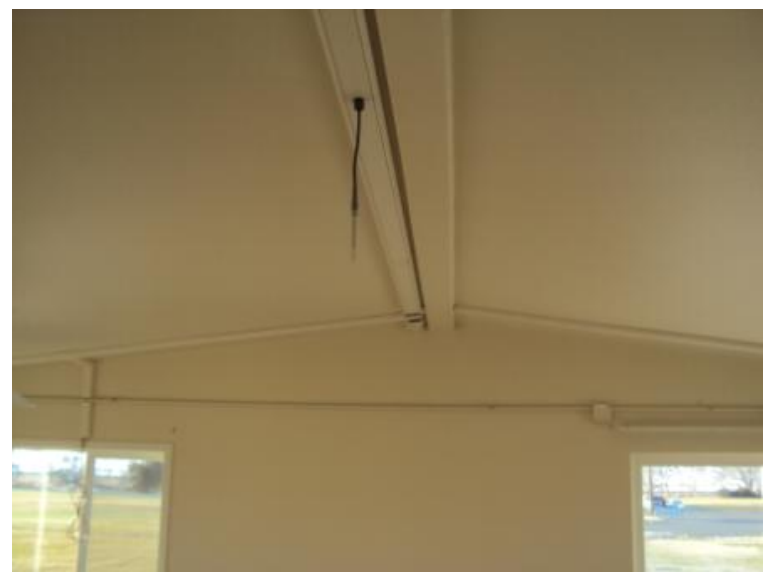

Figure 5.8. Conduit Running Parallel to the House Marriage Line. Interior RH sensor is attached to the conduit. 


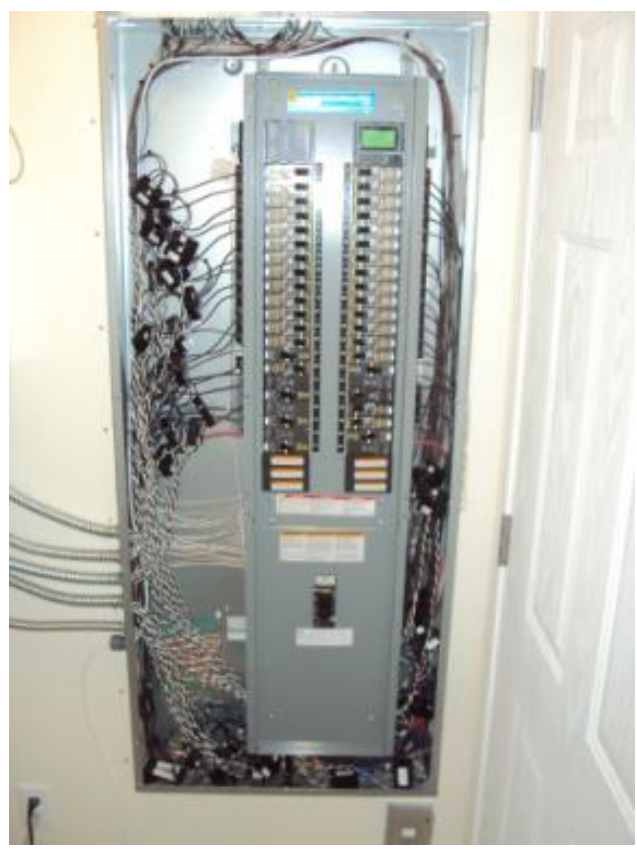

Figure 5.9. Fully Instrumented Electrical Panel with Current Transformers on All 42 Circuits

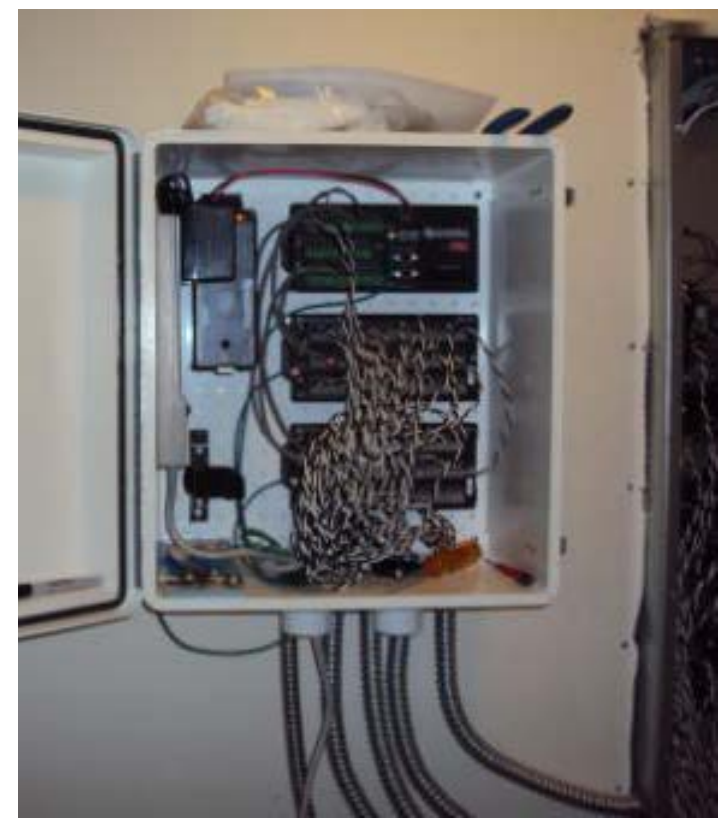

Figure 5.11. The Campbell Scientific Data Logger and Termination Panels Used to Measure Electrical Power via Circuit Transducers

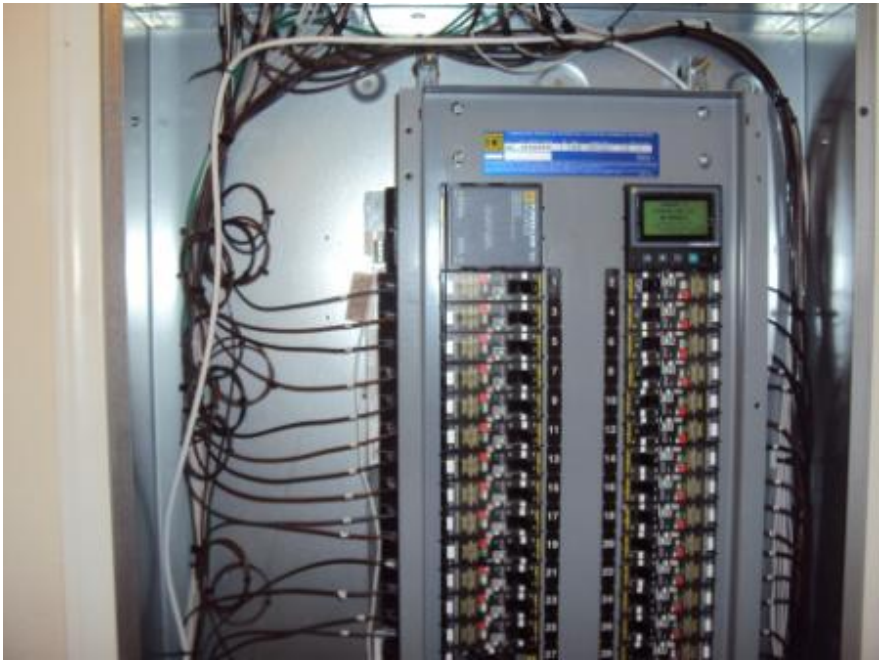

Figure 5.10. Close-Up of the Electrical Panel. Note the manually programmable interface (top right) to control the breakers and the loops on the conductor wire to increase measurement accuracy.

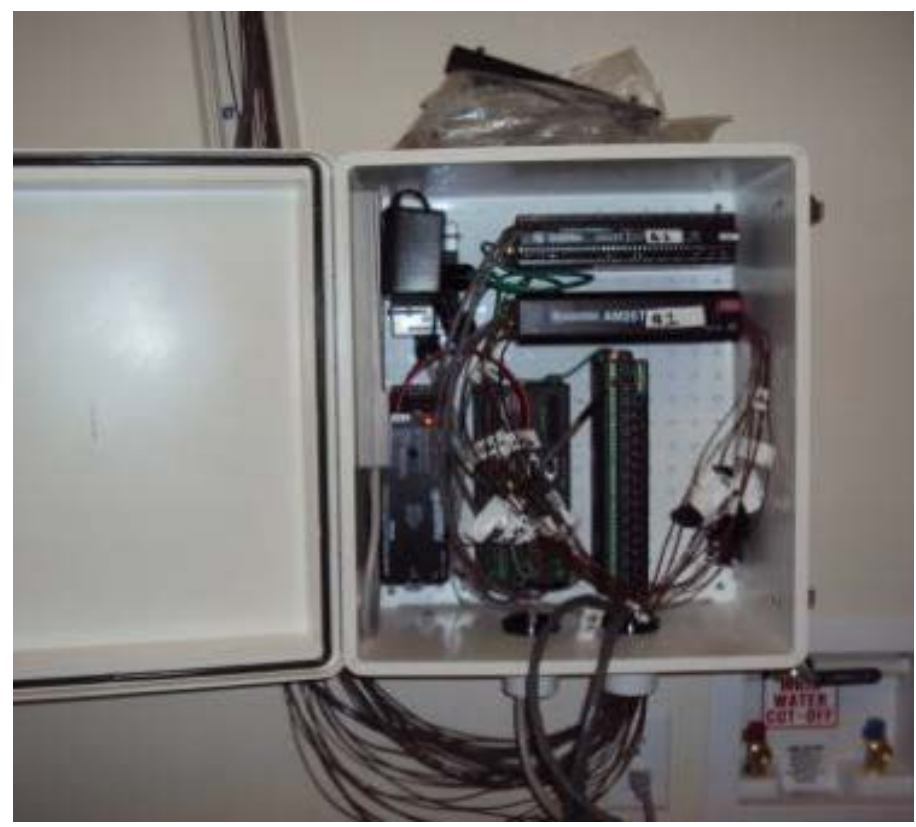

Figure 5.12. The Second Data Logger Used to Measure Temperature, Humidity, and Other Parameters as Well as Control Functions. 


\subsection{Occupancy Simulation}

The Lab Homes will be unoccupied and access to them will be restricted and logged when experiments start. Occupancy will be simulated by turning on light bulbs and heaters, running the wholehouse ventilation fan, and introducing moisture loads in the space. Automation will be controlled by either a Campbell data logger or the controllable breakers in the electrical panel box. No hot water draws are planned for the initial windows experiment for 2012, although the water heater will be turned on and set to $120^{\circ} \mathrm{F}$. The occupancy simulation scheduled will be patterned in accordance with the BA protocols, totaling about $15 \mathrm{kWh} /$ day for internal sensible loads (lights, appliances, and occupancy) and 12 pounds/day for internal moisture loads. This is similar to the internal loads (Figure 5.13) at the FSEC Lab Homes facility in Cocoa, Florida, which are also about $1,500 \mathrm{ft}^{2}$ each.

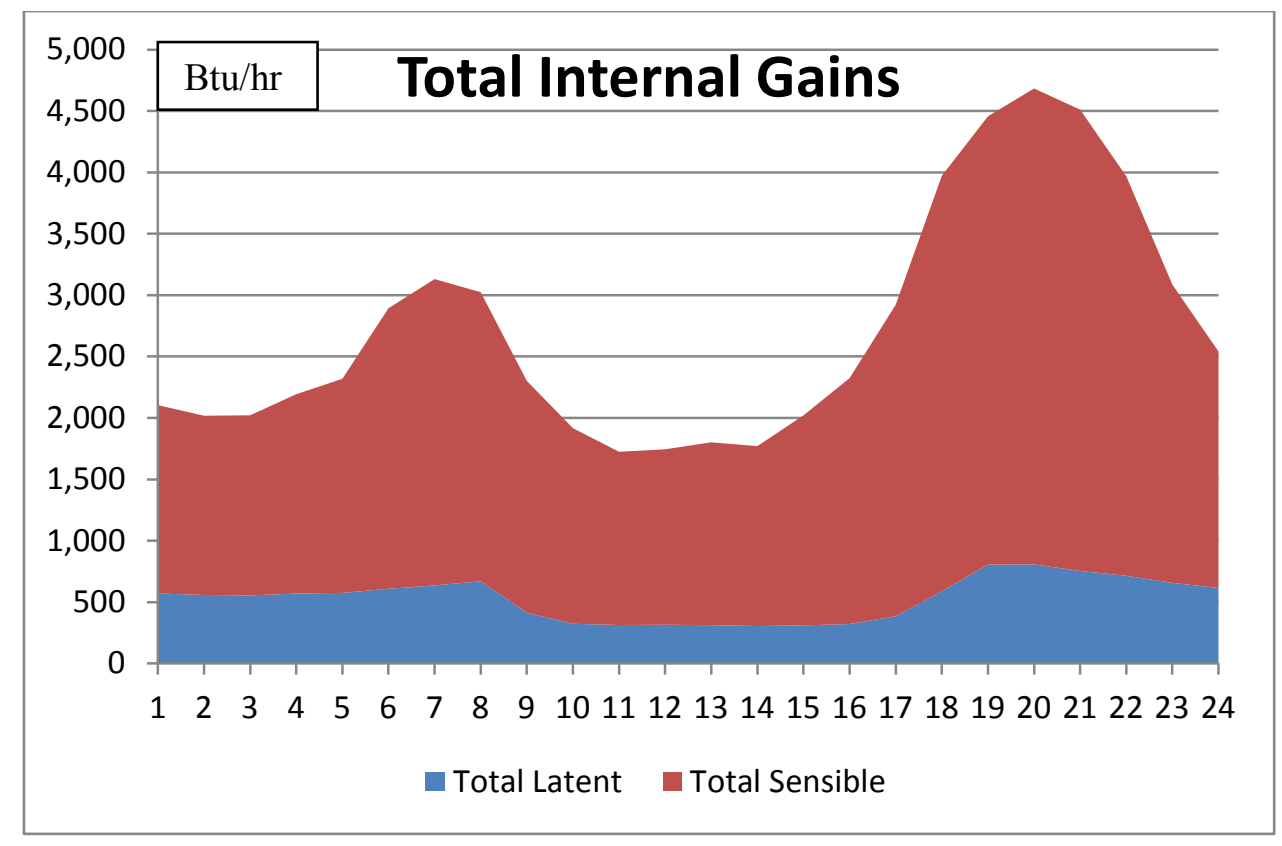

Figure 5.13. Internal Loads Imposed at the FSEC Lab Homes Facility for Each Hour of the Day (courtesy of FSEC) 



\subsection{References}

AEC (Architectural Energy Corporation). 2010. REM/Rate (version 12.96) [Software]. Boulder, Colorado. Retrieved from: http://www.archenergy.com/products/remrate (November 2011).

Akerlof K, R Debono, P Berry, A Leiserowitz, C Roser-Renouf, KL Clarke, A Rogaeva, MC Nisbet, MR Weathers, and EW Maibach. 2010. "Public Perceptions of Climate Change as a Human Health Risk: Surveys of the United States, Canada and Malta." International Journal of Environmental Research and Public Health. 7:2559-606.

American Recovery and Reinvestment Act of 2009. 2009. Public Law 111-5, 123 Statute 115.BA, Program Goals. Accessed December 2011 at

http://www1.eere.energy.gov/buildings/building_america/program_goals.html.

BEDB (Buildings Energy Data Book). 2011. The Buildings Energy Data Book, Table 2.2.1. Accessed December 2011 at http://buildingsdatabook.eren.doe.gov/TableView.aspx?table=2.2.1.

Blasnik M. 2006. Ohio Electric Partnership Program Impact Evaluation. Prepared for the Ohio Office of Energy Efficiency. Michael Blasnik and Associates, Boston, Massachusetts

Blasnik M. 2007. New Hampshire Weatherization Program Impact Evaluation Report. Prepared for the New Hampshire Office of Energy and Planning. Michael Blasnik and Associates, Boston, Massachusetts.

BPI (Building Performance Institute). 2005. Technical Standards for Certified Building Analyst I. Malta, New York. Accessed November 2011 at http://www.bpi.org/documents/Building_Analyst_Standards.pdf.

Chasar D, V vonSchramm, J Sherwin, and S Chandra. 2010. Measured Performance of Side-by-Side South Texas Homes. FSEC-PF-453-10, Florida Solar Energy Center, Cocoa, Florida. Available at http://www.fsec.ucf.edu/en/publications/pdf/FSEC-PF-453-10.pdf.

Chasar D, S Chandra, D Parker, J Sherwin, D Beal, D Hoak, N Moyer, and J Mcilvaine. 2006. Cooling Performance Assessment of Building America Homes. FSEC-CR-1673-06, Florida Solar Energy Center, Cocoa, Florida. Available at http://www.ba-pirc.org/pubs/cooling/index.htm.

EIA (U.S. Energy Information Administration). 2010. July 2010 Monthly Energy Review: Energy Consumption by Sector. DOE/EIA-0035, EIA, U.S. Department of Energy, Washington, D.C. Accessed November 2011 at http://www.eia.gov/FTPROOT/multifuel/mer/00351007.pdf.

FSEC (Florida Solar Energy Center). 2011. EnergyGauge USA (version 2.8.05) [Software]. Cocoa, Florida. Accessed November 2011 at http://energygauge.com/usares/default.htm.

Fuller M, C Kunkel, M Zimring, I Hoffman, KL Soroye, and C Goldman. 2010. Driving Demand for Home Energy Improvements. LBNL-3960E, Lawrence Berkeley National Laboratory, Berkeley, California. Available at http://drivingdemand.lbl.gov/ 
Jackson R, EJ Kim, and S Roberts. 2011. Advancing Residential Retrofits in Atlanta. Draft report, Oak Ridge National Laboratory, Oak Ridge, Tennessee.

NREL (National Renewable Energy Laboratory). 2010. BeOpt (version 1.1) [Software]. Golden, Colorado. Accessed November 2011 at https://beopt.nrel.gov/home.

Parker DS, JP Dunlop, JR Sherwin, SF Barkaszi, Jr., MP Anello, S Durand, D Metzger, and JK Sonne. 1998. Field Evaluation of Efficient Building Technology with Photovoltaic Power Production in New Florida Residential Housing. FSEC-CR-1044-98, Florida Solar Energy Center, Cocoa, Florida. Available at http://www.fsec.ucf.edu/en/publications/html/FSEC-CR-1044-98/index.htm

Schweitzer M. 2005. Estimating the National Effects of the U.S. Department of Energy's Weatherization Assistance Program with State-Level Data: A Metaevaluation Using Studies from 1993 to 2005. ORNL/CON-493, Oak Ridge National Laboratory, Oak Ridge, Tennessee.

U.S. Census Bureau. 2011. "New Residential Construction Chart." Accessed December 2011 at http://www.census.gov/briefrm/esbr/www/esbr020.html.

Widder S and M Baechler. 2011. Potential Health and Safety Impacts of Residential Energy Retrofits A Review of the Literature. PNNL-20231, Pacific Northwest National Laboratory, Richland, Washington. 


\section{Appendix A}

PNNL Research Protocol for Conducting Pilot Deep Energy Retrofits in Residences 



\section{Appendix A}

\section{PNNL Research Protocol for Conducting Pilot Deep Energy Retrofits in Residences}

Compiled and developed by Sarah Widder, James Hand, and Subrato Chandra as part of work funded by the U.S. DOE Building America Program under Pacific Northwest National Laboratory (PNNL) project 59043. We are grateful to the Florida Solar Energy Center, Calcs-Plus, and Building Performance Institute for sharing their protocols with us.

Point of Contact: Sarah Widder; Email: sarah.widder@pnl.gov Phone: (509)372-6396

This protocol was developed to provide technical assistance for conducting pilot deep energy retrofits on at least 50 residences throughout the United States that are estimated to save $30 \%$ to $50 \%$ + in energy use. The protocol was developed for use by PNNL researchers and project subcontractors and project collaborator Oak Ridge National Laboratory (ORNL) to ensure the most efficient and effective home recruitment and data collection. For any given home only parts of this comprehensive protocol may be used, depending on the specific needs of the project. While this PNNL human research protection program (HRPP) approved protocol was developed for use in owner-occupied homes, parts of it may be used for vacant foreclosed homes or for rented dwellings. The protocol for each home will include several phases, as outlined in Table A.1 below.

Table A.1. Summary of Key Project Phases, Associated Activities, and Documentation for Completion of Deep Energy Retrofit Research Project

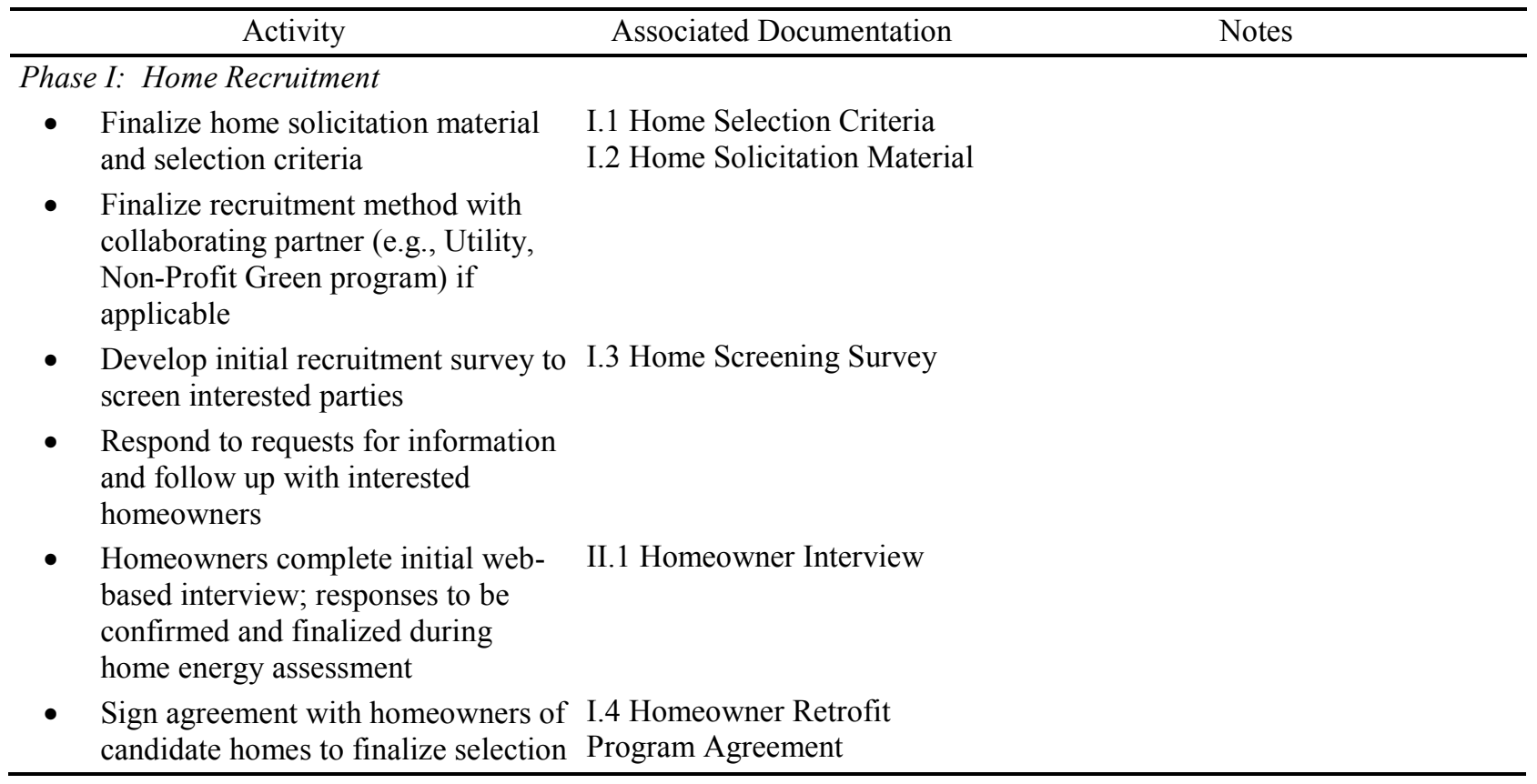


Table A.1. (contd)

\begin{tabular}{ccc}
\hline Activity & Associated Documentation & Notes \\
\hline Phase
\end{tabular}

II: Test-In

- Perform preliminary home audit and II.2 Pre-Retrofit Home Energy homeowner interview

Assessment

Test to include follow-up homeowner interview, blower door depressurization tests, infrared infiltration tests, duct leakage tests, combustion tests, air handler flow and pressure tests, and indoor air-quality tests

- Run results from home audit in several software programs and develop recommendations and budget

Phase III: Perform Retrofit

- If recommended retrofit measures represent sufficiently significant energy savings, install metering equipment in the home

- Secure incentives, if applicable

- Homeowner chooses contractor(s) to perform retrofit work

- Homeowner facilitates discussion between Battelle and contractor

- Install initial instrumentation (in homes that will be metered)

- Work with subcontractor(s) to verify quality of installed retrofit measures

Phase IV: Test-out

- Perform post-retrofit home audit to measure level of savings achieved

- Identify items that do not meet specification and propose measures to correct.

- Provide report of results to homeowner
II.3 Homeowner Metering Agreement

Will work with homeowner for approval before installation of metering equipment (initial point of contact should make request). Ideally, metering equipment will be installed before the retrofit. It may also be installed during the retrofit work or the post-retrofit audit.

PNNL or collaborator may provide a list of qualified contractors

This is crucial to ensuring the scope of work is clearly communicated and to the cost component of the study

IV.1 Post-retrofit Home Energy Assessment including homeowner questionnaire
Test to include blower door depressurization tests, infrared infiltration tests, duct leakage tests, combustion tests, and indoor air-quality tests.

Phase V: Continued Evaluation

- Continued monitoring and/or bill analysis

- $\quad$ Remove metering equipment after needed data have been collected (at least a few months after the retrofit).

- Follow-up questionnaire regarding retrofit outcome 


\section{A.1 Phase I.1: Selection Criteria for Participation in PNNL Retrofit Research Program}

The criteria outlined in Table A.2 may be used to select homes that are good candidates to participate in the residential deep energy retrofit study. The criteria are not definite disqualifiers, rather they will be examined for each home to determine eligibility.

Table A.2. Selection Criteria for Participation in PNNL Retrofit Research Program

\begin{tabular}{|c|c|c|}
\hline Variable & Criteria for Selection & Justification \\
\hline Remodeling scope & $\begin{array}{l}\text { Owners will be making or will } \\
\text { consider improvements to a } \\
\text { combination of heating/cooling } \\
\text { system, water heater, } \\
\text { appliances, windows, } \\
\text { insulation, lighting, fans, air- } \\
\text { sealing, etc. }\end{array}$ & $\begin{array}{l}\text { Ensures that homeowners are open to the } \\
\text { potential scope of a deep energy retrofit }\end{array}$ \\
\hline Age of home & At least 5 years old & $\begin{array}{l}\text { Older homes generally more cost-effective to } \\
\text { retrofit }\end{array}$ \\
\hline Size of home & Prefer less than $3,000 \mathrm{ft}^{2}$ & $\begin{array}{l}\text { Aims to serve middle class and affordable } \\
\text { homes }\end{array}$ \\
\hline Typical utility bill amount & $\begin{array}{l}\text { Prefer higher than average } \\
\text { usage and utility rate (to be } \\
\text { quantified based on region) and } \\
\text { significant difference between } \\
\text { peak and low month }\end{array}$ & $\begin{array}{l}\text { Shorter payback for retrofit measures in homes } \\
\text { with greater initial energy use, thus owners } \\
\text { likely to be more motivated to do deep energy } \\
\text { retrofits. High difference between peak and low } \\
\text { month indicates greater opportunities for } \\
\text { envelope and equipment improvements }\end{array}$ \\
\hline $\begin{array}{l}\text { Business (e.g., catering, day } \\
\text { care) or unusual energy- } \\
\text { intensive equipment in homes }\end{array}$ & $\begin{array}{l}\text { No extreme energy-using } \\
\text { businesses (small home office } \\
\text { OK) }\end{array}$ & Higher energy usage (confounder) \\
\hline Period of time house is occupied & $\begin{array}{l}\text { Year-round (not vacation home } \\
\text { or second home) }\end{array}$ & Not representative energy-use pattern \\
\hline Home is occupied by & Owner & Authority to perform retrofit activities \\
\hline Number of occupants & & $\begin{array}{l}\text { Large number of occupants could confound } \\
\text { energy-savings data }\end{array}$ \\
\hline $\begin{array}{l}\text { Reported severe mold, asbestos, } \\
\text { lead paint or other issues that } \\
\text { would prevent safe retrofits }\end{array}$ & None & Lawsuit, expert testimony, etc. Bad exposure \\
\hline Planned sale or move & No & $\begin{array}{l}\text { No opportunity to retest after retrofit and/or } \\
\text { different pre- and post-retrofit energy-use } \\
\text { information }\end{array}$ \\
\hline Planned addition & Undesirable & Difficult to compare before versus after data \\
\hline Smoking is allowed in the home & No & $\begin{array}{l}\text { Greater opening of windows (confounder), non- } \\
\text { representative indoor air quality (IAQ) }\end{array}$ \\
\hline $\begin{array}{l}\text { Windows are routinely left open } \\
\text { in summer or winter when } \\
\text { heating ventilation and air- } \\
\text { conditioning equipment is } \\
\text { operating }\end{array}$ & No (spring or fall OK) & Confounder \\
\hline
\end{tabular}


Table A.2. (contd)

\begin{tabular}{lll}
\hline Variable & Criteria for Selection & Justification \\
\hline Heating and cooling method & Must have central forced-air & Other systems would be non-representative \\
& heating or cooling system. & \\
& Evaporative coolers, large \\
& whole-house fans, wood stoves \\
& or wood fireplaces cannot serve \\
& as the primary heating or \\
& cooling system. Gas or electric \\
& fireplace ok. \\
\hline
\end{tabular}

\section{A.2 Phase I.2: Sample Invitation for Participation in Retrofit Research Program}

Dear (homeowner),

Are you interested in saving money on your utility bills? Do you wish your home used less energy? [enter local partner] is partnering with Pacific Northwest National Laboratory (PNNL) to help homeowners achieve 30 to 50 percent energy savings through home efficiency retrofits! A number of incentives available through [enter local utility], a free home energy assessment, and free technical assistance from one of the nation's leading national laboratories can help make energy retrofitting affordable, now and in the long run.

In addition, your house will be part of a research study for PNNL that can help inform the nation about retrofit best practices. PNNL and [enter local partner] are looking for homes that meet the following criteria:

- Home is built prior to 2005 (at least 5 yrs old)

- Do not have business (other than small home office) or other unusual energy-intensive equipment in the home

- Are occupied year-round by the owner
- Do not allow smoking in the home

- Primarily use a central heating and cooling system (wood stoves, fireplaces, whole-house fans or other unusual systems cannot be primary heating or cooling system)

- Do not open windows often when the HVAC system is on

If your home meets the preceding criteria and you are interested in saving money on your utility bills and improving the IAQ and comfort in your home, please contact [enter local partner] or complete the online form at XXXX (URL)to express your interest or for more information by DATE.

Please note: Participation in this research project will include construction activity that may produce elevated levels of particulate matter and chemical emissions during the days such activity is conducted and for up to a few days after that. This normally does not pose a hazard to healthy persons, but persons with acute respiratory illness, multiple chemical sensitivities, or other diseases or sensitivities may experience aggravated symptoms as a result of this activity. Homeowners are urged to consider this factor before choosing to participate in this study. 


\section{A.3 Phase I.3: Initial Homeowner Screening Survey for Participation in Retrofit Research Program}

This form is completed by homeowners through a web-based survey tool. Upon completion of the survey, homeowners will be contacted regarding their eligibility and interest in participating in the deep energy retrofit program.

\section{DEEP ENERGY RETROFIT RESEARCH PROGRAM INFORMATION REQUEST}

Please answer the following questions to find out more information about the Retrofit Research Program and how to get involved!

Table A.3. Questions Included in Deep Energy Retrofit Research Program Homeowner Information Request

\begin{tabular}{|c|c|}
\hline Question & Answer \\
\hline \multicolumn{2}{|l|}{ Name } \\
\hline \multicolumn{2}{|l|}{ Street Address } \\
\hline \multicolumn{2}{|l|}{ City, State, and Zip Code } \\
\hline \multicolumn{2}{|l|}{ Telephone Number } \\
\hline \multicolumn{2}{|l|}{ Email } \\
\hline \multicolumn{2}{|l|}{ Best way to contact you } \\
\hline \multicolumn{2}{|l|}{$\begin{array}{l}\text { Are you planning on investing in your homes energy } \\
\text { efficiency? To achieve } 30-50 \% \text { savings, investments of } \\
\$ 7,000-\$ 20,000 \text { are typically necessary (rebates, tax } \\
\text { credits and low-interest loans can help pay for upgrades) }\end{array}$} \\
\hline \multicolumn{2}{|l|}{$\begin{array}{l}\text { Are any major appliances or equipment in need of } \\
\text { replacement? (Refrigerator, HVAC system, hot water } \\
\text { heater, lighting and fans etc.) }\end{array}$} \\
\hline \multicolumn{2}{|l|}{ Year home was built } \\
\hline \multicolumn{2}{|l|}{ How many stories is your home? } \\
\hline \multicolumn{2}{|l|}{$\begin{array}{l}\text { What is the gross floor area of your home in square feet } \\
\text { (estimate if you are unsure)? }\end{array}$} \\
\hline \multicolumn{2}{|l|}{ Does your home have a basement? } \\
\hline Estimated utility bill & $\$ /$ month for peak month, $\$ /$ month for lowest month \\
\hline Do you live in the home year round? & Yes/no \\
\hline Do you own the home? & Yes/no \\
\hline $\begin{array}{l}\text { Do you have business (other than small home office) or } \\
\text { other unusual energy-intensive equipment in the home? }\end{array}$ & Yes/no. If yes, please list. \\
\hline Do you allow smoking in the home? & Yes/no \\
\hline What type of heating system does your house have? & $\begin{array}{l}\text { Multiple choice (select all that apply): central (ducted) } \\
\text { heat pump, central (ducted) electric strip heat, gas } \\
\text { furnace, electric baseboard heaters or portable heaters, } \\
\text { wood stove, fireplace (gas), fireplace (wood), none, } \\
\text { other - please specify }\end{array}$ \\
\hline What type of cooling system does your house have? & $\begin{array}{l}\text { Multiple choice (select all that apply): central (ducted) } \\
\text { A/C or heat pump, window-unit(s), whole-house fan, } \\
\text { ceiling fans, none, other - please specify }\end{array}$ \\
\hline
\end{tabular}


Table A.3. (contd)

\begin{tabular}{ll}
\hline Question & Answer \\
\hline $\begin{array}{l}\text { What type of water heating system does your house } \\
\text { have? }\end{array}$ & $\begin{array}{l}\text { Multiple choice (select all that apply): gas, electric, } \\
\text { tank, tankless (instantaneous), solar, heatpump or } \\
\text { hybrid, none, other - please specify } \\
\text { Yes/no }\end{array}$ \\
$\begin{array}{l}\text { Do you or any members of your household open } \\
\text { windows often when the heat or A/C systems are on? }\end{array}$ & \\
$\begin{array}{l}\text { What are your retrofit goals? } \\
\begin{array}{l}\text { Are you planning on moving, or selling/renting the } \\
\text { house in the next 2 years? }\end{array}\end{array}$ \\
\hline
\end{tabular}

Please note: Participation in this research project will include construction activity that may produce elevated levels of particulate matter and chemical emissions during the days such activity is conducted and for up to a few days after that. This normally does not pose a hazard to healthy persons, but persons with acute respiratory illness, multiple chemical sensitivities, or other diseases or sensitivities may experience aggravated symptoms as a result of this activity. Homeowners are urged to consider this factor before choosing to participate in this study. 


\title{
A.4 Phase I.4: Homeowner Retrofit Agreement
}

\author{
HOMEOWNER AGREEMENT \\ Battelle Memorial Institute, Pacific Northwest Division, \\ Operator of Pacific Northwest National Laboratory \\ Residential Retrofit Research Program
}

ID No.

This agreement is entered into this day of , $20 \ldots$ _ between hereinafter referred to as the Homeowner, residing at , hereinafter referred to as the Residence, and Battelle Memorial Institute, Pacific Northwest Division (Battelle), a non-profit corporation organized and existing under the laws of the State of Ohio, with principal offices in the City of Richland, Washington, in support of its contract with the U.S. Department of Energy for the operation of Pacific Northwest National Laboratory.

Battelle is conducting a research program to document and study home energy retrofits. Accordingly, Battelle is seeking permission from occupants of homes that have been accepted into the retrofit research program to acquire their utility bills (up to 4 years prior to retrofit and 2 years following the retrofit), collect data on Residence characteristics, measure the interior temperature and humidity levels, measure interior formaldehyde and total volatile organic compound concentrations, measure the tightness of the building envelope, measure leakage of duct work, measure energy use, and complete a homeowner satisfaction/home operation questionnaire. Homeowner agrees to participate in the study, and to make its Residence available for use in the study as described in this agreement. Homeowner may withdraw from the study at any time without consequence. All visits to the Residence by Battelle or associated subcontractors will be scheduled in advance with the Homeowner. The period of performance for this contract shall not exceed 2 years from the date the agreement is signed.

An initial visit to last approximately four hours will be scheduled with the Homeowner for Battelle to complete the initial home energy assessment, including a homeowner interview. The home energy assessment is to take place in the Residence. Homeowner agrees to participate in the interview but may choose not to answer any of the questions asked by Battelle that they do not wish to answer. Homeowner agrees to remain present during the entire assessment and to maintain responsibility for all pets and children during the assessment.

During the initial visit Battelle will also collect information on the Residence characteristics by performing a walk-through visual audit. Homeowner generally agrees to allow Battelle to access and photograph all areas of the Residence and associated property, but may verbally refuse Battelle to access any particular areas during the visit. Homeowner agrees to notify Battelle of any known hazards or defects within the Residence or on the property. Battelle will make no alterations to the Residence or component therein.

During the initial visit Battelle or associated subcontractor will perform a home energy assessment. This may include a blower door test, duct leakage test, temperature and RH tests, air handler flow and pressure tests, exhaust fan flow tests, depressurization and combustion zone tests, and indoor air-quality tests, as applicable. Some of the tests will not be necessary in certain homes and will not be performed. 
During this visit, Battelle will make no alterations to the Residence or component therein. The heating and/or cooling system will be turned off during a portion of the visit. For some tests opening or closure of interior doors may be required.

Following the initial home energy assessment, the Homeowner will be presented with information on recommended energy retrofit measures for their home. Homeowners will work with Battelle to determine a list of retrofit measures that will be performed. Homeowner will separately contract for any kind of energy retrofit measures that they consider appropriate. Homeowner will advise Battelle if the contracted list of retrofits differs from the mutually agreed-upon list of retrofits to be performed. Homeowner agrees to engage private contractors for timely completion of all mutually agreed-upon retrofit measures.

During the period of the retrofit, Battelle may wish to consult with the general contractor, subcontractors, and other service providers to ensure specifications are met. Battelle may visit the Residence for additional data collection, photography, and to ensure quality of retrofit work being performed by subcontractors. Battelle will consult with the Homeowner prior to return visits.

A final visit to last approximately four hours will be scheduled with the Homeowner to complete the post-retrofit home energy assessment. Visit is to take place in the Residence. During the final visit, Battelle will collect information on the Residence updated characteristics by performing a walk-through visual audit. Homeowner generally agrees to allow Battelle to access and photograph all areas of the Residence and associated property, but may verbally refuse Battelle to access any particular areas during the visit. Homeowner agrees to notify Battelle of any known hazards or defects within the Residence or on the property.

During the final visit Battelle or associated subcontractor will perform a second home energy assessment. This may include a blower door test, duct leakage test, temperature and RH tests, air handler flow and pressure tests, exhaust fan flow tests, depressurization and combustion zone tests, and indoor air-quality tests, as necessary. Some of the tests will not be necessary in certain homes and will not be performed. During this visit, Battelle will make no alterations to the Residence or component therein. Homeowner agrees to remain present during the entire assessment and to maintain responsibility for all pets and children during the assessment. The heating and/or cooling system will be turned off during a portion of the visit. For some tests opening or closure of interior doors may be required.

Battelle agrees to keep all data collected from Homeowner and Residence anonymous outside of the Battelle study team. Homeowner gives permission to Battelle to publicly publish all data collected from Homeowner and Residence, including answers to individual interview questions, in an anonymous fashion by not linking the data to Homeowner or Residence.

Battelle shall not provide Homeowner with any monetary benefits as a result of this study. Homeowner has no expectation of any monetary benefits. The Homeowner is not expected to pay Battelle for any services.

Homeowner represents and warrants that Homeowner is at least 18 years of age, has the authority to enter into this agreement and that Homeowner is the rightful owner of the residence. Battelle acknowledges that it has relied upon the representations and warranties of the Homeowner set forth in this agreement, without independent investigation of said warranties or representations. 
Battelle does not anticipate any physical risks or discomforts to its agents or to Homeowner, Homeowner's family, or to Residence. Some inconvenience and risk will occur as a result of the retrofit measures to be performed on the home. It is anticipated that this risk is taken on by the party performing the construction work, which is not part of Battelle's work under this agreement. There is a small risk that your private information could be inadvertently released. All personal information will be encrypted on secure servers, kept in locked file cabinets, and not shared outside the research team. Any published information will be kept anonymous. This study has been determined to be exempt from 45 CFR 46 by the Battelle Institutional Review Board.

Battelle assumes any and all risks of personal injury and property damage attributable to the negligent acts or omissions of Battelle and its officers, employees, servants, and agents thereof while acting within the scope of their agency or employment by Battelle in connection with the case study described herein.

This agreement embodies the entire agreement and understanding between the Homeowner and Battelle and supersedes all prior agreements and understandings relating to the subject matter hereof. Except as otherwise expressly provided for herein, this agreement may be changed, waived, discharged or terminated only by an instrument in writing, signed by the party against which enforcement of such change, waiver, discharge or termination is sought.

I have read the procedure described above. I confirm that I as a Homeowner and my home as a Residence meet the following minimum requirements for participation in this study:

Homeowner is at least 18 years of age

Homeowner and other residents occupy the home year round (not seasonally)

Homeowner and other residents do not frequently open windows when heating or cooling system is on

$\square$ Homeowner will coordinate with independent contractor to perform mutually agreed-upon home energy retrofit measures on the Residence

Residence is not occupied by occupants who smoke and smoking is not allowed in the home Residence does not have energy-intensive home based businesses or hobbies

I voluntarily agree to participate in the Procedure and I have received a copy of this description. I consent to:

Participating in the interview

Permitting the home energy assessment audit

Permitting access to utility bills for up to four years prior to the retrofit and two years following

Permitting and independently contracting for the completion of residential home energy retrofit measures on the Residence

Permitting and participating in the final, post-retrofit home energy assessment

Allowing Battelle to use and publish all data anonymously 
Homeowner executes this agreement, fully intending to be bound by the same.

Homeowner (PERMITOR): Date

Homeowner (PERMITOR): Date (if multiple)

BATTELLE MEMORIAL INSTITUTE, PACIFIC NORTHWEST DIVISION

By: Date

Title Contract Specialist Witness 


\section{A.5 Phase II.1: Homeowner Interview - Web or Phone Based Survey}

\section{General Info}

Name

Address

Describe any additions, alterations, or appliance/equipment modifications since moving in:

Do you have plans for increasing the efficiency of your home? If so, what components do you plan on upgrading. If not, are you willing to invest in your homes efficiency (investments of $\$ 7,000-\$ 20,000$ or more are typically needed to reduce energy bills by $30-50 \%)$ ?:

If you are already planning upgrades, what is the estimated start date:

Have you selected a contractor for your upgrades yet? yes no

\section{Occupancy}

Total \# of adults living in home Total \#/age of children living in home

\section{Daily Patterns}

Do any occupants have variable work hours? How many students living in house? (Year-round or summers off?) Stay-at-home mother? Work from home office? Retired or elderly persons?

\section{Anticipated Lifestyle/Occupancy Changes}

House for sale/planned move, New or returning child/parent/other occupant, child leaving for school, or other occupant decrease, Major structural addition or alterations planned, Anything else affecting energy consumption?

\section{Home Operation}

What is your temperature set point for cooling (How often do you change it? Do you set it up during the day or at night manually or via a programmable thermostat?)

If programmable feature is used, please describe:

What is your set point for heating (How often do you change it? Do you set it up during the day or at night manually or via a programmable thermostat?)

If programmable feature is used, please describe:

Do you use supplementary heating systems? E.g., fireplaces, wood stoves, portable electric heaters?

When do you use your ceiling fans (all the time, while sleeping, when you feel uncomfortable)?

When do you use your bath fans and for how long each time?

When do you use your range hood and for how long each time?

How often do you change your return air filter? 
If your home has a whole-house ventilation system, how often do you change its filter?

Do you use florescent lighting, including screw-in compact fluorescent bulbs?

If you home has a sprinkler pump, how often does it run?

On average, how many loads of laundry do you do per week?

On average, how often do you run the dishwasher per week?

On average, how many showers does your family take per week?

What is the typical duration of a shower in your household (in minutes)?

If large variances (i.e., some family members that take long showers), please specify:

\section{How often do you turn off the heating/cooling system and open windows (check all that apply)?}

Winter
Spring
Summer
Fall

Please describe how important the following features are to you in your home. Rank and comment: 1 = very important; 2 = somewhat important; 3 = neutral; $4=$ somewhat unimportant; 5 = don't know.

Energy efficiency/cost

Water efficiency/cost

Maintenance ease/cost

Storage

Safety

Comfort

Healthy indoor environment

Durability

Resale Value

Overall quality of home

Rank Comment

Please describe comfort, or lack of comfort in terms of hot, cold, humid, dry, stuffy, clammy, drafty, unusual odors, mold, etc.

My home is comfortable in the winter.

My home is comfortable in the summer.

My home is comfortable in the spring/fall.

All rooms in my home are equally comfortable.

I am satisfied with the overall comfort of my home.

My home has high electric/gas bills for its size.

I am satisfied with my home overall.

$\mathrm{Y} / \mathrm{N}$ Comment

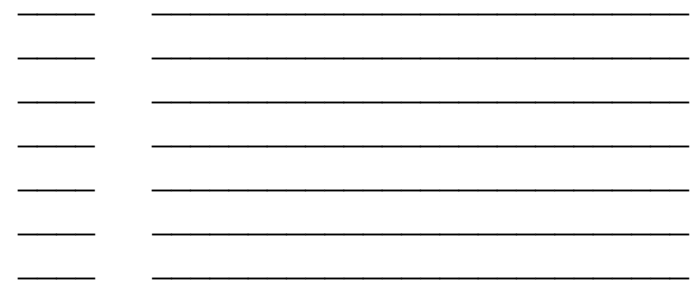


Homeowner Comments (Include here any energy or water conservation efforts):

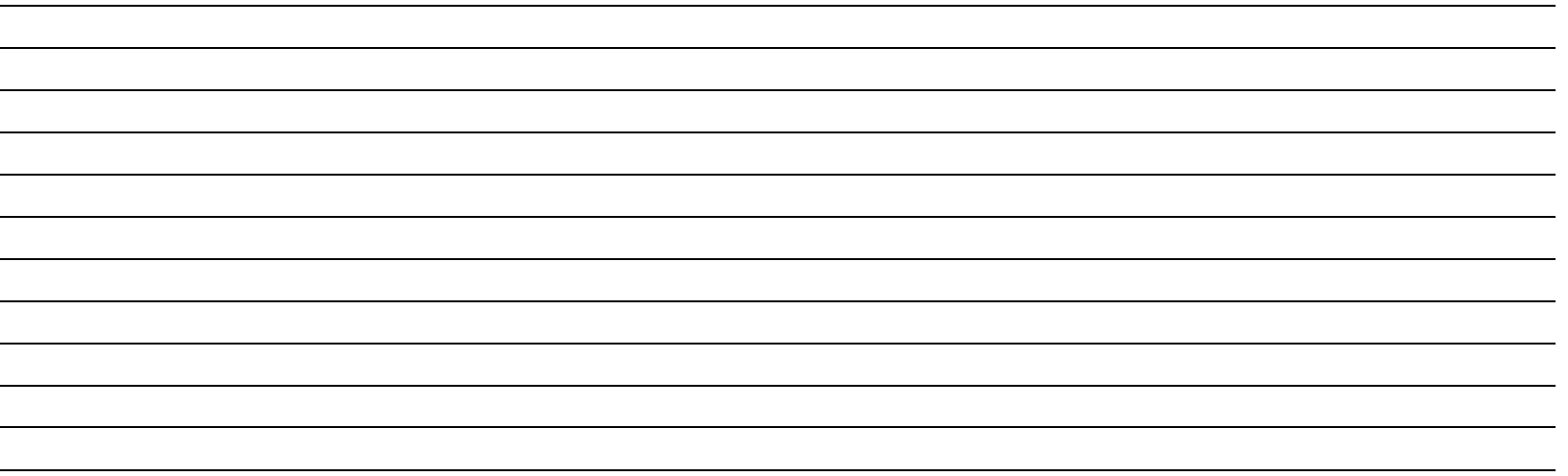

A.13 


\section{A.6 Phase II.2: Pre-Retrofit Home Energy Assessment}

The following sections list the type of tests that may be performed during the pre-retrofit home energy assessment and the tools that will be required. Please consult Building Measurement and Test.xls for complete versions of the form with fill-able sections.

\section{Onsite Energy Audit Data Collection Form}

This information will be collected during a walk-through of the home and with participation of the homeowner. Tools: pencil, tape measure, additional sketch paper, camera.

\section{Blower Door and Duct Leakage Measurements}

Record all relevant information in the spaces provided below or in the Building Measurement and Test.xls spreadsheet. Perform blower door, duct leakage, air handler, and exhaust fan flow tests in accordance with manufacturer's instructions (note that not all of these tests will be performed in each house). Tools: blower door (with accessories), duct blaster, pencil, vanevan anemometer, infrared camera, TrueFlow meter, exhaust fan metering box

\section{Combustion Testing}

Record all relevant information in the spaces provided below or in the Building Measurement and Test.xls spreadsheet. The purpose of this test is to ensure adequate combustion ventilation is provided to all combustion appliances. This test may not be performed in all houses. Perform combustion testing as described in the following sections. Tools: carbon monoxide (CO) meter

\section{IAQ Testing}

Record relevant air pollutant concentrations in the most used room or any areas of concern. Where multiple samples are taken, add rows to the following table. Testing of IAQ is not required. However, it is recommended to ensure health and safety of occupants is maintained.

Tools: $\mathrm{CO}$, nitrous oxide (NOx), and formaldehyde $\left(\mathrm{CH}_{2} \mathrm{O}\right)$ sample tubes (or monitor); $\mathrm{CO}_{2}$ monitor; TVOC photo-ionization detector (PID); radon meter; particle counter. Equivalent equipment may be substituted. 


\title{
A.7 Phase II.3: Homeowner Metering Agreement
}

\author{
RESEARCH ACCESS AGREEMENT \\ ENERGY METERING OF RESIDENTIAL RETROFIT MEASURES
}

I.D. No.

THIS RESEARCH ACCESS AGREEMENT is made between BATTELLE MEMORIAL INSTITUTE, PACIFIC NORTHWEST DIVISION (Battelle), a non-profit corporation organized and existing under the laws of the State of Ohio, with principal offices in the City of Richland, Washington, in support of its contract with the U.S. Department of Energy for the operation of Pacific Northwest National Laboratory, and in the City of (Permitor).

In consideration of the mutual promises of the parties, and intending to be bound hereby, the parties agree as follows:

Battelle is performing a field evaluation of energy use of homes that have undergone home energy retrofits. Battelle wishes to install energy monitoring equipment to evaluate energy use. Upon completion of the field evaluation, all energy monitoring equipment will be removed and affected areas returned to "as-found" or better condition. Battelle agrees to compensate the Permitor_[amount of monthly monetary compensation to be offered to Permitor] for their cooperation with this research program.

A. The Permitor hereby agrees to permit Battelle, its authorized representatives, and subcontractors to:

1. Install energy monitoring equipment for the purposes of determining and characterizing home energy use before and after retrofit measures are completed. .

2. Reasonable access to building for the purposes of install energy monitoring equipment, perform surveys, and complete equipment checks.

B. Project activities are subject to the following conditions:

1. Activities shall commence on or after [date activities will be completed by]_and continue for a period of months.

2. The Permitor shall not be charged for the purchase, use, installation or removal of the energy monitoring equipment.

3. Battelle and its subcontractors will comply with Federal, State and local safety; employer liability; workers' compensation; and building and electrical codes, laws, rules and regulations.

4. Entry to the building will be required for the purpose of installing energy monitoring equipment. Such entry, working and leaving activity for the project period shall be accomplished by prior arrangement with the Permitor at least 24 hours in advance of entry. These activities will be accomplished so as not to unduly interfere with the Permitor's normal routine. The Permitor shall designate a contact for coordinating the project activities at the building.

5. Project equipment (electricity panel monitor) installed by Battelle will be and remain the responsibility of Battelle, or its subcontractors. The Permitor is not responsible for installed project equipment.

6. The Permitor agrees not to disturb installed equipment in any way unless authorized by Battelle or as may become necessary for safety. 
7. The Permitor agrees to notify Battelle of any changes in maintenance practices and alterations to the building during the term of this Research Access Agreement.

8. The Permitor agrees to notify Battelle if the building is to be sold or occupied by someone other than the Permitor as the primary occupant.

9. All data gathered becomes the property of Battelle. Upon request, the Permitor will receive a copy of any report issued by Battelle in which Permitor's facility was involved.

10. Permitor shall not use Battelle's name or identifying characteristics for advertising, sales promotion, or other publicity purposes.

C. Either party may terminate this Agreement by providing thirty (30) days written advance notice to the other party. In the event of early termination, Battelle will arrange to expeditiously remove project equipment, but such removal may require longer than thirty days to complete the effort.

Each party signing this Agreement has the authority to execute and bind the principals involved and represents that there are no other agreements, express or implied, which are not contained in this Research Access Agreement or incorporated specifically by reference.

$\begin{array}{lll}\text { Homeowner (PERMITOR): } & \text { Date__ } \\ \text { Homeowner (PERMITOR): } & \text { Date__ (if multiple) }\end{array}$

\section{BATTELLE MEMORIAL INSTITUTE, PACIFIC NORTHWEST DIVISION}

By:

Date

Title ___ Contract Specialist___ Witness




\section{A.8 Phase III.1: Energy Modeling Results/Proposed Energy Measures}

Data collected from test-in audit is used to create energy models of the existing home and each retrofit measure. Based on the modeled energy savings and the estimated costs, retrofit measures are prioritized based on cost effectiveness, as determined by the measure's payback period. Results are summarized in an audit report that is presented to the homeowner to initiate retrofits. 


\section{A.9 Phase IV.1: Post-Retrofit Home Energy Assessment}

For the post-retrofit home energy assessment, all tests will be performed as they were for the preretrofit home energy assessment.

\section{Onsite Energy Audit Data Collection Form}

See Onsite Energy Audit Data Collection Form, in section A.6, or Building Measurement and Test.xls. For items that have no changes, values can be filled in prior to the home energy assessment.

\section{Blower Door and Duct Leakage Measurements}

See Blower Door and Duct Leakage Measurements, in section A.6, or Building Measurement and Test.xls. This test must be completed separately during the post-retrofit home energy assessment, the preretrofit home energy assessment values do not apply.

\section{Combustion Testing}

See Combustion Testing, in section A.6, or Building Measurement and Test.xls. This test will be performed in all houses to ensure adequate combustion ventilation is provided to all combustion appliances. This test must be completed separately during the post-retrofit home energy assessment, the pre-retrofit home energy assessment values do not apply. This test may not apply after homes have been retrofitted. Homes that no longer have combustion appliances or have sealed combustion appliances will not be tested.

\section{IAQ Testing}

See IAQ Testing, in section A.6, or Building Measurement and Test.xls. This test must be completed separately during the post-retrofit home energy assessment; the pre-retrofit home energy assessment values do not apply. Testing of IAQ is not required, but it is recommended to ensure health and safety of occupants is maintained.

\section{Homeowner Questionnaire}

This survey will query the homeowner's experience and satisfaction with the retrofit. See Building Measurement and Test.xls for a detailed list of questions. 


\section{A.10 Phase V: Risk Mitigation Measures}

\section{Data Handling and Storage to Ensure Homeowner Privacy}

Homeowner data privacy will be maintained to the extent possible throughout the course of the research. Anonymity will be maintained in all publications. All individual homeowner data will be handled by PNNL researchers that are certified by the PNNL Institutional Review Board (HRPP) program and will be coded to preserve anonymity before sharing with other project team members.

\section{Measures to Minimize Physical Risk to Research Participants}

The following strategies were implemented to minimize physical risk to participants who participated in the deep energy retrofit research program:

- Homeowners will be present during the entirety of the home energy assessment.

- Any homes found to have unacceptable situations, as determined by Battelle (PNNL) or contractors operating on behalf of Battelle, will be removed from consideration in the study. No further action will be taken. 

Appendix B

\section{Tri-Fold Brochure}





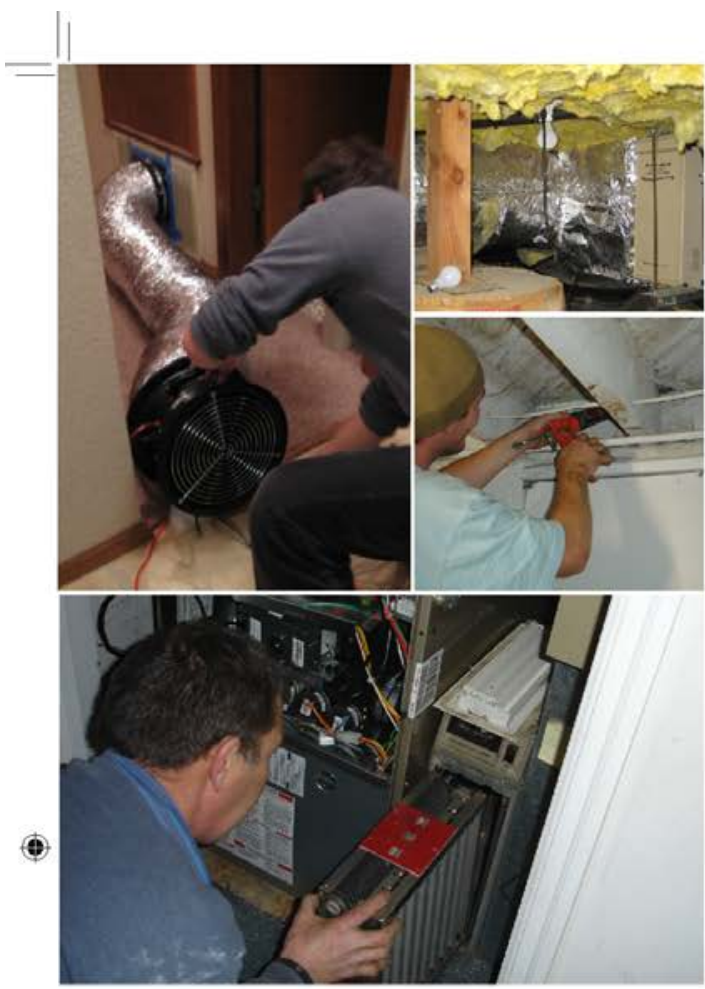

- A one-time post-retrofit home energy assessment will be conducted to measure and document whole house energy savings and improvements in health, safety, and comfort of the home resulting from the home energy upgrades.

- For some homes, we may wish to install energy-metering equipment to collect detailed energy consumption data on deep retrofits or innovative systems ove a longer term. http://deepenergyretrofits. pnnl.gov and complete the informational questionnaire

A researcher will contact

you to discuss the details

of participation.
To participate, please visit

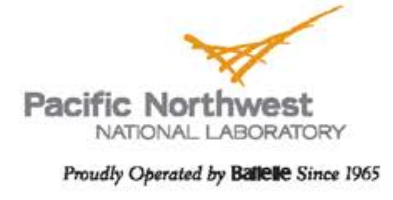

ENERGY AND ENVIRONMENT

Residential Deep

Energy Retrofit

Research Project

Please visit http://deepenergyretrofits.pnnl.gov for answers to common questions addressed in our FAQ sheet or email the project team at deepenergyretrofits@pnl.gov.

\section{Important consideration:}

Homeowners should be aware that participation in this research project will include construction activity in the home that may produce elevated levels of particulate matter and chemrica emissions during the days such activity is conducted and possibly a few days theresafter. This activity usjally will not posea hazard to heathy persons, but is not recormmended tor individuals with acute respiratory inness. chemical sersitivites, or other heath conditions that may be aggravated by corming incontart with construction pardowates. Weugenombownerstoconsider
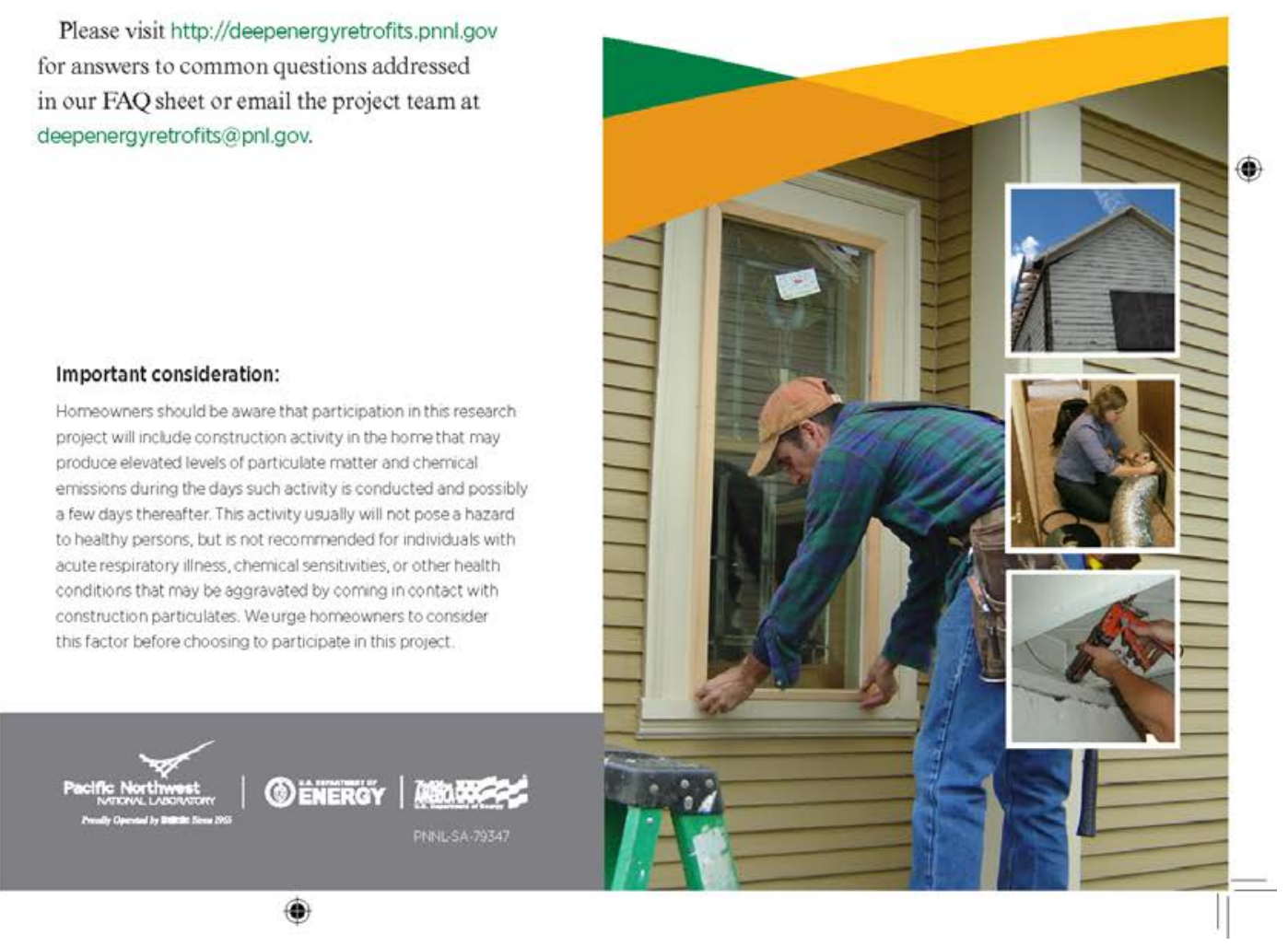


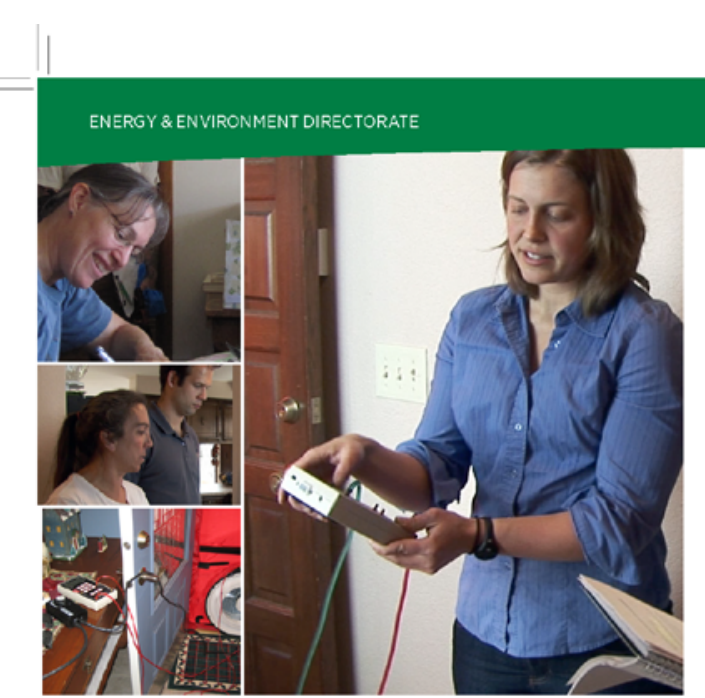

The Residential Deep Energy
Retrofit Research Project is Seeking Participants

ARE YOU INTERESTED in saving money on your utility bills? Do you wish your home used less energy and was more comfortable? The Pacific Northwest National Laboratory (PNNL), one of the nation's leading national laboratories, is seeking homeowners who would like to participate in a research project funded by the U.S. Department of Energy to help them achieve 30 percent or more in energy savings through home-efficiency upgrades! By identifying available incentives, conducting a free home energy assessment, and providing free technical assistance, this project can help you make energy retrofitting your home affordable, now and in the long term. In addition, your home will be part of a research study for PNNL that can help inform the nation about best practices for residential retrofits.
PNNL is seeking homeowners who would like to participate in a research project to help them achieve 30 percent or more in energy savings through home-efficiency upgrades!

If your home meets the following criteria and you are interested in saving money on your utility bills, you may qualify to participate in PNNL's Residential Deep Energy Retrofit Research Project.

Candidate homes must meet the following criteria.

> Home must be at least 5 years old.

> Homeowners do not allow smoking inside the home.

- Homeowners do not operate a business or unusually energy-intensive equipment in the home (small home office allowed).

Home must be occupied year round.

> Residents of the home do not leave windows open while operating the air conditioning system.

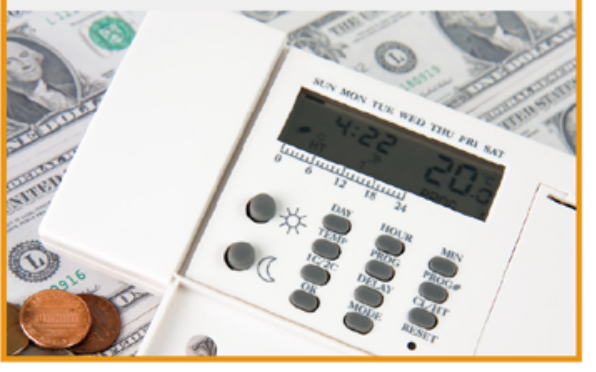

Note: The number d participarts we can accopt in the programis ilrited ard we reg

\section{Summary of Research Project}

Retrofitting your home to decrease energy consumption can save money on utility bills and improve the comfort and safety of your home. Your participation in PNNL's Residential Deep Energy Retrofit Research Project will help us and our utility and industry partners to better understand the energy and economic implications of home energy upgrades and how to improve the health, safety, comfort, and durability of homes. This research will also help utilities and the energy industry to implement this type of energy conservation program for their residential customers.

During the project, the

PNNL research team will apply integrated building science and systems engineering principles to provide technical assistance in implementing residential deep

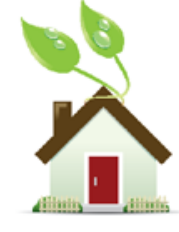
energy retrofits in a variety of climates across the country. The project scope will include the following activities:

- A pre-retrofit assessment of home energy systems will be conducted to characterize the existing health, safety, comfort, and energy efficiency of the home. Recommendations for improvements will be based on assessment findings.

> Coordination will be arranged between researchers, homeowners, and contractors to implement the recommended improvements. Retrofit strategies may include measures such as air sealing, increased insulation, or HVAC water heater, and appliance replacements. 
Appendix C

\section{Informal Questionnaire}





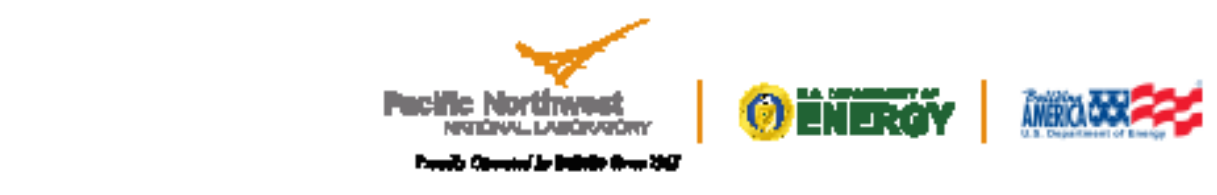

\section{Residential Deep Energy Retrofit Research Project INFORMATION REQUEST}

Please answer the following questions to find out more information about the Retrofit Research Program and how to get irw olved! Mail the completed form to deepenerguretrofits@ipnl. gow. Thank you for your participation!

This information he ps the research team die ntriy good candidate house sforour study and get in contact with you. Your personal in formation will not be shared whh anyone out side the research team and wili not be made public. To protect your priacy, this infomation willony be stored on secure computers and networks.

Name Zp Code

Street Address

Telephone

City, State

Email

1. Are you planning on investing in your homes energy efficiency?

To achieve $30-50 \%$ savings, investments of $\$ 7,000-\$ 20,000$ are typically necessary

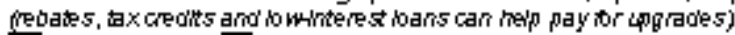

$\square$ Yes $\quad \square$ No

2. Are any major appliances or equipment in need of replacement?

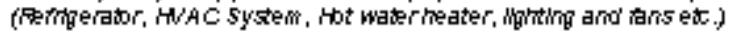

3. Year home was built

4. Howm any stories is your home?

5. What is the gross floor area of your home in square feet (esimate $r$ you are unsure)?

6. Does your home have a basem ent?

$\square$ Yes $\quad \square$ No

7. E stimated utility bill

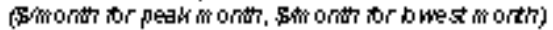

8. Do you live in the home year round?

$\square$ Yes $\square$ No

9. Do you own the home?

$\square$ Yes

$\square$ No

C.1 
10. Do you have business (other than small home office) or other unusual energy intensive equipment in the home? $\square$ Yes, please list.

11. Do you allow smoking inside the home? (Note: this does not include porches, patios, or other outdoor areas of the home.) $\square$ Yes $\square$ No

12. What type of heating system does your house have? (list all that apply):

$\square$ Central (ducted) heat pump

Central (ducted) electric strip heat

Gas furnace

Electric baseboard heaters or portable heaters

Wood stove

Fireplace (gas)

$\square$ Fireplace (electric)

$\square$ None

$\square$ Other (please specify)

13. What type of cooling system does your house have? (list all that apply):

$\square$ Central (ducted) AC or heat pump

$\square$ Window unit(s)

Whole house fan

Ceiling fans

None

Other (please specify)

14. What type of water heating system does your house have? (list all that apply):

$\square$ Gas

Electric

$\square$ Tank

$\square$ Tankless (instantaneous)

Heatpump or hybrid

$\square$ None

$\square$ Other (please specify)

15. Do you or any members of your household open windows often when the heat or AC systems are on?

$\square$ Yes $\square$ No

16. What are your retrofit goals?

17. Are you planning on moving, or selling/renting the house in the next two years? $\square$ Yes $\square$ No

Please note: Participation in this research project will include construction activity that may produce elevated levels of particulate matter and chemical emissions during the days such activity is conducted and for up to a few days after that. This normally does not pose a hazard to healthy persons, but persons with acute respiratory illness, multiple chemical sensitivities, or other diseases or sensitivities may experience aggravated symptoms as a result of this activity. Homeowners are urged to consider this factor before choosing to participate in this study.

If you have additional questions, please contact deepenergyretrofits@pnl.gov 
Appendix D

\section{Legal Agreements}





\title{
Appendix D
}

\section{Legal Agreements}

\section{D.1 Homeowner Agreement}

\author{
HOMEOWNER AGREEMENT \\ Battelle Memorial Institute, Pacific Northwest Division, \\ Operator of Pacific Northwest National Laboratory \\ Residential Retrofit Research Program
}

ID No.

This agreement is entered into this day of , 20 between hereinafter referred to as the Homeowner, residing at hereinafter referred to as the Residence, and Battelle Memorial Institute, Pacific Northwest Division (Battelle), a non-profit corporation organized and existing under the laws of the State of Ohio, with principal offices in the City of Richland, Washington, in support of its contract with the U.S. Department of Energy for the operation of Pacific Northwest National Laboratory.

Battelle is conducting a research program to document and study home energy retrofits. Accordingly, Battelle is seeking permission from occupants of homes that have been accepted into the retrofit research program to acquire their utility bills (up to 4 years prior to retrofit and 2 years following the retrofit), collect data on Residence characteristics, measure the interior temperature and humidity levels, measure interior formaldehyde and total volatile organic compound concentrations, measure the tightness of the building envelope, measure leakage of duct work, measure energy use, and complete a homeowner satisfaction/home operation questionnaire. Homeowner agrees to participate in the study, and to make its Residence available for use in the study as described in this agreement. Homeowner may withdraw from the study at any time without consequence. All visits to the Residence by Battelle or associated subcontractors will be scheduled in advance with the Homeowner. The period of performance for this contract shall not exceed 2 years from the date the agreement is signed.

An initial visit to last approximately four hours will be scheduled with the Homeowner for Battelle to complete the initial home energy assessment, including a homeowner interview. The home energy assessment is to take place in the Residence. Homeowner agrees to participate in the interview but may choose not to answer any of the questions asked by Battelle that they do not wish to answer. Homeowner agrees to remain present during the entire assessment and to maintain responsibility for all pets and children during the assessment.

During the initial visit Battelle will also collect information on the Residence characteristics by performing a walk-through visual audit. Homeowner generally agrees to allow Battelle to access and photograph all areas of the Residence and associated property, but may verbally refuse Battelle to access any particular areas during the visit. Homeowner agrees to notify Battelle of any known hazards or defects within the Residence or on the property. Battelle will make no alterations to the Residence or component therein. 
During the initial visit Battelle or associated subcontractor will perform a home energy assessment. This may include a blower door test, duct leakage test, temperature and RH tests, air handler flow and pressure tests, exhaust fan flow tests, depressurization and combustion zone tests, and indoor air-quality tests, as applicable. Some of the tests will not be necessary in certain homes and will not be performed. During this visit, Battelle will make no alterations to the Residence or component therein. The heating and/or cooling system will be turned off during a portion of the visit. For some tests opening or closure of interior doors may be required.

Following the initial home energy assessment, the Homeowner will be presented with information on recommended energy retrofit measures for their home. Homeowners will work with Battelle to determine a list of retrofit measures that will be performed. Homeowner will separately contract for any kind of energy retrofit measures that they consider appropriate. Homeowner will advise Battelle if the contracted list of retrofits differs from the mutually agreed-upon list of retrofits to be performed. Homeowner agrees to engage private contractors for timely completion of all mutually agreed-upon retrofit measures.

During the period of the retrofit, Battelle may wish to consult with the general contractor, subcontractors, and other service providers to ensure specifications are met. Battelle may visit the Residence for additional data collection, photography, and to ensure quality of retrofit work being performed by subcontractors. Battelle will consult with the Homeowner prior to return visits.

A final visit to last approximately four hours will be scheduled with the Homeowner to complete the post-retrofit home energy assessment. Visit is to take place in the Residence. During the final visit, Battelle will collect information on the Residence updated characteristics by performing a walk-through visual audit. Homeowner generally agrees to allow Battelle to access and photograph all areas of the Residence and associated property, but may verbally refuse Battelle to access any particular areas during the visit. Homeowner agrees to notify Battelle of any known hazards or defects within the Residence or on the property.

During the final visit Battelle or associated subcontractor will perform a second home energy assessment. This may include a blower door test, duct leakage test, temperature and RH tests, air handler flow and pressure tests, exhaust fan flow tests, depressurization and combustion zone tests, and indoor air-quality tests, as necessary. Some of the tests will not be necessary in certain homes and will not be performed. During this visit, Battelle will make no alterations to the Residence or component therein. Homeowner agrees to remain present during the entire assessment and to maintain responsibility for all pets and children during the assessment. The heating and/or cooling system will be turned off during a portion of the visit. For some tests opening or closure of interior doors may be required.

Battelle agrees to keep all data collected from Homeowner and Residence anonymous outside of the Battelle study team. Homeowner gives permission to Battelle to publicly publish all data collected from Homeowner and Residence, including answers to individual interview questions, in an anonymous fashion by not linking the data to Homeowner or Residence.

Battelle shall not provide Homeowner with any monetary benefits as a result of this study. Homeowner has no expectation of any monetary benefits. The Homeowner is not expected to pay Battelle for any services. 
Homeowner represents and warrants that Homeowner is at least 18 years of age, has the authority to enter into this agreement and that Homeowner is the rightful owner of the residence. Battelle acknowledges that it has relied upon the representations and warranties of the Homeowner set forth in this agreement, without independent investigation of said warranties or representations.

Battelle does not anticipate any physical risks or discomforts to its agents or to Homeowner, Homeowner's family, or to Residence. Some inconvenience and risk will occur as a result of the retrofit measures to be performed on the home. It is anticipated that this risk is taken on by the party performing the construction work, which is not part of Battelle's work under this agreement. There is a small risk that your private information could be inadvertently released. All personal information will be encrypted on secure servers, kept in locked file cabinets, and not shared outside the research team. Any published information will be kept anonymous. This study has been determined to be exempt from 45 CFR 46 by the Battelle Institutional Review Board.

Battelle assumes any and all risks of personal injury and property damage attributable to the negligent acts or omissions of Battelle and its officers, employees, servants, and agents thereof while acting within the scope of their agency or employment by Battelle in connection with the case study described herein.

This agreement embodies the entire agreement and understanding between the Homeowner and Battelle and supersedes all prior agreements and understandings relating to the subject matter hereof. Except as otherwise expressly provided for herein, this agreement may be changed, waived, discharged or terminated only by an instrument in writing, signed by the party against which enforcement of such change, waiver, discharge or termination is sought.

I have read the procedure described above. I confirm that I as a Homeowner and my home as a Residence meet the following minimum requirements for participation in this study:

Homeowner is at least 18 years of age

Homeowner and other residents occupy the home year round (not seasonally)

Homeowner and other residents do not frequently open windows when heating or cooling system is on

Homeowner will coordinate with independent contractor to perform mutually agreed-upon home energy retrofit measures on the Residence

Residence is not occupied by occupants who smoke and smoking is not allowed in the home

Residence does not have energy-intensive home based businesses or hobbies

I voluntarily agree to participate in the Procedure and I have received a copy of this description. I consent to:

Participating in the interview

Permitting the home energy assessment audit

Permitting access to utility bills for up to four years prior to the retrofit and two years following

Permitting and independently contracting for the completion of residential home energy retrofit measures on the Residence

Permitting and participating in the final, post-retrofit home energy assessment 
Allowing Battelle to use and publish all data anonymously

Homeowner executes this agreement, fully intending to be bound by the same.

Homeowner (PERMITOR): Date

Homeowner (PERMITOR): Date (if multiple)

\section{BATTELLE MEMORIAL INSTITUTE, PACIFIC NORTHWEST DIVISION}

By: Date

Title Contract Specialist Witness 


\title{
D.2 Research Access Agreement
}

\author{
RESEARCH ACCESS AGREEMENT \\ ENERGY METERING OF RESIDENTIAL RETROFIT MEASURES
}

\begin{abstract}
I.D. No.
THIS RESEARCH ACCESS AGREEMENT is made between BATTELLE MEMORIAL INSTITUTE, PACIFIC NORTHWEST DIVISION (Battelle), a non-profit corporation organized and existing under the laws of the State of Ohio, with principal offices in the City of Richland, Washington, in support of its contract with the U.S. Department of Energy for the operation of Pacific Northwest National Laboratory, and in the City of (Permitor).
\end{abstract}

In consideration of the mutual promises of the parties, and intending to be bound hereby, the parties agree as follows:

Battelle is performing a field evaluation of energy use of homes that have undergone home energy retrofits. Battelle wishes to install energy monitoring equipment to evaluate energy use. Upon completion of the field evaluation, all energy monitoring equipment will be removed and affected areas returned to "as-found" or better condition. Battelle agrees to compensate the Permitor_[amount of monthly monetary compensation to be offered to Permitor] for their cooperation with this research program.

D. The Permitor hereby agrees to permit Battelle, its authorized representatives, and subcontractors to:

1. Install energy monitoring equipment for the purposes of determining and characterizing home energy use before and after retrofit measures are completed. .

2. Reasonable access to building for the purposes of install energy monitoring equipment, perform surveys, and complete equipment checks.

E. Project activities are subject to the following conditions:

1. Activities shall commence on or after _ [date activities will be completed by]_and continue for a period of months.

2. The Permitor shall not be charged for the purchase, use, installation or removal of the energy monitoring equipment.

3. Battelle and its subcontractors will comply with Federal, State and local safety; employer liability; workers' compensation; and building and electrical codes, laws, rules and regulations.

4. Entry to the building will be required for the purpose of installing energy monitoring equipment. Such entry, working and leaving activity for the project period shall be accomplished by prior arrangement with the Permitor at least 24 hours in advance of entry. These activities will be accomplished so as not to unduly interfere with the Permitor's normal routine. The Permitor shall designate a contact for coordinating the project activities at the building.

5. Project equipment (electricity panel monitor) installed by Battelle will be and remain the responsibility of Battelle, or its subcontractors. The Permitor is not responsible for installed project equipment.

6. The Permitor agrees not to disturb installed equipment in any way unless authorized by Battelle or as may become necessary for safety. 
7. The Permitor agrees to notify Battelle of any changes in maintenance practices and alterations to the building during the term of this Research Access Agreement.

8. The Permitor agrees to notify Battelle if the building is to be sold or occupied by someone other than the Permitor as the primary occupant.

9. All data gathered becomes the property of Battelle. Upon request, the Permitor will receive a copy of any report issued by Battelle in which Permitor's facility was involved.

10. Permitor shall not use Battelle's name or identifying characteristics for advertising, sales promotion, or other publicity purposes.

F. Either party may terminate this Agreement by providing thirty (30) days written advance notice to the other party. In the event of early termination, Battelle will arrange to expeditiously remove project equipment, but such removal may require longer than thirty days to complete the effort.

Each party signing this Agreement has the authority to execute and bind the principals involved and represents that there are no other agreements, express or implied, which are not contained in this Research Access Agreement or incorporated specifically by reference.

$\begin{array}{lll}\text { Homeowner (PERMITOR): } & \text { Date__ } \\ \text { Homeowner (PERMITOR): } & \text { Date__ (if multiple) }\end{array}$

\section{BATTELLE MEMORIAL INSTITUTE, PACIFIC NORTHWEST DIVISION}

By:

Date

Title___ Contract Specialist____ Witness


Appendix E

Homeowner Questionnaire 



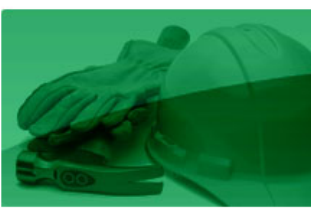

Building America Residential

Deep Energy Retrofit Research Project

\section{Residential Deep Energy Retrofit Research Project Homeowner Questionnaire}

Please fill out as many of the following questions as you can prior to your home energy assessment. If you do not know the answer to a question, leave it blank - do not guess. Mail the completed form to deepenergyretrofits@pnl.gov. Thank you for your participation!

\section{General info}

Name

Address

Describe any additions, alterations, or appliance/equipment modifications since moving in:

Do you have plans for increasing the efficiency of your home? If so, what components do you plan on upgrading. If not, are you willing to invest in your homes efficiency (investments of $\$ 7,000-\$ 20,000$ or more are typically needed to reduce energy bills by $30-50 \%)$ ?:

If you are already planning upgrades, what is the estimated start date:

Have you selected a contractor for your upgrades yet? yes no

\section{Occupancy}

Total \# of adults living in home Total \#/age of children living in home

\section{Daily Patterns}

Do any occupants have variable work hours? How many students living in house? (Year-round or summers off?) Stay-at-home mother? Work from home office? Retired or Elderly persons?

\section{Anticipated lifestyle/occupancy changes}

House for sale/planned move, New or returning child/parent/other occupant, child leaving for school, or other occupant decrease, Major structural addition or alterations planned, Anything else affecting energy consumption?

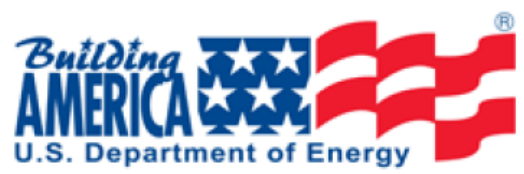




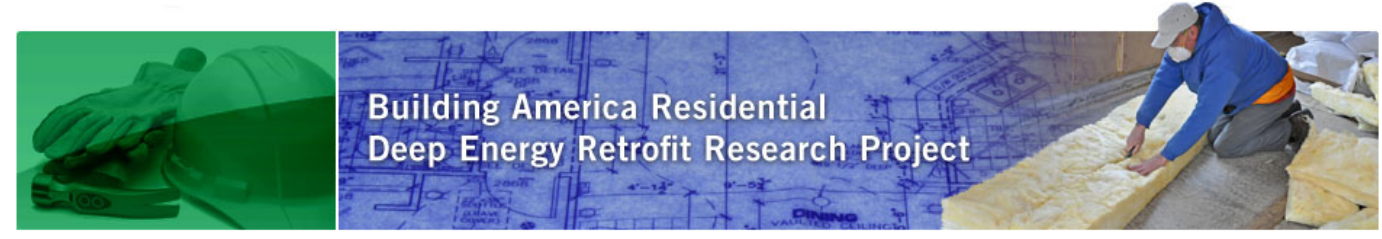

Home Operation

What is your temperature set point for cooling (How often do you change it? Do you set it up during the day or at night manually or via a programmable thermostat?)

If programmable feature is used, please describe:

What is your set point for heating (How often do you change it? Do you set it up during the day or at night manually or via a programmable thermostat?)

If programmable feature is used, please describe:

Do you use supplementary heating systems? E.g. fireplaces, wood stoves, portable electric heaters?

When do you use your ceiling fans (all the time, while sleeping, when you feel uncomfortable)?_

When do you use your bath fans and for how long each time?

When do you use your range hood and for how long each time?

How often do you change your return air filter?

If your home has a whole house ventilation system, how often do you change its filter?

Do you use florescent lighting, including screw-in compact florescent bulbs?

If you home has a sprinkler pump, how often does it run?

On average, how many loads of laundry do you do per week?

On average, how often do you run the dishwasher per week?

On average, how many showers does your family take per week?

What is the typical duration of a shower in your household (in minutes)?

If large variances (i.e. some family members that take long showers), please specify:

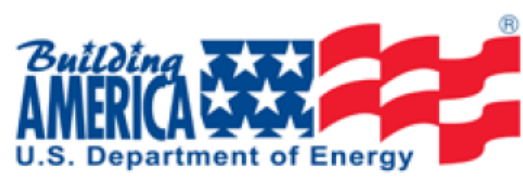


Building America Residential

Deep Energy Retrofit Research Project

E-

How often do you turn off the heating/cooling system and open windows (check all that apply)?

\begin{tabular}{|l|l|l|l|l|l|}
\hline & Never & $\begin{array}{l}\text { Sometimes } \\
\text { during the } \\
\text { day }\end{array}$ & $\begin{array}{l}\text { Sometimes } \\
\text { during the } \\
\text { night }\end{array}$ & $\begin{array}{l}\text { As much as I } \\
\text { can during } \\
\text { the day }\end{array}$ & $\begin{array}{l}\text { As much as I } \\
\text { can during } \\
\text { the night }\end{array}$ \\
\hline Winter & & & & & \\
\hline Spring & & & & & \\
\hline Summer & & & & & \\
\hline Fall & & & & & \\
\hline
\end{tabular}

Please describe how important the following features are to you in your home. Rank and comment: 1 = Very important; 2 = somewhat important; $3=$ neutral; 4 = somewhat unimportant; 5 = don't know.

Energy efficiency / cost

Water efficiency / cost

Maintenance ease / cost

Storage

Safety

Comfort

Healthy indoor environment

Durability

Resale Value

Overall quality of home

Rank Comment

Please describe comfort, or lack of comfort in terms of hot, cold, humid, dry, stuffy, clammy, drafty, unusual odors, mold, etc.

My home is comfortable in the winter.

My home is comfortable in the summer.

My home is comfortable in the spring/fall.

All rooms in my home are equally comfortable.

I am satisfied with the overall comfort of my home.

My home has high electric/gas bills for its size.

I am satisfied with my home overall.

$\mathrm{Y} / \mathrm{N}$ Comment

Homeowner Comments (Include here any energy or water conservation efforts):

If you have additional questions, please contact deepenergyretrofits@pnl.gov.

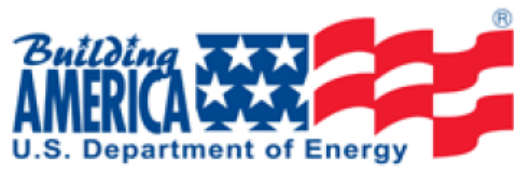

Pacific Northwest

NATIONAL LABORATORY

Proudly Operated by Battelle Since 1965 

Appendix F

Home Audit Data Collection Form 



\section{A. Onsite Energy Audit Data Collection Form}

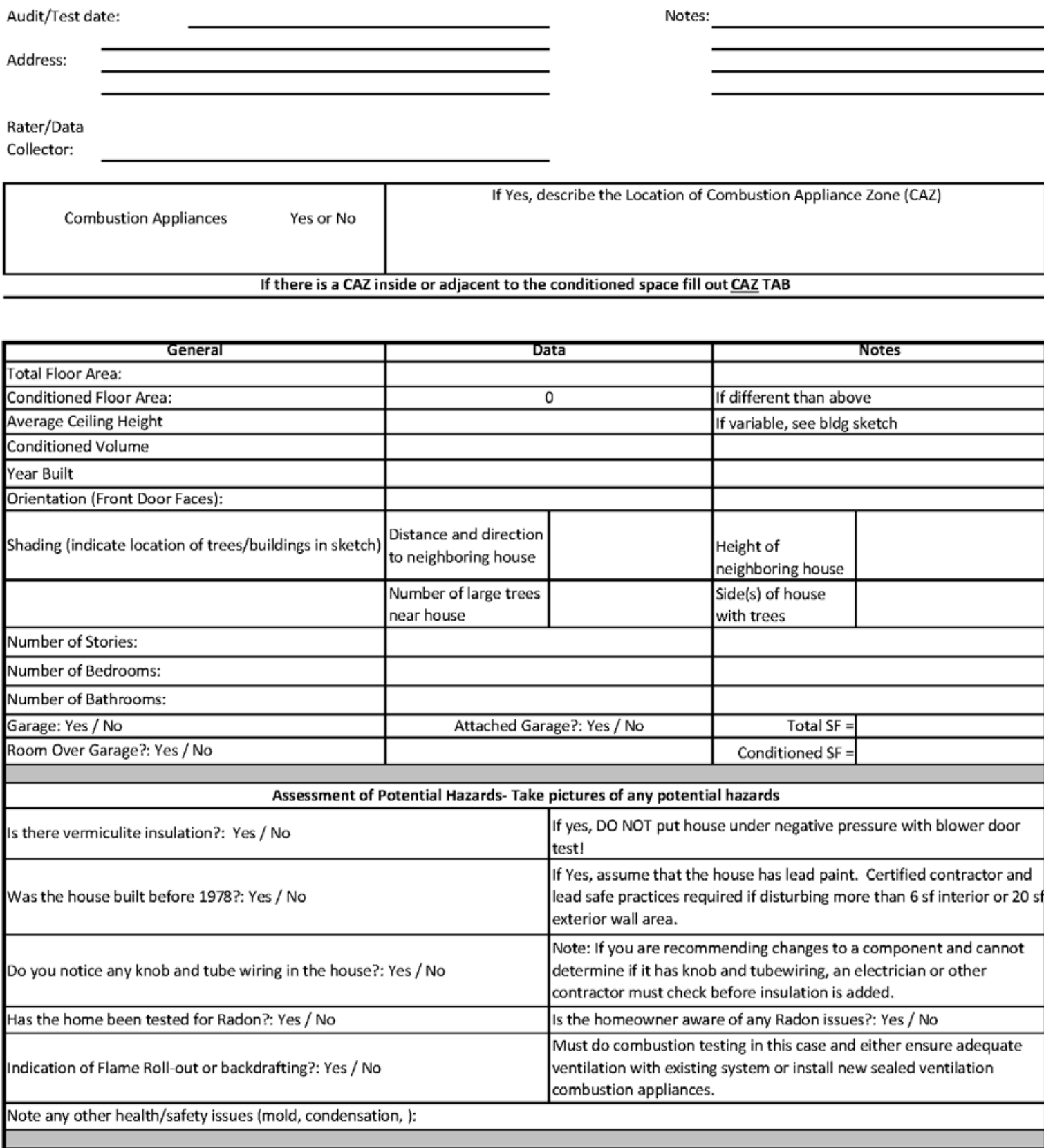




\begin{tabular}{|c|c|c|c|}
\hline Floor & & & \\
\hline Basement / Crawlspace / Slab & Basement & \multicolumn{2}{|c|}{ If split, indicate in drawing } \\
\hline Conditioned Basement?: Yes / No & Yes & \multicolumn{2}{|c|}{ If split, indicate in drawing } \\
\hline Vented Crawlspace?: Yes / No & No & \multicolumn{2}{|c|}{ If split, indicate in drawing } \\
\hline \multicolumn{4}{|l|}{ If basement, average height of above grade foundation: } \\
\hline \multicolumn{4}{|l|}{ Vapor Barrier Installed in Crawlspace? Yes/No } \\
\hline \multirow[t]{2}{*}{ Insulation } & $R=$ & Type & \\
\hline & \multicolumn{3}{|c|}{ Insulation Location: floor joist / foundation wall / under slab } \\
\hline \multirow[t]{2}{*}{ Interior Floor Material } & $\%$ Tile & $\%$ Wood & \\
\hline & $\%$ Laminate & $\%$ Carpet & \\
\hline \multicolumn{4}{|c|}{ Walls - (Indicate wall dimensions on sketches) } \\
\hline Wood-framed / Block / SIP / ICF & $16 "$ o.c. / 24 " o.c. (for wood-framed walls) & & \\
\hline \multicolumn{2}{|c|}{ Batts / Blown-in fiberglass / cellulose / closed-cell SF / open-cell SF } & $R=$ & Inches $=$ \\
\hline I/II/III & \multicolumn{3}{|c|}{ Insulation grade/quality (no gaps, gaps up to $2 \%$ of area, gaps of $2-5 \%$ of area) } \\
\hline Color of outside of house: & White / Light / Medium / Dark & & \\
\hline \multicolumn{4}{|l|}{ Indicate Knee Wall Location and Measurements on sketches } \\
\hline \multicolumn{4}{|l|}{ Ceiling } \\
\hline \multirow[t]{2}{*}{ Ceiling Insulation (if at attic floor) } & Batts / Blown-in fiberglass / cellulose & $R=$ & Inches= \\
\hline & Grade: I/II/III & Attic Floor Area: & \\
\hline \multicolumn{4}{|l|}{ Roof } \\
\hline Gable / Hip / Flat & Shingle / Tile / Metal Roof & & \\
\hline Trusses: Metal / Wood & Roof Color: Light / Medium / Dark & & \\
\hline Weatherstripping on attic hatch? Yes / No & Attic Hatch Insulation Level: $\mathrm{R}=$ & & \\
\hline \multicolumn{4}{|l|}{ Insulation (if vaulted/unvented attic) } \\
\hline \multicolumn{2}{|c|}{ Batts / Blown-in fiberglass / cellulose / closed-cell SF / open-cell SF } & $R=$ & Inches= \\
\hline \multicolumn{4}{|c|}{ If insulation above roof deck, specificy type, thickness, R-value: } \\
\hline Radiant Barrier? Yes / No & \multicolumn{3}{|l|}{ Notes: } \\
\hline Windows & Indicate if there are multiple window types & & \\
\hline Single / Double / Triple Pane & Tinted?: Yes / No & \multicolumn{2}{|c|}{ Low e coating?: Yes / No } \\
\hline Frames: Metal / Vinyl / Wood & Thermal Breaks?: Yes / No & SHGC: & U-Value: \\
\hline Total Window Area: & Window area on North side: & East: & st: \\
\hline Indicate window dimensions, overhangs, and offsets on & n sketches. & & \\
\hline Window to Floor Area Ratio: & & & \\
\hline Cooling System 1 & & & \\
\hline Type: Split / Package / Mini-split & / Window Unit / Wall Unit & If Other, please spe & cify: \\
\hline Manufacturer: & Model \#: & & \\
\hline
\end{tabular}




\begin{tabular}{|c|c|c|c|c|}
\hline \multicolumn{5}{|l|}{ Condensing Unit Model \#: } \\
\hline Ducted System: Yes / No & \multicolumn{4}{|c|}{ Location of Ducts: \% Inside Conditined Space: $\quad$ \% Outside: } \\
\hline Ducts Insulated: Yes / No & \multicolumn{4}{|l|}{ Duct R-Value: } \\
\hline Ducts Sealed?: Yes / No / Unsure & \multicolumn{4}{|l|}{ Number of Returns: } \\
\hline \multicolumn{5}{|c|}{ Duct Location: Attic / Crawlspace / Conditioned Space / knee walls / Other- Describe } \\
\hline System Ratings: & \multicolumn{2}{|l|}{ SEER: } & \multicolumn{2}{|l|}{ EER: } \\
\hline \multicolumn{5}{|l|}{ Capacity (tons or Btu/hr) } \\
\hline Programmable Thermostat: Yes / No & \multicolumn{4}{|c|}{ Describe Schedule and setpoints: } \\
\hline \multicolumn{5}{|l|}{ Cooling System 2} \\
\hline \multicolumn{3}{|c|}{ Type: Split / Package / Mini-split / Window Unit / Wall Unit } & \multicolumn{2}{|c|}{ If Other, please specify: } \\
\hline Manufacturer: & \multicolumn{4}{|l|}{ Model \#: } \\
\hline \multicolumn{5}{|l|}{ Condensing Unit Model \#: } \\
\hline Ducted System: Yes / No & \multicolumn{4}{|c|}{ Location of Ducts: \% Inside Conditined Space: } \\
\hline Ducts Insulated: Yes / No & \multicolumn{4}{|l|}{ Duct R-Value: } \\
\hline Ducts Sealed?: Yes / No / Unsure & \multicolumn{4}{|l|}{ Number of Returns: } \\
\hline \multicolumn{5}{|c|}{ Duct Location: Attic / Crawlspace / Conditioned Space / knee walls / Other- Describe } \\
\hline System Ratings: & \multicolumn{2}{|l|}{ SEER: } & \multicolumn{2}{|l|}{ EER: } \\
\hline \multicolumn{5}{|l|}{ Capacity (tons or Btu/hr) } \\
\hline Programmable Thermostat: Yes / No & \multicolumn{4}{|c|}{ Describe Schedule and setpoints: } \\
\hline Heating System 1 & Manufacturer: & & \multicolumn{2}{|l|}{ Model \#: } \\
\hline \multicolumn{5}{|l|}{ Type of Appliance } \\
\hline \multicolumn{5}{|c|}{ Fuel Type: Electric (Resistance) / Electric (Heat Pump) / Natural Gas / Fuel Oil / Propane / Other: } \\
\hline \multicolumn{5}{|c|}{ Distribution Type: Ducts / Radiator / Radiant Floor / Other } \\
\hline Capacity (Btu/hr): & Efficiency (AFUE / & & & \\
\hline Location of Combustion Appliance: & & Combustion App & liance inside conditio & No \\
\hline Heating System 2 & Manufacturer: & & Model \#: & \\
\hline Type of Appliance & & & & \\
\hline Fuel Type: Electric (Resistance) / El & p) / Natural Gas / Fu & opane / Other: & & \\
\hline Distribution Type: Ducts / Radiator & Other & & & \\
\hline Capacity (Btu/hr): & Efficiency (AFUE / / & & & \\
\hline Location of Combustion Appliance: & & Combustion App & liance inside conditio & No \\
\hline Hot Water System & Manufacturer: & & Model \#: & \\
\hline Appliance Type & & & & \\
\hline Fuel Type & Electric / Hea & Gas / Solar & Direct / Indirect & \\
\hline Location & & & & \\
\hline Capacity (gal) & & & & \\
\hline Pipe Insulation: Yes / No & & & & \\
\hline Is the tank insulated?: Yes / No & R-Value or Thicknes & & & \\
\hline Tank Set Point & & & & \\
\hline Tankless? Yes / No & Recirculat & Yes / No & & \\
\hline Appliances & Manufacturer & Model \# & Age & EFF \\
\hline
\end{tabular}




\begin{tabular}{|c|c|c|c|c|}
\hline \multicolumn{5}{|l|}{ Refrigerator: } \\
\hline \multicolumn{5}{|l|}{ Stove: } \\
\hline \multicolumn{5}{|l|}{ Stove Fuel Type } \\
\hline \multicolumn{5}{|l|}{ Oven: } \\
\hline \multicolumn{5}{|l|}{ Oven Fuel Type } \\
\hline \multicolumn{5}{|l|}{ Microwave: } \\
\hline \multicolumn{5}{|l|}{ Dishwasher: } \\
\hline \multicolumn{5}{|l|}{ Washer: } \\
\hline \multicolumn{5}{|l|}{ Dryer: } \\
\hline \multicolumn{5}{|l|}{ Dryer Fuel Type } \\
\hline \multicolumn{5}{|l|}{ Electronics } \\
\hline \multirow[t]{2}{*}{ Number of Televisions } & Total & & \# CRT & \\
\hline & $\# \mathrm{LCD}$ & & \# Plasma & \\
\hline Number of Computers & Desktops & & Laptops & \\
\hline Number of Cable boxes & Standard & & DVR/Tivo & \\
\hline \multirow[t]{5}{*}{ Other Appliances } & Appliance & Number & Appliance & Number \\
\hline & Gas BBO & & Dehumidifier & \\
\hline & Air purifier & & Space Heater & \\
\hline & Window $\mathrm{A} / \mathrm{C}$ & & Waterbed & \\
\hline & Aquarium & & $\begin{array}{l}\text { Hot water } \\
\text { circulation pump }\end{array}$ & \\
\hline \multicolumn{5}{|l|}{ Other, please speficy } \\
\hline \multicolumn{5}{|c|}{ Ventilation - add space for 2 nd system } \\
\hline \multirow[t]{2}{*}{ Ceiling Fans } & Total & & \#E Star & \\
\hline & CFM@Med Speed & & \# Speeds & \\
\hline \multirow[t]{2}{*}{ ERV/HRV } & Manufacturer & & Model & \\
\hline & Runtime Schedule & & Configuruation & \\
\hline \multirow[t]{2}{*}{ Supply Ventilation } & Integrated w/ Return & & Diameter & \\
\hline & CFM (est.) & & Control/Schedule & \\
\hline \multirow[t]{3}{*}{ Exhaust fans } & Total & & \# E Star & \\
\hline & CFM@Med Speed & & \# Speeds & \\
\hline & Control & & Schedule & \\
\hline \multicolumn{5}{|l|}{ Lighting } \\
\hline \multirow{2}{*}{ (2) } & $\mathrm{CFL}$ & & LED & \\
\hline & Hardwired & & Portable & \\
\hline Recessed Lighting Sealed?: Yes / No & & & & \\
\hline
\end{tabular}




\begin{tabular}{|c|c|c|c|c|}
\hline Plumbing Fixtures & Manufacturer & Model \# & Age & EFF \\
\hline \multicolumn{5}{|l|}{ Domestic Water Pump } \\
\hline \multicolumn{5}{|l|}{ Pool Pumps } \\
\hline Shower Heads & Number & & Flow Rate & \\
\hline Faucets & Number & & Aerators & \\
\hline \multirow[t]{7}{*}{ Pictures of } & \multicolumn{4}{|c|}{ Every face of the exterior } \\
\hline & \multicolumn{4}{|c|}{ Every Appliance with model number captured } \\
\hline & \multicolumn{4}{|c|}{ Air Handler - many photos including plenums } \\
\hline & \multicolumn{4}{|l|}{ Ducts - many photos } \\
\hline & \multicolumn{4}{|c|}{ Ceiling and floor insulation - many photos } \\
\hline & \multicolumn{4}{|c|}{ Every room, including ceiling and floor } \\
\hline & \multicolumn{4}{|l|}{ Any areas of concern } \\
\hline \multicolumn{5}{|c|}{$\begin{array}{l}\text { Draw sketch of building layout/footprint. Include dimensions, any changes in ceiling height, and location of trees or neerby buildings. Also include } \\
\text { dimensions for calculating wall area, window area, overhangs, offsets, and any other additional information. }\end{array}$} \\
\hline \multicolumn{5}{|l|}{ NOTES } \\
\hline & & & & \\
\hline & & & & \\
\hline & & & & \\
\hline
\end{tabular}




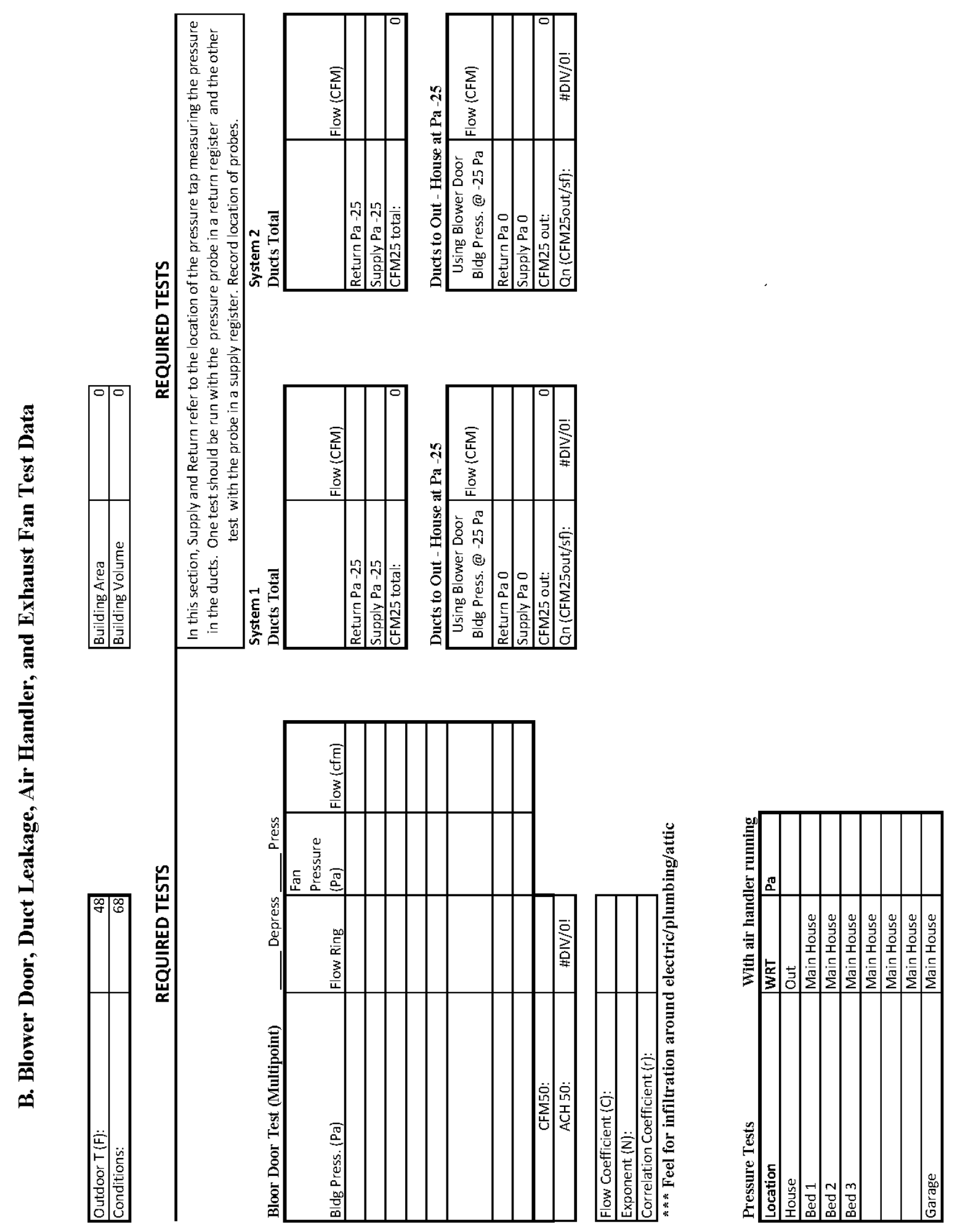




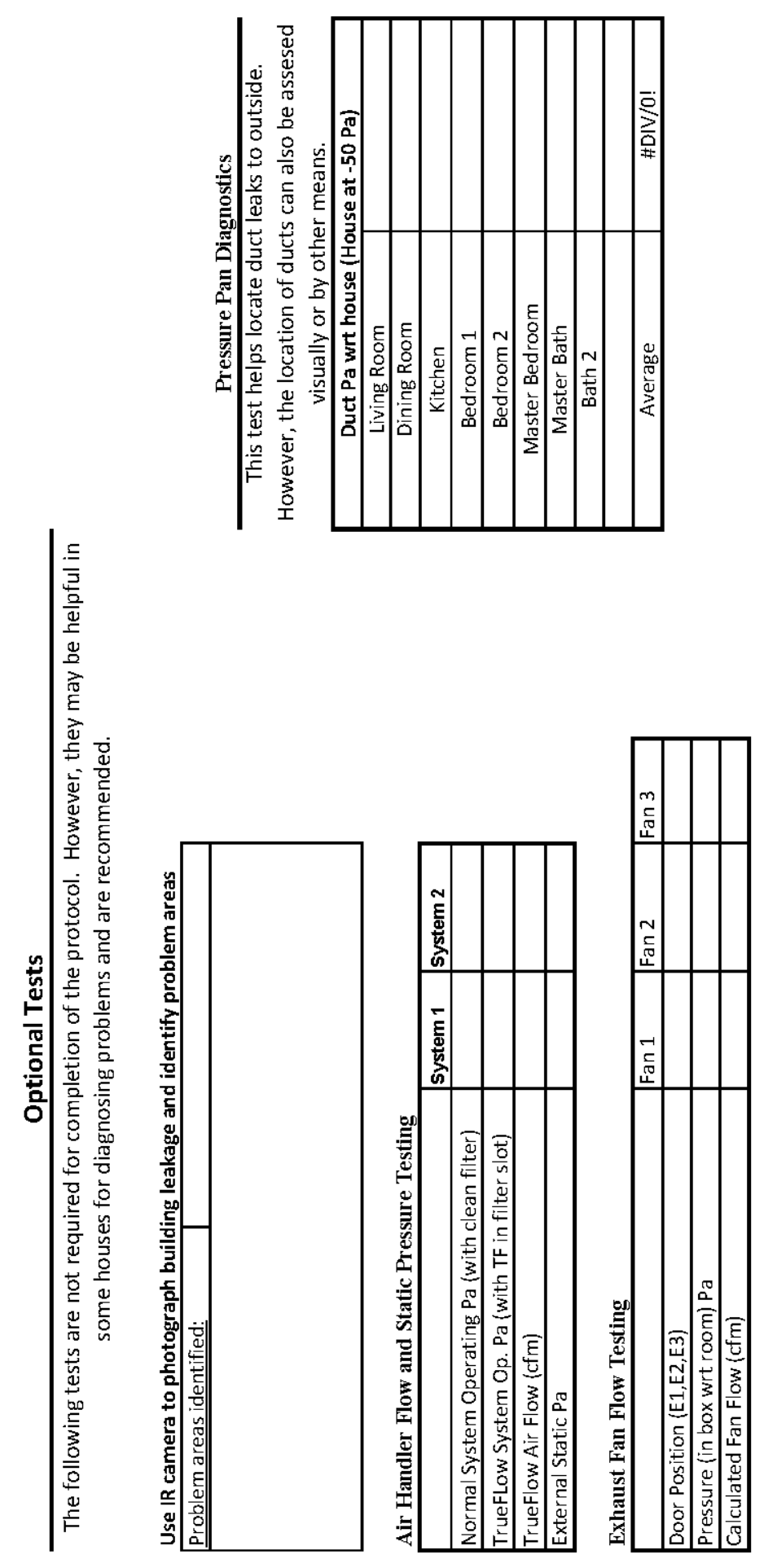

F.7 


\section{Combustion Testing}

The combustion testing outlined in this section was developed with reference to the Building Performance Institute's "Technical Standards for Certified Building Analyst I."

\section{Worse Case Depressurization / Draft Test}

We would like CAZ (combustion appliance zone) testing to be done for all naturally aspirating appliances, even if the appliance will be upgraded to sealed combustion during the retrofit. CAZ testing is not required for electric, power vented, or sealed combustion appliances.

\begin{tabular}{|l|l|l|}
\hline \multicolumn{1}{|c|}{ Preparation- Before Testing } & Check & Condition \\
\hline VISUALLY INSPECT VENTING (of each Combustion Appliance) & & Note indications of roll out \\
\hline TURN OFF ALL COMBUSTION APPLIANCES. & & \\
\hline $\begin{array}{l}\text { CLOSE ALL OPERABLE VENTS AND DAMPERS, not to include AC system supply } \\
\text { diffusers and return grills. If AC system has an outdoor air damper close it. }\end{array}$ & & \\
\hline CHECK DRYER VENT and LINT FILTER, must be clean & & \\
\hline CHECK FURNACE FILTER (clean or replace if needed) & & \\
\hline $\begin{array}{l}\text { Close all doors to put the combustion appliance into the smallest } \\
\text { space possible. }\end{array}$ & & \\
\hline IF BLOWER DOOR IS SET UP, BE SURE FAN IS COVERED. & & \\
\hline
\end{tabular}

Setup Manometer and Pressure hoses to measure CAZ (WRT) Outdoors. Connect the CAZ to the "Input" and the Outdoors to "Reference".

\begin{tabular}{l} 
Worst Case Dep. Steps \\
\hline 1. Record Baseline CAZ wrt outside and record. \\
\hline 2. Establish Worst Case by turning on all exhaust fans and cloths driers. Also open/close interior doors and turn on/off furnace fan \\
until CAZ is the most negative. If the house has a fireplace that the client uses, turn on the blower door to 300 CFM with Ring B to \\
simulate. \\
\hline 3. Record Worst Case CAZ. Record change in CAZ.
\end{tabular}

\begin{tabular}{|l|l|l|l|l|l|l|}
\hline \multirow{2}{*}{} & \multicolumn{3}{|c|}{ CAZ 1 } & \multicolumn{3}{c|}{ CAZ 2 } \\
\cline { 2 - 7 } & Baseline & WC & $\Delta \mathrm{P}$ & Baseline & WC & $\Delta \mathrm{P}$ \\
\hline Pre Retrofit & & & & & & \\
\hline Post Retrofit & & & & & & \\
\hline
\end{tabular}

\begin{tabular}{|c|c|}
\hline Venting Condition & Limit (Pa) \\
\hline Orphan natural draft water heater & -2 \\
\hline $\begin{array}{l}\text { Natural draft boiler of furnace commonly vented with water } \\
\text { neater }\end{array}$ & -3 \\
\hline $\begin{array}{l}\text { Natural draft boiler or furnace with vent damper commonly } \\
\text { vented with water heater }\end{array}$ & -5 \\
\hline Individual natural draft boiler or fumace & -5 \\
\hline $\begin{array}{l}\text { Mechanically assisted draft boiler or furnace commonly vented } \\
\text { with water heater }\end{array}$ & -5 \\
\hline $\begin{array}{l}\text { Mechanically assisted draft boiler or furnace alone, or fan } \\
\text { assisted DHW alone }\end{array}$ & -15 \\
\hline Exhaust to chimney - top draft inducer; & \\
\hline $\begin{array}{l}\text { High static pressure flame retention head oil burner; } \\
\text { Sealed combustion appliance }\end{array}$ & -50 \\
\hline
\end{tabular}


Appliance Draft, Spillage, and co Test

Note: Draft and spillage testing are optional. Do not puncture flue in positive pressure or sealed combustion systems.

Acceptable Draft Readings for Worst Case Draft Test

\begin{tabular}{|c|c|c|c|c|}
\hline$<20^{\circ}$ & $21-40^{\circ}$ & $41-60^{\circ}$ & $61-80^{\circ}$ & $>80^{\circ}$ \\
\hline & & & & \\
$-5 \mathrm{~Pa}$ & $-4 \mathrm{~Pa}$ & $-3 \mathrm{~Pa}$ & $-2 \mathrm{~Pa}$ & $-1 \mathrm{~Pa}$ \\
\hline
\end{tabular}

Periodically check CAZ CO. If exceeds 35 ppm- STOP testing! And open up zone to outside. Have heating professional NOTE: inspect system further.

Perform Worst Case Draft and Combustion Tests for each appliance under worst case condition. Measure draft pressure wrt to CAZ.

\begin{tabular}{|l|l|l|}
\cline { 3 - 3 } \multicolumn{1}{c|}{} & \multirow{2}{c|}{ Vent Draft Pressure } & CO in \\
Vented Appliance & & \\
\hline Furnace & & \\
\hline Water Heater & & \\
\hline
\end{tabular}

Turn appliance on and test for spillage with mirror, lighter, or smoke puffer. Appliance fails if it is still spilling after one minute. Spillage test (Pass or Fail)

Ovens

(Only for gas stove/ovens)

Set oven to highest setting

Test oven exhaust for CO.

Record CO readings after every minute of operation for 15 minutes, or record during worm-up and steady-state.

\begin{tabular}{|r|l|}
\hline Minute & CO reading \\
\hline 1 & \\
\hline 2 & \\
\hline 3 & \\
\hline 4 & \\
\hline 5 & \\
\hline 6 & \\
\hline 7 & \\
\hline 8 & \\
\hline 9 & \\
\hline 10 & \\
\hline 11 & \\
\hline 12 & \\
\hline 13 & \\
\hline 14 & \\
\hline 15 & \\
\hline & \\
\hline
\end{tabular}




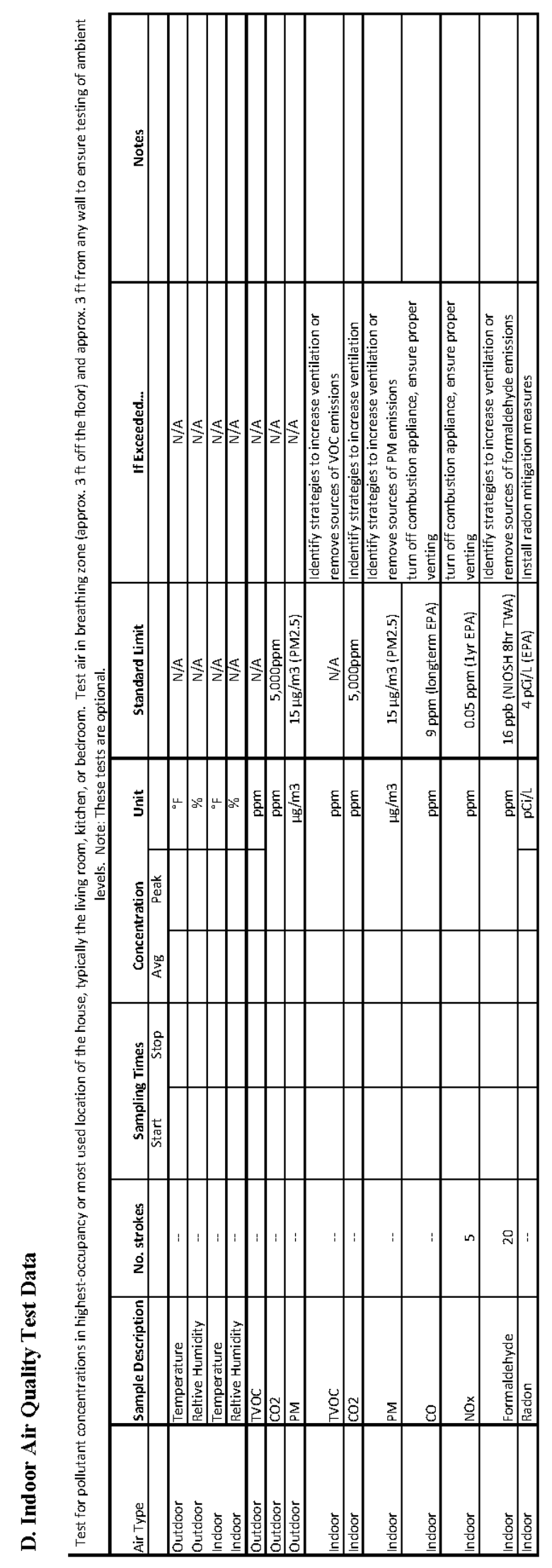

F.10 


\section{E. Post-Retrofit Homeowner Questionaire}

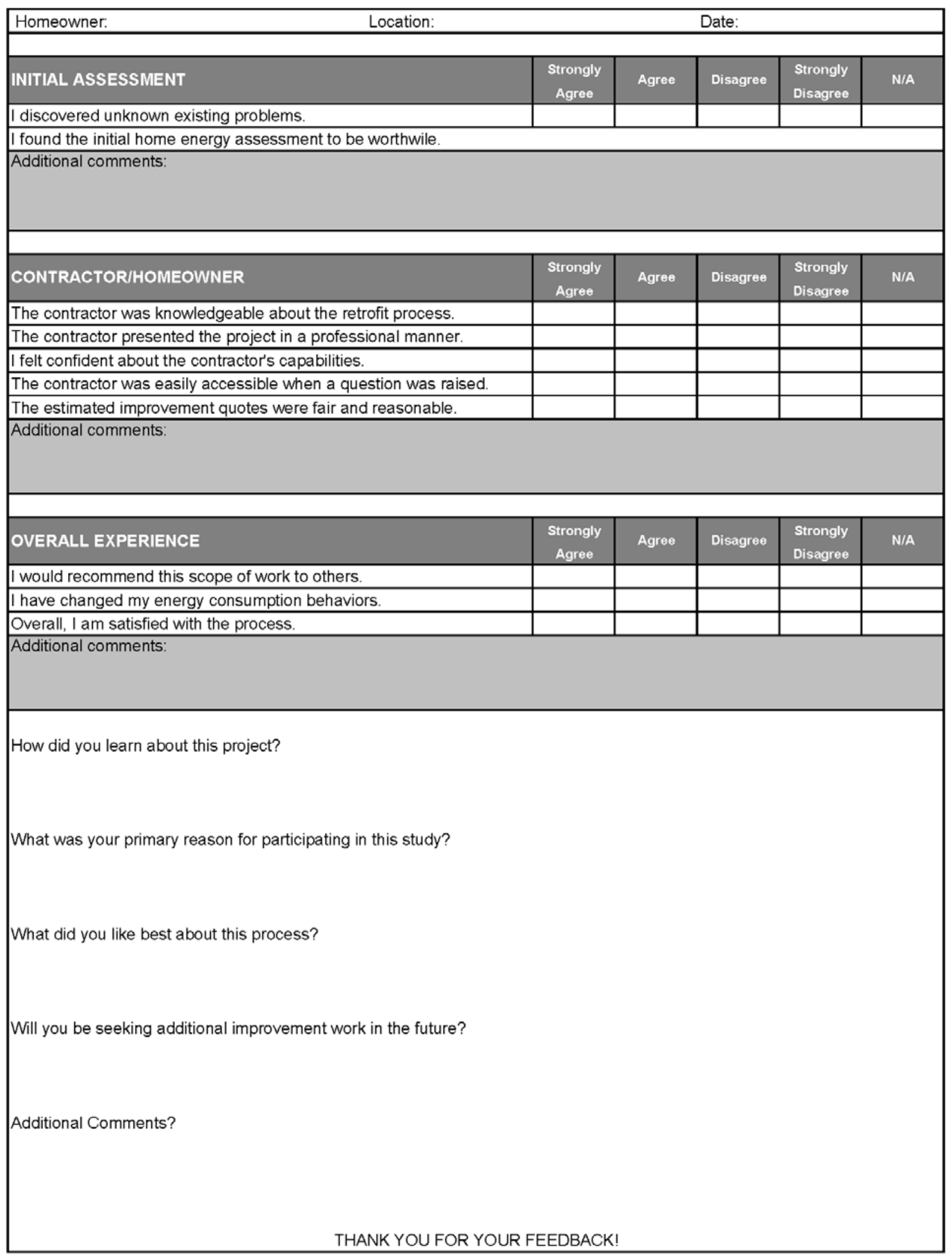




\begin{tabular}{|c|c|c|c|c|c|}
\hline Room & $\begin{array}{l}\text { floor area } \\
\text { ft2 }\end{array}$ & $\begin{array}{l}\text { ceiling } \\
\text { height } \\
\mathrm{ft}\end{array}$ & $\begin{array}{l}\text { volume } \\
\mathrm{ft} 3\end{array}$ & $\begin{array}{l}\text { window } \\
\text { area } \\
\text { ft2 }\end{array}$ & $\begin{array}{l}\text { ex wall } \\
\mathrm{ft} 2\end{array}$ \\
\hline \multicolumn{6}{|c|}{ Basement } \\
\hline \multicolumn{6}{|c|}{ BR1 } \\
\hline \multicolumn{6}{|c|}{ Fam Room } \\
\hline \multicolumn{6}{|c|}{ Laundry } \\
\hline \multicolumn{6}{|l|}{ Bath1 } \\
\hline \multicolumn{6}{|l|}{ LivRm } \\
\hline \multicolumn{6}{|l|}{ DinRm } \\
\hline \multicolumn{6}{|l|}{ Kitchen } \\
\hline \multicolumn{6}{|l|}{ Bath2 } \\
\hline \multicolumn{6}{|l|}{ BR2 } \\
\hline \multicolumn{6}{|l|}{ BR3 } \\
\hline \multicolumn{6}{|l|}{ Master } \\
\hline TOTAL & 0 & & & & 0 \\
\hline
\end{tabular}


Appendix G

Indoor Air-Quality Procedure 



\section{Appendix G}

\section{Indoor Air Quality Procedure}

\section{STANDARD OPERATING PROCEDURE}

\section{SAMPling Indoor AIr FOr AIrborne Pollutants in RETrofit HOMES BEFORE AND AFTER AIRTIGHTENING}

\section{G.1 Introduction}

The purpose of this indoor air quality (IAQ) research is to explore the relationship between IAQ in homes and home airtightness or installation of energy-related retrofit measures in homes. There is concern that air-sealing, installing additional insulation in homes, and other home improvement measures can increase the concentration of hazardous air contaminants in homes, thereby increasing exposure rates for occupants, and causing unhealthy living situations (Widder and Baechler 2011). Previous literature describes some aspects of why this might be a problem, but has not adequately explored the relationship of these IAQ and retrofit measures. Of particular interest is the secondary relationship between concentrations of indoor air contaminants and ventilation. In airtight homes, supplemental ventilation is often installed to meet an established rate of "adequate" ventilation. Typically, this adequate ventilation level is based on the ventilation requirements established in the American Society of Heating, Refrigerating, and Air-Conditioning Engineers (ASHRAE) Standard 62.2, "Minimum Ventilation Rates for Low-Rise Buildings" (ASHRAE 2010). This research aims to establish a quantitative relationship between indoor air pollutant concentrations, ventilation level, and building tightness for homes sampled. Characteristics of building envelope leakage and ventilation system performance are established during a home energy audit prior to the retrofit being performed. Installation of retrofit measures and associated energy savings are tracked throughout the process. Similar building envelope and ventilation system performance values are obtained through a post-retrofit audit, or "test-out." Indoor air pollutant concentrations are measured concurrent with the pre- and post-retrofit home audits. Individual samples of particulate matter $\left(\mathrm{PM}_{2.5}\right)$, nitrogen oxides $\left(\mathrm{NO}_{\mathrm{x}}\right)$, carbon monoxide $(\mathrm{CO})$, carbon dioxide $\left(\mathrm{CO}_{2}\right)$, total volatile organic compounds (TVOCs), formaldehyde, and radon are collected in indoor air of several households in the Northwest.

\section{G.1.1 Location}

Sampling was performed in the Tri-Cities in Washington state and in Portland, Oregon. The homes that will undergo indoor air-quality sampling were selected based on the availability of sampling personnel and equipment. Sampling is performed indoors and outdoors on each occasion in several homes at each site. Outdoor measurement occurs in an open area, away from large trees, $2 \mathrm{~m}$ above the ground. Indoor measurements occurs on the same day in a commonly used room, usually the living room, in the breathing zone. The breathing zone is described as being between $2 \mathrm{ft}$ and $5 \mathrm{ft}$ from the floor and $3 \mathrm{ft}$ from any wall. 


\section{G.1.2 Schedule}

Pre-retrofit audits were conducted in the spring and early summer 2011. Post-retrofit audits will occur after all retrofit work is completed. Post-retrofit indoor air sampling will be scheduled to be on a "seasonally comparable" days.

\section{G.2 Materials and Methods}

The method for characterizing the building envelope and ventilation system consists of measuring air flow and pressure differentials in specific areas with respect to a reference. Building envelope leakage and ventilation system performance testing equipment was selected to represent measurement techniques most commonly used by home auditors in the field.

The method for collecting indoor air-quality samples consists of drawing measured quantities of ambient air through sampling media to determine concentrations. Sampling equipment was chosen to provide rough characterization of the presence of indoor air contaminants at levels that would be of concern. Details about sample collection and submission to the laboratory for analysis are discussed below.

\section{G.2.1 Building Envelope, Ventilation System, and Indoor Air-Quality Sampling Equipment}

For building envelope sampling, test equipment includes a blower door fan, door frame and cloth, monometer, plastic tubing, and a computer with TechTite software installed for multipoint testing. All blower door equipment is manufactured by Minneapolis Blower Door.

For ventilation system performance testing, equipment includes a Truflow meter, exhaust fan flow box, a monometer, and plastic tubing. All ventilation system performance testing is also produced by Minneapolis Blower Door.

For indoor air-quality sampling, several tools are used. For sampling of particulates, TVOCs, $\mathrm{CO}_{2}$, temperature, and RH, sampling is performed by the EVM 7 environmental monitor, produced by $3 \mathrm{M}$. The particulate matter sampling train includes an impactor, an optical engine, a gravimetric filter cassette, a pump, and an orifice-controlled flow sensor. The sample medium is replaceable paper filters. The TVOC sensor is a photo-ionization detector with part-per-million ( $\mathrm{ppm}$ ) sensitivity and the $\mathrm{CO}_{2}$ sensor is a non-dispersive infrared sensor. Both sensors operate with a small fan to pull air across the sensors and exhaust it. The EVM 7 is run for the duration of the sampling period.

For $\mathrm{NO}_{\mathrm{x}}$ and formaldehyde sampling, each sample is collected with a chemical-specific sample collection tube and a hand-operated pump. The aerosol sampler tubes are Drager Color-Detector Tubes, with specific tubes for each individual chemical sample - nitrogen dioxide, 0.5-25 ppm and formaldehyde, $0.2-5 \mathrm{ppm}$. These tubes are operated with the Drager Accubellows. The limit of detection on these samples tubes is directly and linearly related to the volume of air pulled through the sampling media. For this study, the number of strokes are dictated based on when a reliable reading is observed, in multiples of 10. The Drager sample tubes are used for point sampling in the home during particulate and TVOC sampling. 
For sampling of $\mathrm{CO}$, a Testo $\mathrm{CO}$ stick is used to determine ambient $\mathrm{CO}$ concentrations.

For homes that demonstrate or are believed to contain elevated levels of TVOCs or formaldehyde, more accurate sorbent media is used to determine concentrations. These will be passive sample badges with a Carbograph 5 sorbent for TVOC and 2, 4-dinitrophenylhydrazine (DNPH) sorbent for formaldehyde collection. These badges will be sent to an offsite laboratory for sorbent extraction and component analysis using gas chromatography and mass spectrometry in accordance with the U.S. Environmental Protection Agency’s (EPA’s) TO-17 sample analysis method.

For sampling of radon, the sampling equipment is the RadStar R300 radon meter.

\section{G.2.2 Building Envelop and Ventilation System Performance Testing}

Building envelope is characterized by conducting a blower door test to determine building leakage. The test is performed with all doors and windows closed to determine only inadvertent leakage pathways. The blower door pulls a measured volume of air through the doorway and the manometer measures the pressure differential between the indoors and outdoors. The TecTite software is used to determine the fan flow and relative pressure differential at multiple points. The multipoint test gives a more accurate measurement of required fan flow in cubic feet per minute $(\mathrm{cfm})$ to reach -50 pascals $(\mathrm{Pa})$ with respect to the outside (referred to as CFM50).

The ventilation system performance test consists of measuring the flow rates of the air handler and any exhaust fans in the home, as applicable. The flow rate of the air handler is determined using a similar manometer and a TrueFlow plate to measure the pressure differential between the air handler and the house. The measured pressure differential allows the user to calculate an adjusted flow rate through the duct system. Exhaust fan flow is determined using a similar manometer and an exhaust fan box. The manometer measures the pressure differential in the box relative to the ambient room with the exhaust fan running to determine the flow rate in $\mathrm{cfm}$.

For select homes, room-to-room pressure differentials with the air handler running may be determined to ensure good mixing of air throughout the home.

\section{G.2.3 Particulate Matter, TVOC, $\mathrm{CO}_{2}$, and Radon Sample Collection}

For sampling of particulate matter, TVOCs, $\mathrm{CO}_{2}$, and radon, the EVM 7 and radon meters are turned on and checked for proper function. The start time of sampling and initial reading should be recorded. The meter is set up to sample every 15 seconds and average over 5 minutes, or 20 measurements. It is believed that the 15 -second sampling interval is sufficient to capture any fluctuations from pollutant release events and 15-minute averaging is a good representation of expose for that time period.

Particulate matter, TVOCs, and $\mathrm{CO}_{2}$ are first measured outside with the EVM 7 meter to get a baseline reading. Outdoor measurement equipment is installed outdoors prior to building envelope testing and measurement of outdoor concentrations occurs while the home audit is occurring. Outdoor ambient air baselining is expected to occur for approximately 4 hours. At the conclusion of the building leakage tests, the time and ending readings are recorded and the EVM 7 meter turned off. The particulate filter is removed from the EVM 7 meter and properly labeled. A new filter is installed in the test filter cassette. 
The EVM 7 and radon meters are then installed indoors in a commonly used room for 24 hours. The same protocol for recording the start and end sample times should be used for setting up and taking down the meters. The meters are picked up the next day.

\section{G.2.4 $\mathrm{NO}_{x}$, Formaldehyde, and CO Sample Collection}

Sampling of $\mathrm{NO}_{x}$, formaldehyde, and CO occurs as point samples. When the EVM 7 and radon meters are set up indoors, the $\mathrm{CO}$ monitor is also turned on. The start time and beginning concentration are recorded. $\mathrm{NO}_{\mathrm{x}}$ and formaldehyde are sampled in series using the Drager Accubellows and individual chemical sample tubes. $\mathrm{NO}_{\mathrm{x}}$ is sampled with an $\mathrm{NO}_{2}$ chemical sampling tube. The number of strokes, or volume of air sampled, is dictated based on when a reliable reading is observed, in multiples of 10 . Upon completion of $\mathrm{NO}_{\mathrm{x}}$ and formaldehyde sampling, seal sampling tubes using air-impermeable tape and place them in a labeled plastic bag. Record the end time and concentration on the $\mathrm{CO}$ meter and turn off meter.

\section{G.2.5 Sample Transportation and Storage}

Immediately following sample collection, particulate matter (PM) sample filters are placed in filter Petri dishes. The Petri dishes are stored and transported from the monitoring locations to the analytical laboratory in a sealed plastic bag. Upon arrival at the laboratory, the filter Petri dishes are removed from the plastic container for gravimetric analysis.

The filters are stored in individual plastic bags in the freezer to preserve volatile components, in case further analysis is desired.

For $\mathrm{NO}_{\mathrm{x}}$ and formaldehyde Drager tubes, the used sample tubes should have their ends sealed with duct mastic or another air-impermeable tape and they be stored in a sealed, labeled plastic bag at the conclusion of the sampling period.

\section{G.2.6 Laboratory Analysis}

Analysis of PM samples includes gravimetric analysis using a calibrated scale obtained from PNNL's Environmental and Molecular Sciences Laboratory to determine the mass of particulates accumulated during the sampling period. Analysis of TVOC, $\mathrm{CO}, \mathrm{CO}_{2}$, and radon measurements consists of downloading and recording stored data from the respective meters. There is no further analysis.

Analysis of $\mathrm{NO}_{\mathrm{x}}$ and formaldehyde samples consists of recording concentrations from color levels, number of strokes, and corresponding concentrations given on the tube. The number of strokes is used to scale the concentration read on the tube based on the relative volume of air sampled.

\section{G.2.7 Additional Information}

In addition to collecting ambient air samples, weather data is logged as obtained by observation and data from the National Weather Service. Temperature and RH measurements from the EVM 7 is corroborated with these data. 
A detailed sampling protocol is included as Attachment 1.

\section{G.3 Quality Assurance and Quality Control}

Following is a brief discussion regarding QA/QC procedures to be followed during each sampling event.

\section{G.3.1 Field Procedures}

Field QA/QC procedures includes the following:

- PM values are recorded using both optical mirror and gravimetrically.

- PM, TVOC, and $\mathrm{CO}_{2}$ data is taken indoors and outdoors to ensure environmental factors are not confounding results.

- A blank PM filter is collected at each site for comparison.

Sampling flow rates are calibrated and sampling trains (including the sampling media) are checked for leaks and other problems monthly. Proper maintenance is adhered to, as recommended by equipment manufacturers.

\section{G.3.2 Field Log Book}

Relevant field data is recorded on a field data sheet (Attachment 2) and in a field log book. These data include the following, at a minimum:

- date of sample collection

- location of sample collection

- times corresponding to the start of sampling and the end of sampling

- point concentration readings for all sampled pollutants at the start and end of sampling

- weather conditions

- any other relevant information.

\section{G.3.3 Sample Labeling}

All samples are labeled with the following information:

- sampling date

- homeowner name

- indoor or outdoor air sample.

\section{G.3.4 Supplies and Equipment}

An equipment and supply checklist is included as Attachment 3. 


\section{AtTachment 1 - Sampling Protocol}

The following procedures are adhered to during each sampling event and at each monitoring location.

Pre-Sampling Activities:

- Confirm availability of supplies (an Equipment and Supply Checklist is provided as Attachment 3).

- Disassemble PM samplers and clean all parts using disposable isopropyl alcohol pads. Apply nonvolatilizing grease such as vacuum grease to the impaction plates of the samplers before reassembly.

- Label and weigh filters to be used in PM samplers.

- Print appropriate data sheets (a Field Data Sheet is provided as Attachment 2).

Sampling Overview:

1. Set up EVM 7 meter outside.

2. Perform building leakage and ventilation performance test (along with other home audit tests).

3. Set up EVM and radon meters inside.

4. Perform $\mathrm{NO}_{\mathrm{x}}$, formaldehyde, and $\mathrm{CO}$ point sampling.

5. Pick up EVM 7 and radon meters.

Testing Of Outdoor Ambient Air:

1. Take the EVM 7 out of the case and set it up in an area at least $2 \mathrm{~m}$ above the ground.

2. Turn the EVM 7 meter on.

3. Check the PID and PM normalization factors, which should be 1.0.

4. Check the logging interval and averaging. The EVM 7 should be set to 15 -second sampling and averaging every 20 samples.

5. Check that the PM turret is set to the appropriate setting $\left(\mathrm{PM}_{2.5}\right)$.

6. Remove the pump protection cassette and install a clean, weighed filter paper in the test filter cassette in the EVM 7 meter.

7. Turn on the EVM 7 meter and ensure the PM air pump is running.

8. Record the start time and the initial readings of $\mathrm{PM}_{2.5}, \mathrm{CO}_{2}$, and TVOC.

9. Leave the EVM 7 meter running while conducting building leakage and ventilation performance tests.

10. After completing building leakage and ventilation performance tests (and other home audit tests; approximately 4 hours), record the time and final $\mathrm{PM}_{2.5}, \mathrm{CO}_{2}$, and TVOC readings. Press the run/stop button to stop the session.

11. Remove the PM filter from the filter cassette and place in a filter Petri dish and into a sealed plastic bag and label bag.

12. Put a new filter in the filter cassette and replace the cassette in the EVM 7 meter. 
Testing Of Building Leakage And Ventilation System Performance:

\section{Air Handler Flow Rate Test}

1. Open all registers and an outside window.

2. With air handler in "on" position and existing filter in place, insert the static pressure probe into either: 1) the side of the supply plenum, 2) a "dead-end" corner of the supply plenum, or 3) the side of the return plenum at least 24 in. from any obstructions. Point the static pressure probe into the air stream.

3. Connect the static pressure probe to Channel A inlet and leave Channel A Ref open to the house. Measure the normal system operating pressure and record on the field data collection sheet.

4. Set Mode to Pr/AH. Press start to begin the measurement. Once the measurement has stabilized, press ENTER and record the reading on the field collection data sheet.

5. Remove the existing filter and install the appropriately sized metering plate so that the plate completely fills the duct opening (either in the filter slot or in the central return plenum).

\begin{tabular}{|c|c|c|c|}
\hline \multirow{2}{*}{$\begin{array}{l}\text { Filter Slot } \\
\text { (in. } x \text { in.) }\end{array}$} & \multirow{2}{*}{$\begin{array}{c}\text { Flow } \\
\text { Metering } \\
\text { Plate } \\
\end{array}$} & \multicolumn{2}{|c|}{$\begin{array}{c}\text { Spacer Dimension } \\
\text { (in. x in.) }\end{array}$} \\
\hline & & Spacer 1 & Spacer 2 \\
\hline $14 \times 20$ & $\# 14$ & ------ & ------ \\
\hline $14 \times 25$ & \#14 & $5 \times 14$ & ------ \\
\hline $16 \times 20$ & \#14 & $2 \times 20$ & ------ \\
\hline $16 \times 24$ & \#14 & $2 \times 20$ & $4 \times 16$ \\
\hline $16 \times 25$ & \#14 & $2 \times 20$ & $5 \times 16$ \\
\hline $18 \times 20$ & \#14 & $4 \times 20$ & ------ \\
\hline $20 \times 20$ & \#20 & ------ & ------ \\
\hline $20 \times 22$ & \#20 & $2 \times 20$ & ------ \\
\hline $20 \times 24$ & \#20 & $4 \times 20$ & ------ \\
\hline $20 \times 25$ & \#20 & $5 \times 20$ & ------ \\
\hline $20 \times 30$ & \#20 & $10 \times 20$ & ------ \\
\hline $24 \times 24$ & \#20 & $4 \times 20$ & ------ \\
\hline
\end{tabular}

6. Connect red tubing on the TrueFlow plate to the Channel B inlet tap. Connect the green tubing to the Channel B Ref tap. Keep the tubing from before (Ch A to static probe).

7. Adjust the Device to reflect the appropriate TrueFlow plate (\#14 or \#20).

8. Close the filter access opening and be careful not to pinch the tubes.

9. Turn the air handler on (if you turned it off to perform the TrueFlow installation).

10. Record fan flow (DG-700 automatically converts to flow and displays on Channel B Display).

\section{Exhaust Fan Test}

1. Connect B Input tap to exhaust flow metering box.

2. Set Mode to $\mathbf{P r} / \mathbf{F l}$ and Device to $\mathbf{E X H}$.

3. Set door position on box and configuration on gauge. 


\begin{tabular}{ccc}
\hline $\begin{array}{c}\text { Door } \\
\text { Position }\end{array}$ & $\begin{array}{c}\text { Configuration on } \\
\text { DG-700 }\end{array}$ & $\begin{array}{c}\text { Flow Range } \\
\text { (cfm) }\end{array}$ \\
\hline E1 & A1 & $44-124$ \\
E2 & B1 & $21-59$ \\
E3 & C1 & $10-28$ \\
\hline
\end{tabular}

4. Cover exhaust fan inlet with metering box (use handle if necessary).

5. Record fan flow (DG-700 automatically converts to flow and displays on Channel B Display). Indoor Air Sampling:

\section{PM, $\mathrm{CO}_{2}$, TVOC, and Radon Sampling}

1. Set up the EVM 7 meter and the radon meter in a commonly used room where it will not be disturbed for 24 hours (advise homeowners of its presence and recommend they not disturb the measurement equipment).

2. Start the EVM 7 meter as described in testing outdoor air.

3. Turn on the radon meter by plugging the meter into a nearby outlet and turning the key to Measure On. Record the start time of testing.

\section{$\mathrm{CO}, \mathrm{NO}_{\mathrm{x}}$, and Formaldehyde Point Sampling}

1. Turn on the CO monitor by pressing the power button. Record the time and the initial reading.

2. Remove the end caps from one $\mathrm{NO}_{2}$ Drager colorimetric sample tube and install with arrow pointing into the Drager Accubellows.

3. Record the start time of measurement.

4. Fully compress the Drager Accubellows to the stop and let fully expand until the stroke indicator turns white again and accumulates one stroke on the stroke counter.

5. Repeat Step 5until a reliable reading is observed, in multiples of 10.

6. Record the time, reading (directly off the tube) and number of strokes. If no coloration is evident at conclusion of test, record "below detection limit."

7. Remove tube from Accubellows, seal ends using Teflon tape, and place the tube in a plastic bag labeled with the audit date and homeowner name.

8. Repeat Steps 2 through 7 with the $0.2-5-\mathrm{ppm}$ formaldehyde sample tube.

9. If the formaldehyde tube becomes saturated, repeat Steps 2 through 7 with the 2-40-ppm formaldehyde sample tube.

10. Record the end time and concentration on the $\mathrm{CO}$ meter and turn off meter.

11. Pack up point sampling equipment.

\section{Equipment Take Down and Sample Collection}

1. After the 24 hour sampling period, return to collect $\mathrm{PM}, \mathrm{CO}_{2}, \mathrm{TVOC}$, and radon equipment.

2. Turn off radon meter and record time.

3. Record final end time and final $\mathrm{PM}_{2.5}, \mathrm{CO}_{2}$, and TVOC readings. Press the run/stop button to stop the session. 
4. Remove the PM filter from the filter cassette and place in a filter Petri dish and into a sealed plastic bag and label bag.

\section{Laboratory Analysis}

1. Upon arrival at the laboratory, remove the filters from the plastic bags and filter Petri dishes, keeping filter associated with labeled bag at all times.

2. Weigh the particulate filter and record the final weight. Compare results to particulate matter concentration recorded by the meter to assess whether calibration is needed.

3. Replace filter in plastic bag and store it in the freezer. 


\section{AtTAChMent 2 - Field Data Sheet}

Sampling Date:

Sampling Location:

Weather Conditions: Temp:

RH:

\begin{tabular}{|c|c|c|c|c|c|c|c|}
\hline Air Type & $\begin{array}{c}\text { Sample } \\
\text { Description }\end{array}$ & $\begin{array}{l}\text { No. } \\
\text { strokes }\end{array}$ & $\begin{array}{c}\text { Sampling } \\
\text { Times } \\
\text { Start } \\
\text { Stop }\end{array}$ & $\begin{array}{c}\text { Concentra } \\
\text {-tion }\end{array}$ & Unit & Standard Limit & Notes \\
\hline Outdoor & TVOC & -- & & & ppm & N/A & \\
\hline Outdoor & $\mathrm{CO}_{2}$ & -- & & & ppm & $5,000 \mathrm{ppm}$ & \\
\hline Outdoor & PM & -- & & & $\mu \mathrm{g} / \mathrm{m}^{3}$ & $15 \mu \mathrm{g} / \mathrm{m}^{3}\left(\mathrm{PM}_{2.5}\right)$ & \\
\hline Indoor & TVOC & -- & & & ppm & N/A & \\
\hline Indoor & $\mathrm{CO}_{2}$ & -- & & & ppm & $5,000 \mathrm{ppm}$ & \\
\hline Indoor & PM & -- & & & $\mu \mathrm{g} / \mathrm{m}^{3}$ & $15 \mu \mathrm{g} / \mathrm{m}^{3}\left(\mathrm{PM}_{2.5}\right)$ & \\
\hline Indoor & $\mathrm{CO}$ & -- & & & ppm & 9 ppm (long-term EPA) & \\
\hline Indoor & $\mathrm{NO}_{\mathrm{x}}$ & & & & ppm & 0.05 ppm (1yr EPA) & \\
\hline Indoor & $\begin{array}{c}\text { Formaldehyd } \\
\mathrm{e}\end{array}$ & & & & ppm & $16 \mathrm{ppb}$ (NIOSH 8hr TWA) & \\
\hline Indoor & Radon & -- & & & $\mathrm{pCi} / \mathrm{L}$ & 4 pCi/L (EPA) & \\
\hline
\end{tabular}


Particulate Filter Wieghts

\begin{tabular}{|c|c|l|l|l|}
\hline Air Type & $\begin{array}{c}\text { Sample } \\
\text { Description }\end{array}$ & Pre-Weight & Post-Weight & Unit \\
\hline Outdoor & PM & & & $\mu \mathrm{g}$ \\
\hline Indoor & PM & & & $\mu \mathrm{g}$ \\
\hline
\end{tabular}

Air Handler Flow and Static Pressure Testing

\begin{tabular}{|c|c|c|c|}
\hline \multicolumn{3}{|c|}{ ir Handler Flow and Static Pressure Testi } & \\
\hline & System 1 & System 2 & \\
\hline \multicolumn{3}{|c|}{ Normal System Operating $\mathrm{Pa}$ (with clean filter) } & \\
\hline \multicolumn{3}{|c|}{ TrueFLow System Op. Pa (with TF in filter slot) } & \\
\hline \multicolumn{3}{|l|}{ TrueFlow Air Flow (cfm) } & \\
\hline \multicolumn{3}{|l|}{ External Static $\mathrm{Pa}$} & \\
\hline \multicolumn{4}{|l|}{ Exhaust Fan Flow Testing } \\
\hline & Fan 1 & Fan 2 & Fan 3 \\
\hline \multicolumn{4}{|l|}{ Door Position (E1,E2,E3) } \\
\hline \multicolumn{4}{|l|}{ Pressure (in box with respect to room) $\mathrm{Pa}$} \\
\hline Calculated Fan Flow (cfm) & & & \\
\hline
\end{tabular}




\title{
ATTACHMENT 3 - EQUIPMENT AND SUPPLY CHECKLIST
}

\author{
Supplies \\ Aluminum Foil \\ Duct Tape \\ Extension Cords (50') \\ Forceps \\ Labels \\ Multi-tool \\ Pens \\ Sample Baggies \\ Sharpies \\ Teflon Tape \\ Laytex gloves \\ Outlet converter
}

\author{
Equipment \\ EVM 7 \\ RadStar Radon Meter \\ Watch \\ Manuals \\ SOP \\ EVM 7 and RadStar plug chargers \\ Pump Hex-wrench \\ Silicon grease and cotton swabs \\ Dreager Accubellows \\ Zero/HEPA filter \\ Sample cassette \\ $\mathrm{NO}_{\mathrm{x}}$ Sample Tubes \\ Formaldehyde Sample Tubes \\ CO Testo point sampling meter \\ PM sample Petri dishes \\ Weighed PM filters \\ Suitcase \\ Lab Notebook
}




\section{ATTACHMENT 4 - EQUiPMENT CALIBRATION and Maintenance Procedure}

All sampling equipment was calibrated prior to arrival at the lab. The following procedure describes a method to zero the particulate meter and maintain the particulate meter. This should be done prior to each sampling event.

1. Remove the turret housing and use a cotton swab to clean the three impactors. Grease the impactors using a thin film of silicon grease. Replace the turret housing.

2. Turn the PM turret to the PM position (open) and install the zero/HEPA filter.

3. Select calibration and then the "Cal" softkey. Press the start softkey.

4. The meter will stabilize on a reading and display "set" when it is ready. When stabilized, press the "set" softkey.

5. Press the save softkey to save this calibration.

For special or more advanced maintenance or calibration procedures, refer to the EVM 7 users manual. 


\section{ATTACHMENT 5 - REFERENCES AND ADDiTIONAL RESOURCES}

American Society of Heating, Refrigerating, and Air-Conditioning Engineers (ASHRAE) Standards Committee. 2010. "ASHRAE Standard 62.2 - Ventilation and Acceptable Indoor Air Quality in LowRise Residential Buildings.” Atlanta, Georgia.

U.S. Environmental Protection Agency. 1999. "Compendium of Methods for the Determination of Toxic Organic Compounds in Ambient Air; Second Edition. (EPA TO-17 Method). Cincinnati, Ohio. Available at http://www.epa.gov/ttn/amtic/files/ambient/airtox/to-17r.pdf

Widder S and M Baechler. 2011. "Potential Health and Safety Impacts of Residential Energy Retrofits A Review of the Literature.” PNNL 20231, Pacific Northwest National Laboratory, Richland, Washington.

3M. 2010. “EVM Series: Environmental Monitoring Instrument Owner’s Manual; RevD.” Qwest Technologies, Oconomowoc, Wisconsin. 
Appendix $\mathrm{H}$

Calibration Instructions 



\section{Appendix $\mathrm{H}$}

\section{Calibration Instructions}

\section{Instructions for Calibrating Models}

1. Input all audit data into Energy Gauge file. Use collected data whenever possible. You may need to make assumptions. If you right-click on any input, you can get a help page to guide your assumptions.

2. Once you have input all data to the best of you knowledge, run the file (click on Calculate $\rightarrow$ Annual simulation). If there are no errors, you will get an "Annual Energy Summary." You will use that summary, especially the "Total (kWh)" and "Total (therms)" rows to calibrate. Also, if you click on reports $\rightarrow$ Monthly Summary $\rightarrow$ Monthly Energy Summary, you can get monthly breakdowns of heating, cooling, and other energy draws.

3. Before you calibrate, organize your utility files . Ideally, you will have at least one year of utility files.

a. Find an annual average $\mathbf{k W h}$ of electricity and therms of gas. You may want to perform a rolling average if there is more than 1 year of data to see if the energy consumption has varied substantially from year to year.

b. You also need to identify the average summer gas usage (I usually use June, July, and August). This is useful because you know (unless they have gas overs/stoves) that the gas use is only for hot water.

c. Also identify the peak summer electricity use (kWh/month), which usually occurs in July or August, and peak winter gas use (therms/month), which usually occurs in December-January.

4. Calibrate the model. There are many inputs that can be used to calibrate the model, but it is best to have some direction as to which inputs to start with. The sections below describe one possible approach. Also, you may want to use a spreadsheet to track the results of the model as you make changes. This helps keep things organized.

a. Hot Water Use. I start by calibrating hot water use (if it is gas). Compare the therms used in the monthly report from the model to the actual monthly average usage. If they do not match, adjust hot water inputs. Start with inputs that you have the least confidence in-probably the "gallons per day." You may also be able to slightly adjust the "set temperature" or "EF" if you do not know those inputs exactly. Adjust the inputs until the actual and model usage more or less match.

b. Heating. This is easier if the home has gas heat. Again, compare actual to modeled results, stating with the inputs with which you have the least confidence.

i. Temperature. If you do not know the exact setpoints/schedule, you can adjust them. These will have a large impact on modeled results.

ii. R-values. Often, attic or crawlspace insulation varies, so it is hard to know the exact depth/R-value. So, you can adjust them within reason. You may also consider insulation grades. Often crawlspaces may have insulation that is comprressed or falling down; these should be de-rated by giving them a grade "II" or "III." 
iii. Ventilation. If there is mechanical ventilation and we do not know the exact CFM.

c. Anything else that affects heating loads - furnace efficiency (if you do not know it exactly), duct surface area, etc. Also note that electric loads will have some effect on heating, so you may need to re-calibrate heating simultaneously.

d. Cooling, Appliance, and Miscellaneous Loads. You sort of need to calibrate these simultaneously.

i. Miscellaneous loads are handled in the "Appliances and Lights" tab. You can actually just input the "annual use" for miscellaneous loads, but just try to keep them within reason. I tend not to adjust inputs for appliances like washers, dryers, ranges, etc. by very much, but you could.

ii. Use miscellaneous loads and cooling-related inputs (temperatures, insulation levels [not as important], AC efficiency, duct efficiency, etc.). To try to match the annual electricity use to the model.

iii. Peak summer electricity. At the same time, be aware of how the peak monthly kilowatthour ( $\mathrm{kWh}$ ) usage compares between the models and the bills. If the annual use matches but the modeled peak is too high, then you will have to reduce the cooling loads in the model and increase the miscellaneous loads (so that the annual use is still matched).

e. Model the retrofits. In Energy Gauge, you need to create a new file for each retrofit you model (which is a little cumbersome).

f. Decide what retrofits to analyze. Use our initial reports, your own knowledge, recommendations from Lori, or talk to Subrato or Sarah about what measures we should be modeling.

g. Create retrofit files. Start with your calibrated file. Select "save as" and add a brief description of the retrofit in the file name; for example, "Jones - heat pump water heater." After saving the new file, make the appropriate changes. For the previous example, I input a heat pump water heater and its energy factor. When you start a new retrofit, I find it easier to open the original calibrated model, and again save a copy for the next retrofit.

h. Input data into analysis apreadsheet. Go to "Building America_Retrofitlaudit report template" and open the "retrofit analysis tempate" spreadsheet. Save a copy to your participant's folder. Input the utility bill data, calibrated model data, and the names of each retrofit you will analyze.

i. Run the retrofit models. Once the retrofit models are set up, run each one, and copy the annual $\mathrm{kWh}$ and therms usage into the analysis spreadsheet (columns $\mathrm{C}$ and $\mathrm{G}$ ).

j. Complete the analysis spreadsheet. After you input annual $\mathrm{kWh} /$ therms, most cells will update automatically. You will need to update capital cost and incentives (columns X and Y). Use the "costs" and "incentives" tabs for help estimating. Some of the costs for heating/cooling systems are based on the capacity, which you can get (approximately) by running Manual J in Energy Gauge (Calculate $\rightarrow$ ManualJ8 System Sizing $\rightarrow$ Save/Calculate). You may need to search for cost data (try http://www.nrel.gov/ap/retrofits/group listing.cfm ). This includes generating a final suite of recommended measures and modeling the estimated savings as a package. These final data (and each measures information) will go into the "table for report" tab. 
k. Assess payback periods and write the report. In some cases, you will need to remove retrofit measures that are not cost-effective or perform additional analysis. Then, input the data into the template word document, which can be found in "Building America_Retrofitlaudit report template." The table for report can be pasted in directly. The pie charts should be pasted as pictures. Edit the recommendations to reflect the situation in the home and your findings from the analysis. Examples can be found in the example report folder. Specifically, "Jones Audit Report FINAL."

1. Keep in mind, you may want to talk about several measure options for one retrofit (i.e., replacing the hot water heater). That is ok, just do that analysis and present the results for each one. Also, remember that you may be able to size a smaller HVAC unit once you account for air and duct sealing. You can look at the recommended size by running Manual J in Energy Gauge. Look at how that effects the cost.

m. If you have any other thoughts or advice, add them here or edit the document so we can document the process as we go. 



\section{Appendix I}

\section{Audit Reports}




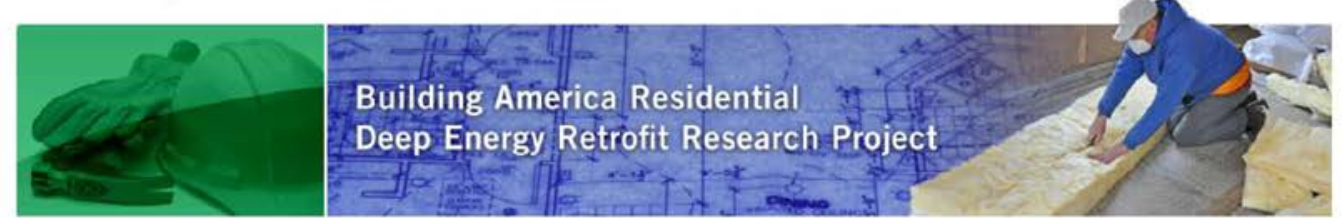

Residential Deep Energy Retrofit Research Project

\section{Audit Report for a Two-Story Richland House}

Audit Date: 5/31/2011

\section{Pacific Northwest National Laboratory Research Team} http://deepenergyretrofits.pnnl.gov/

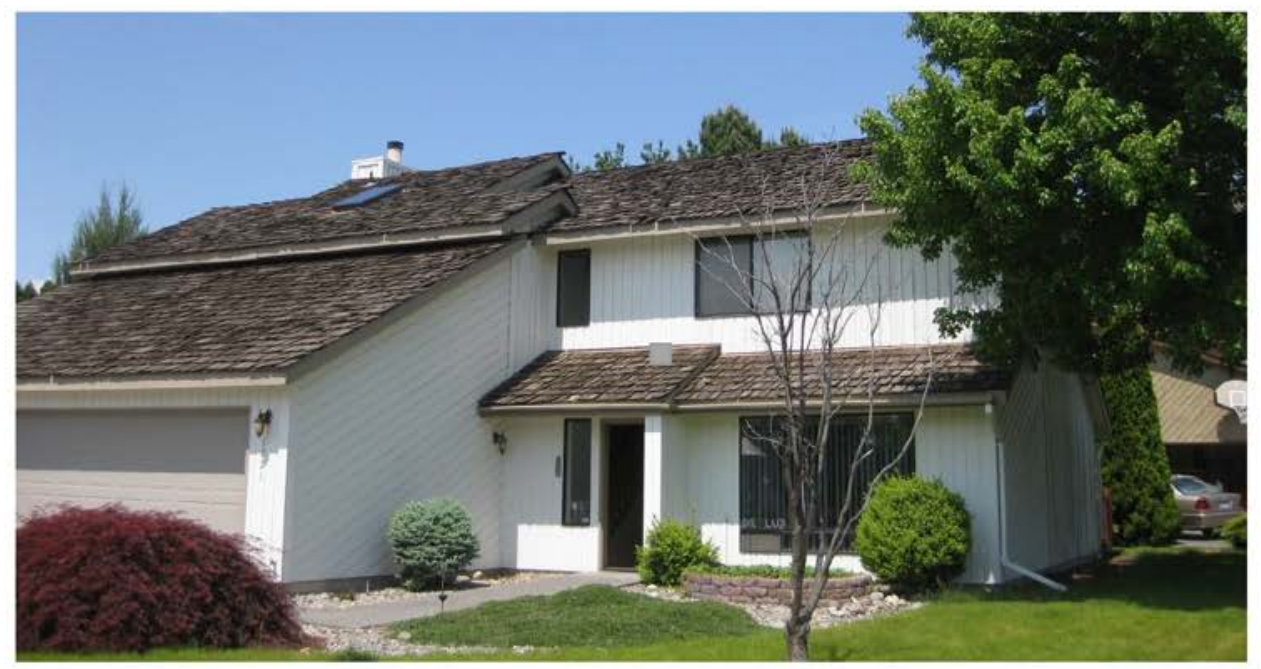

Notices:

1. This report is intended for the sole use of the homeowner(s) and the PNNL deep retrofits study team members (including subcontractors) that have completed training to protect the privacy and other rights of human subjects in research programs. PNNL will not share this report with anyone but may include data and information from this report, in an anonymous manner, in the final report that will be submitted to the U.S. Department of Energy.

2. The quantitative information in this report on energy savings, costs and economic benefits are based on computer models. Please note that actual savings and costs can be quite different (may be even a factor of 2 or more) depending on homeowner lifestyle, actual performance of energy saving equipment and strategies, variations in local weather, contractor business models and other unforeseen factors.

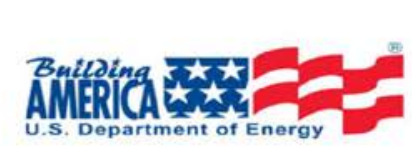

Pacific Northwest NATIONAL LABORATORY

Proudly Operated by Battelle Since 1965

\section{(B.) EN. jepartment ory}




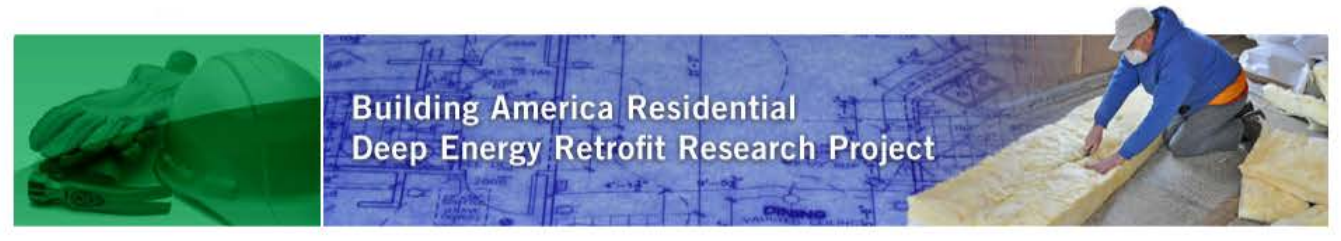

\section{Existing Home Characteristics and Performance}

The house is a single-family, two-story home with an attached garage built in 1987. It has 4 bedrooms and 2 baths; a total conditioned space of 2,448 square feet $\left(\mathrm{ft}^{2}\right)$. The original building envelope is wood-frame construction over a slab with R-19 batt insulation in the walls. The attic is vented with R-38 blown-in fiberglass insulation. The windows are double-pane clear glass with metal frames, including a skylight in the master bath. Heating is provided by two electric forced air furnaces using resistance heat. Cooling is provided by two 2-ton airconditioning units with a seasonal energy efficiency ratio (SEER) of 10 . One unit is used to heat and cool the downstairs and the other is used to heat and cool the upstairs. The forced air ducts that service the downstairs are under the concrete slab. The forced-air ducts that service the upstairs are located in the unconditioned attic and are insulated to R-11 with Fiberglass insulation.

Table 1: Energy Cost

\begin{tabular}{lc}
\hline Energy Costs Information & Electricity, $\mathbf{\$}$ \\
\hline Average Utility Bill & 108.30 \\
\hline Maximum Utility Bill & 275.31 \\
\hline Minimum Utility Bill & 39.33 \\
\hline
\end{tabular}

\section{Recommended Energy Efficiency Retrofit Measures}

The home was audited to quantify its energy performance. The home energy audit consists of several elements: a blower door test to characterize building envelope leakage, a duct test to characterize duct leakage, thermal imaging to identify key leaks, evaluation of insulation levels, and examination of all energy-consuming appliances.

During the audit of your home, we noticed several opportunities to save energy in costeffective ways. The ensuing sections of this report summarize each energy-saving measure and related energy-audit findings and provide the estimated energy savings, cost of each recommended measure, and associated payback period. The simple payback period is the number of years that it will take to pay off the upfront investment with energy cost savings (the shorter, the better). The payback period provides a quick economic metric that can be used to prioritize the measures. The ensuing sections also briefly summarize locally available incentives that may be available to help pay for energy-saving measures. Most of the savings estimates included here are based on computer simulations of your home. The costs provided are rough estimates based on our experiences with the energy-saving measures, quotes from local
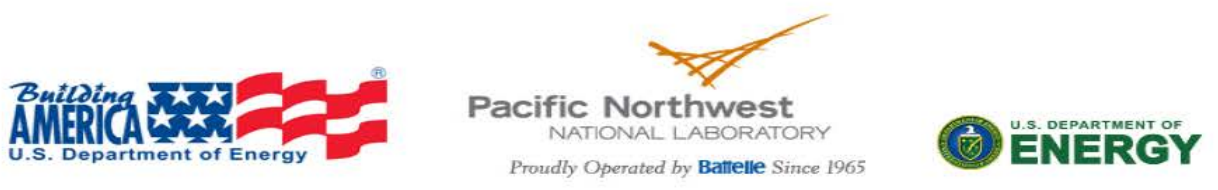


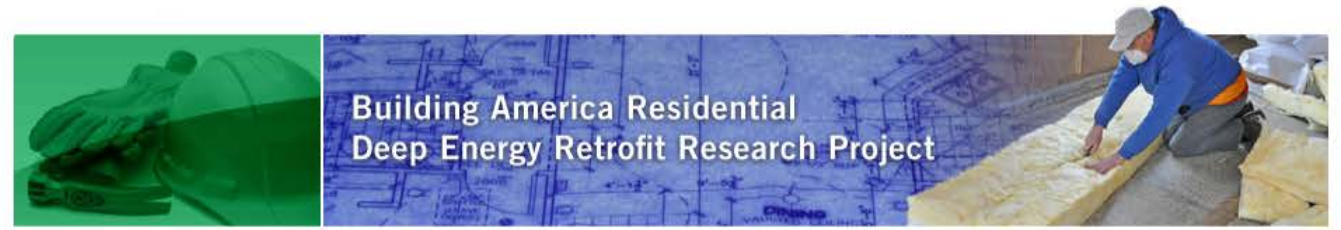

contractors, and publically available information, like the National Renewable Energy Lab's National Measures Database ${ }^{1}$. Your actual costs will depend on the contractor you choose, the final scope of work, and the current material prices. Finally, we have provided payback periods for each measure.

We think that you can reduce your energy bills by around $44.2 \%$. Your actual savings will depend on which measures are implemented (as well as any changes in usage patterns, occupancy, etc.). The savings associated with each measure also will be affected by other measures that you implement, so, as we develop the final package of measures, savings estimates will vary.

Please read through the measures described below and let us know if you have any questions. Once we have discussed the cost-saving measures available to you and agreed on a package that fits your needs, the next step will be to start asking contractors for bids on the energysaving projects (recognizing that you can complete some projects yourself).

\section{Add Attic Insulation and Air Sealing}

Attic insulation reduces the amount of heat transferred through the ceiling. In the winter, heat is lost into the attic. In the summer the attic space, which gets very hot, transfers unwanted heat through the ceiling into the home. Cellulose and fiberglass insulation are typically used when adding insulation into existing homes. Cellulose and fiberglass are blown into the attic through a hose. This application is known as loose-fill (as opposed to batts of insulation). Your attic could also benefit from additional insulation. Currently, the insulation is R-38. We recommend adding about 10 inches of insulation, bringing the total insulation value to about $\mathrm{R}$ 60.

Before adding insulation, it is important to seal any leaks in the attic floor (it is much more difficult to seal leaks afterwards). Cracks, gaps, and holes located throughout your home waste energy by letting in hot air in the summer and cold air in the winter, or conversely, letting conditioned air out! Spray foam and caulk can be used to seal most leaks, though other materials may be used if leaks are very large (fire rated materials must be used where appropriate). Contractors will temporarily move the insulation aside while they air seal. Leaks

\footnotetext{
${ }^{1}$ National Renewable Energy Laboratory. "National Measures Database." Available at: http://www.nrel.gov/ap/retrofits/.
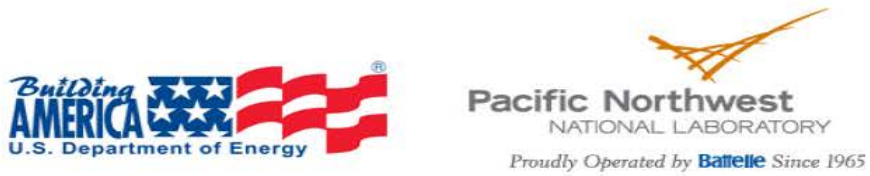


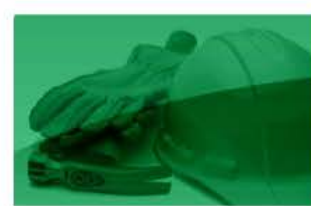

Building America Residential

Deep Energy Retrofit Research Project

are often found around holes drilled for wiring or plumbing, the top plates of interior walls, and attic hatches. (For more information, see the Building America Air Sealing Guide ${ }^{2}$.

During your audit, we performed a blower door test, which uses a calibrated fan and pressure gauges to measure the overall leakiness of your home. We found that if you added up all of the leaks in your home, the cumulative effect would be equivalent to having a hole 10 inches wide by 12 inches tall in the building envelope. This is like leaving a window open all year! These results are given in more detail below.

Table 2. Air Leakage Test Results

\begin{tabular}{lrl}
\hline Conditioned Floor Area & $2,448 \mathrm{ft}^{2}$ \\
\hline Conditioned Volume & $19,584 \mathrm{ft}^{3}$ \\
\hline Airflow in cubic feet per minute at -50 Pascals & $2,285 \mathrm{cfm50}$ \\
\hline Air Changes per Hour at -50 Pascals & $7.00 \mathrm{ACH} 50$ \\
\hline Effective Leakage Area & $125.4 \mathrm{in}^{2}$ \\
\hline Relative airflow at -50 Pascals & $0.93 \quad \mathrm{cfm} 50 / \mathrm{ft}^{2}$ \\
\hline Range of relative airflow for other homes tested in the Tri-cities & $0.8-1.05 \mathrm{cfm} 50 / \mathrm{ft}^{2}$ \\
\hline
\end{tabular}

This report includes the suggestion of insulating your attic and exterior walls. Included in the insulation process is the sealing of all penetrations in the exterior envelope of the building. As such, the energy savings for reducing the air leakage in your home will be reflected in the insulation recommendations contained in this report.

\section{Locally Available Incentives}

Insert information about locally available incentives

- The City of Richland offers on incentive of $\$ .05 /$ square foot for adding insulation to an existing R-38 attic

- A federal tax credit is also available for $10 \%$ of material costs (does not include labor)

\footnotetext{
${ }^{2}$ Building America's Air Sealing Guide can be found here; http://wwwl.eere.energy.gov/library/asset handler.aspx? src=http $/ /$ appsl.eere.energy.gov/buildings/publications/pdf s/building america/ba airsealing report.pdf\&id $=4663$

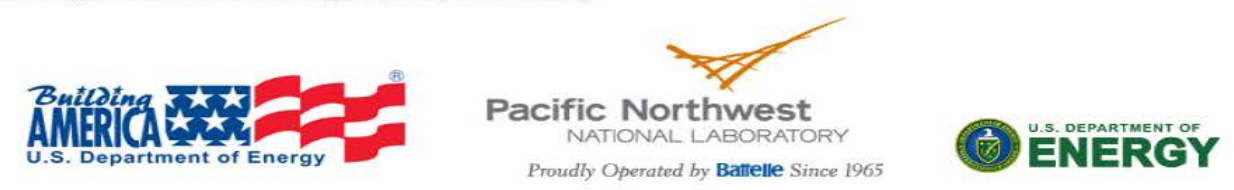




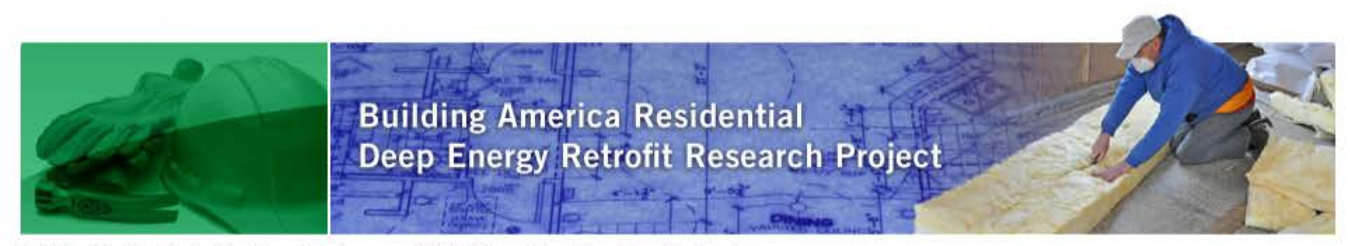

Table 3: R-60 Attic Insulation and $10 \%$ reduction in air leakage

\begin{tabular}{cccc} 
Estimated Cost & $\begin{array}{c}\text { Estimated Annual } \\
\text { Savings }\end{array}$ & Payback Period & $\begin{array}{c}\text { Payback Period } \\
\text { (after incentives) }\end{array}$ \\
$\$ 939$ & $\$ 229 / \mathrm{yr}$ & $4 \mathrm{yr}$ & $3 \mathrm{yr}$ \\
\hline
\end{tabular}

\section{Add $\mathrm{R}-\mathbf{1 0}$ Insulation to the Walls and Reduce Air Leakage by $\mathbf{2 0} \%$}

The walls in your house are insulated to R-19. Adding wall insulation will reduce the amount of heat lost during the winter and heat gained during the summer. In addition to reducing the heat transfer through the walls, insulation will help reduce the amount of drafts that leaks through the walls.

Since you have shown an interest in re-siding your house you have an excellent opportunity to add insulation to the outside of your walls. You can install insulation on top of the old siding, or remove the original siding first. Exterior insulation is typically done with polyisocyanurate and polyurethane foam board. Although foam board can be purchased at a local hardware store and installed yourself we found a local contractor who is very experienced in this technique. We assumed you would add $11 / 2^{\prime \prime}$ of foam board over your existing siding. This would add an additional R-10 to your wall insulation value. We included the price of the insulation and the labor cost provided by Robert Construction. Other contractors, as well as Robert's Construction, that are on the City of Richland's approved contractor list can be found at http://www.ci.richland.wa.us/DocumentView.aspx?DID=1052 We did not include the price of the new siding.

When installing exterior foam insulation, the thicker the better. However, you need to be sure your new siding fits within the existing jams of your windows and doors if you are not also replacing windows and doors. This is because the window jam is a very important part of protecting your house and wall assembly from getting wet. For helpful tips installing exterior foam insulation, see:

- http://www.ornl.gov/sci/roofs+walls/facts/RetrofitBestPractices/homeownerguide15b1 pdf

- http:/www.greenbuildingadvisor.com/how-install-rigid-foam-insulation-outside-house

- http://www.remodelingmagazine.net/high-performance-building/deep-energyretrofits.aspx
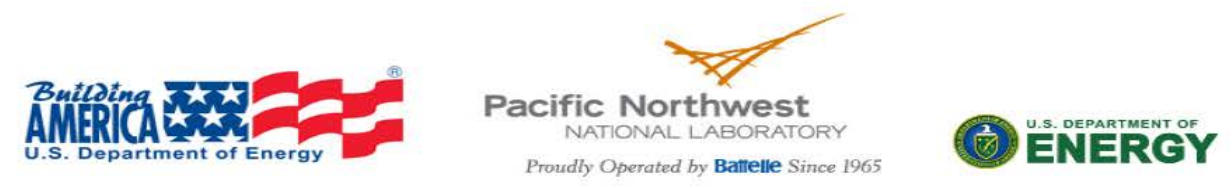


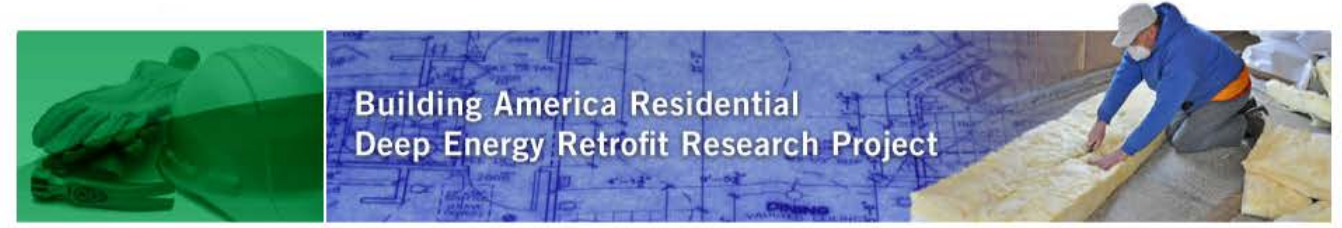

- http://www1.eere.energy.gov/librarv/asset handler.aspx?src=http://apps1.eere.energy .gov/buildings/publications/pdfs/building america/guide insulating sheathing.pdf\&id= $\underline{4796}$

- http://www1.eere.energv.gov/librarv/asset handler.aspx?src=http://apps1.eere.energy .gov/buildings/publications/pdfs/building america/ba cs retrofit vakama.pdf\&id=3851

\section{Locally Available Incentives}

- The City of Richland has a low interest loan that can be used for wall insulation.

- A federal tax credit is also available for $10 \%$ of material costs (does not include labor)

Table 4: Add R-10 Insulation to the Walls and Reduce Air Leakage by $20 \%$

\begin{tabular}{|cccc|}
\hline Estimated Cost & $\begin{array}{c}\text { Estimated Annual } \\
\text { Savings }\end{array}$ & Payback Period & $\begin{array}{c}\text { Payback Period } \\
\text { (after incentives) }\end{array}$ \\
\hline$\$ 2,420$ & $\$ 182 / \mathrm{yr}$ & $13 \mathrm{yr}$ & $13 \mathrm{yr}$ \\
\hline
\end{tabular}

\section{Replace Your Furnace/AC units with a Heat Pump and seal the ducts}

Your electric furnaces appear to be original to the house and are about 14 years old. Electric furnace efficiency is rated by the coefficient of performance (COP); yours has a COP of about 1. This means that all of the electricity delivered to your furnace winds up as heat. However, heat pumps can have COPs from 1.5 to 4 and, thus, offer higher energy cost savings. In the heat mode, heat pumps are rated by their heating season performance factor (HSPF). For new units, the current minimum allowable efficiencies for heat pumps are HSPF 7.7. Some models have an HSPF over 10.

Your $A C$ units also appear to be original to the house and are about 14 years old. The efficiency of AC units is rated by their SEER. Your unit has a SEER of about 10 . The current minimum allowable SEER for heat pumps is 13. Some heat pumps have a SEER over 20.

At the moment, the economics of replacing your heating and cooling systems are not great. However, as energy prices rise, the economics will improve. Also, over the next 5-10 years, your furnace and air conditioner will approach the end of their useful lives. If you do not replace
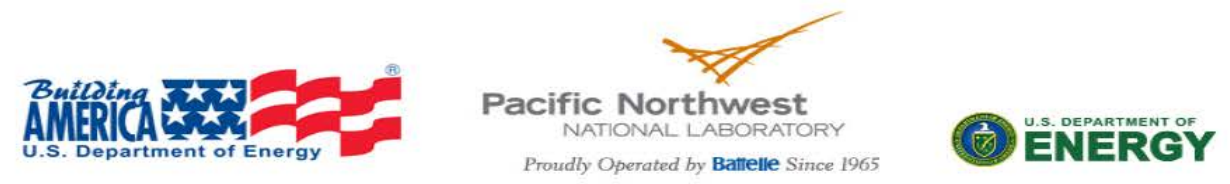


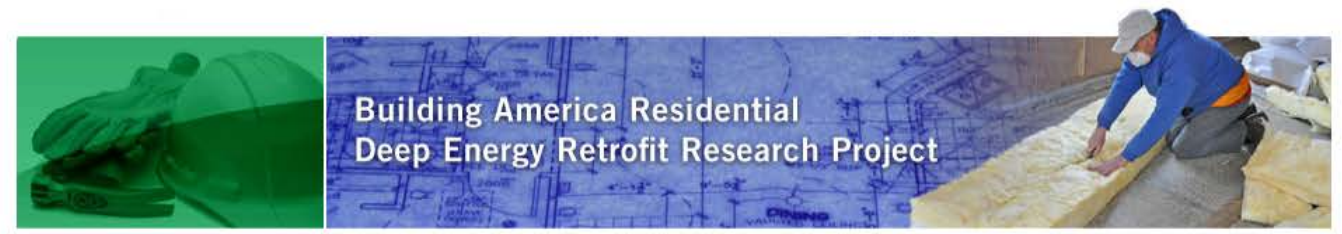

them now, keep these recommendations in mind. The economics of high efficiency units will greatly improve if only the incremental cost of installing a higher efficiency unit is considered.

Duct sealing is often a cost-effective measure. Duct sealing should be performed if a new heating or cooling system is installed. Not only does duct sealing save energy, it also reduces the heating or cooling load. As a result, a smaller heat pump (or furnace/AC) can be used, reducing upfront costs. The other insulation and air sealing measures will also reduce the required equipment size, so they should be performed first.

The ducts that service the downstairs are located under the slab and are tight and well insulated. The upstairs ducts are located in the unconditioned attic and are well insulated at R11. Although the actual amount of air lost is small, these ducts leaked about 3 times as much air as a new system would. However, these ducts are still delivering a lot of air to your upstairs bedrooms. Because the return is located in the hallway, the delivered, or supply air, has nowhere to escape in the rooms when the doors are closed and can build up a lot of pressure, which is slamming doors and creating comfort problems in your upstairs bedrooms. During the audit, we also measured the pressure imbalance between the bedrooms and central hallway. We found significant pressure imbalances, which we discussed with you at the audit. Some methods for supplying a return air pathway between rooms or through a door are provided in Figure 1.

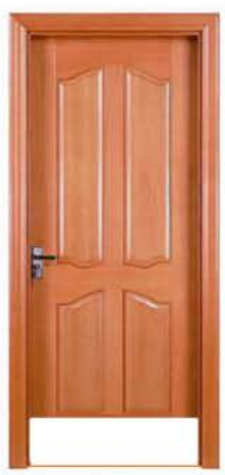

Undercut Doors

CALCS-PLUS

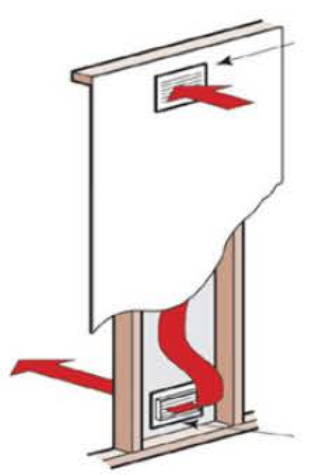

High-Low Pass Thru

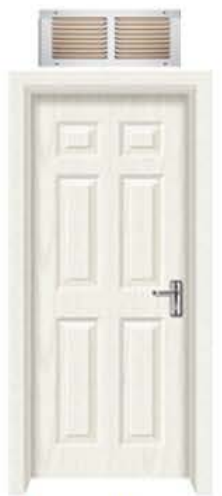

Direct Pass Thru

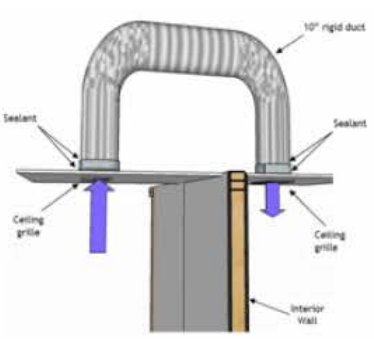

Jump Ducts

Figure 1. Types of Return Air Pathways to Ensure Pressure Balance Between Rooms.
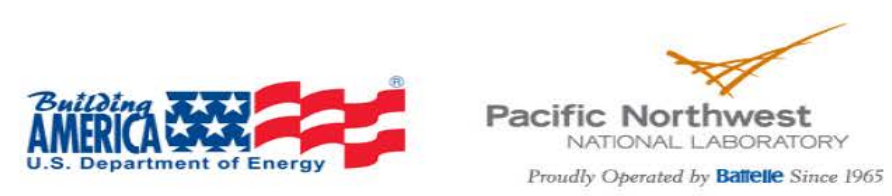


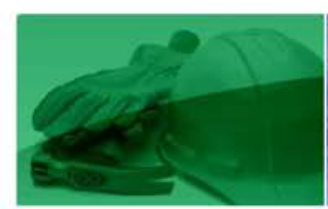

Building America Residential

Deep Energy Retrofit Research Project

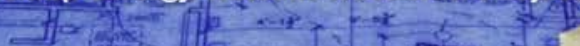

The PowerPoint file attached to this presentation has more information on each of these. For information on sizing the different pressure relief configurations, see $\underline{h t t p}: / / w w w . b a-$ pirc.org/casestud/return air/index.htm. One 8 in. jumper duct or a large direct pass-thru should be sufficient for your rooms. A jumper duct will be the quietest and most aesthetically pleasing solution, but is also more expensive.

Table 5. Summary of duct testing results for the top floor duct system*

\begin{tabular}{lrl}
\hline Total duct leakage of upstairs unit at -25 Pascals & $165 \mathrm{cfm} 25$ \\
Duct Air Loss as a percent of total air flow & $11 \%$ \\
\hline Relative leakage per $\mathrm{ft}^{2}$ of floor area & $0.1309 \mathrm{cfm} 25 / \mathrm{ft}^{2}$ \\
\hline Typical leakage to outside (or attic), Tri-cities & $46-500 \mathrm{cfm} 25$ \\
\hline
\end{tabular}

*the ducts in the slab were not assessed because they are assumed to be airtight.
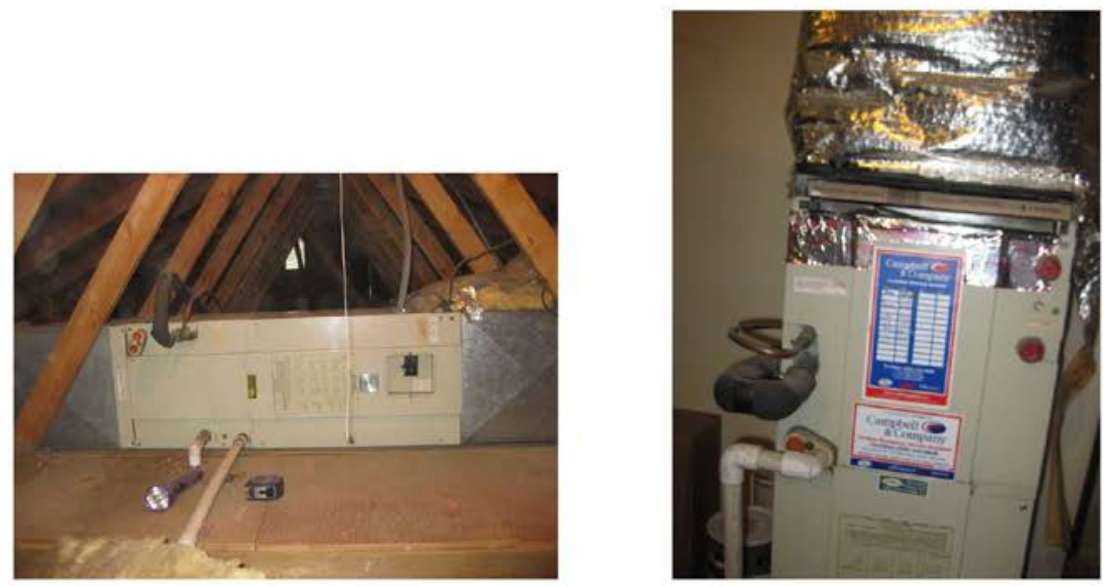

Left: Upstairs air handler. Sheet metal ducts are lined with insulated sound board. The majority of the ducts are insulated to R-11 Right: Air Handler in the Garage. The ducts in the garage lead under the slab to service the downstairs area of the house. The majority of the ducts are assumed to be insulated to R-8.
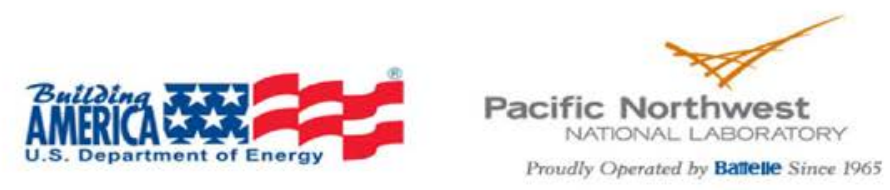


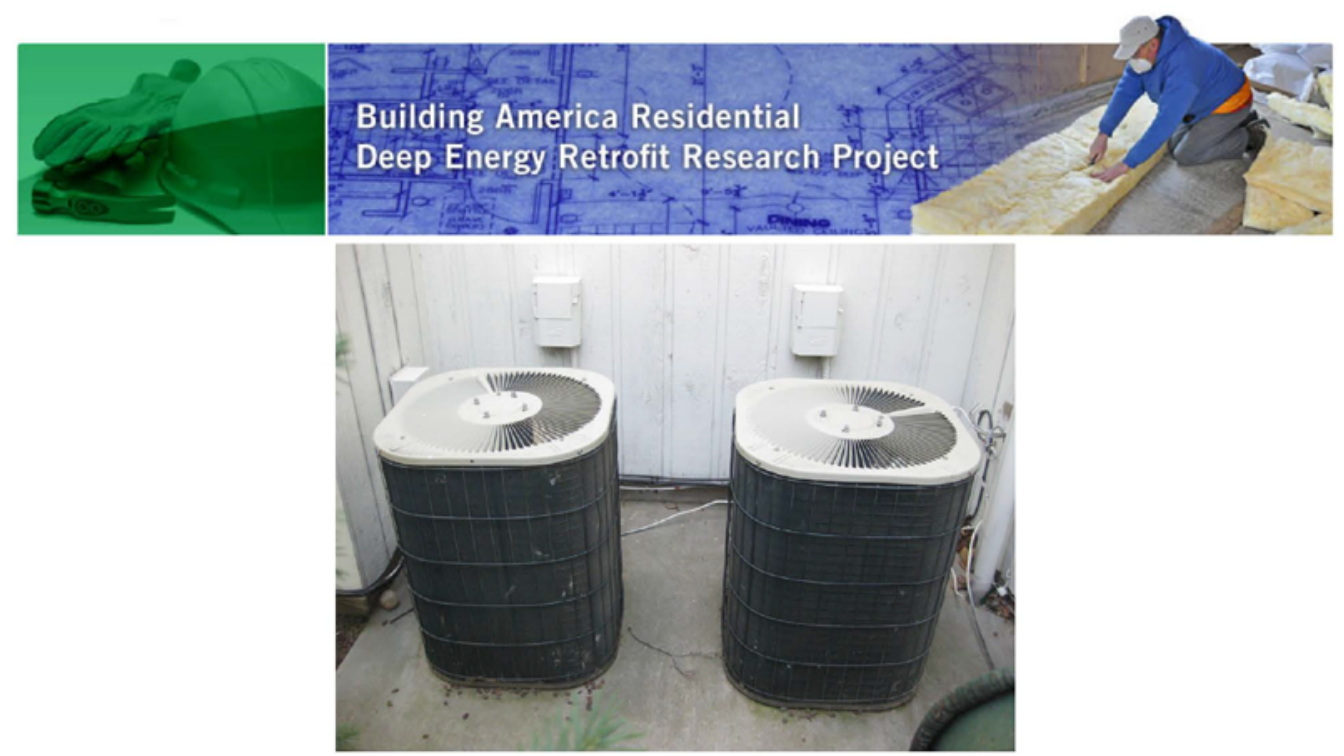

Above: Two air conditioning units which are original to the house and about 14 years old with a SEER 10.

\section{Locally Available Incentives}

- The City of Richland offers $\$ 1,000$ rebates for qualifying units (1 per house)

- A Federal tax credit of $\$ 300$ is available for qualifying models.

In our analysis, we used a SEER 15, HSPF 12.5 heat pump. This model would currently qualify for energy star tax credits. High efficiency models are available, which would result in greater savings.

Table 6: Replace your Furnace/AC with Heat Pumps and Seal the Ducts

\begin{tabular}{|cccc|}
\hline Estimated Cost & $\begin{array}{c}\text { Estimated Annual } \\
\text { Savings }\end{array}$ & Payback Period & $\begin{array}{c}\text { Payback Period } \\
\text { (after incentives) }\end{array}$ \\
\hline$\$ 11,200$ & $\$ 705 / \mathrm{yr}$ & $16 \mathrm{yr}$ & $14 \mathrm{yr}$ \\
\hline
\end{tabular}

\section{Replace Your Windows}

Currently, you have double-pane, metal-frame windows. Upgrading to energy efficient windows will reduce your energy costs substantially. Window replacements typically have higher upfront costs and a longer payback period than most other retrofit options. However, considering the existing conditions, and available incentives, window replacement could still be a good investment for your home.
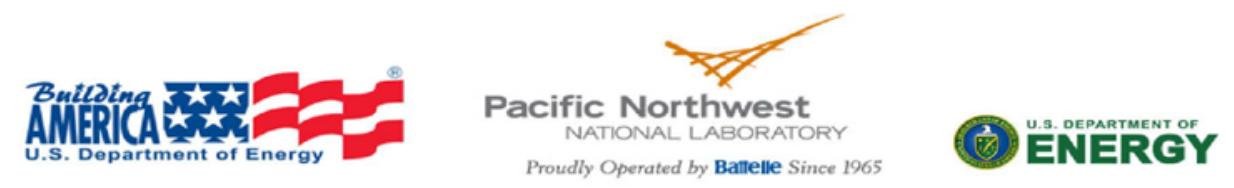


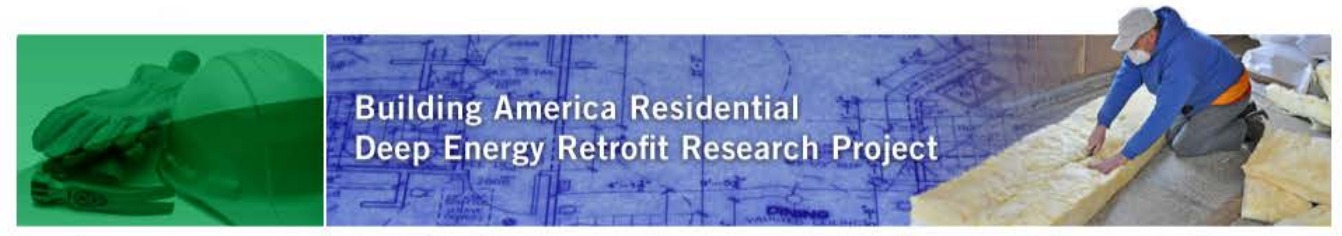

Windows are commonly rated with two measurements: their U-factor and their solar heat gain coefficient (SHGC). U-factors measure how much heat is transferred through the window; the lower the better. Your windows probably have a U-Factor of around 0.87 New ENERGY STAR windows have R-values of less than 0.3 . Windows are also rated by a SHGC, although SHGCs are less important in heating-dominated climates. SHGCs measure the fraction of light that passes through the window as heat; low-SHGC windows help in the winter, but let in more heat during the summer.

When discussing your windows options with a local contractor, we were able to get a very good price quote on triple pane windows. Recently the Department of Energy participated in a program to buy-down the cost of triple pane windows. This may explain why the local contractor was able to offer a price for triple pane windows that was comparable to a competitively priced double pane window.

\section{Locally Available Incentives}

Insert information about locally available incentives

- The City of Richland offers a rebate of $\$ 6 /$ square foot for qualified windows

- A federal tax credit for windows, not to exceed $\$ 200$, is available

Table 7: Replace your Wind ows with Triple Pane

\begin{tabular}{cccc|} 
Estimated Cost & $\begin{array}{c}\text { Estimated Annual } \\
\text { Savings }\end{array}$ & Payback Period & $\begin{array}{c}\text { Payback Period } \\
\text { (after incentives) }\end{array}$ \\
$\$ 5,487$ & $\$ 350 / \mathrm{yr}$ & $16 \mathrm{yr}$ & $11 \mathrm{yr}$ \\
\hline
\end{tabular}

\section{Install a Solar Water Heater}

Solar water heaters use the sun to warm up water for use in showers, faucets, and the dishwasher. Solar water heaters are more expensive that other water-heating options, but they save money over the life of the system. Depending on the size of the system, solar water heaters typically provide $30-75 \%$ of the hot water load. Solar collectors typically perform best when the roof faces due south and the roof angle is about the same as the latitude, $47^{\circ}$, although this can vary based on design considerations.

Your home has very good solar exposure on the south-facing roof and would be a good candidate for a solar hot water system. It is common to save $\$ 125-\$ 150$ / year in a location such as yours. Silk Road Environmental, a local installer of solar panels, installs most systems for
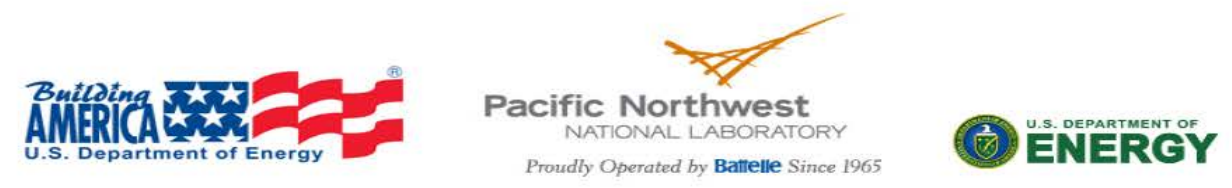


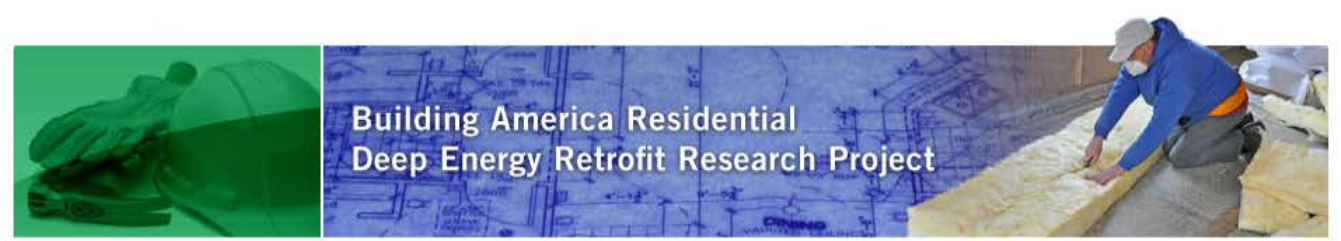

approximately $\$ 2,000$. If you were to consider the $30 \%$ tax credit that is available from the Federal Government you could potentially see a payback of 10 years. You can contact Silk Road Environmental at http://www.silkroadenvironmental.com/We can provide more information if you are interested in installing a solar water heater.

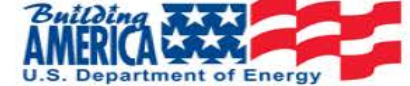

U.S. Department of Energy

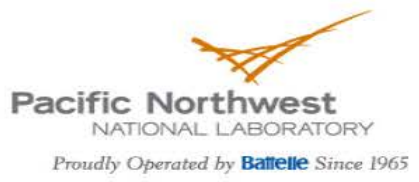

- Enerer 

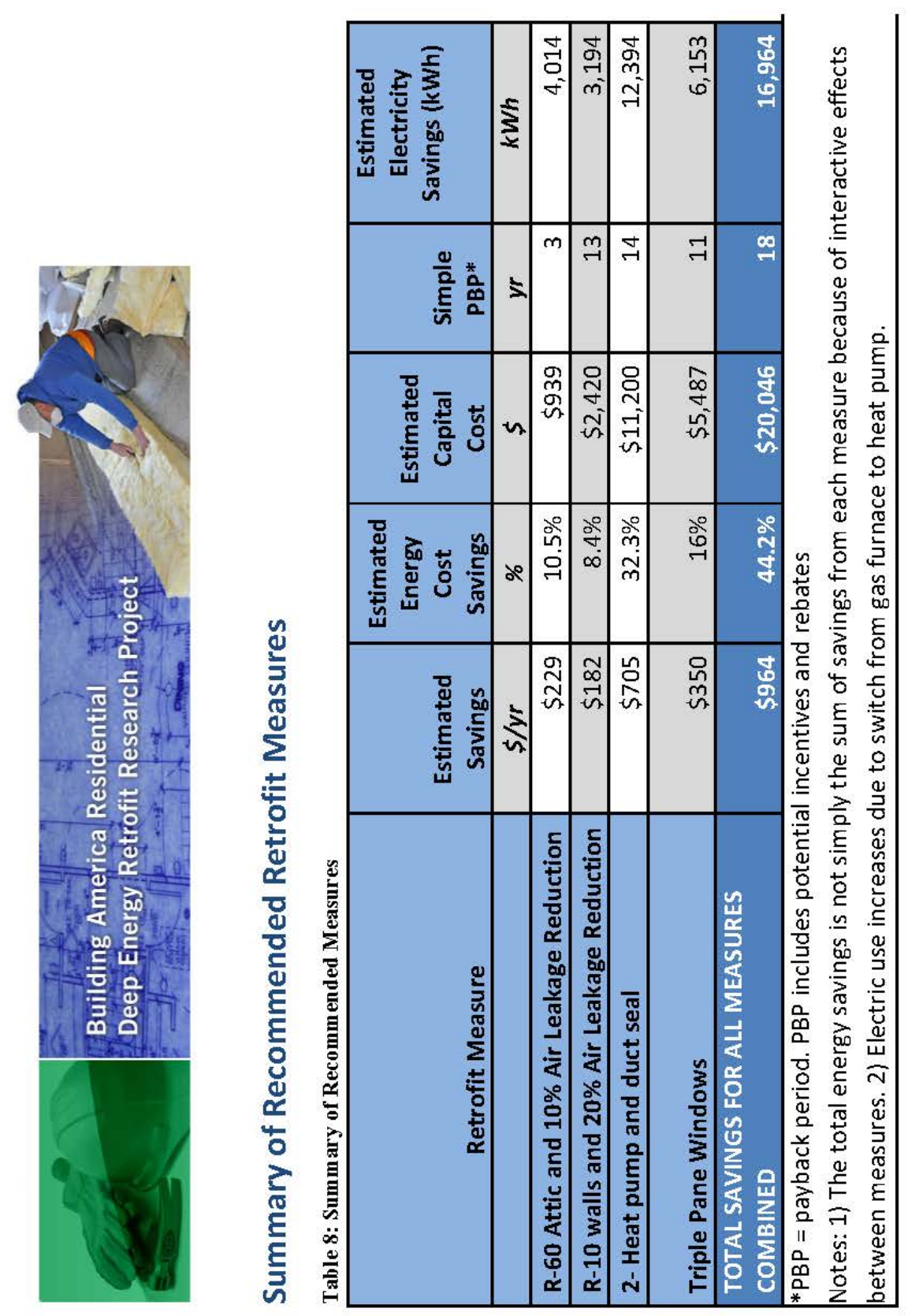


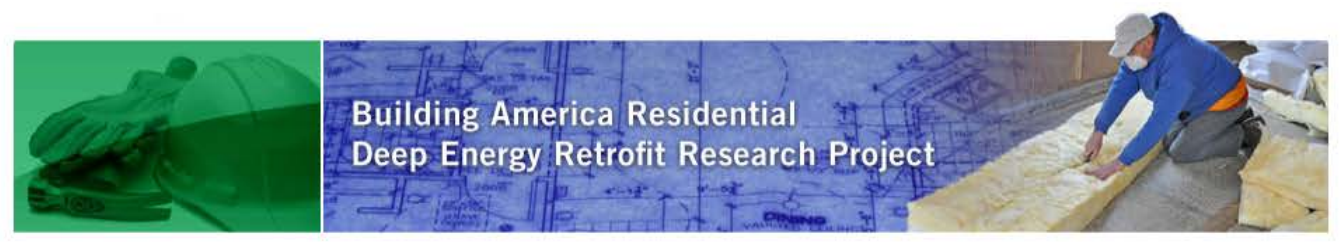

\section{Easy Do-It-Yourself Improvements}

\section{Use Power Strips to Turn Off Appliances That are Not Being Used}

Some home appliances draw power even when they are not being used. These draws on power are often called "phantom loads." One way to avoid phantom loads is to plug non-essential appliances into a power strip. When the appliances are not in use, simply turn off the power strip. Be sure to use a separate power strip or outlet for any essential appliances.

\section{Additional Resources}

For more information, the following websites provide additional energy-saving tips for home owners looking to make energy efficiency improvements to their homes:

- http://www.energvsavers.gov/

- http://www.aceee.org/consumer

- http://www.energystar.gov/

- http://www.nahb.com/

- http://www1.eere.energy.gov/buildings/

In addition, the Building America website (http://www1.eere.energy.gov/buildings/building america/) and the Building Science Corporation website (http://www.buildingscience.com/index html) provide a number of good resources related building design and construction of energy efficient homes.

\section{Incentives and Rebates}

Various incentives are available to help pay for energy efficiency measures. For example, many of local utilities offer incentives. Several of these incentive or rebate options are identified in the audit information provided above. In addition to the incentives and direct rebates identified for your specific recommendations above, the City of Richland offers low-interest loans to help finance energy efficiency projects. These loans can be used instead of (but not in addition to) the project-specific rebates. More information can be found on your local utilities
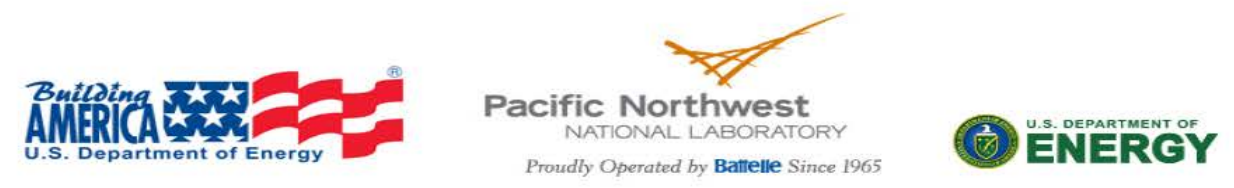


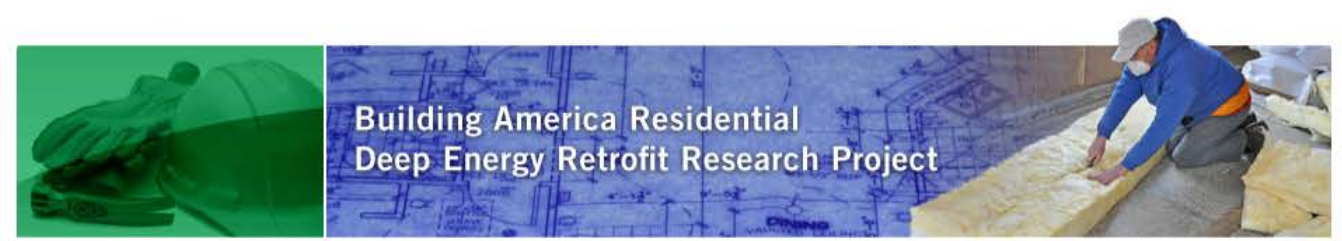

website. Another good resource for finding energy efficiency rebates anywhere throughout the country is www.dsireusa.org/.

Federal tax incentives are also available for ENERGY STAR products. Many of the recommended measures may be eligible for a tax credit worth $10 \%$ of the materials cost, or a specified amount (for example, ENERGY STAR furnaces are eligible for a $\$ 150$ tax credit). These incentives have also been identified in the cost estimates provided above. More information about this program is available at the following website:

http://www.energystar.gov/index.cfm?c=tax credits.tx index.
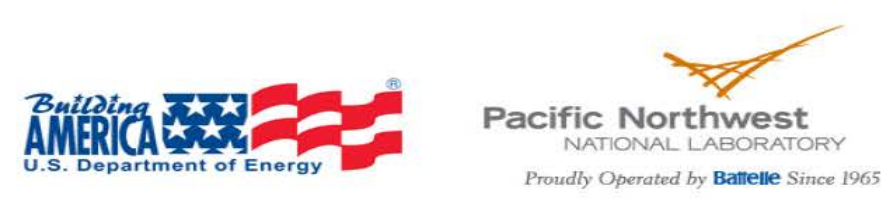

- Oenergur 


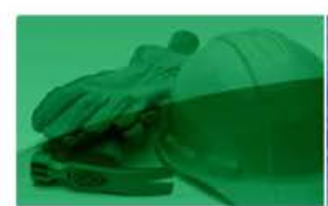

Building America Residential Deep Energy Retrofit Research Project

Residential Deep Energy Retrofit Research Project

\section{Audit Report for a Small Richland "B-1" Style 1940's Home}

Audit Date: $7 / 8 / 2011$

Pacific Northwest National Laboratory Research Team http://deepenergyretrofits.pnnl.gov/

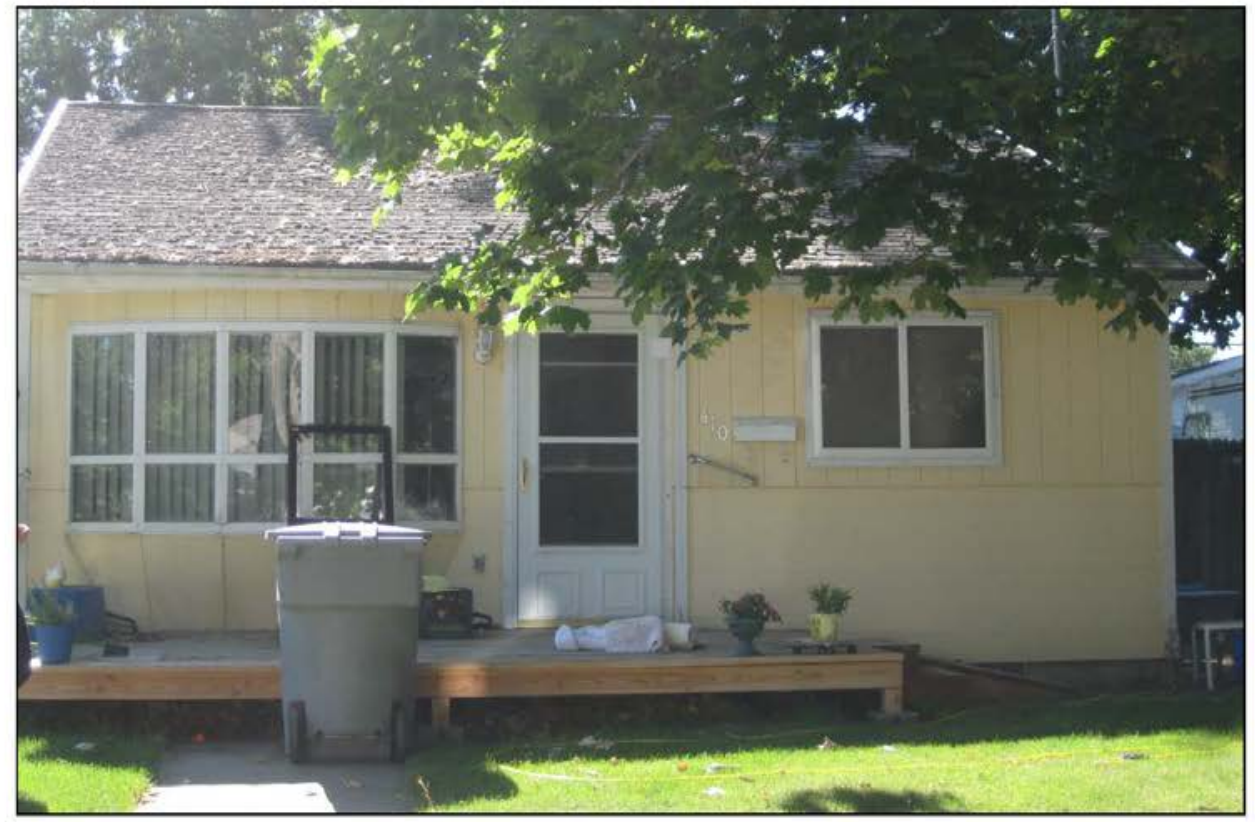

Notices:

1. This report is intended for the sole use of the homeowner(s) and the PNNL deep retrofits study team members (including subcontractors) that have completed training to protect the privacy and other rights of human subjects in research programs. PNNL will not share this report with anyone but may include data and information from this report, in an anonymous manner, in the final report that will be submitted to the U.S. Department of Energy.

2. The quantitative information in this report on energy savings, costs and economic benefits are based on computer models. Please note that actual savings and costs can be quite different (may be even a factor of 2 or more) depending on homeowner lifestyle, actual performance of energy saving equipment and strategies, variations in local weather, contractor business models and other unforeseen factors.

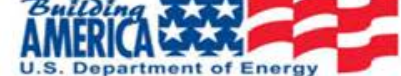

\section{Pacific Northwest} NATIONAL LABORATORY

Proudly Operated by Banelle Since 1965

\section{OENERGY}




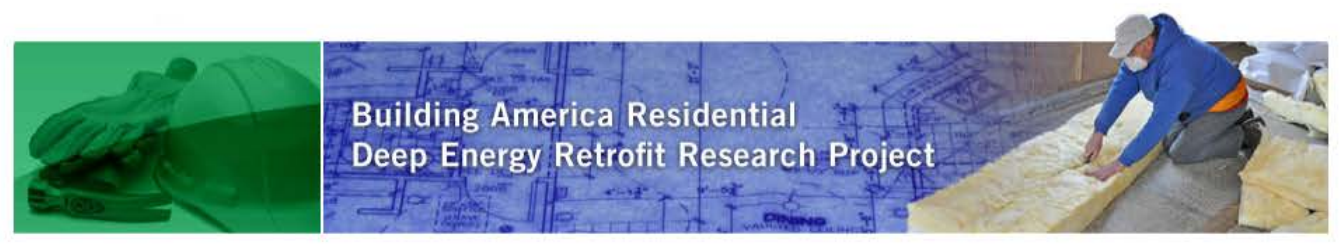

\section{Existing Home Characteristics and Performance}

The house is a single-family, one-story "B-1" style home built in 1940's. It has 2 bedrooms and 1 bath; a total conditioned space of 675 square feet $\left(\mathrm{ft}^{2}\right)$. The original building envelope is 2 " $\times 2$ " wood-frame construction over a crawlspace with no insulation in most of the original walls and R-19 fiberglass batt insulation on the crawlspace ceiling. Some of the original walls have been replaced and the newer walls are 2 " $\times 4$ " construction and have been insulated with fiberglass batts. The attic is insulated with two layers of R-19 fiberglass batts, giving it an overall $R$ value of R-38. The windows are mostly double-pane clear glass with vinyl frames, except for the bay windows which are wood-framed. Heating is provided by a small electric space heater and cooling is provided by an old, through-the-wall air-conditioning (AC) unit.

Table 1. Average Utility Bill Information for April 2010 through March 2011.

\begin{tabular}{lc}
\hline Energy Costs Information & Electricity, \$ \\
\hline Average Utility Bill & 89.77 \\
Maximum Utility Bill & 150.76 \\
\hline Minimum Utility Bill & 65.62 \\
\hline
\end{tabular}

\section{Recommended Energy Efficiency Retrofit Measures}

The home was audited to quantify its energy performance. The home energy audit consists of several elements: a blower door test to characterize building envelope leakage, a duct test to characterize duct leakage, evaluation of insulation levels, and examination of all energyconsuming appliances.

Following the audit we created a calibrated model of your house using the Energy Gauge (EG) software, developed by the Florida Solar Energy Center This software is a general analysis tool that is valid for all climates and has met software validation tests

(http://www.energygauge.com/usares/default.htm). The model was calibrated, to match your annual utility bills as shown in Figure 1 for electricity. While the annual consumptions match closely, there are significant variations on a monthly basis. This is probably because it is difficult for us to match exactly how you use your home and due to weather variations. Figure shows the EG model breakdown of your energy consumption.
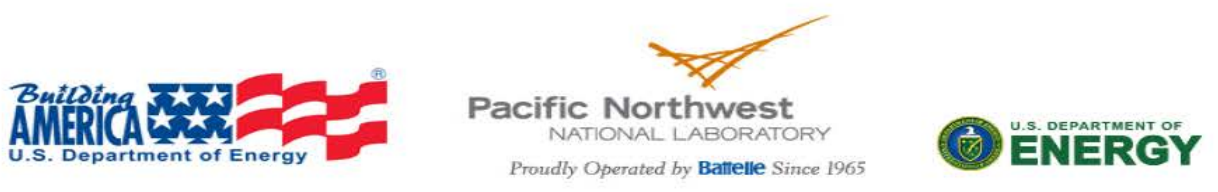

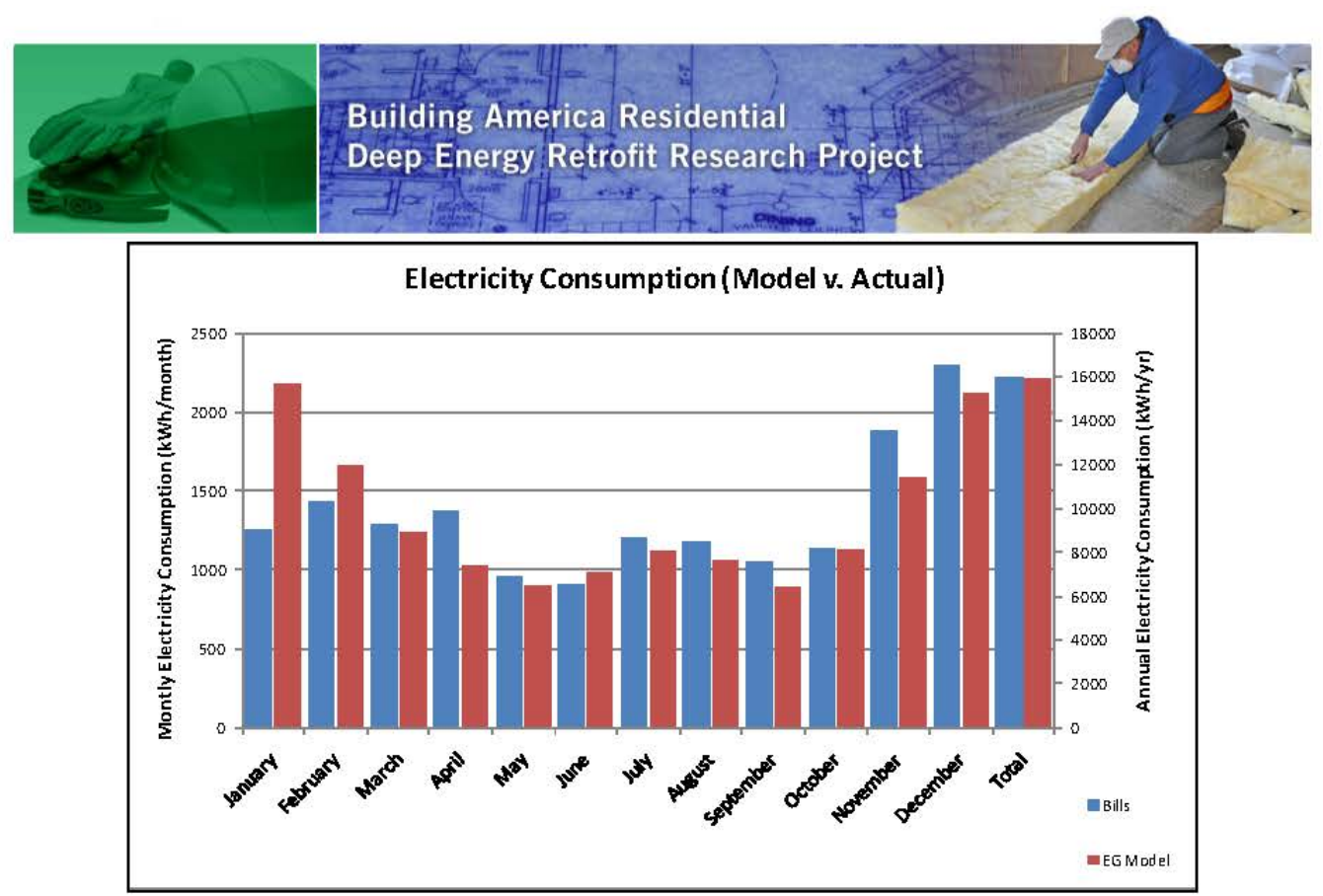

Figure 1. Comparison of monthly electricity consumption for utility bill and EG model. The annual comparison is also included on the secondary (right) vertical axis.

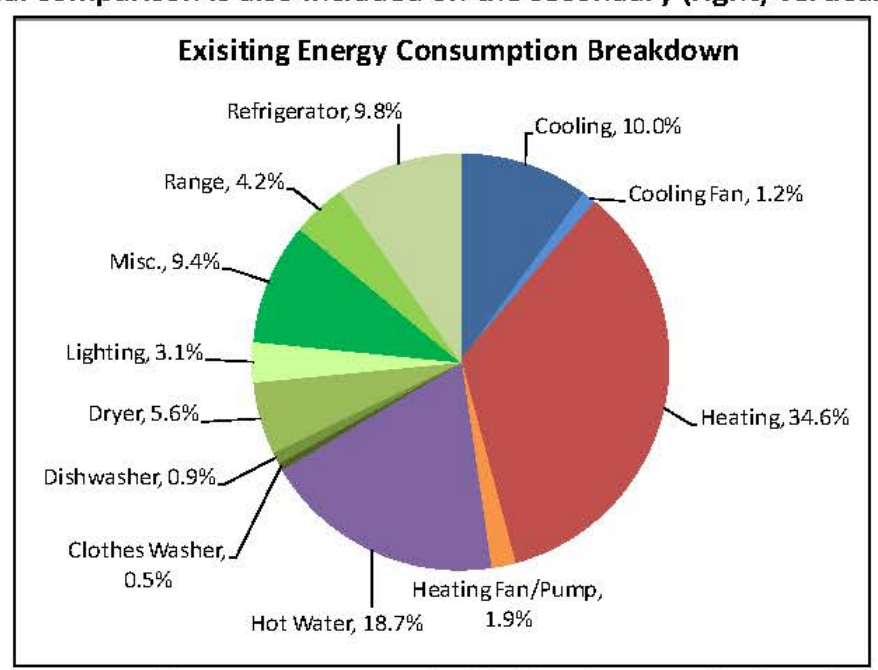

Figure 2. Percentage of energy consumption for heating, ventilation, air conditioning equipment, lighting, appliances and miscellaneous base loads. The energy consumption is calculated based on a British Thermal Unit (Btu) conversion basis. Kilowatt-hours of electricity are converted to Btus using the mean Btu conversion ( $1 \mathrm{kWh}=3412.14 \mathrm{Btu}$ ).
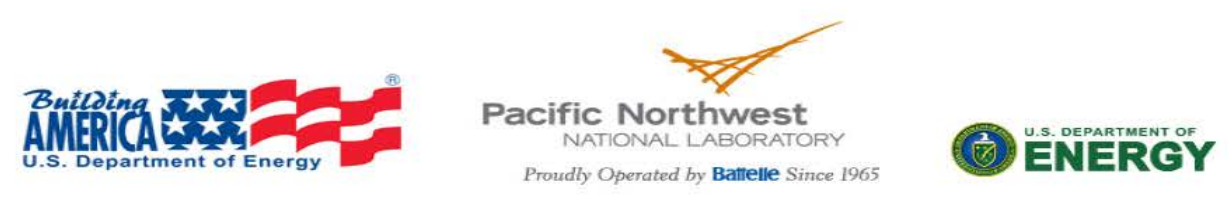


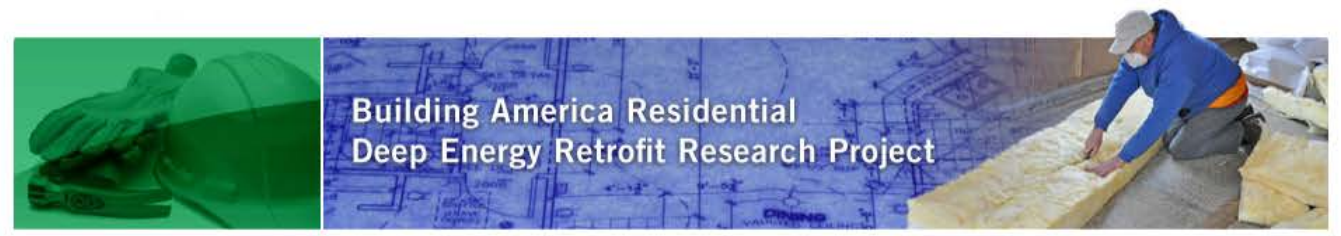

Based on this and things we noticed during the audit, we then modeled a number of energy efficiency measures to assess which measures would save the most energy and be the most cost effective without compromising combustion safety in your home. These include insulating your attic and walls with exterior foam board, replacing your heating and cooling systems with a new heat pump, and replacing your hot water heater. These measures together could save about $48 \%$ on your energy bills!

During the audit of your home, we noticed several opportunities to save energy in costeffective ways. The ensuing sections of this report summarize each energy-saving measure and related energy-audit findings and provide the estimated energy savings, cost of each recommended measure, and associated payback period. The simple payback period is the number of years that it will take to pay off the upfront investment with energy cost savings (the shorter, the better). The payback period provides a quick economic metric that can be used to prioritize the measures. The ensuing sections also briefly summarize locally available incentives that may be available to help pay for energy-saving measures. Most of the savings estimates included here are based on computer simulations of your home. The costs provided are rough estimates based on our experiences with the energy-saving measures, quotes from local contractors, and publically available information, like the National Renewable Energy Lab's National Measures Database ${ }^{1}$. Your actual costs will depend on the contractor you choose, the final scope of work, and the current material prices. Finally, we have provided payback periods for each measure.

We think that you can cost-effectively reduce your energy use by around $48 \%$. Your actual savings will depend on which measures are implemented (as well as any changes in usage patterns, occupancy, etc.). The savings associated with each measure also will be affected by other measures that you implement, so, as we develop the final package of measures, savings estimates will vary.

Please read through the measures described below and let us know if you have any questions. Once we have discussed the cost-saving measures available to you and agreed on a package that fits your needs, the next step will be to start asking contractors for bids on the energysaving projects (recognizing that you can complete some projects yourself).

\footnotetext{
${ }^{1}$ National Renewable Energy Laboratory. "National Measures Database." Available at: http://www.nrel.gov/ap/retrofits/.
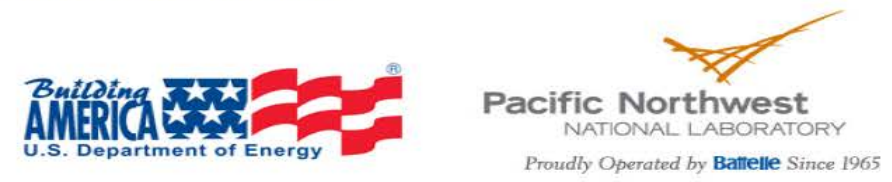


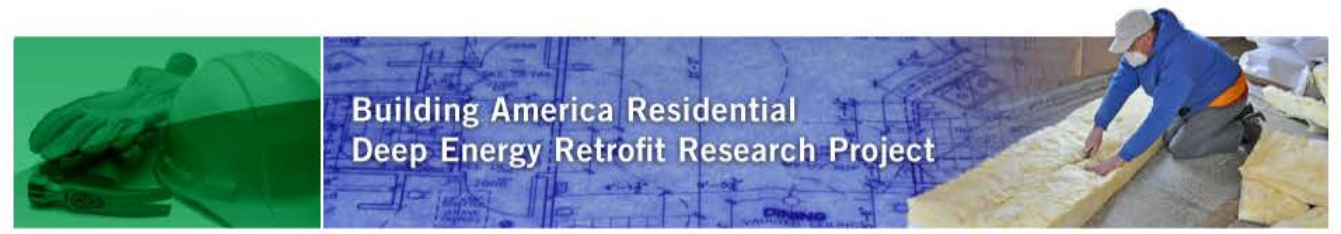

\section{Air Sealing}

Cracks, gaps, and holes located throughout your home waste energy by letting in hot air in the summer and cold air in the winter, or conversely, letting conditioned air out! During our audit, we performed a blower door test, which uses a calibrated fan and pressure gauges to measure the overall leakiness of your home. We found that if you added up all of the leaks in your home, the cumulative effect would be equivalent to having a hole 10 inches wide by 6 inches tall in the building envelope. This is like leaving a window cracked all year! These results are given in more detail below.

Table 2. Air Leakage Test Results

\begin{tabular}{lrl}
\hline Conditioned Floor Area & $675 \mathrm{ft}^{2}$ \\
\hline Conditioned Volume & $4,671 \mathrm{ft}^{3}$ \\
\hline Airflow in cubic feet per minute at -50 Pascals & $1987 \mathrm{cfm50}$ \\
\hline Air Changes per Hour at -50 Pascals & $12.7 \mathrm{ACH} 50$ \\
\hline Effective Leakage Area & $58.1 \mathrm{in}^{2}$ \\
\hline Relative airflow at -50 Pascals & $1.46 \mathrm{cfm50/ \textrm {ft } ^ { 2 }}$ \\
\hline Range of relative airflow for other homes tested in the Tri-cities & $0.8-1.46 \mathrm{cfm} 50 / \mathrm{ft}^{2}$ \\
\hline
\end{tabular}

In new homes that are Energy Star rated the target for air sealing is 4 Air Changes per Hour at $50 \mathrm{~Pa}(\mathrm{ACH} 50)$. Your home is currently rated at $12.7 \mathrm{ACH} 50$.

Most of the improvement in leakage to the outside can be made by installing exterior foam board to the outside of your house and residing. This will be discussed in a later section of the report.

Other means of sealing up holes and cracks are to use caulk, expanding spray foam, door weather-stripping, and a variety of other materials. Several leaks were also found in your ceiling where electrical or plumbing penetrate go into the attic, as can be seen in the picture in Figure 3. This air sealing should occur both from the ceiling and from the attic. As such, it is often easier to air seal prior to installing additional insulation. Thus, we recommend you air seal any penetrations leading from your ceiling into the attic prior to adding insulation. Energy savings from sealing the penetrations in your attic will also be addressed in the next section of this report.
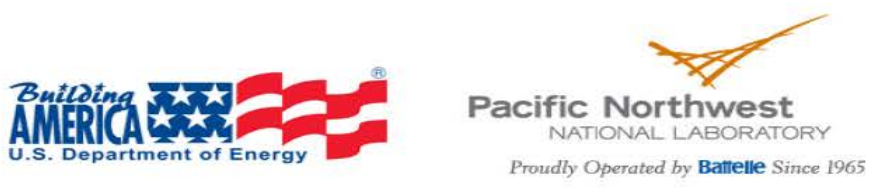


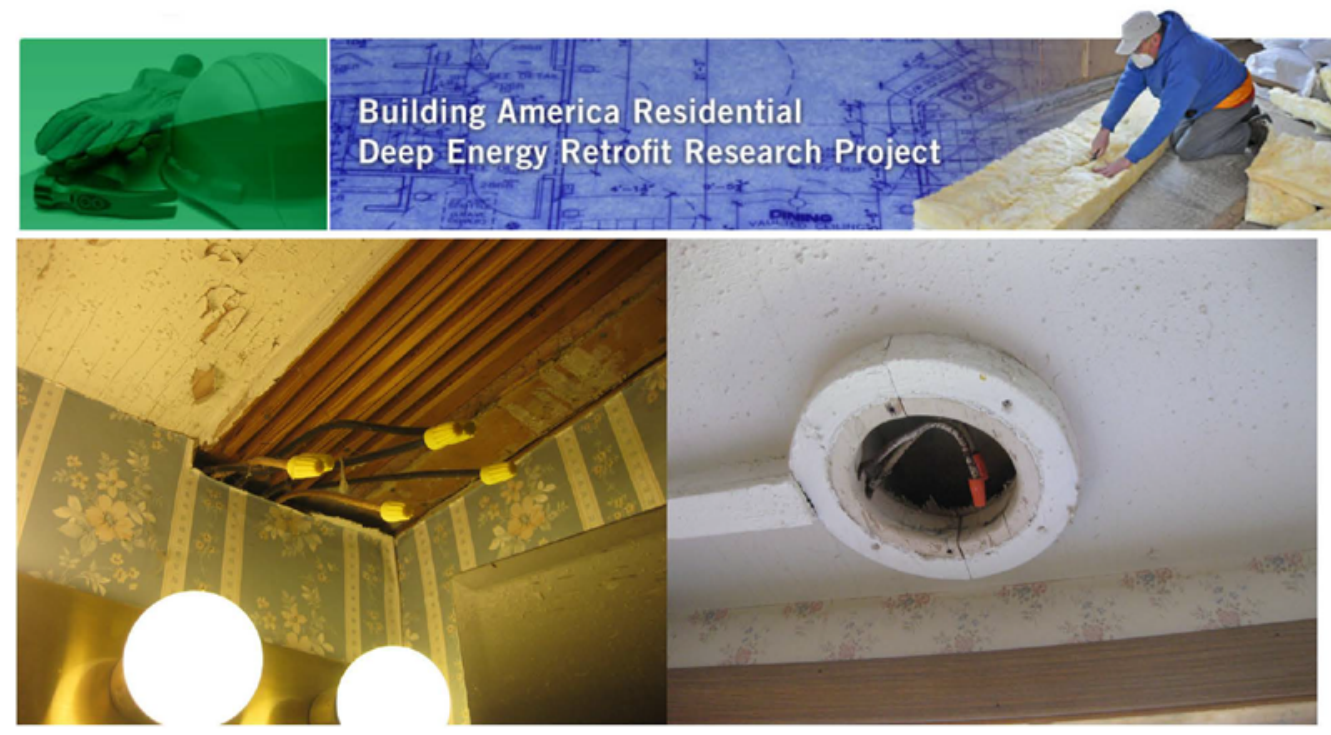

Figure 3. Wires penetrating the ceiling plane are a source of air leakage in your home. Block these holes with foam board, drywall, or another air barrier-material and caulk.

If you implement these recommended retrofit measures and tighten your home, it is very important that your kitchen range and bathroom have adequate exhaust ventilation. This is typically accomplished with an exhaust fan vented to the outside (not the attic). This will prevent moisture and other cooking-related pollutants from building up within your home and causing problems. It is recommended that you install a fan with 50 CFM capacity in the bathroom and 100 CFM capacity in the kitchen. Also, be sure to use these fans whenever you generate moisture in these spaces!

\section{Add Insulation to the Exterior of Your Home and Re-Side.}

The walls in your house are completely un-insulated in some places. Adding wall insulation will reduce the amount of heat lost during the winter and heat gained during the summer. In addition to reducing the heat transfer through the walls, insulation will help reduce the amount of air leaks and drafts through the walls. Adding insulation to walls in existing homes is typically done by blowing cellulose, fiberglass, or polyurethane foam insulation into the wall cavity through small holes drilled in the exterior siding.

Because your home has some walls that are $2^{\prime \prime} \times 2^{\prime \prime}$ wood-frame construction, it will be very difficult to get enough insulation in the walls without moving the interior walls in. This will cause you to lose some floor space, which is probably not desirable in your small home. Instead, we recommend you insulate your home on the outside of the walls. You can install insulation on top of the old siding, or remove the original siding first. Exterior insulation is typically done with polyisocyanurate and polyurethane foam board. This foam board can be purchased at a local hardware store. Be sure to get the highest R-value product you can find.
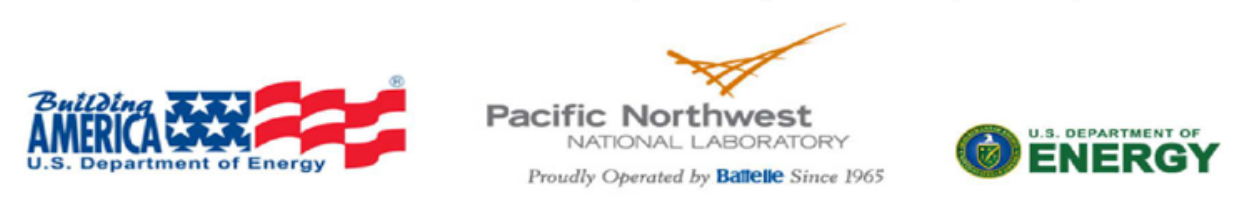


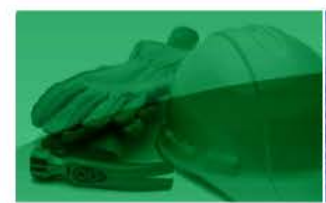

Building America Residential

Deep Energy Retrofit Research Project

We estimated you could add 2 " of exterior foam insulation and then install new siding on top of the insulation. The cost estimated below includes materials for 2 " of foam board and the new siding. If you have this professionally done, the cost may be slightly more than what we have estimated here. When installing exterior foam insulation, the thicker the better. However, you need to be sure your new siding fits within the existing jams of your windows and doors if you are not also replacing windows and doors. This is because the window jam is a very important part of protecting your house and wall assembly from getting wet. For helpful tips installing exterior foam insulation, see:

- http:/www.ornl.gov/sci/roofs+walls/facts/RetrofitBestPractices/homeownerguide15b1 pdf

- http://www.greenbuildingadvisor.com/how-install-rigid-foam-insulation-outside-house

- http://www.remodelingmagazine.net/high-performance-building/deep-energyretrofits.aspx

- http://www1.eere.energy.gov/library/asset handler.aspx?src=http://apps1.eere.energy gov/buildings/publications/pdfs/building america/guide insulating sheathing.pdf\&id= $\underline{4796}$

- http://www1.eere.energy.gov/librarv/asset handler.aspx?src=http://apps1.eere.energy gov/buildings/publications/pdfs/building america/ba cs retrofit vakama.pdf\&id=3851

\section{Locally Available Incentives}

- The City of Richland has a low interest loan that can be used for attic insulation.

- A federal tax credit is also available for $10 \%$ of material costs (does not include labor)

Table 3. Estimated cost and savings for exterior insulation and new siding.

\begin{tabular}{cccc} 
Estimated Cost & $\begin{array}{c}\text { Estimated Annual } \\
\text { Savings }\end{array}$ & Payback Period & $\begin{array}{c}\text { Payback Period } \\
\text { (after incentives) }\end{array}$ \\
$\$ 1,102$ & $\$ 358 / \mathrm{yr}$ & $3 \mathrm{yr}$ & $3 \mathrm{yr}$ \\
\hline
\end{tabular}

\section{Add Insulation in the Attic and Air Sealing}

Attic insulation reduces the amount of heat transferred through the ceiling. In the winter, heat is lost into the attic. In the summer the attic space, which gets very hot, transfers unwanted
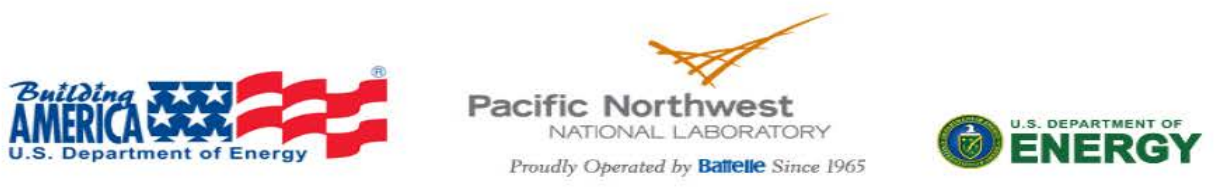


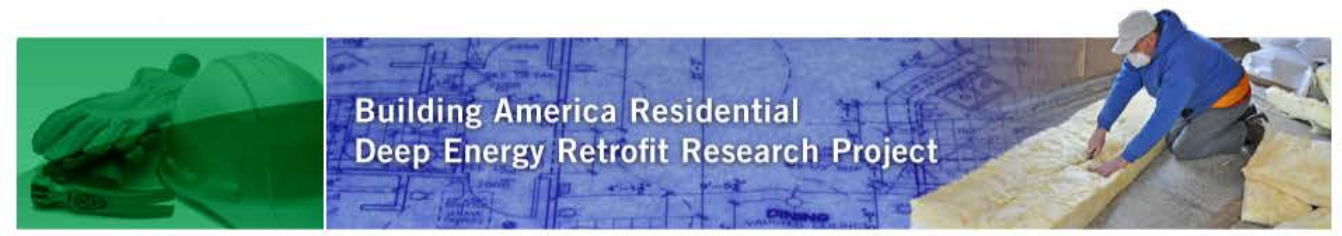

heat through the ceiling into the home. Cellulose and fiberglass insulation are typically used when adding insulation into existing homes. Cellulose and fiberglass are blown into the attic through a hose. This application is known as loose-fill (as opposed to batts of insulation). Before adding insulation, it is important to seal any leaks in the attic floor (it is much more difficult to seal leaks afterwards). Spray foam and caulk can be used to seal most leaks, though other materials may be used if leaks are very large (fire rated materials must be used where appropriate). Contractors will temporarily move the insulation aside while they air seal. Leaks are often found around holes drilled for wiring or plumbing, and the the top plates of interior walls. (For more information, see the Building America Air Sealing Guide ${ }^{2}$, Available at: http://www1.eere.energv.gov/librarv/asset handler.aspx?src=http://apps1.eere.energy.gov/b uildings/publications/pdfs/building america/ba airsealing report.pdf\&id=4663).

Your attic could also benefit from additional insulation. Currently, the insulation value is about $\mathrm{R}-38$. The original insulation is two layers of R-19 fiberglass batts. This insulation is still in good shape, but installing additional insulation will help you save even more energy! It would be useful to blow an additional R-22 of fiberglass insulation (giving you a total of R-60) into the attic to provide an added thermal barrier between the conditioned house and the attic.

Another option, which we discussed with you at the audit, is installing insulation at the roof deck, leaving more space on the attic floor for storage. If you choose to use the attic for storage, be sure to put down boards on the rafters to walk on or hold any items to prevent the current insulation from being crushed. To insulate at the roof deck, a product called spray foam is commonly used. Closed-cell spray foam has a higher R-value than fiberglass because it is more dense. You can achieve an additional R-36 of insulation on the roof deck with just 6" of spray foam insulation. This option will also save slightly more energy than installing insulation at the ceiling level because spray foam is also an air barrier, meaning it also makes your house tighter, as well as increasing its thermal resistance.

\section{Locally Available Incentives}

- The City of Richland has a low interest loan that can be used for attic insulation.

- A federal tax credit is also available for $10 \%$ of material costs (does not include labor)

${ }^{2}$ Building America's Air Sealing Guide can be found here; http://wwwl.eere.energy.gov/library/asset handler.aspx? src=http $/ /$ appsl.eere.energy.gov/buildings/publications/pdf s/building america/ba airsealing report.pdf\&id $=4663$
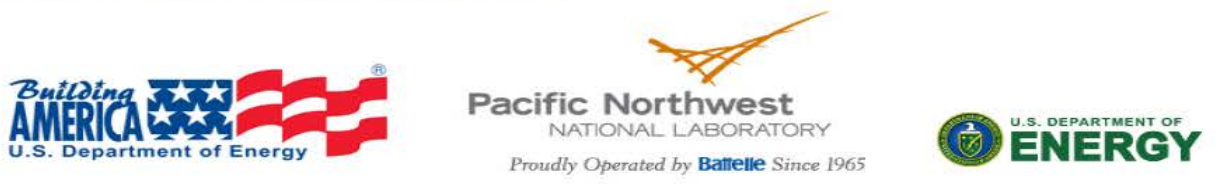


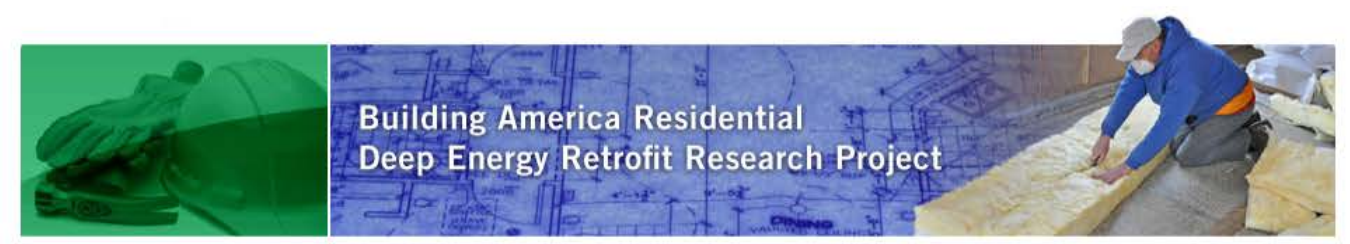

Table 4. Estimated cost and savings for additional attic insulation and air sealing.

\begin{tabular}{|ccccc|}
\hline Measure & $\begin{array}{c}\text { Estimated } \\
\text { Cost }\end{array}$ & $\begin{array}{c}\text { Estimated } \\
\text { Annual Savings }\end{array}$ & $\begin{array}{c}\text { Payback } \\
\text { Period }\end{array}$ & $\begin{array}{c}\text { Payback } \\
\text { Period (after } \\
\text { incentives) }\end{array}$ \\
\hline $\begin{array}{c}\text { Additional R-22 of } \\
\text { fiberglass insulation at } \\
\text { ceiling level }\end{array}$ & $\$ 540$ & $\$ 17 / \mathrm{yr}$ & $31 \mathrm{yr}$ & $28 \mathrm{yr}$ \\
$\begin{array}{c}\text { Additional R-36 spray } \\
\text { foam at the roof deck }\end{array}$ & $\$ 833$ & $\$ 30 / \mathrm{yr}$ & $27 \mathrm{yr}$ & $25 \mathrm{yr}$ \\
\hline
\end{tabular}

\section{Install Adequate Mechanical Ventilation}

All homes need a certain amount of fresh air. Currently, air leaks into your home through cracks and gaps in the walls, ceiling, and foundation. These leaks add to your heating and cooling costs, can bring air pollutants into the home, and can lead to mold and damaged building materials. Air sealing will prevent air leaks, but once air sealing has been completed, there may not be enough fresh air getting into the home. We will perform a blower door test after air sealing to determine whether more fresh air is needed.

Heat Recovery Ventilators (HRVs) and Energy Recovery Ventilators (ERVs) bring fresh air into the home and exhaust stale air from bathrooms and kitchens. The advantage of HRVs and ERVs is that they transfer energy between the exhaust and fresh air streams. For example, in the winter, heat from the exhaust stream is used to warm up fresh air from outside. This way, less energy is needed to condition the fresh air.

An alternative way to ventilate the home is to use exhaust fans, but exhaust fans are not able to recover any energy from the exhaust air.

\section{Replace Your Air Conditioner and Space Heater with Heat Pump}

Your AC unit is about fairly old and inefficient. The efficiency of AC units is rated by their SEER. Your unit has a SEER of about 6 . Your space heater is $100 \%$ efficient (all electric appliances are), but it is not providing the level of comfort you should have in your home. We believe a ductless heat pump will provide the best combination of efficiency and comfort in your home.
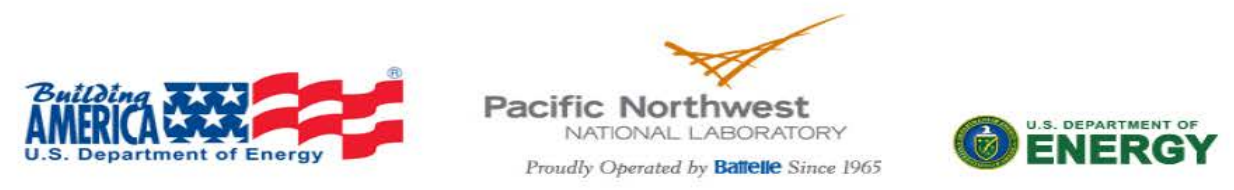


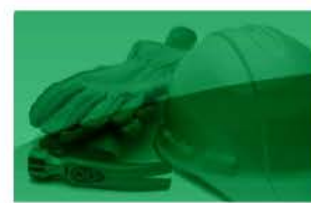

Building America Residential

Deep Energy Retrofit Research Project

In the heat mode, heat pumps are rated by their heating season performance factor (HSPF). For new units, the current minimum allowable efficiencies for heat pumps are a SEER of 13 and an HSPF of 7.7. Some models have SEERS of over 20 and HSPFs of over 10 !

\section{Locally Available Incentives}

- The city of Richland is currently running a pilot program for ductless heat pumps which offers an incentive of $\$ 1,500$ for approved models. This pilot program ends September 31, 2011. See http://www.ci.richland.wa.us/index.aspx?NID=181 for more information. Because of this opportunity, now would be a great time to replace your heat pump. We encourage you to call the City of Richland Heat Pump Pilot Program to find out more.

- A Federal tax credit of $\$ 300$ is available for qualifying models.

We estimated the savings associated with installing a 3/4 ton SEER 16, HSPF 10 heat pump. This model would currently qualify for energy star tax credits. High efficiency models are available, which would result in greater savings. You should talk with local HVAC companies about the specific unit that would be best for your house. A list of local HVAC contractors is available at: http://www.ci.richland.wa.us/DocumentView.aspx?DID $=1052$

Table 5. Estimated cost and savings for new heat pump.

\begin{tabular}{cccc|} 
Estimated Cost & $\begin{array}{c}\text { Estimated Annual } \\
\text { Savings }\end{array}$ & Payback Period & $\begin{array}{c}\text { Payback Period } \\
\text { (after incentives) }\end{array}$ \\
$\$ 6,469$ & $\$ 238 / \mathrm{yr}$ & $27 \mathrm{yr}$ & $20 \mathrm{yr}$ \\
\hline
\end{tabular}

\section{Replace Your Hot Water Heater}

Your hot water heater is very old and much more efficient models are available. The efficiency of hot water heaters is rated by the efficiency factor $(E F)$, which describes the fraction of energy that actually is delivered as hot water. The EF accounts for losses due to combustion efficiency (for combustion hot water heaters), standby losses, and through-the-tank losses. We estimate your hot water heater is currently rated a 0.86 , based on its age. However, your hot water heater is nearing the end of its life. When you decide to replace your hot water heater, it is worthwhile to choose the most efficient model, which has an EF of 0.95 . We calculated that this investment would save you $8 \%$ on your energy bills and payback in just 8 years.
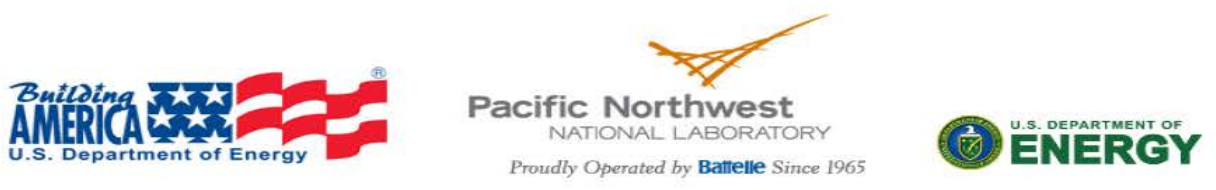


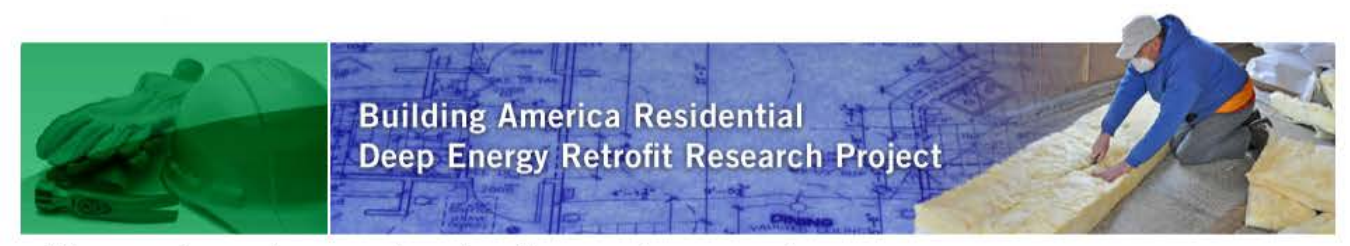

Table 5. Estimated cost and savings for new hot water heater.

\begin{tabular}{cccc|} 
Estimated Cost & $\begin{array}{c}\text { Estimated Annual } \\
\text { Savings }\end{array}$ & Payback Period & $\begin{array}{c}\text { Payback Period } \\
\text { (after incentives) }\end{array}$ \\
$\$ 700$ & $\$ 87 / \mathrm{yr}$ & $8 \mathrm{yr}$ & $8 \mathrm{yr}$ \\
\hline
\end{tabular}

\section{Install a Solar Water Heater}

Solar water heaters use the sun to warm up water for use in showers, faucets, and the dishwasher. Solar water heaters are more expensive that other water-heating options, but they save money over the life of the system. Depending on the size of the system, solar water heaters typically provide $30-75 \%$ of the hot water load. Solar collectors typically perform best when the roof faces due south and the roof angle is about the same as the latitude, $47^{\circ}$, although this can vary based on design considerations.

Although the economics are not that great, your home seems like it would be a good candidate for a solar hot water system. We estimate that you can decrease your utility bills by about $7 \%$ by adding a solar thermal system.

We also modeled the possibility of adding solar panels to your home to generate even more free electricity. We estimate the solar panels would generate another $7 \%$ of your energy consumption, but a very expensive and so are not that cost effective.

\section{Locally Available Incentives}

- City of Richland provides an incentive of $\$ 500 / \mathrm{kW}$ installed (solar PV only) or a low interest loan for solar PV and solar thermal systems. More information is available at: http://www.ci.richland.wa.us/index.aspx? NID=584

- There is a Federal tax credit of $30 \%$ of the installed cost for solar thermal and solar PV systems.

Table 6. Estimated cost and savings for solar hot water and solar photovoltaic systems.

\begin{tabular}{|ccccc|}
\hline Measure & $\begin{array}{c}\text { Estimated } \\
\text { Cost }\end{array}$ & $\begin{array}{c}\text { Estimated } \\
\text { Annual Savings }\end{array}$ & $\begin{array}{c}\text { Payback } \\
\text { Period }\end{array}$ & $\begin{array}{c}\text { Payback } \\
\text { Period (after } \\
\text { incentives) }\end{array}$ \\
\hline Solar Hot Water & $\$ 3,094$ & $\$ 80 / \mathrm{yr}$ & $39 \mathrm{yr}$ & $27 \mathrm{yr}$ \\
Solar Panels & $\$ 8,000$ & $\$ 76 / \mathrm{yr}$ & $105 \mathrm{yr}$ & $67 \mathrm{yr}$ \\
\hline
\end{tabular}

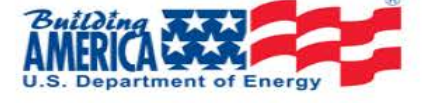

Pacific Northwest

NATIONAL LABORATORY

Proudly Operated by Battelle Since 1965

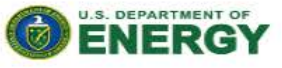



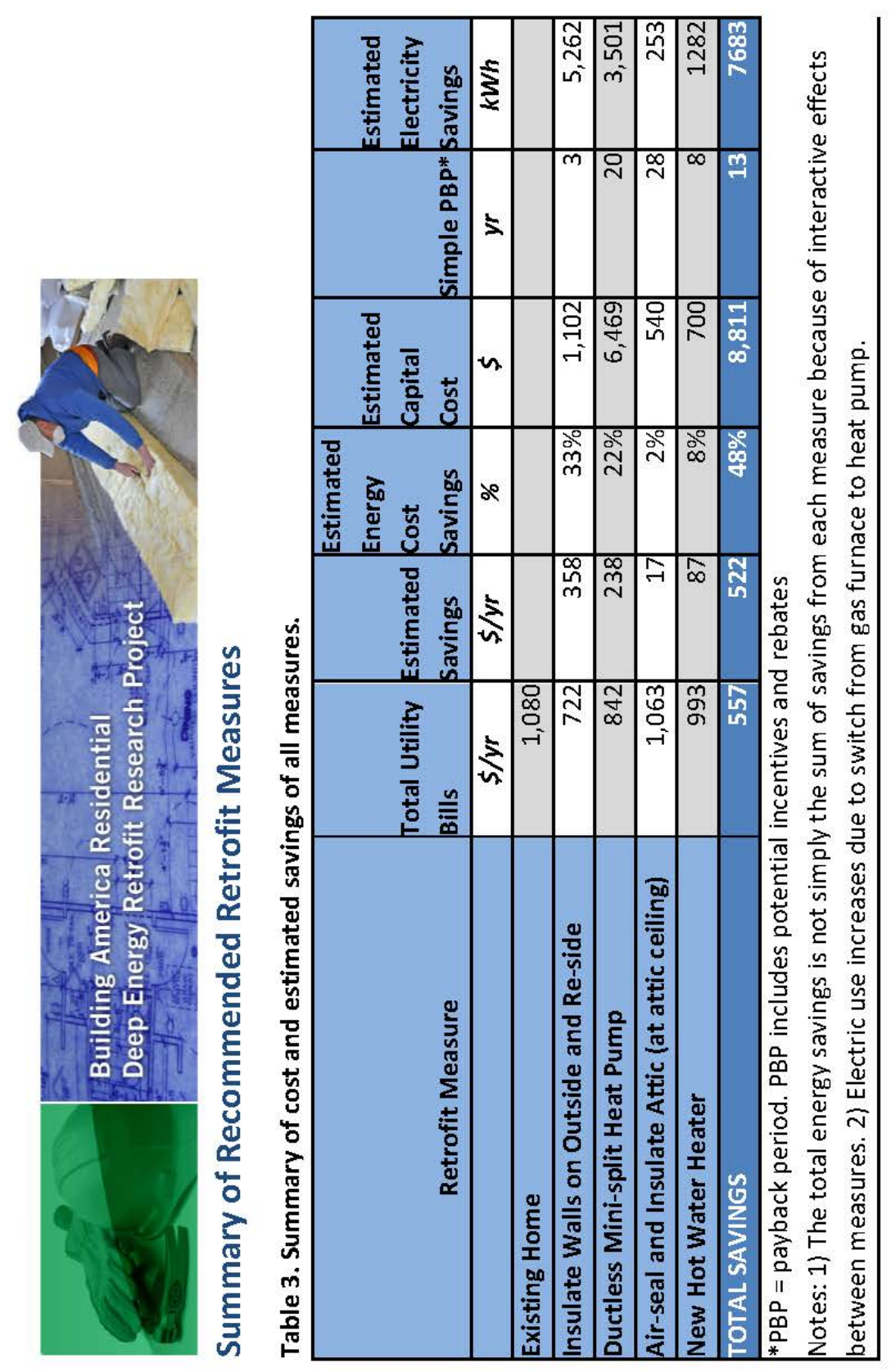


\section{Easy Do-It-Yourself Improvements}

\section{Lower the Hot Water Tank Set Point}

Most households only require hot water at $120^{\circ} \mathrm{F}$. If your hot water tank setpoint is higher than $120^{\circ} \mathrm{F}$, you can save energy by lowering the setpoint. A lower setpoint reduces the amount of heat lost through the tank. Note that it is generally not recommended to reduce the temperature below $120^{\circ} \mathrm{F}$.

\section{Use Power Strips to Turn Off Appliances That are Not Being Used}

Some home appliances draw power even when they are not being used. These draws on power are often called "phantom loads." One way to avoid phantom loads is to plug non-essential appliances into a power strip. When the appliances are not in use, simply turn off the power strip. Be sure to use a separate power strip or outlet for any essential appliances.

\section{Install Low-flow Showerheads and Faucet Aerators}

A simple way to save on your water heater costs is to use low-flow plumbing fixtures. New showerheads offer suitable spray while using less hot water. There are many available models that use around 2 gallons per minute (gpm). Older showerheads can use more than $5 \mathrm{gpm}$.

Similarly, hot water use in faucets can be reduced by using installing faucet aerators. Look for aerators that limit the faucet flow to about $1 \mathrm{gpm}$. Also, when shopping for aerators or lowflow showerheads, look for the WaterSense label. WaterSense is a U.S. Envivronmental Protection Agency program that certifies water-saving fixtures.

\section{Replace Your Appliances with Energy Star Appliances}

If and when you plan on replacing your stove, clothes washer, or other major household appliance, be sure to find a model with the ENERGY STAR label. New ENERGY STAR models are much more efficient than non-qualified models. Add can save up to $7 \%$ on your energy consumption.

\section{Locally Available Incentives}

- The City of Richland currently offers a \$25 incentive for most new Energy Star appliances. See http://www.ci.richland.wa.us/index.aspx?NID=178 for more details.
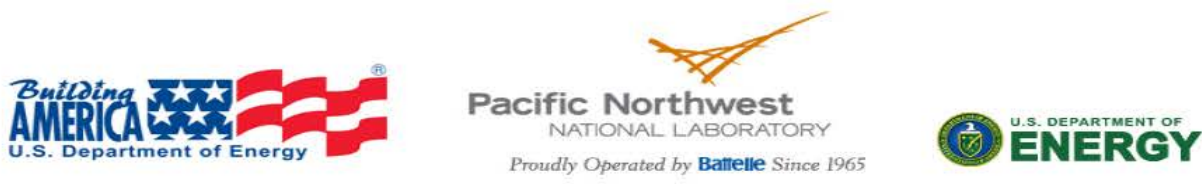


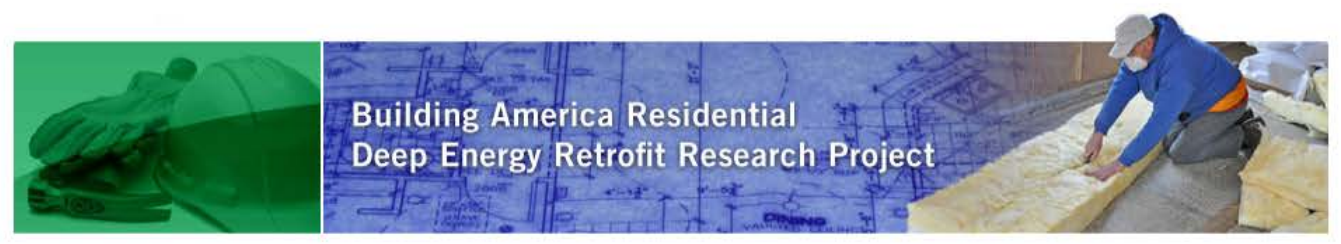

\section{Additional Resources}

For more information, the following websites provide additional energy-saving tips for home owners looking to make energy efficiency improvements to their homes:

- http://www.energysavers.gov/

- http://www.aceee.org/consumer

- http://www.energystar.gov/

- http://www.nahb.com/

- http://www1.eere.energv.gov/buildings/

In addition, the Building America website (http://www1.eere.energy.gov/buildings/building america/) and the Building Science Corporation website (http://www.buildingscience.com/index html) provide a number of good resources related building design and construction of energy efficient homes.

\section{Incentives and Rebates}

Various incentives are available to help pay for energy efficiency measures. For example, many of local utilities offer incentives. Several of these incentive or rebate options are identified in the audit information provided above. In addition to the incentives and direct rebates identified for your specific recommendations above, the City of Richland offers low-interest loans to help finance energy efficiency projects. These loans can be used instead of (but not in addition to) the project-specific rebates. More information can be found on your local utilities website. Another good resource for finding energy efficiency rebates anywhere throughout the country is www.dsireusa.org/.

Federal tax incentives are also available for ENERGY STAR products. Many of the recommended measures may be eligible for a tax credit worth $10 \%$ of the materials cost, or a specified amount (for example, ENERGY STAR furnaces are eligible for a $\$ 150$ tax credit). These incentives have also been identified in the cost estimates provided above. More information about this program is available at the following website:

http://www.energystar.gov/index.cfm?c=tax credits.tx index.
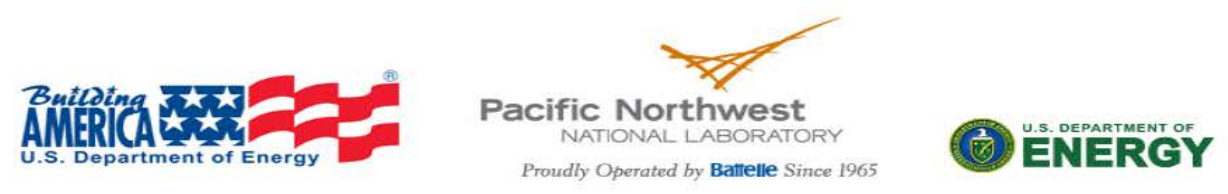

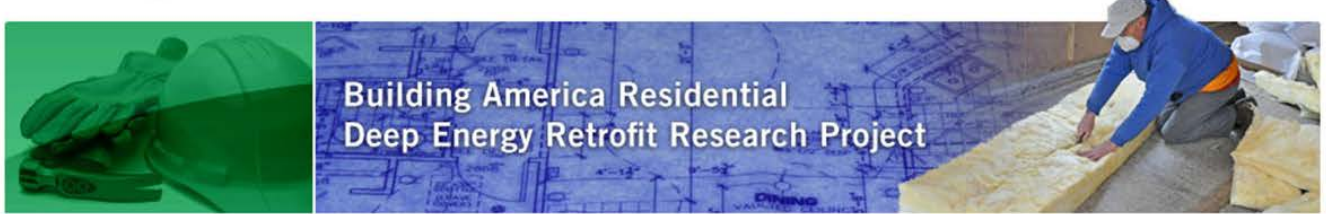

Residential Deep Energy Retrofit Research Project

\section{Audit Report for a Two-story Richland "F model" 1940s Home}

Audit Date: 4/27/2011

Pacific Northwest National Laboratory Research Team

http://deepenergyretrofits.pnnl.gov/

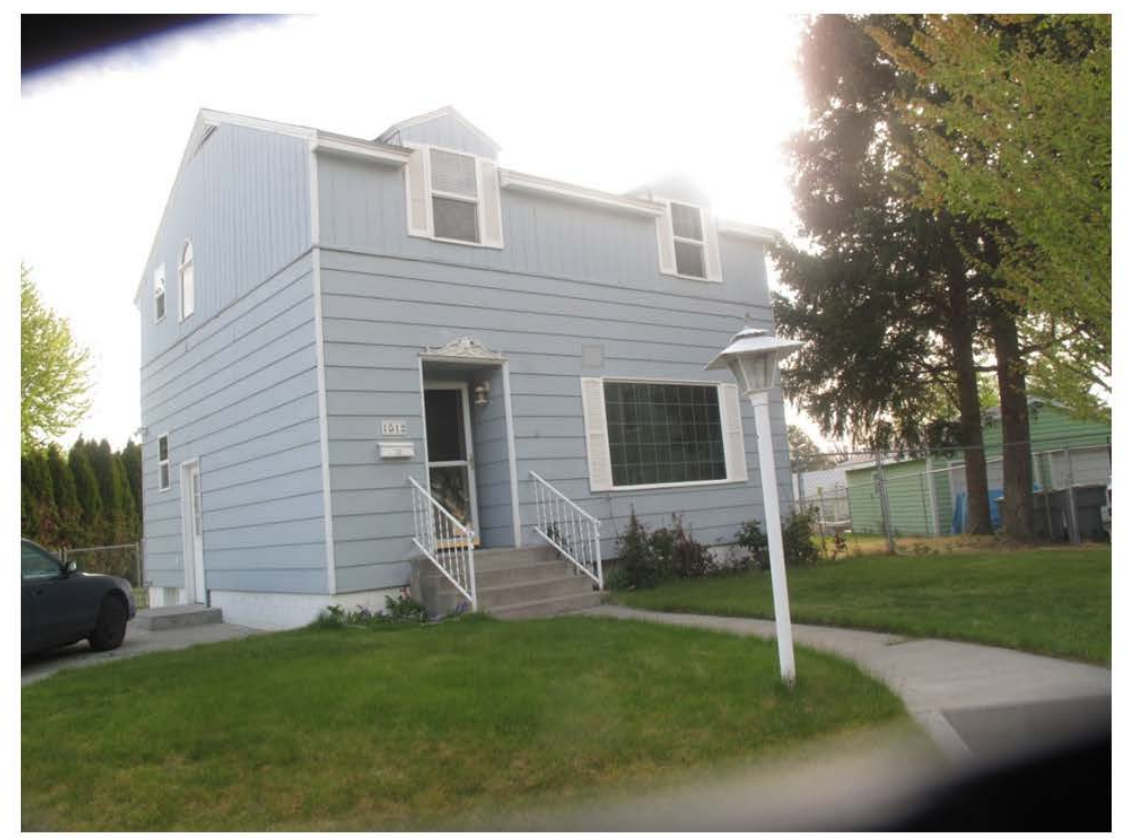

Notices:

1. This report is intended for the sole use of the homeowner(s) and the PNNL deep retrofits study team members (including subcontractors) that have completed training to protect the privacy and other rights of human subjects in research programs. PNNL will not share this report with anyone but may include data and information from this report, in an anonymous manner, in the final report that will be submitted to the U.S. Department of Energy.

2. The quantitative information in this report on energy savings, costs and economic benefits are based on computer models. Please note that actual savings and costs can be quite different (may be even a factor of 2 or more) depending on homeowner lifestyle, actual performance of energy saving equipment and strategies, variations in local weather, contractor business models and other unforeseen factors.
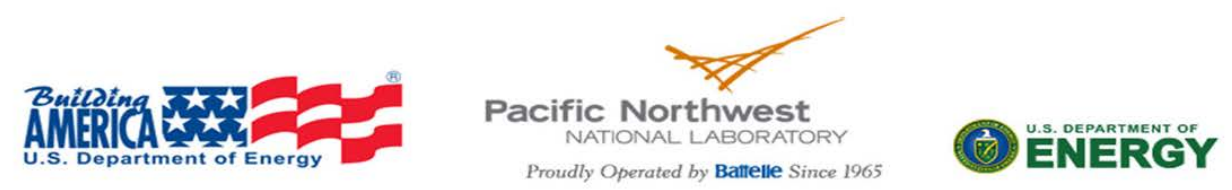


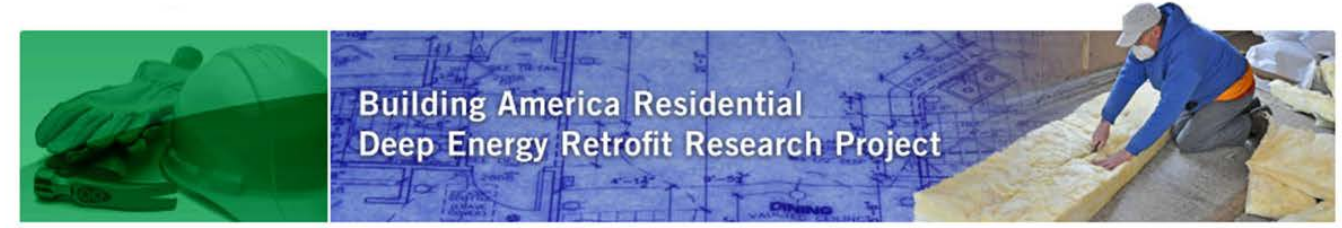

\section{Existing Home Characteristics and Performance}

Your home is a single-family, two-story home over a full conditioned basement built in the 1940s. It is a " $F$ " model home similar to other such homes in the area. It has 3 bedrooms and 2 baths; a total conditioned space of about 1,223 square feet $\left(\mathrm{ft}^{2}\right)\left(1,835 \mathrm{ft}^{2}\right.$ including the basement). The building envelope is wood-frame construction. It has about R-11 insulation in the walls and R-30 batt insulation in the vented attic. There is an uninsulated closet on the first floor. There are some insulated attic knee walls near the upstairs windows. The basement is partially insulated and partially uninsulated concrete walls. The floor between the basement and first floor is insulated. The windows are double-pane clear glass with metal frames and a wood French door in the back. The Heating is provided by a $25+$ year gas furnace with an estimated efficiency of $70 \%$ and cooling is provided by 15 year old 3 ton SEER 10 central air conditioner. The metal ducts are uninsulated and primarily located in the basement. The water heater is a very old gas fired unit estimated to be only $40 \%$ efficient. The basement is often too cold and thus supplementary electric heat is used there.

Your utility bill information is provided in Table 1, below. Bills for some missing months were estimated.

Table 1. Utility Bill Information for June 2010 through May, 2011.

\begin{tabular}{lcc}
\hline Energy Costs Information & Gas, \$ & Electricity, \$ \\
\hline Average Utility Bill & 57 & 52 \\
\hline Maximum Utility Bill & 132 (Dec) & 68 (Jul) \\
\hline Minimum Utility Bill & 19 (Aug) & 42 (Oct) \\
\hline
\end{tabular}

\section{Recommended Energy Efficiency Retrofit Measures}

Your home was audited to quantify its energy performance. The home energy audit consists of several elements: a blower door test to characterize building envelope leakage, a duct test to characterize duct leakage, thermal imaging to identify key leaks, evaluation of insulation levels, and examination of all energy-consuming appliances.

Following the audit we created a calibrated model of your house using the Energy Gauge (EG) software, developed by the Florida Solar Energy Center This software is a general analysis tool that is valid for all climates and has met software validation tests

(http://www.energygauge.com/usares/default.htm ). However, it cannot model basements very well and homes where two heating systems are used such as yours (gas and strip heat). In
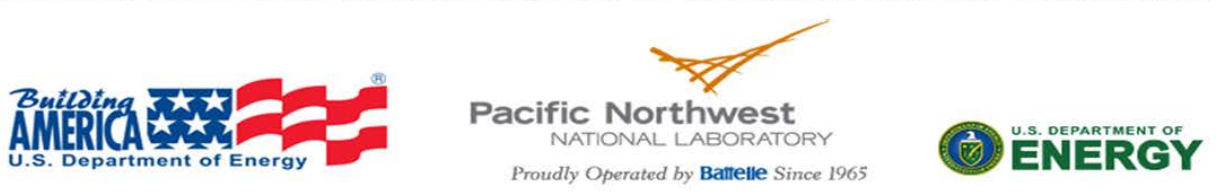

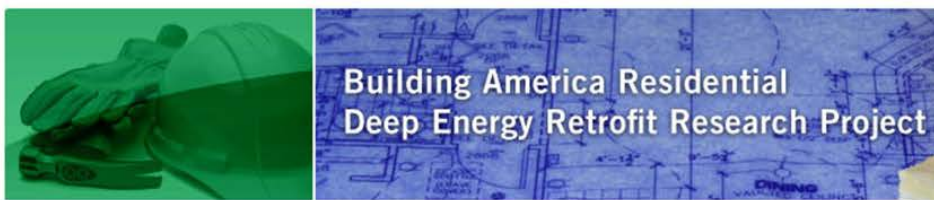

any event, the model was calibrated, to match your annual utility bills as shown in Figure 1 for electricity and Figure 2 for natural gas. While the annual consumptions match closely, there are significant variations on a monthly basis.

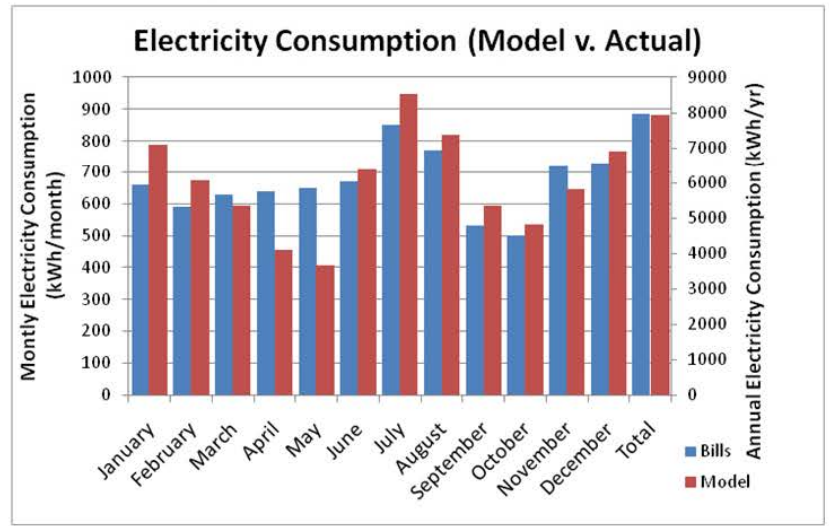

Figure 1. Comparison of monthly electricity consumption for utility bill and EG model. The annual comparison is also included on the secondary (right) vertical axis.

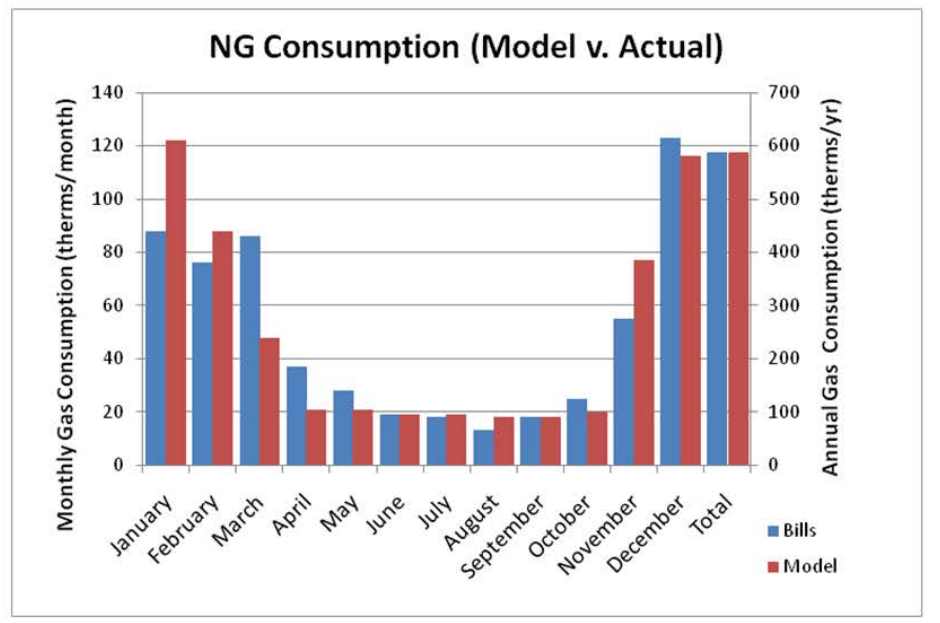

Figure 2. Comparison of monthly natural gas consumption for utility bill and EG model. The annual comparison is also included on the secondary (right) vertical axis.

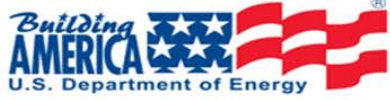

\section{Pacific Northwest}

NATIONAL LABORATORY

Proudly Operated by Batrelle Since 1965

\section{O- OENERGY}




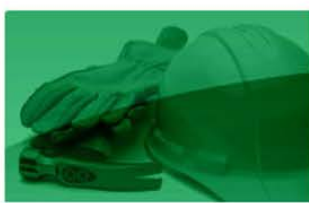

Building America Residential

Deep Energy Retrofit Research Project

Figure 3 shows the EG model breakdown of your energy consumption. Notice that more than $50 \%$ of your energy consumption is associated with heating due to the inefficiency of your old furnace and strip heat.

\section{Exisiting Energy Consumption Breakdown}

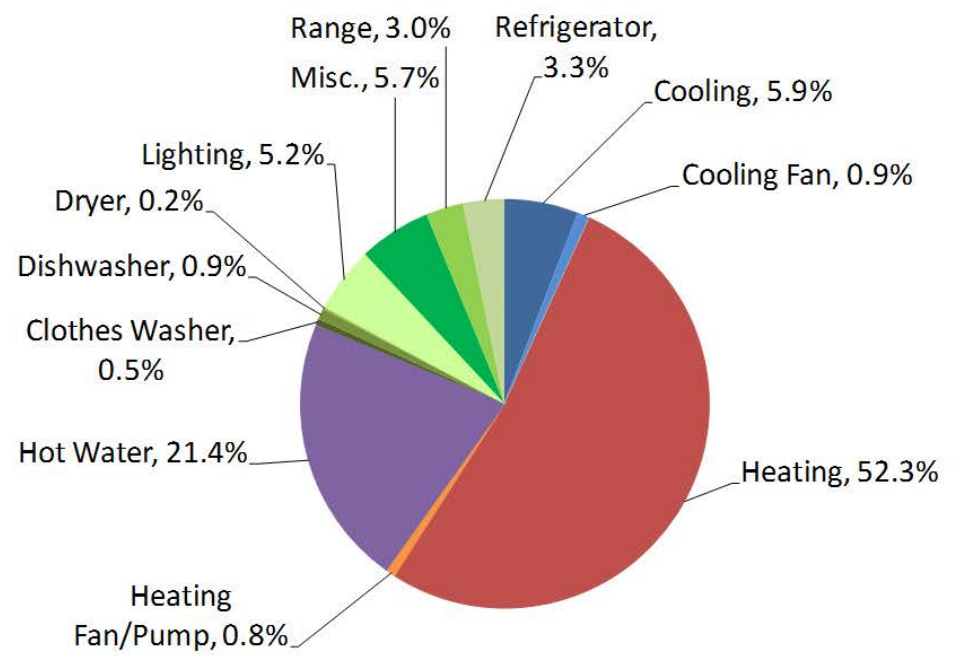

Figure 3. Percentage of energy consumption for heating, ventilation, air conditioning equipment, lighting, appliances and miscellaneous base loads. The energy consumption is calculated based on a British Thermal Unit (Btu) conversion basis. Kilowatt-hours of electricity and therms of natural gas are converted to Btus using the mean Btu conversion (1 $\mathrm{kWh}=3412.14 \mathrm{Btu} ; 1$ therm = 100,000 Btu).

Based on this and things we noticed during the audit, we then modeled a number of energy efficiency measures to assess which measures would save the most energy and be the most cost effective without compromising combustion safety in your home. These include insulating your basement, replacing your heating and cooling system with a new heat pump, and replacing your hot water heater with a tankless hot water heater. These measures together could save about $37 \%$ on your energy bills!
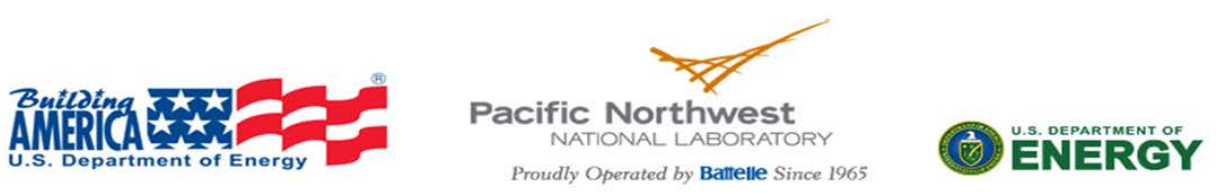

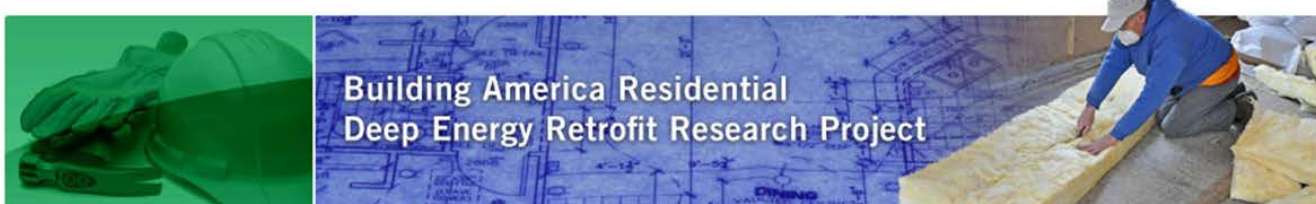

Please note that this analysis is preliminary and does not include expensive options such as window replacement, or options that may compromise combustion safety. We will be happy to analyze additional options if you decide to go forward with energy retrofits that are likely to save at least $30 \%$ of your energy use.

In addition to the measures outlined below, air sealing could save a significant amount of energy in your home. For example, the blower door tests show that your house leaks are considerably higher than other homes we have tested in the area. Your air leakage was measured to be $2,354 \mathrm{cfm} 50$ which is $1.28 \mathrm{cfm} 50 / \mathrm{ft}^{2}$, while typical homes have leakage values of between 0.8 and $1.1 \mathrm{cfm} 50 / \mathrm{ft}^{2}$. However, because you have four naturally aspirated combustion devices (furnace, water heater, dryer and range) inside the conditioned space in your home, air sealing might introduce unacceptable combustion risks by limiting the amount of combustion and make up air in your home. Accordingly, we are not recommending this generally cost effective measure in your home currently. However, we will be pleased to discuss this subject further with you, if you wish. It may be appropriate to air seal your house if you replace your heating/cooling system with an all electric heat pump and replace the gas water heater inside the home with a tankless gas water heater installed outside your home.

Likewise, your air distribution ducts are inside the conditioned space. Duct tests revealed that very little air is escaping to the outside from the ducts. Consequently sealing the ducts (another generally cost effective measure) is not recommended for your house as it is unlikely to save any energy. However, if you go ahead with the heating cooling system replacement, the ductwork should be evaluated and adjusted as needed for optimum air flow distribution.

Another option which is not analyzed (as the software is not able to do it) but that may be worthwhile for your home if you replace your heating cooling system is zoning. Since your house is on three floors, with a zoned system you will have a thermostat for each floor and be able to independently set the temperature for each of the three zones for optimum comfort and energy efficiency. It will be worthwhile to explore zoning if you decide to replace your heating/cooling system.

The ensuing sections of this report summarize each energy-saving measure analyzed and provides the estimated energy savings, cost of each recommended measure, and associated payback period. The simple payback period is the number of years that it will take to pay off the upfront investment with energy cost savings (the shorter, the better). The payback period provides a quick economic metric that can be used to prioritize the measures. The ensuing sections also briefly summarize locally available incentives that may be available to help pay for energy-saving measures. Most of the savings estimates included here are based on computer
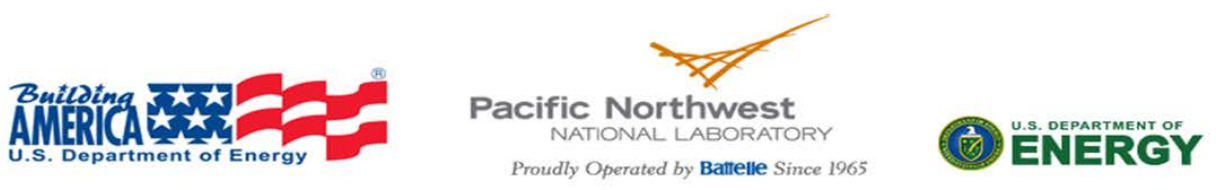

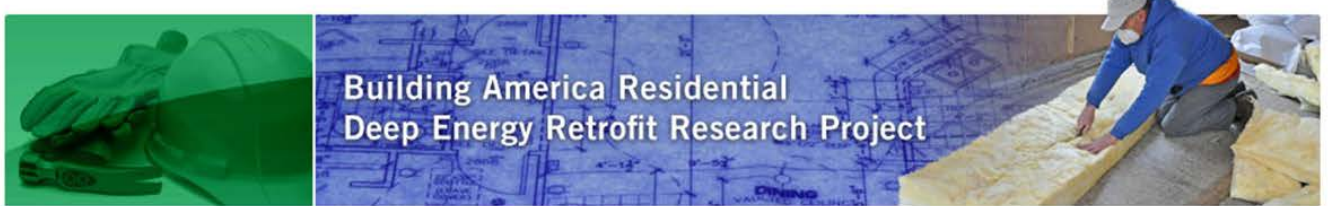

simulations of your home. The costs provided are rough estimates based on our experiences with the energy-saving measures, quotes from local contractors, and publically available information, like the National Renewable Energy Lab's National Measures Database ${ }^{1}$. Your actual costs will depend on the contractor you choose, the final scope of work, and the current material prices.

Please read through the measures described below and let us know if you have any questions. Once we have discussed the cost-saving measures available to you and agreed on a package that fits your needs, the next step will be to start asking contractors for bids on the energysaving projects (recognizing that you can complete some projects yourself).

\section{Add Basement and Wall Insulation}

You have already begun to insulate your basement walls. We recommend you finish the job and insulate all your walls. The analysis assumes all walls will be insulated to R-13 and it costs $\$ 2 / \mathrm{sq}$. $\mathrm{ft}$. of wall for the 3 uninsulated walls remaining. If insulated to R-11, the energy savings will decrease slightly. Also while it is not analyzed, you of course want to insulate the uninsulated exterior wall(s) of the closet on the first floor.

\section{Locally Available Incentives}

- A federal tax credit is available for $10 \%$ of material costs (does not include labor)

Table 2. Estimated Cost and Savings for R-13 Basement wall insulation

\begin{tabular}{ccc|c} 
Estimated Cost & $\begin{array}{c}\text { Estimated Annual } \\
\text { Savings }\end{array}$ & Payback Period & $\begin{array}{c}\text { Payback Period } \\
\text { (after incentives) }\end{array}$ \\
$\$ 1,022$ & $\$ 116 / \mathrm{yr}$ & $8.8 \mathrm{yrs}$ & $8.4 \mathrm{yrs}$ \\
\hline
\end{tabular}

\section{Replace water heater with a tankless gas unit}

Replacing your aging hot water heater with a tankless gas hot water heater is likely to result in substantial savings and a decent payback. A heat pump water heater is not recommended for your house as it produces cold air that will further cool down your basement. Your current hot water tank is old, inefficient (only about $40 \%$ efficient), and probably near the end of its life, so

\footnotetext{
${ }^{1}$ National Renewable Energy Laboratory. "National Measures Database." Available at:
} http://www.nrel.gov/ap/retrofits/.
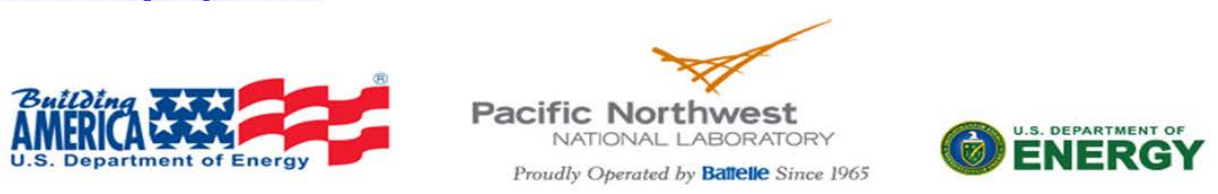

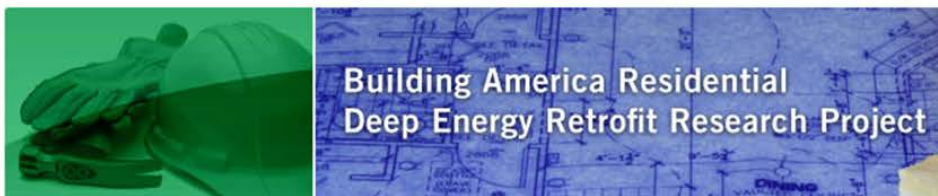

replacing it with a more efficient tankless gas water heater with a flue (rated efficiency about $84 \%$, field efficiency about $74 \%$, the value used in the analysis) is likely to provide substantial energy savings. Note that there is an even higher efficiency (rated at 95\% but higher cost) condensing tankless gas water heater that is available, which will further decrease your energy consumption. However, that system was not analyzed. Also note that it may be possible to install the tankless gas water heaters outside your house. This option should be explored as it increases combustion safety.

\section{Locally Available Incentives}

- A federal tax credit of $\$ 300$ is currently available for heat pumps with an efficiency factor (EF) of above 2 or for gas water heaters with an EF greater than 0.82

Table 3. Estimated Cost and Savings for a New Tankless Gas Hot Water Heater

\begin{tabular}{|c|c|c|c|c|}
\hline Measure & $\begin{array}{c}\text { Estimated } \\
\text { Cost }\end{array}$ & \multicolumn{1}{c}{$\begin{array}{c}\text { Estimated } \\
\text { Annual Savings }\end{array}$} & $\begin{array}{c}\text { Payback } \\
\text { Period }\end{array}$ & \multicolumn{1}{c|}{$\begin{array}{c}\text { Payback Period } \\
\text { (after incentives) }\end{array}$} \\
\hline $\begin{array}{c}\text { Gas Tankless } \\
\text { WH }\end{array}$ & $\$ 1,800$ & $\$ 150 / \mathrm{yr}$ & $12 \mathrm{yr}$ & $10 \mathrm{yr}$ \\
\hline
\end{tabular}

\section{Replace Your Furnace/AC units with a Heat Pump}

Your furnace and AC units are over 15 years old. The efficiency of AC units is rated by their SEER. Your unit has a SEER of about 10. Furnace efficiency is rated by the AFUE; yours has an AFUE of about $70 \%$. While new furnaces can have AFUEs of $95 \%$, we believe that heat pumps offer higher energy cost savings. In the heat mode, heat pumps are rated by their heating season performance factor (HSPF). For new units, the current minimum allowable efficiencies for heat pumps are a SEER of 13 and an HSPF of 7.7. Some models have SEERs of over 20 and HSPFs of over 10 ! Heat pumps will also increase the combustion safety and indoor air quality in your home.

In our analysis, we used a SEER 16, HSPF 9 heat pump. This model would currently qualify for energy star tax credits. High efficiency models are available, which would result in greater savings. In addition, consider zoning of your three levels to enhance the comfort and increase the energy savings even more as discussed above.

\section{Locally Available Incentives}

- A Federal tax credit of $\$ 300$ is available for qualifying models.
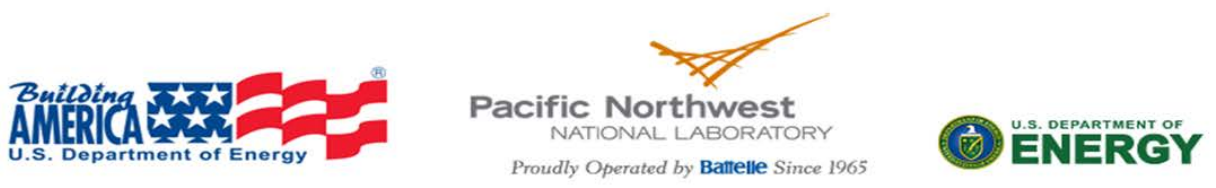


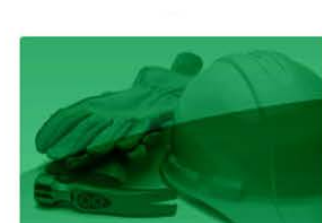

Building America Residential

Deep Energy Retrofit Research Project

Table 4. Estimated Cost and Savings for New Heat Pump

\begin{tabular}{|c|c|c|c|c|}
\hline Measure & $\begin{array}{c}\text { Estimated } \\
\text { Cost }\end{array}$ & $\begin{array}{c}\text { Estimated } \\
\text { Annual Savings }\end{array}$ & $\begin{array}{c}\text { Payback } \\
\text { Period }\end{array}$ & \multicolumn{1}{c|}{$\begin{array}{c}\text { Payback Period } \\
\text { (after incentives) }\end{array}$} \\
\hline Heat Pump & $\$ 5,100$ & $\$ 237 / \mathrm{yr}$ & $21.5 \mathrm{yrs}$ & $20.3 \mathrm{yrs}$ \\
\hline
\end{tabular}

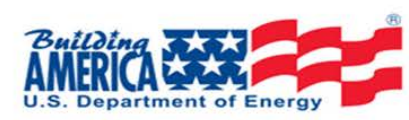

Pacific Northwest 


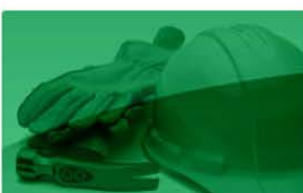

Building America Residential

Deep Energy Retrofit Research Project

\section{Summary of Recommended Retrofit Measures}

The table below summarizes our initial recommended package of measures for achieving at least $30 \%$ savings. As we move forward, some of the measures may change, but as you can see, it is certainly possible to achieve a $30 \%$ savings.

Table 5. Estimated Costs and Savings of Total Retrofit Package

\begin{tabular}{|c|c|c|c|c|c|c|c|}
\hline Retrofit Measure & $\begin{array}{l}\text { Total Utility } \\
\text { Bills }\end{array}$ & $\begin{array}{l}\text { Estimat } \\
\text { ed } \\
\text { Savings }\end{array}$ & \begin{tabular}{|l|} 
Estimated \\
Energy \\
Cost \\
Savings
\end{tabular} & $\begin{array}{l}\text { Estimated } \\
\text { Capital } \\
\text { Cost }\end{array}$ & \begin{tabular}{|l|} 
\\
Simple \\
PBP*
\end{tabular} & \begin{tabular}{|l} 
Estimated \\
Gas \\
Savings \\
(therms)
\end{tabular} & \begin{tabular}{|l|} 
Estimated \\
Electricity \\
Savings \\
(kWh)
\end{tabular} \\
\hline & $\$ / y r$ & $\$ / y r$ & $\%$ & $\$$ & \begin{tabular}{|l|l|}
$y r$ \\
\end{tabular} & & \\
\hline Actual Utility Bills & 1,280 & - & - & - & - & & \\
\hline Calibrated Energy Gauge model & 1,281 & & & & & & \\
\hline Insulate Basement to R13 walls & 1,164 & 116 & $9 \%$ & 1022 & 8.8 & 23 & 1134 \\
\hline Tankless gas dhw EF $=.82$ & 1,131 & 150 & $12 \%$ & 1,800 & 12.0 & 136 & 0 \\
\hline SEER 16 HSPF 9 heat pump & 1,044 & 237 & $18 \%$ & 5,100 & 21.5 & 344 & -1772 \\
\hline All three above options & 810 & 470 & $37 \%$ & 7,922 & 16.8 & 478 & -693 \\
\hline
\end{tabular}

*PBP = payback period. PBP includes potential incentives and rebates

Notes: 1) The total energy savings is not simply the sum of savings from each measure because of interactive

effects between measures. 2) Electric use increases due to switch from gas furnace to heat pump.

\section{Easy Do-It-Yourself Improvements}

\section{Replace Your Refrigerator}

Your refrigerators are not old or inefficient enough to justify replacement (unless you are replacing one for aesthetic or other reasons), but the following information may be helpful.

Newer refrigerators are significantly more efficient. If you are shopping for a new refrigerator, units with top-mounted freezers typically save the most energy. Select a unit with only as much volume as needed (larger units use more electricity). Also, through-the-door ice makers and internal ice makers increase energy use and should be avoided unless deemed necessary.

Efficient new refrigerators, depending on the size and features, consume about 350-450 kWh per year. Older units often consume 1000-2000 kWh per year! Your unit probably uses closer to $700-1000 \mathrm{kWh}$ per year. This means that you could save roughly $\$ 20-\$ 45$ per year by upgrading to a new refrigerator.
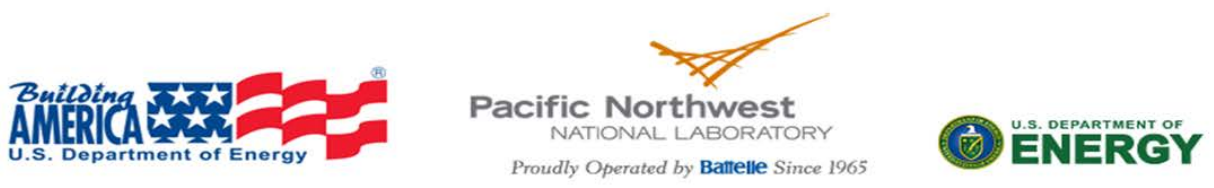

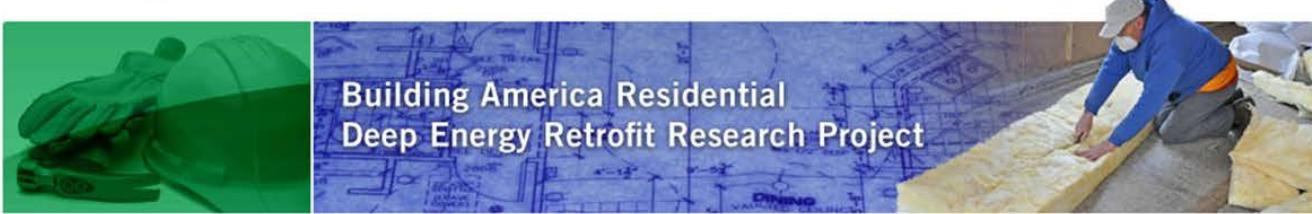

Locally Available Incentives

- The city of Richland offers a \$25 rebate for Energy Star models

- $\quad$ \$ $\$ 30$ rebate through the city of Richland is available for recycling your old refrigerator. They will come pick it up. This could be a good option if you decide that you do not need the extra refrigerator in the garage.

\section{Replace Your Clothes Washer}

If you plan on replacing your clothes washer, be sure to find a model with the ENERGY STAR label. New ENERGY STAR models are 37\% more efficient than non-qualified models (according to the ENERGY STAR website). In addition to using less hot water, ENERGY STAR models pull more water out of the clothes before they go into the dryer, thereby reducing the amount of drying time and energy consumed.

\section{Locally Available Incentives}

- The City of Richland offers a \$25 rebate for Energy Star models

\section{Lower the Hot Water Tank Set Point}

Most households only require hot water at $120^{\circ} \mathrm{F}$. Your tank does not display the actual temperature setpoint, but it is set between 'hot' and 'very hot.' You may be able to set the temperature lower while still having hot enough water for showers and dishwashing. A lower setpoint reduces the amount of heat lost through the tank. Note that it is generally not recommended to reduce the temperature below $120^{\circ} \mathrm{F}$.

\section{Use Power Strips to Turn Off Appliances That are Not Being Used}

Some home appliances draw power even when they are not being used. These draws on power are often called "phantom loads." One way to avoid phantom loads is to plug non-essential appliances into a power strip. When the appliances are not in use, simply turn off the power strip. Be sure to use a separate power strip or outlet for any essential appliances.
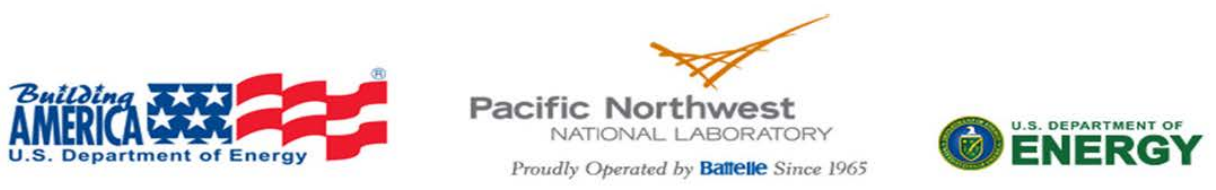


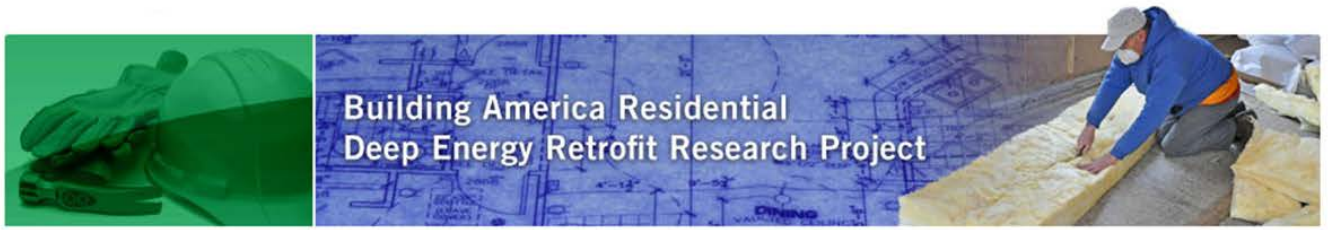

\section{Replace Your Incandescent Lights with Compact Fluorescents}

You have already replaced much of you lighting with CFLs, but the information below may be useful for future reference.

ENERGY STAR-qualified compact fluorescent lamp (CFL) bulbs use about 75\% less energy than standard incandescent light bulbs. They also last about 10 times longer than comparable incandescent bulbs. Annual savings depend on how many hours you use each bulb, but CFLs typically pay for themselves with energy savings within 1-2 years.

A note about CFLs: CFLs contain a small amount of mercury. At the end of their

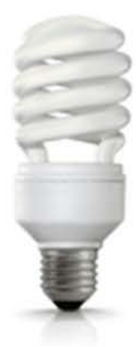
life, be sure to recycle the bulbs properly. Some stores, such as Home Depot, will accept bulbs that no longer work. For more guidance on recycling bulbs and what to do if a bulb breaks, see this document from the City of Richland (available at: http://www.ci.richland.wa.us/DocumentView.aspx?DID=1051).

\section{Install Low-flow Showerheads and Faucet Aerators}

A simple way to save on your water heater costs is to use low-flow plumbing fixtures. New showerheads offer suitable spray while using less hot water. There are many available models that use around 2 gallons per minute (gpm). Some older showerheads can use more than 5 gpm.

Similarly, hot water use in faucets can be reduced by using installing faucet aerators. Look for aerators that limit the faucet flow to about $1 \mathrm{gpm}$. Also, when shopping for aerators or lowflow showerheads, look for the WaterSense label. WaterSense is a U.S. Environmental Protection Agency program that certifies water-saving fixtures.
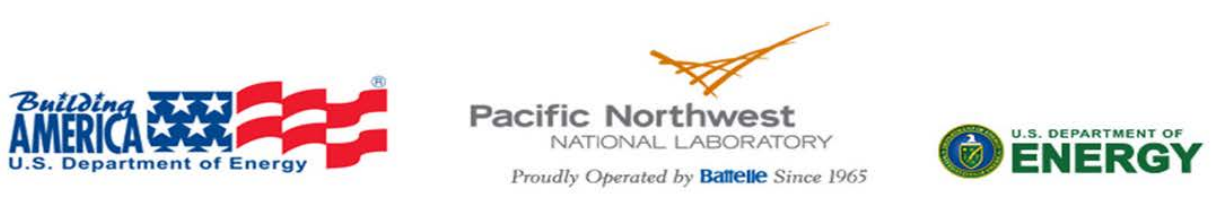


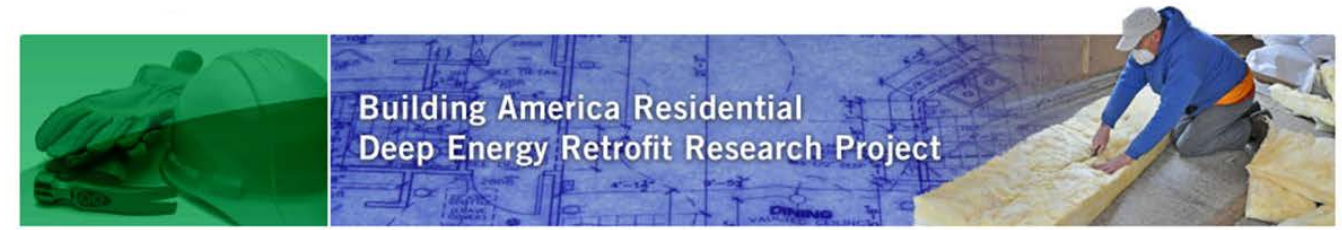

\section{Additional Resources}

For more information, the following websites provide additional energy-saving tips for home owners looking to make energy efficiency improvements to their homes:

- $\quad$ http://www.energysavers.gov/

- http://www.aceee.org/consumer

- http://www.energystar.gov/

- http://www.nahb.com/

- http://www1.eere.energy.gov/buildings/

In addition, the Building America website

(http://www1.eere.energy.gov/buildings/building america/) and the Building Science

Corporation website (http://www.buildingscience.com/index html) provide a number of good resources related building design and construction of energy efficient homes.

\section{Incentives and Rebates}

Various incentives are available to help pay for energy efficiency measures. For example, many of local utilities offer incentives. Several of these incentive or rebate options are identified in the audit information provided above. In addition to the incentives and direct rebates identified for your specific recommendations above, the City of Richland offers low-interest loans to help finance energy efficiency projects. These loans can be used instead of (but not in addition to) the project-specific rebates. More information can be found on your local utilities website. Another good resource for finding energy efficiency rebates anywhere throughout the country is www.dsireusa.org/.

Federal tax incentives are also available for ENERGY STAR products. Many of the recommended measures may be eligible for a tax credit worth $10 \%$ of the materials cost, or a specified amount (for example, ENERGY STAR furnaces are eligible for a \$150 tax credit). These incentives have also been identified in the cost estimates provided above. More information about this program is available at the following website:

http://www.energystar.gov/index.cfm?c=tax credits.tx index.
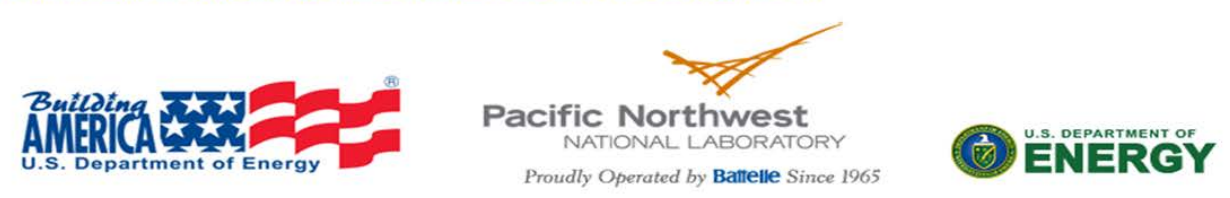

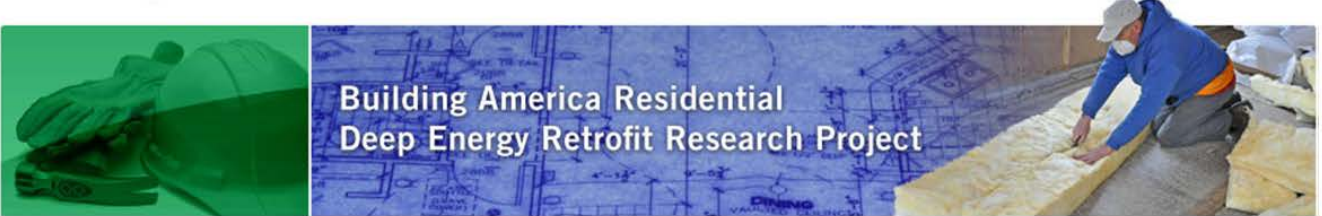

Residential Deep Energy Retrofit Research Project

\section{Audit Report for a Single-story Richland House}

Audit Date: 4/12/2011

Pacific Northwest National Laboratory Research Team http://deepenergyretrofits.pnnl.gov/

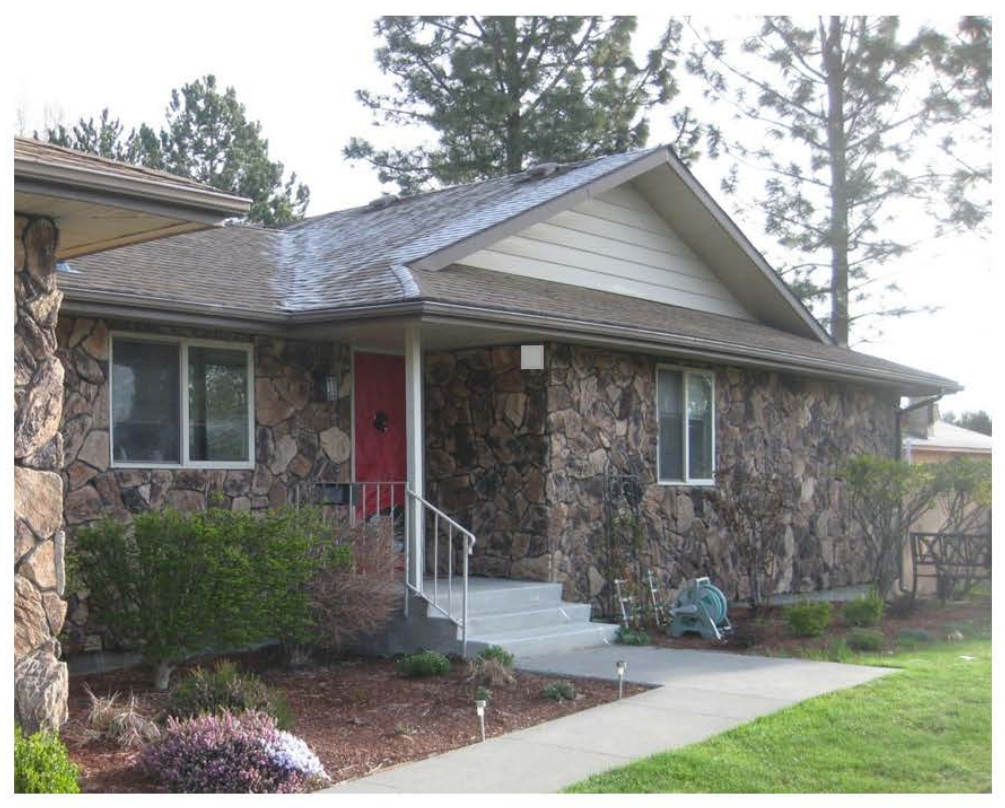

Notices:

1. This report is intended for the sole use of the homeowner(s) and the PNNL deep retrofits study team members (including subcontractors) that have completed training to protect the privacy and other rights of human subjects in research programs. PNNL will not share this report with anyone but may include data and information from this report, in an anonymous manner, in the final report that will be submitted to the U.S. Department of Energy.

2. The quantitative information in this report on energy savings, costs and economic benefits are based on computer models. Please note that actual savings and costs can be quite different (may be even a factor of 2 or more) depending on homeowner lifestyle, actual performance of energy saving equipment and strategies, variations in local weather, contractor business models and other unforeseen factors.

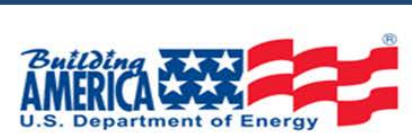

Pacific Northwest NATIONAL LABORATORY Proudly Operated by Banelle Since 1965 


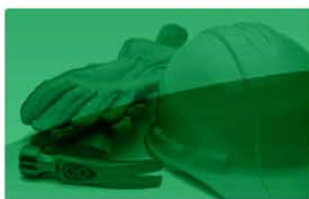

Building America Residential

Deep Energy Retrofit Research Project

Hor

\section{Existing Home Characteristics and Performance}

The house is a single-family, one-story home with an attached garage built in 1978 . It has 5 bedrooms and 2 baths; a total conditioned space of 2,763 square feet $\left(\mathrm{ft}^{2}\right)$, including a 1,237 $\mathrm{ft}^{2}$ finished basement. The original building envelope is $2 \times 4$ wood-frame construction, over a basement, with R-13 batt insulation in the walls. The attic contains R-19 loose-fill cellulose insulation. A $189 \mathrm{ft}^{2}$ sun room was added to the original home, over a crawlspace with R-19 batt insulation in the floor joists. The windows are double-pane with vinyl frames. Heating is provided by electric strip heat and cooling is provided by a 3 ton seasonal energy efficiency ratio (SEER) 7.8 air-conditioning $(\mathrm{AC})$ unit. The forced-air ducts are located mostly in conditioned space, with the exception of the sun room ducts.

\begin{tabular}{lc}
\hline Energy Costs Information & Electricity, $\$$ \\
\hline Average Utility Bill & $\$ 136.72$ \\
\hline Maximum Utility Bill & $\$ 258.42$ \\
Minimum Utility Bill & $\$ 75.34$ \\
\hline
\end{tabular}

\section{Recommended Energy Efficiency Retrofit Measures}

The home was audited to quantify its energy performance. The home energy audit consists of several elements: a blower door test to characterize building envelope leakage, a duct test to characterize duct leakage, thermal imaging to identify key leaks, evaluation of insulation levels, and examination of all energy-consuming appliances.

Following the audit we created a calibrated model of your house using the Energy Gauge (EG) software, developed by the Florida Solar Energy Center This software is a general analysis tool that is valid for all climates and has met software validation tests (http://www.energygauge.com/usares/default.htm ). The model was calibrated, on a monthly basis, using your utility bills. The monthly comparison of your utility bills from 2007 through 2011 is shown in Figure 1, where the annual consumption varies around 15 percent. Figure 2 shows the comparison of the calibrated model to your average utility bills. The modeled annual consumption of electricity is within 1 percent of your utility bills.
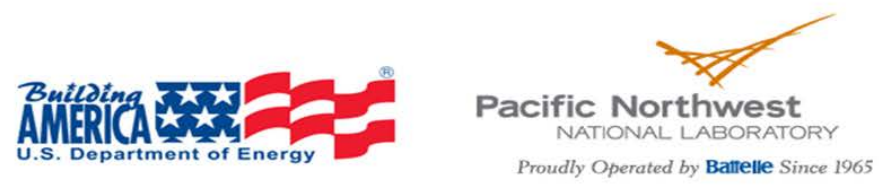

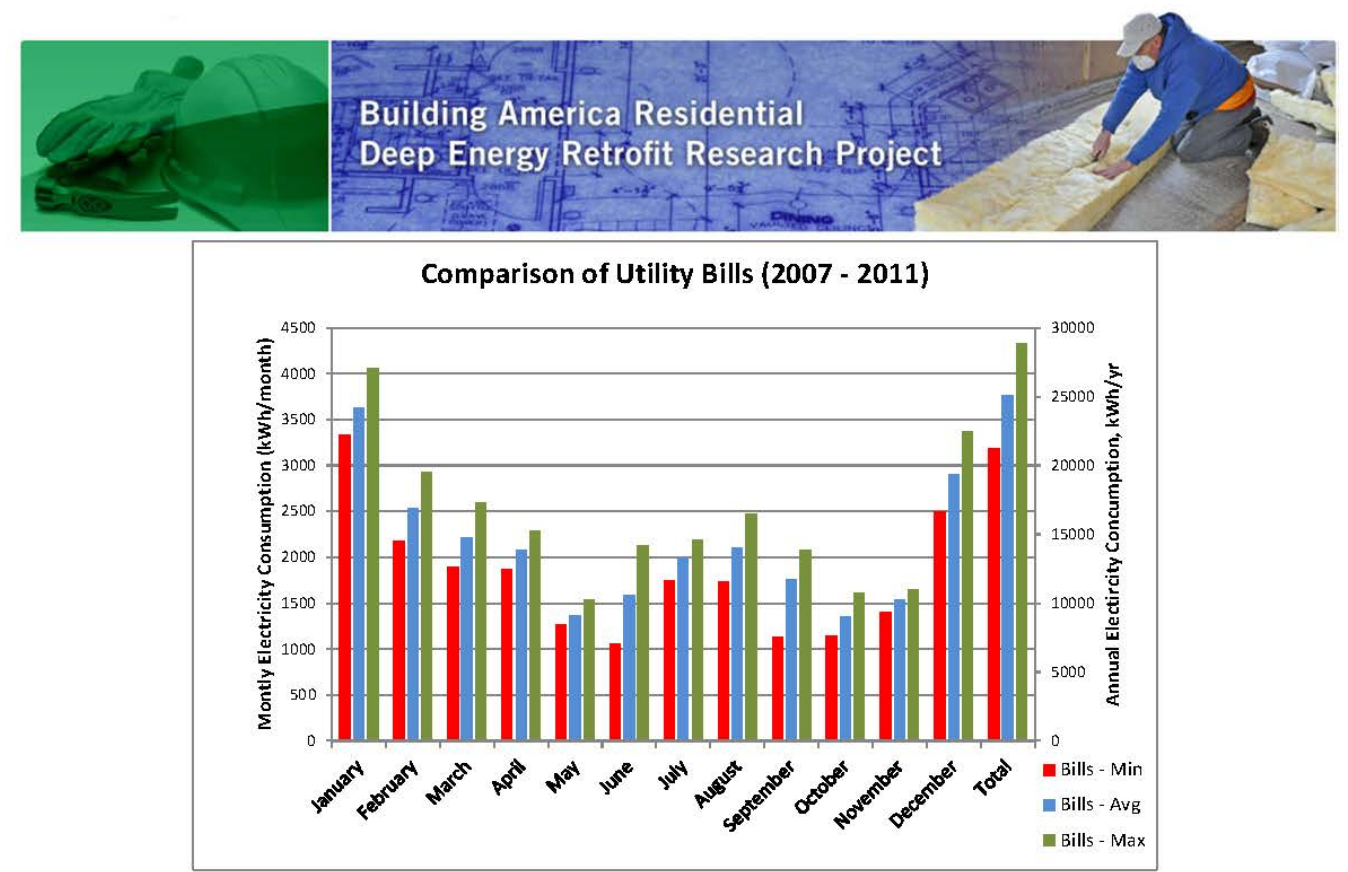

Figure 1. Comparison of monthly electricity consumption from 2007 through 2011, where 2007 and 2011 only had 5 and 2 months of data, respectively.

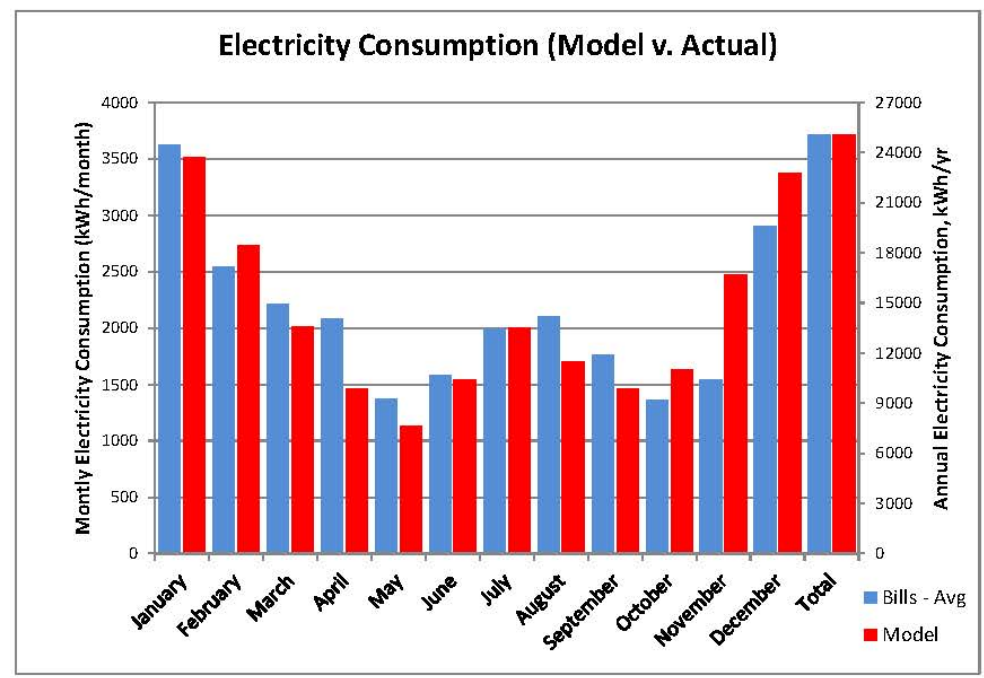

Figure 2. Comparison of monthly electricity consumption for utility bills and EG model. The annual comparison is also included on the secondary (right) vertical axis.
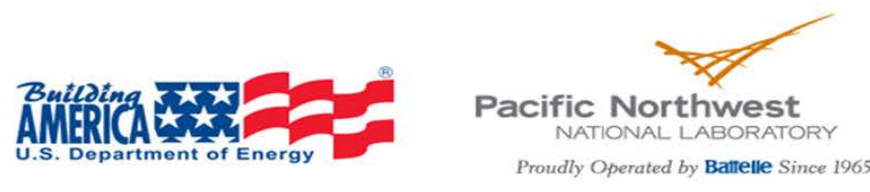

(10) ENEREY 


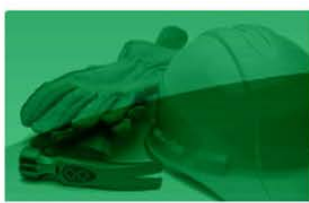

Building America Residential

Deep Energy Retrofit Research Project

Figure 3 shows the EG model breakdown of your present energy consumption. Notice that more than $62 \%$ of your energy consumption is associated with heating and cooling.

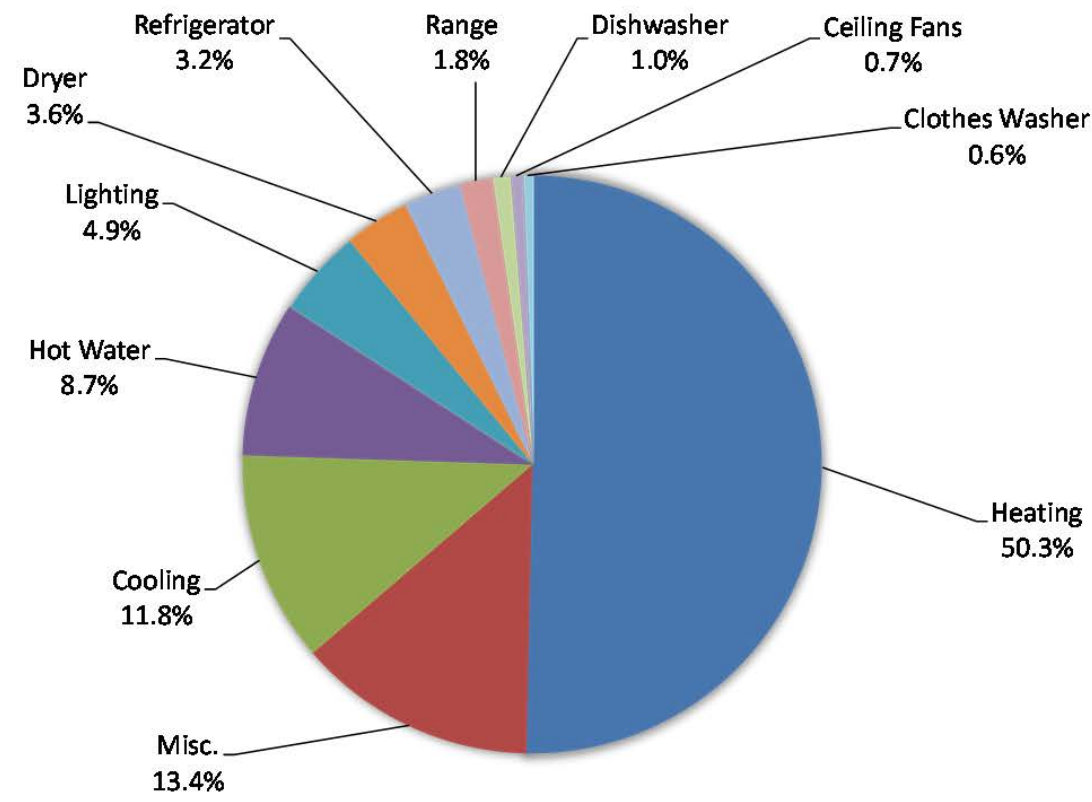

Figure 3. Percentage of energy consumption for heating, ventilation, air conditioning equipment, lighting, appliances and miscellaneous base loads as determined by EG using standard occupancy schedules.

During the audit of your home, we noticed several opportunities to save energy. The ensuing sections of this report summarize each energy-saving measure and related energy-audit findings and provide the estimated energy savings, cost of each recommended measure, and associated payback period. The simple payback period is the number of years that it will take to pay off the upfront investment with energy cost savings (the shorter, the better). The payback period provides a quick economic metric that can be used to prioritize the measures. The ensuing sections also briefly summarize locally available incentives that may be available to help pay for energy-saving measures. Most of the savings estimates included here are based on computer simulations of your home. The costs provided are rough estimates based on our
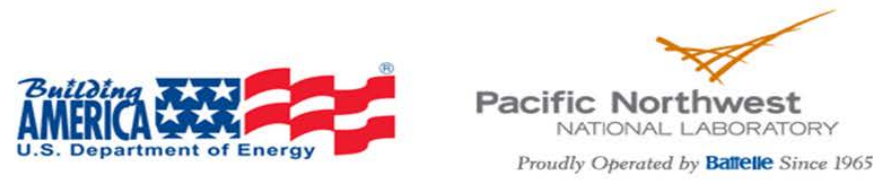

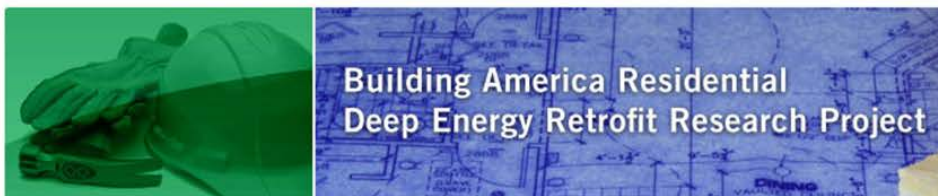

experiences with the energy-saving measures, quotes from local contractors, and publically available information, like the National Renewable Energy Lab's National Measures Database ${ }^{1}$. Your actual costs will depend on the contractor you choose, the final scope of work, and the current material prices. Finally, we have provided payback periods for each measure.

We think that you can reduce your energy use by around $43 \%$. Your actual savings will depend on which measures are implemented (as well as any changes in usage patterns, occupancy, etc.). The savings associated with each measure also will be affected by other measures that you implement, so, as we develop the final package of measures, savings estimates will vary. Should you decide to participate in this retrofit study and implement enough retrofit measures to qualify for an expected savings of $30 \%$ or more, we would look more carefully at the energy savings associated with each measure; both with modeling and metering.

Please read through the measures described below and let us know if you have any questions. Once we have discussed the cost-saving measures available to you and agreed on a package that fits your needs, the next step will be to start asking contractors for bids on the energysaving projects (recognizing that you can complete some projects yourself).

\section{Air Sealing}

Cracks, gaps, and holes located throughout your home waste energy by letting in hot air in the summer and cold air in the winter, or conversely, letting conditioned air out! During our audit, we performed a blower door test, which uses a calibrated fan and pressure gauges to measure the overall leakiness of your home. We found that if you added up all of the leaks in your home, the cumulative effect would be equivalent to having a hole 13 inches wide by 10 inches tall in the building envelope. This is like leaving a window half-open all year! These results are given in more detail below.

\footnotetext{
${ }^{1}$ National Renewable Energy Laboratory. "National Measures Database." Available at: http://www.nrel.gov/ap/retrofits/.
}
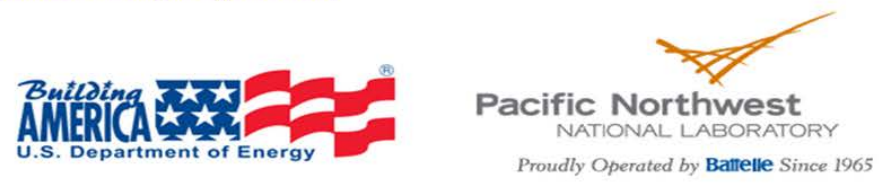

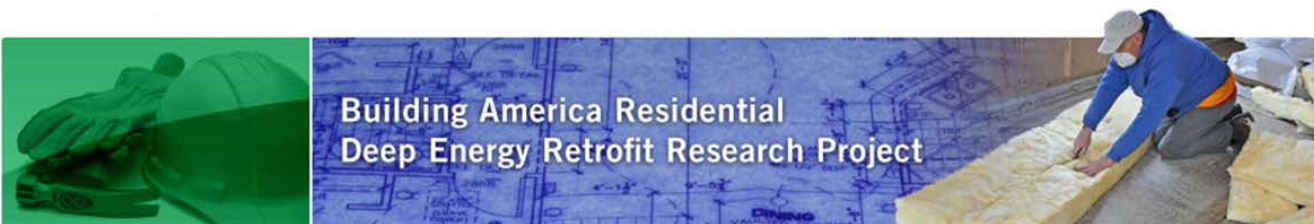

Table 1. Blower door air leakage test results

\begin{tabular}{lrl}
\hline Conditioned Floor Area & $2,763 \mathrm{ft}^{2}$ \\
\hline Conditioned Volume & $11,567 \mathrm{ft}^{3}$ \\
\hline Airflow in cubic feet per minute at -50 Pascals & $2,354 \mathrm{cfm50}$ \\
\hline Air Changes per Hour at -50 Pascals & $6.70 \mathrm{ACH} 50$ \\
\hline Effective Leakage Area & $129 \mathrm{in}^{2}$ \\
\hline Relative airflow at -50 Pascals & $0.85 \mathrm{cfm}^{2} / \mathrm{ft}^{2}$ \\
\hline Range of relative airflow for other homes tested in the Tri-cities & $0.4-1.2 \mathrm{cfm} 50 / \mathrm{ft}^{2}$ \\
\hline
\end{tabular}

Though your house is not tight, it is not that leaky either. In general, 5 air changes per hour $(\mathrm{ACH} 5 \mathrm{O})$ is considered average infiltration, which you are slightly above. By sealing up cracks and holes with caulk, expanding spray foam, and a variety of other materials, we estimate that you could reduce the amount of air leakage by $1-5 \%$. However, given you have a finished basement; air sealing becomes a bit more difficult. Your attic is the only reasonable place to achieve significant air sealing. Air sealing is generally performed at the same time as other measures. For example, you may hire a contractor to seal leaks in your attic then add insulation.

\section{Add Attic Insulation and Air Sealing}

Attic insulation reduces the amount of heat transferred through the ceiling. In the winter, heat is lost into the attic. In the summer the attic space, which gets very hot, transfers unwanted heat through the ceiling into the home. Cellulose and fiberglass insulation are typically used when adding insulation into existing homes. Cellulose and fiberglass are blown into the attic through a hose. This application is known as loose-fill (as opposed to batts of insulation). Before adding insulation, it is important to seal any leaks in the attic floor (it is much more difficult to seal leaks afterwards). Spray foam and caulk can be used to seal most leaks, though other materials may be used if leaks are very large (fire rated materials must be used where appropriate). Contractors will temporarily move the insulation aside while they air seal. Leaks are often found around holes drilled for wiring or plumbing, the top plates of interior walls, and attic hatches. (For more information, see the Building America Air Sealing Guide ${ }^{2}$ ).

\footnotetext{
${ }^{2}$ Building America's Air Sealing Guide can be found here; http://wwwl.eere.energy.gov/library/asset handler.aspx?src=http://apps1.eere.energy.gov/buildings/publications/pdf s/building_america/ba_airsealing_report.pdf\&id $=4663$
}
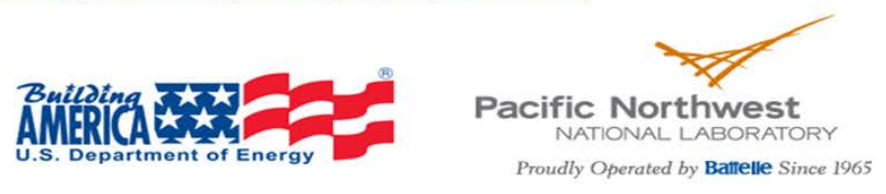

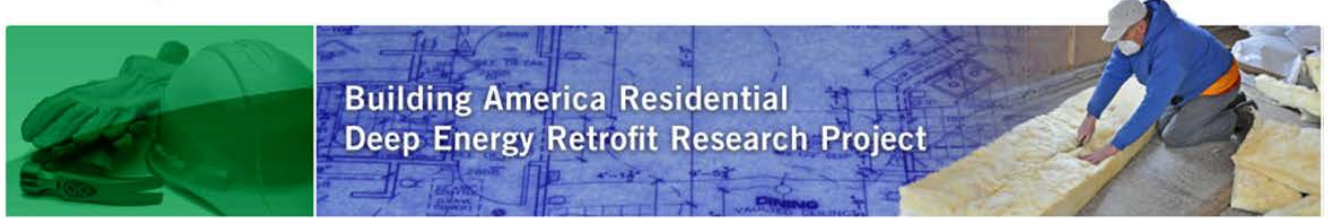

A few areas of leakage or places needing additional insulation are identified in Figure 4, through the use of an infrared camera. Your attic could also benefit from additional insulation. We recommend increasing your attic insulation to $\mathrm{R}-60$ and air sealing at the same time.

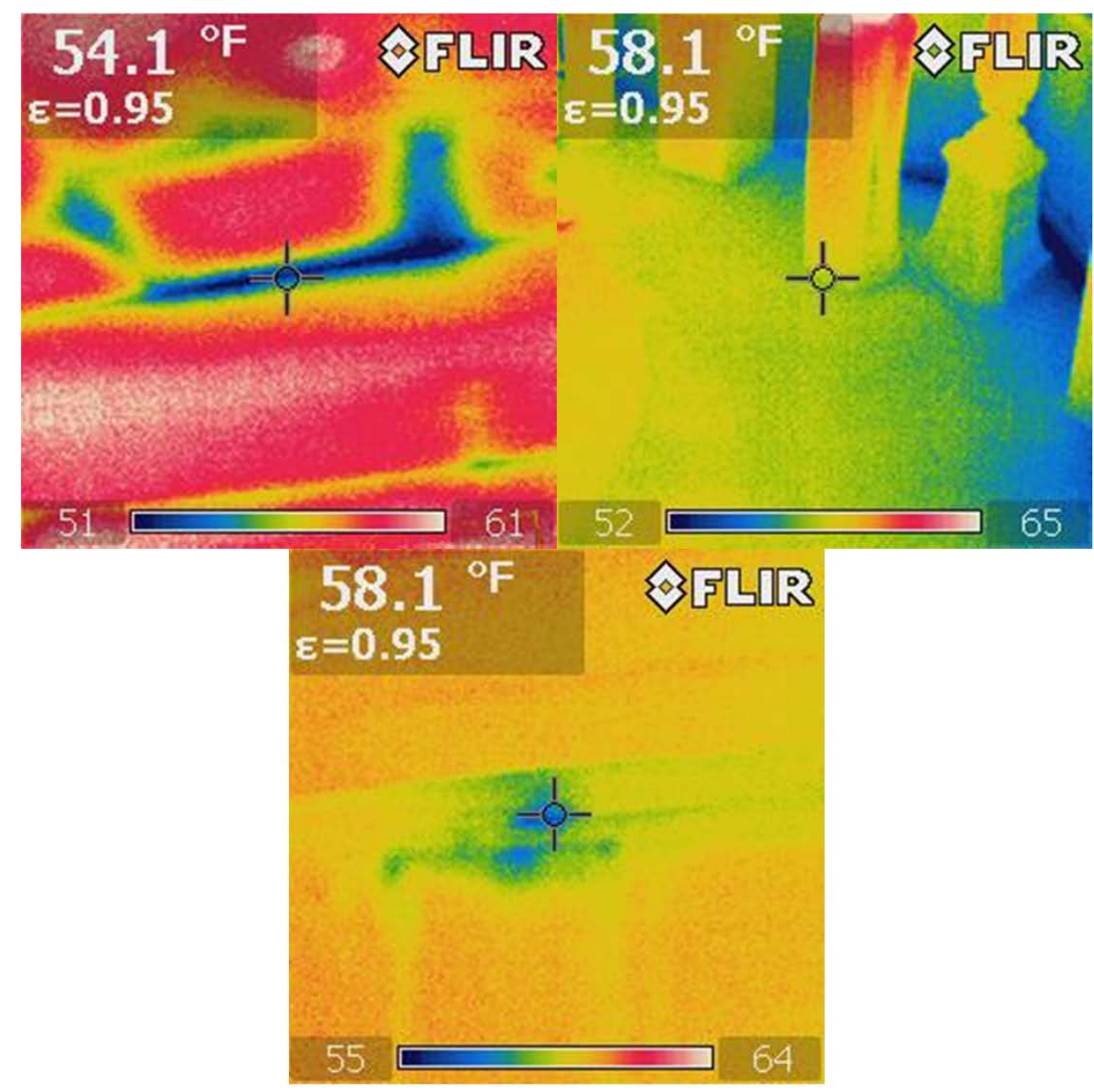

Figure 4. Upper Left: Air leakage around the attic hatch. Upper Right: Air leakage around baseboard in the sun room. Lower Center: Settled insulation in your living room wall.
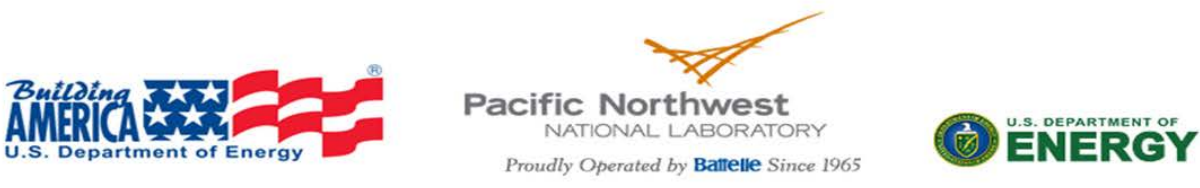


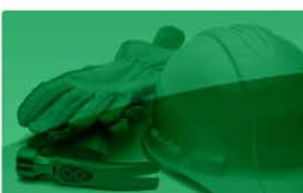

Building America Residential

Deep Energy Retrofit Research Project

Locally Available Incentives

- A federal tax credit is available for $10 \%$ of material costs (does not include labor).

Table 2. Estimated cost and savings for additional attic insulation and air sealing.

\begin{tabular}{cccc} 
Estimated Cost & $\begin{array}{c}\text { Estimated Annual } \\
\text { Savings }\end{array}$ & Payback Period & $\begin{array}{c}\text { Payback Period } \\
\text { (after incentives) }\end{array}$ \\
$\$ 1,300$ & $\$ 125 / \mathrm{yr}$ & $10 \mathrm{yr}$ & $9 \mathrm{yr}$ \\
\hline
\end{tabular}

\section{Duct Performance Testing}

Ducts located in unconditioned attics and crawlspaces can be a huge source of energy waste. In the summer, for example, the cold air from the air conditioner is subjected to extremely high temperatures. The opposite is true during winter. Ducts should be airtight and well insulated. Ideally, ducts should all be located within conditioned space (although this is not always possible). Duct joints are generally sealed with either duct mastic or tape made specifically for duct systems (standard duct tape will not work!!).

Your ducts are located in conditioned space, which is ideal. Additionally, your ducts are very tight which indicates, assuming the ducts are sized and located correctly, the supply air should be distributed evenly.

Table 3. Duct performance testing results.

\begin{tabular}{lrl}
\hline Duct leakage to outside (or attic) at -25 Pascals & 40.5 cfm25 \\
\hline Duct air loss to outside (or attic) as a percent of total air flow & $1.99 \%$ \\
\hline Duct leakage to outside per $\mathrm{ft}^{2}$ of floor area & $0.02 \quad \mathrm{cfm}^{25} / \mathrm{ft}^{2}$ \\
\hline Typical leakage to outside (or attic), Tri-cities & $40-513 \mathrm{cfm} 25$ \\
\hline
\end{tabular}

\section{Replace Your Air Conditioner}

Your air conditioner appears to be about 33 years old. New air conditioners are significantly more efficient. Air-conditioner efficiency is rated using the seasonal energy efficiency ratio (SEER). Your unit is likely operating with a SEER of approximately 7.8. Currently, the minimum allowable SEER for new AC units is 13 . Many models have SEERs of over 20 ! We recommend upgrading to a new unit that will supply the same cooling effect with much less energy use.

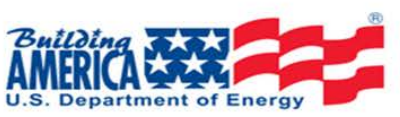




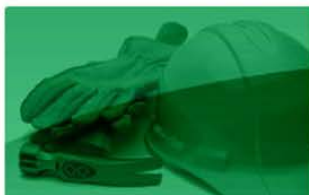

Building America Residential

Deep Energy Retrofit Research Project

The economics associated with replacing your AC unit are summarized in Table 4 . The first line indicates the cost and savings associated purchasing a new SEER 16 AC unit. The second line presents the incremental costs if you were to wait and buy a more efficient $A C$ when your current $A C$ is at the end of its life. Since, in this scenario, you would be buying a new $A C$ anyway, we only account for the incremental cost between a baseline efficiency SEER 13 unit and the additional cost of a SEER 16 system. You can see that buying a more efficient AC when your current unit wears out can really improve the payback period for increased efficiency. This is true for other equipment as well.

\section{Locally Available Incentives}

- A federal tax credit of $\$ 300$ is available for new SEER 16 or greater AC systems

Table 4. Estimated cost and savings for SEER 16 air conditioning system. The incremental costs and savings, assuming you were replacing your old AC unit, is also provided.

\begin{tabular}{|cccc|}
$\begin{array}{c}\text { Estimated } \\
\text { Cost }\end{array}$ & $\begin{array}{c}\text { Estimated Annual } \\
\text { Savings }\end{array}$ & $\begin{array}{c}\text { Payback } \\
\text { Period }\end{array}$ & $\begin{array}{c}\text { Payback Period } \\
\text { (after incentives) }\end{array}$ \\
$\$ 5,400$ & $\$ 121 / \mathrm{yr}$ & $45 \mathrm{yr}$ & $42 \mathrm{yr}$ \\
$\$ 1,440$ & $\$ 35 / \mathrm{yr}$ & $42 \mathrm{yr}$ & $33 \mathrm{yr}$ \\
\hline
\end{tabular}

\section{Replace Your Strip Heat/AC with a Heat Pump}

Your furnace and AC units are both very old. Another option for replacing your $A C$ and your furnace at the same time is to replace both units with a heat pump. We believe that heat pumps offer the highest energy savings. In the heat mode, heat pumps are rated by their heating season performance factor (HSPF). For new units, the current minimum allowable efficiencies for heat pumps are a SEER of 13 and an HSPF of 7.7. High efficiency models are available, which would result in greater savings. Some models have SEERs of over 20 and HSPFs of over 10 !

In our analysis, we used a SEER 16, HSPF 8.6 heat pump. This model would currently qualify for energy star tax credits. The economics of replacing your strip heat and AC with a heat pump are shown in Table 5. The second line, again, presents the incremental costs if you were to wait and buy a heat pump when your current $A C$ is at the end of its life.

\section{Locally Available Incentives}

- A Federal tax credit of $\$ 300$ is available for qualifying models.
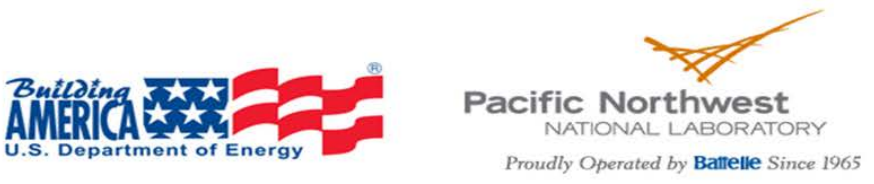


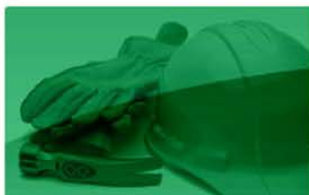

Building America Residential

Deep Energy Retrofit Research Project

Hor

Table 5. Estimated Cost and Savings for New Heat Pump

\begin{tabular}{|c|c|c|c|}
\hline $\begin{array}{c}\text { Estimated } \\
\text { Cost }\end{array}$ & \multicolumn{1}{c}{$\begin{array}{c}\text { Estimated } \\
\text { Annual Savings }\end{array}$} & \multicolumn{1}{c|}{$\begin{array}{c}\text { Payback } \\
\text { Period }\end{array}$} & \multicolumn{1}{c|}{$\begin{array}{c}\text { Payback Period } \\
\text { (after incentives) }\end{array}$} \\
\hline$\$ 8,000$ & $\$ 569 / \mathrm{yr}$ & $14 \mathrm{yrs}$ & $13.5 \mathrm{yrs}$ \\
\hline$\$ 4,040$ & $\$ 483 / \mathrm{yr}$ & $8.5 \mathrm{yrs}$ & $8 \mathrm{yrs}$ \\
\hline
\end{tabular}

\section{Replace Your Hot Water Heater}

Your current hot water heater is about 10 years old and has an Energy Factor (EF) of about 0.87 . Heat pump water heaters can have energy factors of about 2.35. There are now several manufacturers that offer energy star qualified (EF of 2 or above) heat pump water heaters. A heat pump water heater is the most energy-saving option for replacing your hot water heater.

One possible concern with a heat pump water heater is that it will cool the air in the basement. This could be a benefit in the summer, but may be unwanted in the winter. Heat pump water heaters are produced by many of the major manufacturers and they are installed in cold climates (though they perform better in warm climates). However, they are still a relatively new technology. Because of this, local installers may not be familiar with heat pump water heaters and it may be difficult or more expensive to have them installed and/or serviced. We recommend speaking with local plumbers about this measure to see if there is any local experience with the technology.

The economics of each water heater replacement option are presented in Table 11, below. A new electric tank water heater is also shown for reference, though the savings are not substantial. The incremental cost of replacing your existing hot water heater, at the end of its life, is also shown.

\section{Locally Available Incentives}

- A federal tax credit of $\$ 300$ is currently available for heat pumps with an EF of above 2 .
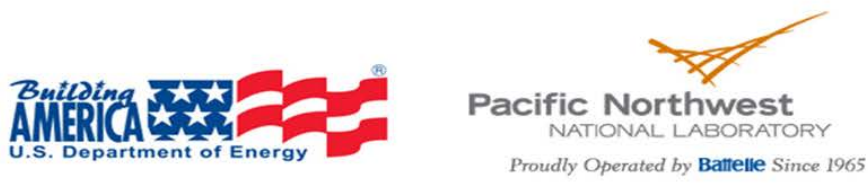


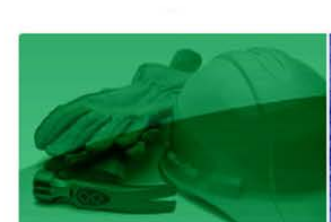

Building America Residential

Deep Energy Retrofit Research Project

Table 6. Estimated Cost and Savings for New Hot Water Heaters

\begin{tabular}{|c|c|c|c|c|}
\hline \multicolumn{1}{|c}{ Measure } & \multicolumn{1}{c}{$\begin{array}{c}\text { Estimated } \\
\text { Cost }\end{array}$} & \multicolumn{1}{c}{$\begin{array}{c}\text { Estimated } \\
\text { Annual Savings }\end{array}$} & $\begin{array}{c}\text { Payback } \\
\text { Period }\end{array}$ & $\begin{array}{c}\text { Payback Period } \\
\text { (after incentives) }\end{array}$ \\
\hline Heat Pump WH & $\$ 1,700$ & $\$ 76 / \mathrm{yr}$ & $22 \mathrm{yr}$ & $18 \mathrm{yr}$ \\
\hline $\begin{array}{c}\text { Heat Pump WH } \\
\text { Incremental }\end{array}$ & $\$ 1,050$ & $\$ 65 / \mathrm{yr}$ & $16 \mathrm{yr}$ & $12 \mathrm{yr}$ \\
\hline Tank Electric WH & $\$ 650$ & $\$ 11 / \mathrm{yr}$ & $57 \mathrm{yr}$ & $57 \mathrm{yr}$ \\
\hline
\end{tabular}

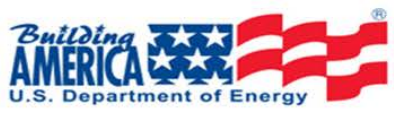



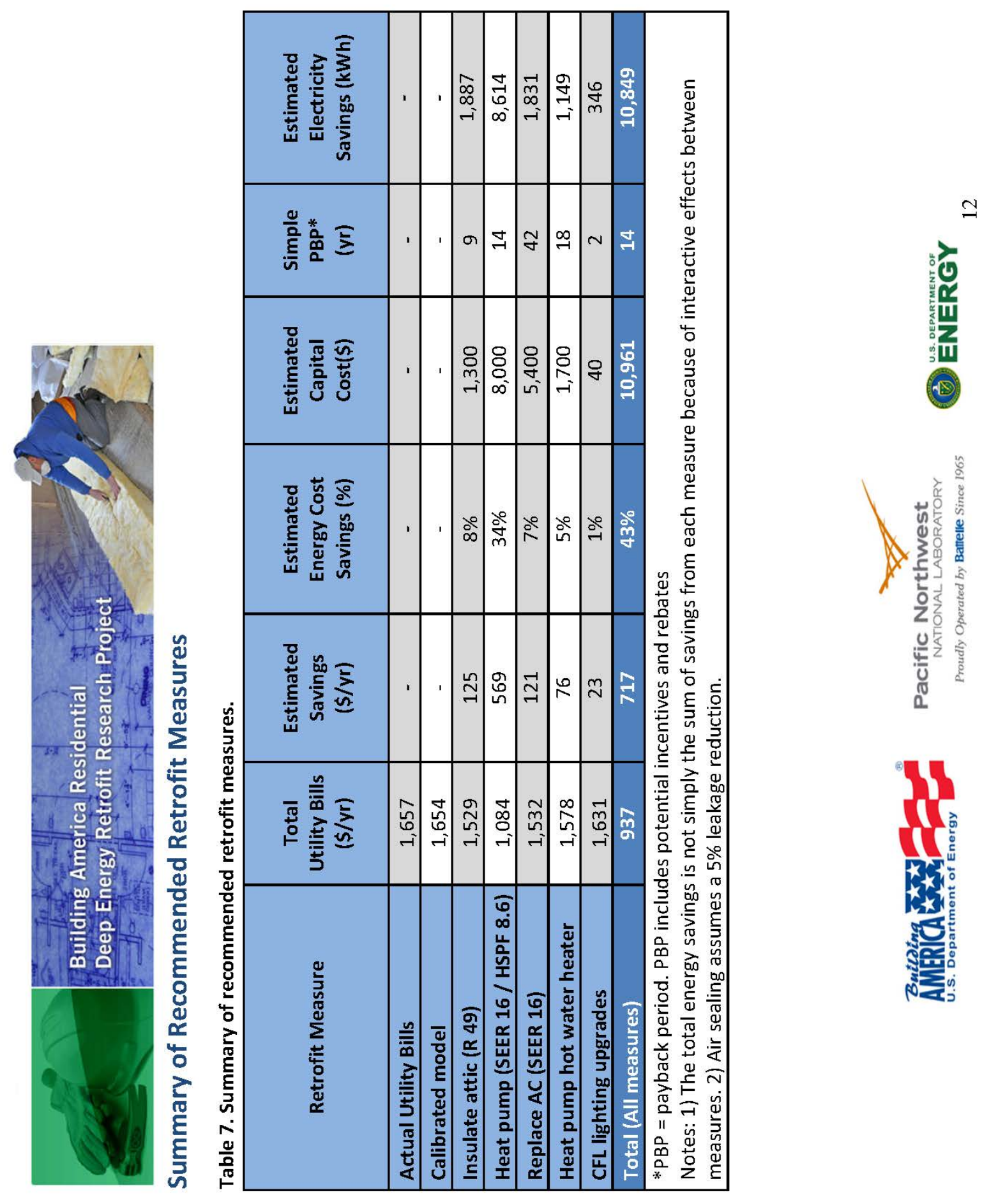


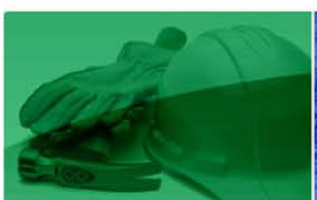

Building America Residential

Deep Energy Retrofit Research Project

Figure 5 provides a comparison of the pre-retrofit and post-retrofit energy consumption of your home, assuming you implemented all recommended retrofit measures. The easy do-it-yourself improvements are not included in the predicted savings, with the exception of replacing incandesent lights.

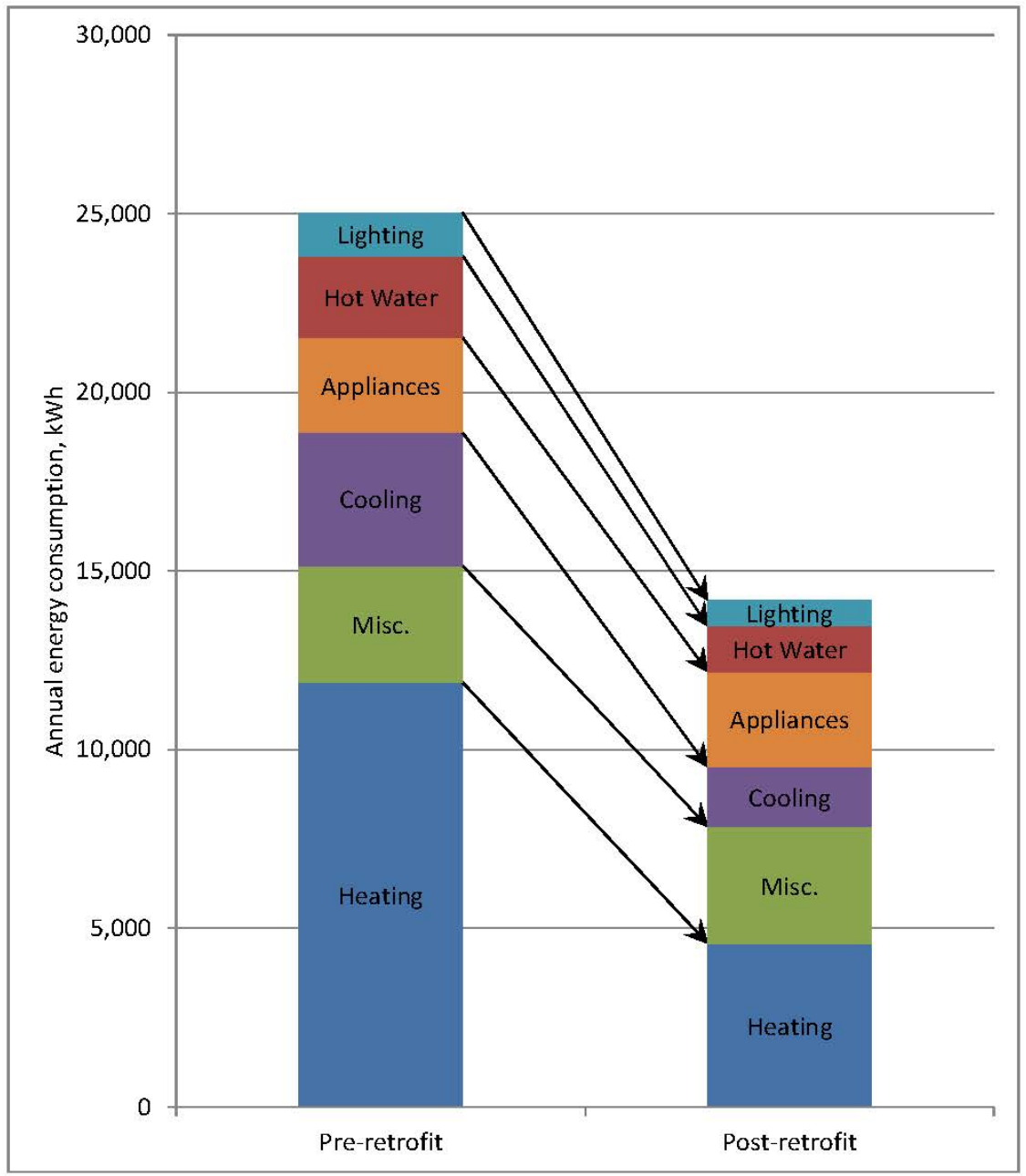

Figure 5. Comparison of pre-retrofit and post-retrofit energy consumption as modeled using EG.

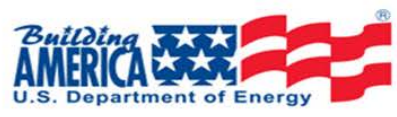

Pacific Northwest 


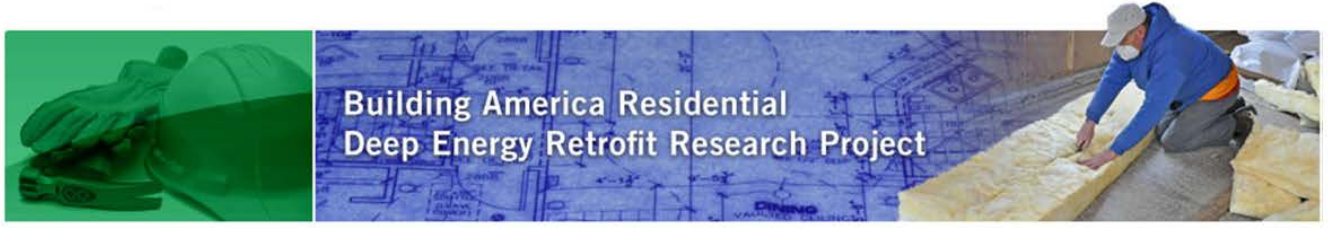

\section{Easy Do-It-Yourself Improvements}

\section{Lower the Hot Water Tank Set Point}

Most households only require hot water at $120^{\circ} \mathrm{F}$. (Your tank is set at around $135^{\circ} \mathrm{F}$ ) If your hot water tank set point is higher than $120^{\circ} \mathrm{F}$, you can save energy by lowering the set point. Also, since you have a hot water re-circulation system, you should not require as high of a set point. A lower set point reduces the amount of heat lost through the tank. Note, however, that it is generally not recommended to reduce the temperature below $120^{\circ} \mathrm{F}$.

\section{Use Power Strips to Turn Off Appliances That are Not Being Used}

Some home appliances draw power even when they are not being used. These draws on power are often called "phantom loads." One way to avoid phantom loads is to plug non-essential appliances into a power strip. When the appliances are not in use, simply turn off the power strip. Be sure to use a separate power strip or outlet for any essential appliances.

\section{Replace Your Incandescent Lights with Compact Fluorescents}

ENERGY STAR-qualified compact fluorescent lamp (CFL) bulbs use about 75\% less energy than standard incandescent light bulbs. They also last about 10 times longer than comparable incandescent bulbs. Annual savings depend on how many hours you use each bulb, but CFLs typically pay for themselves with energy savings within 1-2 years.

We estimate that 35 bulbs could be replaced throughout your home, yielding a total annual savings of $1607 \mathrm{kWh}$ and $\$ 80$. A note about CFLs: CFLs contain a small amount of mercury. At the end of their life, be sure to recycle the bulbs properly. Some stores, such as Home Depot, will accept bulbs that no longer work. For more guidance on recycling bulbs and what to do if a bulb breaks, see this document from the City of Richland (available at:

http://www.ci.richland.wa.us/DocumentView.aspx?DID=1051).
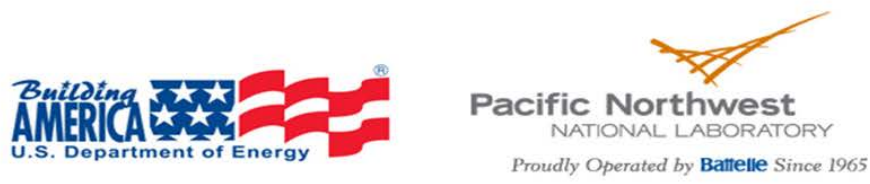


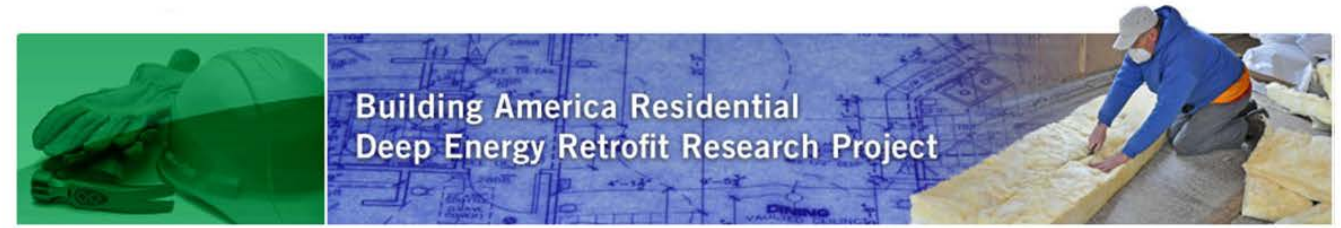

Table 8. Estimated cost and savings for replacing incandescent lights with CFLs.

\begin{tabular}{cccc|} 
Estimated Cost & $\begin{array}{c}\text { Estimated Annual } \\
\text { Savings }\end{array}$ & Payback Period & $\begin{array}{c}\text { Payback Period } \\
\text { (after incentives) }\end{array}$ \\
$\$ 40$ & $\$ 23 / \mathrm{yr}$ & $2 \mathrm{yr}$ & $2 \mathrm{yr}$ \\
\hline
\end{tabular}

\section{Replace Washing Machine}

Your present washing machine is fairly old and may be in need of replacement soon. New washing machines, especially front-loading or ENERGY STAR qualified clothes washers use about $37 \%$ less energy and use over $50 \%$ less water than regular washers. Many qualified clothes washers also have a greater capacity than conventional models, meaning fewer loads of laundry.

The city of Richland also offers a \$25 incentive for purchasing ENERGY STAR qualified clothes washers, assuming they are serviced by an electric hot water heater.

\section{Install Low-flow Showerheads and Faucet Aerators}

A simple way to save on your water heater costs is to use low-flow plumbing fixtures. New showerheads offer suitable spray while using less hot water. There are many available models that use around 2 gallons per minute (gpm). Older showerheads can use more than $5 \mathrm{gpm}$.

Similarly, hot water use in faucets can be reduced by using installing faucet aerators. Look for aerators that limit the faucet flow to about $1 \mathrm{gpm}$. Also, when shopping for aerators or lowflow showerheads, look for the WaterSense label. WaterSense is a U.S. Envivronmental Protection Agency program that certifies water-saving fixtures.

\section{Additional Resources}

For more information, the following websites provide additional energy-saving tips for home owners looking to make energy efficiency improvements to their homes:

- http://www.energysavers.gov/

- http://www.aceee.org/consumer

- http://www.energystar.gov/

- http://www.nahb.com/
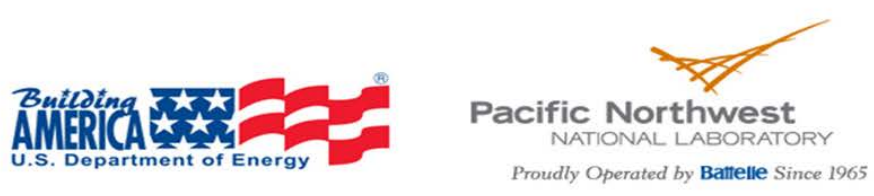

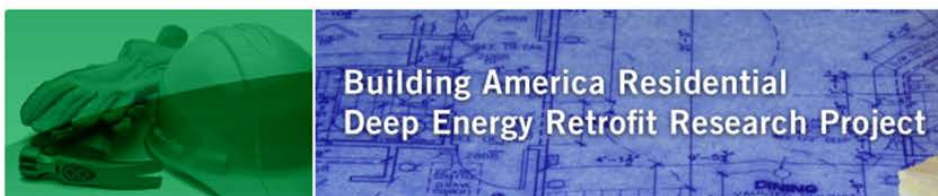

- http://www1.eere.energy.gov/buildings/

In addition, the Building America website

(http://www1.eere.energy.gov/buildings/building america/) and the Building Science Corporation website (http://www.buildingscience.com/index html) provide a number of good resources related building designs and construction of energy efficient homes.

\section{Incentives and Rebates}

Various incentives are available to help pay for energy efficiency measures. For example, many of local utilities offer incentives. Several of these incentive or rebate options are identified in the audit information provided above. In addition to the incentives and direct rebates identified for your specific recommendations above, the City of Richland offers low-interest loans to help finance energy efficiency projects. These loans can be used instead of (but not in addition to) the project-specific rebates. More information can be found on the City of Richland's website. Another good resource for finding energy efficiency rebates anywhere throughout the country is www.dsireusa.org/.

Federal tax incentives are also available for ENERGY STAR products. Many of the recommended measures may be eligible for a tax credit worth $10 \%$ of the materials cost, or a specified amount (for example, ENERGY STAR furnaces are eligible for a $\$ 150$ tax credit). These incentives have also been identified in the cost estimates provided above. More information about this program is available at the following website:

http://www.energystar.gov/index.cfm?c=tax credits.tx index.
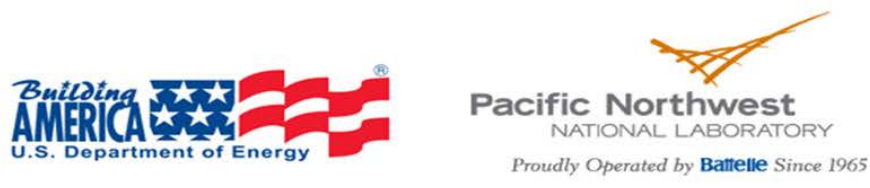

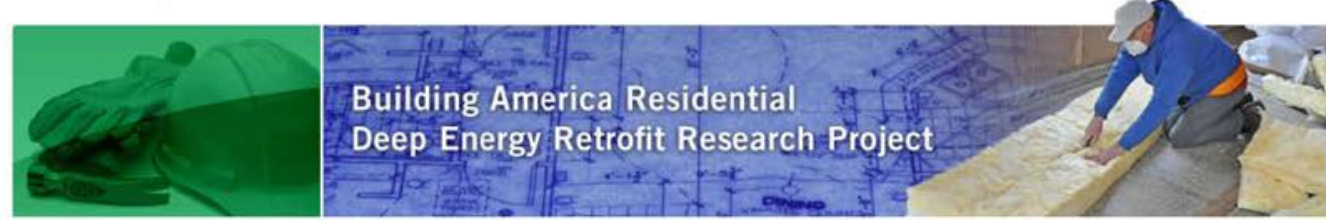

Residential Deep Energy Retrofit Research Project

\section{Audit Report for a Two-story Richland House}

Audit Date: $3 / 25 / 2011$

Pacific Northwest National Laboratory Research Team http://deepenergyretrofits.pnnl.gov/

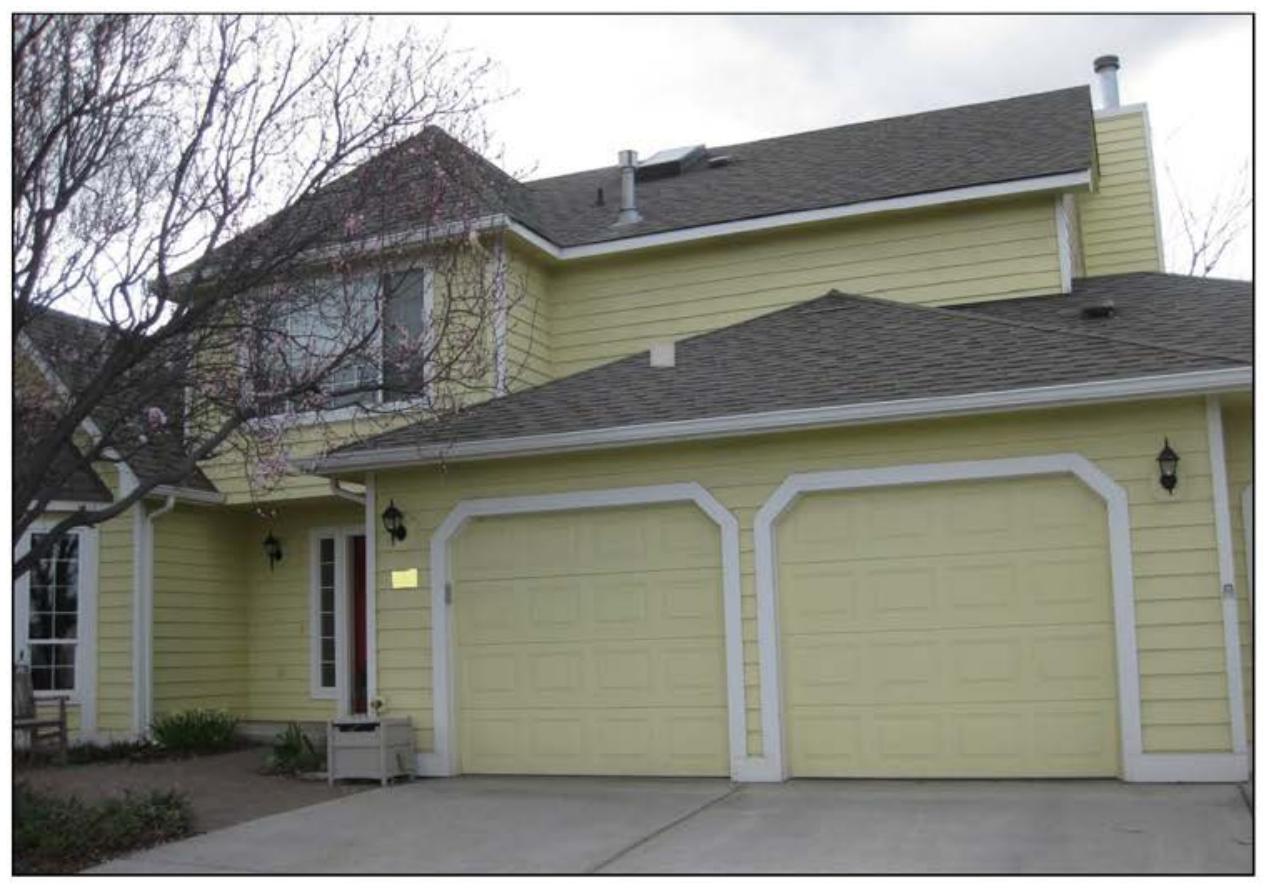

Notices:

1. This report is intended for the sole use of the homeowner(s) and the PNNL deep retrofits study team members (including subcontractors) that have completed training to protect the privacy and other rights of human subjects in research programs. PNNL will not share this report with anyone but may include data and information from this report, in an anonymous manner, in the final report that will be submitted to the U.S. Department of Energy.

2. The quantitative information in this report on energy savings, costs and economic benefits are based on computer models. Please note that actual savings and costs can be quite different (may be even a factor of 2 or more) depending on homeowner lifestyle, actual performance of energy saving equipment and strategies, variations in local weather, contractor business models and other unforeseen factors.

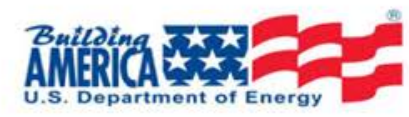

Pacific Northwest NATIONAL LABORATORY

Proudly Operated by Battelle Since 1965

\section{Oennergr}




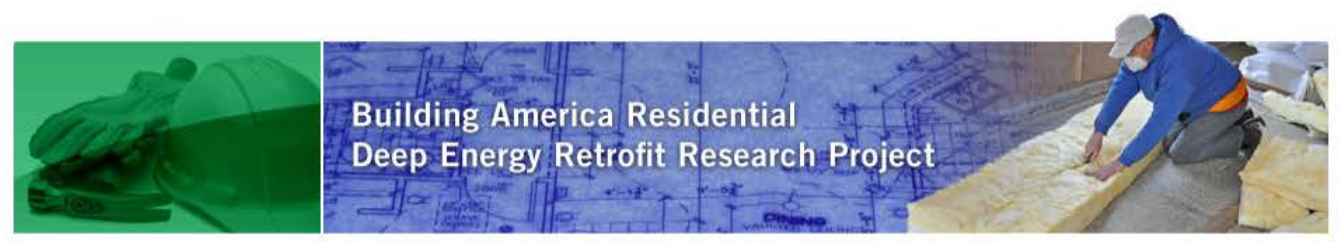

\section{Existing Home Characteristics and Performance}

Your home is a single-family, two-story home with an attached garage built in 1993. It has 3 bedrooms and 2 baths; a total conditioned space of about 2,375 square feet $\left(\mathrm{ft}^{2}\right)\left(3,000 \mathrm{ft}^{2}\right.$ including the garage). The building envelope is wood-frame construction over a crawlspace. It has about R-13 batt insulation in the walls and R-14 fiberglass batt insulation on the crawlspace ceiling. The attic is vented with R-24 blown-in fiberglass insulation. The windows are doublepane clear glass with vinyl frames. Heating is provided by a $81 \mathrm{kBtu} / \mathrm{hr}$ gas furnace with an annual fuel utilization efficiency (AFUE) of $80 \%$ and cooling is provided by a seasonal energy efficiency ratio (SEER) 10, 3.5 ton air-conditioning ( $A C$ ) unit. The metal ducts are primarily located in unconditioned space (crawlspace) and insulated to about R-5. Your average utility bill information is provided in Table 1, below.

Table 1. Average Utility Bill Information for July 2008 through January 2011.

\begin{tabular}{lcc}
\hline Energy Costs Information & Gas, \$ & Electricity, \$ \\
\hline Average Utility Bill & 76.39 & 50.41 \\
Maximum Utility Bill & 241.51 & 107.73 \\
\hline Minimum Utility Bill & 15.37 & 26.79 \\
\hline
\end{tabular}

\section{Recommended Energy Efficiency Retrofit Measures}

Your home was audited to quantify its energy performance. The home energy audit consists of several elements: a blower door test to characterize building envelope leakage, a duct test to characterize duct leakage, thermal imaging to identify key leaks, evaluation of insulation levels, and examination of all energy-consuming appliances.

Following the audit we created a model of your house using Energy Gauge software developed by the Florida Solar Energy Center and calibrated the model to your utility bills to match them on an annual basis. Figure 1 shows that more than half of your energy consumption is associated with your heating and cooling system.
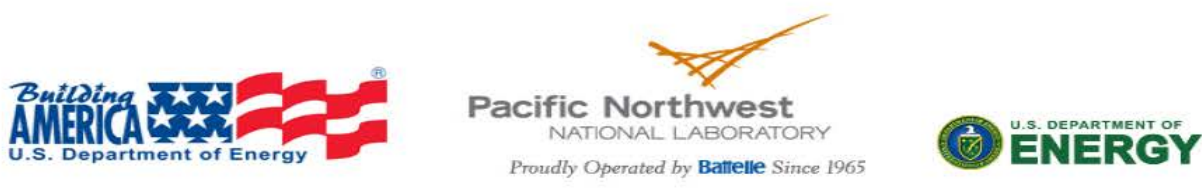


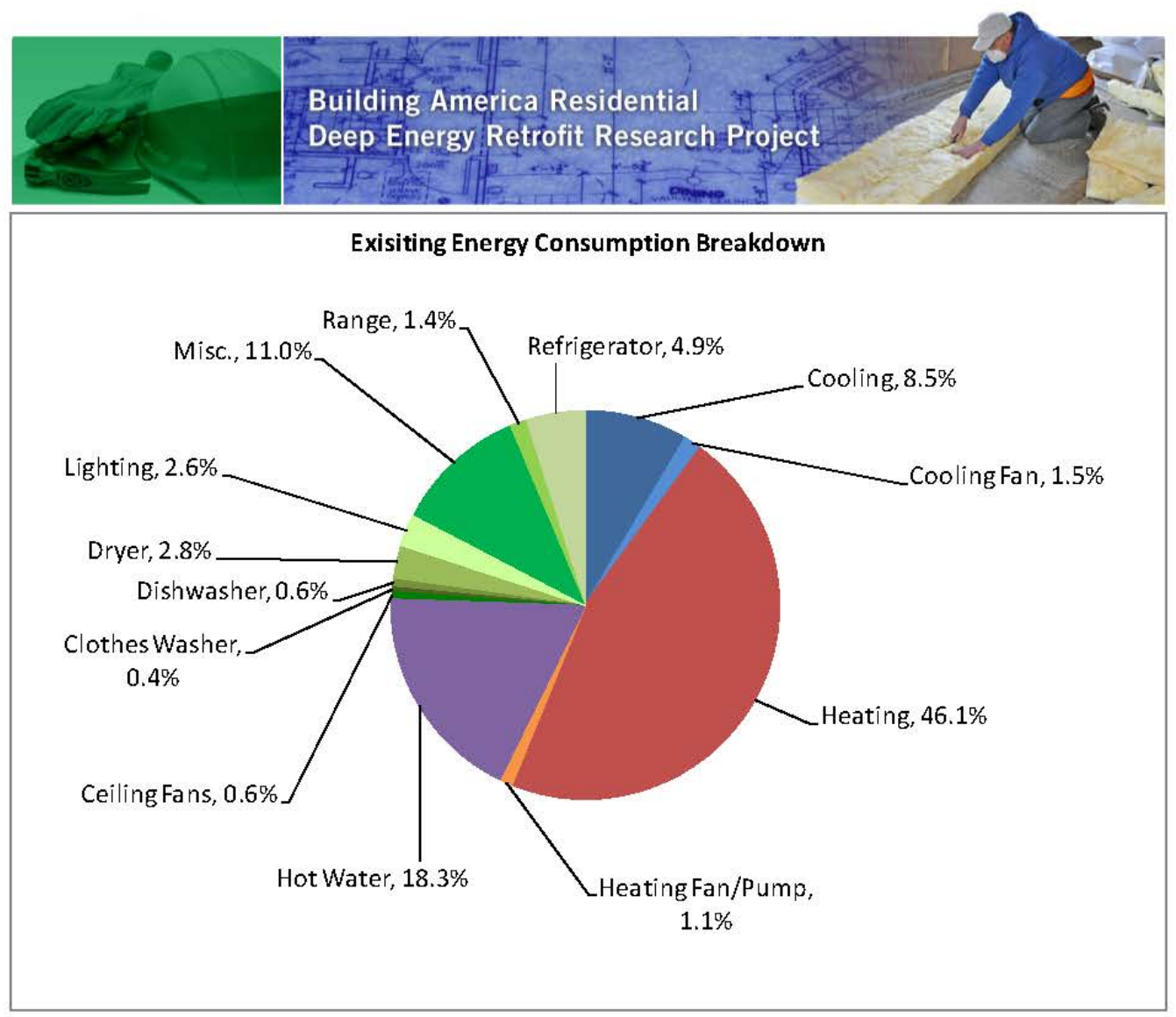

Figure 1. Percentage Energy Consumption of Major Appliances and Heating, Ventilation, and Air Conditioning Equipment in Your Home. This chart is calculated in terms of site energy consumption on a British Thermal Unit (Btu) basis. Kilowatt-hours of electricity and therms of natural gas are converted to Btus using the mean Btu conversion ( $1 \mathrm{kWh}=3412.14 \mathrm{Btu}$ (mean); 1 Therm $=100,000 \mathrm{Btu}$ )

Based on this and things we noticed during the audit, we then modeled a number of energy efficiency measures to assess which measures would save the most energy and be the most cost effective for your home. Because much of your energy consumption is due to heating and cooling, most of the measures address those areas. The ensuing sections of this report summarize each energy-saving measure and related energy-audit findings and provide the estimated energy savings, cost of each recommended measure, and associated payback period. The simple payback period is the number of years that it will take to pay off the upfront investment with energy cost savings (the shorter, the better). The payback period provides a
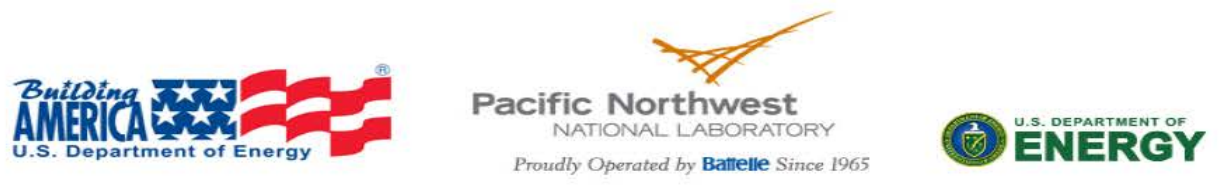


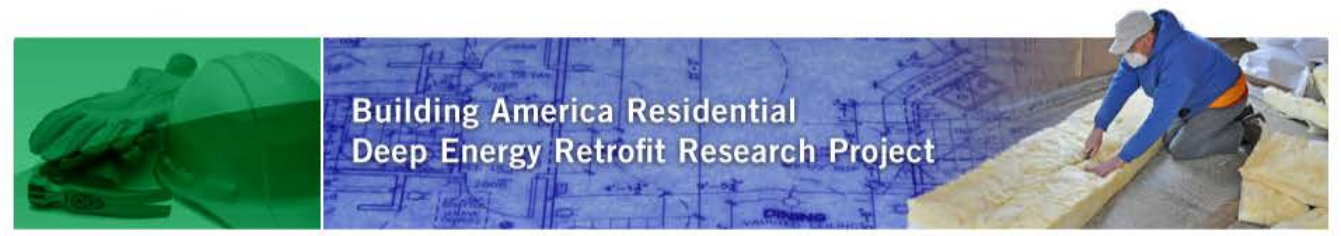

quick economic metric that can be used to prioritize the measures. The ensuing sections also briefly summarize locally available incentives that may be available to help pay for energysaving measures. Most of the savings estimates included here are based on computer simulations of your home. The costs provided are rough estimates based on our experiences with the energy-saving measures, quotes from local contractors, and publically available information, like the National Renewable Energy Lab's National Measures Database ${ }^{1}$. Your actual costs will depend on the contractor you choose, the final scope of work, and the current material prices.

We think that you can reduce your site energy consumption by around $54 \%$ and you energy bills by about $36 \%$. These numbers are different because of the different prices for electricity and natural gas. Our models show that, with the recommended package of measures (shown in Table 13), you can reduce your natural gas consumption by 690 therms, which equates to a savings of about $\$ 759$ annually. However, your electricity consumption will increase by about $3,216 \mathrm{kWh}$ for an additional annual electricity cost of $\$ 219$. Your electricity use will increase because we found it was most cost effective to install an electric heat pump when you replace your furnace and a heat pump hot water heater when you replace your hot water heater. Other options that still use gas, like a high efficiency furnace or a tankless hot water heater, are also explored in the recommendations presented below, and can achieve a similar level of savings.

While these are significant energy and cost savings, the estimated overall payback period is still fairly high (about 24 years, counting incentives). However, the economics improve significantly if systems need to be replaced anyway, which may soon be the case for your hot water and HVAC systems. Your actual savings will depend on which measures are implemented (as well as any changes in usage patterns, occupancy, etc.). The savings associated with each measure also will be affected by other measures that you implement, so, as we develop the final package of measures, savings estimates will vary.

Please read through the measures described below and let us know if you have any questions. Once we have discussed the cost-saving measures available to you and agreed on a package that fits your needs, the next step will be to start asking contractors for bids on the energysaving projects (recognizing that you can complete some projects yourself).

\footnotetext{
${ }^{1}$ National Renewable Energy Laboratory. "National Measures Database." Available at: http://www.nrel.gov/ap/retrofits/.
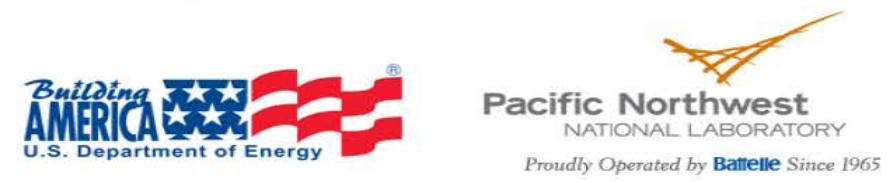


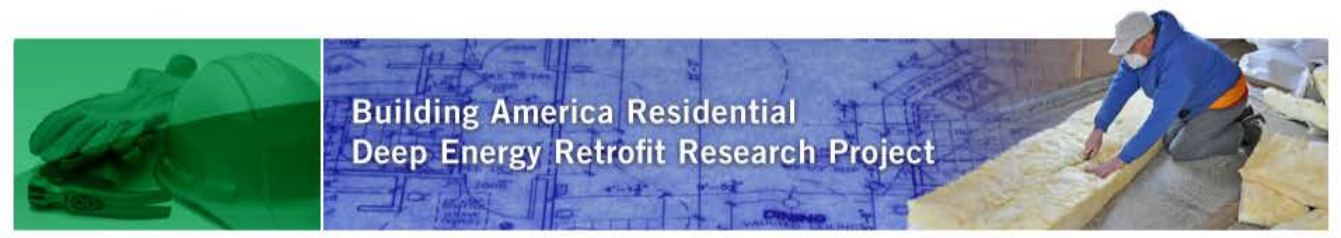

\section{Air Sealing}

Cracks, gaps, and holes located throughout your home waste energy by letting in hot air in the summer and cold air in the winter, or conversely, letting conditioned air out! During our audit, we performed a blower door test, which uses a calibrated fan and pressure gauges to measure the overall leakiness of your home. We found that if you added up all of the leaks in your home, the cumulative effect would be equivalent to having a hole 6 inches wide by 12 inches tall in the building envelope. This is like leaving a window open all year! These results are given in more detail below.

Table 2. Air Leakage Test Results

\begin{tabular}{lrl}
\hline Conditioned Floor Area & $2,375 \mathrm{ft}^{2}$ \\
\hline Conditioned Volume & $19,000 \mathrm{ft}^{3}$ \\
\hline Airflow in cubic feet per minute at -50 Pascals & $2,378 \mathrm{cfm} 50$ \\
\hline Air Changes per Hour at -50 Pascals & $7.51 \mathrm{ACH} 50$ \\
\hline Effective Leakage Area & $72.3 \mathrm{in}^{2}$ \\
\hline Relative airflow at -50 Pascals & $1.00 \mathrm{cfm} 50 / \mathrm{ft}^{2}$ \\
\hline Range of relative airflow for other homes tested in the Tri-cities & $0.8-1.05 \mathrm{cfm} 50 / \mathrm{ft}^{2}$ \\
\hline
\end{tabular}

By sealing up cracks and holes with caulk, expanding spray foam, and a variety of other materials, we estimate that you can reduce the amount of air leakage by $15-30 \%$. Air sealing is generally performed at the same time as other measures. For example, you may hire a contractor to seal leaks in your attic then add insulation. Because measures are often performed together, we have added the costs and savings associated with air sealing to the attic and crawlspace measures, below.

\section{Add Attic Insulation and Air Sealing}

Attic insulation reduces the amount of heat transferred through the ceiling. In the winter, heat is lost into the attic. In the summer the attic space, which gets very hot, transfers unwanted heat through the ceiling into the home. Cellulose and fiberglass insulation are typically used when adding insulation into existing homes. Cellulose and fiberglass are blown into the attic
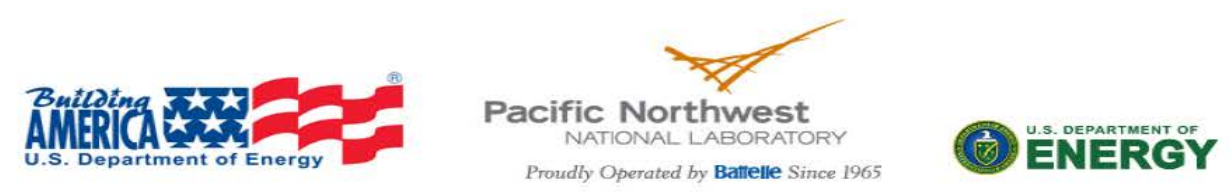


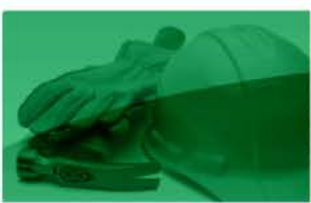

Building America Residential Deep Energy Retrofit Research Project

through a hose. This application is known as loose-fill (as opposed to batts of insulation). Before adding insulation, it is important to seal any leaks in the attic floor (it is much more difficult to seal leaks afterwards). Spray foam and caulk can be used to seal most leaks, though other materials may be used if leaks are very large (fire rated materials must be used where appropriate). Contractors will temporarily move the insulation aside while they air seal. Leaks are often found around holes drilled for wiring or plumbing, the top plates of interior walls, and attic hatches. (For more information, see the Building America Air Sealing Guide ${ }^{2}$.)
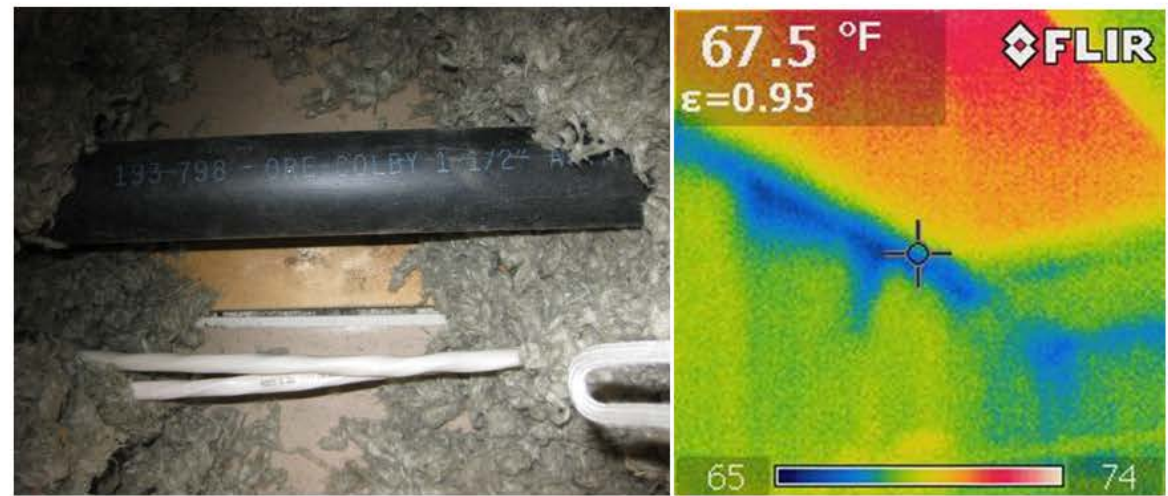

Figure 2. Left: Attic air leak. This is the top plate of an interior wall as seen from the attic. As you can see, there is crack between the top plate and the sheetrock that allows air to move between the attic and interior walls. The crack is small, but it runs the entire length of every interior wall. Right: This is an infrared image of a $2^{\text {nd }}$ floor interior wall. Colder air from the attic is moving down into the walls. Air leaks in the attic can be sealed with caulk or spray foam (again, fire-rated materials must be used where appropriate).

Your attic could also benefit from additional insulation. Currently, attic has about 8 inches of blown-in fiberglass insulation with an insulation value with almost R-24 (about R-2.8 per inch). We recommend adding about 10-13 inches of insulation (blown-in, either cellulose or fiberglass), bringing the insulation value to about R- 60 .

\section{Locally Available Incentives}

- A federal tax credit is available for $10 \%$ of material costs (does not include labor)

\footnotetext{
${ }^{2}$ Building America's Air Sealing Guide can be found here; http://www1.eere.energy.gov/library/asset handler.aspx?src=http://apps1.eere.energy.gov/buildings/publications/pdf s/building america/ba airsealing report.pdf\&id $=4663$
}
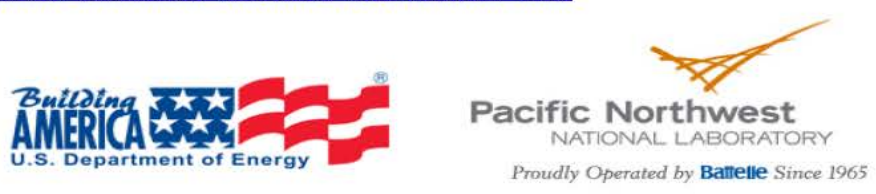


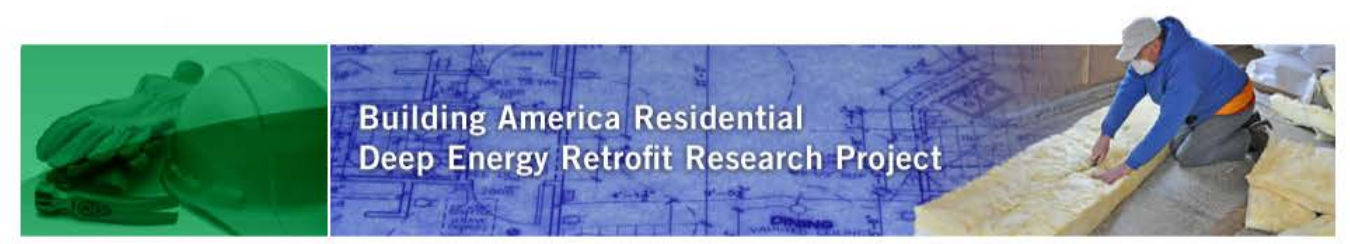

Table 3. Estimated Cost and Savings for R-60 Attic Insulation and Air Sealing

\begin{tabular}{cccc} 
Estimated Cost & $\begin{array}{c}\text { Estimated Annual } \\
\text { Savings }\end{array}$ & Payback Period & $\begin{array}{c}\text { Payback Period } \\
\text { (after incentives) }\end{array}$ \\
$\$ 1,950$ & $\$ 116 / \mathrm{yr}$ & $21 \mathrm{yr}$ & $20 \mathrm{yr}$ \\
\hline
\end{tabular}

\section{Add Insulation in the Crawlspace}

Currently, your crawlspace has about 4-5 inches of fiberglass located between the floor joists. Insulation in this location typically does not perform well because it is compressed, installed with gaps, and because air leaks move through the insulation. We recommend sealing any floor penetrations and adding insulation (the joists are about $8^{\prime \prime}$ ). Talk with insulation contractors about this measure. They may recommend adding additional fiberglass or new, thicker batts. Alternatively, closed-cell spray foam can be used. Closed cell foam insulates and air seals very well, however, it will likely be more expensive. Also, spray foam typically needs a fire barrier applied as the outer most layer to meet code. An added benefit of increasing the insulation in your crawlspace is that the floors should stay slightly warmer in the winter. Cold floors can be a major comfort issue, especially over vented crawlspaces. Your crawlspace could benefit from additional insulation. Currently, the insulation value is about R-14. We recommend bringing the insulation value up to at least R-24.

\section{Locally Available Incentives}

- A federal tax credit is also available for $10 \%$ of material costs (does not include labor)

Table 4. Estimated Cost and Savings for R-24 Crawlspace Insulation

\begin{tabular}{cccc|} 
Estimated Cost & $\begin{array}{c}\text { Estimated Annual } \\
\text { Savings }\end{array}$ & Payback Period & $\begin{array}{c}\text { Payback Period } \\
\text { (after incentives) }\end{array}$ \\
$\$ 1,750$ & $\$ 41 / \mathrm{yr}$ & $43 \mathrm{yr}$ & $41 \mathrm{yr}$ \\
\hline
\end{tabular}

\section{Seal and Insulate the Ducts}

Ducts located in unconditioned attics and crawlspaces can be a huge source of energy waste. In the summer, for example, the cold air from the air conditioner is subjected to extremely high temperatures. The opposite is true during winter. Ducts should be airtight and well insulated. Ideally, ducts should all be located within conditioned space (although this is not always possible). Duct joints are generally sealed with either duct mastic or tape made specifically for duct systems (standard duct tape will not work!!). The results of your duct test are given in
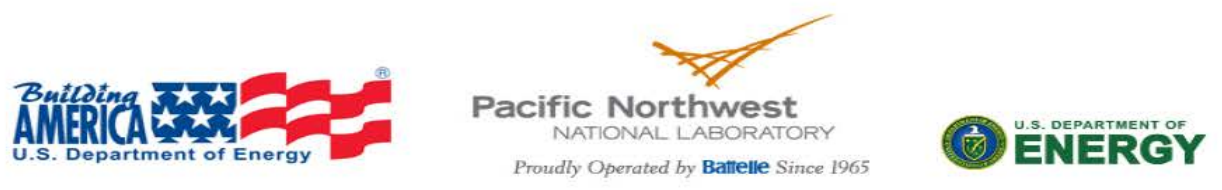


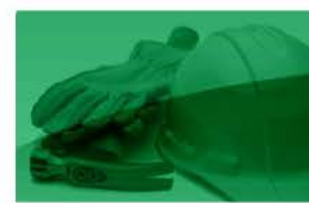

Building America Residential

Deep Energy Retrofit Research Project

Table 5. Your ducts were average tightness for what we have seen in the Tri Cities, but still about $15.6 \%$ of conditioned air is lost through leaks in your duct system.

Table 5. Duct Leakage Test Results

\begin{tabular}{lrl}
\hline Duct leakage to outside (or attic) at -25 Pascals & 280 & $\mathrm{cfm} 25$ \\
\hline Duct Air Loss as a percent of total air flow & $15.6 \%$ \\
\hline Relative leakage to outside per $\mathrm{ft}^{2}$ of floor area & $0.11 \mathrm{cfm} 25 / \mathrm{ft}^{2}$ \\
\hline Typical leakage to outside (or attic), Tri-cities & $46-350 \quad \mathrm{cfm} 25$ \\
\hline
\end{tabular}

Most of your supply ducts are located in the crawlspace, however, the majority the joints appear to be sealed. The connections through the floor to the registers should be sealed. Also, the return airways in your home use wall cavities instead of ducts. The air handler is depressurizing the wall cavities, which pulls dust (and possibly carbon monoxide and other pollutants from the garage) into the ducts system. Installing metal ducts or duct board in the return would help alleviate these problems.

Since the return air pathways in your home are through building cavities, they would be hard to seal. Consequently, we assumed a $30 \%$ reduction in duct leakage from sealing the supply ducts. The savings from duct sealing are not huge, and alone would not really justify the costs. We do, however, recommend these measures for improved comfort, health and safety. Also, if you do replace your heating or cooling system, duct sealing should be performed. It is often cheaper for a contractor to seal the ducts at the same time. Also, sealed ducts may allow you to install and smaller (and cheaper) HVAC system. The cost savings from installing a smaller unit may allow you to recoup much of the duct sealing costs.

\section{Locally Available Incentives}

- Cascade Natural Gas offers a $\$ 150$ incentive for duct sealing. However, the incentive will only be available if you keep a gas heating system.

Table 6. Estimated Cost and Savings for Sealing Ducts

\begin{tabular}{cccc} 
Estimated Cost & $\begin{array}{c}\text { Estimated Annual } \\
\text { Savings }\end{array}$ & Payback Period & $\begin{array}{c}\text { Payback Period } \\
\text { (after incentives) }\end{array}$ \\
$\$ 900$ & $\$ 22 / \mathrm{yr}$ & $41 \mathrm{yr}$ & $34 \mathrm{yr}$ \\
\hline
\end{tabular}
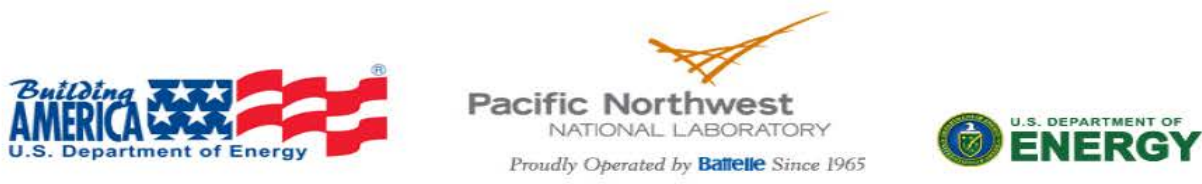


\section{Replace Your Furnace/AC units with a Heat Pump}

Your furnace and $A C$ unites are about 17 years old. The efficiency of $A C$ units is rated by their SEER. Your unit has a SEER of about 10. Furnace efficiency is rated by the AFUE; yours has an AFUE of about $80 \%$. While new furnaces can have AFUEs of $95 \%$, we believe that heat pumps offer higher energy cost savings. In the heat mode, heat pumps are rated by their heating season performance factor (HSPF). For new units, the current minimum allowable efficiencies for heat pumps are a SEER of 13 and an HSPF of 7.7. Some models have SEERs of over 20 and HSPFs of over 10 !

In our analysis, we used a SEER 19, HSPF 9.5 heat pump. This model would currently qualify for energy star tax credits. High efficiency models are available, which would result in greater savings. We also analyzed lower efficiency units, for example a SEER 16, HSPF 9 unit. Table 7 presents a comparison of the higher and lower efficiency heat pumps, as well as a new SEER 18 air conditioner and high efficiency condensing gas furnace (in Table 9).

At the moment, the economics of replacing your heating and cooling systems are decent, but not great. The payback period is about 21 years. However, as energy prices rise, the economics will improve. Also, your existing systems are approaching the end of their useful lives. The economics of a high efficiency heat pump greatly improve when your current HVAC equipment reaches the end of its life. Table 8 , below, shows that the payback period of installing a high efficiency SEER 19 model instead of a minimum efficiency (SEER 13, HSPF 7.7) unit is approximately 10.6 years.

If you do upgrade your HVAC system, it would be a good time to seal your ducts. You should also perform other insulation and air sealing measures before installing a new heat pump. That way, your heating and cooling loads will be lower and a smaller unit can be installed. Our models estimated that the size of your system could be reduced to $36 \mathrm{kBtu} / \mathrm{hr}$ ( 3 Tons from the current 3.5 ton system), for an approximate cost savings of $\$ 850$.

\section{Locally Available Incentives}

- A Federal tax credit of $\$ 300$ is available for qualifying models.

Table 7. Estimated Cost and Savings for New Heat Pump

\begin{tabular}{|c|c|c|c|c|}
\hline Measure & $\begin{array}{c}\text { Estimated } \\
\text { Cost }\end{array}$ & $\begin{array}{c}\text { Estimated } \\
\text { Annual Savings }\end{array}$ & \multicolumn{1}{c|}{$\begin{array}{c}\text { Payback } \\
\text { Period }\end{array}$} & \multicolumn{1}{c|}{$\begin{array}{c}\text { Payback Period } \\
\text { (after incentives) }\end{array}$} \\
\hline SEER 19, & $\$ 6,120$ & $\$ 324 / \mathrm{yr}$ & $19 \mathrm{yr}$ & $18 \mathrm{yr}$ \\
\hline
\end{tabular}




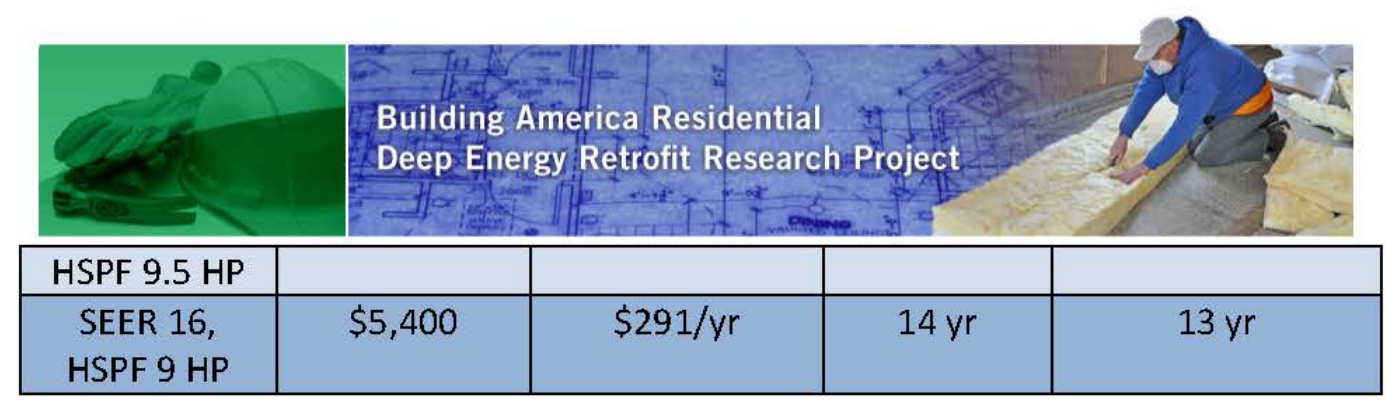

Table 8. Economics of installing a high efficiency unit instead of a standard unit (when the current system fails)

\begin{tabular}{|cccc|}
\hline $\begin{array}{c}\text { Estimated } \\
\text { Incremental Cost }\end{array}$ & $\begin{array}{c}\text { Estimated Annual } \\
\text { Savings }\end{array}$ & Payback Period & $\begin{array}{c}\text { Payback Period } \\
\text { (after incentives) }\end{array}$ \\
\hline$\$ 1,340$ & $\$ 126 / \mathrm{yr}$ & $13 \mathrm{yr}$ & $10.6 \mathrm{yr}$ \\
\hline
\end{tabular}

\section{Replace Your Air Conditioner and Furnace}

Note: This is one option for increasing the efficiency of your heating and cooling systems. According to our calculations, installing an electric heat pump will provide better cost savings and cost-effectiveness, but you may have reasons to stay with natural gas heating.

New air conditioners are significantly more efficient than older models. Air-conditioner efficiency is rated using the seasonal energy efficiency ratio (SEER). Your unit has a SEER rating of 10. Currently, the minimum allowable SEER for new AC units is 13 . Many models have SEERs of over 20 ! We recommend upgrading to a new unit that will supply the same cooling effect with much less energy use.

Your furnace appears is also quite old. New furnaces are significantly more efficient and can reduce your heating bills. Furnaces are rated by their AFUE (annual fuel utilization efficiency). Your house has a fan-assisted gas furnace with an AFUE of around $80 \%$. Newer condensing furnaces can have AFUEs well above $90 \%$.

We modeled a new, high-efficiency SEER 18 AC unit and condensing sealed-combustion $96 \%$ AFUE furnace for your home. The results are shown below. At this point, the payback period is quite long and probably does not justify costs.

\section{Locally Available Incentives}

- Cascade Natural Gas offers a $\$ 150$ incentive for new furnaces with an AFUE of $90 \%$ or greater

- Federal tax credits of $\$ 300$ are available for both AC units (SEER 16 or higher) and gas furnaces (AFUE of $95 \%$ or higher)
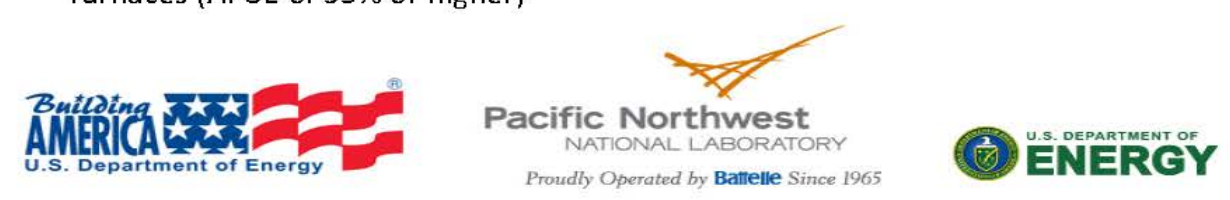


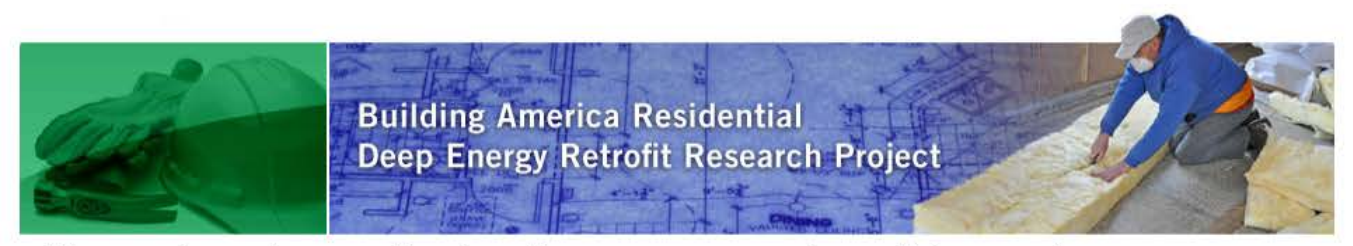

Table 9. Estimated Cost and Savings for a New SEER 16 Air Conditioner and AFUE 96 Furnace

\begin{tabular}{|cccc|}
\hline Estimated Cost & $\begin{array}{c}\text { Estimated Annual } \\
\text { Savings }\end{array}$ & Payback Period & $\begin{array}{c}\text { Payback Period } \\
\text { (after incentives) }\end{array}$ \\
\hline$\$ 5,400$ & $\$ 144 / \mathrm{yr}$ & $37 \mathrm{yr}$ & $33 \mathrm{yr}$ \\
\hline
\end{tabular}

When your current heating systems reach the end of their life, they will need to be replaced. At that point, the economics of high efficiency equipment look better. The table below shows the economics of purchasing the high efficiency HVAC equipment, rather than standard (SEER13, $80 \%$ AFUE) equipment.

Table 10. Economics of high efficiency equipment relative to standard equipment (when current systems fail)

\begin{tabular}{|cccc|}
\hline $\begin{array}{c}\text { Estimated Cost } \\
\text { Difference }\end{array}$ & $\begin{array}{c}\text { Estimated Relative } \\
\text { Annual Savings }\end{array}$ & Payback Period & $\begin{array}{c}\text { Payback Period } \\
\text { (after incentives) }\end{array}$ \\
\hline$\$ 1,240$ & $\$ 109 / \mathrm{yr}$ & $17 \mathrm{yr}$ & $11 \mathrm{yr}$ \\
\hline
\end{tabular}

\section{Replace Your Hot Water Heater}

Replacing your hot water heater with a tankless gas hot water heater (condensing type as opposed ones which need a regular flue) will result in substantial savings and a decent payback. A heat pump water heater could also be a good option, although its performance in cold climates is still being explored. A condensing gas tank water heaters will also result in energy savings over your existing model, though the economics are not as promising. Your current hot water tank is old, inefficient, and probably near the end of its life, so replacing it with a more efficient tankless or heat pump water heater will provide substantial energy savings.

Your water heater has an Energy Factor (EF) of about 0.57. A tankless gas condensing water heater has a operational EF of slightly less than 0.9 and a heat pump water heaters can have energy factors of about 2.35. There are now several manufacturers that offer energy star qualified ( $E F$ of 2 or above) heat pump water heaters. A heat pump water heater is the most energy-saving option for replacing your hot water heater.

One possible concern with heat pump water heater is that it would cool the air in the garage. This would be a probably be a benefit in the summer, but may be unwanted in the winter. Heat pump water heaters are produced by many of the major manufacturers and they are installed in cold climates (though they work better in warm climates), but they are still a relatively new

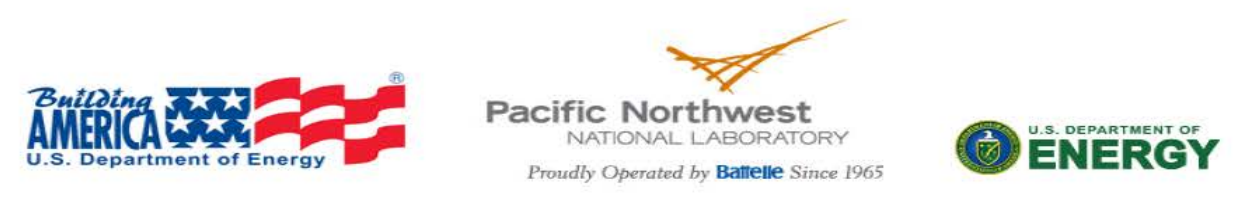




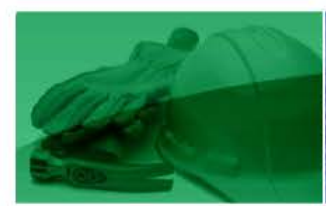

Building America Residential

Deep Energy Retrofit Research Project

technology. Because of this, local installers may not be familiar with heat pump water heaters and it may be difficult or more expensive to have them installed or serviced. We recommend talking with local plumbers about this measure to see if there is any local experience with the technology.

A condensing tankless gas water heater is an especially good option if you do not have a lot of small draws of hot water on your system. This is because there is no energy losses associated with storage of the hot water, but each time you call for hot water, the hot water pipes must fill up in order to deliver the hot water you want. If you turn on the hot water frequently, for short amounts of time, you are losing a lot of energy in your pipes. There is also a concern of excess water consumption with tankless hot water heaters. Conversely, a tanked hot water heater has a fixed storage loss associated with heat loss through the tank and up the flue. But, because the hot water is already there in the tank a tanked hot water heater can perform better when there are a number of small draws on the system. For all high efficiency hot water heaters, there is an incremental cost associated with the increased efficiency of the unit. Because of this, any high efficiency hot water heater is more cost effective the more hot water you use. The economics of each water heater replacement option are presented in Table 11, below.

\section{Locally Available Incentives}

- A federal tax credit of $\$ 300$ is currently available for heat pumps with an EF of above 2 or for gas water heaters with an EF greater than 0.82

- A $\$ 25$ incentive is available through the city of Richland for qualifying heat pumps

Table 11. Estimated Cost and Savings for a New Hot Water Heaters

\begin{tabular}{|c|c|c|c|c|}
\hline Measure & $\begin{array}{c}\text { Estimated } \\
\text { Cost }\end{array}$ & $\begin{array}{c}\text { Estimated } \\
\text { Annual Savings }\end{array}$ & $\begin{array}{l}\text { Payback } \\
\text { Period } \\
\end{array}$ & $\begin{array}{l}\text { Payback Period } \\
\text { (after incentives) }\end{array}$ \\
\hline $\begin{array}{c}\text { Heat Pump } \\
\text { WH }\end{array}$ & $\$ 2,100$ & $\$ 116 / y r$ & $18 \mathrm{yr}$ & $15 \mathrm{yr}$ \\
\hline $\begin{array}{c}\text { Gas Tankless } \\
\text { WH }\end{array}$ & $\$ 1,800$ & $\$ 99 / \mathrm{vr}$ & $18 \mathrm{yr}$ & $15 \mathrm{yr}$ \\
\hline $\begin{array}{l}\text { High EF gas } \\
\text { tank WH }\end{array}$ & $\$ 2,000$ & $\$ 89 / \mathrm{yr}$ & $22 \mathrm{yr}$ & $19 \mathrm{yr}$ \\
\hline
\end{tabular}

When your current hot water tank reaches the end of its life, it will need to be replaced. At that point, the economics of a heat pump water heater (or other high efficiency water heating

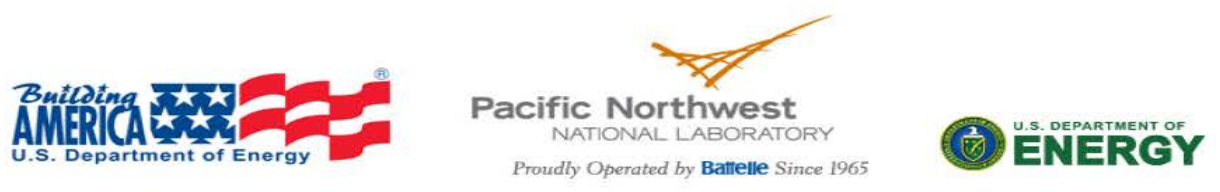




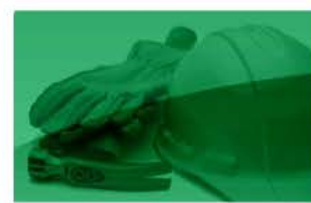

Building America Residential

Deep Energy Retrofit Research Project

system) look better. The table below shows the economics of purchasing the high efficiency heat pump water heater, rather than a standard $(0.6 \mathrm{EF})$ gas hot water tank. This type of analysis would also apply to a tankless or more efficient tank hot water heater, although the numbers would vary slightly.

Table 22. Economics of high efficiency heat pump relative to standard equipment (when current systems fail)

\begin{tabular}{cccc}
$\begin{array}{c}\text { Estimated Cost } \\
\text { Difference }\end{array}$ & $\begin{array}{c}\text { Estimated Annual } \\
\text { Savings }\end{array}$ & Payback Period & $\begin{array}{c}\text { Payback Period } \\
\text { (after incentives) }\end{array}$ \\
$\$ 1,250$ & $\$ 85 / \mathrm{yr}$ & $15 \mathrm{yr}$ & $11 \mathrm{yr}$ \\
\hline
\end{tabular}

Both a heat pump water heater or a tankless gas condensing water heater (EF is about 0.94 , but de-rated to 0.86 using a method included in California's energy code) could be good options. We recommend talking to local plumbers and installers to get actual price quotes and information about local trade support of these options. Note that we are not recommending the more popular non-condensing type of tankless gas water heater as their rated EF is about 0.84 and operational efficiency, after derating, is about 0.76 , not much better than a conventional gas water heater which has ratings close to 0.6 .

\section{Replace Your Refrigerator}

Your refrigerators are not old or inefficient enough to justify replacement (unless you are replacing one for aesthetic or other reasons), but the following information may be helpful.

Newer refrigerators are significantly more efficient. If you are shopping for a new refrigerator, units with top-mounted freezers typically save the most energy. Select a unit with only as much volume as needed (larger units use more electricity). Also, through-the-door ice makers and internal ice makers increase energy use and should be avoided unless deemed necessary.

Efficient new refrigerators, depending on the size and features, consume about 350-450 kWh per year. Older units often consume 1000-2000 kWh per year! Your unit probably uses closer to $700-1000 \mathrm{kWh}$ per year. This means that you could save roughly $\$ 20-\$ 45$ per year by upgrading to a new refrigerator.

Locally Available Incentives
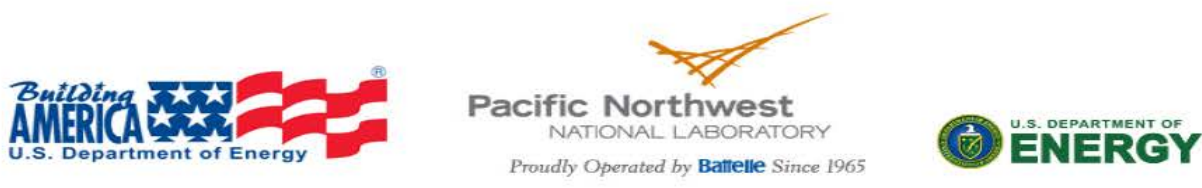


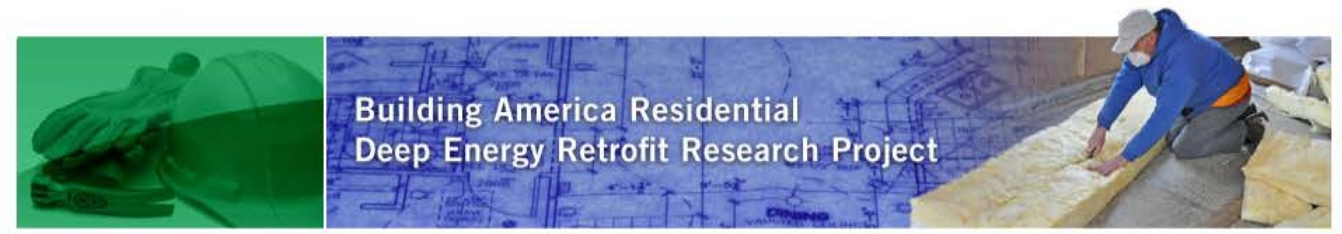

- The city of Richland offers a $\$ 25$ rebate for Energy Star models

- A $\$ 30$ rebate through the city of Richland is available for recycling your old refrigerator. They will come pick it up. This could be a good option if you decide that you do not need the extra refrigerator in the garage.

\section{Replace Your Clothes Washer}

If you plan on replacing your clothes washer, be sure to find a model with the ENERGY STAR label. New ENERGY STAR models are 37\% more efficient than non-qualified models (according to the ENERGY STAR website). In addition to using less hot water, ENERGY STAR models pull more water out of the clothes before they go into the dryer, thereby reducing the amount of drying time and energy consumed.

\section{Locally Available Incentives}

- The City of Richland offers a $\$ 25$ rebate for Energy Star models

\section{Install a Solar Water Heater}

Solar water heaters use the sun to warm up water for use in showers, faucets, and the dishwasher. Solar water heaters are more expensive that other water-heating options, but they save money over the life of the system. Depending on the size of the system, solar water heaters typically provide $30-75 \%$ of the hot water load. Solar collectors typically perform best when the roof faces due south and the roof angle is about the same as the latitude, $47^{\circ}$, although this can vary based on design considerations.

Your house could be a candidate for a solar hot water system, but the economics are not great. The payback period, including a $30 \%$ federal tax credit, is over 40 years. Because gas is cheap in this area and you do not use too much hot water anyway, the costs of a solar water heating system are hard to justify.
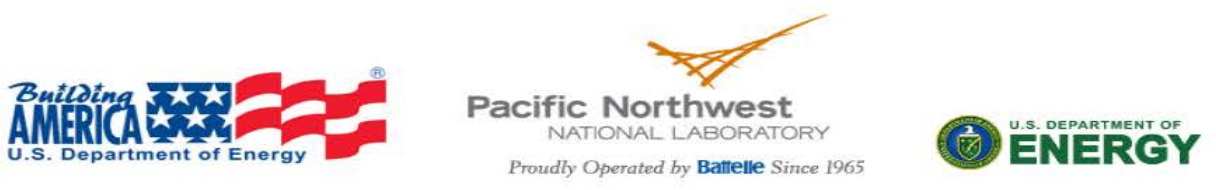


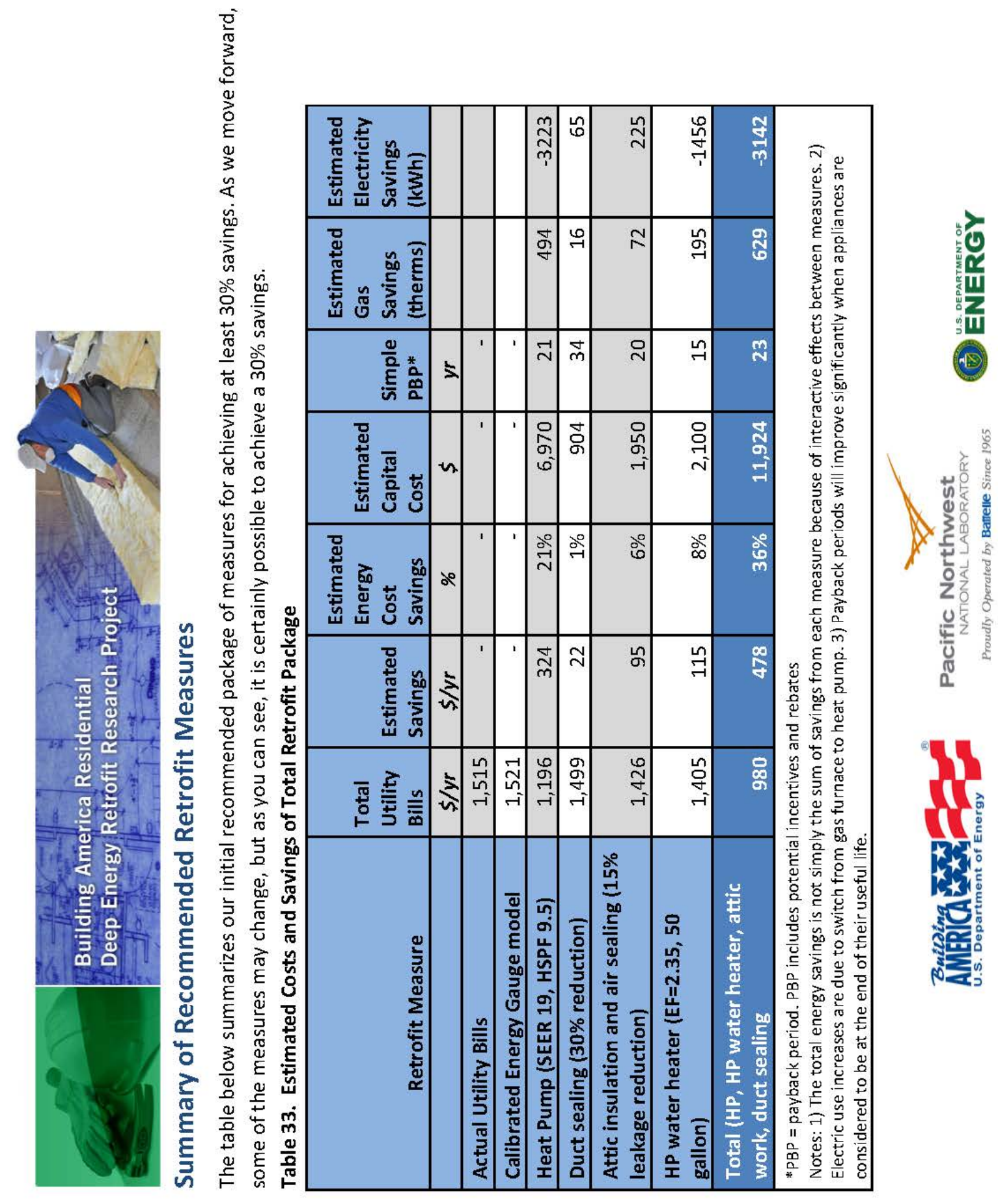




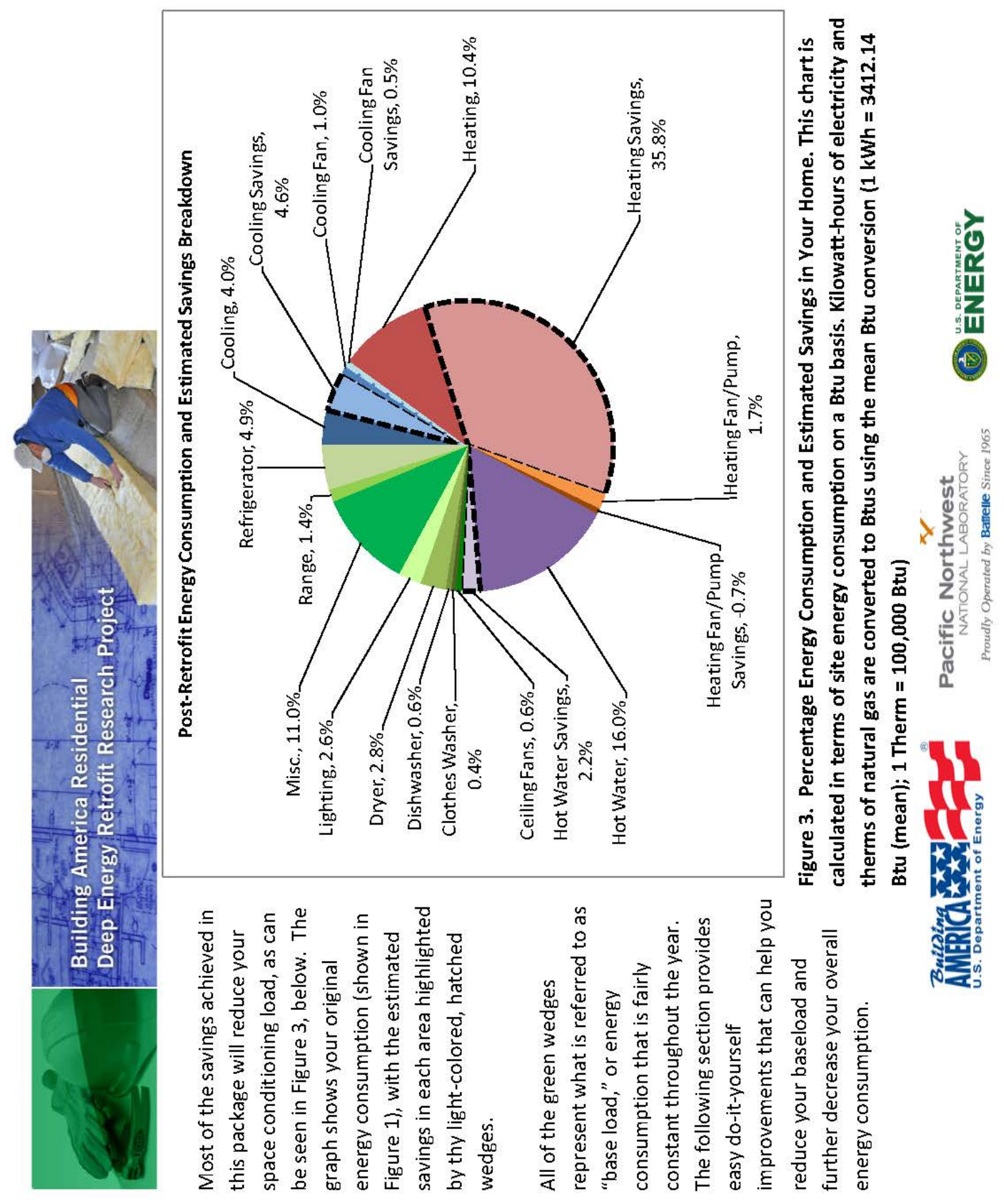




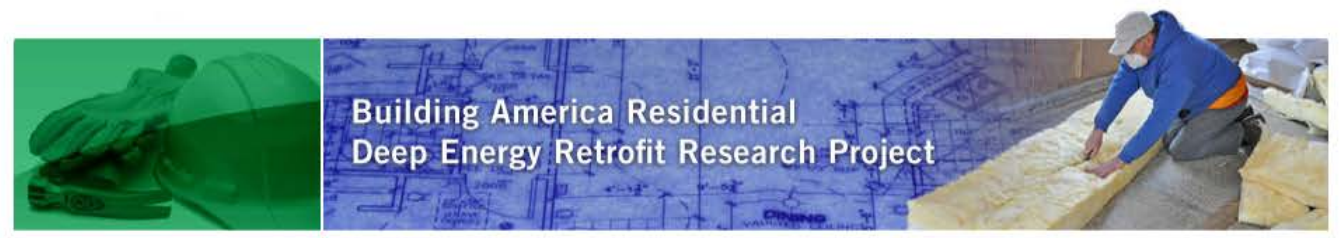

\section{Easy Do-It-Yourself Improvements}

\section{Lower the Hot Water Tank Set Point}

Most households only require hot water at $120^{\circ} \mathrm{F}$. Your tank does not display the actual temperature setpoint, but it is set between 'hot' and 'very hot.' You may be able to set the temperature lower while still having hot enough water for showers and dishwashing. A lower setpoint reduces the amount of heat lost through the tank. Note that it is generally not recommended to reduce the temperature below $120^{\circ} \mathrm{F}$.

\section{Use Power Strips to Turn Off Appliances That are Not Being Used}

Some home appliances draw power even when they are not being used. These draws on power are often called "phantom loads." One way to avoid phantom loads is to plug non-essential appliances into a power strip. When the appliances are not in use, simply turn off the power strip. Be sure to use a separate power strip or outlet for any essential appliances.

\section{Replace Your Incandescent Lights with Compact Fluorescents}

You have already replaced much of you lighting with CFLs, but the information below may be useful for future reference.

ENERGY STAR-qualified compact fluorescent lamp (CFL) bulbs use about $75 \%$ less energy than standard incandescent light bulbs. They also last about 10 times longer than comparable incandescent bulbs. Annual savings depend on how many hours you use each bulb, but CFLs typically pay for themselves with energy savings within 1-2 years.

A note about CFLs: CFLs contain a small amount of mercury. At the end of their life, be sure to recycle the bulbs properly. Some stores, such as Home Depot, will accept bulbs that no longer work. For more guidance on recycling bulbs and what to do if a bulb breaks, see this document from the City of Richland (available at:

http://www.ci.richland.wa.us/DocumentView.aspx?DID=1051).
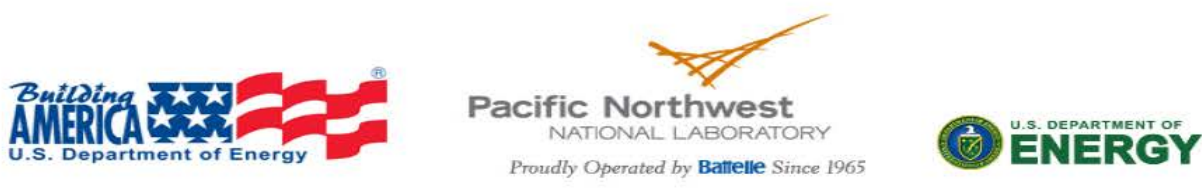


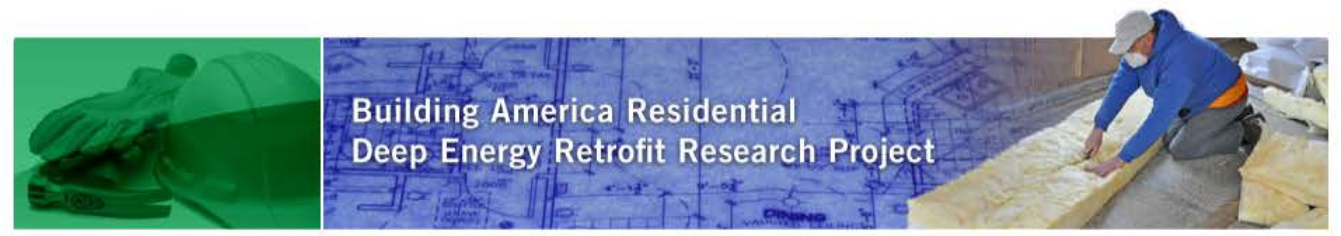

\section{Install Low-flow Showerheads and Faucet Aerators}

A simple way to save on your water heater costs is to use low-flow plumbing fixtures. New showerheads offer suitable spray while using less hot water. There are many available models that use around 2 gallons per minute $(\mathrm{gpm})$. Some older showerheads can use more than 5 gpm.

Similarly, hot water use in faucets can be reduced by using installing faucet aerators. Look for aerators that limit the faucet flow to about $1 \mathrm{gpm}$. Also, when shopping for aerators or lowflow showerheads, look for the WaterSense label. WaterSense is a U.S. Environmental Protection Agency program that certifies water-saving fixtures.

\section{Additional Resources}

For more information, the following websites provide additional energy-saving tips for home owners looking to make energy efficiency improvements to their homes:

- http://www.energysavers.gov/

- http://www.aceee.org/consumer

- http://www.energystar.gov/

- http://www.nahb.com/

- http://www1.eere.energy.gov/buildings/

In addition, the Building America website

(http://www1.eere.energy.gov/buildings/building america/) and the Building Science Corporation website (http://www.buildingscience.com/index html) provide a number of good resources related building design and construction of energy efficient homes.
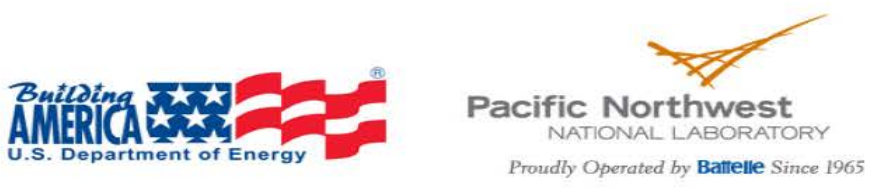

(0) EsNERGY 


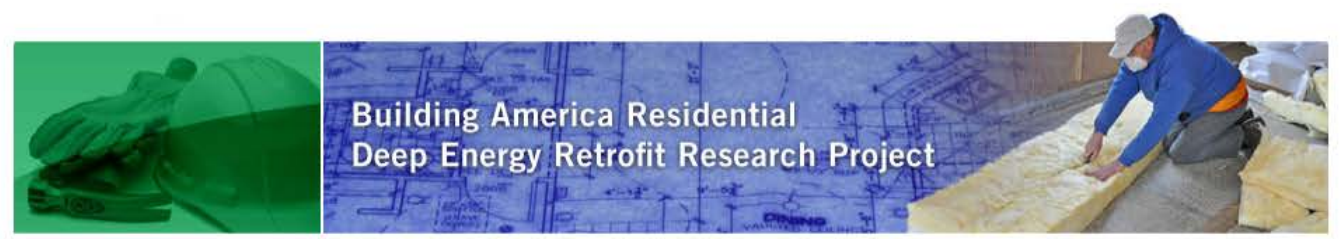

\section{Incentives and Rebates}

Various incentives are available to help pay for energy efficiency measures. For example, many of local utilities offer incentives. Several of these incentive or rebate options are identified in the audit information provided above. In addition to the incentives and direct rebates identified for your specific recommendations above, the City of Richland offers low-interest loans to help finance energy efficiency projects. These loans can be used instead of (but not in addition to) the project-specific rebates. More information can be found on your local utilities website. Another good resource for finding energy efficiency rebates anywhere throughout the country is www.dsireusa.org/.

Federal tax incentives are also available for ENERGY STAR products. Many of the recommended measures may be eligible for a tax credit worth $10 \%$ of the materials cost, or a specified amount (for example, ENERGY STAR furnaces are eligible for a $\$ 150$ tax credit). These incentives have also been identified in the cost estimates provided above. More information about this program is available at the following website:

http://www.energystar.gov/index.cfm?c=tax credits.tx index.
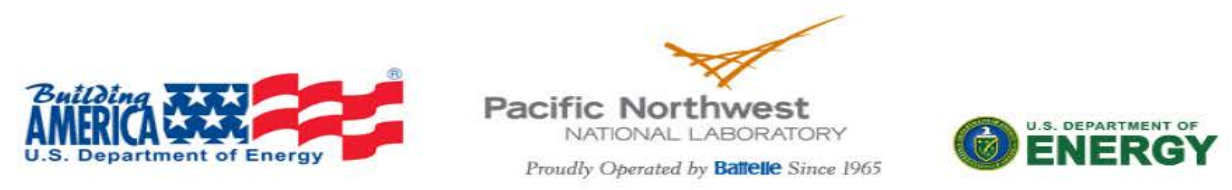


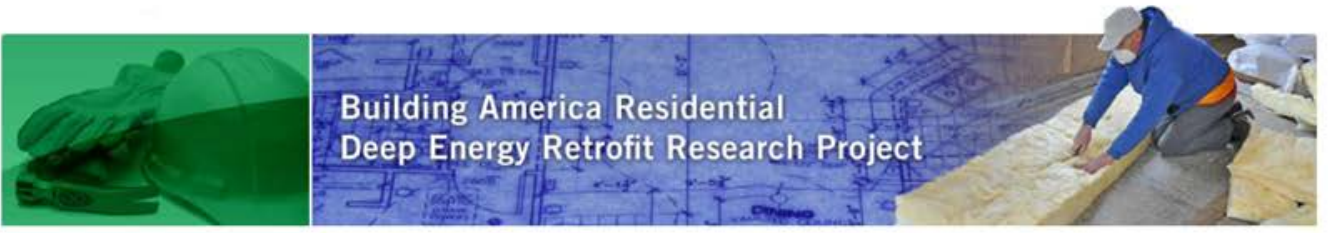

Residential Deep Energy Retrofit Research Project

\section{Audit Report for a Two-story Dayton Home}

Audit Date: 5/18/2011

Pacific Northwest National Laboratory Research Team http://deepenergyretrofits.pnnl.gov/

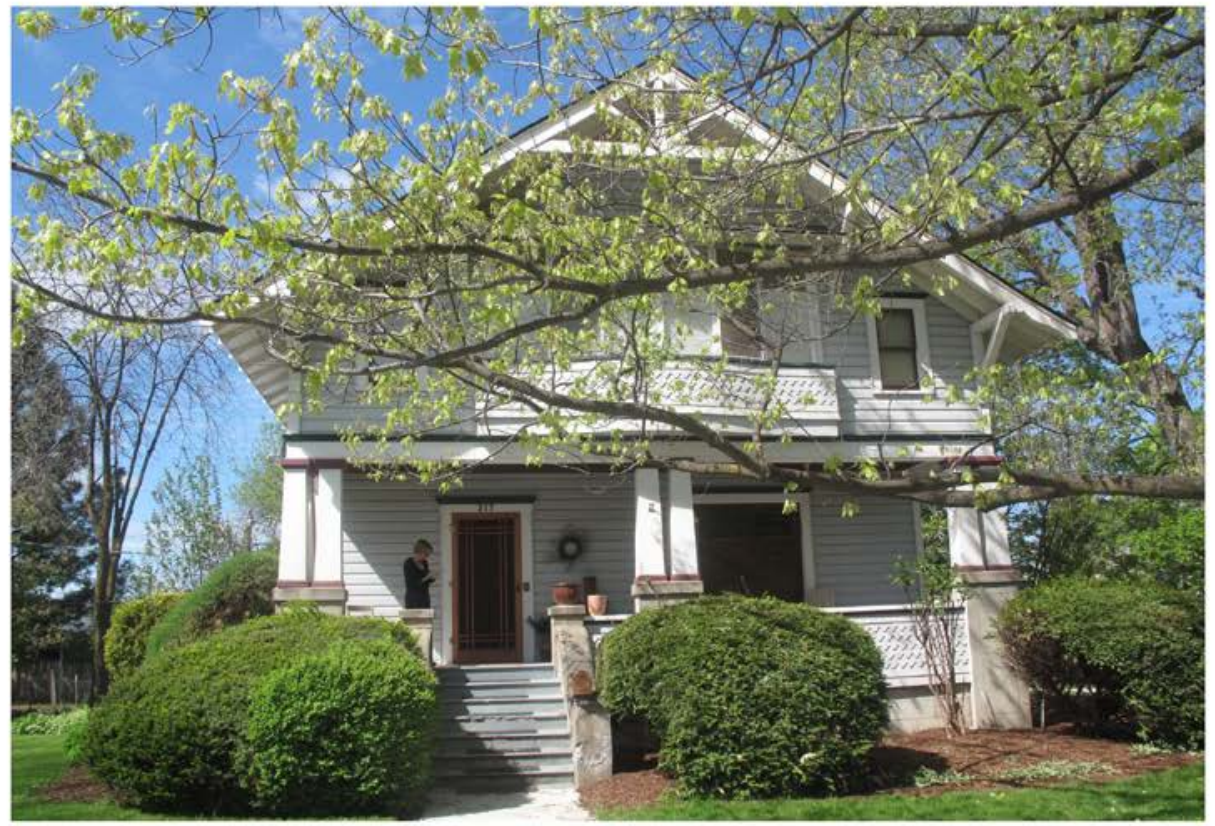

Notices:

1. This report is intended for the sole use of the homeowner(s) and the PNNL deep retrofits study team members (including subcontractors) that have completed training to protect the privacy and other rights of human subjects in research programs. PNNL will not share this report with anyone but may include data and information from this report, in an anonymous manner, in the final report that will be submitted to the U.S. Department of Energy.

2. The quantitative information in this report on energy savings, costs and economic benefits are based on computer models. Please note that actual savings and costs can be quite different (may be even a factor of 2 or more) depending on homeowner lifestyle, actual performance of energy saving equipment and strategies, variations in local weather, contractor business models and other unforeseen factors.
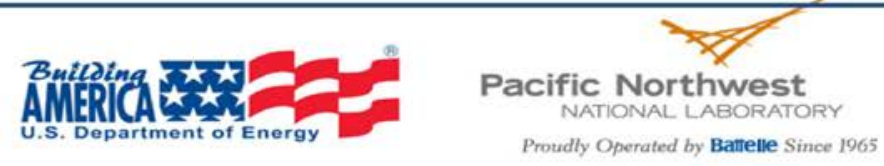

\section{(3) ENERGY}




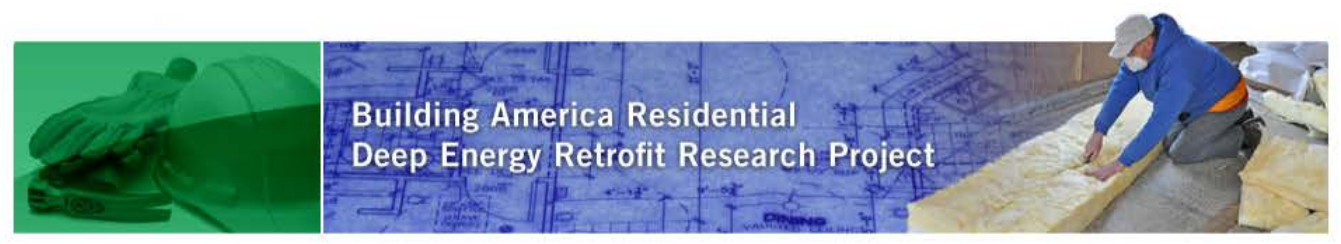

\section{Existing Home Characteristics and Performance}

The house is a single-family, two-story home built in 1915 . It has 3 bedrooms and 1.5 baths; a total conditioned space of 2,638 square feet $\left(\mathrm{ft}^{2}\right)$, not including the semi-conditioned basement. The original building envelope is wood-frame construction with about R-10 insulation in the walls and no insulation in the basement. The attic is vented with $\mathrm{R}-30$ blown-in cellulose insulation. The windows are single-pane clear glass with wood frames. Heating is provided by a diesel fired boiler, which heats hot water for the hydronic heating system and there currently is no cooling system.

Table 1. Average Utility Bill Information for April 2010 through March 2011.

\begin{tabular}{llc}
\hline Energy Costs Information & Diesel, $\mathbf{\$}$ & Electricity, $\mathbf{~}$ \\
\hline Average Utility Bill & 503.10 & 45.71 \\
Maximum Utility Bill & 701.13 & 60.11 \\
Minimum Utility Bill & 308.49 & 31.12 \\
\hline
\end{tabular}

\section{Recommended Energy Efficiency Retrofit Measures}

The home was audited to quantify its energy performance. The home energy audit consists of several elements: a blower door test to characterize building envelope leakage, thermal imaging to identify key leaks, evaluation of insulation levels, and examination of all energyconsuming appliances.

Following the audit we created a calibrated model of your house using the Energy Gauge (EG) software, developed by the Florida Solar Energy Center This software is a general analysis tool that is valid for all climates and has met software validation tests (http://www.energvgauge.com/usares/default.htm ). The model was calibrated, on a monthly basis, using your utility bills as shown in Figure 1 for electricity and Figure 2 for \#2 diesel fuel. The modeled annual consumption of electricity and diesel are within 1 percent of your utility bills.
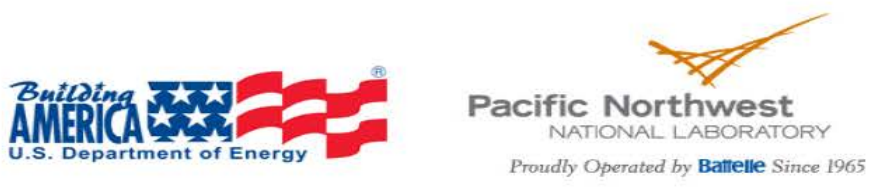

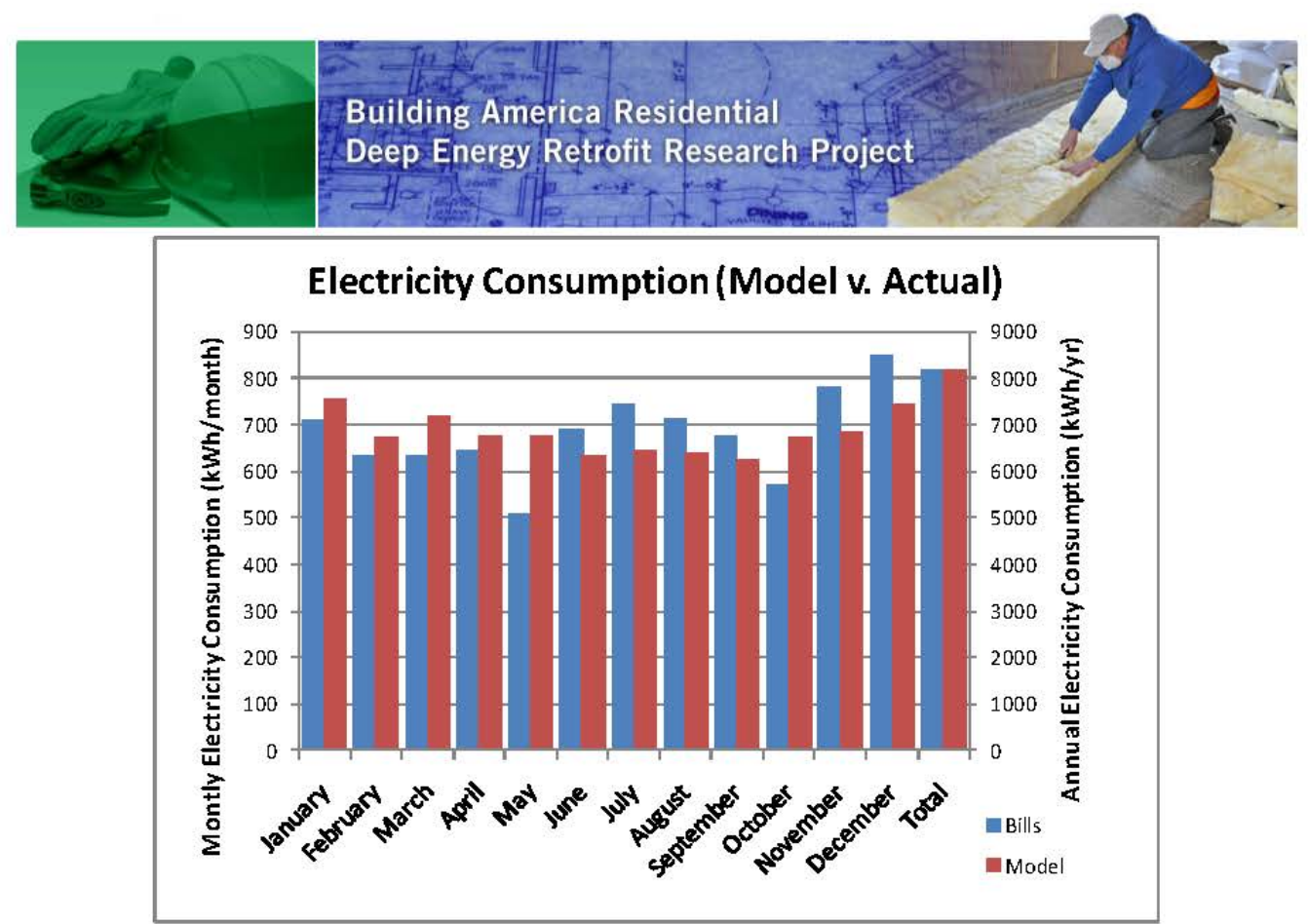

Figure 1. Comparison of monthly electricity consumption for utility bill and EG model. The annual comparison is also included on the secondary (right) vertical axis.

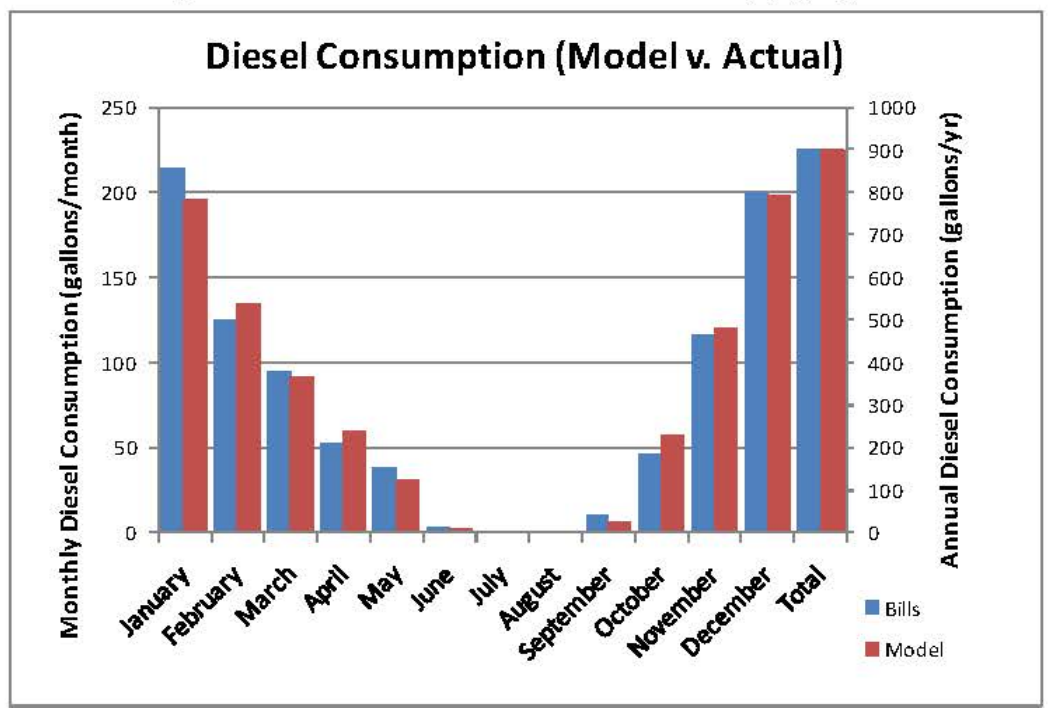

Figure 2. Comparison of monthly natural gas consumption for utility bill and EG model. The annual comparison is also included on the secondary (right) vertical axis.

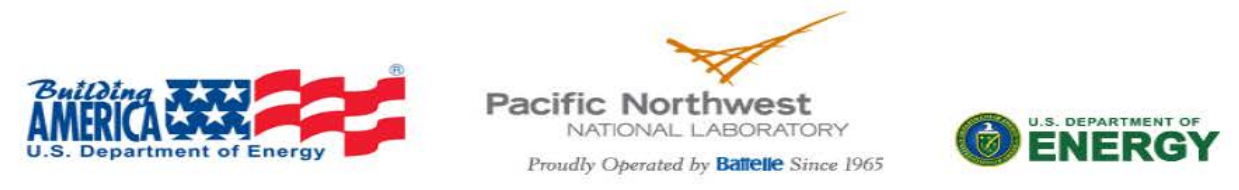




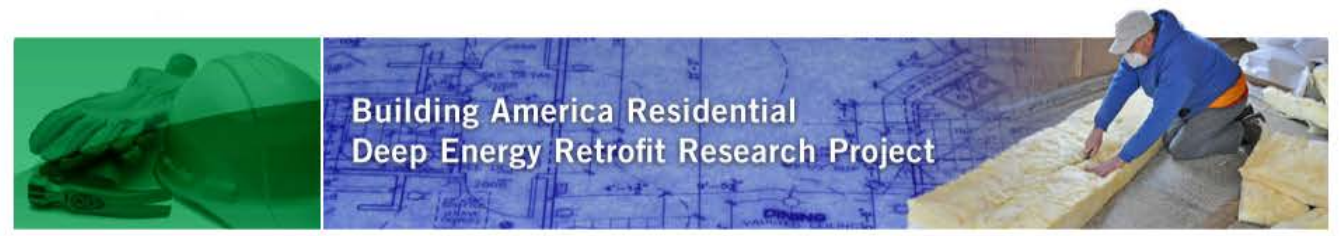

Figure 3 shows the EG model breakdown of your energy consumption. Notice that more than $75 \%$ of your energy consumption is associated with heating due to the inefficiency of your old boiler.

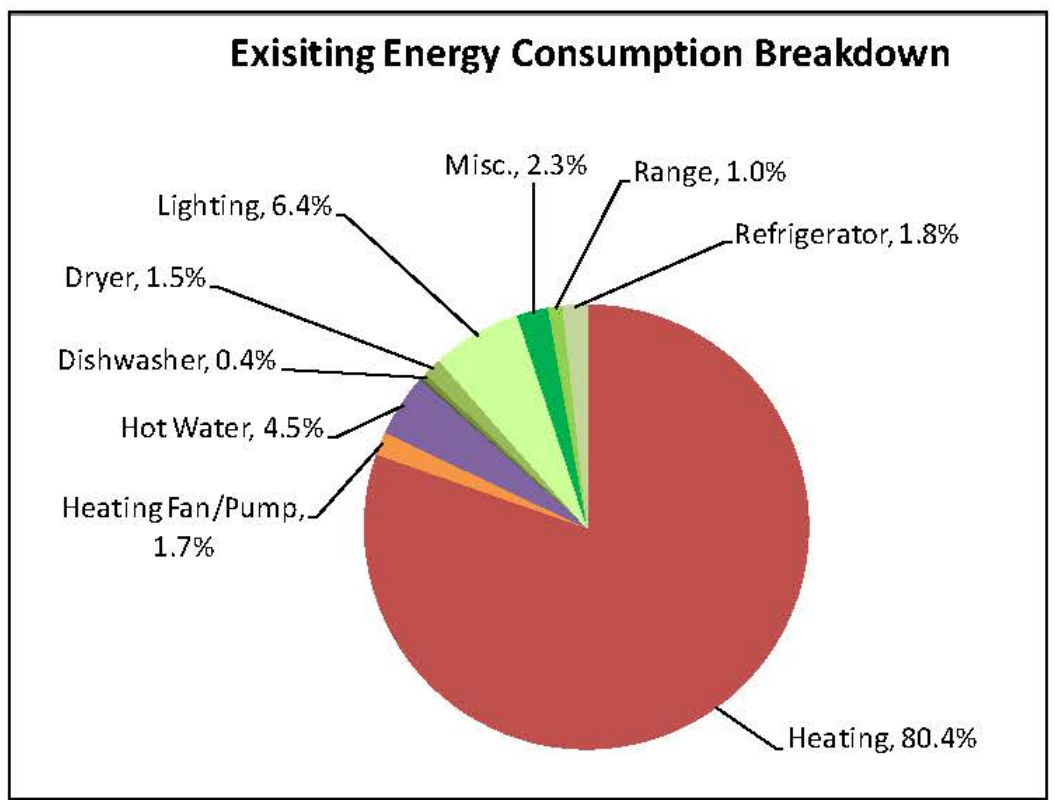

Figure 3. Percentage of energy consumption for heating, ventilation, air conditioning equipment, lighting, appliances and miscellaneous base loads. The energy consumption is calculated based on a British Thermal Unit (Btu) conversion basis. Kilowatt-hours of electricity and therms of natural gas are converted to Btus using the mean Btu conversion (1 $\mathrm{kWh}=3412.14 \mathrm{Btu} ; 1$ therm = 100,000 Btu).

During the audit of your home, we noticed several opportunities to save energy in costeffective ways. The ensuing sections of this report summarize each energy-saving measure and related energy-audit findings and provide the estimated energy savings, cost of each recommended measure, and associated payback period. The simple payback period is the number of years that it will take to pay off the upfront investment with energy cost savings (the shorter, the better). The payback period provides a quick economic metric that can be used to prioritize the measures. The ensuing sections also briefly summarize locally available incentives
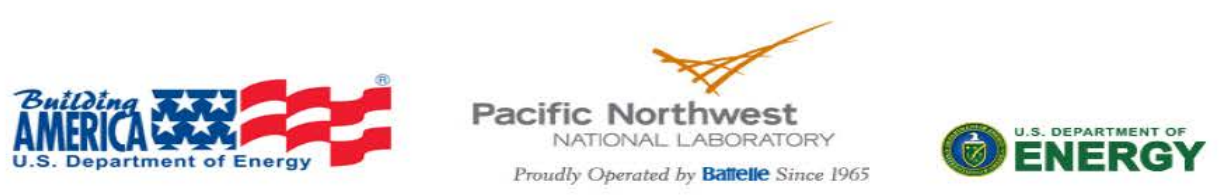


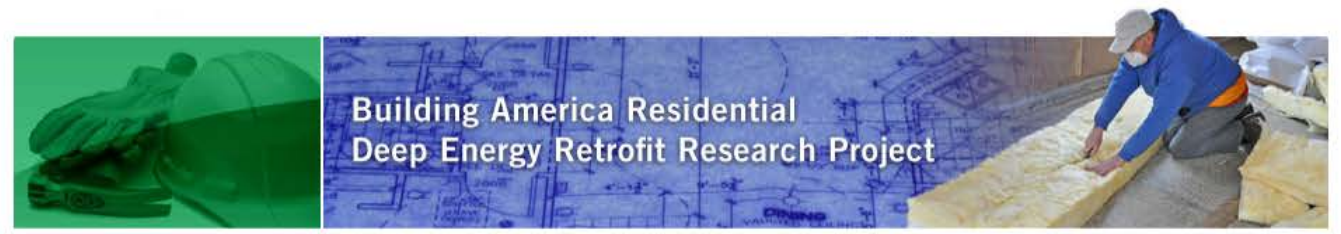

that may be available to help pay for energy-saving measures. Most of the savings estimates included here are based on computer simulations of your home. The costs provided are rough estimates based on our experiences with the energy-saving measures, quotes from local contractors, and publically available information, like the National Renewable Energy Lab's National Measures Database ${ }^{1}$. Your actual costs will depend on the contractor you choose, the final scope of work, and the current material prices. Finally, we have provided payback periods for each measure.

We think that you can cost-effectively reduce your energy use by around $62 \%$ ! Your actual savings will depend on which measures are implemented (as well as any changes in usage patterns, occupancy, etc.). The savings associated with each measure also will be affected by other measures that you implement, so, as we develop the final package of measures, savings estimates will vary.

Please read through the measures described below and let us know if you have any questions. Once we have discussed the cost-saving measures available to you and agreed on a package that fits your needs, the next step will be to start asking contractors for bids on the energysaving projects (recognizing that you can complete some projects yourself).

\section{Air Sealing}

Cracks, gaps, and holes located throughout your home waste energy by letting in hot air in the summer and cold air in the winter, or conversely, letting conditioned air out! During our audit, we performed a blower door test, which uses a calibrated fan and pressure gauges to measure the overall leakiness of your home. We found that if you added up all of the leaks in your home, the cumulative effect would be equivalent to having a hole 10 inches wide by 20 inches tall in the building envelope. This is like leaving a window open all year! These results are given in more detail below.

${ }^{1}$ National Renewable Energy Laboratory. "National Measures Database." Available at: http://www.nrel.gov/ap/retrofits/.
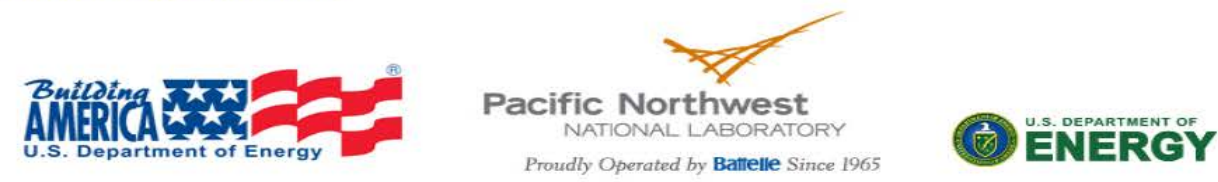


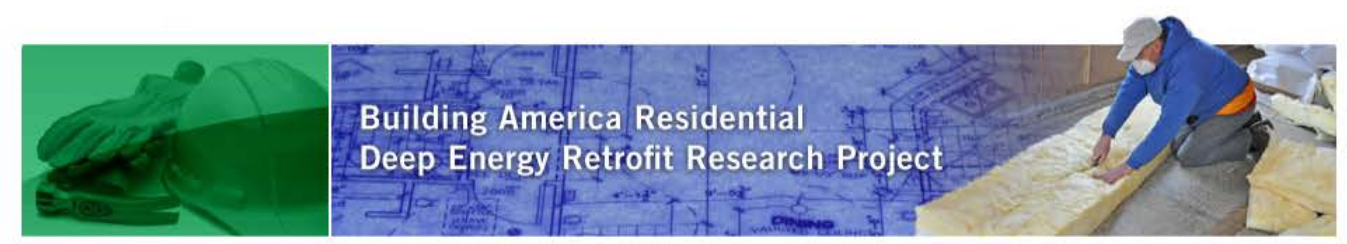

Table 2. Air Leakage Test Results

\begin{tabular}{lrl}
\hline Conditioned Floor Area & $2,638 \mathrm{ft}^{2}$ \\
\hline Conditioned Volume & $21,104 \mathrm{ft}^{3}$ \\
\hline Airflow in cubic feet per minute at -50 Pascals & $3,676 \mathrm{cfm50}$ \\
\hline Air Changes per Hour at -50 Pascals & $7.19 \mathrm{ACH} 50$ \\
\hline Effective Leakage Area & $201.8 \mathrm{in}^{2}$ \\
\hline Relative airflow at -50 Pascals & $1.39 \mathrm{cfm} 50 / \mathrm{ft}^{2}$ \\
\hline Range of relative airflow for other homes tested in the Tri-cities & $0.65-1.05 \mathrm{cfm} 50 / \mathrm{ft}^{2}$ \\
\hline
\end{tabular}

By sealing up cracks and holes with caulk, expanding spray foam, and a variety of other materials, we estimate that you can reduce the amount of air leakage by $25 \%$. Air sealing is generally performed at the same time as other measures. For example, you may hire a contractor to seal leaks in your attic then add insulation. Because measures are often performed together, we have added the costs and savings associated with air sealing to the attic and crawlspace measures, below.

\section{Add Attic Insulation and Air Sealing}

Attic insulation reduces the amount of heat transferred through the ceiling. In the winter, heat is lost into the attic. In the summer the attic space, which gets very hot, transfers unwanted heat through the ceiling into the home. Cellulose and fiberglass insulation are typically used when adding insulation into existing homes. Cellulose and fiberglass are blown into the attic through a hose. This application is known as loose-fill (as opposed to batts of insulation). Before adding insulation, it is important to seal any leaks in the attic floor (it is much more difficult to seal leaks afterwards). Spray foam and caulk can be used to seal most leaks, though other materials may be used if leaks are very large (fire rated materials must be used where appropriate). Contractors will temporarily move the insulation aside while they air seal. Leaks are often found around holes drilled for wiring or plumbing, the top plates of interior walls, and attic hatches. (For more information, see the Building America Air Sealing Guide ${ }^{2}$.

\footnotetext{
${ }^{2}$ Building America's Air Sealing Guide can be found here; http://wwwl.eere.energy.gov/library/asset handler.aspx? src=http $/ /$ appsl. eere.energy.gov/buildings/publications/pdf s/building america/ba airsealing report.pdf\&id $=4663$

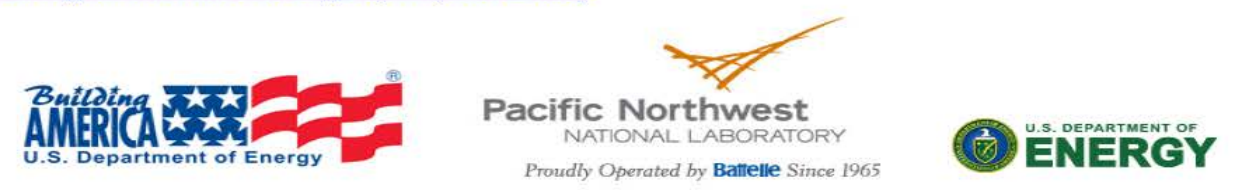




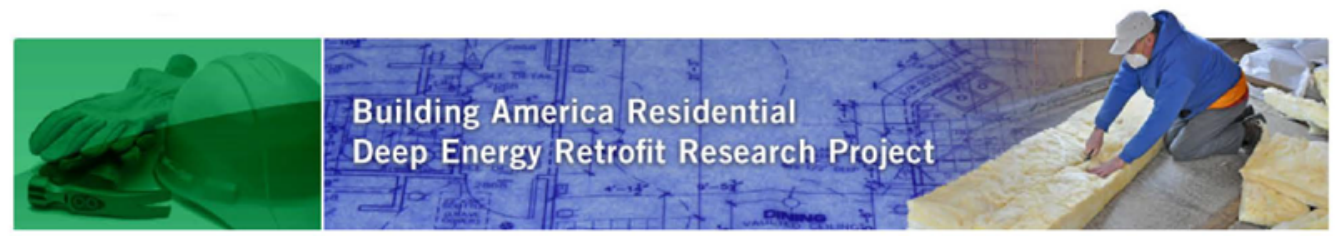

A list of specific problem areas we noticed at the audit and ways to address them are listed below:

- From the attic you can see down the slopes of the 2 nd floor kneewall (see Figure and about $20 \%$ of the slope cavities had inadequate insulation. The blown insulation did not fill the cavities, allowing the insulation to fall down into the cavity or allowed a path for airflow to wash over the insulation. Fill the cavities of the sloped roof with as much blown fiberglass as possible. At the top of the insulation install and seal a plug made from duct board or Styrofoam. This will greatly reduce the airflow through the balloon framing.

- The chimney of an abandoned wood stove had rockwool around the perimeter with a slight thermal bypass. Seal around chimney with fire foam.

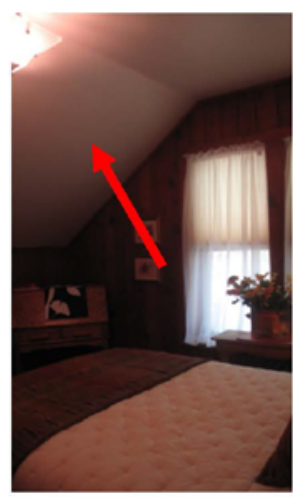

Figure 4. Example of sloping kneewall cavity between attic By insulating and air sealing your attic alone, we believe you could save about $\$ 40 / y r$ and improve the comfort of your home.

floor and exterior wall.

\section{Locally Available Incentives}

- Pacific Power offers an incentive of $\$ 0.25$ per square foot for attic insulation.

- A federal tax credit is also available for $10 \%$ of material costs (does not include labor)

Table 2. Estimated cost and savings for additional attic insulation in the knee walls only and air sealing.

\begin{tabular}{|cccc|}
\hline Estimated Cost & $\begin{array}{c}\text { Estimated Annual } \\
\text { Savings }\end{array}$ & Payback Period & $\begin{array}{c}\text { Payback Period } \\
\text { (after incentives) }\end{array}$ \\
\hline$\$ 1,161$ & $\$ 40 / \mathrm{yr}$ & $29 \mathrm{yr}$ & $17 \mathrm{yr}$ \\
\hline
\end{tabular}

Your attic could also benefit from additional insulation. Currently, the insulation value in your attic is about an R-15. You could save additional energy by adding insulation to your attic. Recommended Levels for your geographic area are R-49. Our model showed that you could
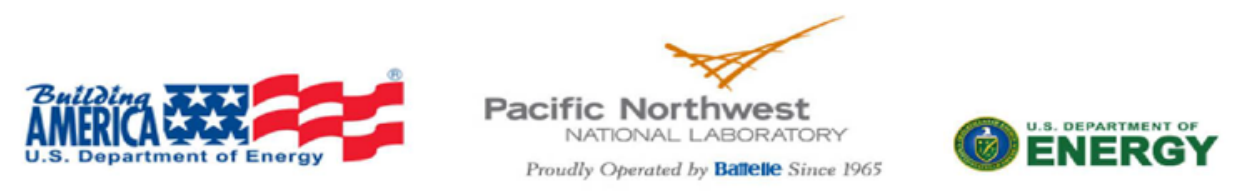


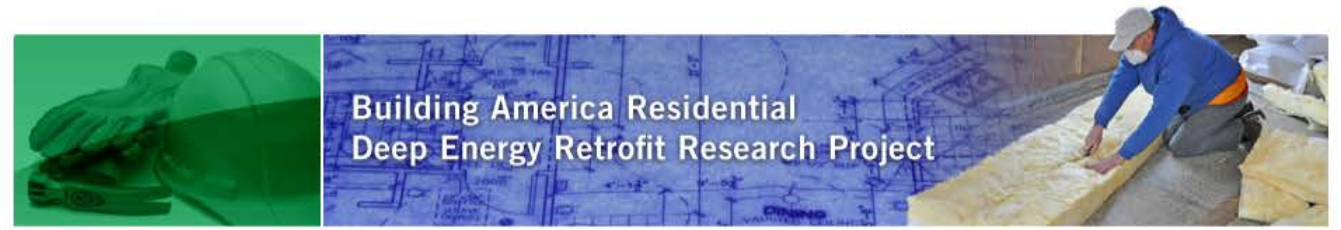

save an additional $3 \%$ on your utility bills, over $\$ 100$ annually, by insulating your attic to R-49. However, because your attic has knob and tube wiring, this would require rewiring your house because knob and tube wiring cannot have insulation placed on top of it. Because of this added expense, insulating your attic is not terribly cost effective with the current price of electricity. We estimate a payback period of 30 years, including incentives. If you chose to rewire your house in the future, we would recommend adding insulation in the attic space at that time.

\section{Add Insulation in the Walls}

The walls in your house are mostly insulated. There is also $1 / 4$ foam that is covered with a reflective foil type of material below the vinyl siding. This makes for an effective radiant barrier. However, we found a few areas that were not well insulated or were not insulated at all. Adding wall insulation will reduce the amount of heat lost during the winter and heat gained during the summer. In addition to reducing the heat transfer through the walls, insulation will help reduce the amount of air leaks and drafts through the walls. Adding insulation to walls in existing homes is typically done by blowing cellulose, fiberglass, or polyurethane foam insulation into the wall cavity through small holes drilled in the exterior siding. The east upstairs wall, the west downstairs wall, and both closet kneewall areas did not appear to be insulated. To avoid cold spots, the uninsulated wall areas should be insulated.

The floor of the cantilevered window in the master bedroom is also not insulated. The joist is 10 " so an R-30 batt should fit nicely. Vapor barrier should be facing up to the winter warm side of the house.

\section{Locally Available Incentives}

- Pacific Power offers an incentive of $\$ 0.35$ per square foot for wall insulation.

- A federal tax credit is also available for $10 \%$ of material costs (does not include labor)

Table 3. Estimated cost and savings for additional wall insulation and air sealing.

\begin{tabular}{|cccc|}
\hline Estimated Cost & $\begin{array}{c}\text { Estimated Annual } \\
\text { Savings }\end{array}$ & Payback Period & $\begin{array}{c}\text { Payback Period } \\
\text { (after incentives) }\end{array}$ \\
\hline$\$ 924$ & $\$ 70 / \mathrm{yr}$ & $13 \mathrm{yr}$ & $8 \mathrm{yr}$ \\
\hline
\end{tabular}
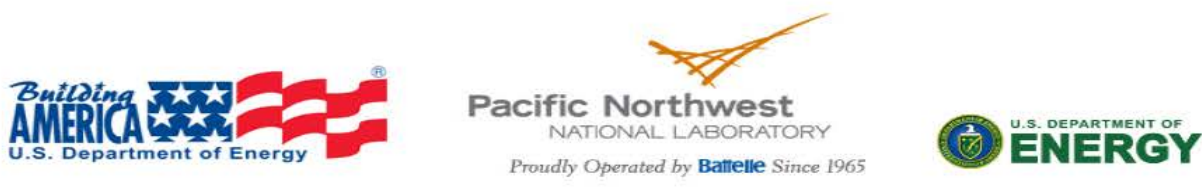


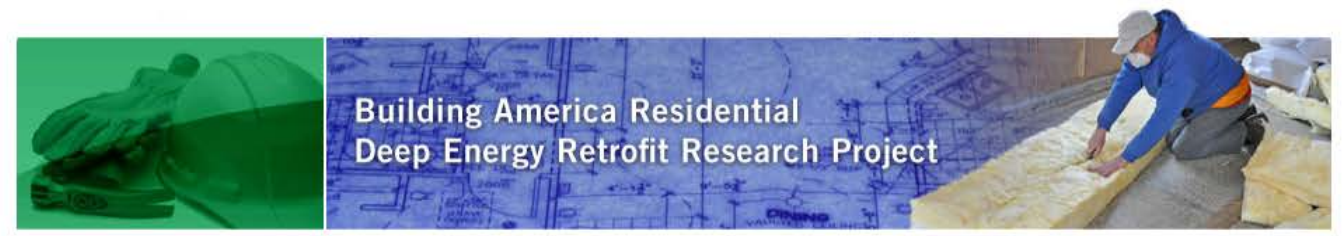

\section{Finish the Basement}

Your basement is also uninsulated and leaky. Concrete and cinder blocks are very poor insulators. A 12-inch-thick concrete wall has an insulation value of around R-1-similar to a single pane of glass! Foundation walls can be insulated on the inside or outside of the wall. Rigid foam board is often used, as is spray-applied foam because they are good moisture barriers as well. Alternatively, stud walls can be constructed in the basement and batt insulation can be installed (this would be a good option if you wanted to finish the basement anyway). If the foundation is insulated on the outside, rigid foam board is typically applied to the wall and a protective barrier is added over the insulation (stucco, cement plaster board, or rolled metal).

For your home, we looked at options of just air sealing your basement, without adding insulation, and finishing your basement with R-11 walls. Air sealing your basement only saved an estimated $2 \%$ on your utility bills, while finishing your basement and insulating the basement walls saved $11 \%$ ! The additional cost of finishing your basement makes the payback period of this measure a little longer than just air sealing, 12 yrs versus $6 y r s$. However, due to the additional energy savings, we recommend framing the walls in your basement and adding fiberglass batts or foam board on the inside of the foundation wall to bring the walls to R- 11 .

The rim joist in the basement is not insulated and you can see daylight in some places. The cavities should be sealed using OSB or rigid foam to block and seal closed the ends of the cantilevered area from the basement. After air sealing, R-19 should be installed in the rim joist with a vapor barrier facing the winter warm side of the house.

\section{Locally Available Incentives}

- A federal tax credit is also available for $10 \%$ of material costs (does not include labor)

Table 4. Estimated cost and savings for finishing basement and air sealing.

\begin{tabular}{|cccc|}
\hline Estimated Cost & $\begin{array}{c}\text { Estimated Annual } \\
\text { Savings }\end{array}$ & Payback Period & $\begin{array}{c}\text { Payback Period } \\
\text { (after incentives) }\end{array}$ \\
\hline$\$ 5,107$ & $\$ 511 / \mathrm{yr}$ & $13 \mathrm{yr}$ & $12 \mathrm{yr}$ \\
\hline
\end{tabular}
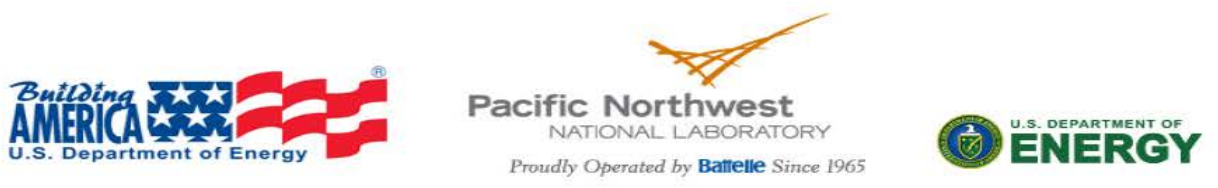


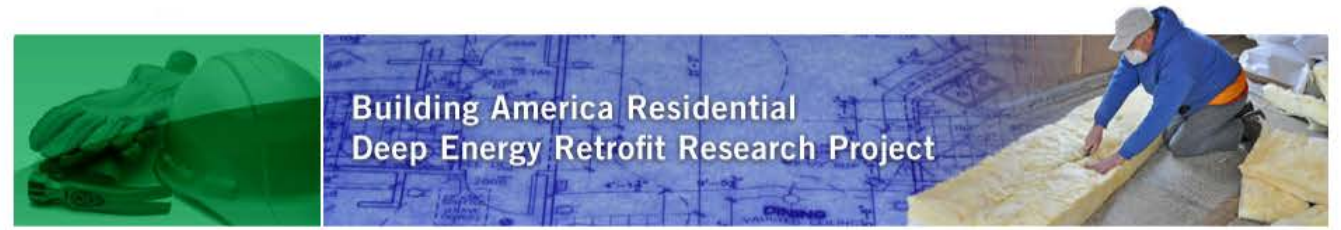

\section{Replace Your Diesel Boiler with a Heat Pump}

Your diesel boiler is old and very inefficient. We estimate that the diesel boiler has an annual fuel utilization efficiency (AFUE) of only slightly over 50\%. There are two primary options for replacing your diesel boiler, one is to replace your existing boiler with a new propane or electric boiler. A new condensing boiler has an AFUE of $91 \%$ and will save $32 \%$ on your energy consumption. A new electric boiler will save $29 \%$. A new boiler will save even more on your energy costs, as both electricity and propane are less expensive than the diesel you are currently purchasing. You should check with your local HVAC contractors about their ability to install these types of boilers and remove the old boiler. Note that removing the old boiler will require a contractor that is licensed for asbestos removal. The costs presented below for new boilers include the cost of removing the existing boiler.

The other option is moving away from hydronic heating and installing a ductless heat pump. We believe that heat pumps offer higher energy cost savings. In the heat mode, heat pumps are rated by their heating season performance factor (HSPF). For new units, the current minimum allowable efficiencies for heat pumps are a SEER of 13 and an HSPF of 7.7. Some models have SEERS of over 20 and HSPFs of over 10 ! There is also the potential to combining ductless heat pumps with limited hydronic heat using your existing diesel boiler during the very cold months, which would drastically reduce your diesel use. However, this would potentially require two thermostats and sophisticated controls. We estimate that a ductless heat pump could reduce your energy consumption by $62 \%$ and your utility bills by $68 \%$ ! In our analysis, we used a SEER 16, HSPF 8.5 heat pump. We would recommend installing at least 4 heads for your home, to ensure good air distribution and thermal comfort. This model would currently qualify for Energy Star tax credits. High efficiency models are available, which would result in greater savings.

\section{Locally Available Incentives}

- A Federal tax credit of $\$ 300$ is available for qualifying heat pump models.

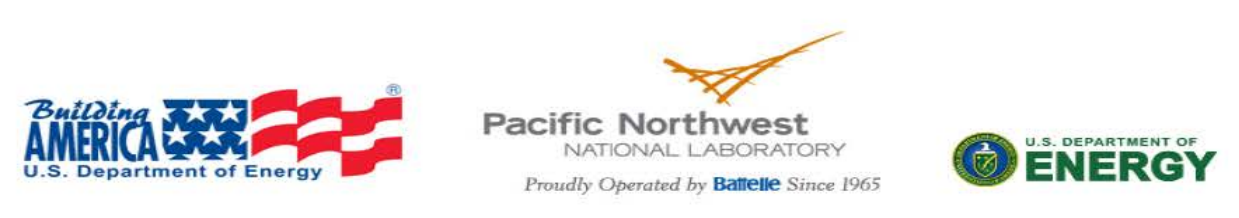




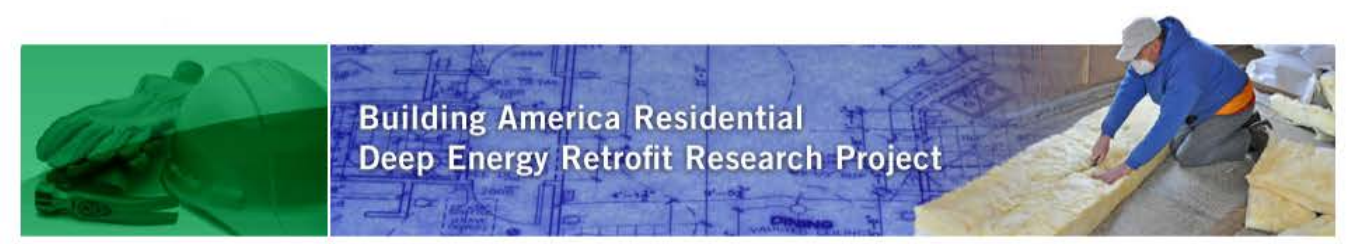

Table 6. Estimated cost and savings for new heating systems.

\begin{tabular}{|c|c|c|c|c|}
\hline Measure & $\begin{array}{c}\text { Estimated } \\
\text { Cost }\end{array}$ & $\begin{array}{c}\text { Estimated } \\
\text { Annual Savings }\end{array}$ & $\begin{array}{c}\text { Payback } \\
\text { Period }\end{array}$ & $\begin{array}{c}\text { Payback Period } \\
\text { (after incentives) }\end{array}$ \\
\hline $\begin{array}{c}\text { Ductless Heat } \\
\text { Pump }\end{array}$ & $\$ 9,300$ & $\$ 2393 / \mathrm{yr}$ & $4 \mathrm{yr}$ & $4 \mathrm{yr}$ \\
\hline $\begin{array}{c}\text { High Efficiency } \\
\text { Propane Boiler }\end{array}$ & $\$ 3,135$ & $\$ 783 / \mathrm{yr}$ & $4 \mathrm{yr}$ & $4 \mathrm{yr}$ \\
\hline $\begin{array}{c}\text { High Efficiency } \\
\text { Electric Boiler }\end{array}$ & $\$ 3,675$ & $\$ 1386 / \mathrm{yr}$ & $3 \mathrm{yr}$ & $3 \mathrm{yr}$ \\
\hline $\begin{array}{c}\text { High Efficiency } \\
\text { Oil Boiler }\end{array}$ & $\$ 3,615$ & $\$ 1079 / \mathrm{yr}$ & $3 \mathrm{yr}$ & $3 \mathrm{yr}$ \\
\hline
\end{tabular}

\section{Replace Your Windows}

Currently, you have single pane wood frame windows. Many of your windows are casements, which are very leaky. Upgrading to energy efficient windows will reduce your energy costs substantially. However, window replacements typically have higher up-front costs and a longer payback period than most other retrofit options. Because of this, new windows are not a cost effective investment for your home. They would save $\$ 278$ a year, but would take 40 years to pay back the upfront cost. You could consider replacing only the upstairs bedroom windows. The original windows are in poor condition and are very leaky. Similar looking casement windows are available with $\mathrm{U}$-values of $<.30$.

Another option to improve the energy efficiency and comfort of your windows is interior storm windows. Interior storms can be installed permanently at all fixed windows and seasonally for all operable windows. The interior storms will increase the efficiency of your windows to about 0.28 and will greatly decrease the drafts you feel next to the cold windows in the winter. Then, in the summer, you can easily remove the interior storms from your operable windows if you are not conditioning your home in the summer. Interior storms are not terribly cost effective either, they have a payback period of 31 years. Again, this could be considered only for the leakiest windows.
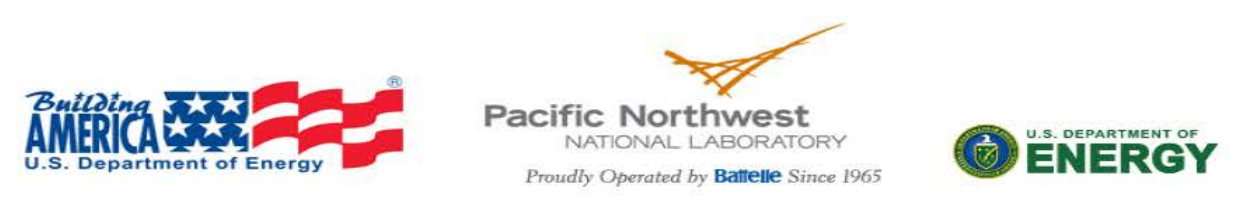
One thing to keep in mind is the increased comfort new windows or interior storms. This value is not reflected in the payback period.

\section{Locally Available Incentives}

- A Federal tax credit is available for up to $\$ 200$ for new windows.

- Pacific Power offers an incentive of $\$ 1.50 /$ sqft for new windows.

- There are no tax credits or incentives available for interior storm windows.

Table 7. Estimated cost and savings for new windows and interior storms.

\begin{tabular}{|c|c|c|c|c|}
\hline Measure & $\begin{array}{c}\text { Estimated } \\
\text { Cost }\end{array}$ & $\begin{array}{c}\text { Estimated } \\
\text { Annual } \\
\text { Savings }\end{array}$ & Payback Period & $\begin{array}{c}\text { Payback Period } \\
\text { (with incentives) }\end{array}$ \\
\hline New Windows & $\$ 11,880$ & $\$ 278 / \mathrm{yr}$ & $44 \mathrm{yr}$ & $40 \mathrm{yr}$ \\
\hline Interior Storms & $\$ 3,156$ & $\$ 100 / \mathrm{yr}$ & $31 \mathrm{yr}$ & $31 \mathrm{yr}$ \\
\hline
\end{tabular}

\section{Install a Solar Thermal System}

Solar water heaters use the sun to warm up water for use in showers, faucets, and the dishwasher. Since you use hydronic heat, solar hot water systems can also be used to pre-heat the hot water before it enters the boiler. Solar water heaters are more expensive that other water-heating options, but they save money over the life of the system. Depending on the size of the system, solar water heaters typically provide $30-75 \%$ of the hot water load. Solar collectors typically perform best when the roof faces due south and the roof angle is about the same as the latitude, $47^{\circ}$, although this can vary based on design considerations.

Your southwest-facing roof has very good solar exposure and would be a good place to locate a solar thermal system. However, it would be very expensive. The results below show the cost and savings for an electric boiler with solar pre-heat, assuming an 80 square foot closed loop
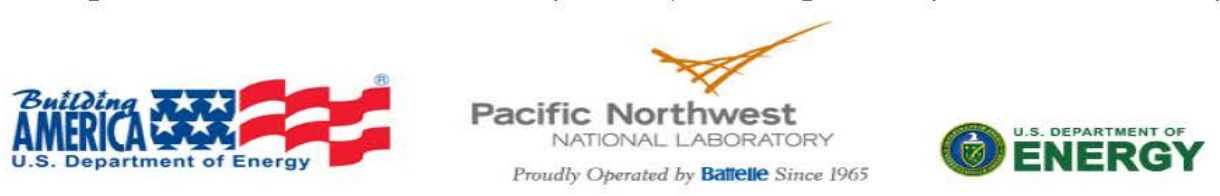


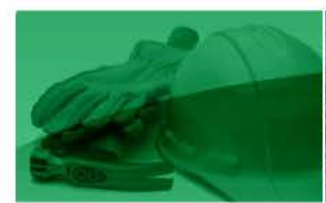

Building America Residential

Deep Energy Retrofit Research Project

solar thermal system. The results would be similar for a new propane boiler or oil boiler. Results are also shown for just installing a solar pre-heat to your diesel system, however this is not as cost effective. Solar thermal is not included in your final recommendation package, due to the additional expense. If you wish to install a solar hot water system, you should check with a solar contractor about the specifics of installing a solar pre-heater to your hydronic system and the best solar thermal system for your home. This would also require you to install a new storage tank. Figure 4 on the next page depicts one possible set up for the solar hydronic system.

\section{Locally Available Incentives}

- There is a $30 \%$ Federal tax credit for solar systems

Table 7. Estimated cost and savings for solar water heating systems. The information for solar hot water pre-heat with an efficient boiler includes the savings of the new boiler.

\begin{tabular}{|c|c|c|c|c|}
\hline Measure & $\begin{array}{c}\text { Estimated } \\
\text { Cost }\end{array}$ & $\begin{array}{c}\text { Estimated } \\
\text { Annual } \\
\text { Savings }\end{array}$ & Payback Period & $\begin{array}{c}\text { Payback Period } \\
\text { (with incentives) }\end{array}$ \\
\hline $\begin{array}{c}\text { Solar water pre- } \\
\text { heat with } \\
\text { existing diesel }\end{array}$ & $\$ 7,500$ & $\$ 295 / \mathrm{yr}$ & $25 \mathrm{yr}$ & $24 \mathrm{yr}$ \\
\hline $\begin{array}{c}\text { Solar water pre- } \\
\text { heat with new } \\
\text { efficient boiler }\end{array}$ & $\$ 11,175$ & $\$ 2172 / \mathrm{yr}$ & $5 \mathrm{yr}$ & $4 \mathrm{yr}$ \\
\hline
\end{tabular}

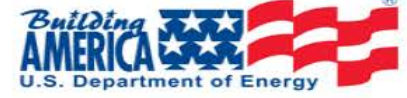

Pacific Northwest

NATIONAL LABORATORY

Proudly Operated by Battelle Since 1965

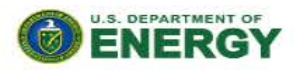




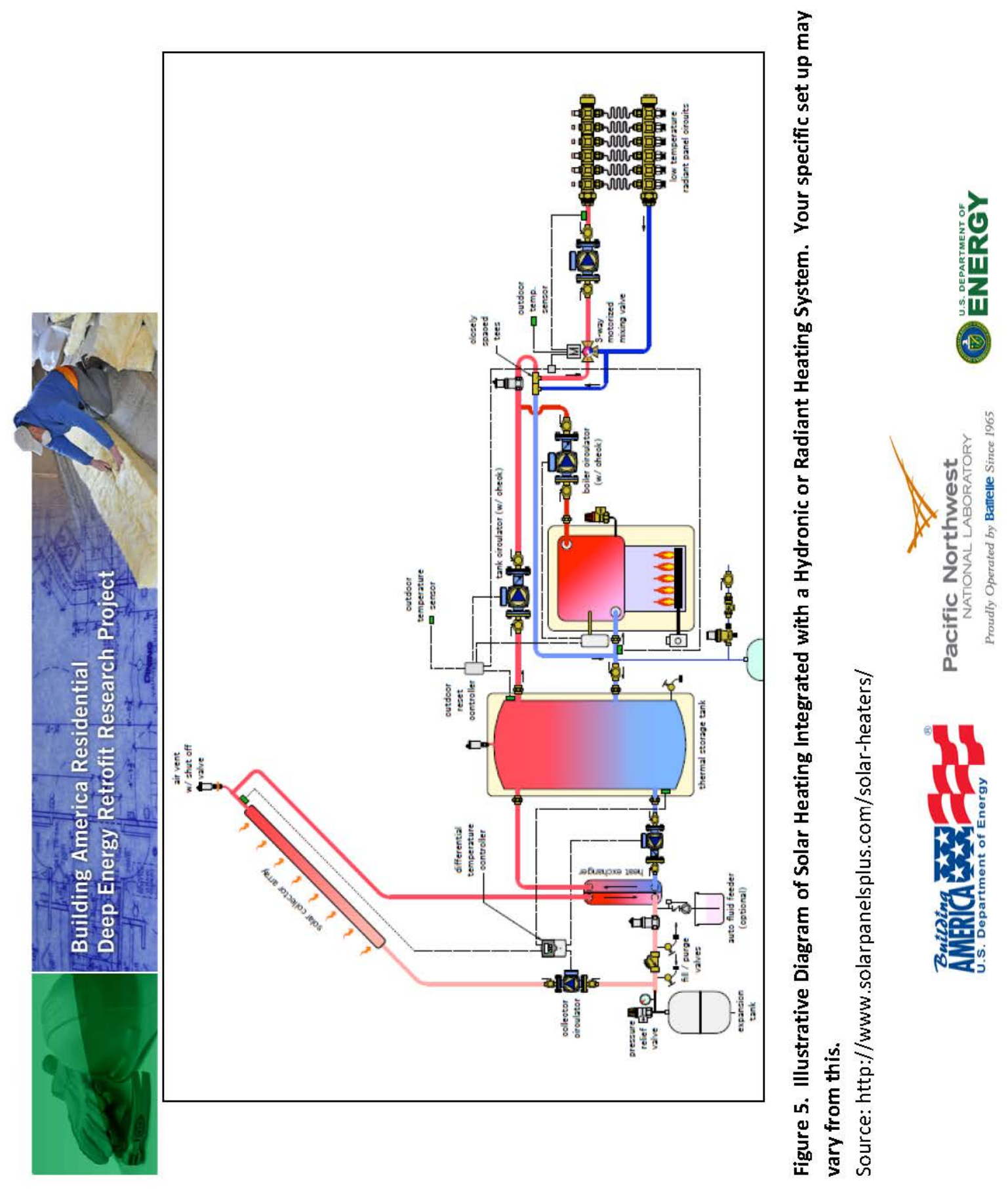




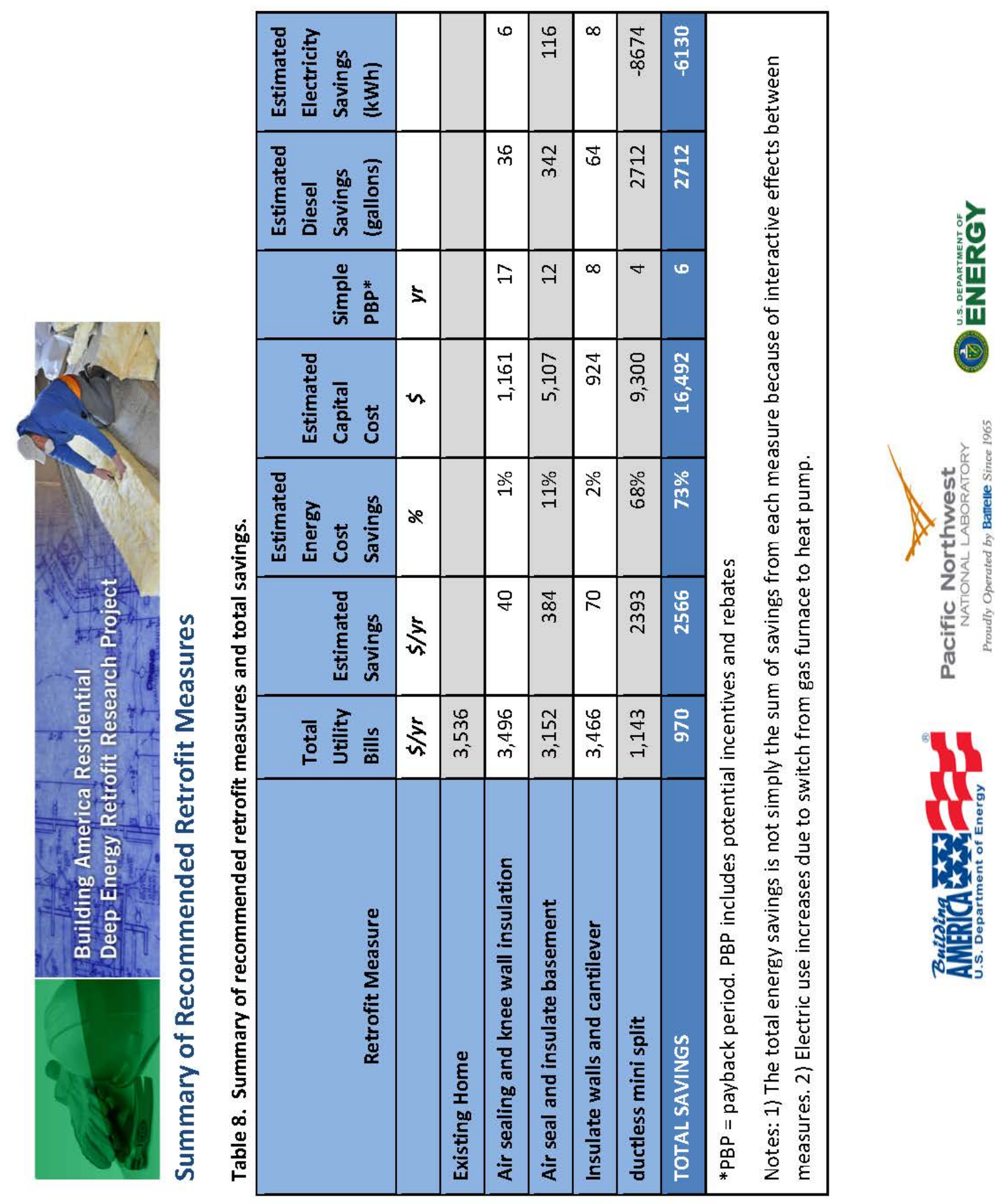



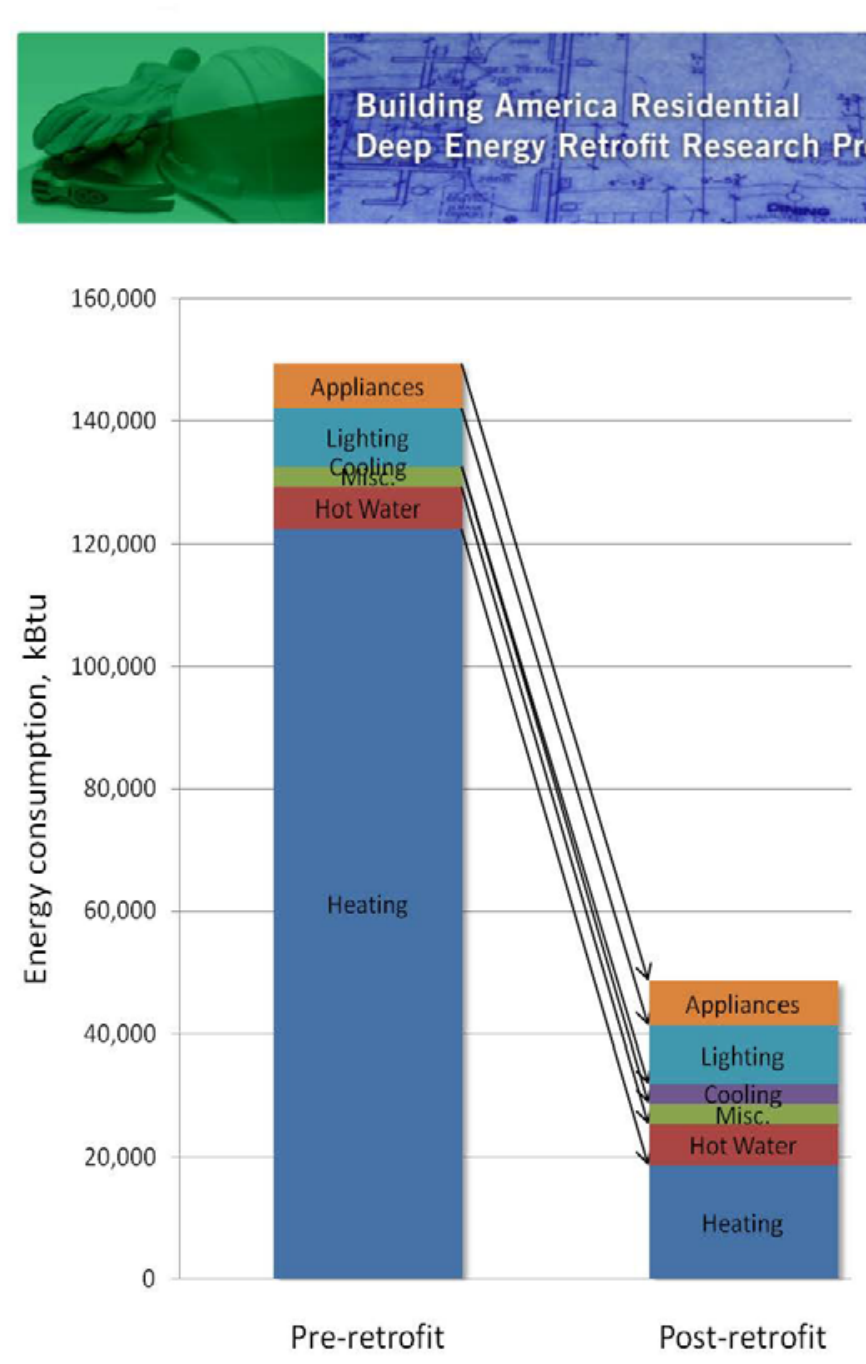

Figure 6. Percentage Energy Consumption and Estimated Savings in Your Home. This chart is calculated in terms of site energy consumption on a Btu basis. Kilowatt-hours of electricity and therms of natural gas are converted to Btus using the mean
Most of the savings achieved in this package will reduce your space conditioning load, as can be seen in Figure 5, at left. The graph shows your original energy consumption compared to your energy consumption after your have completed all the recommended retrofits.

The Appliances, Lighting, and Misc. categories represent what is referred to as "base load," or energy consumption that is fairly constant throughout the year. The following section provides easy doit-yourself improvements that can help you reduce your base load and further decrease your overall energy consumption.
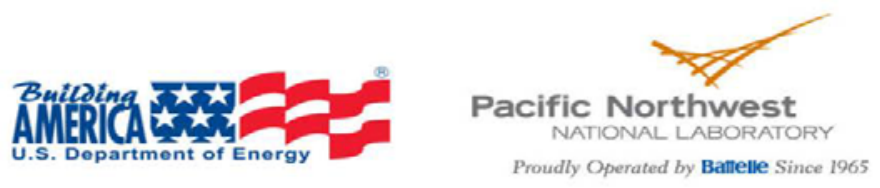

\section{OENERGY}




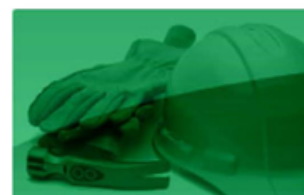

Building America Residential

Deep Energy Retrofit Research Project

\section{Easy Do-It-Yourself Improvements}

\section{Add Pipe Insulation to Your Hot Water Pipes}

Pipe insulation is a simple energy-saving measure you can implement yourself. Pipe foam (or fiberglass pipe insulation) should be installed on at least the first few feet of pipe leaving the hot water tank (especially the hot side). Pipe foam can be purchased at local hardware stores for around $\$ 1.50-\$ 2.00$ per foot. If you install pipe foam, be sure that it is secured to the pipe. Estimated annual savings are about $\$ 8$ and per year.

\section{Use Power Strips to Turn Off Appliances That are Not Being Used}

Some home appliances draw power even when they are not being used. These draws on power are often called "phantom loads." One way to avoid phantom loads is to plug non-essential appliances into a power strip. When the appliances are not in use, simply turn off the power strip. Be sure to use a separate power strip or outlet for any essential appliances.

\section{Replace Your Incandescent Lights with Compact Fluorescents}

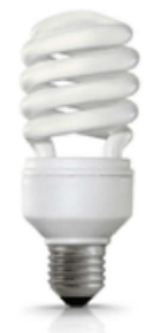

ENERGY STAR-qualified compact fluorescent lamp (CFL) bulbs use about $75 \%$ less energy than standard incandescent light bulbs. They also last about 10 times longer than comparable incandescent bulbs. Annual savings depend on how many hours you use each bulb, but CFLs typically pay for themselves with energy savings within 1-2 years.

We estimate that 46 bulbs could be replaced throughout your home, yielding a total annual savings of $2112 \mathrm{kWh}$ and $\$ 105$. A note about CFLs: CFLs contain a small amount of mercury. At the end of their life, be sure to recycle the bulbs properly. Some stores, such as Home Depot, will accept bulbs that no longer work. For more guidance on recycling bulbs and what to do if a bulb breaks, see this website from Pacific Power (available at: http://www.pacificpower.net/res/sem/het/lighting/pcd.html).
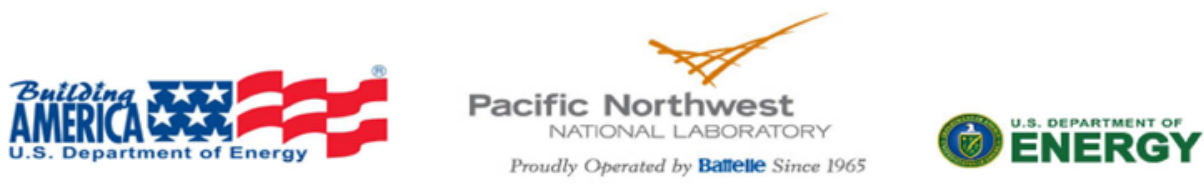


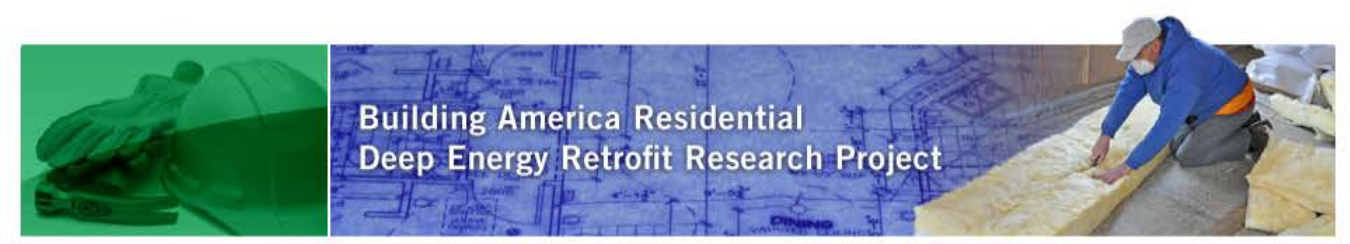

Table 8. Estimated cost and savings for CFL lightbulb replacement.

\begin{tabular}{|cccc|}
\hline Estimated Cost & $\begin{array}{c}\text { Estimated Annual } \\
\text { Savings }\end{array}$ & Payback Period & $\begin{array}{c}\text { Payback Period } \\
\text { (after incentives) }\end{array}$ \\
$\$ 184$ & $\$ 105 / \mathrm{yr}$ & $2.6 \mathrm{yr}$ & $2.6 \mathrm{yr}$ \\
\hline
\end{tabular}

\section{Install Low-flow Showerheads and Faucet Aerators}

A simple way to save on your water heater costs is to use low-flow plumbing fixtures. New showerheads offer suitable spray while using less hot water. There are many available models that use around 2 gallons per minute (gpm). Older showerheads can use more than $5 \mathrm{gpm}$.

Similarly, hot water use in faucets can be reduced by using installing faucet aerators. Look for aerators that limit the faucet flow to about $1 \mathrm{gpm}$. Also, when shopping for aerators or lowflow showerheads, look for the WaterSense label. WaterSense is a U.S. Envivronmental Protection Agency program that certifies water-saving fixtures.

\section{Additional Resources}

For more information, the following websites provide additional energy-saving tips for home owners looking to make energy efficiency improvements to their homes:

- http://www.energvsavers.gov/

- http://www.aceee.org/consumer

- http://www.energystar.gov/

- http://www.nahb.com/

- http://www1.eere.energy.gov/buildings/

In addition, the Building America website (http://www1.eere.energy.gov/buildings/building america/) and the Building Science Corporation website (http://www.buildingscience.com/index html) provide a number of good resources related building design and construction of energy efficient homes.
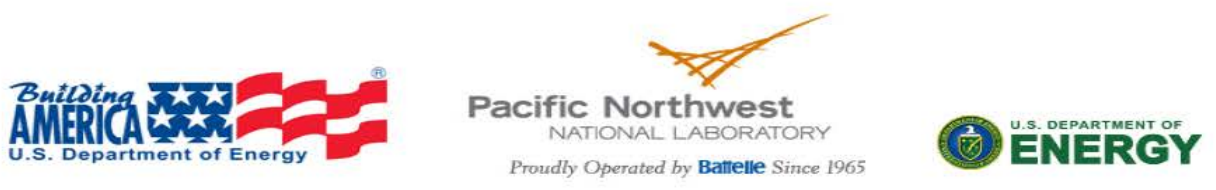


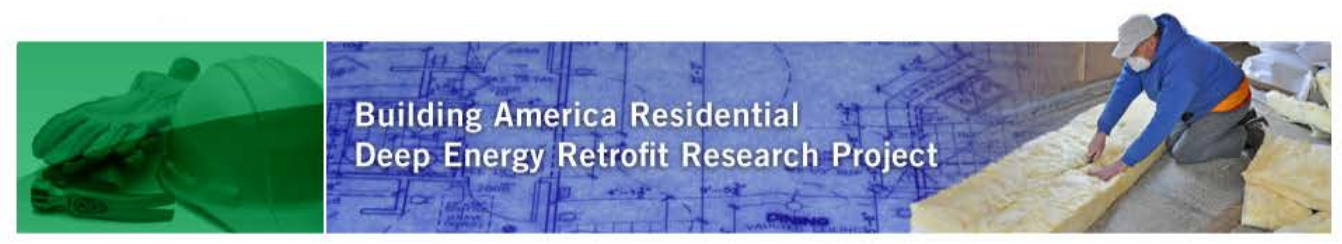

\section{Incentives and Rebates}

Various incentives are available to help pay for energy efficiency measures. For example, many of local utilities offer incentives. Several of these incentive or rebate options are identified in the audit information provided above. In addition to the incentives and direct rebates identified for your specific recommendations above, the Bonneville Power Association offers a "custom incentive" of $\$ 0.27$ per kWh saved. This custom incentive can be used instead of (but not in addition to) the project-specific rebates. More information can be found on your local utilities website (http://www.pacificpower.net/res/sem/epi.html). Another good resource for finding energy efficiency rebates anywhere throughout the country is www.dsireusa.org/.

Federal tax incentives are also available for ENERGY STAR products. Many of the recommended measures may be eligible for a tax credit worth $10 \%$ of the materials cost, or a specified amount (for example, ENERGY STAR furnaces are eligible for a $\$ 150$ tax credit). These incentives have also been identified in the cost estimates provided above. More information about this program is available at the following website:

http://www.energystar.gov/index.cfm?c=tax credits.tx index.
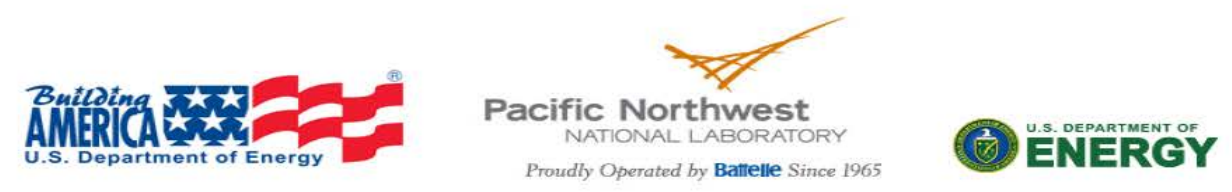

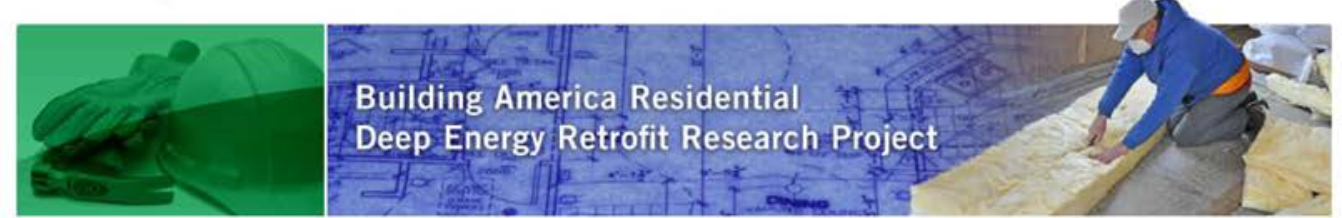

\section{Residential Deep Energy Retrofit Research Project}

\section{Audit Report for a Split-Level Home in Richland}

Audit Date: 6/07/2011

Pacific Northwest National Laboratory Research Team http://deepenergyretrofits.pnnl.gov/

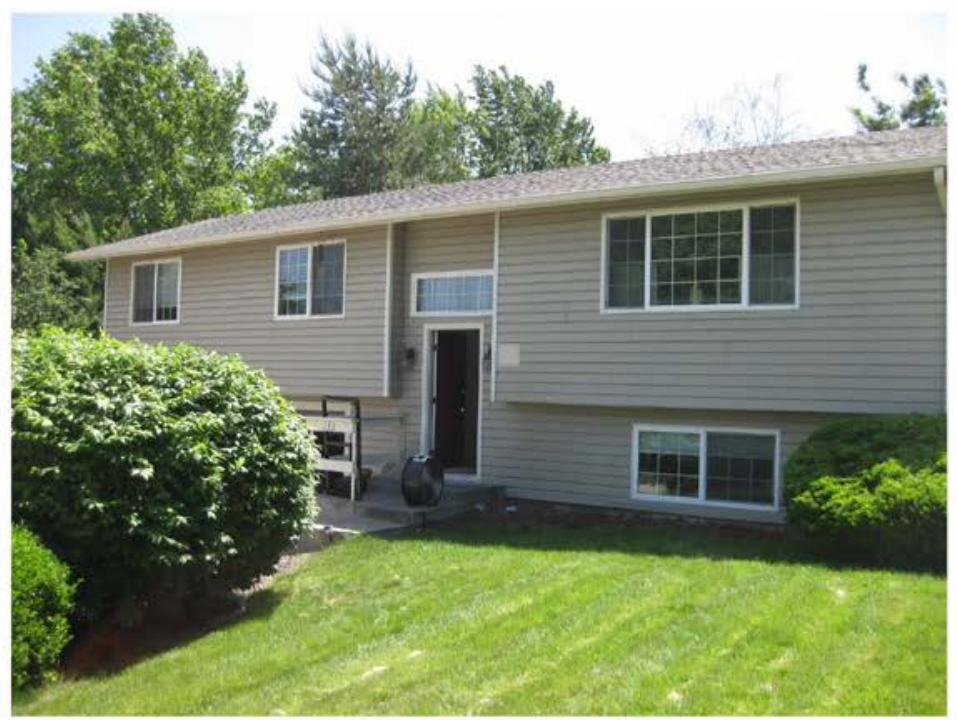

Notices:

1. This report is intended for the sole use of the homeowner(s) and the PNNL deep retrofits study team members (including subcontractors) that have completed training to protect the privacy and other rights of human subjects in research programs. PNNL will not share this report with anyone but may include data and information from this report, in an anonymous manner, in the final report that will be submitted to the U.S. Department of Energy.

2. The quantitative information in this report on energy savings, costs and economic benefits are based on computer models. Please note that actual savings and costs can be quite different (may be even a factor of 2 or more) depending on homeowner lifestyle, actual performance of energy saving equipment and strategies, variations in local weather, contractor business models and other unforeseen factors.

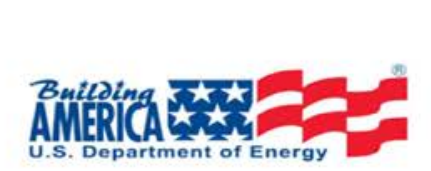

\section{Pacific Northwest}




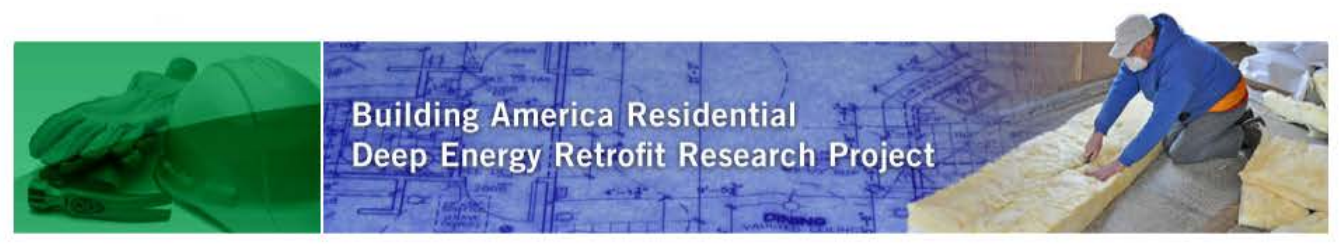

\section{Existing Home Characteristics and Performance}

The house is a single-family, two-story split-level home with an attached garage built in 1971. It has 3 bedrooms and 2 baths; a total conditioned space of 1,692 square feet $\left(\mathrm{ft}^{2}\right)$. The original building envelope above grade is wood-frame construction with an R-11 batt in the walls. Below grade the walls are concrete with an R-11 batt added to the walls. The floor is an uninsulated slab. The concrete walls are finished with sheetrock with the exception of a small area below the stairs. The attic is vented and has R-19 fiberglass batt insulation over R-9 fiberglass blown insulation. The windows are double-pane glass with a low-e film and vinyl frames. Heating is provided by a forced air furnace using resistance heat. Cooling is provided by a 3 ton air-conditioning unit with a seasonal energy efficiency ratio (SEER) of 10 . There is a pellet stove in the basement. The pellet stove was not considered in this report due to intermittent use and occasional interruption of supply of pellets. Because of this, actual savings and payback periods may vary from those reported. The forced-air ducts are constructed with sheet metal and run within the conditioned space of the basement and the unconditioned space of the garage.

\begin{tabular}{lc}
\hline Energy Costs Information & Electricity, \$ \\
\hline Average Utility Bill & 147.50 \\
\hline Maximum Utility Bill & 289.38 \\
\hline Minimum Utility Bill & 73.21 \\
\hline
\end{tabular}

\section{Recommended Energy Efficiency Retrofit Measures}

The home was audited to quantify its energy performance. The home energy audit consists of several elements: a blower door test to characterize building envelope leakage, a duct test to characterize duct leakage, thermal imaging to identify key leaks, evaluation of insulation levels, and examination of all energy-consuming appliances.

During the audit of your home, we noticed several opportunities to save energy in costeffective ways. The ensuing sections of this report summarize each energy-saving measure and related energy-audit findings and provide the estimated energy savings, cost of each recommended measure, and associated payback period. The simple payback period is the number of years that it will take to pay off the upfront investment with energy cost savings (the shorter, the better). The payback period provides a quick economic metric that can be used to
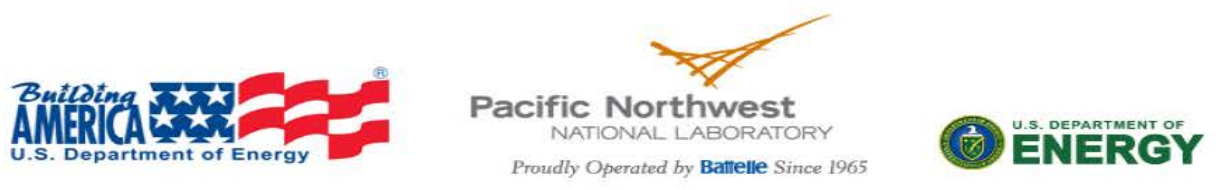


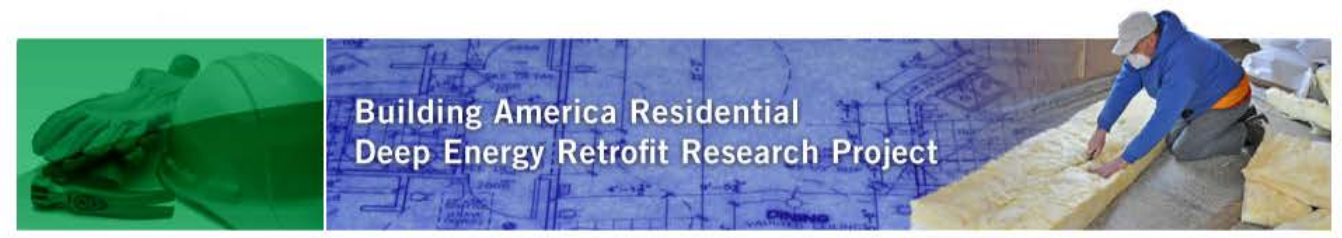

prioritize the measures. The ensuing sections also briefly summarize locally available incentives that may be available to help pay for energy-saving measures. Most of the savings estimates included here are based on computer simulations of your home. The costs provided are rough estimates based on our experiences with the energy-saving measures, quotes from local contractors, and publically available information, like the National Renewable Energy Lab's National Measures Database ${ }^{1}$. Your actual costs will depend on the contractor you choose, the final scope of work, and the current material prices. Finally, we have provided payback periods for each measure.

We think that you can cost-effectively reduce your energy use by around $43.3 \%$. Your actual savings will depend on which measures are implemented (as well as any changes in usage patterns, occupancy, etc.). The savings associated with each measure also will be affected by other measures that you implement, so, as we develop the final package of measures, savings estimates will vary.

Please read through the measures described below and let us know if you have any questions. Once we have discussed the cost-saving measures available to you and agreed on a package that fits your needs, the next step will be to start asking contractors for bids on the energysaving projects (recognizing that you can complete some projects yourself).

\section{Air Sealing}

Cracks, gaps, and holes located throughout your home waste energy by letting in hot air in the summer and cold air in the winter, or conversely, letting conditioned air out! During our audit, we performed a blower door test, which uses a calibrated fan and pressure gauges to measure the overall leakiness of your home. We found that if you added up all of the leaks in your home, the cumulative effect would be equivalent to having a hole 10 inches wide by 10 inches tall in the building envelope. This is like leaving a window open all year! These results are given in more detail below.

${ }^{1}$ National Renewable Energy Laboratory. "National Measures Database." Available at: http://www.nrel.gov/ap/retrofits/.
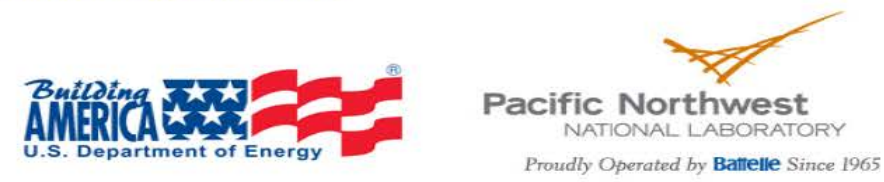


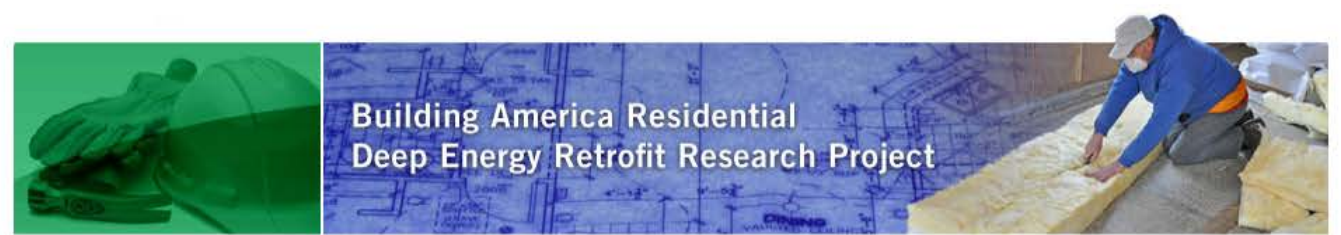

Table 1. Air Leakage Test Results

\begin{tabular}{lrl}
\hline Conditioned Floor Area & $1,692 \mathrm{ft}^{2}$ \\
\hline Conditioned Volume & $12,690 \mathrm{ft}^{3}$ \\
\hline Airflow in cubic feet per minute at -50 Pascals & $1,870 \mathrm{cfm50}$ \\
\hline Air Changes per Hour at -50 Pascals & $8.84 \mathrm{ACH} 50$ \\
\hline Effective Leakage Area & $102.6 \mathrm{in}^{2}$ \\
\hline Relative airflow at -50 Pascals & $1.105 \mathrm{cfm} 50 / \mathrm{ft}^{2}$ \\
\hline Range of relative airflow for other homes tested in the Tri-cities & $0.8-1.18 \mathrm{cfm} 50 / \mathrm{ft}^{2}$ \\
\hline
\end{tabular}

In new homes that are Energy Star rated the target for air sealing is 4 Air Changes per Hour at 50pa (ACH50). Your home is currently rated at $8.84 \mathrm{ACH} 50$.

Most of the improvement in leakage to the outside can be made by sealing your duct system, which will be addressed in a later section of this report.

Other means of sealing up holes and cracks are to use caulk, expanding spray foam, door weather-stripping, and a variety of other materials. Several leaks were also found in your attic. Typically, it is more cost effective to air seal prior to installing additional insulation in the attic. As such, the energy savings from sealing the penetrations and addition insulation in your attic will be addressed together in the next section of this report.

\section{Add Insulation and Air Sealing}

Attic insulation reduces the amount of heat transferred through the ceiling. In the winter, heat is lost into the attic. In the summer the attic space, which gets very hot, transfers unwanted heat through the ceiling into the home. Cellulose and fiberglass insulation are typically used when adding insulation into existing homes. Cellulose and fiberglass are blown into the attic through a hose. This application is known as loose-fill (as opposed to batts of insulation). Before adding insulation, it is important to seal any leaks in the attic floor (it is much more difficult to seal leaks afterwards). Spray foam and caulk can be used to seal most leaks, though other materials may be used if leaks are very large (fire rated materials must be used where appropriate). Contractors will temporarily move the insulation aside while they air seal. Leaks

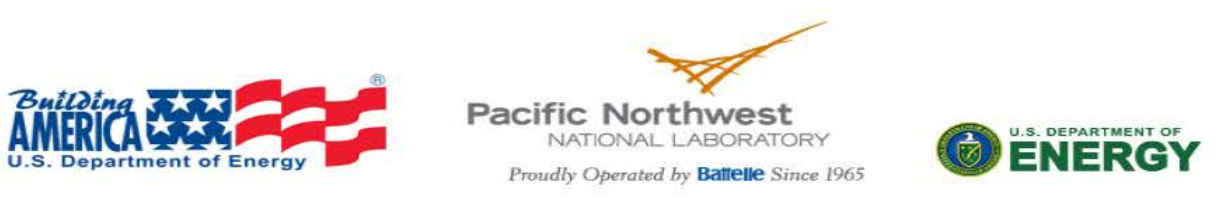




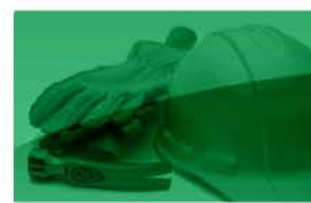

Building America Residential

Deep Energy Retrofit Research Project

are often found around holes drilled for wiring or plumbing, the top plates of interior walls, and attic hatches. (For more information, see the Building America Air Sealing Guide ${ }^{2}$.

Your attic could also benefit from additional insulation. Currently, the insulation value varies from around R-9 to R-28. The original insulation is about $3^{\prime \prime}$ of blown-in fiberglass. On top of this was added R-19 fiberglass batts. There are several gaps around the edges of the batts, which degrades the overall R-value considerably. It would be useful to blow an additional R-32 of fiberglass insulation (giving you a total of R-60) into the attic to level out the existing insulation as well as provide an added thermal barrier between the conditioned house and the attic.

Other areas that need insulation include the small uninsulated portion of the basement wall under the stairs, as well as the cantilever under the bedroom floor that is accessible through the garage.

\section{Locally Available Incentives}

- The City of Richland has a low interest loan that can be used for attic insulation.

- A federal tax credit is also available for $10 \%$ of material costs (does not include labor)

Table 2

\begin{tabular}{cccc|} 
Estimated Cost & $\begin{array}{c}\text { Estimated Annual } \\
\text { Savings }\end{array}$ & Payback Period & $\begin{array}{c}\text { Payback Period } \\
\text { (after incentives) }\end{array}$ \\
$\$ 1,200$ & $\$ 151$ & $8 \mathrm{yr}$ & $8 \mathrm{yr}$ \\
\hline
\end{tabular}

\section{Reconfigure, Seal, and Insulate the Ducts}

During the interview you had mentioned that comfort was an issue in both the summer and winter. A true-flow test was performed and found that your duct system is significantly undersized and restricts air flow to only $1 / 2$ of the air required for a system of your size. A 3 ton air conditioner requires $1,200 \mathrm{cfm}$ to operate as designed. The measured airflow in your duct system was only $660 \mathrm{cfm}$. This is due to a poor design of the original return air register

\footnotetext{
${ }^{2}$ Building America's Air Sealing Guide can be found here; http://wwwl.eere.energy.gov/library/asset handler.aspx? src=http:/appsl.eere.energy.gov/buildings/publications/pdf s/building america/ba airsealing report.pdf\&id $=4663$
}

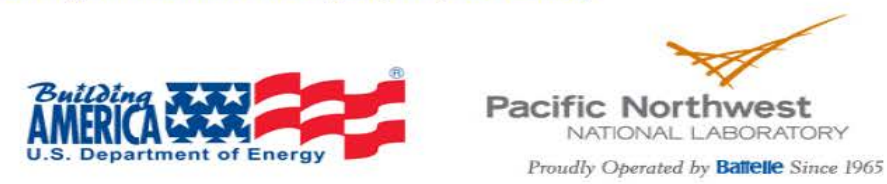




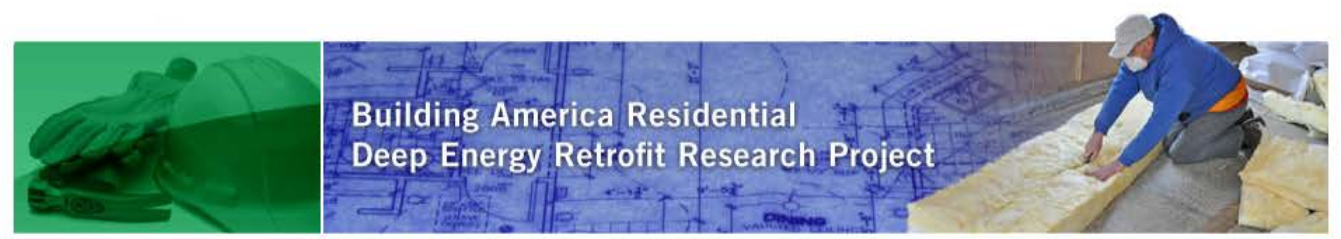

and duct. After talking to HVAC professionals it was determined that the constricted ducts reduced your $A C$ efficiency by about $15 \%$.

To compensate for the lack of air flow, it appears that an additional return air grill was installed in the garage. Due to the constraints of the existing return duct size this additional return did not help matters. It actually reduced the efficiency of both your air conditioner and your electric furnace by introducing unconditioned air from the garage. Due to the proximity and size of the added return duct about $1 / 4$ of the air entering the air handler is unconditioned air. Fortunately, you do not park your car or keep other hazardous chemicals in your garage. However, if you chose to convert your garage back to its original purpose (to park your car and store paint, cleaning supplies, and other items) or if future homeowners did so, this return air grill in your garage would pose a significant health and safety concern. Reconfiguring your return ducts will improve your comfort levels, reduce your energy usage, and eliminate pollutants that may have been entering you home through the garage.

Ducts located in unconditioned attics, crawlspaces, and garages can be a huge source of energy waste. In the summer, for example, the cold air from the air conditioner is subjected to extremely high temperatures. The opposite is true during winter. The ducts in the garage are covered with a thin foil wrap the has an $\mathrm{R}$ value of about 1 . Each time you double the $\mathrm{R}$ value you cut the heat loss in $1 / 2$. It's recommended that ducts in an unconditioned space, such as the garage, should be a minimum of R-11.

Ducts should be both well insulated and air tight. Duct joints are generally sealed with either duct mastic or tape made specifically for duct systems (standard duct tape will not work!!). A test of the ducts revealed that they are leaking to both the interior of the home as well as the exterior. For energy savings purposes we are only concerned about leakage to the outside of the house. For air quality purposes you may want to consider having some of the ducts in the interior of the house reconstructed and sealed. Your current duct system uses building cavaties as part of the duct system. This type of duct system is difficult to clean and also builds up dust, bits of insulation, and other debris more readily. Below is an analysis of how your ducts performed. A new home of your size, built to Energy Star standards, would require the ducts to be have no more than 63 cfm@25 leakage.
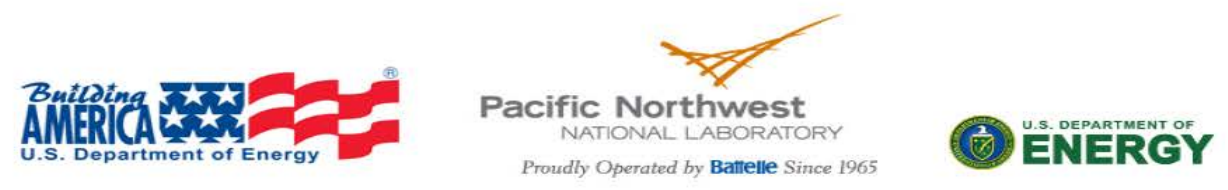

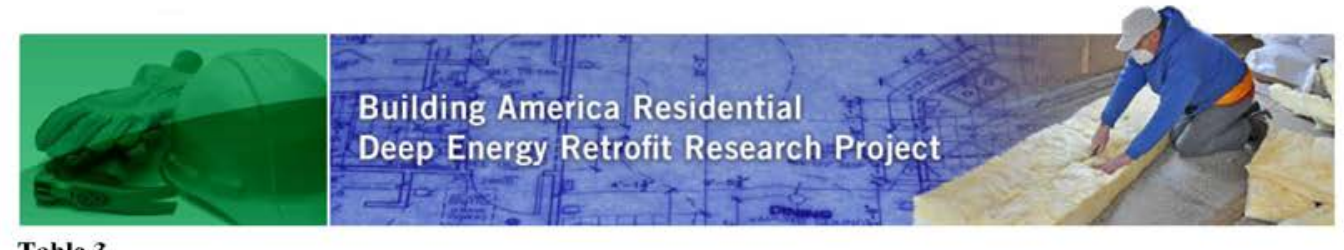

Table 3

\begin{tabular}{lrl}
\hline Total duct leakage at -25 Pascals & $700 \mathrm{cfm} 25$ \\
\hline Duct leakage to outside (or garage) at -25 Pascals & $400 \mathrm{cfm} 25$ \\
Relative leakage per ft ${ }^{2}$ of floor area & $0.23 \quad \mathrm{cfm}^{25} / \mathrm{ft}^{2}$ \\
\hline Typical leakage to outside, Tri-cities & $46-500 \mathrm{cfm} 25$ \\
\hline
\end{tabular}

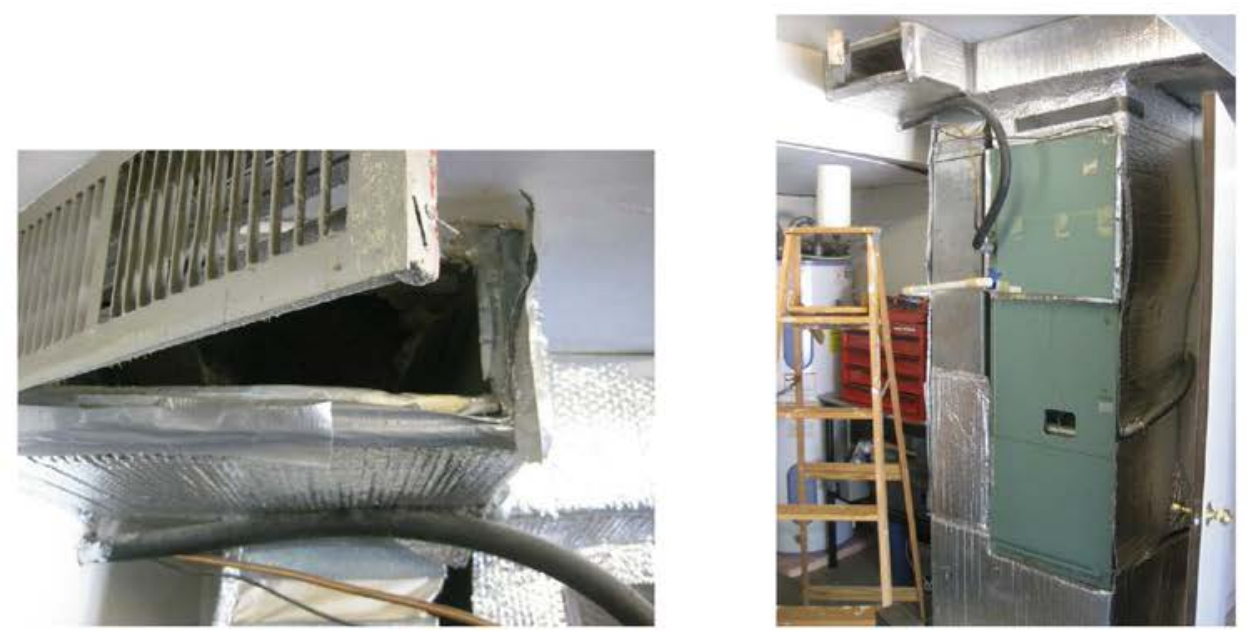

Left: Return duct that introduces unconditioned air and pollutants from the garage. Right: Air Handler and ducts in the garage. Foil wrap is not adequate insulation.
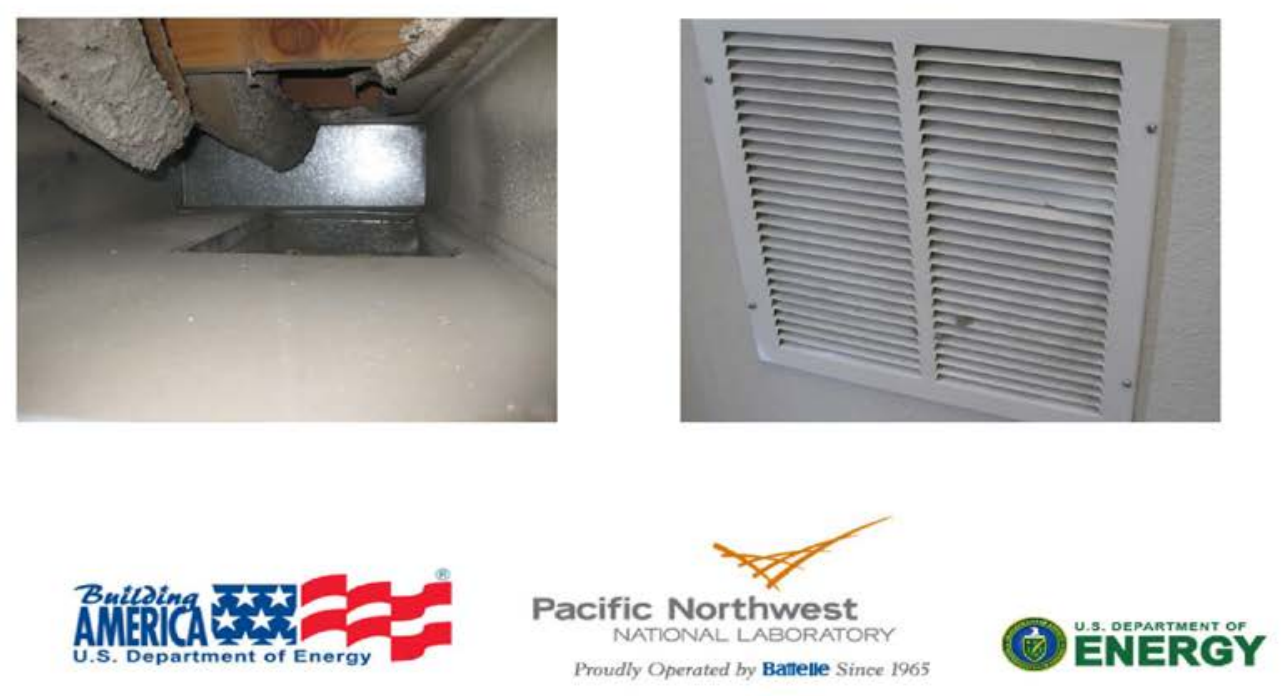


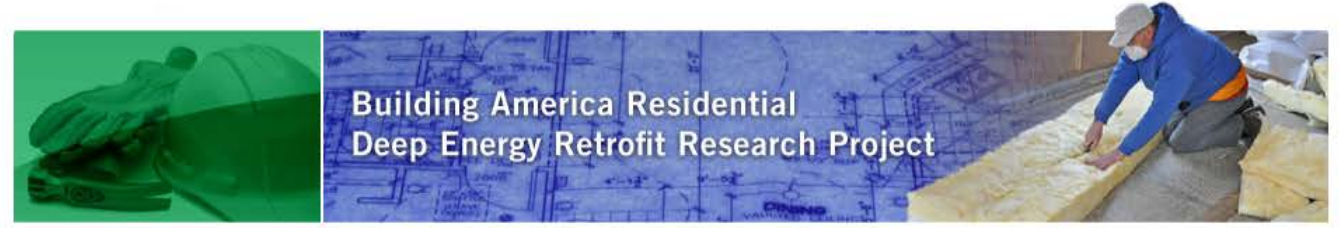

Left: Inside of return duct in upstairs hall. While leakage to the inside is not considered a factor in energy efficiency, this type of construction could very well be leaking to the outside through the joist between the floors. Right: Since it's not possible to professionally clean this type of duct system (notice the insulation on the left) our test pushed a large amount of dust through the system, indicating that air quality could be a problem.

The duct system is the key to comfort and efficiency in your house. The chart below will show you the energy savings and payback for implementing our recommendations. Since reconstructing the return air is a large part of the solution you should consider moving the entire air handling system into the conditioned space of the house. This would save energy by bringing your duct system entirely into conditioned space and eliminating any leakage to the outside.

\section{Locally Available Incentives}

- The City of Richland has a low interest loan that can be used for improvements to the duct system.

Table 4

\begin{tabular}{|cccc|}
\hline Estimated Cost & $\begin{array}{c}\text { Estimated Annual } \\
\text { Savings }\end{array}$ & Payback Period & $\begin{array}{c}\text { Payback Period } \\
\text { (after incentives) }\end{array}$ \\
\hline$\$ 1,000$ & $\$ 176 / \mathrm{yr}$ & $4 \mathrm{yr}$ & $4 \mathrm{yr}$ \\
\hline
\end{tabular}

\section{Replace Your Furnace/AC units with a Heat Pump}

Your furnace is about 30 years old. Your AC unit appears to be newer and was probably installed in the last 3-5 years. The efficiency of AC units is rated by their SEER. Your unit has a SEER of about 10 . Electric furnace efficiency is rated by the coefficient of performance (COP); yours has a COP of about 1 . This means that all of the electricity delivered to your furnace winds up as heat. However, heat pumps can have COPs from 1.5 to 4 and, thus, offer higher energy cost savings. In the heat mode, heat pumps are rated by their heating season performance factor (HSPF). For new units, the current minimum allowable efficiencies for heat pumps are a SEER of 13 and an HSPF of 7.7. Some models have SEERS of over 20 and HSPFs of over 10 !

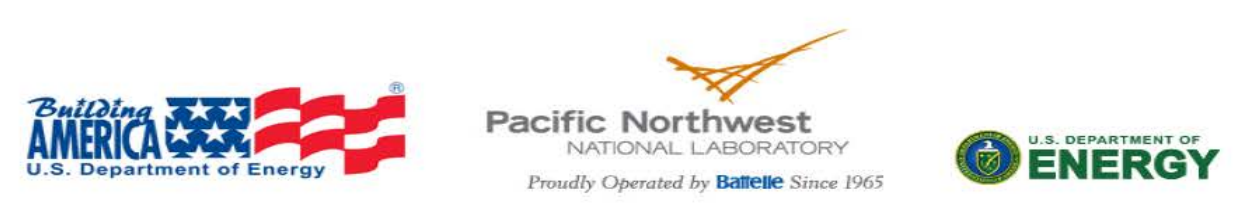




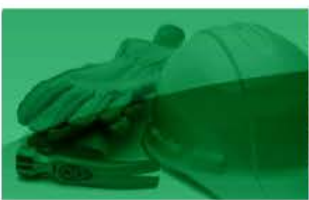

Building America Residential

Deep Energy Retrofit Research Project

At the moment, the economics of replacing your heating and cooling systems are not great. However, as energy prices rise, the economics will improve. If you do not replace your system now, keep these recommendations in mind. Over the next 5-10 years, your systems will approach the end of their useful lives, and the economics of high efficiency units will greatly improve if only the incremental cost of installing a higher efficiency unit is considered. If other measures that have been recommended are completed you could reduce the size of a new heat pump resulting in less cost and a longer life of a new unit.

\section{Locally Available Incentives}

- A Federal tax credit of $\$ 300$ is available for qualifying models. In our analysis, we used a SEER 17, HSPF 10 heat pump. This model would currently qualify for energy star tax credits. High efficiency models are available, which would result in greater savings.

- The City of Richland has a low interest loan program that allows for a new heat pump.

Table 5

\begin{tabular}{|cccc|}
\hline Estimated Cost & $\begin{array}{c}\text { Estimated Annual } \\
\text { Savings }\end{array}$ & Payback Period & $\begin{array}{c}\text { Payback Period } \\
\text { (after incentives) }\end{array}$ \\
\hline$\$ 7,000$ & $\$ 285 / \mathrm{yr}$ & $18 \mathrm{yr}$ & $18 \mathrm{yr}$ \\
\hline
\end{tabular}

\section{Replace Your Furnace/AC units with a Heat Pump, Reconfigure, Insulate, and Seal your Ducts}

Replacing your forced air electric furnace and air conditioner with a heat pump might best be considered as a package along with reconfiguring, insulating, and sealing your ducts. When combined with these measures the payback is more reasonable.

Table 6

\begin{tabular}{|cccc|}
\hline Estimated Cost & $\begin{array}{c}\text { Estimated Annual } \\
\text { Savings }\end{array}$ & Payback Period & $\begin{array}{c}\text { Payback Period } \\
\text { (after incentives) }\end{array}$ \\
\hline$\$ 8,000$ & $\$ 685 / \mathrm{yr}$ & $12 \mathrm{yr}$ & $12 \mathrm{yr}$ \\
\hline
\end{tabular}

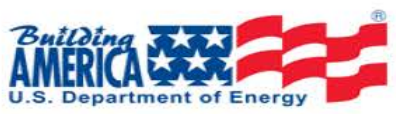

Pacific Northwest

NATIONAL LABORATORY

Proudly Operated by Battelle Since 1965 


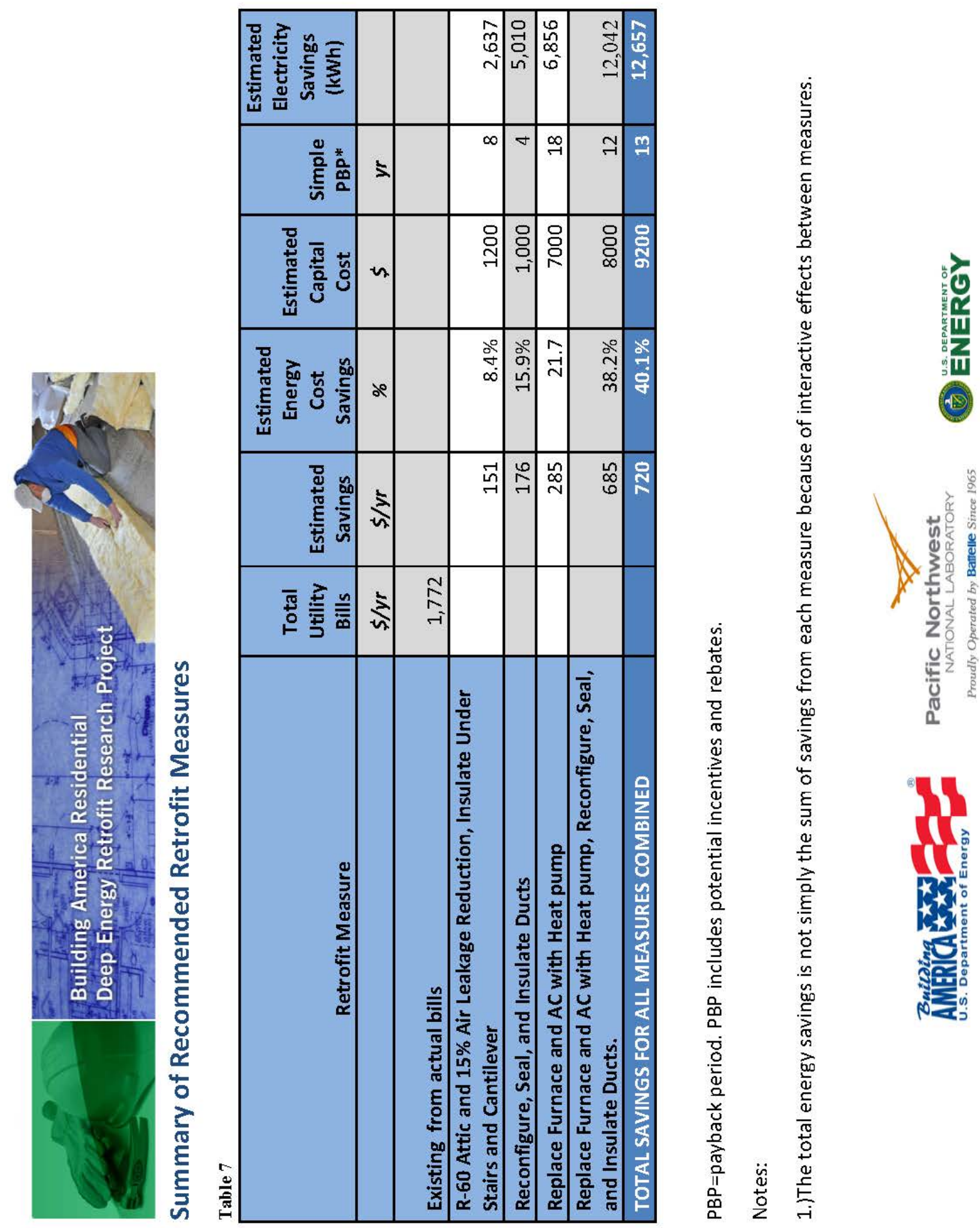




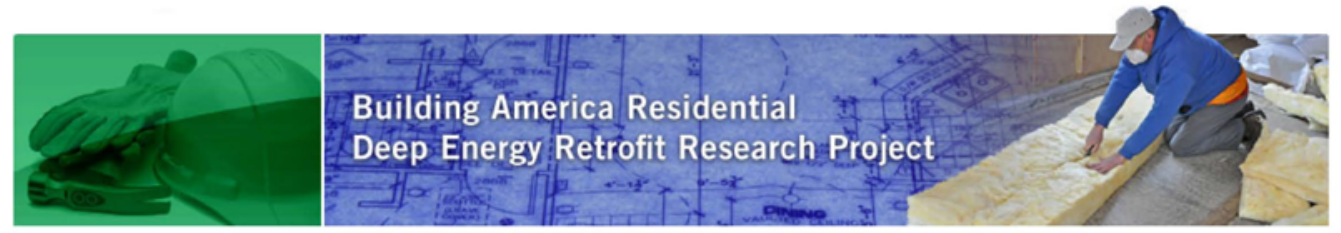

\section{Easy Do-It-Yourself Improvements}

\section{Add Pipe Insulation to Your Hot Water Pipes}

Pipe insulation is a simple energy-saving measure you can implement yourself. Pipe foam (or fiberglass pipe insulation) should be installed on at least the first few feet of pipe leaving the hot water tank (especially the hot side). Pipe foam can be purchased at local hardware stores for around

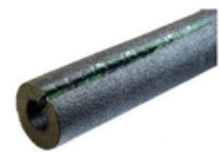
$\$ 1.50-\$ 2.00$ per foot. If you install pipe foam, be sure that it is secured to the pipe. Also, be sure that the insulation is at least 6 inches away from the flue (for gas water heaters). If pipes are located close to the flue, fiberglass insulation is probably your best bet. Estimated annual savings are between $\$ 15$ and $\$ 60$ and up to $600 \mathrm{kWh}$ per year.

\section{Use Power Strips to Turn Off Appliances That are Not Being Used}

Some home appliances draw power even when they are not being used. These draws on power are often called "phantom loads." One way to avoid phantom loads is to plug non-essential appliances into a power strip. When the appliances are not in use, simply turn off the power strip. Be sure to use a separate power strip or outlet for any essential appliances.

\section{Locally Available Incentives}

- City of Richland offers free power strips to their customers. Contact Dawn Senger at 942-7436

\section{Replace Your Incandescent Lights with Compact}

\section{Fluorescents}

ENERGY STAR-qualified compact fluorescent lamp (CFL) bulbs use about $75 \%$ less energy than standard incandescent light bulbs. They also last about 10 times longer than comparable incandescent bulbs. Annual savings depend on
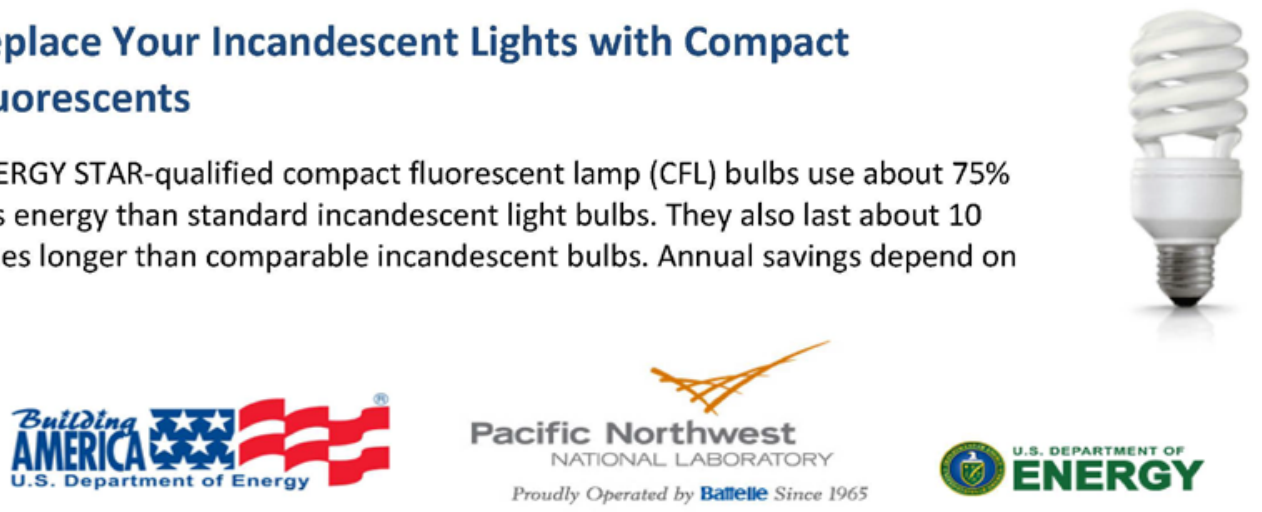


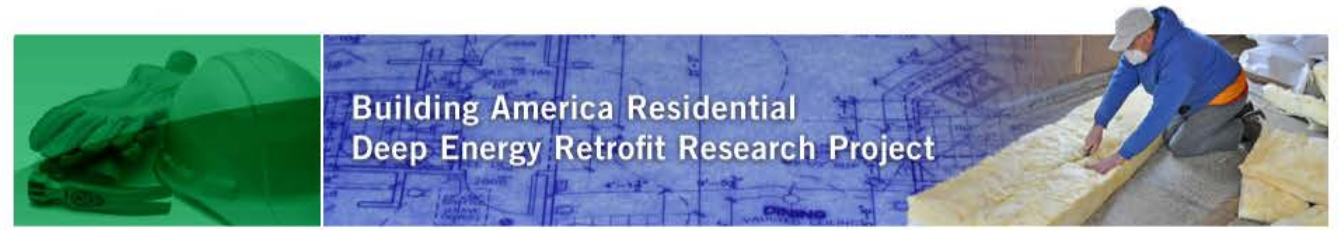

how many hours you use each bulb, but CFLs typically pay for themselves with energy savings within $1-2$ years.

A note about CFLs: CFLs contain a small amount of mercury. At the end of their life, be sure to recycle the bulbs properly. Some stores, such as Home Depot, will accept bulbs that no longer work. For more guidance on recycling bulbs and what to do if a bulb breaks, see this document from the City of Richland (available at:

http://www.ci.richland.wa.us/DocumentView.aspx?DID=1051).

\section{Locally Available Incentives}

- The City of Richland offers free CFL's to their customers contact Dawn Senger at 942-7436

Table 8

\section{Install Low-flow Showerheads and Faucet Aerators}

A simple way to save on your water heater costs is to use low-flow plumbing fixtures. New showerheads offer suitable spray while using less hot water. There are many available models that use around 2 gallons per minute (gpm). Older showerheads can use more than $5 \mathrm{gpm}$.

Similarly, hot water use in faucets can be reduced by using installing faucet aerators. Look for aerators that limit the faucet flow to about $1 \mathrm{gpm}$. Also, when shopping for aerators or lowflow showerheads, look for the WaterSense label. WaterSense is a U.S. Envivronmental Protection Agency program that certifies water-saving fixtures.

\section{Locally Available Incentives}

- Low-Flow Showerheads and faucet aerators are offered free from The City of Richland to their customers.

\section{Additional Resources}

For more information, the following websites provide additional energy-saving tips for home owners looking to make energy efficiency improvements to their homes:

- http://www.energysavers.gov/

- http://www.aceee.org/consumer

- http://www.energystar.gov/

- http://www.nahb.com/

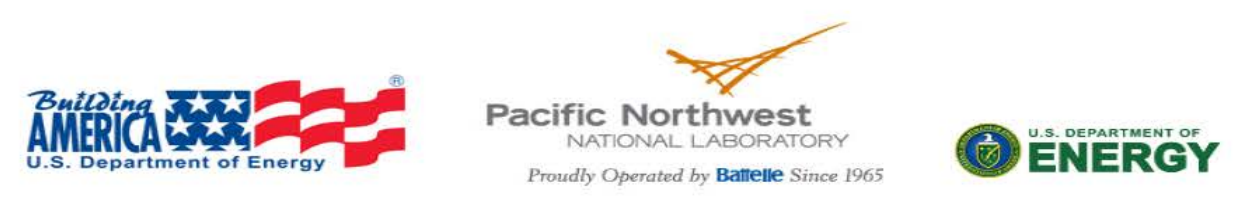




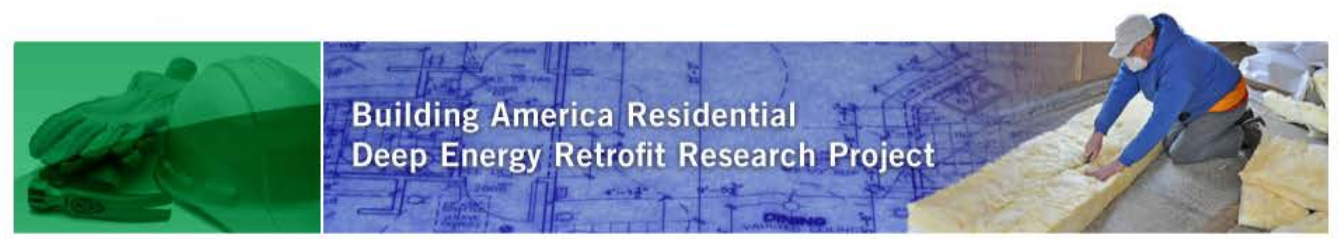

- http://www1.eere.energy.gov/buildings/

In addition, the Building America website

(http://www1.eere.energy.gov/buildings/building america/) and the Building Science Corporation website (http://www.buildingscience.com/index html) provide a number of good resources related building design and construction of energy efficient homes.

\section{Incentives and Rebates}

Various incentives are available to help pay for energy efficiency measures. For example, many of local utilities offer incentives. Several of these incentive or rebate options are identified in the audit information provided above. In addition to the incentives and direct rebates identified for your specific recommendations above, the City of Richland offers low-interest loans to help finance energy efficiency projects. These loans can be used instead of (but not in addition to) the project-specific rebates. More information can be found on your local utilities website. Another good resource for finding energy efficiency rebates anywhere throughout the country is www.dsireusa.org/.

Federal tax incentives are also available for ENERGY STAR products. Many of the recommended measures may be eligible for a tax credit worth $10 \%$ of the materials cost, or a specified amount (for example, ENERGY STAR furnaces are eligible for a $\$ 150$ tax credit). These incentives have also been identified in the cost estimates provided above. More information about this program is available at the following website:

http://www.energystar.gov/index.cfm?c=tax credits.tx index.
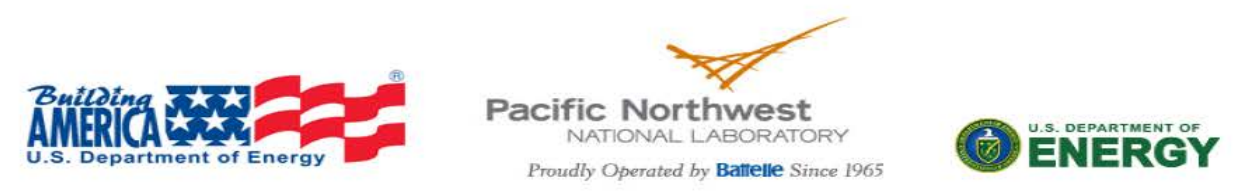

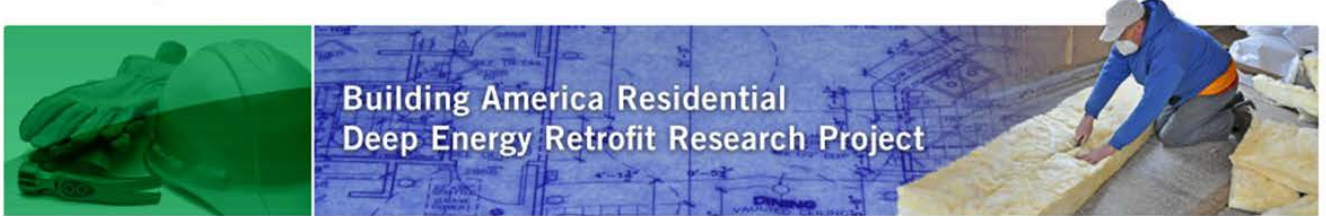

\section{Residential Deep Energy Retrofit Research Project}

\section{Audit Report for a Richland Tri-level Home}

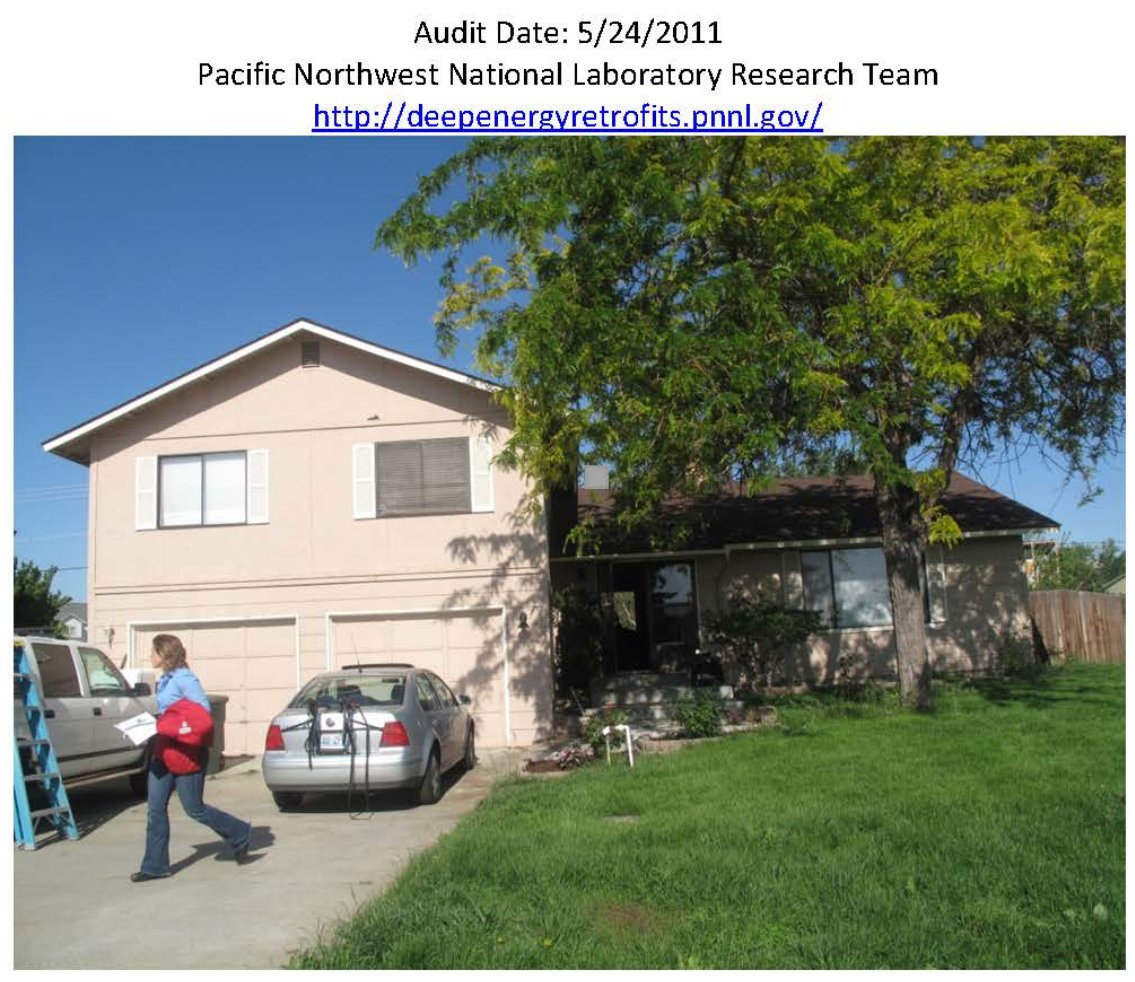

Notices:

1. This report is intended for the sole use of the homeowner(s) and the PNNL deep retrofits study team members (including subcontractors) that have completed training to protect the privacy and other rights of human subjects in research programs. PNNL will not share this report with anyone but may include data and information from this report, in an anonymous manner, in the final report that will be submitted to the U.S. Department of Energy.

2. The quantitative information in this report on energy savings, costs and economic benefits are based on computer models. Please note that actual savings and costs can be quite different (may be even a factor of 2 or more) depending on homeowner lifestyle, actual performance of energy saving equipment and strategies, variations in local weather, contractor business models and other unforeseen factors. 


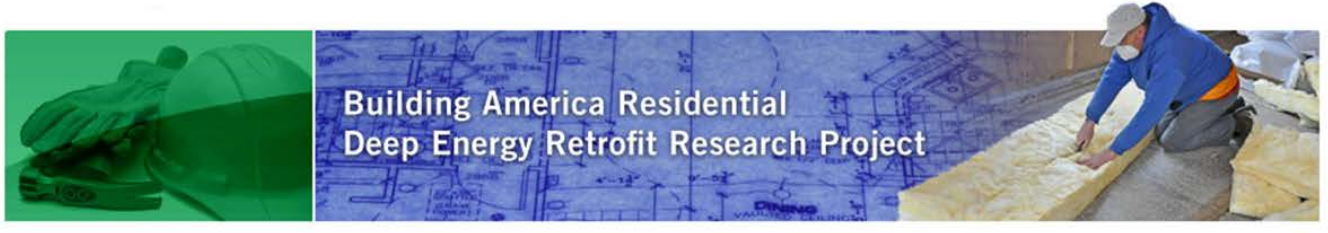

\section{Existing Home Characteristics and Performance}

The house is a single-family, tri-level home with an attached garage built in 1974 . It has 3 bedrooms and 2 baths; a total conditioned space of 2,106 square feet $\left(\mathrm{ft}^{2}\right)$. The original building envelope is wood-frame construction. The lower level is on an uninsulated slab, the mid level is over a crawlspace with an R-19 fiberglass batt of insulation, the upper level is partially over conditioned space and partially over a garage with R-19 fiberglass blown in between the conditioned space and the garage. The upper attic is vented with R-30 blown-in fiberglass insulation. The lower attic is R-19 blown-in fiberglass. The windows are double-pane clear glass with metal frames. Heating is provided by an electric furnace that uses resistance heat. Cooling provided by a 2.5 -ton seasonal energy efficiency ratio (SEER) 8 air-conditioning (AC) unit. The forced-air ducts are sheet metal and flex ducts located $40 \%$ in unconditioned crawl space, $40 \%$ in conditioned space, and $20 \%$ in unconditioned garage. Ducts in unconditioned spaces are insulated to R-11.

Since you are fairly new occupants of the house the billing history was limited. The first utility bill available was in January 2011. Even with such limited data it is clear that the HVAC system is the driver of the higher bills.

Table 1

\begin{tabular}{lc}
\hline Energy Costs Information & Electricity, \$ \\
\hline Average Utility Bill & 38.63 \\
\hline Maximum Utility Bill & 148.77 \\
\hline Minimum Utility Bill & 30.78 \\
\hline
\end{tabular}

\section{Recommended Energy Efficiency Retrofit Measures}

The home was audited to quantify its energy performance. The home energy audit consists of several elements: a blower door test to characterize building envelope leakage, a duct test to characterize duct leakage, thermal imaging to identify key leaks, evaluation of insulation levels, and examination of all energy-consuming appliances.

During the audit of your home, we noticed several opportunities to save energy in costeffective ways. The ensuing sections of this report summarize each energy-saving measure and related energy-audit findings and provide the estimated energy savings, cost of each recommended measure, and associated payback period. The simple payback period is the number of years that it will take to pay off the upfront investment with energy cost savings (the shorter, the better). The payback period provides a quick economic metric that can be used to prioritize the measures. The ensuing sections also briefly summarize locally available incentives 

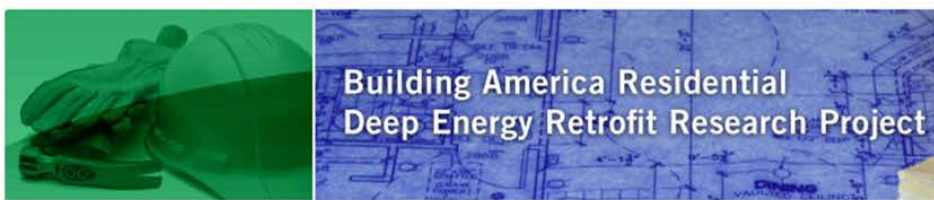

that may be available to help pay for energy-saving measures. Most of the savings estimates included here are based on computer simulations of your home. The costs provided are rough estimates based on our experiences with the energy-saving measures, quotes from local contractors, and publically available information, like the National Renewable Energy Lab's National Measures Database ${ }^{1}$. Your actual costs will depend on the contractor you choose, the final scope of work, and the current material prices. Finally, we have provided payback periods for each measure.

We think that you can cost-effectively reduce your energy use by around $54 \%$. Your actual savings will depend on which measures are implemented (as well as any changes in usage patterns, occupancy, etc.). The savings associated with each measure also will be affected by other measures that you implement, so, as we develop the final package of measures, savings estimates will vary.

Please read through the measures described below and let us know if you have any questions. Once we have discussed the cost-saving measures available to you and agreed on a package that fits your needs, the next step will be to start asking contractors for bids on the energysaving projects (recognizing that you can complete some projects yourself).

\section{Air Sealing}

Cracks, gaps, and holes located throughout your home waste energy by letting in hot air in the summer and cold air in the winter, or conversely, letting conditioned air out! During our audit, we performed a blower door test, which uses a calibrated fan and pressure gauges to measure the overall leakiness of your home. We found that if you added up all of the leaks in your home, the cumulative effect would be equivalent to having a hole 10 inches wide by 13.5 inches tall in the building envelope. This is like leaving a window open all year! These results are given in more detail below.

\footnotetext{
${ }^{1}$ National Renewable Energy Laboratory. "National Measures Database." Available at: http://www.nrel.gov/ap/retrofits/.
} 


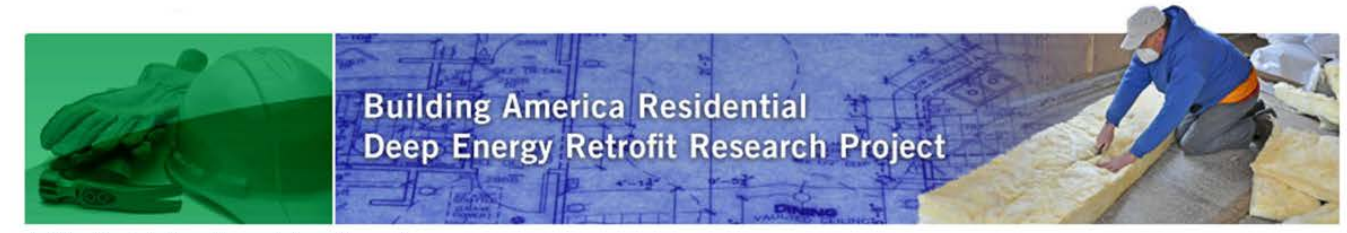

Table 2. Air Leakage Test Results

\begin{tabular}{lrl}
\hline Conditioned Floor Area & $2,106 \mathrm{ft}^{2}$ \\
\hline Conditioned Volume & $16,848 \mathrm{ft}^{3}$ \\
\hline Airflow in cubic feet per minute at -50 Pascals & $2,493 \mathrm{cfm50}$ \\
\hline Air Changes per Hour at -50 Pascals & $8.88 \mathrm{ACH} 50$ \\
\hline Effective Leakage Area & $136.9 \mathrm{in}^{2}$ \\
\hline Relative airflow at -50 Pascals & $1.18 \mathrm{cfm} 50 / \mathrm{ft}^{2}$ \\
\hline Range of relative airflow for other homes tested in the Tri-cities & $0.65-1.18 \mathrm{cfm} 50 / \mathrm{ft}^{2}$ \\
\hline
\end{tabular}

By sealing up cracks and holes with caulk, expanding spray foam, and a variety of other materials, we estimate that you can reduce the amount of air leakage by $44 \%$. This translates to a $10.1 \%$ reduction in overall energy use and a $\$ 277.00$ reduction in your annual energy bills.

The majority of the air sealing will be done in conjunction with insulating your attic, crawlspace, kneewalls, and sealing your ducts. The cost/benefit analysis of air sealing these areas will be addressed in those sections of this report.

\section{Add Attic Insulation and seal leaks}

Attic insulation reduces the amount of heat transferred through the ceiling. In the winter, heat is lost into the attic. In the summer the attic space, which gets very hot, transfers unwanted heat through the ceiling into the home. Cellulose and fiberglass insulation are typically used when adding insulation into existing homes. Cellulose and fiberglass are blown into the attic through a hose. This application is known as loose-fill (as opposed to batts of insulation). Before adding insulation, it is important to seal any leaks in the attic floor (it is much more difficult to seal leaks afterwards). Spray foam and caulk can be used to seal most leaks, though other materials may be used if leaks are very large (fire rated materials must be used where appropriate). Contractors will temporarily move the insulation aside while they air seal. Leaks are often found around holes drilled for wiring or plumbing, the top plates of interior walls, and attic hatches. (For more information, see the Building America Air Sealing Guide ${ }^{2}$.

\footnotetext{
${ }^{2}$ Building America's Air Sealing Guide can be found here; http://www1 .eere.energy.gov/library/asset_handler.aspx?src=http://apps1.eere.energy.gov/buildings/publications/pdf s/building_america/ba_airsealing_report.pdf\&id $=4663$
} 

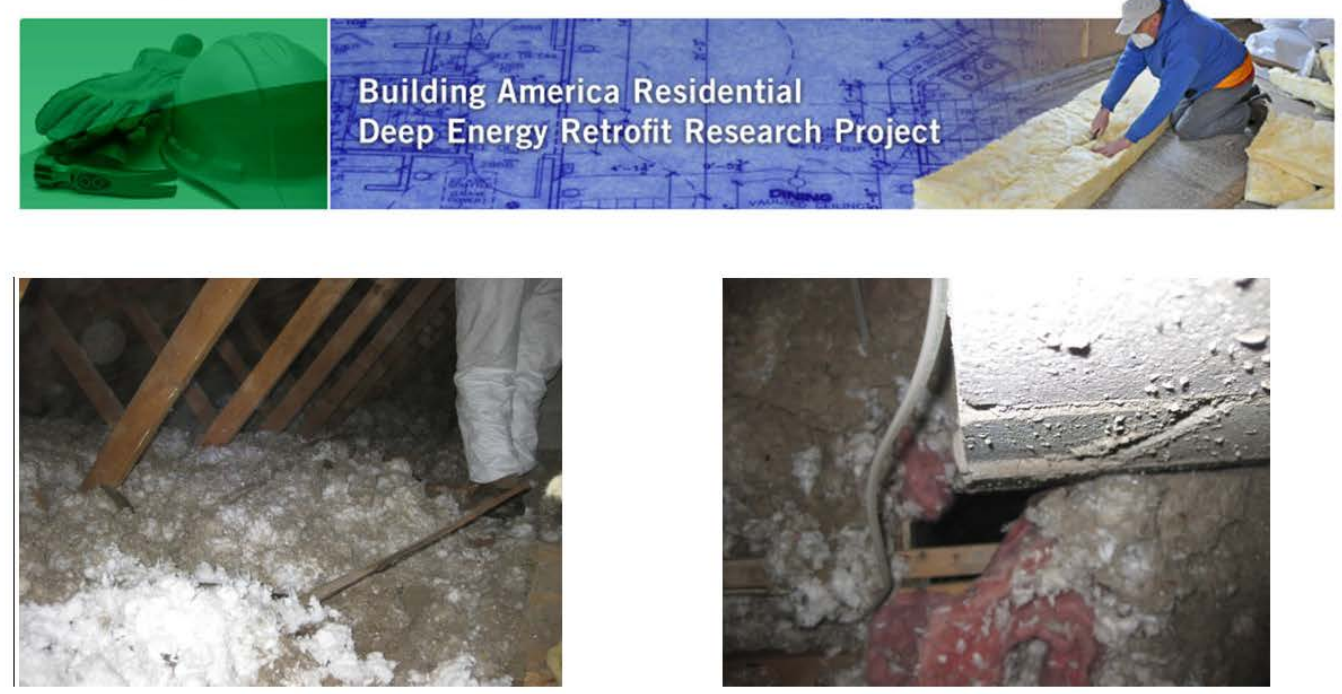

Left: Insulation in the lower attic is R-19. The insulation in the upper attic is R-30. Right: In the lower attic, next to the chimney, is a thermal bypass that goes from the crawlspace all the way up to the attic. This allows air leakage around the fireplace and into the interior walls that frame the fireplace. This should be sealed with a non-combustible material such as drywall and fire foam sealant. Top plates should be also be sealed in the attic with caulk or spray foam (again, fire-rated products should be used when appropriate).

Your attic could also benefit from additional insulation. Currently, the insulation value varies from around R-19 to R-30. We recommend adding enough insulation to bring the value to about R-60.

The kitchen exhaust fan terminates in the attic instead of outside the attic as it should. This raises the humidity in your attic and could case water damage. This also could contribute to a fire hazard if cooking with greasy foods. The exhaust duct should be vented all the way through the roof.

In new construction it would be recommended to install and seal a rigid backing to all vertical kneewalls. This would effectively block leakage to these areas. If the material used is rigid insulation you have the added benefit of improving your thermal barrier while at the same time sealing air leaks. Due to limited access in retrofit projects it may be easier and just as effective to remove the insulation, spray foam for sealing, and replace the insulation.

Around the chimney there is a thermal bypass that allows air to enter from the crawlspace, and travel through the interior walls surrounding the fireplace, and exit the gap in the attic. The gap that is visible in the above picture is just a portion of the triangular shaped opening that exists around the chimney. This area should be covered with drywall and sealed with fire foam before it is insulated with the rest of the attic.

\section{Locally Available Incentives}

- The City of Richland offers low interest loans for residential insulation 

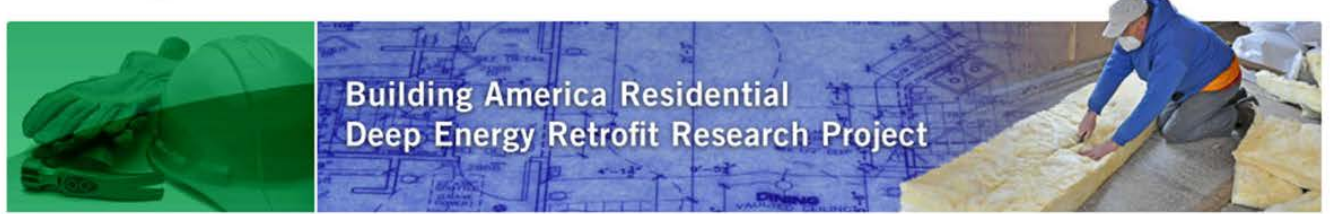

- A federal tax credit is also available for $10 \%$ of material costs (does not include labor)

Table 3

\begin{tabular}{|cccc|}
\hline Estimated Cost & $\begin{array}{c}\text { Estimated Annual } \\
\text { Savings }\end{array}$ & Payback Period & $\begin{array}{c}\text { Payback Period } \\
\text { (after incentives) }\end{array}$ \\
$\$ \$ 1,131$ & $\$ 239 / \mathrm{yr}$ & $5 \mathrm{yr}$ & $5 \mathrm{yr}$ \\
\hline
\end{tabular}

\section{Add Insulation in the Walls}

The walls in your house are insulated to R-11. Adding wall insulation to the existing cavity is not feasible. If you chose to change the exterior siding on your house it is recommended that you explore the possibility of adding a rigid insulation underneath the new siding. This is often done with stucco or to some extent vinyl siding. This will reduce the amount of heat lost during the winter and heat gained during the summer. In addition to reducing the heat transfer through the walls, insulation will help reduce the amount of air leaks and drafts through the walls. This option is generally not cost effective unless the incremental cost of insulation is the only factor considered.

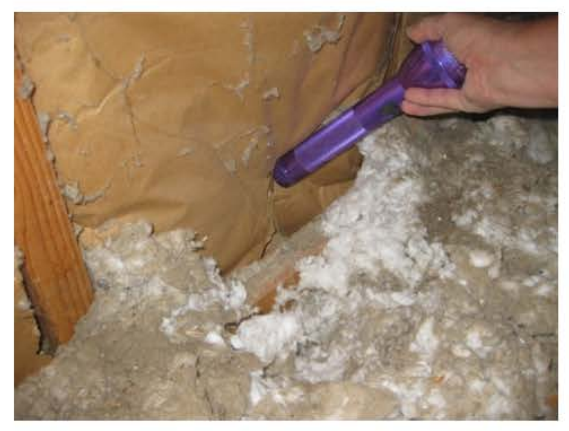

Right: There is air leakage occurring along the bottom of the upper attic kneewall. In the winter cold outside attic air is allowed into the interior walls by passing through fiberglass insulation and traveling along the gap between the wall insulation and the drywall.

The walls in the attic and crawl space are another story. As shown above the walls in the attic that are between the upstairs conditioned space and the unconditioned attic leak and do not come into full contact with the drywall. The model used actually downgraded your R-19 wall 

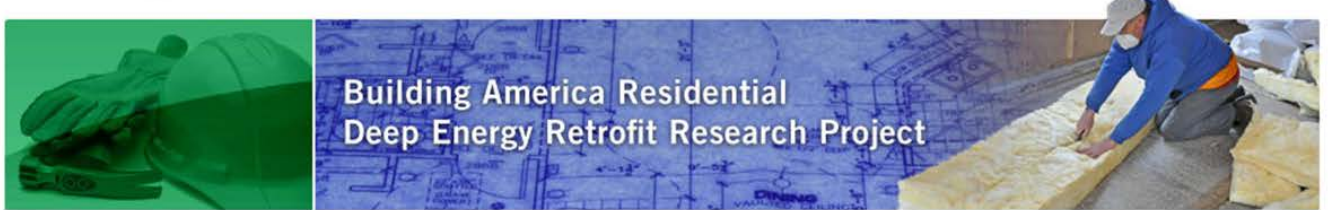

insulation to a grade III. This diminished the insulating value of the existing fiberglass batts. You could remove the existing insulation and add 3 " of spray foam. This would increase the insulation to R-21 and reduce air leakage at the same time.

The underside of the stairs in the crawl space (considered a part of the crawl kneewall) is improperly insulated. The insulation runs along the diagonal of the stairs at a 45 degree angle, instead of following the run and rise of the stairs. This gives the same effect as if there were no insulation at all along the stairs. The stairs also were a significant source of air leakage. It is recommended that you seal spray $3^{\prime \prime}$ of foam under the stairs. This will give a thermal rating of R-21 and eliminate a substantial amount of air leakage into the house.

\section{Local available Incentives}

- The City of Richland offers low interest loans for residential insulation

- A federal tax credit is also available for $10 \%$ of material costs (does not include labor)

Table 4

\begin{tabular}{cccc|} 
Estimated Cost & $\begin{array}{c}\text { Estimated Annual } \\
\text { Savings }\end{array}$ & Payback Period & $\begin{array}{c}\text { Payback Period } \\
\text { (after incentives) }\end{array}$ \\
$\$ 1153$ & $\$ 139 / \mathrm{yr}$ & $9 \mathrm{yr}$ & $9 \mathrm{yr}$ \\
\hline
\end{tabular}

\section{Add Insulation in the Crawlspace}

Currently, your crawlspace has about 6 inches of fiberglass located between the floor joists. Insulation in this location typically does not perform well because it is compressed, installed with gaps, and because air leaks move through the insulation. We recommend sealing any floor penetrations and adding insulation (the joists are about $10^{\prime \prime}$ and will allow for R-30). Talk with insulation contractors about this measure. They may recommend adding additional fiberglass or new, thicker batts. Alternatively, closed-cell spray foam can be used. Closed cell foam insulates and air seals very well, however, it will likely be more expensive. Also, spray foam typically needs a fire barrier applied as the outer most layer to meet code.

Your crawlspace could benefit from additional insulation. Currently, the insulation value is about R-19. We recommend bringing the insulation value up to at least $\mathrm{R}-30$ 

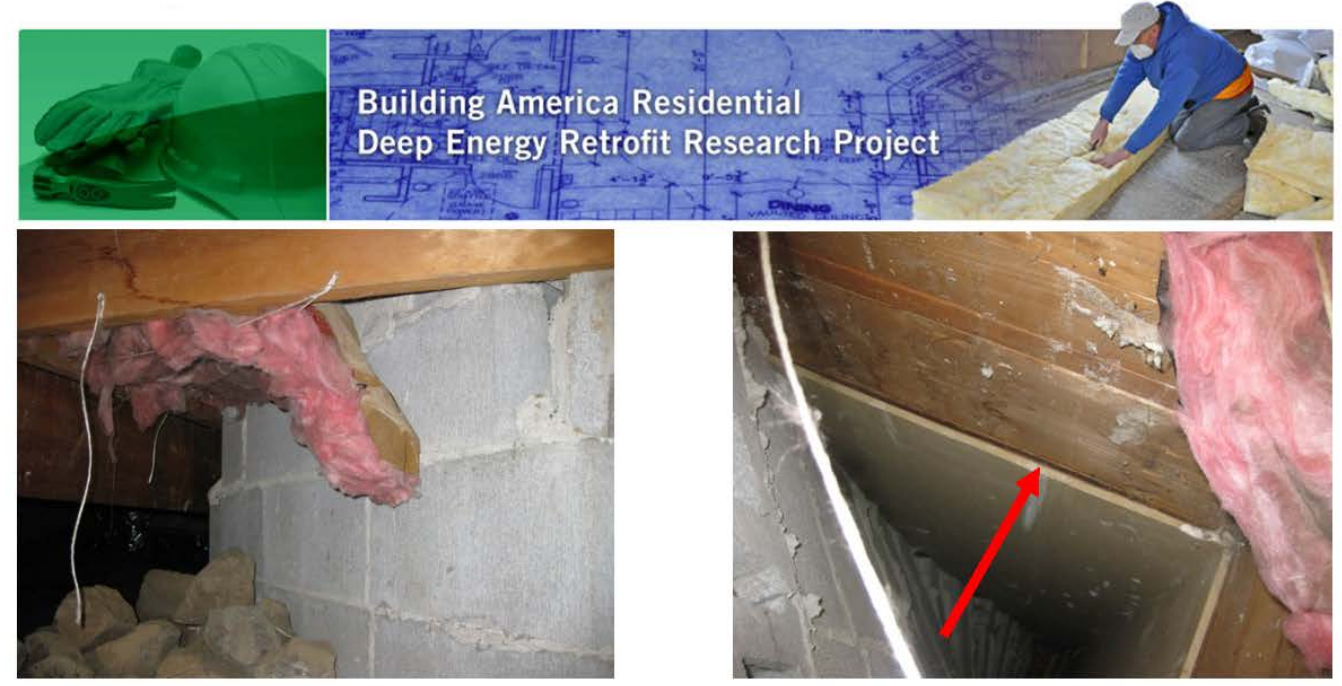

Left: Floor insulation. Some areas compressed with gaps. Right: view of thermal bypass looking up from the crawl space toward the attic. Gaps between drywall and floor joist shows were air leakage passes through.

\section{Locally Available Incentives}

- The City of Richland offers low interest loans for residential insulation

- A federal tax credit is also available for $10 \%$ of material costs (does not include labor)

Table 5

\begin{tabular}{|cccc|}
\hline Estimated Cost & $\begin{array}{c}\text { Estimated Annual } \\
\text { Savings }\end{array}$ & Payback Period & $\begin{array}{c}\text { Payback Period } \\
\text { (after incentives) }\end{array}$ \\
\hline$\$ 990$ & $\$ 113 / \mathrm{yr}$ & $9 \mathrm{yr}$ & $9 \mathrm{yr}$ \\
\hline
\end{tabular}

\section{Seal and Insulate the Ducts}

Ducts located in unconditioned attics and crawlspaces can be a huge source of energy waste. In the summer, for example, the cold air from the air conditioner is subjected to extremely high temperatures. The opposite is true during winter. Ducts should be airtight and well insulated. Ideally, ducts should all be located within conditioned space (although this is not always possible). Duct joints are generally sealed with either duct mastic or tape made specifically for duct systems (standard duct tape will not work!!). 

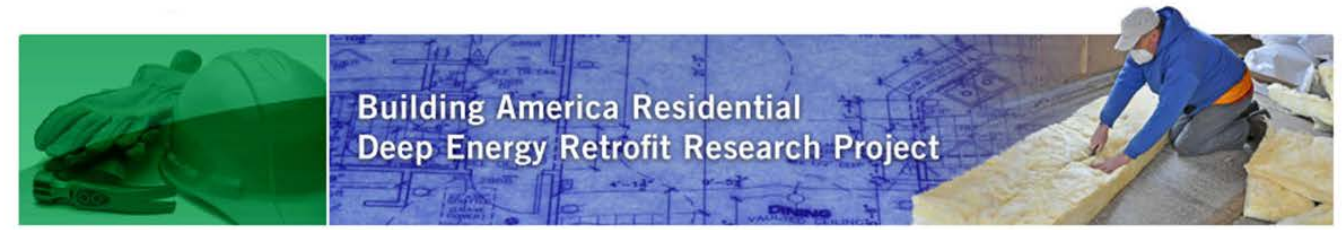

Table 6

\begin{tabular}{lrl}
\hline Total duct leakage at -25 Pascals & 500 cfm25 \\
\hline Duct leakage to outside (or attic) at -25 Pascals & $350 \mathrm{cfm} 25$ \\
\hline Duct Air Loss as a percent of total air flow & $19.5 \%$ \\
\hline Relative leakage per $\mathrm{ft}^{2}$ of floor area & $0.166 \mathrm{cfm} 25 / \mathrm{ft}^{2}$ \\
\hline Typical leakage to outside (or attic), Tri-cities & $46-350 \mathrm{cfm} 25$ \\
\hline
\end{tabular}

The duct work in the unconditioned garage is in very poor condition. Air quality may be negatively impacted due to fumes from vehicles and household chemicals stored in the garage. Pressure pans test were done on the supply ducts to determine if the ducts were generally leaky or if there was a source of 1 or 2 major leaks. The pressure pan test showed all supply ducts to have substantial leakage. The return air supply is located in the stairwell. The return air is using an interior cavity as the duct. The top is capped with sheet metal but may be leaking to the attic. The return air also appears to be leaking between the floor joists that separate the upper level from the lower level.
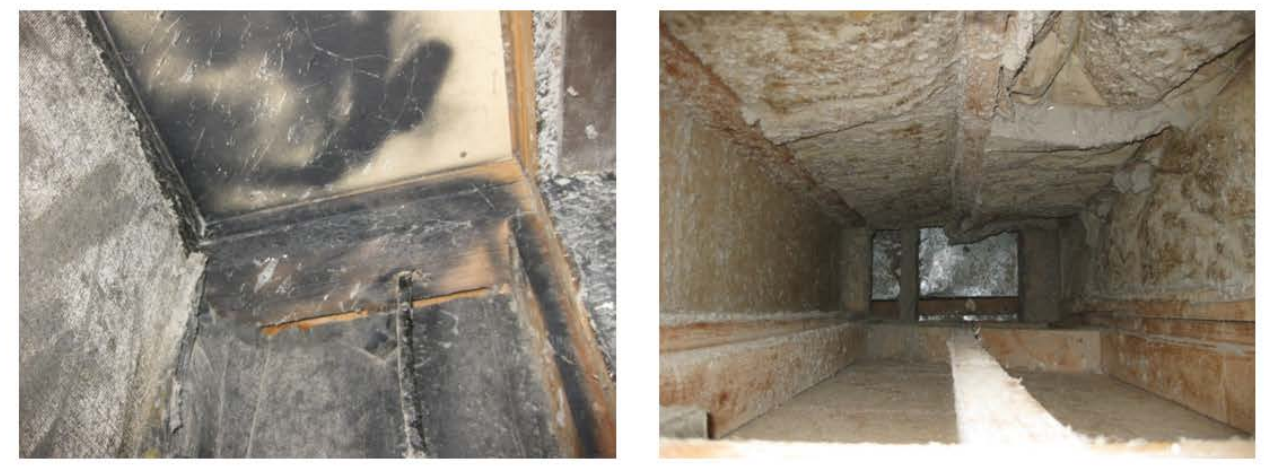

Left: view inside the return air duct looking up to the attic. Right: view from inside the return air duct looking down to the return air pan behind the air handler in the garage. 


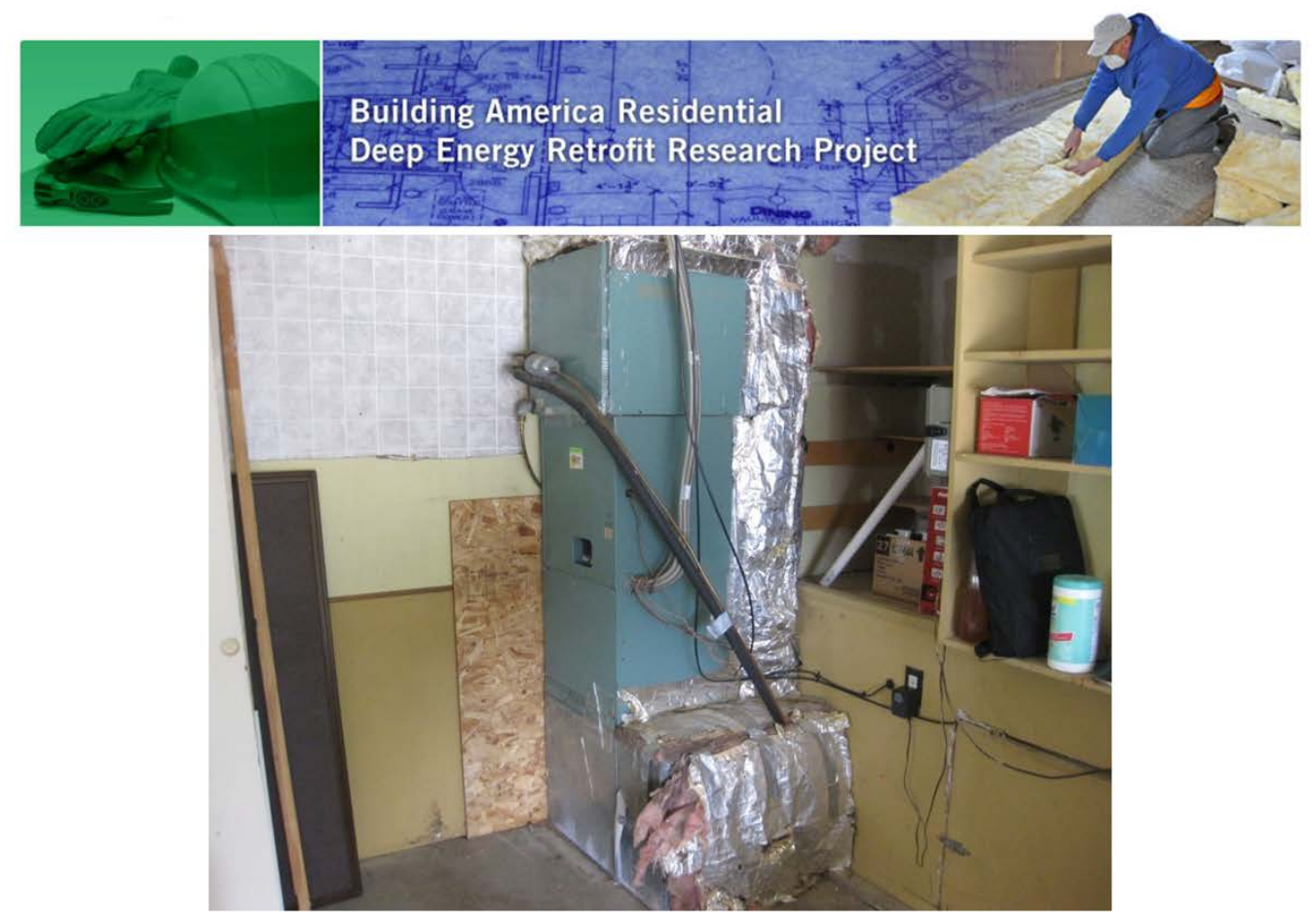

Above: air handler in the garage. Return air comes down a framed chase that is behind the air handler. The supply comes of the right of the air handler and enter the crawl space.

\section{Locally Available Incentives}

- The City of Richland offers low interest loans for duct seal

- A federal tax credit is also available for $10 \%$ of material costs (does not include labor)

Table 7

\begin{tabular}{|cccc|}
\hline Estimated Cost & $\begin{array}{c}\text { Estimated Annual } \\
\text { Savings }\end{array}$ & Payback Period & $\begin{array}{c}\text { Payback Period } \\
\text { (after incentives) }\end{array}$ \\
\hline$\$ 600$ & $\$ 230 / \mathrm{yr}$ & $3 \mathrm{yr}$ & $3 \mathrm{yr}$ \\
\hline
\end{tabular}

\section{Replace Your Furnace/AC units with a Heat Pump}

Your furnace is original to the house and is about 37 years old. The AC unit appears to be about 10-15 years old. The efficiency of AC units is rated by their SEER. Your unit has a SEER of about 8. Electric furnace efficiency is rated by the coefficient of performance (COP); yours has a COP of about 1 . This means that all of the electricity delivered to your furnace winds up as heat. However, heat pumps can have COPs from 1.5 to 4 and, thus, offer higher energy cost savings. In the heat mode, heat pumps are rated by their heating season performance factor (HSPF). For 

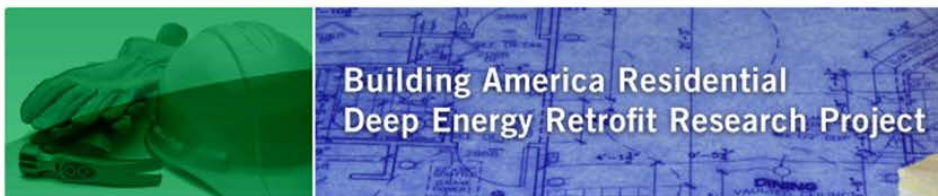

new units, the current minimum allowable efficiencies for heat pumps are a SEER of 13 and an HSPF of 7.7. Some models have SEERS of over 20 and HSPFs of over 10 !

Duct sealing is often a cost-effective measure. Duct sealing should be performed if a new heating or cooling system is installed. Not only does duct sealing save energy, it also reduces the heating or cooling load. As a result, a smaller heat pump (or furnace/AC) can be used, reducing upfront costs. The other insulation and air sealing measures will also reduce the required equipment size, so they should be performed first.

\section{Locally Available Incentives}

- The City of Richland offers low interest loans for heat pumps

- A federal tax credit is also available for $\$ 500$

Table 8.

\begin{tabular}{cccc|} 
Estimated Cost & $\begin{array}{c}\text { Estimated Annual } \\
\text { Savings }\end{array}$ & Payback Period & $\begin{array}{c}\text { Payback Period } \\
\text { (after incentives) }\end{array}$ \\
$\$ 7,000$ & $\$ 704 / \mathrm{yr}$ & $10 \mathrm{yr}$ & $9 \mathrm{yr}$ \\
\hline
\end{tabular}

Combining duct sealing with replacing the heat pump improves the payback substantially. Most incentive programs require the ducts to be sealed when replacing the HVAC unit

Table 9

\begin{tabular}{cccc} 
Estimated Cost & $\begin{array}{c}\text { Estimated Annual } \\
\text { Savings }\end{array}$ & Payback Period & $\begin{array}{c}\text { Payback Period } \\
\text { (after incentives) }\end{array}$ \\
$\$ 7,600$ & $\$ 1,152 / \mathrm{yr}$ & $7 \mathrm{yr}$ & $6 \mathrm{yr}$ \\
\hline
\end{tabular}

\section{Replace Your Windows}

Currently, you have double-pane metal windows. Upgrading to energy efficient windows will reduce your energy costs substantially. Window replacements typically have higher up-front costs and a longer payback period than most other retrofit options. However, considering the existing conditions, window replacement could still be a good investment for your home.

Windows are commonly rated with two measurements: their U-factor and their solar heat gain coefficient (SHGC). U-factors measure how much heat is transferred through the window; the lower the better. Your windows probably have a U-Factor of around 0.87 . New ENERGY STAR windows have R-values of less that 0.3 . Windows are also rated by SHGCs, although SHGCs are less important in heating-dominated climates. SHGCs measure the fraction of light that passes 


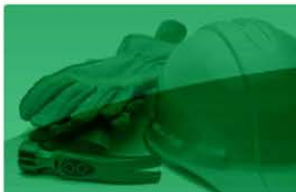

Building America Residential

Deep Energy Retrofit Research Project

through the window; high-SHGC windows help in the winter, but let in more heat during the summer.

When discussing new windows options with a contractor, be sure to ask for ENERGY STAR windows.

\section{Locally Available Incentives}

- The City of Richland offers low interest loans for residential windows

- A federal tax credit is also available for $10 \%$ of material costs, capped at $\$ 200$ for windows (does not include labor)

Table 10

\begin{tabular}{cccc} 
Estimated Cost & $\begin{array}{c}\text { Estimated Annual } \\
\text { Savings }\end{array}$ & Payback Period & $\begin{array}{c}\text { Payback Period } \\
\text { (after incentives) }\end{array}$ \\
$\$ 8,580$ & $\$ 356 / \mathrm{yr}$ & $24 \mathrm{yr}$ & $24 \mathrm{yr}$ \\
\hline
\end{tabular}

\section{Install a Solar Water Heater}

Solar water heaters use the sun to warm up water for use in showers, faucets, and the dishwasher. Since you are interested in using hydronic heat, solar hot water systems can also be used to heat the hot water used in the hydronic system. Solar water heaters are more expensive that other water-heating options, but they save money over the life of the system. Depending on the size of the system, solar water heaters typically provide $30-75 \%$ of the hot water load. Solar collectors typically perform best when the roof faces due south and the roof angle is about the same as the latitude, $47^{\circ}$, although this can vary based on design considerations.

Your south-facing roof has very good solar exposure and would be a good place to locate a solar thermal system. However, it could be very expensive. Your interest in a solar radiant heat system for your home may have lead you to resources on the web. We've also collected resources on the subject that might be of interest:

- http://www.radiantec.com/retrofit/ and http://www.radiantsolar.com/optionll.php

- http://www.thermo-dynamics.com/solar radiant heat.html

- http://www.radiantcompany.com/system/overview.shtml

- http://www.energysavers.gov/your home/space heating cooling/index.cfm/mytopic= $\underline{12590}$

- http://www.solarpanelsplus.com/solar-hydronic-heating/ 


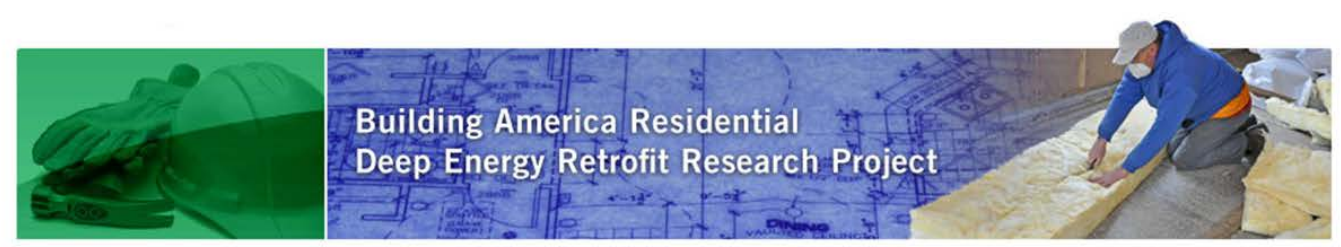

- http://www.oregon.gov/ENERGY/CONS/RES/tax/Radiant.shtml

- http://www.builditsolar.com/Projects/SpaceHeating/Space Heating.htm

Once we know more about the specific design of the solar system you are planning on installing, we can provide you with more detailed modeling of the projected energy savings.

\section{Locally Available Incentives}

- There is a $30 \%$ Federal tax credit for solar systems

- Low interest loans are available at The City of Richland. 


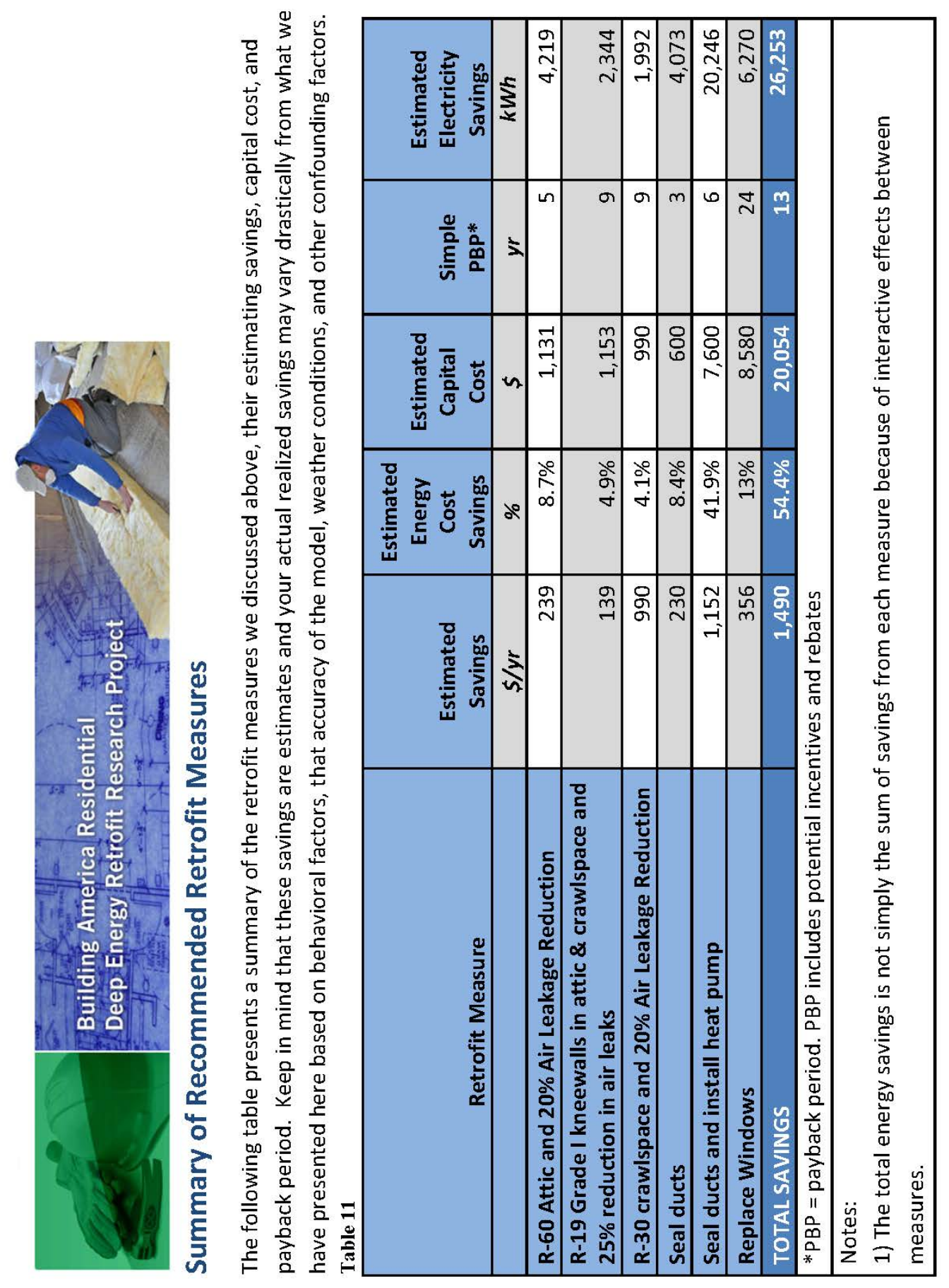




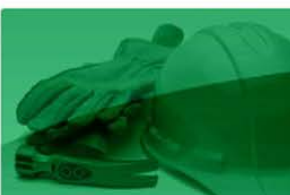

Building America Residential

Deep Energy Retrofit Research Project

\section{Easy Do-It-Yourself Improvements}

\section{Add Pipe Insulation to Your Hot Water Pipes}

Pipe insulation is a simple energy-saving measure you can implement yourself. Pipe foam (or fiberglass pipe insulation) should be installed on at least the first few feet of pipe leaving the hot water tank (especially the hot side). Pipe foam can be purchased at local hardware stores for around \$1.50-\$2.00 per foot. If you install pipe foam, be sure that it is secured to the pipe. Also, be sure that the insulation is at least 6 inches away from the flue (for gas water heaters). If pipes are located close to the flue, fiberglass insulation is probably your best bet. Estimated annual savings are between $\$ 15$ and $\$ 60$ and up to $600 \mathrm{kWh}$ per year.

\section{Insulate Your Hot Water Tank}

Your hot water tank has little insulation. We recommend adding an insulating "jacket" or "blanket" to your hot water tank. These typically cost $\$ 20-\$ 40$ and can be found at local hardware stores. Estimated annual savings are about $7 \%$ of water heating energy.

\section{Use Power Strips to Turn Off Appliances that are not Being Used}

Some home appliances draw power even when they are not being used. These draws on power are often called "phantom loads." One way to avoid phantom loads is to plug non-essential appliances into a power strip. When the appliances are not in use, simply turn off the power strip. Be sure to use a separate power strip or outlet for any essential appliances.

\section{Install Low-flow Showerheads and Faucet Aerators}

A simple way to save on your water heater costs is to use low-flow plumbing fixtures. New showerheads offer suitable spray while using less hot water. There are many available models that use around 2 gallons per minute $(\mathrm{gpm})$. Older showerheads can use more than $5 \mathrm{gpm}$. Similarly, hot water use in faucets can be reduced by using installing faucet aerators. Look for aerators that limit the faucet flow to about $1 \mathrm{gpm}$. Also, when shopping for aerators or lowflow showerheads, look for the WaterSense label. WaterSense is a U.S. Envivronmental Protection Agency program that certifies water-saving fixtures.

\section{Locally Available Incentives}

- http://www.ci.richland.wa.us/index.aspx?NID=182

- The City of Richland provides free low-flow shower heads and power strips

\section{Additional Resources}



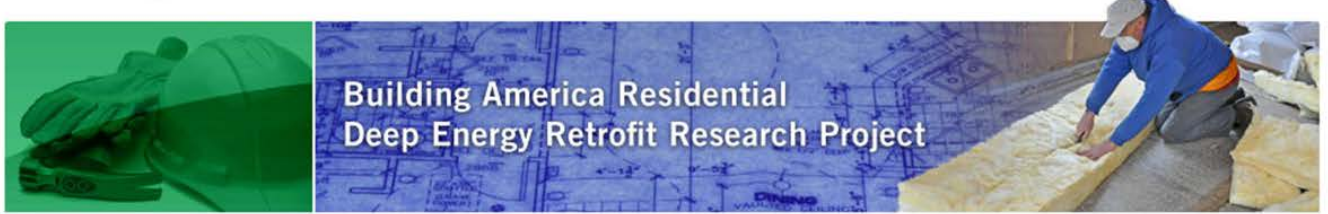

For more information, the following websites provide additional energy-saving tips for home owners looking to make energy efficiency improvements to their homes:

- http://www.energysavers.gov/

- http://www.aceee.org/consumer

- http://www.energystar.gov/

- http://www.nahb.com/

- http://www1.eere.energy.gov/buildings/

In addition, the Building America website

(http://www1.eere.energy.gov/buildings/building america/) and the Building Science

Corporation website (http://www.buildingscience.com/index html) provide a number of good resources related building design and construction of energy efficient homes.

\section{Incentives and Rebates}

Various incentives are available to help pay for energy efficiency measures. For example, many of local utilities offer incentives. Several of these incentive or rebate options are identified in the audit information provided above. In addition to the incentives and direct rebates identified for your specific recommendations above, the City of Richland offers low-interest loans to help finance energy efficiency projects. These loans can be used instead of (but not in addition to) the project-specific rebates. More information can be found on your local utilities website. Another good resource for finding energy efficiency rebates anywhere throughout the country is www.dsireusa.org/.

Federal tax incentives are also available for ENERGY STAR products. Many of the recommended measures may be eligible for a tax credit worth $10 \%$ of the materials cost, or a specified amount (for example, ENERGY STAR furnaces are eligible for a \$150 tax credit). These incentives have also been identified in the cost estimates provided above. More information about this program is available at the following website:

http://www.energystar.gov/index.cfm?c=tax_credits.tx_index. 



\section{Appendix J}

\section{Case Studies of Retrofit Projects}





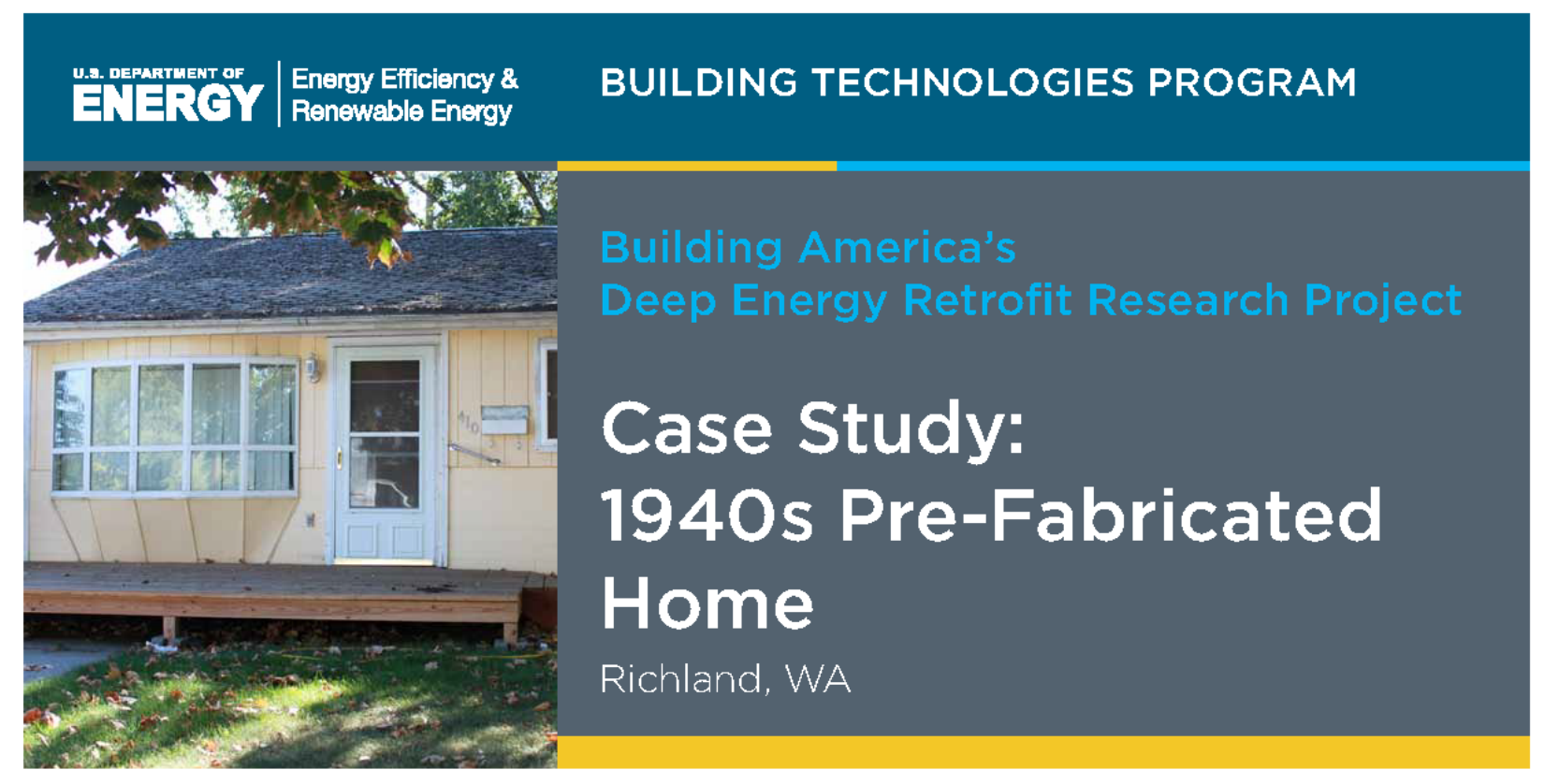

This 1940 s pre-fabricated home was built with $2 \times 2$ studs, making the walls too thin for cavity insulation. Building America researchers recommended installing rigid foam insulation on the exterior of the house, under new siding. Computer modeling predicts that insulating the walls will cut the owner's energy bills by $33 \%$ and pay for itself in just 3 years.

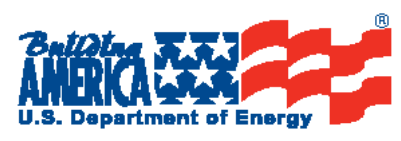

\section{Exterior insulation will help cut energy bills in half}

Hundreds of houses in Richland, Washington, were hastily constructed by the federal government in the 1940s to serve workers on the Hanford Nuclear Reservation. This two-bedroom, $700-\mathrm{ft}^{2}$ cottage is one of those pre-fabricated, wood-framed homes. Its $2 \times 2$ stud walls were too thin for cavity insulation, and it has never had a heating system. Today, most of the walls are still uninsulated, the house is drafty, and energy bills are high for such a small house.

When researchers from the Pacific Northwest National Laboratory conducted a whole-house energy assessment, they confirmed what the owner already knew. The home needs wall insulation. The space heater the owner relies on in winter is inadequate and the "through-the-wall" air conditioner is old and inefficient. The researchers identified additional causes of energy loss-an inefficient water heater and a number of holes in the ceiling that allow conditioned air to escape to the attic.

The researchers from PNNL conducted the assessment in support of the U.S. Department of Energy's Building America program. They used computer modeling to identify the most cost-effective ways to fix the home's problems. Together, the recommended measures will cut the owner's energy bills an estimated $48 \%$ and can all be completed for about $\$ 8,800$. The projected $\$ 557$ anmual savings means the project will pay for itself in 13 years. Meanwhile, the home will be much more comfortable. 


\section{Building America's Deep Energy Retrofit Research Project}

This assessment is part of Building America's Deep Energy Retrofit Research Project, conducted by the U.S. Department of Energy's Pacific Northwest National Laboratory (PNNL), Oak Ridge National Laboratory, and other research partners. The researchers are coordinating deep energy retrofits for at least 50 residences throughout the United States

Deep energy retrofits use comprehensive, whole-house strategies to reach the highest cost-effective level of energy efficiency. For each home, the Building America researchers identify a package of cost-effective technologies and strategies to reduce energy use by more than $30 \%$.

A deep energy retrofit usually requires an investment of $\$ 7,000$ to $\$ 20,000$ Rebates, tax credits, and low-interest loans are often available.

Once upgrades are complete, the Building America researchers measure energy savings and improvements in comfort, health, and safety. Analysts will use the data to evaluate the benefits and cost-effectiveness of deep energy retrofits. These analyses will inform the U.S. Department of Energy's best practices for retrofitting homes in climate zones across the country.
Insulating the walls will be much simpler than the owner expected. A few years ago, she gutted the bedroom walls from inside, then put a new stud in front of each existing stud to create cavities deep enough to hold insulation. However, in making the walls thicker, she lost $25 \mathrm{ft}^{2}$ in floor space. In her $700-\mathrm{ft}^{2}$ house, that is a big loss. To achieve comfort and energy savings, the owner assumed she would have to re-frame the rest of her house, further reducing her square footage. The Building America researchers identified an easier, more cost-effective way to insulate that will allow her to keep every inch of floor space.

\section{The Home Energy Assessment}

The assessment is part of Building America's Deep Energy Retrofit Research Project (see Sidebar). Researchers are identifying cost-effective technologies and strategies for reducing energy use in existing homes by more than $30 \%$. When the upgrades are complete, the researchers will measure and analyze the results to develop best practices for deep energy retrofits in a variety of climates.

In the Richland home, the researchers evaluated insulation levels, conducted a blower door test to measure whole-house air leakage, and checked the energy-consuming appliances. Using audit data and computer modeling, they provided the homeowner with a list of upgrade options, giving estimated costs and projected savings. The researchers met with the homeowner to study the results and identify the best options for her needs and budget.

\section{Problems, Options and Recommendations}

Over the years, the home has had a few energy improvements. The attic and crawlspace were insulated, and the original windows have been replaced with double-paned, vinyl-framed ones. However, other problems - the uninsulated walls, the ceiling holes, and the lack of a heating system-make the home cold in winter and hot in summer.

Wall insulation. Rather than gutting and extending the walls to add insulation, the Building America researchers recommend installing exterior rigid foam insulation. Two inches of polyurethane or polystyrene foam board under new siding will insulate the walls to R-15. Rigid foam offers the highest R-value per inch of any insulation, and installing it will cause no disruption inside the house. The work will cost $\$ 1,100$. Since it will save an estimated $\$ 358$ a year in energy costs, the insulation will pay for itself in just three years. 
Attic insulation. The Building America researchers recommend sealing the holes in the attic floor where pipes and wires penetrate. For additional attic insulation, the researchers offer two options: The attic floor currently has two layers of R-19 fiberglass batts, equivalent to $\mathrm{R}-38$. Blowing loose fiberglass over the existing batts would insulate the attic to R-60. Alternatively, the attic vents could be sealed, and 6 inches of closed-cell spray foam insulation could be applied to the roof deck for a total R-value of 74 .

\begin{tabular}{|l|l|l|l|l|l|}
\hline Measure & $\begin{array}{l}\text { Estimated } \\
\text { Reduction } \\
\text { in Energy } \\
\text { Bills }\end{array}$ & $\begin{array}{l}\text { Estimated } \\
\text { Cost }\end{array}$ & $\begin{array}{l}\text { Estimated } \\
\text { Savings }\end{array}$ & $\begin{array}{l}\text { Payback } \\
\text { Period }\end{array}$ & $\begin{array}{l}\text { Payback } \\
\text { Period } \\
\text { (after } \\
\text { incentives) }\end{array}$ \\
\hline $\begin{array}{l}\text { Add loose } \\
\text { fiberglass } \\
\text { insulation at } \\
\text { ceiling level }\end{array}$ & $2 \%$ & $\$ 540$ & $\$ 17 / \mathrm{yr}$ & $31 \mathrm{yr}$ & $28 \mathrm{yr}$ \\
\hline $\begin{array}{l}\text { Add spray } \\
\text { foam } \\
\text { insulation at } \\
\text { roof deck }\end{array}$ & $2 \%$ & $\$ 833$ & $\$ 30 / \mathrm{yr}$ & $27 \mathrm{yr}$ & $25 \mathrm{yr}$ \\
\hline
\end{tabular}

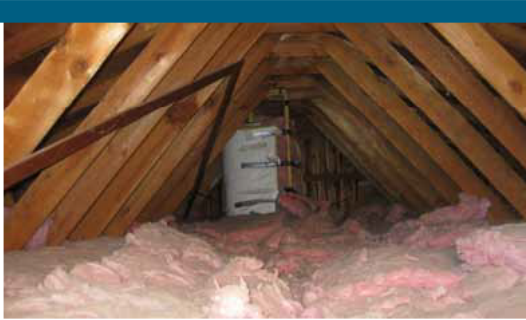

The Building America researchers recommend adding insulation to the attic at either the floor or ceiling level. This will yield only minor savings but will increase comfort in the rooms below.

Heating and cooling system. Installing a central heating system will bring a major improvement in comfort. It will also cut the owner's energy bills by an estimated $22 \%$. Since the home has no ducts, the Building America researchers recommend installing a mini-split heat pump. This innovative system has an outdoor unit like any heat pump. Instead of connecting to ducts, however, the outdoor unit sends compressed gas through small-diameter, insulated refrigerant lines to one or more indoor units. Mounted on a wall or ceiling, these units heat or cool the house. This small house needs only one or two indoor units.

A federal tax credit and local incentives will reduce the cost of the heating and cooling system to about $\$ 6,500$, so it should pay for itself in 20 years. Meanwhile, the efficient system will increase the home's value and provide comfortable temperatures year-round.

Water heating. The home's electric water heater is 23 years old and inefficient. Replacing it with a high-efficiency model will cost about $\$ 700$. It will save an estimated $\$ 87$ a year in energy bills and pay for itself in just 8 years.

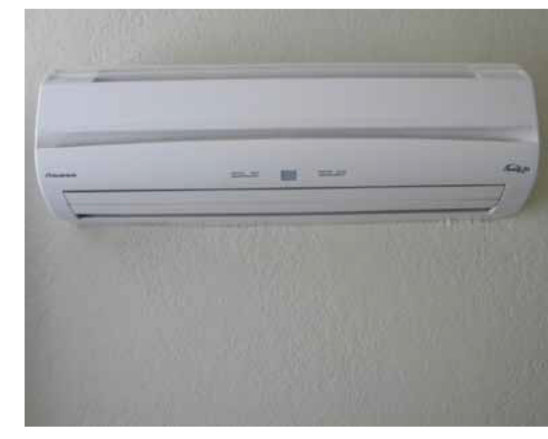

The home has never had a heating system. Building America researchers recommend installing a ductless, mini-split heat pump that will bring a year-round improvement in comfort. Wall-mounted units like this one will provide heating and cooling. 


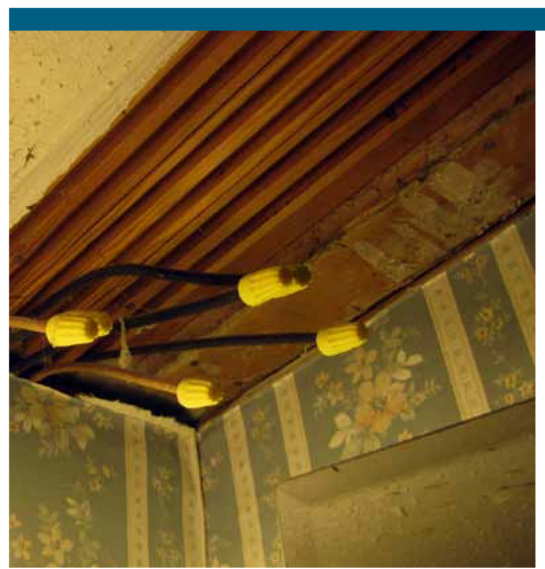

A number of holes in the ceiling allow conditioned air to escape to the attic. This gap should be covered and sealed.

\section{The Bottom Line}

With a total investment of less than $\$ 9,000$, the homeowner can make all these improvements and cut her energy bill nearly in half. Since she plans to stay in this home for the rest of her life, the improvements will benefit her for years to come. When the 13-year payback period is up, the annual energy savings will be money in her pocket.

\begin{tabular}{|c|c|c|c|c|c|}
\hline Measure & \begin{tabular}{|l} 
Estimated \\
Reduction \\
in Energy \\
Bills \\
\end{tabular} & $\begin{array}{l}\text { Estimated } \\
\text { Cost }\end{array}$ & $\begin{array}{l}\text { Estimated } \\
\text { Savings }\end{array}$ & \begin{tabular}{|l} 
Payback \\
Period
\end{tabular} & \begin{tabular}{|l} 
Payback \\
Period \\
(after \\
incentives) \\
\end{tabular} \\
\hline $\begin{array}{l}\text { Insulate } \\
\text { walls }\end{array}$ & $33 \%$ & $\$ 1,102$ & $\$ 358 /$ year & 3 years & 3 years \\
\hline $\begin{array}{l}\text { Add loose } \\
\text { fiberglass } \\
\text { insulation } \\
\text { to attic } \\
\text { floor }\end{array}$ & $2 \%$ & $\$ 540$ & $\$ 17 /$ year & 31 years & 28 years \\
\hline $\begin{array}{l}3 / 4 \text { ton } \\
\text { SEER } 16 \\
\text { mini-split } \\
\text { heat pump }\end{array}$ & $22 \%$ & $\$ 6,469$ & $\$ 238 /$ year & 27 years & 20 years \\
\hline $\begin{array}{l}\text { EF } 0.95 \\
\text { electric } \\
\text { water } \\
\text { heater }\end{array}$ & $8 \%$ & $\$ 700$ & $\$ 87 /$ year & 8 years & 8 years \\
\hline $\begin{array}{l}\text { TOTAL } \\
\text { SAVINGS }\end{array}$ & $48 \%$ & $\$ 8,811$ & $\$ 522 /$ year & & 13 years \\
\hline \multicolumn{6}{|c|}{$\begin{array}{l}\text { * Total savings is not simply the sum of savings from each measure because } \\
\text { the changes are interactive. Actual savings will depend on which measures are } \\
\text { implemented, as well as any changes in usage patterns. Costs are calculated with } \\
\text { data from the National Residential Efficiency Measures Database, assembled by the } \\
\text { U.S. Department of Energy's National Renewable Energy Laboratory. These values } \\
\text { are compared to local prices and quotes. Savings are modeled with Energy Gauge } \\
\text { software, based on the local electric rate of } \$ 0.068 / \mathrm{kWh} \text {. A simple payback period is } \\
\text { used, without adjustments for interest, inflation, or depreciation. Federal tax credits } \\
\text { and locally available incentives reduce the cost of some projects. }\end{array}$} \\
\hline
\end{tabular}

\section{For More Information}

Www. buildingamerica.gov

EERE Information Center

1-877-EERE-INF (1-877-337-3463)

eere.energy.gov/informationcenter

\section{u.s. Departuent of | Energy Efficiency \& Z1 Zir $\mathrm{C}$ Renewable Energy}




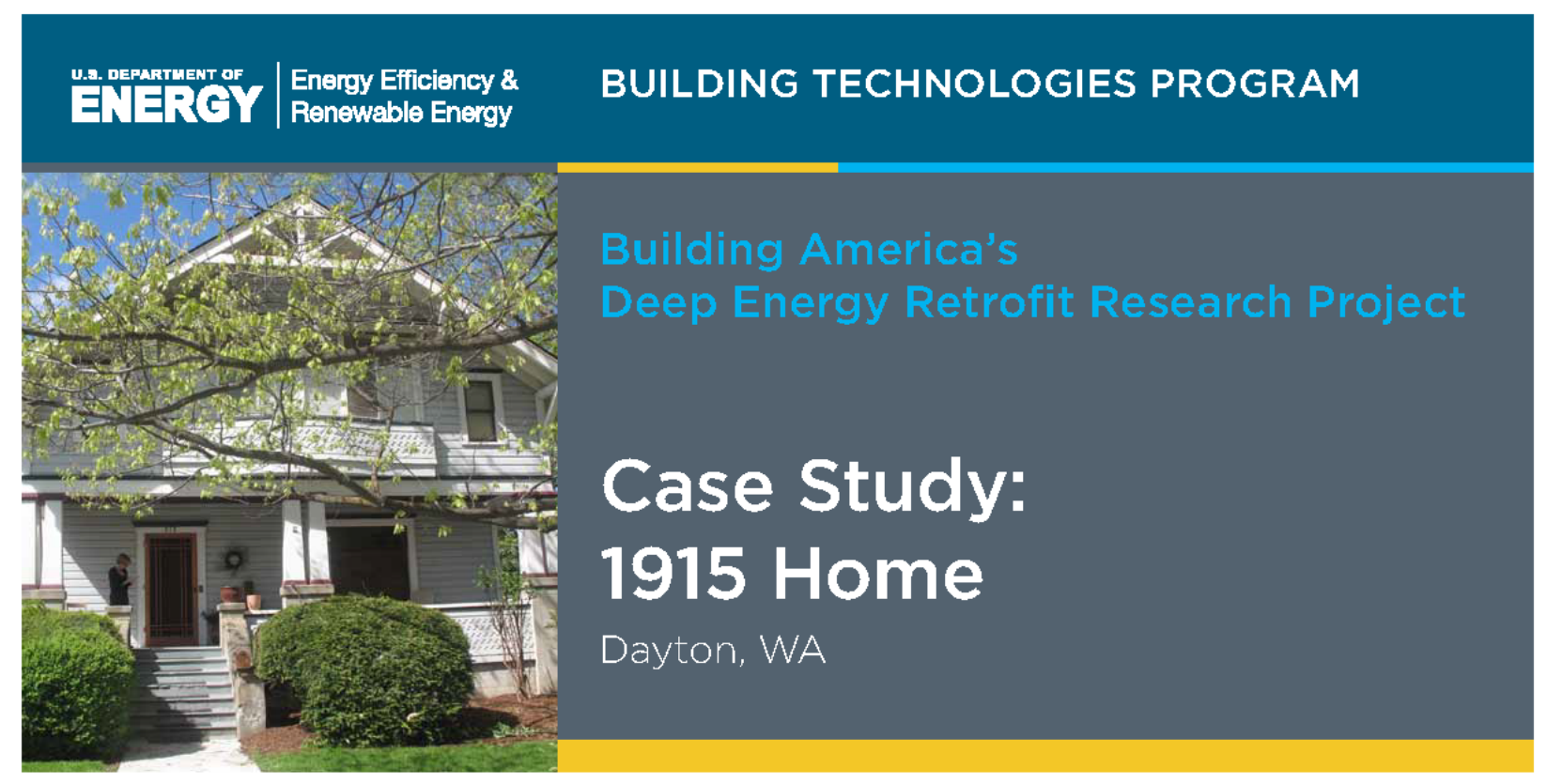

A deep energy retrofit of this 1915 home in Dayton, Washington, could save the homeowners $73 \%$ on their energy bills, according to an assessment conducted by Building America.

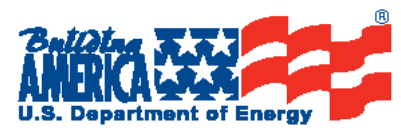

\section{Deep Energy Retrofit Offers 73\% Savings for Century-old Home}

The homeowners' complaint is a big one. The diesel-burning furnace in their 1915 home rings up energy bills that can top $\$ 700$ in a single month. However, good news comes from the Building America researchers who performed an energy assessment for the home in Dayton, Washington. Using assessment data and computer modeling, they project a $73 \%$ reduction in heating costs by installing an innovative heating system and adding air-sealing and insulation. The estimated cost looks steep- $\$ 16,492$. But, with a projected annual savings of $\$ 2,500$, it will take only 6 years for the homeowners to fully recoup the investment. After that, the $\$ 2,500$ will simply be money in their pocket.

The assessment is part of Building America's Deep Energy Retrofit Research Project (see sidebar on page 3). It was conducted by the Pacific Northwest National Laboratory (PNNL) for the U.S. Department of Energy. PNNL and other researchers are identifying cost-effective technologies and strategies for reducing energy use in existing homes by more than $30 \%$. When the upgrades are complete, the researchers will measure and analyze the results to develop best practices for deep energy retrofits in various climates.

The Dayton home is in eastern Washington state, a dry area with cold winters and hot summers. Although the wood-framed house is nearly 100 years old, "its bones are good," said the owners. The 3-bedroom home has 2,600 $\mathrm{ft}^{2}$ of living space on two floors, not counting the unfinished basement. 

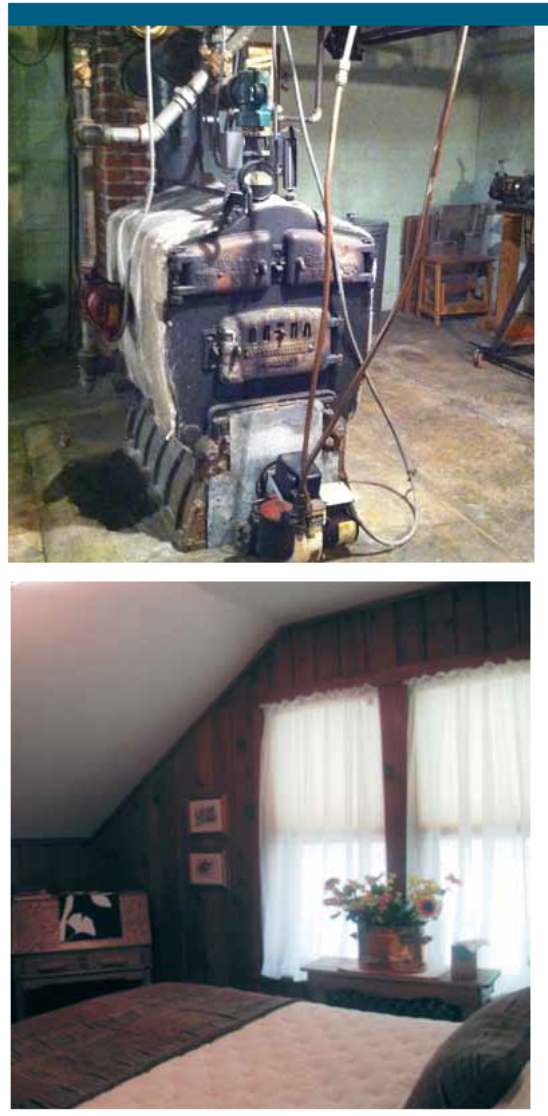

(To, $)$ The hundred-year-old diesel boiler can cost $\$ 700$ a month to fuel. Installing a new boiler means removing the old one and disturbing the asbestos on its top and sides, creating a health hazard. Instead, the Building America researchers recommend installing an innovative alternative, a ductless mini-split heat pump.

(Bottom) The upstairs rooms are often uncomfortable. The insulation for the sloped ceilings has slipped off and fallen into the wall cavities.
The Building America researchers conducted a blower door test to measure whole-house air leakage and used thermal imaging to identify key leaks. They evaluated insulation levels and checked all appliances. Using assessment data and computer modeling, the researchers provided the homeowners with a list of upgrade options, giving the estimated cost and projected savings for each. The researchers met with the homeowners to identify the best options for their needs and budget.

\section{Problems, Options and Recommendations}

The heating system. The Building America researchers identified two alternatives for heating the home: an efficient electric boiler and a ductless mini-split heat pump.

A new boiler would continue to supply hot water to the home's radiators, a heat source the homeowners have enjoyed. However, removing the diesel boiler could create a health hazard. Asbestos covers the boiler's top and sides. When asbestos is disturbed, microscopic fibers can become airborne and may be inhaled. Safe removal is difficult and expensive. The team included this expense when calculating the cost of a replacement boiler.

The Building America researchers recommend the second option, a ductless mini-split heat pump. This energy-efficient system includes an outdoor unit like any heat pump. Instead of connecting to indoor ducts, however, it sends compressed gas through small-diameter insulated refrigerant lines to one or more indoor units. Mounted on a wall or ceiling, each unit heats or cools an area of the house. The Building America researchers calculate that four indoor units will effectively heat the Dayton home. If the homeowners choose a ductless heat pump, the old diesel boiler — and the asbestos — can remain undisturbed.

The heat pump costs much more up front than the electric boiler. However, according to computer models, it offers a whopping $68 \%$ reduction in the homeowners' energy bills and a short payback period just 4 years. The big savings will continue for years to come.

\begin{tabular}{|l|l|l|l|l|}
\hline Measure & $\begin{array}{l}\text { Estimated } \\
\text { Reduction in } \\
\text { Energy Bills }\end{array}$ & Estimated Cost & $\begin{array}{l}\text { Estimated } \\
\text { Savings }\end{array}$ & $\begin{array}{l}\text { Payback } \\
\text { Period }\end{array}$ \\
\hline $\begin{array}{l}\text { High Efficiency } \\
\text { Electric Boiler }\end{array}$ & $39 \%$ & $\$ 3,675$ & $\$ 1,386 /$ year & 3 years \\
\hline $\begin{array}{l}\text { Ductless } \\
\text { Heat Pump } \\
\text { Recommended }\end{array}$ & $68 \%$ & $\$ 9,300$ & $\$ 2,393 /$ year & 4 years \\
\hline
\end{tabular}


Attic Insulation. Parts of the home are poorly insulated. The upstairs has sloped ceilings where the attic insulation has fallen into the wall cavities. This leaves the rooms uninsulated at the slope. The Building America researchers recommend filling the cavities of the sloped ceiling with blown fiberglass. Although savings from the project will be small - an estimated $\$ 40$ a year - the bedrooms will be warmer in winter and cooler in summer.

The rest of the attic floor has R-15 loose-fill cellulose; R-49 is recommended. Ordinarily, insulating an attic floor is one of the least expensive energy upgrades. However, the Dayton home has active knob-and-tube wiring on the attic floor. Covering this old wiring with insulation could overheat it, creating a fire hazard. Rewiring and adding insulation would be expensive. With an estimated $\$ 100$ reduction in annual energy bills, it would take 30 years to recoup the cost. The homeowner might consider replacing the old wiring for general safety, but the Building America researchers are not recommending it for energy savings.

Wall insulation. The exterior kitchen wall is uninsulated. Upstairs, the master bedroom has no insulation in the wall facing the street, and the room extends over an open porch, with no insulation in the cantilevered floor. To insulate the walls, the Building America researchers recommend the "drill and fill" method. Workers will remove a piece of siding on each wall and drill holes to blow in insulation. Fiberglass batts are recommended for insulating the cantilevered floor in the master bedroom. (Because the home is in a dry climate, it is acceptable to use fiber insulation in the floor.) With federal tax credits and local incentives, the cost of this project will be recouped in 8 years.

Basement. The Dayton home has a full, unfinished basement. It has no insulation, and active knob-and-tube wiring hangs from the ceiling. Air leaks abound. Daylight comes through cracks in the rim joist. The dining room above the basement is cantilevered over open space, and the cavity around its floor joists is uninsulated and open to the basement.

The drafty basement compromises the comfort, air quality, and energy efficiency of the entire house. In any house that is not airtight, warm air rises and escapes through air leaks in the attic. This "stack effect" creates negative air pressure in the lower part of the house, so replacement air gets pulled from outside, into the basement, and up into the home.

The Building America researchers recommend sealing the rim joist cavities with oriented strand board (OSB) or rigid foam, air-sealed around the edges, and then filling the cavities with R-19 fiberglass batts. The cavity formed by the dining room cantilever should be insulated, blocked off, and air-sealed. Rigid foam insulation should be installed against the basement walls, with the edges of the foam panels air-sealed. Estimates show a minor $2 \%$ reduction in energy use. However, these measures are inexpensive and cost-effective, paying for themselves in just 6 years.
Building America's Deep Energy Retrofit Research Project

This assessment is part of Building America's Deep Energy Retrofit Research Project, conducted by the U.S. Department of Energy's Pacific Northwest National Laboratory (PNNL), Oak Ridge National Laboratory, and other research partners. The researchers are coordinating deep energy retrofits for at least 50 residences throughout the United States.

Deep energy retrofits use comprehensive, whole-house strategies to reach the highest cost-effective level of energy efficiency. For each home, the Building America researchers identify a package of cost-effective technologies and strategies to reduce energy use by more than $30 \%$.

A deep energy retrofit usually requires an investment of $\$ 7,000$ to $\$ 20,000$. Rebates, tax credits and low-interest loans are often available.

Once upgrades are complete, the researchers measure energy savings and improvements in comfort, health, and safety. Analysts will use the data to evaluate the benefits and costeffectiveness of deep energy retrofits. These analyses will inform the U.S. Department of Energy's best practices for retrofitting homes in climate zones across the country 


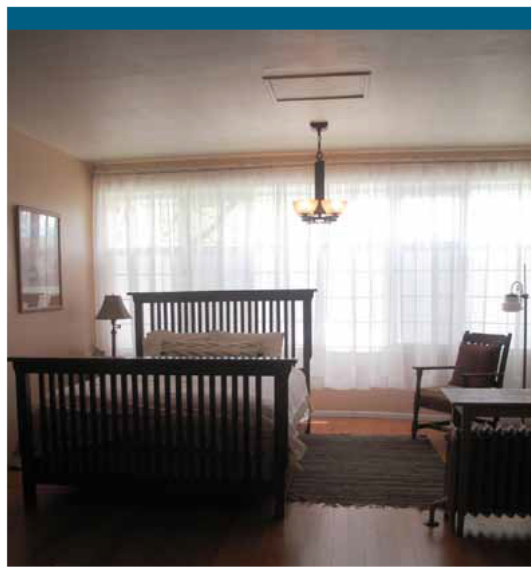

In the master bedroom, breezes stir the curtains even when the leaky casement windows are closed. The uninsulated floor is also chilly; it extends over the open front porch.
For More Information

Www buildingamerica.gov

EERE Information Center

1-877-EERE-INF (1-877-337-3463)

eere.energy.gov/informationcenter

\begin{tabular}{l|l} 
u.s. Departuent or | Energy Efficiency \& \\
Renewable Energy
\end{tabular}

PNNL-SA-83161 September 2011
The basement work altogether will reduce energy bills by an estimated $11 \%$, according to computer modeling. While the full project is expensive, it's important. Besides offering significant energy savings, it will reduce the stack effect, which can make the whole house colder.

Windows and other air leaks. The home's single-paned windows fit loosely. With these and other gaps and cracks in the old walls, the house has air leaks equivalent to a 10 -inch by 20 -inch window open yearround. Cost-effective air sealing can be performed as part of insulation projects in the sloped ceilings, walls, floors, and basement. However, replacing the windows is not cost-effective as an energy-saving measure. It would take 40 years, according to the researchers' calculations, to recoup the cost of new windows. Interior storm windows would help to block the drafts, but they also would have a long payback period-31 years. The Building America researchers are not including window replacement in their energy efficiency recommendations, although the homeowners may wish to replace some of them for comfort.

\section{The Bottom Line}

The Dayton homeowners currently pay $\$ 3,536$ a year for energy. If they choose to implement all the recommendations of the Building America researchers, their anmual energy bill will be reduced to an estimated $\$ 970$.

\begin{tabular}{|c|c|c|c|c|c|}
\hline Measure & $\begin{array}{l}\text { Estimated } \\
\text { Reduction } \\
\text { in Energy } \\
\text { Bills } \\
\end{array}$ & $\begin{array}{l}\text { Estimated } \\
\text { Cost }\end{array}$ & $\begin{array}{l}\text { Estimated } \\
\text { Savings }\end{array}$ & $\begin{array}{l}\text { Payback } \\
\text { Period }\end{array}$ & $\begin{array}{l}\text { Payback } \\
\text { Period } \\
\text { (after } \\
\text { incentives) }\end{array}$ \\
\hline $\begin{array}{l}\text { Ductless } \\
\text { Heat Pump }\end{array}$ & $68 \%$ & $\$ 9,300$ & $\$ 2,393 /$ year & 4 years & 4 years \\
\hline $\begin{array}{l}\text { Insulate } \\
\text { sloped } \\
\text { ceilings } \\
\text { and air-seal } \\
\text { attic }\end{array}$ & $1 \%$ & $\$ 1,161$ & $\$ 40 /$ year & 29 years & 17 years \\
\hline $\begin{array}{l}\text { Insulate } \\
\text { walls and } \\
\text { cantilevered } \\
\text { floor }\end{array}$ & $2 \%$ & $\$ 924$ & $\$ 70 /$ year & 13 years & 8 years \\
\hline $\begin{array}{l}\text { Air seal and } \\
\text { insulate } \\
\text { bas ement } \\
\text { walls }\end{array}$ & $11 \%$ & $\$ 5,107$ & $\$ 511 /$ year & 13 years & 12 years \\
\hline $\begin{array}{l}\text { TOTAL } \\
\text { SAVINGS* }\end{array}$ & $73 \%$ & $\$ 16,492$ & $\$ 2,566$ & 6 years & 6 years \\
\hline \multicolumn{6}{|c|}{$\begin{array}{l}\text { * Total savings is not simply the sum of savings from each measure because the changes are } \\
\text { interactive. Actual savings will depend on which measures are implemented, as well as any } \\
\text { changes in usage patterns. Costs are calculated with data from the National Residential Efficiency } \\
\text { Measures Database, assembled by the U.S. Department of Energys National Renewable Energy } \\
\text { Laboratory. These values are compared to local prices and quotes. Savings are modeled with } \\
\text { Energy Gauge software, based on the local electric rate of } \$ 0.068 / \mathrm{kWh} \text {. A simple payback period } \\
\text { is used, without adjustments for interest, inflation, or depreciation. }\end{array}$} \\
\hline
\end{tabular}




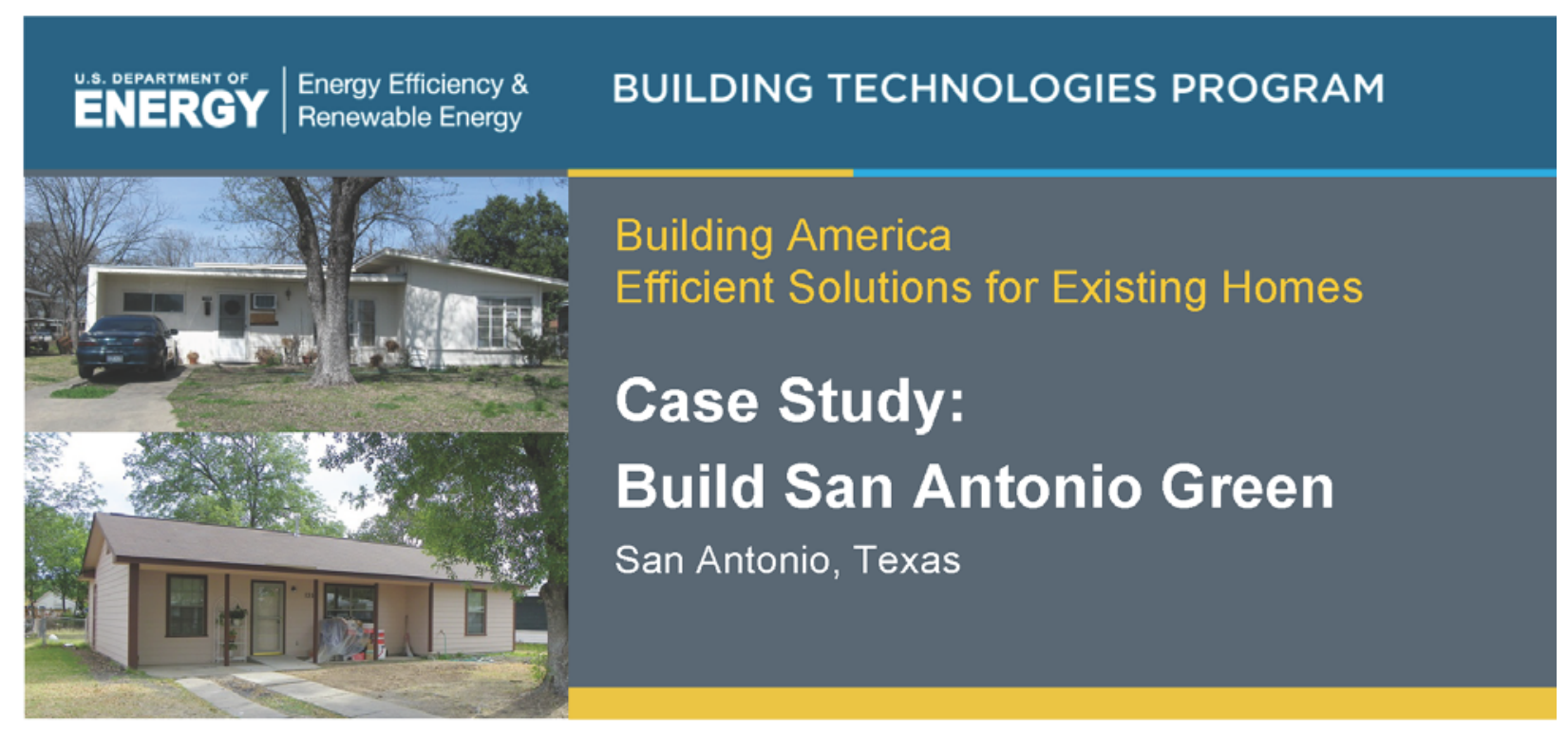

\section{PROJECT INFORMATION}

Construction: Deep energy retrofit

Type: Single-family, affordable, total interior rehab of foreclosed single story home

Partners: Build San Antonio Green, CPS Energy, T \& J Builder, City of San Antonio

Size: $1,047 \mathrm{ft}^{2}$

Total Rehab Cost: about $\$ 50,000$

Date Completed: May 2011

Climate Zone: Hot-humid

\section{PERFORMANCE DATA}

HERS Index: pre- and post-retrofit: pre-161 and post-93

Projected annual energy cost savings: $\$ 545$

Projected annual energy reduction: Site $=33 \%$, Source $=46 \%$

Total cost of energy-efficiency measures: $\$ 9,620$

Rate of return: $5.66 \%$

Billing data:

Will be available in 2012

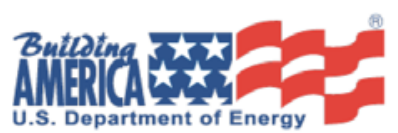

\section{Project Description}

Building America researchers provided technical assistance to Build San Antonio Green (BSAG, www.buildsagreen.org) for three of their deep energy and green retrofits. BSAG is a well established non-profit organization in the community that has certified more than 710 new homes and 15 retrofits through its Green Retrofit Program to date.

Technical assistance provided by the Pacific Northwest National Laboratory (PNNL) team included retrofitting strategy assessments, performance testing, quality assurance, and metering. The PNNL team includes Calcs-Plus, which led the field work, and the Florida Solar Energy Center, which led the metering effort.

This San Antonio home is one of three deep energy renovations of occupied affordable homes certified in 2011. The homes were selected through the City of San Antonio's Owner-Occupied Housing Rehabilitation Program. Built in 1949, this slab-on-grade, threebedroom, one-bath, 942-square-foot home had only a basic level of cooling and heating provided by three window air conditioners, one of which was a heat pump. The renovation increased the floor area to 1,047 square feet. The thermal envelope consisted of a shallow, uninsulated, single-assembly roof and frame walls with minimal insulation estimated to be R-4. Extensive retrofitting work was required to bring the home up to modern standards including removal of all drywall and installation of a new 6:12 pitch roof.

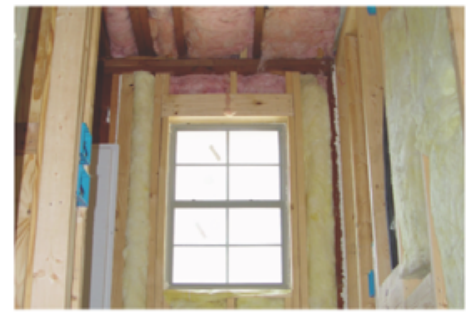

Insulation was well installed in this project without gaps or compression (Photo sources - BSAG and CalcsPlus) 


\section{KEY ENERGY-EFFICIENCY MEASURES}

\section{HVAC:}

- SEER 14, 2-ton air conditioner combined with an $80 \%$ AFUE gas furnace in vented attic

- Mastic-sealed, R-6 and flex ducts. Transfer grills in all bedrooms. Leakage to outside=46 cfm@25 Pa

- Positive pressure whole house ventilation system (run-time only) with electric damper that prevents entry of outside air when compressor shuts off

- Kitchen and baths vented to outside

- Carbon Monoxide detector

\section{Envelope:}

- Radiant barrier roof decking over R-30 ceiling insulation

- 2x4 walls with R-13 insulation

- Double-pane, low-e, metal windows. $\mathrm{U}=0.54, \mathrm{SHGC}=0.30$

- House $\mathrm{ACH} 50=7.5$ (pre-retrofit was 22.3)

\section{Lighting, Appliances,} and Water Heating:

- $100 \%$ CFL

- Standard older appliance

- Energy feedback display

- $0.62 \mathrm{EF}$ gas water heater in exterior closet

For more Information, please visit: www. buildings.energy.gov
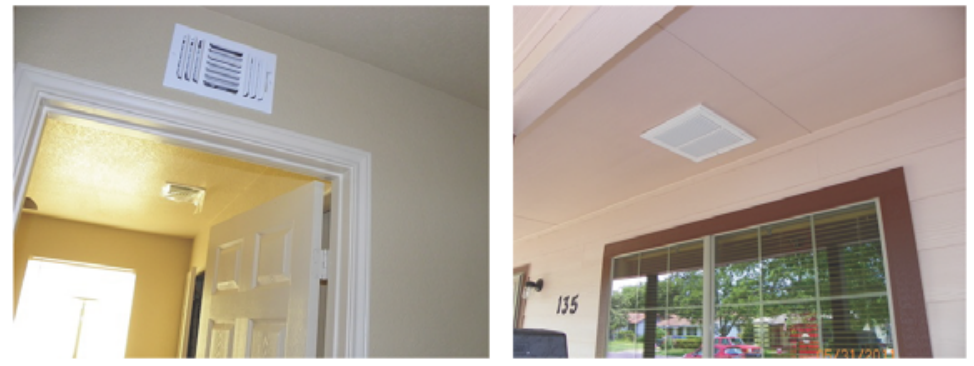

Transfer grills (left photo) were provided to assure good return air flow even when the bedroom doors are closed. The outside air intake is through a filter backed grill (right) that assures dust and pollen are removed from the ventilation air (Photo sources - BSAG and Calcs-Plus)

\section{Lessons Learned}

- To ensure combustion safety, the gas furnace was installed in the attic and the gas water heater in an exterior closet.

- Tight duct systems, the transfer grills, and the outside air ventilation system proved to be implementation challenges even with an HVAC contractor willing to learn. As a result, multiple site visits, onsite duct testing, and training were required to achieve the project goals.

- The availability of the pre-retrofit utility bills permitted the team to calibrate the analysis model, which was then used to estimate the post-retrofit savings. To better understand actual energy use and occupant lifestyle, all three project homes are being metered.

"Participating in the Building America Deep Energy Retrofit study has had a great effect on Build San Antonio Green. After all the retrofit work was done, we walked away with knowledge of new techniques and features that we have incorporated into our program. The BSAG Green Retrofit Program now incorporates measures that will further the energy efficiency and comfort of these homes. The study was a great benefit not only to BSAG, but to our homeowners as well."

Lina Luque, Certification Manager Build San Antonio Green
Energy Efficiency \& Renewable Energy
EERE Information Center 1-877-EERE-INFO (1-877-337-3463) eere.energy.gov/informationcenter

Publication-SA-XXXXX December 2011
For information on Building America visit buildingamerica.gov.

The website contains expanded case studies, technical reports, and best practices guides. 


\section{BUILDING TECHNOLOGIES PROGRAM}

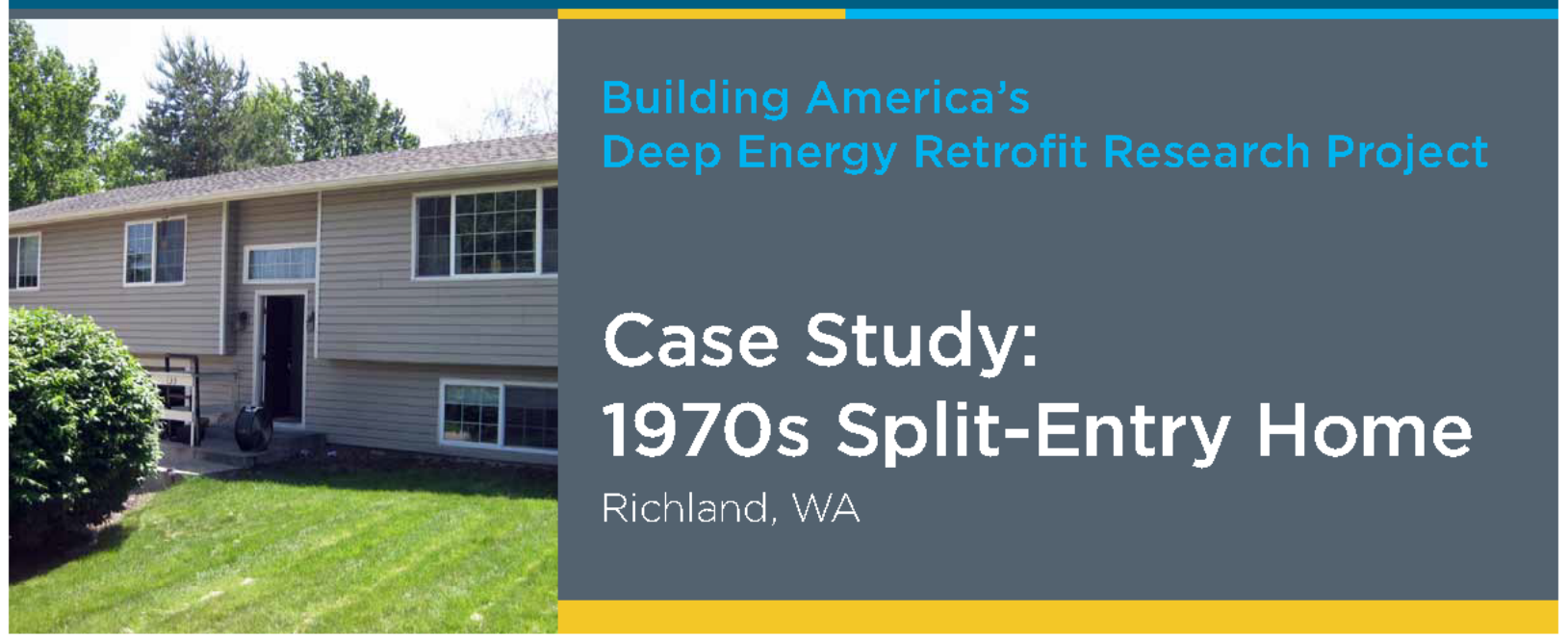

The duct work in this 1970 s home is poorly designed and undersized, creating year-round temperature problems. An assessment by the Pacific Northwest National Laboratory found that solving the home's comfort problems will also cut the owners' energy bills by an estimated $40 \%$.

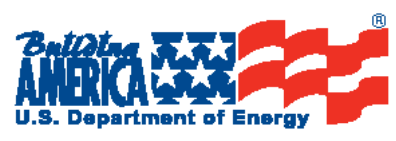

\section{Fixing a poorly designed duct system will help save $40 \%$ on energy costs}

Maintaining comfort is difficult for the owners of a two-story, split-entry house in Richland, Washington. If the owners heat the cold basement in winter, the upstairs becomes too hot. In summer, the whole house is hot. However, a home energy assessment conducted by researchers from the Pacific Northwest National Laboratory brought good news: The same measures that will make the home comfortable will also cut its energy costs by $40 \%$. The PNNL researchers conducted the work in support of the U.S. Department of Energy's Building America program.

The assessment revealed that the home's ductwork is poorly designed and undersized, restricting air flow and causing temperature problems. Reconfiguring the ductwork and installing more insulation and a new heat pump will save an estimated $\$ 720$ a year, with a 13 -year payback period. In the meantime, the home's comfort problems will be solved.

\section{The Home Energy Assessment}

This work is part of Building America's Deep Energy Retrofit Research Project (see Sidebar). Researchers are identifying cost-effective technologies and strategies for reducing energy use in existing homes by more than $30 \%$. When the upgrades are complete, the researchers will measure and analyze the results to develop best practices for deep energy retrofits in a variety of climates. 


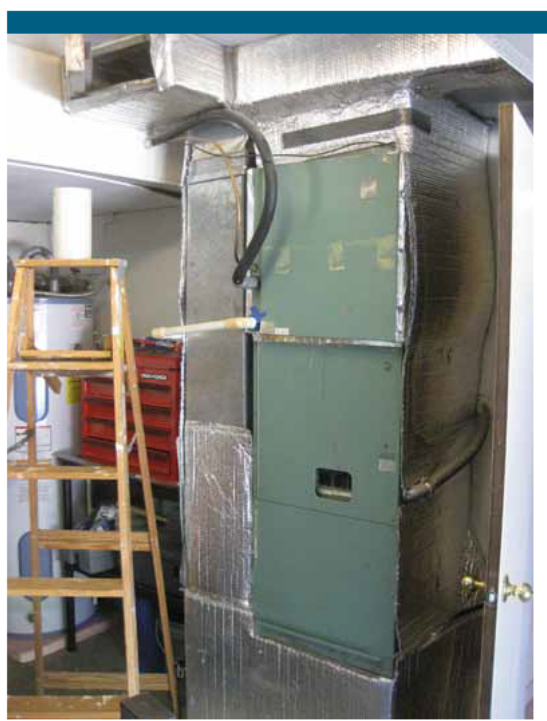

An air handler keeps air circulating through the home's duct system. The diameter of the return duct connecting to this air handler is too small for sufficient air flow.
As part of the energy assessment, the Building America researchers conducted a blower door test to measure air leakage and a pressurized duct test to measure duct leakage. They inspected insulation levels throughout the house and examined energy consuming appliances. The researchers entered the data in a computer model and identified the most cost-effective measures for improving the home's energy efficiency.

\section{Problems, Opportunities, and Recommendations}

The 1970s Richland home is located in the dry climate of eastern Washington, which has hot summers and cold winters. It has three bedrooms, 1,692 $\mathrm{ft}^{2}$ of living space, and an attached garage. The upper story has front and back cantilevered floors that create cold spots during the winter.

HVAC upgrades. Duct systems distribute and return heated and cooled air to maintain comfortable temperatures throughout the home. The Richland home's ducts are poorly sealed and insulated. More importantly, the duct system has two major design flaws.

First, the builder used a framed building cavity for return air instead of installing a metal duct. When building cavities are used as return ducts, leaky joints in the building materials can lose conditioned air or pull in outdoor air and harmful pollutants.

The second design flaw is in the duct sizing. Tests show the ducted portion of the return register is too small for the heating and cooling system. This restricts the air supply by $50 \%$. To compensate for the poor airflow, a previous owner installed an additional return duct in the garage. This failed to solve the air flow problem, since it didn't increase the overall diameter of the return duct. Worse, it created health and safety risks by pulling garage air into the duct system. Garage air often contains pollutants, such as carbon monoxide from car exhaust and fumes from paint or solvents stored in the garage. The hot or cold air entering from the garage also increases the load on the air conditioner and furnace.

The Building America researchers recommend reconfiguring, sealing, and insulating the entire duct system. This will not only increase the energy efficiency of the heating, ventilation, and air conditioning (HVAC) system, it will also improve comfort and air quality. According to the researchers' computer models, the recommended ductwork will cost the homeowners $\$ 1,000$ upfront and save them an estimated $\$ 176$ annually. In 6 years, the project will pay for itself. 


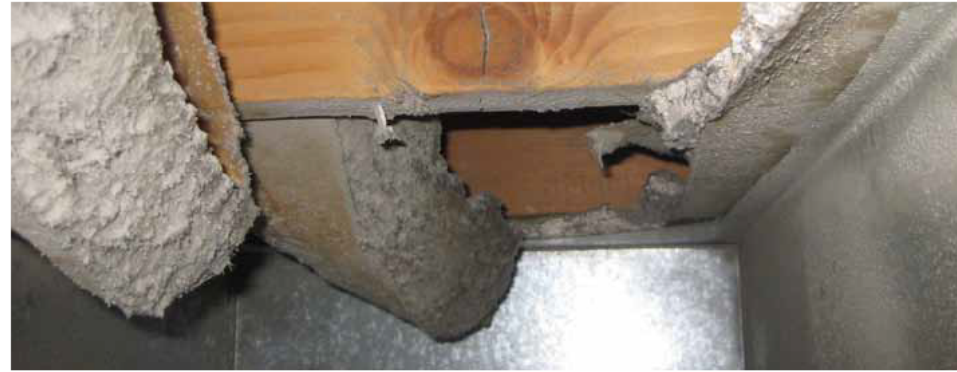

The home's builder avoided installing a metal duct for return air by using this building cavity instead. Worn fiberglass batt insulation can be seen in this close-up of the building cavity. Fiberglass inside a duct may pose a health hazard. Minute shards of glass can be pulled into the airstream and circulated around the house.

The Building America researchers also recommend replacing the air conditioner and the 30-year-old electric furnace with a high-efficiency heat pump. This improvement will provide the biggest savings, cutting their energy bills an estimated $16 \%$, for a savings of $\$ 285$ per year. However, these energy savings come with a big price tag. New energyefficient heat pumps typically cost about $\$ 7,000$. With the low cost of electricity in the Richland area, it will take about 18 years to recoup the upfront cost.

However, if the homeowners choose to buy the heat pump and reconfigure the ducts at the same time, the purchase will be much more cost-effective. The estimated annual savings on their energy bill will jump to $\$ 685$ per year, much higher than the sum of the separate projects. The reason for the jump is simple. Efficient ducts will reduce the heating and cooling load, so the heat pump will run less often. The homeowners will save enough energy to recoup the cost of the combined projects in 12 years. Meanwhile, their home will have good air quality and comfortable temperatures year-round.

\begin{tabular}{|l|l|l|l|l|}
\hline Measure & $\begin{array}{l}\text { Estimated } \\
\text { Reduction in } \\
\text { Energy Bills }\end{array}$ & $\begin{array}{l}\text { Estimated } \\
\text { Cost }\end{array}$ & $\begin{array}{l}\text { Estimated } \\
\text { Savings }\end{array}$ & $\begin{array}{l}\text { Payback } \\
\text { Period }\end{array}$ \\
\hline $\begin{array}{l}\text { Reconfigure, seal and insulate } \\
\text { ducts }\end{array}$ & $10 \%$ & $\$ 1,000$ & $\$ 176 /$ year & 4 years \\
\hline Install heat pump & $16 \%$ & $\$ 7,000$ & $\$ 285 /$ year & 18 years \\
\hline $\begin{array}{l}\text { Reconfigure, seal and insulate } \\
\text { ducts and install heat pump } \\
\text { Recommended }\end{array}$ & $38 \%$ & $\$ 8,000$ & $\$ 685 /$ year & 12 years \\
\hline
\end{tabular}

\section{Building America's Deep Energy Retrofit Research Project}

\author{
This assessment is part of Building \\ America's Deep Energy Retrofit \\ Research Project, conducted by the \\ U.S. Department of Energy's Pacific \\ Northwest National Laboratory (PNNL), \\ Oak Ridge National Laboratory, and \\ other research partners. The researchers \\ are coordinating deep energy retrofits \\ for at least 50 residences throughout \\ the United States.
}

Deep energy retrofits use comprehensive, whole-house strategies to reach the highest cost-effective level of energy efficiency. For each home, the Building America researchers identify a package of cost-effective technologies and strategies to reduce energy use by more than $30 \%$.

\section{A deep energy retrofit usually requires an investment of $\$ 7,000$ to $\$ 20,000$. Rebates, tax credits and low-interest loans are often available.}

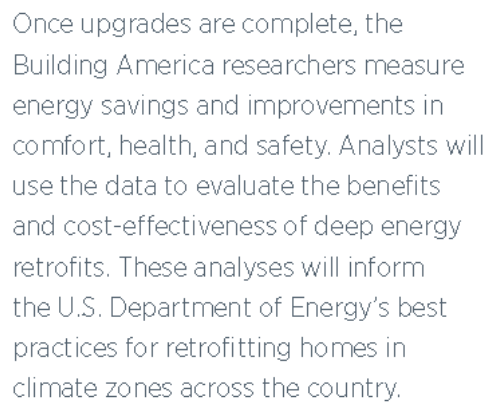

Once upgrades are complete, the Building America researchers measure energy savings and improvements in comfort, health, and safety. Analysts will use the data to evaluate the benefits and cost-effectiveness of deep energy retrofits. These analyses will inform the U.S. Department of Energy's best practices for retrofitting homes in climate zones across the country. 


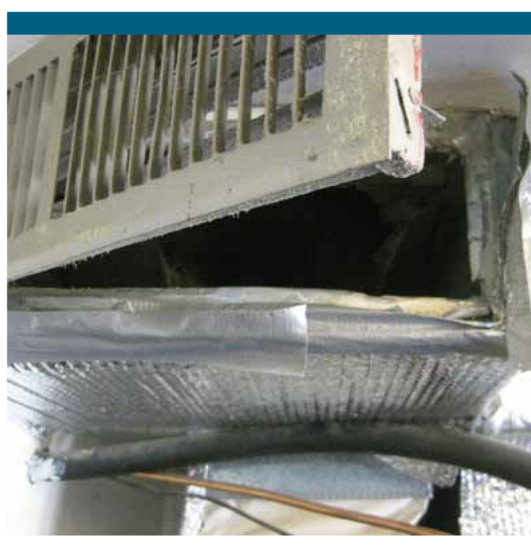

A previous owner tried to improve the duct system by installing a second return air duct in the garage. This failed to solve the problem. Worse, it increased the home's energy use and created a safety risk. Garage air that is sucked into the home's ventilation system can carry carbon monoxide from car exhaust and fumes from paint and solvents stored in the garage.

\section{For More Information}

WWw buildingamerica.gov

EERE Information Center

1-877-EERE-INF (1-877-337-3463)

eere.energy.gov/informationcenter

\begin{tabular}{l|l} 
u.s. Departuent or | Energy Efficiency \& \\
Renewable Energy
\end{tabular}
Improving insulation. Attic insulation reduces the amount of unwanted heat transfer through the ceiling. Currently, the attic has about 3 inches of blown-in fiberglass with R-19 batts added on top. Because gaps around the edges of the batts degrade the R-value, the insulation varies from R-9 to R-28. The Building America researchers recommend blowing additional fiberglass insulation on top of the batts to fill in the gaps and increase the total value of the attic insulation to R-60.

The researchers identified other areas of the house needing insulation, including a portion of the basement wall under the stairs and the cantilever under the bedroom floor.

At a cost of $\$ 1,200$, the additional insulation will increase comfort and reduce the homeowner's energy bills by an estimated $8 \%$ anmually, with a payback period of just 8 years.

\section{The Bottom Line}

The Richland homeowners currently pay $\$ 1,772$ in energy bills each year. The Deep Energy Retrofit measures recommended by the Building America researchers will cost a combined $\$ 9,200$, but will reduce the annual energy bill by $\$ 720$. This $40 \%$ savings should allow them to recoup their total investment in 13 years. Meanwhile, they will enjoy a healthier and more comfortable home.

\begin{tabular}{|l|l|l|l|l|}
\hline Measure & $\begin{array}{l}\text { Estimated } \\
\text { Reduction in } \\
\text { Energy Bills }\end{array}$ & $\begin{array}{l}\text { Estimated } \\
\text { Cost }\end{array}$ & $\begin{array}{l}\text { Estimated } \\
\text { Savings }\end{array}$ & $\begin{array}{l}\text { Payback } \\
\text { Period }\end{array}$ \\
\hline $\begin{array}{l}\text { Reconfigure, } \\
\text { seal and } \\
\text { insulate ducts } \\
\text { and install } \\
\text { heat pump }\end{array}$ & $38 \%$ & $\$ 8,000$ & $\$ 685 /$ year & 12 years \\
\hline $\begin{array}{l}\text { Add insulation } \\
\text { and air seal }\end{array}$ & $8 \%$ & $\$ 1,200$ & $\$ 151 /$ year & 8 years \\
\hline $\begin{array}{l}\text { TOTAL } \\
\text { SAVINGS* }\end{array}$ & $40 \%$ & $\$ 9,200$ & $\$ 720 /$ year & 13 years \\
\hline $\begin{array}{l}\text { Total savings is not simply the sum of savings from each measure because the changes } \\
\text { are interactive. Actual savings will depend on which measures are implemented, as } \\
\text { well as any changes in usage patterns. Costs are calculated with data from the National } \\
\text { Residential Efficiency Measures Database, assembled by the U.S. Department of } \\
\text { Energy's National Renewable Energy Laboratory. These values are compared to local } \\
\text { prices and quotes. Savings are modeled with REMRate software, based on the local } \\
\text { electric rate of } \$ 0.068 / \text { kWh. A simple payback period is used, without adjustments for } \\
\text { interest, inflation, or depreciation. Federal tax credits and locally available incentives } \\
\text { may reduce the cost of some projects. }\end{array}$ \\
\hline
\end{tabular}




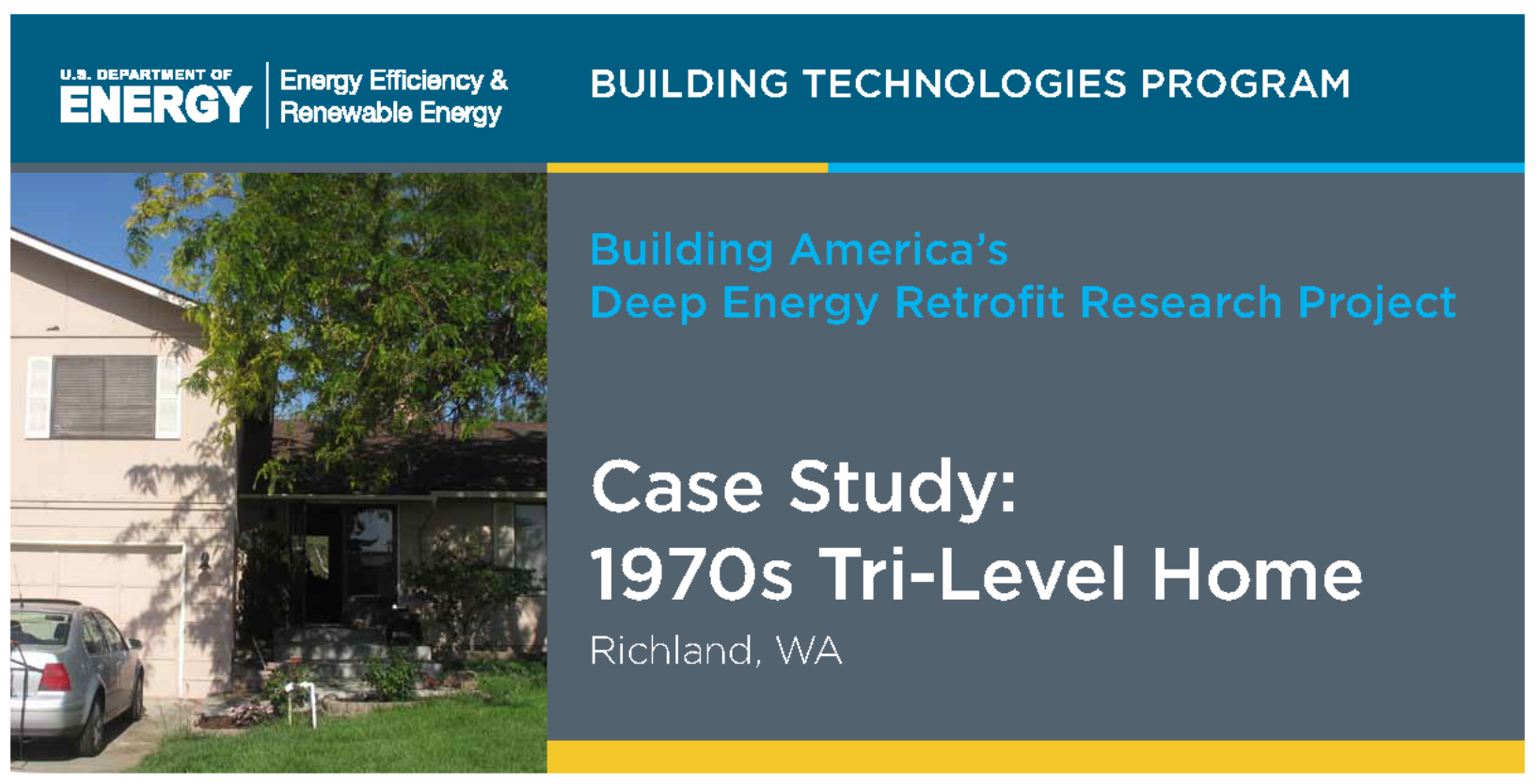

The 1970 s tri-level house in Richland, Washington, has big air leaks that undermine comfort, air quality, and energy efficiency. The owners plan to install an efficient heat pump and new windows, but the full benefit of these upgrades won't be realized unless air gaps are sealed and the duct system repaired.

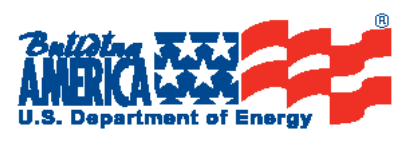

\section{Air sealing and duct repairs will help cut energy bills by $57 \%$}

The couple was planning a total remodel when they bought their $1970 \mathrm{~s}$ tri-level home in Richland, Washington. They knew the decades-old furnace, windows, and appliances needed replacing. However, there was a big problem they were not aware of.

In a whole-house energy assessment, Building America researchers identified air gaps, thermal bypasses, and leaky ducts that allow air to constantly flow in and out of the house. True, the owners can replace the electric furnace and air conditioner with an efficient heat pump. Unless they seal the air leaks and repair the ducts, however, much of the air they pay to heat and cool will simply escape the house.

The assessment is part of Building America's Deep Energy Retrofit Research Project (see sidebar on page 3). It was conducted by the Pacific Northwest National Laboratory (PNNL) for the U.S. Department of Energy. PNNL and other research teams are identifying cost-effective technologies and strategies for reducing energy use in existing homes by more than $30 \%$. When the upgrades are complete, the researchers will measure and analyze the results to develop best practices for deep energy retrofits in various climates.

As part of the assessment, the Building America researchers measured the home's air leaks with a blower door test and identified leaky ducts with duct blaster and pressure pan tests. An analyst inspected insulation and checked for air gaps in the home's crawlspace and two attics. Using the assessment data and computer modeling, the researchers provided the Richland homeowners with a list of cost-effective recommendations that can reduce the homeowner's energy use by an estimated $57 \%$. 


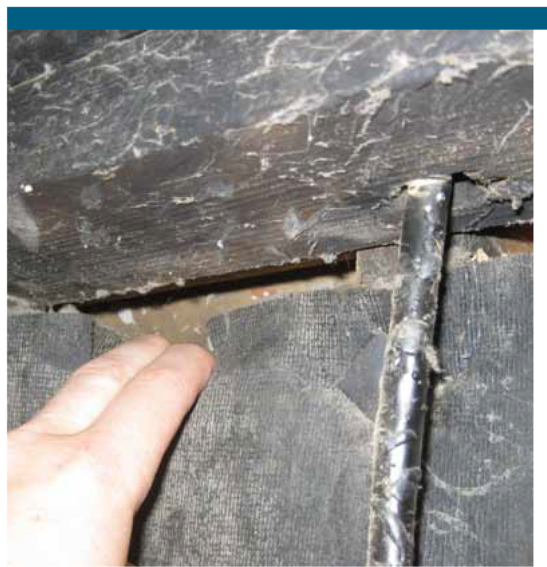

An energy analyst pulls away duct liner to reveal a gap in the return air pathway. The gap allows warm air to escape the house in winter and hot air to enter in summer. This is a common problem when builders use framed building cavities as return air ducts instead of installing metal ductwork.

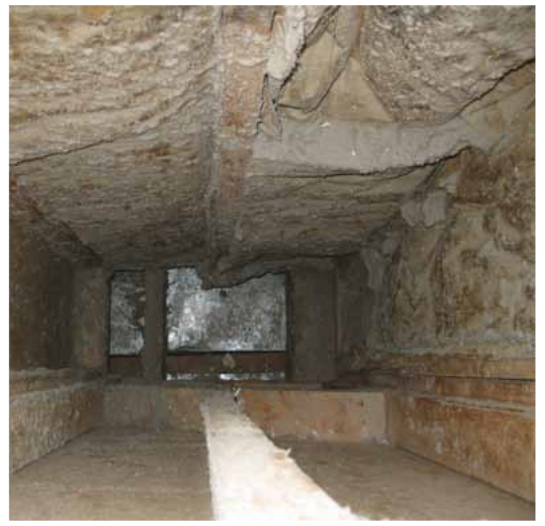

Among the home's design flaws are empty building cavities that directly connect the crawlspace and attic, creating a year-round escape path for conditioned air

\section{Air Leaks Undermine Comfort, Air Quality and Energy Efficiency}

Richland has a dry climate with cold winters and hot summers. The home's warmth collects on the upper floor, leaving the other two floors cold in winter. It's no wonder. In a house that's not airtight, warm air rises from the lower floors to the upper floors, then escapes through gaps into the attic. This "stack effect" creates negative air pressure in the lower part of the house, so replacement air gets pulled in from outside. The Building America researchers' measurements showed the home's air leaks are equivalent to having a 10 -inch by 13.5 -inch window open all year.

Air from garage and crawlspace circulates through home. The door between the garage and family room is so poorly fitted that daylight can be seen around it. Air sucked through these gaps into the family room can hold fumes from cars and stored paints and solvents. These contaminants can also enter the duct system and be circulated through the home, since more than half the home's ducts pass through the garage and adjoining crawlspace.

Thermal bypasses compound energy losses. Design flaws in the Richland home make it easy for conditioned air to escape. The walls hide three empty vertical chases that are "thermal bypasses." These framed-in cavities directly connect the crawlspace and the attic, creating a yearround escape path for conditioned air. In winter, cold crawlspace air moves behind the walls. Only a half-inch of drywall separates that air from the living space.

Crawlspace insulation is inadequate. Batts hang loosely off the crawlspace ceiling. On the underside of the home's lower staircase, batt insulation runs along the stairs' diagonal instead of following the run and rise of the stairs. The air gaps make the insulation useless.

Mid-level attic has air leaks and inadequate insulation. The Building America researchers found several problems in the mid-level attic. A building cavity next to the chimney extends all the way down to the crawlspace. This thermal bypass goes behind the fireplace in the living room, allowing air to leak around the fireplace. Air also leaks around the attic kneewall into the living space, and the attic floor's loose-fill fiberglass insulation is compressed and unevenly spread, giving a thermal rating of just R-19 (R-38 to R-60 is recommended). Finally, the attic has air leaks wherever wires, pipes, and recessed "can" lights penetrate the ceiling. 


\section{HVAC System Wastes Energy}

Energy is squandered by each part of the home's heating, ventilation and air conditioning system.

Ducts leak throughout home. Tests performed by the Building America researchers show that $19.5 \%$ of the air in the ducts leaks out through loose joints and seams. This air moves behind walls, through building cavities, and escapes to the outside. Some ducts are crushed, as the homeowners discovered.

Building cavity is used for return air. To compound the problem, metal ducts were never installed to return indoor air to the furnace and air conditioner. The builder took a shortcut and used a framed building cavity instead. When building cavities are used as return ducts, outside air gets pulled in through joints in the building materials. In the Richland home, this design flaw also carries a health risk. The building cavity is lined on one side with fiberglass insulation, allowing loose glass fibers to be drawn into the ventilation system.

Other problems include the inefficient furnace and air conditioner and the leaky air handler.

\section{Recommended Upgrades}

The homeowners hoped for a $60 \%$ reduction in energy use, and they may hit that ambitious target. At the time of the audit, they had already reduced their energy use by upgrading the electrical system and installing efficient appliances. Now their consumption can be cut by an additional $57.1 \%$, according to computer modeling performed by Building America.

Air sealing and insulation for attics and crawlspace. The Building America researchers recommend upgrading the insulation in both attics to R-60 and air sealing the thermal bypasses from the attic side. The building cavity next to the chimney should be covered with a non-combustible material and sealed with a fire-rated sealant. The researchers recommend using spray foam insulation to air seal and insulate the base of the kneewalls in the mid-level attic and the underside of the stairs in the crawlspace. Penetrations through the crawlspace floor for pipes, ducts, and wires should be caulked or sealed with spray foam. Another recommendation includes adding batt insulation in the crawlspace ceiling to reach a value of R-30. (Crawlspace ceiling insulation is acceptable in the dry climate of eastern Washington; in humid climates it can cause moisture problems.)

HVAC upgrades. According to the researchers' computer models, repairing and sealing ducts will reduce energy consumption by $8.9 \%$. Replacing the furnace and air conditioner with an efficient heat pump will reduce consumption by an estimated $26.9 \%$. However, implementing the two together is predicted to reduce consumption by $44 \%$. The total

\section{Building America's Deep Energy Retrofit Research Project}

This assessment is part of Building

America's Deep Energy Retrofit

Research Project, conducted by the

U.S. Department of Energy's Pacific

Northwest National Laboratory (PNNL). Oak Ridge National Laboratory, and other research partners. The researchers are coordinating deep energy retrofits for at least 50 residences throughout the United States.

Deep energy retrofits go further than simple weatherization. The retrofits use comprehensive, whole-house strategies to reach the highest cost-effective level of energy efficiency. For each home, the Building America researchers identify a package of cost-effective technologies and strategies to reduce energy use by more than $30 \%$.

A deep energy retrofit usually requires an investment of $\$ 7,000$ to $\$ 20,000$. Rebates, tax credits and low-interest loans are often available.

Once upgrades are complete, the researchers measure energy savings and improvements in comfort, health, and safety. Analysts will use the data to evaluate the benefits and cost-effectiveness of deep energy retrofits. These analyses will inform best practices for retrofitting homes in climate zones across the country. 


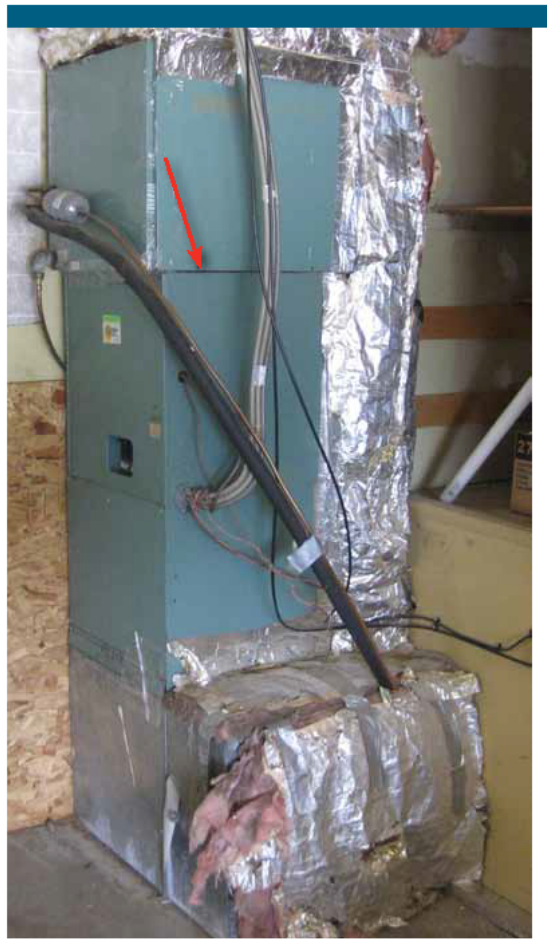

The sections of the air handler are so poorly fitted that air rushes out through gaps.

\section{For More Information}

WWw. buildingamerica.gov

EERE Information Center

1-877-EERE-INF (1-877-337-3463)

eere.energy.gov/informationcenter

\section{U.8. Departuent of | Energy Efficiency \& Renewable Energy}

PNNL-SA-84227 September 2011 reduction is greater than the sum of what each project would achieve separately because a more efficient duct system reduces a home's heating and cooling load. The total dollar savings is also greater. With federal tax credits and locally available incentives, estimates show the couple will recoup their investment in just 6 years. After that, the $\$ 1,152$ in annual savings will be money in their pocket. Just as important, the improved system will keep the entire home comfortable in all seasons.

New windows. Window replacements typically have high up-front costs and a long payback period, but can reduce energy costs substantially. The Building America researchers recommend vinyl-framed, doublepane windows with a low-emissivity coating. At a cost of $\$ 8,500$ and a predicted annual savings of $\$ 356$, it will take 24 years to recoup the investment. However, the tight windows will reduce energy use an estimated $13.6 \%$, contribute to the homeowners' comfort, and improve the resale value of the home.

\section{The Bottom Line}

The deep energy retrofit measures recommended by the Building America researchers will cost $\$ 19,454$ altogether. The projected $57.1 \%$ reduction in site energy use will yield an estimated anmual savings of $\$ 1,490$. The investment will be recouped in 13 years. Meanwhile, the homeowners will enjoy a safer, more comfortable home.

\begin{tabular}{|c|c|c|c|c|c|}
\hline Measure & $\begin{array}{l}\text { Estimated } \\
\text { Decrease } \\
\text { in Energy } \\
\text { Use }\end{array}$ & $\begin{array}{l}\text { Estimated } \\
\text { Cost }\end{array}$ & $\begin{array}{l}\text { Estimated } \\
\text { Savings }\end{array}$ & $\begin{array}{l}\text { Payback } \\
\text { Period }\end{array}$ & $\begin{array}{l}\text { Payback } \\
\text { Period } \\
\text { (After } \\
\text { Incentives) }\end{array}$ \\
\hline $\begin{array}{l}\mathrm{R}-60 \text { attic and } \\
20 \% \text { air leakage } \\
\text { reduction }\end{array}$ & $9.1 \%$ & $\$ 1,131$ & $\$ 239 /$ year & 5 years & \\
\hline $\begin{array}{l}\text { R-19 attic kneewalls } \\
\& \text { under stairs and } \\
25 \% \text { air leakage } \\
\text { reduction }\end{array}$ & $5.1 \%$ & $\$ 1,153$ & $\$ 139 /$ year & 9 years & \\
\hline $\begin{array}{l}\mathrm{R}-30 \text { crawlspace } \\
\text { and } 20 \% \text { air } \\
\text { leakage reduction }\end{array}$ & $4.3 \%$ & $\$ 990$ & $\$ 113 /$ year & 9 years & \\
\hline $\begin{array}{l}\text { Seal ducts and } \\
\text { install heat pump }\end{array}$ & $44.0 \%$ & $\$ 7,600$ & $\begin{array}{l}\$ 1,152 / \\
\text { year }\end{array}$ & 7 years & 6 years \\
\hline Replace windows & $13.6 \%$ & $\$ 8,580$ & $\$ 356 /$ year & 24 years & 24 years \\
\hline TOTAL SAVINGS* & $57.1 \%$ & $\$ 19,454$ & $\begin{array}{l}\$ 1,490 / \\
\text { year }\end{array}$ & & 13 years \\
\hline \multicolumn{6}{|c|}{$\begin{array}{l}\text { Total savings is not simply the sum of savings from each measure because the changes } \\
\text { are interactive. Actual savings will depend on which measures are implemented, as } \\
\text { well as any changes in usage patterns. Costs are calculated with data from the National } \\
\text { Residential Efficiency Measures Database, assembled by the U.S. Department of } \\
\text { Energy/s National Renewable Energy Laboratory. These values are compared to local } \\
\text { prices and quotes. Savings are modeled with REMRate software, based on the local } \\
\text { electric rate of } \$ 0.068 / \mathrm{kWh} \text {. A simple payback period is used, without adjustments for } \\
\text { interest, inflation, or depreciation. }\end{array}$} \\
\hline
\end{tabular}




\title{
BUILDING TECHNOLOGIES PROGRAM
}

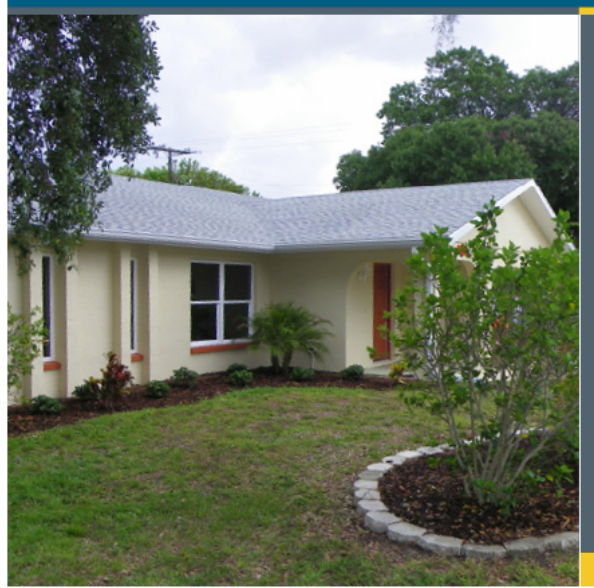

\section{Building America}

Efficient Solutions for Existing Homes

Case Study:

Habitat for Humanity South Sarasota County

\author{
Venice, Florida
}

\section{PROJECT INFORMATION}

Construction: Deep energy retrofit

Type: Single-family, affordable, total interior rehab of foreclosed single story home

Builder: Habitat for Humanity South Sarasota County, FL www.habitatsouthsarasota.org

Size: $1,814 \mathrm{ft}^{2}$

Total Rehab Cost: about $\$ 57,000$

Date Completed: July 2011

Climate Zone: Hot-humid

\section{PERFORMANCE DATA}

HERS Index: pre- and post-retrofit: pre-185 and post-57

Projected annual energy cost savings: $\$ 1,500$

Projected annual energy reduction: $>50 \%$

Total cost of energy-efficiency measures: $\$ 32,550$

Rate of return: $4.6 \%$

Billing data:

Will be available in 2012

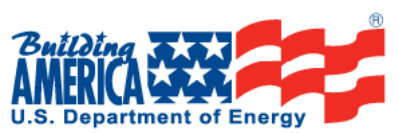

\section{Project Description}

Building America researchers provided technical assistance to Habitat for Humanity $(\mathrm{HFH})$ of South Sarasota County, Florida, to achieve a deep energy retrofit featuring an innovative way to air seal an entire home, which also moved its ducts and air handler inside the thermal boundary. This home (a 1978, single-story, three-bedroom, two-bath with attached-garage) is typical of many in central and south Florida, and Building America plans to use monitored utility data from the home to analyze the effectiveness of the energy retrofit measures.

Construction funding for this retrofit in Venice, Florida, was provided by the U.S. Department of Housing and Urban Development's State Housing Initiatives Partnership program. Technical assistance was provided by the U.S. Department of Energy's Building America Program, primarily through Calcs-Plus, a member of the Pacific Northwest National Laboratory (PNNL) team. The HFH of South Sarasota County, founded in 1992, has built more than 60 new homes and renovated 16 . The lessons learned from this deep energy retrofit and from ongoing energy monitoring will help inform future retrofit construction and research.

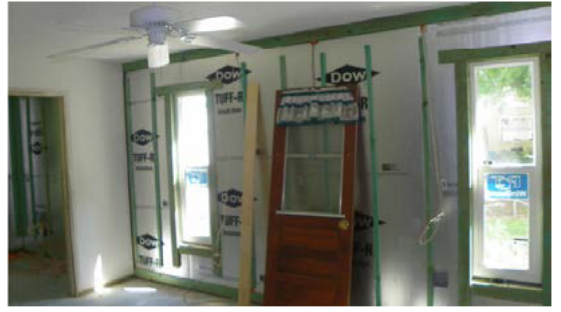

$\mathrm{HFH}$ removed old drywall and filled numerous holes in the concrete block walls before insulating them with continuous R-7.5 foil-faced rigid insulation. Boratetreated furring strips were attached over the insulation to provide an air gap behind the new drywall. (Photo Source: Calcs-P/us) 


\section{KEY ENERGY-EFFICIENCY MEASURES}

\section{HVAC:}

- SEER 16.25, HSPF 9, 2-ton heat pump

- Well-sealed, R-4 to R-6 insulated metal and flex ducts inside unvented attic. Return air ducts in all bedrooms. Leakage to outside $=$ 34 cfm @ $25 \mathrm{~Pa}$

-7-day programmable thermostat

- Positive pressure whole house ventilation system (run-time only) with electric damper that prevents entry of outside air when compressor shuts off

- Kitchen and baths vented to outside

\section{Envelope:}

- White shingle roof over peel-andstick impermeable underlayment

- R-21 open-cell foam insulation in unvented attic

- R-7.5 foil-faced rigid insulation on the inside of concrete block walls

- Double-pane, low-e, vinyl, impactresistant windows. $\mathrm{U}=0.33$, SHGC $=0.22$

- House $\mathrm{ACH} 50=5.5$

(pre-retrofit was 31.3)

\section{Lighting, Appliances,} and Water Heating:

- $100 \%$ CFL

- ENERGY STAR ${ }^{\circledR}$ ceiling fans

- ENERGY STAR ${ }^{\circledR}$ refrigerator, dishwasher

- Heat pump water heater

For more Information, please visit: www.buildings.energy.gov
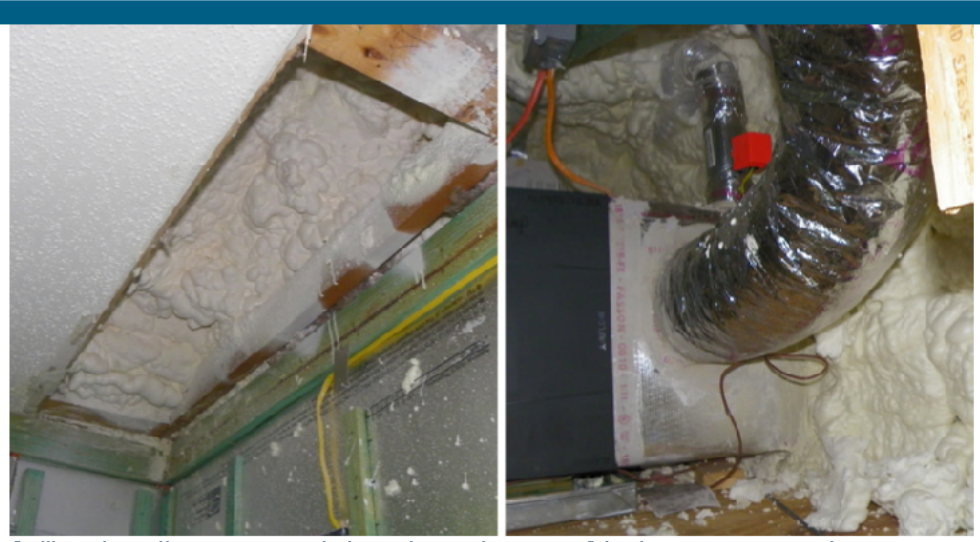

Ceiling drywall was removed along the perimeters of the home to access the attic. Open-cell spray foam was sprayed along the underside of the low-pitch roof to provide an R-21 air sealed, insulated attic space to house the new SEER 16.25 heat pump. (Photo Sources: Calcs-Plus)

\section{Lessons Learned}

- Uninsulated concrete block walls require removal of all interior wallboard to seal numerous holes and add continuous foil-faced rigid insulation (see photo on first page).

- An unvented attic was implemented to air seal the whole house, bring the ducts and air handler inside the thermal envelope, and add insulation to the attic. An unvented attic was the best solution because of numerous large air pathways from the existing vented attic to the house. Perimeter ceiling drywall was removed and replaced after spraying the attic with open-cell foam (see photos).

- All measures listed on the left sidebar were required to achieve $50 \%$ energy savings. The biggest contributors were the two measures in bullets above and the new heat pump and windows. All were installed to work as an integrated system solution to provide a comfortable, affordable energy efficient home.

- Water management details are a critical part of energy retrofits in hot-humid climates. For this project, all windows were sealed and properly flashed and a new white shingle roof was installed over an impermeable underlayment for added protection from rain- and solardriven moisture in this hurricane-prone climate.
"The benefit for our homeowner is a lower energy bill. For our affiliate, going energy efficient, going green, using better building techniques, and better products was a nobrainer. We want to build homes that are healthy, durable, efficient, and sustainable."

Michael Sollitto Construction Manager, HFH South Sarasota County

\section{U.S. DEPARTMENT OF ENEROY}

Energy Efficiency \& Renewable Energy
EERE Information Center 1-877-EERE-INFO (1-877-337-3463) eere.energy.gov/informationcenter

PNNL-SA-84343 November 2011
For information on Building America visit buildingamerica.gov. The website contains expanded case studies, technical reports, and best practices guides. 


\section{Appendix K}

Completed Retrofits in Florida 



\section{Appendix K}

\section{Completed Retrofits in Florida}

This appendix provides details about the eight completed retrofits in Florida where the technical assistance was led by the Florida Solar Energy Center (FSEC). Another completed Florida retrofit in Venice, Florida, is described in a case study in Appendix J. In the body of the text, these pilot retrofit homes are designated by a numbering system that starts with EH- etc. Thus home \#FL-1 corresponds to EH-02 etc.

\section{K.1 Deep Energy Retrofit \#FL-1 (Occupied May 2011 completed April 2011)}

This unoccupied, single-family detached home in Lakeland, Florida, is the first of two renovations completed in 2011 by the City of Lakeland, Community Development Department, Neighborhood Services Division (www.lakelandgov.net/commdev/Housing.aspx ). Table K.1 summarizes the projected annual energy use and cost savings for deep energy retrofit candidate EH-02. Table K.2 relates the anticipated financing and payback associated with the whole package of improvements.

Table K.1. EH-02 Annual Energy Use and Cost Simulation

\begin{tabular}{lccc}
\hline \multicolumn{1}{c}{ Home Components } & As-Found & Minimal Improvement & Actual Retrofit \\
\hline HERS Index & 177 & 160 & 85 \\
Annual Simulation kWh (BABM08) & 18,412 & 17,116 & 10,998 \\
Annual MBtu Usage (BABM08) & 62.8 & 58.4 & 37.5 \\
Annual Energy Cost (BABM08) & $\$ 2,393$ & $\$ 2,225$ & $\$ 1,431$ \\
Project Status: Completed 4/30/11 & & \\
\hline "Minimal Improvement" reflects improvement for replacing the mechanical system with a Seasonal Energy \\
$\begin{array}{l}\text { Efficiency Ratio (SEER) 13 air conditioner with electric resistance heating, the minimum efficiency system } \\
\text { available. }\end{array}$ \\
\hline
\end{tabular}

Table K.2. EH-02 Annual Energy-Savings Analysis

\begin{tabular}{lcc}
\hline & $\begin{array}{c}\text { Preliminary and Estimated } \\
\text { Full Cost \& Savings } \\
\text { (As Found vs. Actual) }\end{array}$ & $\begin{array}{c}\text { Preliminary and Estimated } \\
\text { Incremental Cost \& Savings } \\
\text { (Minimal vs. Actual) }\end{array}$ \\
\hline HERS Index Improvement (\%) & $52 \%$ & $47 \%$ \\
Annual Energy Cost Savings (\$) & $\$ 962$ & $\$ 794$ \\
Annual Energy Cost Savings (\%) & $40 \%$ & $36 \%$ \\
Improvement Costs & $\$ 19,097$ & $\$ 2,761$ \\
Monthly Mortgage & $\$ 128$ & $\$ 19$ \\
Monthly Energy Cost Savings & $\$ 80$ & $\$ 66$ \\
Monthly Cash Flow & $-\$ 48$ & $\$ 48$ \\
Simple Payback (years) & 20 & 3 \\
\hline HERS = home energy rating system & & \\
\hline
\end{tabular}


Built in 1960, this three-bedroom, two-bath home (Figure K.1) has 1,250 $\mathrm{ft}^{2}$ of conditioned space. The slab-on-grade, primarily concrete block home had a white block exterior and dark asphalt single roof. By the time a partnership was in place with the city, deconstruction had already occurred. Some wall and ceiling cavities were exposed, and many appliances had been removed.

The thermal envelope included a $338-\mathrm{ft}^{2}$ section with a shallow pitch, which restricted the level of ceiling insulation. The ceiling for this section was composed of acoustical tiles, and its exterior walls were frame. Ceiling insulation for the entire ceiling consisted of a mixture of batt fiberglass and blown-in cellulous and was estimated to be an average of R-9. The existing windows, a mixture of awning style, single hung, and one jalousie-type, were all single-pane, clear, with metal frame. A few were broken, and replacement was slated for all. Appliances and lighting included an older 50-gallon electric hot water heater and $100 \%$ incandescent lighting.

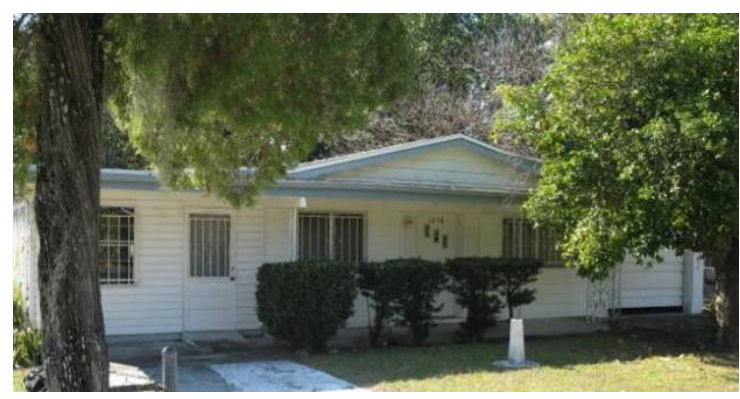

Figure K.1. EH-02 Pre-Retrofit (post-retrofit exterior unchanged)

The air heating and conditioning systems (Figures K.2) included the following:

- a forced-air, Seasonal Energy Efficiency Ratio (SEER) 10, package unit central air conditioner with electric resistance heating

- two older air conditioner window units

- an old abandoned furnace built into an interior wall.
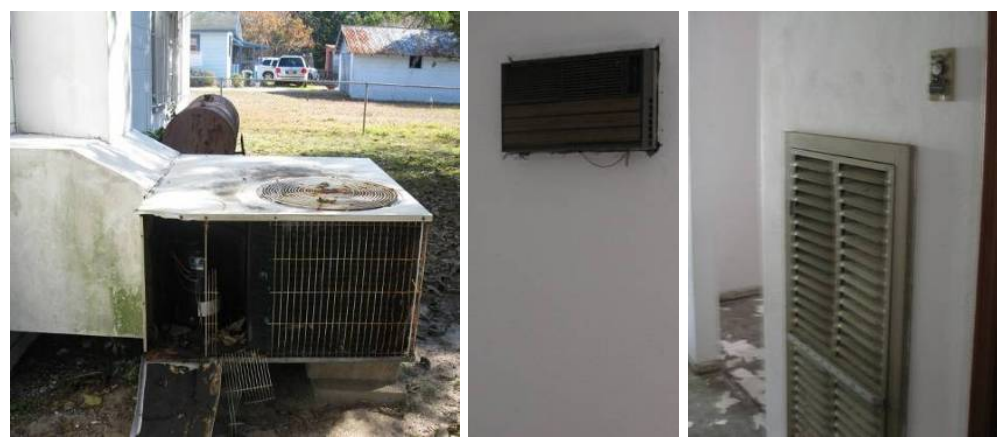

Figure K.2. Retrofit EH-02: Pre-Retrofit Package Unit (left), Wall Unit (center), Abandoned Furnace (right)

Partial deconstruction, broken windows, large exterior wall penetrations, and the appearance of mold prevented whole-house airtightness tests. In order to model the home, an ACH50 of 22 was used, an estimate made using pre-retrofit test results from prior research. Duct leakage testing was limited to total leakage given the inability to depressurize the home, and the distribution system was found to be exceptionally leaky $(\mathrm{Qn}, \mathrm{total}=0.30)$. 
Among several efficiency measure recommendations, researchers presented the concept of bringing outside air into the mechanical system. Citing a lack of funding, however, the partner was unable to incorporate the outside air detail as part of the retrofit process. Additional efficiency recommendations the partner did not implement were insulating the attic to R-38, installing slightly more efficient windows, wrapping the hot water tank and insulating pipes, and installing a programmable thermostat.

The renovation, completed April 30, 2011, was considerable. The measures with the greatest impact on projected energy cost savings (in order of contribution) were the installation of a forced-air, central heat pump (SEER 15), significant reduction in duct leakage, almost exclusive use of efficient lighting, reduction in whole-house infiltration, insulation of the attic to R-30, and installation of double-pane, low-E, vinyl frame windows. Figures K.3 show the pre- and post-retrofit windows and new lighting. The entire package of improvements, listed in Table K.3, is estimated to produce $\$ 962$ in annual energy cost savings.
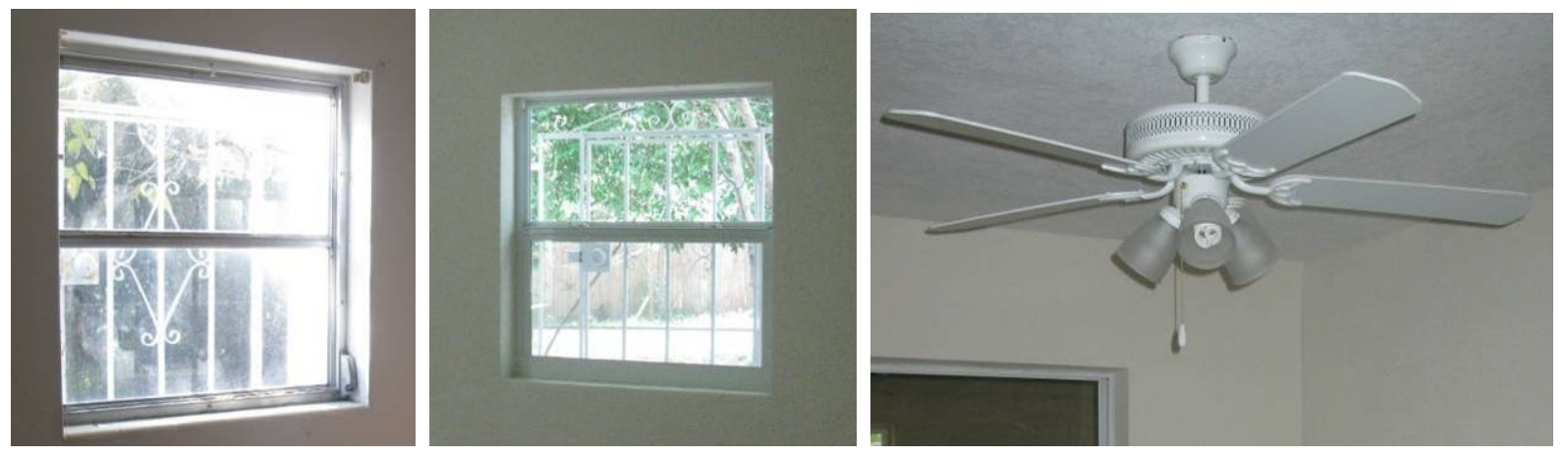

Figure K.3. Retrofit EH-02: Pre-Retrofit Awning Window (left), Post-Retrofit Low-E (center), Post-Retrofit Fan with Compact Fluorescent Lamps (right).

Table K.3. EH-02 Key Energy Efficiency Measures

\begin{tabular}{|c|c|}
\hline Component & Pre and Post-Retrofit Characteristics \\
\hline Roof & $\begin{array}{l}\text { From dark (solar absorption }(a b s p)=0.92) \text { to white asphalt shingles }(\text { solar absp }= \\
0.75)\end{array}$ \\
\hline Ceiling Insulation & From $1,250 \mathrm{ft}^{2} \mathrm{R}-9$ to $912 \mathrm{ft}^{2}$ blown-in fiberglass, $\mathrm{R}-30$ \\
\hline Exterior Walls & From R-0 to R-11 in 3 frame walls \\
\hline Windows & $\begin{array}{l}\text { From single pane, clear, metal frame } \mathrm{U}=1.20 ; \mathrm{SHGC}=0.80 \text { to double pane, low-E } \\
\mathrm{U}=0.65 ; \mathrm{SHGC}=0.35\end{array}$ \\
\hline Doors & From 2 wood \& 1 wood with jalousie windows to 3 insulated metal, 1 with storm \\
\hline Floors & From $100 \%$ concrete to $30 \%$ carpet $60 \%$ laminate $10 \%$ tile \\
\hline Whole-House Infiltration & From $\mathrm{ACH} 50=22$ (est.) to $\mathrm{ACH} 50=12.2$ \\
\hline Heating and Cooling System & $\begin{array}{l}\text { From SEER } 10 \text { with integral electric resistance heat to SEER } 15 \text { heat pump; } \\
\text { HSPF }=8.7\end{array}$ \\
\hline Air Distribution System & From $\mathrm{Qn}$, out $=0.30$ to $\mathrm{Qn}, \mathrm{out}=0.10$ \\
\hline Water Heating System & From 50 gal, electric, $\mathrm{EF}=0.88$ (est.) to 40 gal, electric; $\mathrm{EF}=0.92$ \\
\hline Refrigerator & From default to Energy Guide label of $416 \mathrm{kWh} / \mathrm{yr}$ \\
\hline Lighting & From 0 CFLs to $80 \%$ CFLs \\
\hline Fans & From no fans to ENERGY STAR fans \\
\hline
\end{tabular}


The removal of the old furnace provided the space for the new split-system air handler unit. As noted above, a highly efficient mechanical system was chosen. However, the mechanical closet was poorly designed, with an open return in the closet and airflow-restricting door allowing air passage only though the bottom grille.
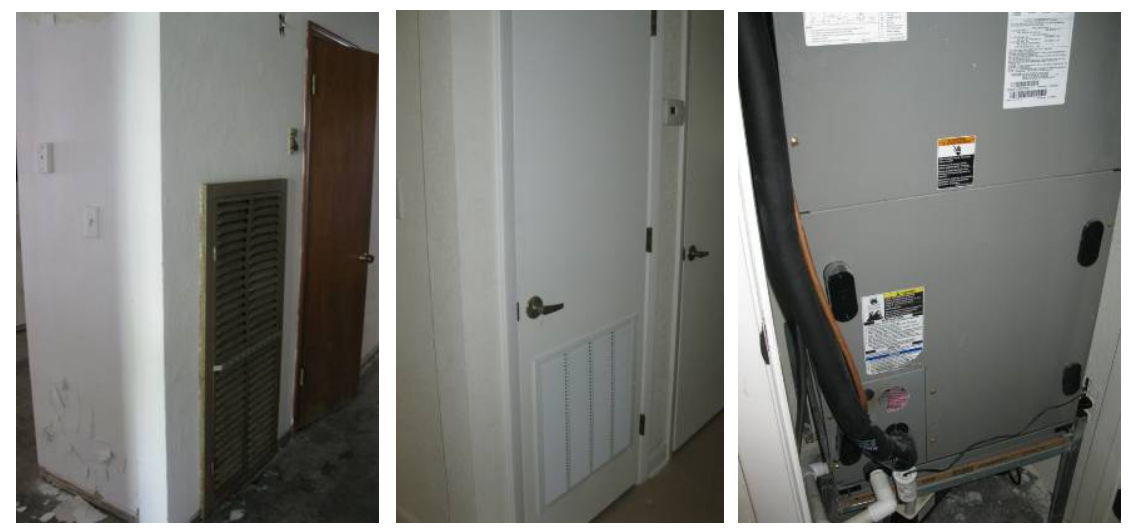

Figure K.4. Retrofit EH-02: Pre-Retrofit Abandoned Heater (left), Post-Retrofit Closet (center), and Post-Petrofit Open Return with Airflow-Restricted Louvered Doors (right)

The post-retrofit duct leakage test results were poor $(\mathrm{Qn}$,out $=0.10)$, but markedly improved from the pre-retrofit condition. Sources of leakage identified by researchers included a bathroom supply register, the unsealed seam at the floor of the air handler closet, and the condensate line entering the closet ceiling. The whole-house leakage test results were also poor $(\mathrm{ACH} 50=12.2)$, especially considering the installation of new windows and doors as well as drywall repair. The poorly sealed air handler closet and electrical panel were determined to be the primary sources of infiltration. These findings and the implications were shared with the partner, and at the partner's request, researchers met with the contractor to identify the above-referenced infiltration and duct leakage issues that needed repair. Researchers offered to conduct testing after repairs to ensure issues were resolved, but the partner declined. This partner's interest in participation dwindled. During the post-retrofit audit, pressure mapping was performed to test the balance of mechanical system air flow through the house. Researchers created a "worst case" scenario by running the air handler and exhaust fans, and shutting all bedroom doors. Operating under "worst case" conditions, the home was depressurized to $-4.3 \mathrm{~Pa}$, and there was excessive positive pressure in all bedrooms. Citing budgetary constraints, the partner was unwilling to install the above door transfer grilles into the plaster walls to correct the mechanically induced house pressure imbalances, opting instead to create a larger gap between the bottom of the bedroom doors and the floor, which did not provide adequate return air pathways. Post-retrofit pressure mapping results are presented in Table K.4.

Table K.4. EH-02 Post-Retrofit Pressure Mapping

\begin{tabular}{lc}
\hline Location & Pressure $(\mathrm{Pa})$ \\
\hline House WRT Out & -4.3 \\
Master WRT House & 9.0 \\
Bedroom 2 WRT House & 7.1 \\
Bedroom 3 WRT House & 11.1 \\
Back Room WRT House & 3.8 \\
Air Handler Closet WRT House & -17.0 \\
\hline WRT = with respect to & \\
\hline
\end{tabular}


In summary, the pre-retrofit condition of this house provided ample opportunity for a deep energy retrofit. The projected energy cost savings of $40 \%$ was achieved through the installation of a forced air, central air conditioner (SEER 15) with heat pump, significant reduction in duct leakage, almost exclusive use of efficient lighting, reduction in whole-house infiltration, insulation of the attic to R-30, and installation of double-pane, low-E, vinyl frame windows. There were two issues with this project: 1) the design and construction of the mechanical closet resulted in high duct leakage and whole-house infiltration, and 2) return airflow restriction from bedrooms. Because the interior walls were plaster, the partner was unwilling to incorporate researchers' recommended correction to the house pressure imbalances - the installation of above door transfer grilles.

Total costs for the energy-related portion of the renovation equaled $\$ 19,097$. The projected annual energy cost savings was $\$ 962$, for a projected monthly loss of $\$ 48$ per year and a 20 -year simple payback. However, considering the incremental cost of higher efficiency options for replacement of worn out equipment and components, the monthly net is a positive $\$ 48$, with a 3 -year simple payback.

\section{K.2 Deep Energy Retrofit \#FL-2 (Occupied June 2011, completed in May 2011)}

This, unoccupied, foreclosed, single-family detached home in Green Acres, Florida, is the first of five renovations initiated in 2011 by Habitat for Humanity Palm Beach County, Inc. (www.habitatpbc.org), a non-profit, affordable housing organization. Table K.5 summarizes the projected annual energy use and cost savings for deep energy retrofit project EH-03. Table K.6 relates the anticipated financing and payback associated with the whole package of improvements.

Table K.5. EH-03 Annual Energy Use and Cost Simulation

\begin{tabular}{lccc}
\hline \multicolumn{1}{c}{ Home Components } & As-Found & Minimal Improvement & Actual Retrofit \\
\hline HERS Index & 97 & 97 & 75 \\
Annual Simulation kWh (BABM08) & 12,773 & 12,773 & 9,421 \\
Annual MBtu Usage (BABM08) & 43.6 & 43.6 & 32.2 \\
Annual Energy Cost (BABM08) & $\$ 1,656$ & $\$ 1,656$ & $\$ 1,225$ \\
Project Status Completed 5/26/11 & & & \\
\hline
\end{tabular}

"Minimal Improvement" reflects improvement for replacing the mechanical system with a SEER 13 air conditioner with electric resistance heating, the minimum efficiency system available.

Table K.6. EH-03 Annual Energy-Savings Analysis

\begin{tabular}{lcc}
\hline & $\begin{array}{c}\text { Full Cost \& Full Savings } \\
\text { (As-Found vs. Actual) }\end{array}$ & $\begin{array}{c}\text { Incremental Cost \& Incremental } \\
\text { Savings (Minimal vs. Actual) }\end{array}$ \\
\hline HERS Index Improvement (\%) & $23 \%$ & $23 \%$ \\
Annual Energy Cost Savings (\$) & $\$ 431$ & $\$ 431$ \\
Annual Energy Cost Savings (\%) & $26 \%$ & $26 \%$ \\
Improvement Costs & $\$ 3,246$ & $\$ 2,246$ \\
Monthly Mortgage & $\$ 22$ & $\$ 15$ \\
Monthly Energy Cost Savings & $\$ 36$ & $\$ 36$ \\
Monthly Cash Flow & $\$ 14$ & $\$ 21$ \\
Simple Payback (years) & 8 & 5 \\
\hline
\end{tabular}


Built in 2003, this three-bedroom, two-bath, frame-construction home has $1,373 \mathrm{ft}^{2}$ of conditioned space. In February 2011, a test-in audit was conducted to document the home's pre-retrofit characteristics, which served as the retrofit base case model. The 8-year-old home (Figure K.5) had many energy-efficient elements incorporated into its original construction. The existing home characteristics were a light-colored exterior, a white shingle roof, R-19 attic insulation, above bedroom door transfer grilles, and extensive shading of the large, east-facing window. Windows were single-pane, metal frame, with clear glazing. Appliances and lighting in place included an ENERGY STAR labeled refrigerator, a few compact fluorescent lamp (CFLs), a minimally efficient electric water heater, and a central, forced-air heating and cooling system. The mechanical system, a SEER 12 air conditioner with a heat pump, exceeded the minimal efficiency available at the time.

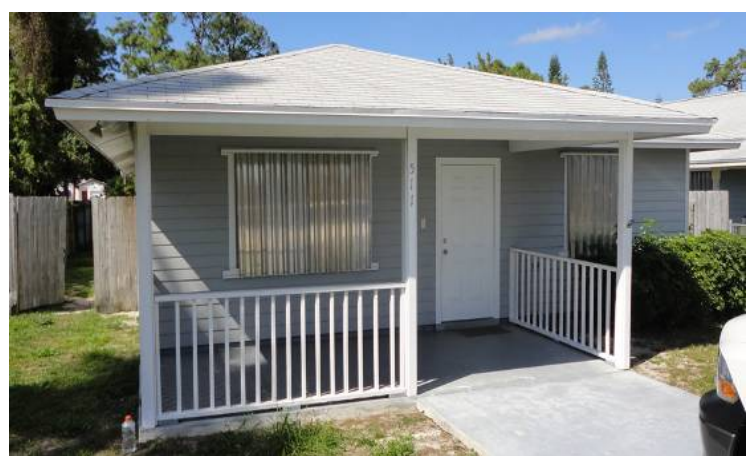

Figure K.5. EH-03 Pre-Retrofit with Hurricane Shutters in Place (exterior unchanged during retrofit)

The whole house was tight $(\mathrm{ACH} 50=5.9)$ and duct leakage was low $(\mathrm{Qn}$,out $=0.047)$. Pressure pan diagnostics were performed to highlight potential areas of concern within the supply duct system, and none were found. Findings are presented in Table K.7.

Table K.7. EH-03 Pre-Retrofit Pressure Pan Diagnostics

\begin{tabular}{lc}
\hline Register Location & Pressure $(\mathrm{Pa})$ \\
\hline Kitchen 1 & 0.3 \\
Kitchen 2 & 0.8 \\
Kitchen 3 & 0.1 \\
Living Room & 0.5 \\
Bedroom 1 & 0.4 \\
Bedroom 2 & 0.2 \\
Bedroom 3 & 0.3 \\
\hline
\end{tabular}

Our partner decided the mechanical system, only 8 years old, had enough useful life to be retained. The partner was willing, however, to incorporate a passive outside air ventilation system. The package of improvements included replacing the domestic hot water heater with a hybrid heat pump water heater $(\mathrm{COP}=2.35)$, insulating the attic to R-38, insulating one wall (found to be without insulation) to R-13, replacing the outdated ENERGY STAR refrigerator with a currently qualified model, and an extensive use of CFL bulbs. 
This retrofit, completed May 26, 2011, consisted of a package of measures (Table K.8) that resulted in an estimated $\$ 431$ in annual energy cost savings. Based on the partner-provided renovation costs of $\$ 3,246$, these savings outweigh the added mortgage cost by an average of $\$ 14$ per month. In addition, researchers analyzed the incremental first costs for the higher efficiency options. The monthly cash flow increased to $\$ 21$ with a 5-year simple payback.

The estimated annual energy savings, added mortgage costs, and anticipated positive cash flow are presented in Table K.6.

Table K.8. EH-03 Key Energy Efficiency Measures

\begin{tabular}{ll}
\hline \multicolumn{1}{c}{ Component } & \multicolumn{1}{c}{ Pre- and Post-Retrofit Specification } \\
\hline Ceiling Insulation & From R-19 to R-38, blown-in fiberglass \\
Exterior Walls & Insulated one non-insulated wall with R-13 fiberglass batts \\
Whole-House Infiltration & $\begin{array}{l}\text { From ACH50 }=5.9 \text { to ACH50 }=6.26, \text { installation of passive runtime outside air } \\
\text { ventilation system }\end{array}$ \\
& $\begin{array}{l}\text { From } 50 \text { gal, electric, EF }=0.88 \text { to } 50 \text { gal, electric heat pump hybrid water heater, } \\
\text { Water Heating System }\end{array}$ \\
& FoP $=2.35$ \\
Refrigerator & From $10 \%$ CFLs to $80 \%$ CFLs \\
\hline
\end{tabular}

The slight increase in the whole-house infiltration can likely be attributed to the installation of the passive runtime ventilation system into the return plenum, as there were no other penetrations into the envelope during the renovation. Although auditors attempted to block the fresh air intake for the airtightness tests, duct mask did not adhere well to the boot or surrounding plywood.

The duct leakage-to-out was essentially unchanged between test-in and test-out, but there was a worsening of the total duct leakage. The air handler and single, central return system were interior, with supply distribution running through the attic. With the house depressurized to $-50 \mathrm{~Pa}$, the attic registered at $+47 \mathrm{~Pa}$ with reference to the main body of the house. This result indicated good separation between the conditioned space and the attic. Neither the mechanical system nor its duct work was replaced as part of this retrofit. Predictably, duct leakage to the outside $(\mathrm{Qn}$,out $=0.05)$ was essentially unchanged at testout; however Qn,total increased from 0.09 to 0.12 . Again, researchers attribute this finding to the outside air ventilation installation. Duct leakage test results are presented in Table K.9.

Table K.9. EH-03 Pre-Retrofit vs. Post-Retrofit Duct Leakage

\begin{tabular}{ccc}
\hline Duct Testing & Pre-Retrofit & Post-Retrofit \\
\hline CFM 25,total: & & \\
Return & 118 & 153 \\
Supply & 129 & 174 \\
Qn,total & 0.09 & 0.12 \\
CFM 25,out: & & \\
Return & 56 & 55 \\
Supply & 72 & 81 \\
Qn,out & 0.047 & 0.05 \\
\hline
\end{tabular}


During the post-retrofit audit, pressure mapping was performed to assess whole-house system pressure boundaries. Auditors induced a "worst case" scenario by running the air handler and exhaust fans and shutting all bedroom doors. Operating under "worst case" conditions, the home was only slightly depressurized (-0.5 Pa) and excessive pressure did not build up in any of the bedrooms. Therefore, the existing above-door transfer grilles are doing an adequate job of balancing mechanically induced house pressures. See Table K.10 for a summary of the post-retrofit pressure mapping results. Figure K.6 is a picture of above door transfer grilles.

Table K.10. EH-03 Post-Retrofit Pressure Mapping

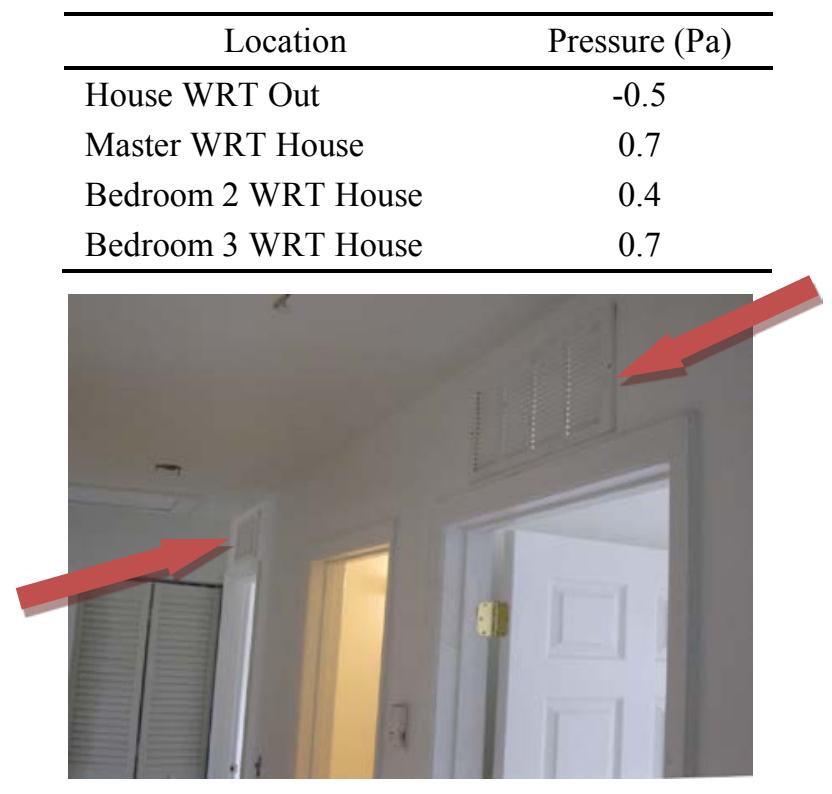

Figure K.6. Retrofit EH-03: Above-Door Transfer Grilles

The retrofit components responsible for the bulk of the projected energy cost savings are the hybrid heat pump water heater, added ceiling insulation and extensive use of CFLs. These measures, in addition to the installation of the mechanical runtime ventilation system, are highlighted in the following discussion.

As noted earlier, the existing mechanical system was determined to have several years of useful life and was not slated for replacement. The partner agreed to work with researchers, however, to bring fresh air into the home via the mechanical system. Our recommended passive, runtime ventilation strategy involves connecting duct work from the outside into the return plenum near the air handler where it is mixed with house air when the system is running. The outside air is drawn through an inlet mounted in the soffit. In this design, the outside air is being filtered at the entry to the air handler rather than at the soffit. We have found partners, in general, are reluctant to install filter-back grilles for the outside air. The filter-back component requires depth at the soffit to accommodate a manufactured or fabricated boot. For low pitch, there is not adequate vertical space to accommodate this component. In addition, partners are skeptical that residents will replace an outside filter. The reasoning seems to be concern about homeowner's general awareness of the filter in the long term as well as lack of availability of correct size filters from the retail outlets. Because the outside air must be filtered prior to crossing the cooling coil, the configuration implemented in this house has been accepted. An insect screen, however, was provided at the intake. Figures K.7 show images of this installation. 

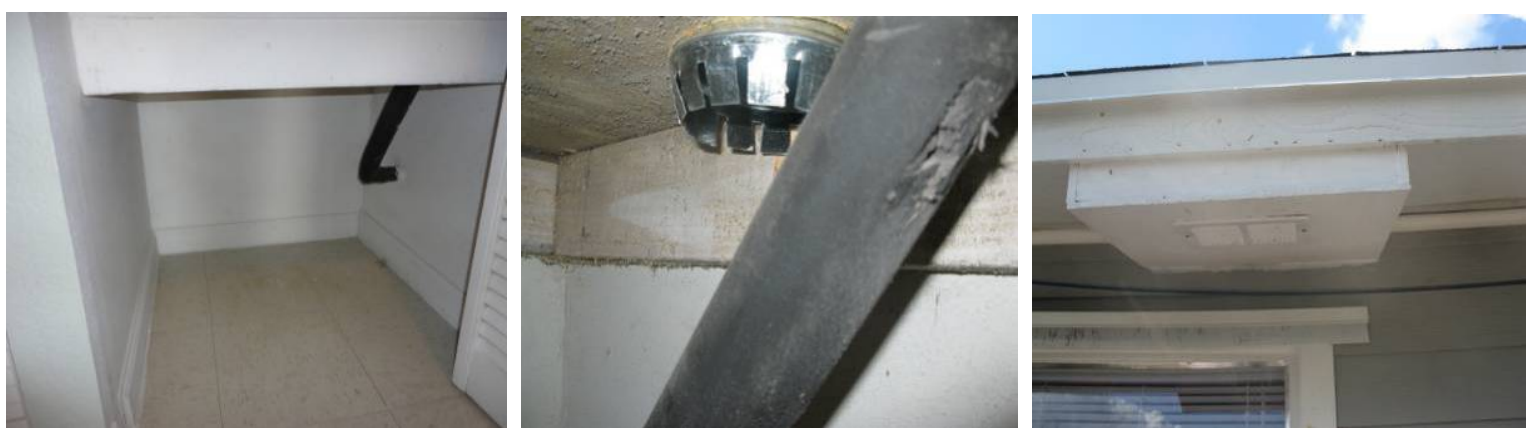

Figure K.7. Retrofit EH-03: Pre-Retrofit Return Plenum (left), Outside Air Ducted into the PostRetrofit Return Plenum (middle), and Soffit Retrofit for the Air Intake (right)

The attached, unconditioned storage room measuring $7 \mathrm{ft} \times 8 \mathrm{ft} \times 9 \mathrm{ft}$, was large enough to house a heat pump water heater (Figure K.8). The installation of the hybrid water heater with heat pump in this location has the added benefit of dehumidifying and cooling this storage area and the attic, which the room is open to.
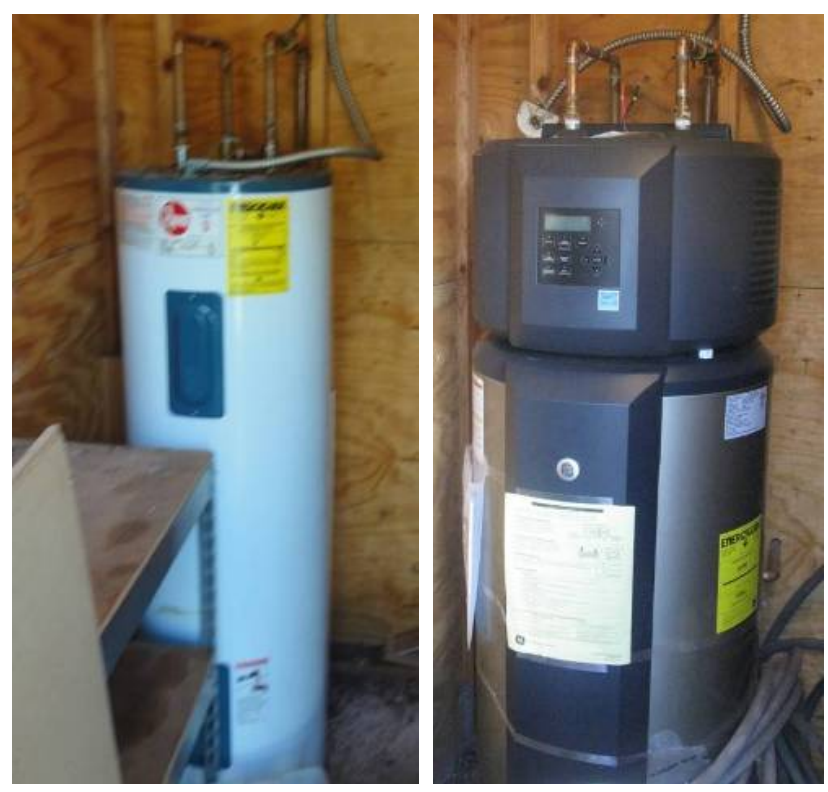

Figure K.8. Retrofit EH-03: Pre-Retrofit Electric Tank Water Heater, EF =0.88 (left), Hybrid Heat Pump Water Heater, COP = 2.35 (right)

The existing ceiling insulation consisted of R-19 fiberglass batts laid on top of the ceiling drywall. Blown-in fiberglass insulation was added to the existing batt, yielding R-38 total. Figures K.9 illustrates the pre- and post-retrofit ceiling insulation.

The final significant retrofit measure was the installation of approximately $80 \%$ CFLs.

Several low-cost, energy-saving recommendations not incorporated into the retrofit may have enabled this home to reach the $30 \%$ energy cost savings threshold. Our suggestions were to install a programmable thermostat, apply window film to the east and west facing windows, select ENERGY STAR qualified ceiling fans, and insulate the hot water system pipes. 

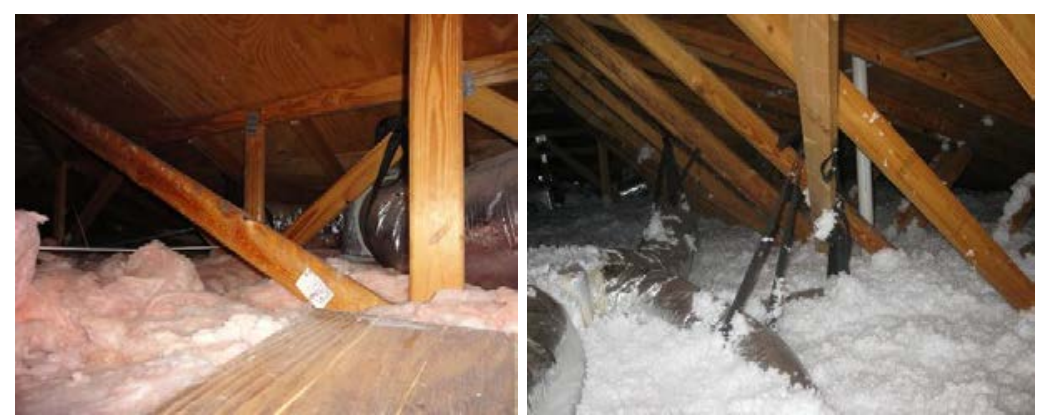

Figure K.9. Retrofit EH-03: Pre-Retrofit (left) and Post-Retrofit (right) Ceiling Insulation

In summary, had the mechanical system been at or near the end of its life and replaced, or if some of the lower-cost suggestions above had been incorporated into the renovation, this project would have easily achieved or exceeded the $30 \%$ energy cost savings goal. As noted previously, this retrofit attained a $26 \%$ projected energy cost savings with a projected annual energy cost of $\$ 1,225$ and a projected annual cost savings of $\$ 431$. This includes the slight energy use increase from the passive ventilation system. Using costs provided by our partner to address the cost-effectiveness of this retrofit, we see a monthly cash flow of $\$ 14$ and a simple payback of 8 years. Considering incremental first costs only, the monthly cash flow is increased to $\$ 21$ with a 5-year simple payback. Although this retrofit fell short of our savings goal it is an impressive example of energy-efficiency gains that can be cost-effectively achieved in a newer home.

\section{K.3 Deep Energy Retrofit \#FL-3 (Occupied in September 2011, completed August 2011)}

This home was unoccupied at the time of renovation which was completed in August of 2011. In the fall, a new owner purchased and occupied the premises. Table K.11 summarizes the projected annual energy use and cost savings for deep energy retrofit project EH-04. Table K.12 relates the anticipated financing and payback associated with the whole package of improvements. This project has been selected for monitoring.

This slab-on-grade, single-family, ranch-style home located in Eustis, Florida, was purchased and renovated by Lake-Sumter Habitat for Humanity for resale as affordable housing. The house was built in 1981 with concrete block construction, 1,040 $\mathrm{ft}^{2}$ of conditioned space, three bedrooms and two baths. Figures K.10 show the pre- and post-retrofit condition of the exterior finishes. The home had been vacant for a significant period of time and underwent substantial renovations including both energy and nonenergy-related upgrades.

A pre-retrofit audit was conducted on February 24, 2011. Data collected during the audit were used to generate a home energy rating system (HERS) Index of 132. Annual energy consumption was calculated at 51.2 MBtu, resulting in a total energy cost of $\$ 1,733$ annually at $\$ 0.13 \mathrm{kWh}$. The heating, ventilation, and air conditioning (HVAC) system consisted of an air handler installed in an interior closet, a SEER 9 air conditioner, and a gas furnace estimated at 0.68 AFUE coupled with a remarkably leaky duct system (Qn,out=0.32). The attic was insulated with R-19 fiberglass batts, and the exterior block walls were insulated with $1 / 2$-in. of expanded polystyrene board insulation. The windows were metal frame with a combination of single and double-pane clear and frosted glass. 
Table K.11. EH-04 Annual Energy Use and Cost Simulation

\begin{tabular}{lccc}
\hline \multicolumn{1}{c}{ Home Components } & As-Found & Minimal Improvement & Actual Retrofit \\
\hline HERS Index & 132 & & 78 \\
Annual kWh & 11,920 & Same as "Actual" & 7,750 \\
Annual Therms & 106 & & 0 \\
Annual MBtu Usage & 51.3 & & 26.5 \\
Annual Energy Cost & $\$ 1,733$ & $\$ 1,008$ \\
Project Status: Completed & & \\
"Minimal Improvement" reflects improvement for replacing the mechanical system with a SEER 13 air conditioner \\
$\begin{array}{l}\text { with electric resistance heating, the minimum efficiency system available. In this house, that was the specification } \\
\text { in the actual retrofit so there is no difference between the two scenarios. }\end{array}$
\end{tabular}

Table K.12. EH-04 Annual Energy-Savings Analysis

\begin{tabular}{lcc}
\hline & $\begin{array}{c}\text { Full Cost \& Savings } \\
\text { (As-Found vs. Actual) }\end{array}$ & $\begin{array}{c}\text { Incremental Cost \& Savings } \\
\text { (Minimal vs. Actual) }\end{array}$ \\
\hline HERS Index Improvement (\%) & & $41 \%$ \\
Annual Energy Cost Savings (\$) & & $\$ 725$ \\
Annual Energy Cost Savings (\%) & $42 \%$ \\
Improvement Costs & Full First Cost Not Available & $\$ 5,310$ \\
Monthly Mortgage & & $\$ 36$ \\
Monthly Energy Cost Savings & & $\$ 60$ \\
Monthly Cash Flow & & $\$ 25$ \\
Simple Payback (years) & 7 \\
\hline
\end{tabular}
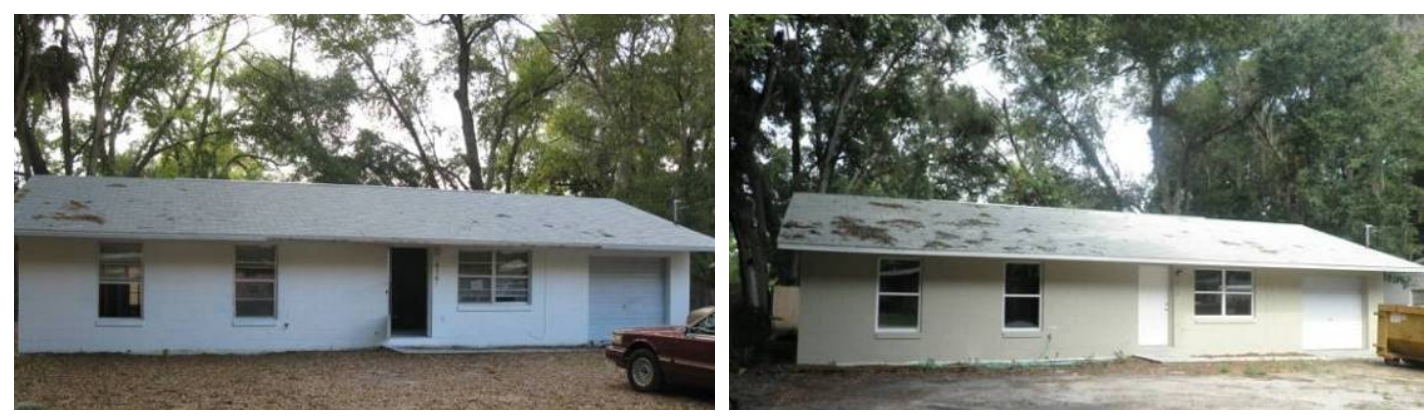

Figure K.10. EH-4 Pre-Retrofit (left) and Post-Retrofit (right)

Using Energy Gauge USA ${ }^{\circledR}$ and the Building America benchmark 2008 thermostat schedules, the predicted annual savings attributed to efficiency measures was $\$ 725$, a $42 \%$ reduction from the "asfound" building. The greatest reduction in energy use was attained by replacing the old SEER 9 air conditioner and gas furnace, with a SEER 13 heat pump (Figures K.11). Another significant measure that considerably improved the efficiency of the home was the reduction of duct leakage, both total leakage and leakage to outside. Window replacement, attic insulation, installation of CFLs, and refrigerator replacement also contributed to increased efficiency. Table K.13 summarizes the project energyefficiency measures. 
Table K.13. EH-04 Key Energy Efficiency Measures

\begin{tabular}{ll}
\hline Component & \multicolumn{1}{c}{ Pre- and Post-Retrofit Characteristics } \\
\hline Ceiling Insulation & From R-19 to R-38, Residential Energy Services Network (RESNET) Grade I \\
Windows & Installed new double-pane from (5) single, clear, metal (U=1.20; SHGC $=$ \\
& $\begin{array}{l}0.80) ;(3) \text { double, tinted, metal to ENERGY STAR windows (U = 0.51; } \\
\text { SHGC }=0.25)\end{array}$ \\
Heating and Cooling System & $\begin{array}{l}\text { From 2-ton SEER 9; gas furnace AFUE }=0.68 \text { to SEER 13; 2-ton A/C heat } \\
\text { pump; HSPF 7.7 }\end{array}$ \\
Air Distribution System & Reduced Duct Leakage trom Qn Out $=0.32$ to Qn out $=0.046$ \\
Refrigerator & From standard model to ENERGY STAR refrigerator \\
Lighting & From 8 fixtures; 2 CFL to 9 fixtures; 9 CFL 100\% \\
\hline
\end{tabular}
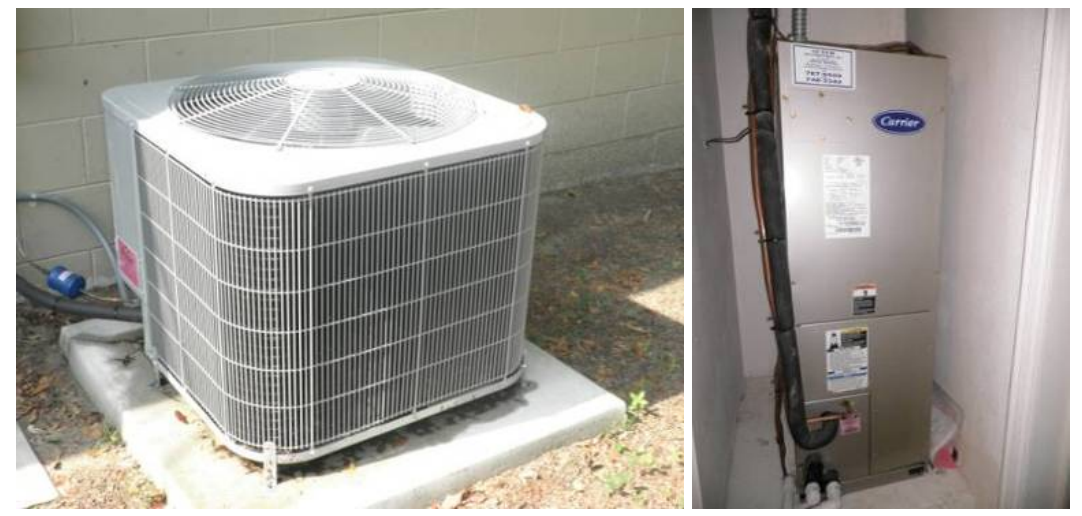

Figure K.11. Replacing the SEER 9 Air Conditioner and Gas Furnace with a SEER 13 Heat Pump Accounted for the Greatest Reduction in Estimated Annual Energy Cost (\$277) of Any Single Measure in this Project.

In order to install the new air handler, the closet was reconfigured, and a new return plenum with a ducted plenum was constructed. When the return grille and filter were removed for the duct leakage test during the post-retrofit audit, fiberglass insulation from the attic was observed in the return plenum. Further investigation led to the discovery that the interior wall cavity forming the front of the air handler closet was not sealed (Figure K.12). Attic air and insulation were being pulled through this leakage pathway when the air handler was operating. The project manager left the site and returned with fiberglass insulation and a can of expanding foam insulation to seal the opening.
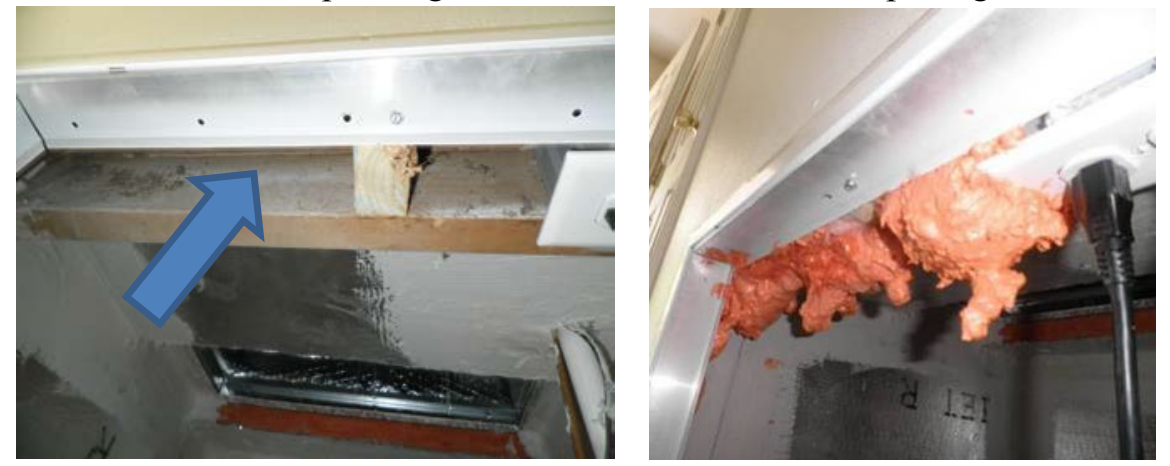

Figure K.12. An Open Wall Cavity Connecting the Return Plenum to the Attic Was Discovered During the Test-Out (left photo with arrow marking air pathway). The opening was sealed using a combination of fiberglass (filler) and expandable foam sealant/insulation (photo right). The excess foam was trimmed before reinstalling the air handler filter and grille. 
The mechanical contractor did not itemize the cost for duct sealing and construction of the air handler closet and return plenum from the total HVAC replacement cost, which included a 2-ton SEER 13 heat pump. Duct leakage was the second most significant repair, reducing the HERS Index by 16 points and saving an estimated \$207 in annual energy costs.

The fiberglass batt ceiling insulation was matted and compressed throughout the attic and completely missing in many areas (Figure K.13). The insulation contractor did an excellent job of ensuring the new insulation was evenly distributed and at the depth required to attain R-38 thermal performance (Figure K.13 right).
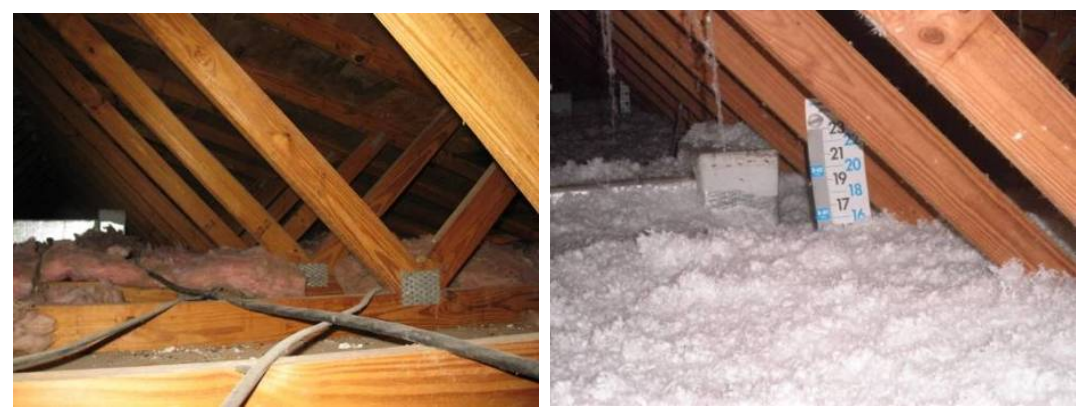

Figure K.13. Pre-Retrofit Compressed Fiberglass Insulation (left) Was Improved to R-38 with Blown-in Fiberglass

Several of the windows in the pre-retrofit house were broken, and others did not lock. Windows were replaced for security and functionality reasons as opposed to concerns about energy consumption. If the window replacement was removed from the post-retrofit energy analysis, there would still be a $38 \%$ reduction in annual energy cost and a 36\% reduction in HERS Index, which reduces the project's simple payback from 7 to 6 years. This emphasizes that a 30-year-old home with an air-conditioning efficiency and duct system typical of the early 1990 s can achieve $30 \%$ improvement with relatively moderate improvements in HVAC, ceiling insulation, appliances (ENERGY STAR refrigerator), and lighting. In addition, this home had a gas-heating pre-retrofit, which the partner chose to replace with a minimum efficiency electric heat pump. The majority of homes in this and other FSEC studies of similarly aged houses have electric rather than gas heating where air conditioning is typically paired with electric resistance heating rather than heat pump units. Such a configuration in the "as-found" condition of this home would have produced higher estimated pre-retrofit annual energy cost and similarly larger estimated energy savings for the minimum-efficiency heat pump replacement.

Adding outside air to the return system was recommended and discussed with the partner. When the low-pitched roof and lack of access was considered along with the house's relatively high ACH50 of 9.27, the partner decided that cost and installation difficulty outweighed the benefit. Pressure-relief transfer grilles were installed in all of the bedrooms. Table K.14 details the results of pressure mapping conducted during the test-out.

The total annual energy consumption in the post-retrofit house is estimated at $\$ 1,012$, down from $\$ 1,733$ at test-in. This represents a $42 \%$ reduction in annual energy costs to the homeowner, $\$ 60$ per month in savings, and an estimated simple payback of 7 years. These figures clearly show that the potential for cost-effective energy use reductions of $30 \%$ or greater are possible with homes of similar 
size and condition in the hot-humid climate. To verify the savings predictions, this project has been selected for post-retrofit monitoring. More information on the specifics on the monitoring of this home is available in the monitored homes section of this report.

Table K.14. EH-04 Post-Retrofit Pressure Mapping

\begin{tabular}{lc}
\hline \multicolumn{1}{c}{ Location } & Pressure $(\mathrm{Pa})$ \\
\hline House WRT Out & 0.8 \\
Master WRT House & 3.0 \\
Bedroom 2 WRT House & 0.2 \\
Bedroom 3 WRT House & 0.3 \\
\hline
\end{tabular}

\section{K.4 Deep Energy Retrofit \#FL-4 (Occupied and completed in August 2011)}

This unoccupied, foreclosed, single-family detached home in Melbourne, Florida, is the second of four renovations initiated in 2011 by Habitat for Humanity of Brevard County, Inc.

(http://brevardhabitat.com), a non-profit, affordable housing organization. Table K.15 summarizes the projected annual energy use and cost savings for deep energy retrofit project EH-06. Table K.16 relates the anticipated financing and payback associated with the whole package of improvements.

Table K.15. EH-06 Annual Energy Use and Cost Simulation

\begin{tabular}{lccc}
\hline \multicolumn{1}{c}{ Home Components } & As-Found & Minimal Improvement & Actual Retrofit \\
\hline HERS Index & 117 & 117 & 76 \\
Annual Simulation kWh (BABM08) & 16,077 & 16,077 & 10,450 \\
Annual MBtu Usage (BABM08) & 54.9 & 54.9 & 35.7 \\
Annual Energy Cost (BABM08) & $\$ 2,091$ & $\$ 2,091$ & $\$ 1,360$ \\
Project Status: Completed 8/13/11 & & & \\
\hline "Minimal Improvement" reflects improvement for replacing the mechanical system with a SEER \\
13 air conditioner with electric resistance heating, the minimum efficiency system available. \\
\hline
\end{tabular}

Table K.16. EH-06 Annual Energy-Savings Analysis

\begin{tabular}{lcc}
\hline & $\begin{array}{c}\text { Full Cost \& Savings } \\
\text { (As-Found vs. Actual) }\end{array}$ & $\begin{array}{c}\text { Incremental Cost \& Savings } \\
\text { (Minimal vs. Actual) }\end{array}$ \\
\hline HERS Index Improvement (\%) & $35 \%$ & $35 \%$ \\
Annual Energy Cost Savings (\$) & $\$ 731$ & $\$ 731$ \\
Annual Energy Cost Savings (\%) & $35 \%$ & $35 \%$ \\
Improvement Costs & $\$ 7,867$ & $\$ 3,459$ \\
Monthly Mortgage & $\$ 53$ & $\$ 23$ \\
Monthly Energy Cost Savings & $\$ 61$ & $\$ 61$ \\
Monthly Cash Flow & $\$ 8$ & $\$ 38$ \\
Simple Payback (years) & 11 & 5 \\
\hline
\end{tabular}

Built in 1962, this three-bedroom, two-bath home (Figures K.14) has 1,583 $\mathrm{ft}^{2}$ of conditioned space. 
Nearly 50 years old, this slab-on-grade, concrete block home had a light-colored exterior and light asphalt single roof. The thermal envelope included a $285-\mathrm{ft}^{2}$ enclosed porch with a shallow pitch, which restricted the level of ceiling insulation. Ceiling insulation consisted of a mixture of batt and blown-in fiberglass and was estimated to be an average of R-11 for the entire ceiling. The existing windows, a mixture of awning style and single hung, were all single-pane, clear, with metal frame, and all were planned for replacement. The mechanical system was a forced air, SEER 12, central air conditioner with a heat pump. Appliances and lighting in place included an older 40-gal electric hot water heater, no refrigerator, and $100 \%$ incandescent lighting.

The home was exceptionally leaky $(\mathrm{ACH} 50=16.3)$. The predominant causes of infiltration included several wall penetrations, an abandoned mechanical system return drop creating an open pathway to the attic, and a previously retrofitted bathroom lighting fixture. The air handler closet design consisted of a stand, no platform return, and was installed behind airflow-restricting louvered doors. The resulting dust buildup in the closet prevented researchers from performing duct leakage tests. A Qn,out of 0.13 was used as a default, the average pre-retrofit duct leakage found in prior research.

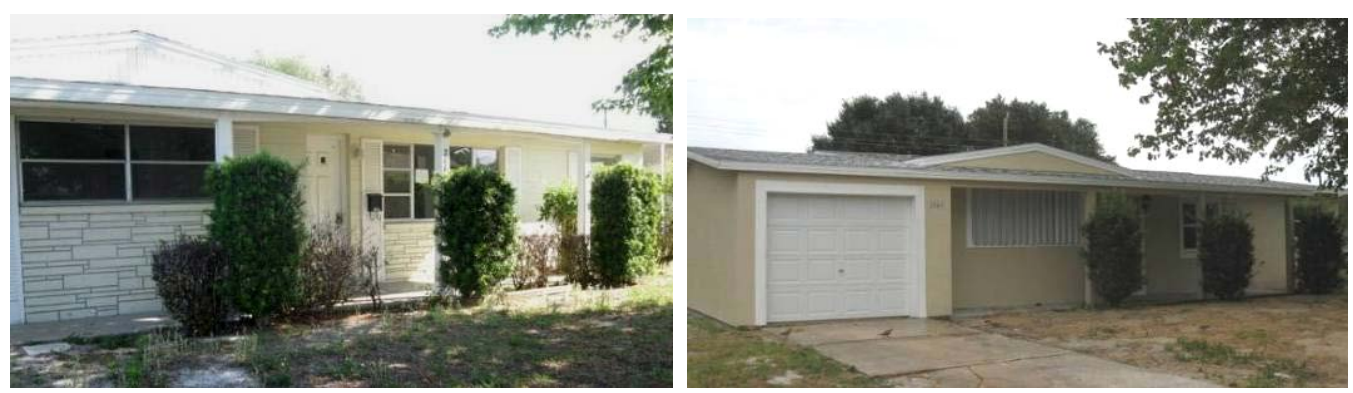

Figure K.14. EH-06 Pre-Retrofit (left) and Post-Retrofit (right)

The retrofit was completed on August 13, 2011. Measures with the most significant contribution to projected energy cost savings were the almost exclusive use of efficient lighting, the installation of low-E windows, the reduction in house and duct leakage, and the installation of R-38 ceiling insulation. The entire package of improvements, listed in Table K.17, is estimated to produce $\$ 731$ in annual energy cost savings. The partner has reported the costs for all of these measures to be $\$ 7,867$. Based on these costs, projected savings outweigh the added mortgage cost by an average of $\$ 8$ per month for an 11-year simple payback. Researchers also analyzed the incremental first costs for the higher efficiency options. Considering only incremental costs, monthly cash flow is increased to $\$ 38$, and simple payback is reduced to 5 years. The estimated annual energy cost savings, added mortgage costs, and anticipated positive cash flow are presented in Table K.16.

The partner's election to install an air conditioner with integral electric resistance heat rather than with a heat pump was a missed energy-savings opportunity. The projected annual energy cost savings of the resistance heat system installed was only $\$ 15$, whereas the heat pump had a projected annual energy cost savings of $\$ 174$, a difference of $\$ 159$ annually. 
Table K.17. EH-06 Key Energy Efficiency Measures

\begin{tabular}{|c|c|}
\hline Component & Pre- and Post-Retrofit Characteristics \\
\hline Roof & Light asphalt shingles, same as pre-retrofit \\
\hline Ceiling Insulation & From R-11 to R-38 in accessible section $\left(1,298 \mathrm{ft}^{2}\right)$ \\
\hline Exterior Walls & New paint, light color, same as pre-retrofit \\
\hline Windows & $\begin{array}{l}\text { From single pane, clear, metal frame }(\mathrm{U}=1.20 ; \mathrm{SHGC}=0.80) \text { to double-pane, } \\
\text { low-E, vinyl frame }(\mathrm{U}=0.30 ; \mathrm{SHGC}=0.29)\end{array}$ \\
\hline Doors & From wood to insulated ( 1 door) \\
\hline Whole-House Infiltration & From $\mathrm{ACH} 50-16.3$ to $\mathrm{ACH} 50=6.23$ \\
\hline Heating and Cooling System & $\begin{array}{l}\text { From SEER } 12 \text { with heat pump; HSPF } 6.8 \text { (est.) to SEER } 14 \text { with integral } \\
\text { electric resistance heat }\end{array}$ \\
\hline Air Distribution System & From Qn,out $=0.13$ (est.) to Qn,out 0.033 \\
\hline Water Heating System & From 40 gal, electric, $\mathrm{EF}=0.92$ to 40 gal, electric, $\mathrm{EF}=0.92$ \\
\hline Refrigerator & From default to Energy Guide label of $383 \mathrm{kWh} / \mathrm{yr}$ \\
\hline Lighting & From 0 CFLs to 12 of 14 fixtures with CFLs \\
\hline
\end{tabular}

As previously mentioned, the existing mechanical closet was poorly designed with an open return in a closet with airflow-restricting louvered doors. Such a design allowed for uncontrolled airflow and resulted in dust buildup. The mechanical system retrofit included constructing a ducted return and bringing filter access to the wall plane (Figures K.15). Outside air ventilation via a runtime vent was not incorporated into this mechanical system retrofit. Although the deep energy retrofit package proposed to the partner recommended outside air, researchers prioritized efficiency measures at this early stage in the partnership. Post-retrofit duct leakage tests confirmed that the contractor performed a good job with respect to sealing the supply plenum and return plenum. If post-retrofit whole-house airtightness testing had revealed an extremely tight envelope, researchers would have re-visited the issue with the partner.

During the post-retrofit audit, pressure mapping was performed to assess whole-house system pressure boundaries. Auditors induced a "worst case" scenario by running the air handler and exhaust fans and shutting all bedroom doors. Operating under "worst case" conditions, the home was depressurized to $-2.5 \mathrm{~Pa}$. Bedrooms were moderately pressurized. Table K.18 shows a summary of the post-retrofit pressure mapping results.

Table K.18. EH-06 Post-Retrofit Pressure Mapping

\begin{tabular}{cl}
\hline Location & Pressure $(\mathrm{Pa})$ \\
\hline House WRT Out & -2.5 \\
Master WRT House & 2.7 \\
Bedroom 2 WRT House & 3.2 \\
Bedroom 3 WRT House & 3.3 \\
\hline
\end{tabular}



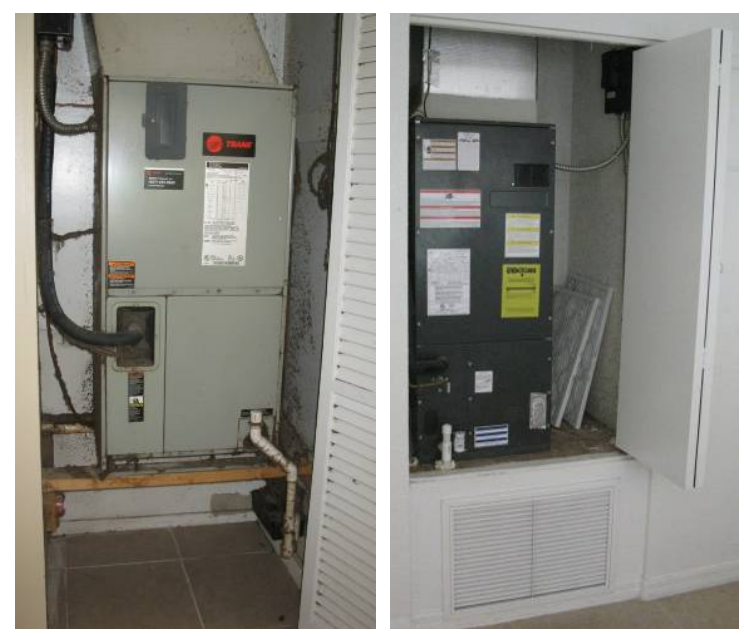

Figure K.15. Retrofit EH-06: Air Handler Closet Pre-Retrofit Without Return Plenum and Installed Behind Airflow-Restricting Louvered Doors (left), and Post-Retrofit Platform Return Plenum with Filter Access on Same Plane as Wall (right)

During the test-out audit, researchers observed no change in the attic insulation, which was previously estimated to be an average of R-11 (Figures K.16). Our partner understood the insulation contractor had completed this work before scheduling our post-retrofit audit. Ultimately, fiberglass was blown-in to achieve R-38. However, this measure would have potentially been skipped had it not been for our involvement in this retrofit.
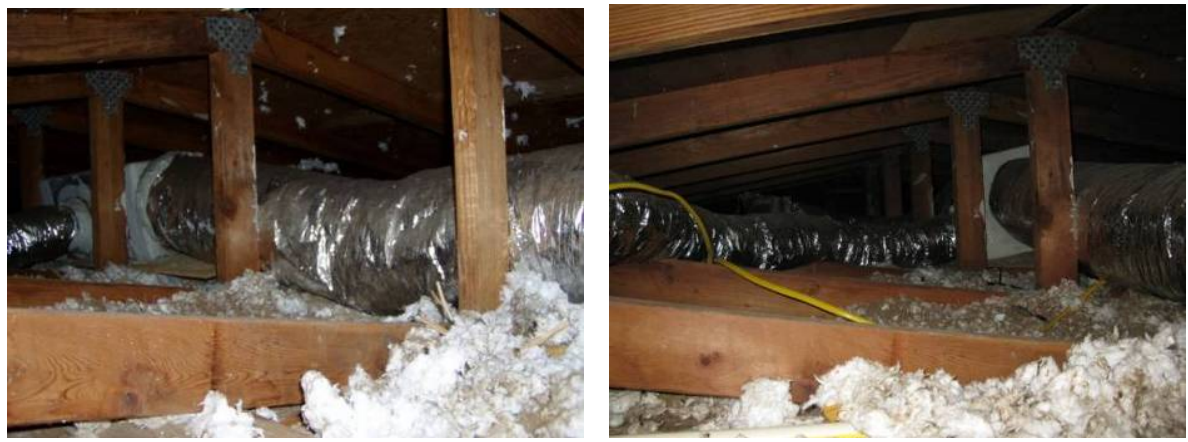

Figure K.16. Retrofit EH-06: Ceiling Insulation Pre-Retrofit Estimated Average of R-11 (left) and PostRetrofit No Additional Insulation (right)

In summary, a combination of low-cost and high-cost measures helped this project exceed its deep energy retrofit goal, for a projected energy cost savings of 35\%. Savings were achieved primarily through the installation of efficient lighting, low-E windows, R-38 ceiling insulation, a drastic reduction in wholehouse leakage, and tight duct work. There were two shortcomings of this project, however:

- The mechanical system chosen for this retrofit was suboptimal. An air conditioner with a heat pump rather than an integral resistance heat is the preferred system for this location.

- The partner failed to confirm the completion of all subcontractor work. This lapse in communication and lack of central oversight indicate a gap in the contracting paradigm.

Despite the issues noted above, the project cost-effectively achieved its deep energy retrofit goal. With total costs of $\$ 7,867$ for the energy-related retrofit measures and projected annual energy cost 
savings of $\$ 731$, the projected monthly cash flow is $\$ 8$ for an 11-year simple payback. Monthly cash flow is increased to $\$ 38$ for a 5-year simple payback when only the incremental first costs are considered.

\section{K.5 Deep Energy Retrofit \#FL-5(Occupied August 2011, completed July 2011 )}

This unoccupied, foreclosed, single-family detached home in Melbourne, Florida, is the first of four renovations completed in 2011 by Habitat for Humanity of Brevard County, Inc.

(http://brevardhabitat.com ), a non-profit, affordable housing organization. Table K.19 summarizes the projected annual energy use and cost savings for deep energy retrofit project EH-07. Table K.19 relates the anticipated financing and payback associated with the whole package of improvements.

Table K.19. EH-07 Annual Energy Use and Cost Simulation

\begin{tabular}{lccc}
\hline \multicolumn{1}{c}{ Home Components } & As-Found & Minimal Improvement & Actual Retrofit \\
\hline HERS Index & 136 & 121 & 85 \\
$\begin{array}{l}\text { Annual Simulation } \\
\text { kWh (BABM08) }\end{array}$ & 17,386 & 15,870 & 11,628 \\
$\begin{array}{l}\text { Annual MBtu Usage } \\
\text { (BABM08) }\end{array}$ & 59.3 & 54.2 & 39.7 \\
$\begin{array}{l}\text { Annual Energy Cost } \\
\text { (BABM08) }\end{array}$ & $\$ 2,260$ & $\$ 2,063$ & $\$ 1,511$ \\
$\begin{array}{l}\text { Project Status: Completed 7/30/11 } \\
\text { "Minimal Improvement" reflects improvement for replacing the mechanical system with a SEER 13 air conditioner } \\
\text { with electric resistance heating, the minimum efficiency system available. }\end{array}$ \\
\hline
\end{tabular}

Table K.20. EH-07 Annual Energy-Savings Analysis

\begin{tabular}{lcc}
\hline & $\begin{array}{c}\text { Full Cost \& Savings } \\
\text { (As-Found vs. Actual) }\end{array}$ & $\begin{array}{c}\text { Incremental Cost \& Savings } \\
\text { (Minimal vs. Actual) }\end{array}$ \\
\hline HERS Index Improvement (\%) & $38 \%$ & $30 \%$ \\
Annual Energy Cost Savings (\$) & $\$ 749$ & $\$ 552$ \\
Annual Energy Cost Savings (\%) & $33 \%$ & $27 \%$ \\
Improvement Costs & $\$ 7,923$ & $\$ 2,567$ \\
Monthly Mortgage & $\$ 53$ & $\$ 17$ \\
Monthly Energy Cost Savings & $\$ 62$ & $\$ 46$ \\
Monthly Cash Flow & $\$ 9$ & $\$ 29$ \\
Simple Payback (years) & 11 & 5 \\
\hline
\end{tabular}

Built in 1964, this four-bedroom, two-bath home (Figures K.17) has 1,608 $\mathrm{ft}^{2}$ of conditioned space. Renovations to this home were underway by the time a partnership was in place with this Habitat affiliate. The test-in audit was conducted to document as much as possible of the pre-retrofit character of the home as possible. Additional information was gathered from project staff. Pre-retrofit, the home was conditioned by a central, forced-air heating and cooling system with a SEER 10 air conditioner and electric resistance heating. The foundation is slab-on-grade with concrete block walls. The thermal envelope included a $276-\mathrm{ft}^{2}$ enclosed porch with a shallow pitch, restricting potential ceiling insulation 
levels and cramping supply duct work. The remaining ceiling insulation was also very poor, and an R-9 average was estimated for the entire ceiling. Worn out single-pane, clear, metal frame windows were slated for replacement.
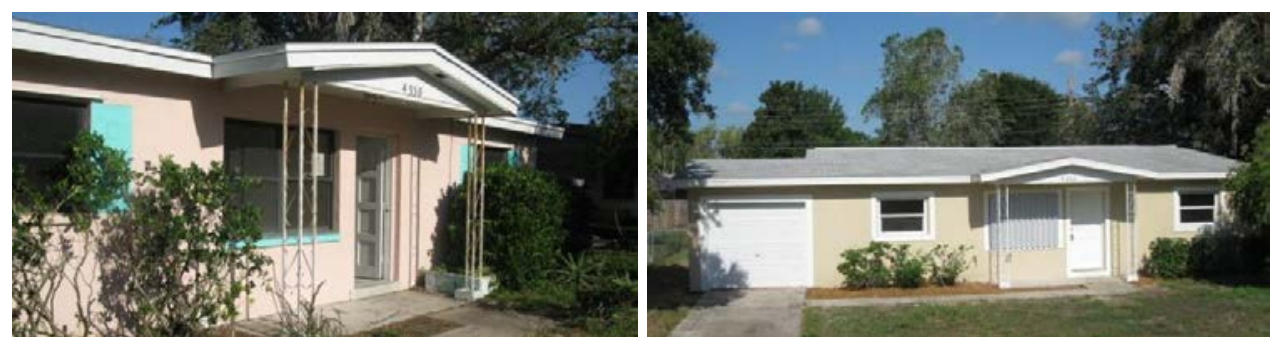

Figure K.17. EH-07 Pre-Retrofit (left) and Post-Retrofit (right)

At the time a partnership was formed with this Habitat affiliate, renovations were already underway, including installation of a new, forced air, central air conditioner (SEER 13) with electric resistance heating. Because the mechanical closet had already been rebuilt, there was no discussion of incorporating outside air. The partner was willing, however, to incorporate recommendations including installing double-pane, low-E, vinyl frame windows, insulating the attic to R-38, and selecting higher efficiency appliances and lighting. The package of improvements (Table K.21) is estimated to produce \$749 in annual energy savings. Based on the partner provided renovation costs of $\$ 7,923$, these savings outweigh the added mortgage cost by an average of $\$ 9$ per month.

In further analysis, researchers assumed some minimum efficiency upgrades along with the incremental costs for higher efficiency options. Allowing for the fact that the mechanical system could not have been replaced with a less efficient unit, the projected energy cost savings over the minimal replacement is reduced to $\$ 552$. This, in consideration with incremental first costs only, means the monthly cash flow is increased to $\$ 29$ with a 5 year simple payback. The estimated annual energy savings, added mortgage costs, and anticipated positive cash flow are presented in Table K.20.

Most of the energy cost savings for this renovation, completed July 30, 2011, resulted from installing high-efficiency windows, using efficient lighting almost exclusively, and increasing ceiling insulation to R-38. Replacement of the mechanical distribution system was also fairly significant in its contribution to energy cost savings.

Working with limited air handler closet space proved to be a challenge for the mechanical contractor. Unsealed holes in the ceiling of the air handler closet resulted in ceiling insulation being pulled into the air handler closet when the mechanical system was running (Figures K.18). Leaving a large hole in the closet is a result of poor quality assurance. Although researchers offered to retest the home, the partner declined post-corrective testing. The subcontractor returned to correct this installation. In contrast, the new return air plenum was notably well constructed by reversing the duct board (shiny side in) and sealing all seams well with mastic (Figure K.19). This achieves an adequately sealed plenum. However, when researchers discussed this approach with engineering staff at one manufacturer and no known problems with this installation were in evidence, two concerns were raised. First, this approach is not consistent with manufacturer guidance on product use and therefore would likely not be supported in the case of a dispute involving the product in this configuration. Second, the foil side is a vapor flow retarder, which should not be on the cold side of the assembly. This installation is inside the conditioned space so that the temperature and moisture conditions on both sides of the material are similar; however, if this were in an unconditioned space it would warrant a more thorough review. 
Table K.21. EH-07 Key Energy Efficiency Measures

\begin{tabular}{|c|c|}
\hline Component & Pre- and Post-Retrofit Characteristics \\
\hline Ceiling Insulation & $\begin{array}{l}\text { From R-11 to R-38 in } 1,320 \mathrm{ft}^{2} \text { of accessible section (single assembly ceiling over } \\
\text { enclosed porch inaccessible) }\end{array}$ \\
\hline Exterior Walls & From light colored exterior to light colored exterior \\
\hline Windows & $\begin{array}{l}\text { From single pane, metal frame, clear windows }(\mathrm{U}=1.20 ; \mathrm{SHGC}=0.80) \text { to } \\
\text { Double-pane, low-E, vinyl frame }(\mathrm{U}=0.30 ; \mathrm{SHGC}=0.29)\end{array}$ \\
\hline Doors & From wood to- insulated ( 2 doors- - -- \\
\hline Floors & From $70 \%$ carpet, $20 \%$ tile, $10 \%$ vinyl to $80 \%$ vinyl, $20 \%$ tile \\
\hline Whole-House Infiltration & From $\mathrm{ACH} 50=11$ (est.) to $\mathrm{ACH} 50=7.22$ \\
\hline Heating and Cooling System & $\begin{array}{l}\text { From SEER } 10 \text { with integral electric resistance heat to SEER } 13 \text { with integral } \\
\text { electric resistance heat }\end{array}$ \\
\hline Air Distribution System & $\begin{array}{l}\text { From R-4.2 (est.) flex ducts; Qn,out }=0.13 \text { (est.) to R-6 flex ducts; Qn,out }=0.57 \\
\text { and duct board return air plenum }\end{array}$ \\
\hline Water Heating System & From 40 gal, electric, $\mathrm{EF}=0.88$ (est.) to $40 \mathrm{gal}$, electric; $\mathrm{EF}=0.92$ \\
\hline Refrigerator & From default to Energy Guide label of $383 \mathrm{kWh} / \mathrm{yr}$ \\
\hline Lighting & From 0 CFLs to $80 \%$ CFLs \\
\hline Ceiling Fans & From no fans to Non-ENERGY STAR fans \\
\hline
\end{tabular}
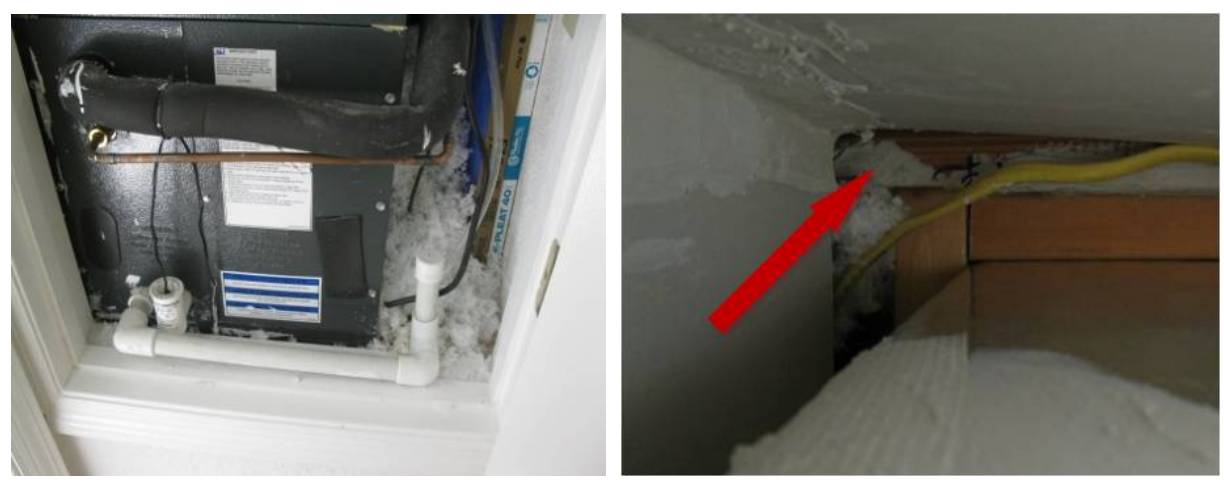

Figure K.18. Retrofit EH-07: White Attic Insulation Around Air Handler (left) Fell Through Spaces in the Closet Ceiling (right, looking up at closet ceiling framing)

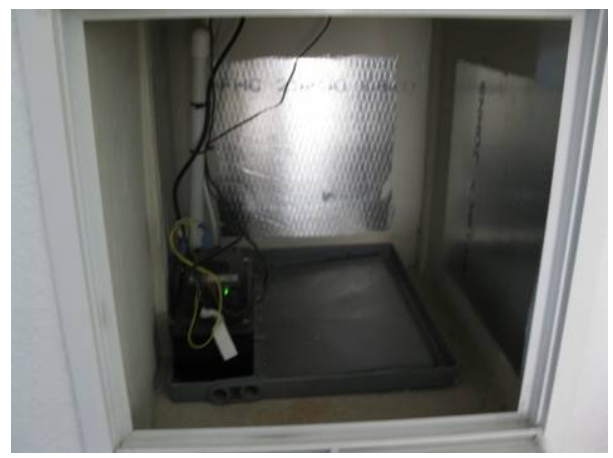

Figure K.19. Retrofit EH-07: New Return Air Plenum Constructed of Foil-Faced Duct Board, Shiny Side Facing In 
Testing of the new duct work found higher than expected leakage, especially considering the apparently well-sealed return plenum. Researchers performed pressure pan diagnostics. The results of this test pointed to leakage at the small, cramped supply registers at the entrance into the enclosed porch. Inadequate work space prevented the contractor from addressing the problems near this register. Findings are presented in Table K.22.

Table K.22. EH-07 Pre-Retrofit Pressure Pan Diagnostics

\begin{tabular}{lc}
\hline \multicolumn{1}{c}{ Register Location } & Pressure $(\mathrm{Pa})$ \\
\hline Kitchen & 0.2 \\
Utility Room & 1.5 \\
Living Room 1 & 0.3 \\
Living Room 2 & 0.4 \\
Florida Room 1 & 0.8 \\
Florida Room 2 & 0.4 \\
Florida Room 3 & 3.5 \\
Bedroom 1 & 0.4 \\
Bedroom 2 & 0.4 \\
Bedroom 3 & 0.4 \\
Bedroom 4 & 0.3 \\
Bathroom 1 & 0.8 \\
Bathroom 2 & 0.0 \\
\hline
\end{tabular}

During the post-retrofit audit, pressure mapping was performed to assess whole-house system pressure boundaries. Auditors induced a "worst case" scenario by running the air handler and exhaust fans and shutting all bedroom doors. Operating under "worst case" conditions, the home was depressurized only slightly, $-0.5 \mathrm{~Pa}$. All bedrooms were moderately pressurized. The home had no passive air transfer grilles or jump ducts from the bedrooms. Table K.23 shows a summary of the postretrofit pressure mapping results.

Researchers informed the partner of the pressure pan and the pressure mapping results and recommended correction action. Citing inaccessibility to the problem registers and plans for immediate occupancy of the home, the partner was unable to address either issue.

Table K.23. EH-07 Post-Retrofit Pressure Mapping

\begin{tabular}{lc}
\hline Location & Pressure $(\mathrm{Pa})$ \\
\hline House WRT Out & -0.5 \\
Master WRT House & 3.4 \\
Bedroom 2 WRT House & 3.8 \\
Bedroom 3 WRT House & 2.2 \\
Bedroom 4 WRT House & 5.1 \\
\hline
\end{tabular}


In summary, this retrofit highlights two retrofit challenges:

- Lack of quality assurance - The missing ceiling in the air handler closet points to a need for better quality assurance processes. Although the construction manager was aware of the need for this detail, it did not get implemented. The construction manager did not identify it under regular quality assurance procedures. Integrating new details into the existing framework of subcontractor communications remains a major challenge to achieving high performance in the retrofitting arena.

- Confined work spaces - Performing an adequate job requires sufficient work space. An airdistribution system housed within the attic of a shallow pitched roof continues to be a challenge for existing home retrofits.

Despite the issues during the retrofit and considering that the mechanical equipment installed was of minimal efficiency, the project easily met its goal of a deep energy retrofit with $33 \%$ projected energy cost savings, projected energy costs of $\$ 1,511$, and a projected annual cost savings of $\$ 749$. Using costs provided by our partner to address the cost-effectiveness of this retrofit, we see a monthly cash flow of $\$ 9$ and a simple payback of 11 years.

\section{K.6 Deep Energy Retrofit \#FL-6 (Occupied in November 2011, completed October, 2011)}

This single-story, concrete block house (Figures K.20) located in Indian Harbor Beach, Florida, was renovated by the homeowner, who also served as the general contractor. The renovation was completed in October, and the owners moved in immediately. Table K.24 summarizes the projected annual energy use and cost savings for deep energy retrofit project EH-14. Table K.25 relates the anticipated financing and payback associated with the whole package of improvements.

The homeowner's goal was to make the existing house energy efficient and attractive and to use the house as a model to showcase his remodeling workmanship. The house was newly purchased and remained unoccupied during renovation.

Table K.24. EH-14 Annual Energy Use and Cost Simulation

\begin{tabular}{|c|c|c|c|}
\hline Home Components & As-Found & $\begin{array}{c}\text { Minimal } \\
\text { Improvement }\end{array}$ & Actual Retrofit \\
\hline HERS Index & 122 & \multirow{5}{*}{ Same as Actual } & 70 \\
\hline Annual kWh & 19,661 & & 12,690 \\
\hline Annual Therms & 231 & & 151 \\
\hline Annual MBtu Usage & 90.2 & & 58.4 \\
\hline Annual Energy Cost & $\$ 3,045$ & & $\$ 1,969$ \\
\hline Project Status Completed & & & \\
\hline
\end{tabular}


Table K.25. EH-14 Annual Energy-Savings Analysis

\begin{tabular}{lcc}
\hline & $\begin{array}{c}\text { Full Cost \& Savings } \\
\text { (As-Found vs. Actual) }\end{array}$ & $\begin{array}{c}\text { Incremental Cost \& Savings } \\
\text { (Minimal vs. Actual) }\end{array}$ \\
\hline HERS Index Improvement (\%) & & $43 \%$ \\
Annual Energy Cost Savings (\$) & & $\$ 1,076$ \\
Annual Energy Cost Savings (\%) & Cost Data Not & $35 \%$ \\
Improvement Costs & Available & NA \\
Monthly Mortgage & & NA \\
Monthly Energy Cost Savings & & $\$ 90$ \\
Monthly Cash Flow & NA \\
Simple Payback (years) & NA \\
\hline
\end{tabular}
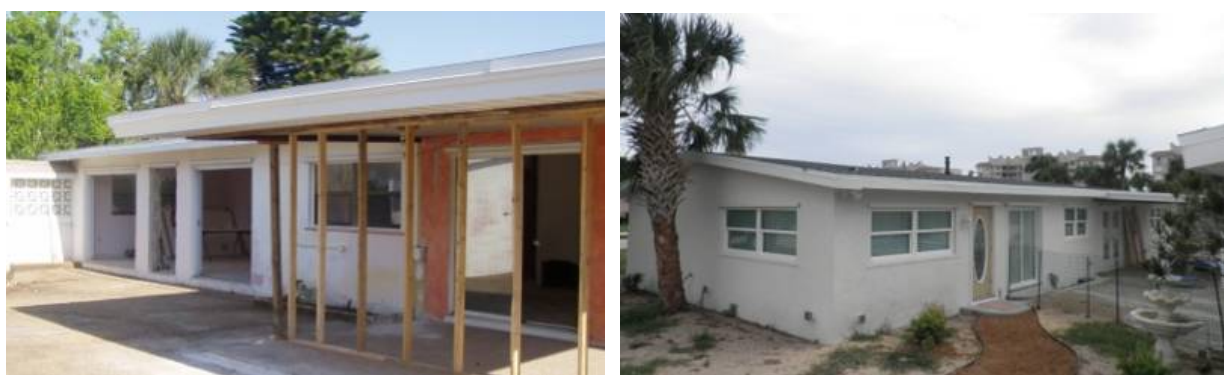

Figure K.20. EH-14 Pre-Retrofit with Deconstruction Already in Progress (left) and Post-Retrofit (right)

The house is single-story, slab-on-grade, with a low pitch (3/12) gable roof, 1,962 $\mathrm{ft}^{2}$ of conditioned space, with four bedrooms, three baths, and a detached garage. On May 18, 2011, a pre-retrofit audit was conducted. Default values for infiltration and total duct leakage were used because some deconstruction of the envelope and HVAC system had begun at the time of the test. The HVAC system is a ground source heat pump with a cooling capacity of 58,000 GWHP (18.0 EER) and a heating capacity of 48,000 GWHP (4.0 COP) rated at entering water temperatures of $59^{\circ} \mathrm{F}$ during the cooling season and $50^{\circ} \mathrm{F}$ during the heating season. The windows were metal, clear, single-pane, and the block walls were uninsulated. The attic was vented, and the ceiling was insulated with a combination of fiberglass batts and blown-in insulation (estimated $\mathrm{R}$ value of 12 ).

The water heater was a 50-gal natural-gas storage tank (EF 0.58) located in the detached garage. The HERS Index of the "as-found" house was 122, with an estimated annual energy cost of $\$ 3,045$.

During the retrofit, the thermal boundary was realigned by removing the ceiling insulation and applying $5-1 / 2$ in. of open cell spray foam to the underside of the roof deck. Prior to installing the foam insulation, the soffits were blocked at the top wall plate. This unvented attic configuration effectively places the attic-mounted duct system inside the thermal envelope and air barrier. After moving in, the owner intends to install transfer ducts with fireproof dampers to connect the attic and conditioned space, reducing the temperature difference between the two spaces. 

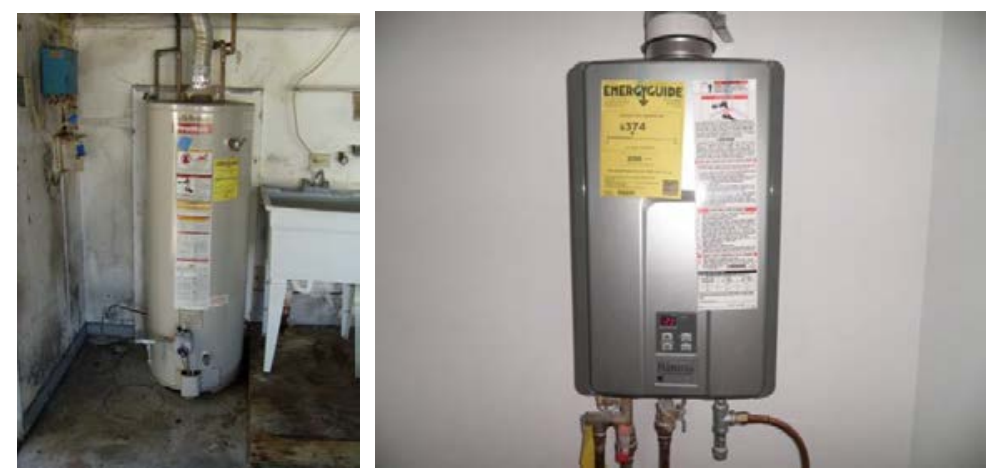

Figure K.21. Externally and Internally Located Water Tanks. Switching from an exterior located gas hot water tank (left photo) to an interior mounted instantaneous tank (right photo) reduced the HERS index by 7 points and saved an estimated $\$ 491 / \mathrm{yr}$. in energy use.

A single layer of radiant barrier was installed on the interior side of all exterior walls, and the block cores were filled with injected foam insulation. The exterior was finished with an elastomeric white paint. The single-pane windows and sliding glass doors were replaced with vinyl ENERGY STAR rated double-pane glass with a $U$ value of 0.28 and SHGC of 0.21 . The gas water heater was removed from the garage and replaced with an interior mounted-on instantaneous gas water heater rated at $0.82 \mathrm{EF}$.

The old duct system was replaced with R-6 flex duct, and the location of the supply ducts was brought inside by the realignment of the thermal boundary. These combined renovations reduced duct leakage to Qn out $=0.006$. Window replacement and insulation of the roof deck helped substantially tighten the house. Air infiltration was reduced from an estimated ACH50 of 22 (based on results of audits conducted in a different study) to an ACH50 of 1.99, well below the threshold that outside air would be recommended. However, no outside air provisions were implemented.
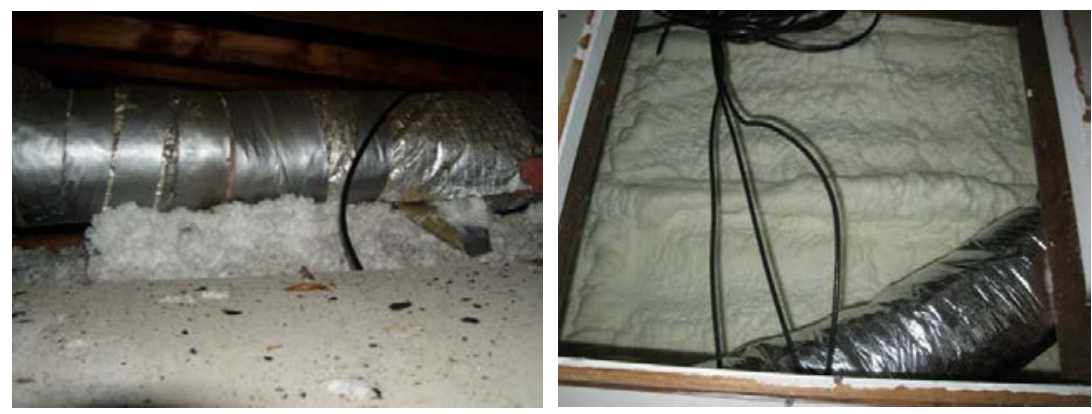

Figure K.22. Old Duct Work with Blown-In Ceiling Insulation Pre-Retrofit (left photo) and Looking Up at Insulated Roof Deck with New Ductwork Inspected Prior to Hanging Sheetrock Ceiling (right photo)

CFLs were installed in $63 \%$ of hardwired fixtures, and a new programmable thermostat was also installed. The combined benefit of these measures reduced the HERS Index rating at test-out to 70, resulting in an estimated reduction in annual energy consumption of 35\%. The partner has not supplied cost data for the efficiency measures. 
Table K.26. EH-14 Key Energy Efficiency Measures

\begin{tabular}{ll}
\hline \multicolumn{1}{c}{ Component } & \multicolumn{1}{c}{ Pre- and Post-Retrofit Characteristics } \\
\hline Roof & From ceiling insulation, R-12 to roof deck insulated with open cell foam to R-20 \\
Exterior Walls & From no insulation to Fi Foil installed on interior side R-4.2 \\
Exterior Walls & From standard uninsulated block to foam fill block core U $=0.204$ \\
Exterior Walls & $\begin{array}{l}\text { From mixed color block walls; (solar absp. 0.40 and 0.75) to elastomeric finish } \\
\text { (White) (solar absp. 0.40) }\end{array}$ \\
Windows & $\begin{array}{l}\text { From double pane, clear, metal }(\mathrm{U}=0.80 ; \text { SHGC }=0.70) \text { to ENERGY STAR } \\
\text { double-pane, low-E, vinyl frame }(\mathrm{U}=0.28, \text { SHGC }=0.21)\end{array}$ \\
Infiltration & From ACH50 $=22$ to ACH50 $=1.99$ \\
Air Distribution & From attic located supply ducts, Qn out $=0.17$ to interior duct system Qn \\
& out $=0.006$ \\
Supply/Return/AHU location & From attic/interior/interior to all interior \\
Water Heating System & From 50 gal. gas (EF $=0.58)$ located in garage to interior tankless gas system \\
& (EF $=0.82)$ \\
Lighting & From 31\% CFL's to 63\% CFL's \\
Controls & From non-programmable thermostat to programmable thermostat \\
\hline
\end{tabular}

Despite numerous discussions of building science conflicts that did not lead to resolutions, the research team decided to conduct a test-out audit at this location that was previously reported as "dropped." Many aspects of this retrofit are commendable, and it has attained an estimated annual energy savings of $35 \%$ and a HERS Index rating of 70 at test-out. However, it is not exemplary in several respects.

The principal area of concern is indoor humidity, and researchers have advised the homeowner to carefully observe or measure indoor humidity levels over the course of the first year of occupancy. The whole-house airtightness test result post-retrofit indicates an extremely tight air barrier (ACH50 $=1.99)$, greatly in excess of the threshold for recommending outside air ventilation. Unfortunately, the owner opted not to include that recommendation. Granted, the configuration of the air handler and the air handler closet would have made the design challenging, but possible. Very little local exhaust has been provided to handle internally generated moisture. Significant moisture from the roof assembly is a high possibility. The unvented attic was created by applying open cell spray foam to the underside of the existing roof decking. The roof finish was not replaced, so the typical tar paper underlayment is assumed for this roof assembly. Based on pressure difference measures during blower door testing, the attic appears to be fully coupled with the conditioned space, likely through ceiling penetrations. Recent field experiment data collected by FSEC has raised concerns about absolute moisture content in unvented attics, even with newer underlayment. The combined effect of a moisture gain from this attic and moisture gains from household activity may exceed the capacity of the HVAC system, especially in this home, where a conscious effort to reduce the heating and cooling loads has been made. This effort will, in turn, reduce HVAC run time.

A second area of concern arises from pressure dynamics associated with inadequate return air pathways. During previous site visits, the owner was advised to correct the duct compression (Figure K.23). When the foam insulation (applied to the underside of the roof decking) in a very shallow pitch roof expanded, it compressed some of the ducts. Some of these were jump ducts, and, at test-out, researchers did find unexpectedly high pressure differences in two bedrooms under normal operating conditions. We again advised repair of the compressed ducts. This, combined with the very low infiltration level, may result in severe discomfort. Table K.27 details pressure mapping data collected during the test-out. 
Table K.27. EH-14 Post-Retrofit Pressure Mapping

\begin{tabular}{lc}
\hline Location & Pressure $(\mathrm{Pa})$ \\
\hline House WRT Out, at rest & 0.8 \\
House WRT Out, Worst Case & -6.4 \\
Master WRT House & 6.9 \\
Bedroom 2 WRT House & 7.9 \\
Bedroom 3 WRT House & 4.9 \\
Bedroom 4 WRT House & 5.5 \\
AHU WRT House & -3.0 \\
\hline
\end{tabular}

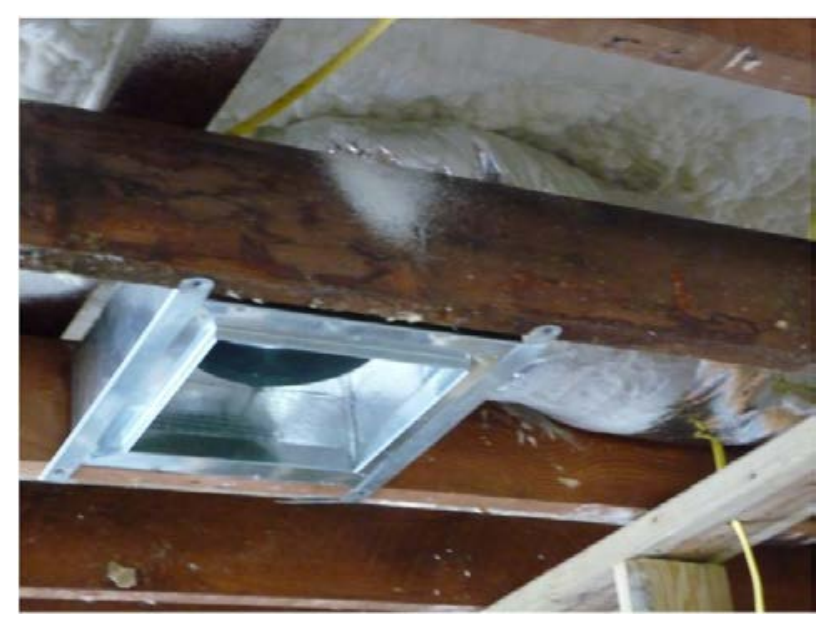

Figure K.23. Retrofit EH-14: A Very Shallow Unvented Attic with Foam Insulation at Roof Deck Resulting in Duct Compression and an Area of Thinner Insulation

A third concern is that the homeowner applied spray-foam insulation into the cores of his exterior block walls against our recommendation. At the test-out, insufficient temperature differences prevented characterizing the thermal signature of this insulation. The cost of this improvement vastly outweighs the benefit; however, the homeowner made this final decision.

A final concern arose over code official objections to providing a small amount of conditioned air to the unvented attic with an appropriate draw of return air. Researchers advised this partner in preliminary discussions that any unusual details should be discussed with the code official prior to implementation. This was not done. In essence, the fire code does not allow the space to be designated as "occupiable" because it does not have a fire-retardant coating applied to the exposed surface of the foam; therefore, it cannot be conditioned. These coatings are expensive and impractical once the house is completed due to poor access to the eave area. Researchers advised the need to minimize the temperature difference across the ceiling plane. This typically implies direct supply and return to the space or passive air flow pathways to allow mixing of house and attic air. Neither solution was acceptable to the local code body. At testout, this appears to be less of an issue than anticipated because no pressure difference was measured between the attic and main body of the house under operating or under test conditions suggesting that house air and attic will be able to circulate freely in response to temperature-driven air movement and likely pressure-driven air movement also in response to depressurization of the main space when the air handler is operating with bedroom doors closed. As always, a planned, controlled air flow pathway would be preferable. 
While this project does incorporate high-performance windows, a high-efficiency tankless gas water heater, and other efficiency measures, it does not successfully meet the other criteria for our project, including a moisture management plan, pressure balance, and a proactive approach with code officials when implementing unfamiliar details.

\section{K.7 Deep Energy Retrofit \#FL-7 (Occupied October 2011, completed in September 2011)}

Table K.28 summarizes the projected annual energy use and cost savings for deep energy retrofit project EH-19. Table K.29 relates the anticipated financing and payback associated with the whole package of improvements.

Table K.28. EH-19 Annual Energy Use and Cost Simulation

\begin{tabular}{lccc}
\hline \multicolumn{1}{c}{ Home Components } & As-Found & Minimal Improvement & Actual Retrofit \\
\hline HERS Index & 109 & 105 & 70 \\
Annual Simulation kWh (BABM08) & 13,061 & 12,719 & 7,856 \\
Annual MBtu Usage (BABM08) & 44.6 & 43.4 & 26.8 \\
Annual Energy Cost (BABM08) & $\$ 1,698$ & $\$ 1,653$ & $\$ 1,022$ \\
Project Status: Completed 9/10/2011 & & & \\
\hline
\end{tabular}

"Minimal Improvement" reflects improvement for replacing the mechanical system with a SEER 13 air conditioner with electric resistance heating, the minimum efficiency system available.

Table K.29. EH-19 Annual Energy-Savings Analysis

\begin{tabular}{lcc}
\hline & $\begin{array}{c}\text { Full Cost \& Savings } \\
\text { (As-Found vs. Actual) }\end{array}$ & $\begin{array}{c}\text { Incremental Cost \& Savings } \\
\text { (Minimal vs. Actual) }\end{array}$ \\
\hline HERS Index Improvement (\%) & $36 \%$ & $33 \%$ \\
Annual Energy Cost Savings (\$) & $\$ 676$ & $\$ 631$ \\
Annual Energy Cost Savings (\%) & $40 \%$ & $38 \%$ \\
Improvement Costs & $\mathrm{NA}$ & $\mathrm{NA}$ \\
Monthly Mortgage & $\mathrm{NA}$ & $\mathrm{NA}$ \\
Monthly Energy Cost Savings & $\$ 56$ & $\$ 53$ \\
Monthly Cash Flow & $\mathrm{NA}$ & $\mathrm{NA}$ \\
Simple Payback (years) & $\mathrm{NA}$ & $\mathrm{NA}$ \\
\hline
\end{tabular}

This unoccupied, foreclosed, single-family detached home in West Palm Beach, Florida, was the second of five renovations initiated in 2011 by Habitat for Humanity of Palm Beach County, Inc. (www.habitatpbc.org), a non-profit, affordable housing organization. Built in 2000, this three-bedroom, two-bath home (Figures K.24) has 1,176 $\mathrm{ft}^{2}$ of conditioned space.

The slab-on-grade home with concrete block walls had a light-colored exterior, a white asphalt single roof, and an attached shed. Ceiling insulation was R-19 fiberglass batts. The windows were single hung, single-pane, clear, with metal frame. Appliances and lighting included a 40-gal electric hot water heater, a non-ENERGY STAR refrigerator, and 100\% incandescent lighting. 

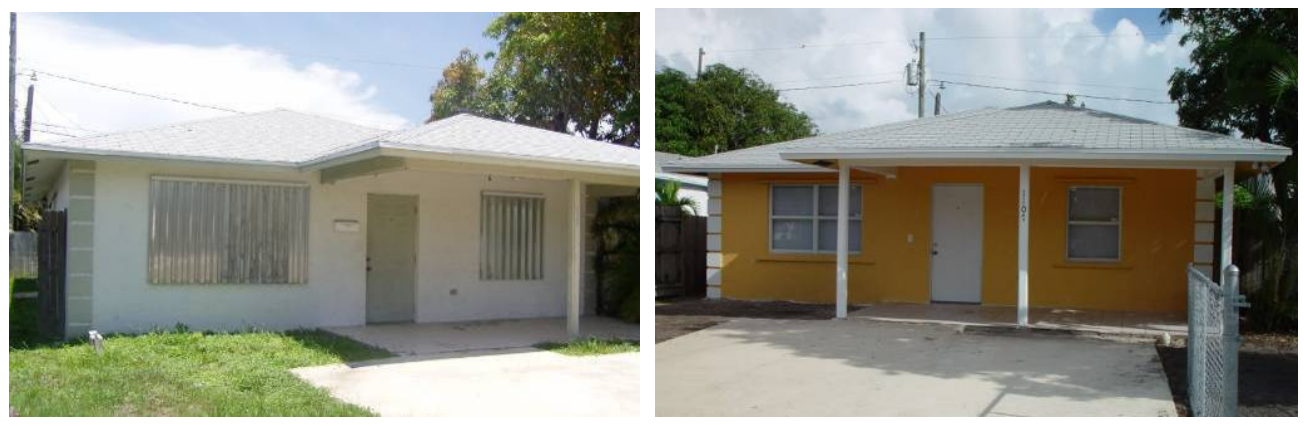

Figure K.24. EH-19 Pre-Retrofit (left) and Post-Retrofit (right)

The air heating and conditioning system was a central, forced-air system with a SEER 12 air conditioner and electric resistance eating. The property had been vandalized and some materials stolen. Both the air handler and the compressor had been gutted, and the bathrooms and the laundry area had large wall penetrations where plumbing lines had been removed. Because the envelope was compromised and the air handler was not intact, researchers were unable to conduct whole-house leakage and duct leakage tests. In order to perform energy modeling, averages from prior research were used for preretrofit whole-house air leakage $(\mathrm{ACH} 50=11)$ and duct leakage $(\mathrm{Q}$,out $=0.13)$.
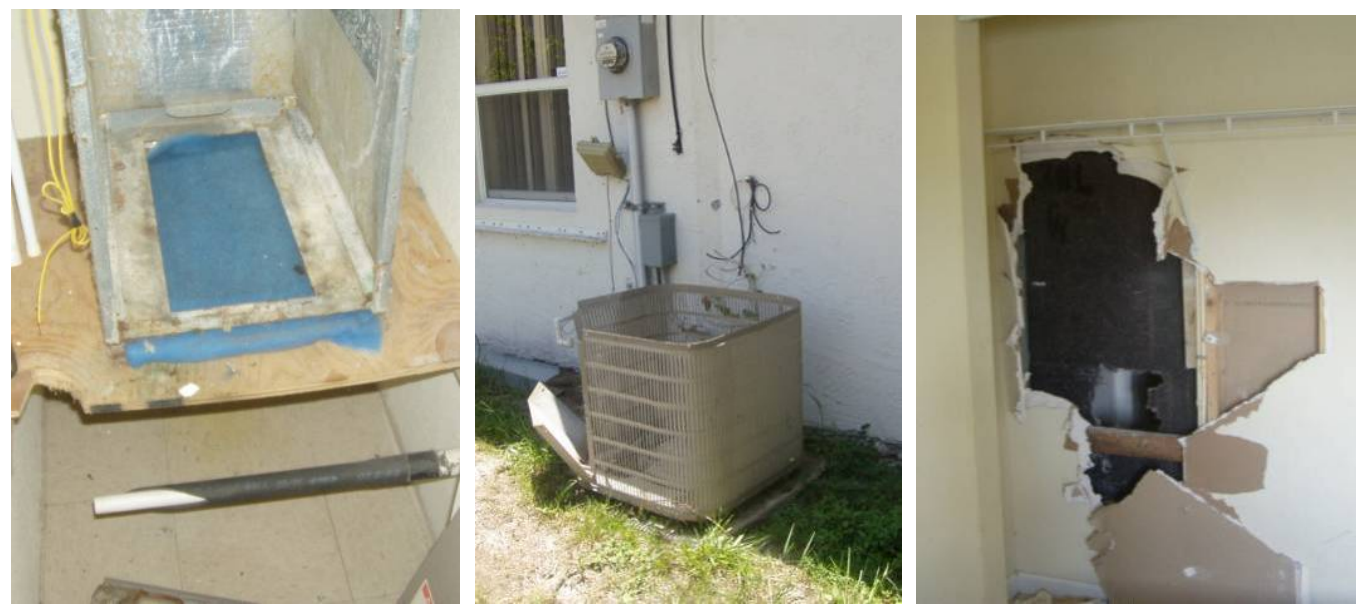

Figure K.25. Retrofit EH-19: Pre-Retrofit Air Handler (left), Compressor (center), and Interior Wall Destruction (right)

The scope of work for this renovation was hefty for this 11-year-old home, but much of the work was non-energy-related. The measures with the greatest impact on projected energy cost savings (in order of contribution) were the installation of a hybrid heat pump water heater ( $\mathrm{COP}=2.35)$, almost exclusive use of efficient lighting, installation of a central, forced air conditioner (SEER 15) with heat pump, installation of an ENERGY STAR refrigerator, and the increasing of the ceiling insulation level to R-38. Figures K.26 present post-retrofit pictures, including lighting and appliances. The entire package of improvements for this retrofit was completed on September 10, 2011 (Table K.30) and is estimated to produce $\$ 676$ in annual energy cost savings.

The attached shed, measuring $12 \times 5 \times 8 \mathrm{ft}$, was large enough to house a heat pump water heater. The installation of the hybrid water heater with heat pump in this location has the added benefit of dehumidifying and cooling the utility shed and the attic, which the shed is open to. 

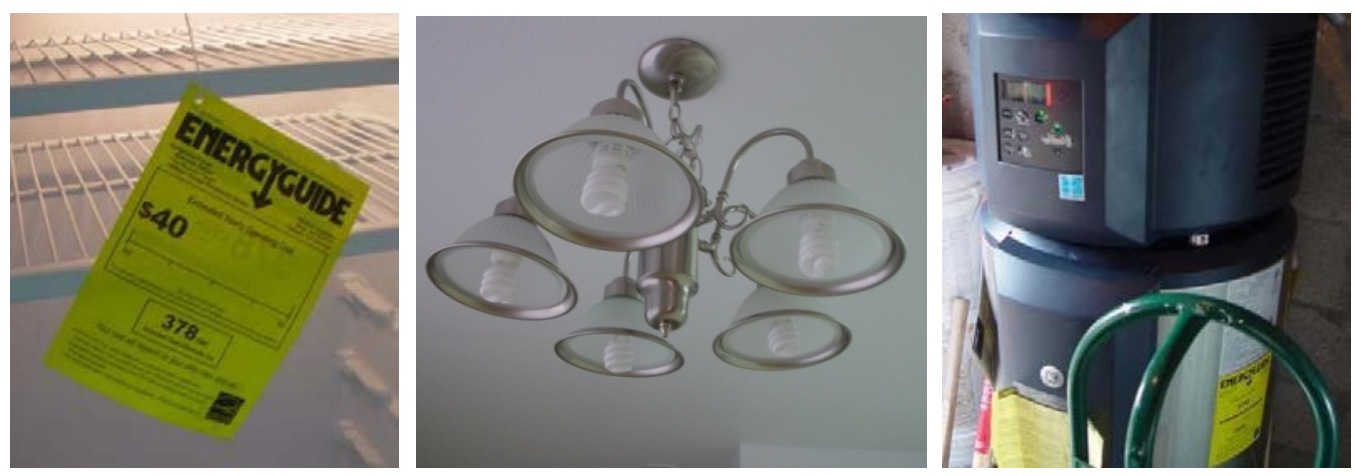

Figure K.26. Retrofit EH-19: Post-Retrofit ENERGY STAR Refrigerator (left), CFL Fixture (center), and Heat Pump Water Heater

Table K.30. EH-19 Key Energy Efficiency Measures

\begin{tabular}{|c|c|}
\hline Component & Pre/Post-Retrofit Characteristics \\
\hline Ceiling Insulation & From R-9 to R-38, blown-in fiberglass \\
\hline Exterior Walls & From light $($ solar absp. $=0.45)$ to dark color $($ solar absp. $=0.60)$ \\
\hline Whole-House Infiltration & From $\mathrm{ACH} 50=11$ (est.) to $\mathrm{ACH} 50=6.86$; Installed a mechanical runtime vent \\
\hline Heating and Cooling System & $\begin{array}{l}\text { From SEER } 12 \text { with integral electric resistance heat to SEER } 15 \text { with integral } \\
\text { electric resistance heat }\end{array}$ \\
\hline Air Distribution System & From Qn,out $=0.13$ (est.) to Qn,out $=0.052$ \\
\hline Water Heating System & $\begin{array}{l}\text { From } 40 \text { gal, electric, } \mathrm{EF}=0.88 \text { (est.) to } 50 \text { gal, electric tank with heat pump, } \\
\mathrm{COP}=2.35\end{array}$ \\
\hline Refrigerator & From default to Energy Guide label of $378 \mathrm{kWh} / \mathrm{yr}$ \\
\hline Lighting & From 0 CFLs to $80 \%$ CFLs \\
\hline Fans & From fans with default efficiency to 100 cfm @ medium sped \\
\hline Controls & From no programmable thermostat to a programmable thermostat \\
\hline
\end{tabular}

Confined by limited space, the mechanical contractor performed a fair job of retrofitting the air handler cabinet with a platform return, installing the new, larger air handler, and incorporating the outside air runtime ventilation detail. The post-retrofit duct leakage test result was Qn,out $=0.052$; therefore, the newly constructed platform return was fairly well sealed. However, the access to the plenum remained behind the airflow-restricting louvered doors rather than on the same plane as the hallway wall. The partner incorporated an existing attic ventilation duct into the outside air runtime ventilation scheme. This did not allow filtering at the intake, and the opening was ignored by the painting contractor who painted over it, leaving it partially obstructed. Post-retrofit pictures of the air handler closet and return plenum are shown in Figures K.27.

Among the improvement to the house envelope was the replacement of one broken window and the reconstruction of several wall cavities. The whole-house leakage test result $(\mathrm{ACH} 50=6.86)$ suggests a moderately low level of infiltration. 

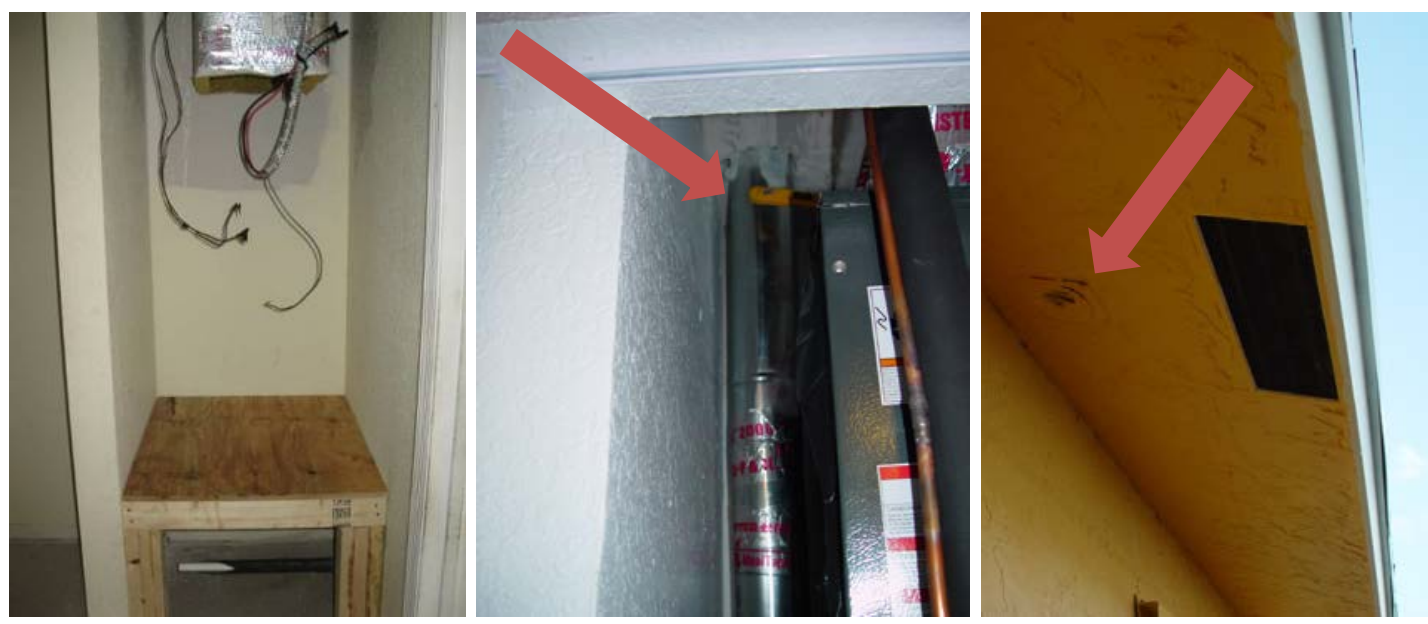

Figure K.27. Retrofit EH-19: Mid-Point Construction of Air Handler Closet (left), Post-Retrofit Incorporation of Outside Air Ventilation into Air Handler Closet (center), and Post-Retrofit Return Air Intake at Soffit (right)

During the post-retrofit audit, pressure mapping was performed to test the balance of mechanical system air flow through the house. Researchers created a "worst case" scenario by running the air handler and exhaust fans and shutting all bedroom doors. Operating under "worst case" conditions, the home was depressurized slightly $(-3.0 \mathrm{~Pa})$, and there was excessive positive pressure in one bedroom. Researchers suggested the partner install an above-door transfer grille between this bedroom and the main body to allow passive air transfer out of the bedroom. Post-retrofit pressure mapping results are presented in Table K.31.

Table K.31. EH-19 Post-Retrofit Pressure Mapping

\begin{tabular}{lc}
\hline \multicolumn{1}{c}{ Location } & Pressure $(\mathrm{Pa})$ \\
\hline House WRT Out & -3.0 \\
Master WRT House & 4.1 \\
Bedroom 2 WRT House & 1.1 \\
Bedroom 3 WRT House & 2.0 \\
\hline
\end{tabular}

In summary, the partner successfully achieved a deep energy retrofit with projected annual energy cost savings of $40 \%$. The estimated savings was accomplished primarily by installing a hybrid heat pump water heater $(\mathrm{COP}=2.35)$, almost exclusive use of efficient lighting, installing a central, forced air conditioner (SEER 15) with heat pump, installing an ENERGY STAR refrigerator, and bringing the ceiling insulation level up to R-38.

Researchers found a couple of problems with this retrofit. The design of the mechanical closet was lacking in that the well-constructed return platform was blocked by airflow-restricting louvered doors, and a lack of central oversight was exemplified by the painting over of the outside air intake.

When the partner provides cost data for the energy-related elements of the renovation, researchers will complete the economic calculations. 


\section{K.8 Deep Energy Retrofit \#FL-8 (Occupied in November 2011, completed in October 2011)}

The renovation of this unoccupied, foreclosed home was completed in October. Table K.32 summarizes the projected annual energy use and cost savings for deep energy retrofit project EH-21. Table K.33 relates the anticipated financing and payback associated with the whole package of improvements.

Table K.32. EH-21 Annual Energy Use and Cost Simulation

\begin{tabular}{lccc}
\hline \multicolumn{1}{c}{ Home Components } & As-Found & Minimal Improvement & Actual Retrofit \\
\hline HERS Index & 120 & 107 & 78 \\
Annual Simulation kWh (BABM08) & 17,386 & 16,021 & 10,688 \\
Annual MBtu Usage (BABM08) & 59.3 & 54.7 & 36.5 \\
Annual Energy Cost (BABM08) & $\$ 2,260$ & 2,083 & 1,388 \\
Project Status: Completed 10/22/2011 & \multicolumn{3}{l}{} \\
"Minimal Improvement" reflects improvement for replacing the mechanical system with a SEER 13 air \\
conditioner with electric resistance heating, the minimum efficiency system available. \\
\hline
\end{tabular}

Table K.33. EH-21 Annual Energy-Savings Analysis

\begin{tabular}{lcc}
\hline & $\begin{array}{c}\text { Full Cost \& Savings } \\
\text { (As-Found vs. Actual) }\end{array}$ & $\begin{array}{c}\text { Incremental Cost \& Savings } \\
\text { (Minimal vs. Actual) }\end{array}$ \\
\hline HERS Index Improvement (\%) & $35 \%$ & $27 \%$ \\
Annual Energy Cost Savings (\$) & $\$ 872$ & $\$ 695$ \\
Annual Energy Cost Savings (\%) & $39 \%$ & $33 \%$ \\
Improvement Costs & $\mathrm{NA}$ & $\mathrm{NA}$ \\
Monthly Mortgage & $\mathrm{NA}$ & $\mathrm{NA}$ \\
Monthly Energy Cost Savings & $\$ 77$ & $\$ 58$ \\
Monthly Cash Flow & $\mathrm{NA}$ & $\mathrm{NA}$ \\
Simple Payback (years) & $\mathrm{NA}$ & $\mathrm{NA}$ \\
\hline
\end{tabular}

This unoccupied, foreclosed, single-family detached home in Lake Worth, Florida, is the fourth of five renovations initiated in 2011 by Habitat for Humanity of Palm Beach County, Inc.

(www.habitatpbc.org), a non-profit, affordable housing organization. Built in 1996, this three-bedroom, two-bath home (Figure K.28) has 1,573 $\mathrm{ft}^{2}$ of conditioned space.

The slab-on-grade, concrete block, two-story home had a light-colored exterior and a medium-dark clay, barrel tile roof. Ceiling insulation was R-19 batt fiberglass. The existing windows were singlehung, single-pane, clear, with metal frame; all were in good shape. Appliances and lighting included an older, 30-gal electric hot water heater and 100\% incandescent lighting. 


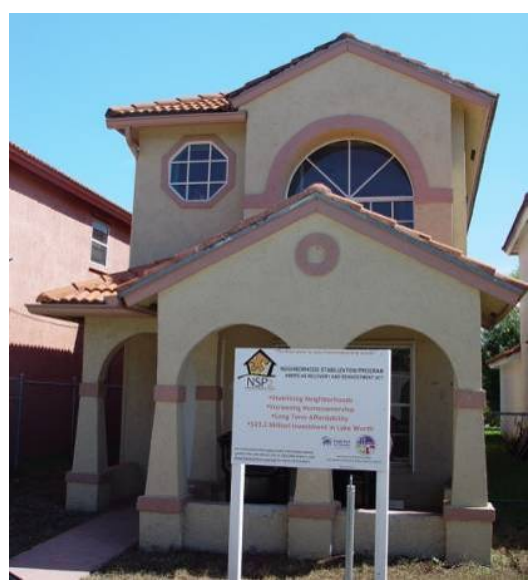

Figure K.28. EH-21 Post-Retrofit (exterior unchanged between pre-retrofit and post-retrofit)

The air heating and conditioning systems included a window air conditioning unit and a forced air, SEER 10, central air conditioner with electric resistance heating. The air handler was in a narrow interior closet (Figures K.29).
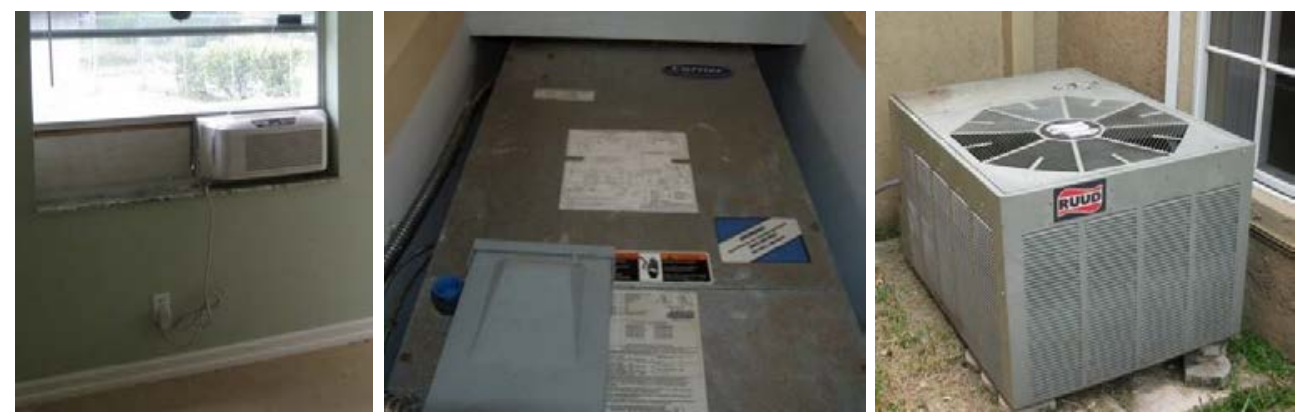

Figure K.29. Retrofit EH-21: Pre-Retrofit Wall Unit (left), Pre-Retrofit Condenser (center), and PreRetrofit Air Handler (right)

Results from the whole-house airtightness test were high (ACH50 of 15.05). The air handler closet was a primary source of leakage. Other sources were the small storage compartment under the stairwell and a pocket door into the upstairs bathroom.

Given the design of the air handler closet, researchers were unable to include the closet in the duct leakage tests. Even with the closet excluded from the test, leakage was high $(\mathrm{Q}$,out $=0.10)$. Given the air movement between the attic and the closet under the house depressurization test, true duct leakage has been underrepresented.

The renovation, completed on October 22, 2011, was limited, but a few combined measures had a big impact on the overall projected energy cost savings. The most significant measures (in order of contribution) were the installation of an electric hybrid water heater with heat pump, almost exclusive use of efficient lighting, reduction in whole-house infiltration, and installation of a forced air, central air conditioner (SEER 14.5) with integral resistance heat. The existing R-19 ceiling insulation was supplemented to achieve R-38. Figures K.30 show the pre- and post-retrofit domestic water heaters. The entire package of improvements, listed in Table K.34, is estimated to produce $\$ 872$ in annual energy cost savings. 

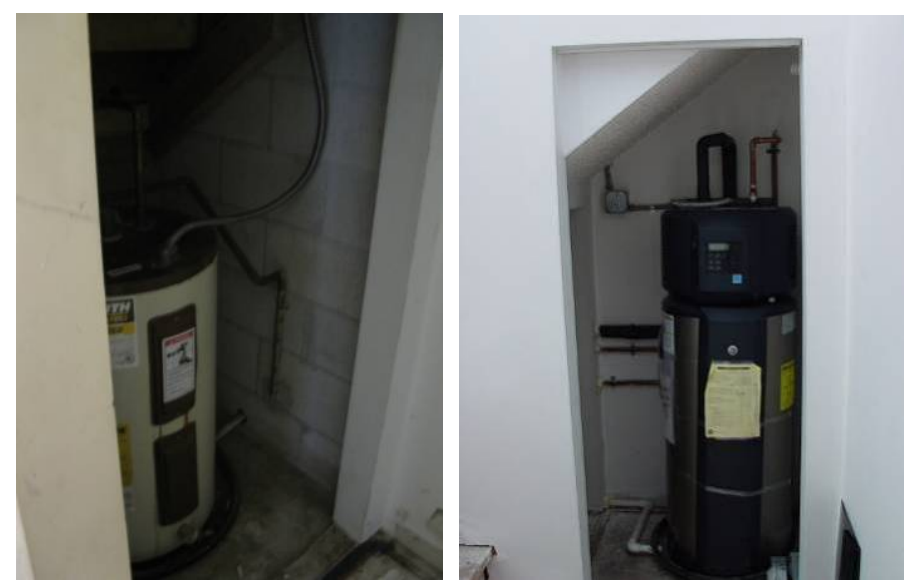

Figure K.30. Retrofit EH-21: Pre-Retrofit Electric Tank Water Heater (left) and Post-Retrofit Electric Hybrid Water Heater with Heat Pump (right)

Table K.34. EH-21 Key Energy Efficiency Measures

\begin{tabular}{ll}
\hline \multicolumn{1}{c}{ Component } & \multicolumn{1}{c}{ Pre- and Post-Retrofit Characteristics } \\
\hline $\begin{array}{l}\text { Ceiling Insulation } \\
\text { Whole-House Infiltration }\end{array}$ & From R-19 to R-38 with blown-in fiberglass \\
Heating and Cooling System & $\begin{array}{l}\text { From ACH50 }=15.05 \text { to ACH50 }=6.15 \\
\text { From SEER 10 with integral electric resistance heat to SEER 14.5 with integral } \\
\text { electric resistance heat }\end{array}$ \\
Air Distribution System & From Qn,out $=0.10$ to Qn,out $=0.065$ \\
Water Heating System & From 30 gal, electric, EF $=0.89$ to 50 gal, electric tank with heat pump, \\
& COP = 2.35 \\
Refrigerator & From default to Energy Guide label of 378 kWh/yr \\
Lighting & From 0 CFLs to 80\% CFLs \\
Controls & From no programmable thermostat to a programmable thermostat \\
\hline
\end{tabular}

The new air handler was installed into the existing, narrow air handler closet, and it proved to be challenging. The mechanical contractor left a hole, roughly 4 x15 in., between the closet ceiling and the attic. After several failed attempts, the partner successfully patched the gap with a piece of drywall and caulk to seal the seams. The confined space did not allow the partner to incorporate outside air ventilation, a detail they have been incorporating into the other retrofits we partnered on. The mechanical distribution system was poorly designed, with a supply trunk running through the platform return, and this was sealed with caulk, rather than mastic. Access to the return plenum was behind airflow-restricting louvered doors, rather than on the same plane as the hallway wall. Figures K.31 show post-retrofit pictures of the air handler closet.

The post-retrofit duct leakage test results were much improved $(\mathrm{Qn}, \mathrm{out}=0.065)$, with room for improvement, nonetheless. Researchers suggested that mastic be used to better seal the seams of the return plenum. The whole-house leakage $(\mathrm{ACH} 50=6.15)$ was drastically improved over the pre-retrofit condition.

During the post-retrofit audit, pressure mapping was performed to test the balance of mechanical system airflow through the house. Researchers created a "worst case" scenario by running the air handler and exhaust fans, in addition to shutting all bedroom doors. Operating under "worst case" conditions, the 
home was depressurized only slightly (-1.6 Pa), and there was excessive positive pressure in one bedroom. The partner installed an above door transfer grille between this bedroom and the main body to allow passive air transfer out of the bedroom. Post-retrofit pressure mapping results are presented in Table K.35.
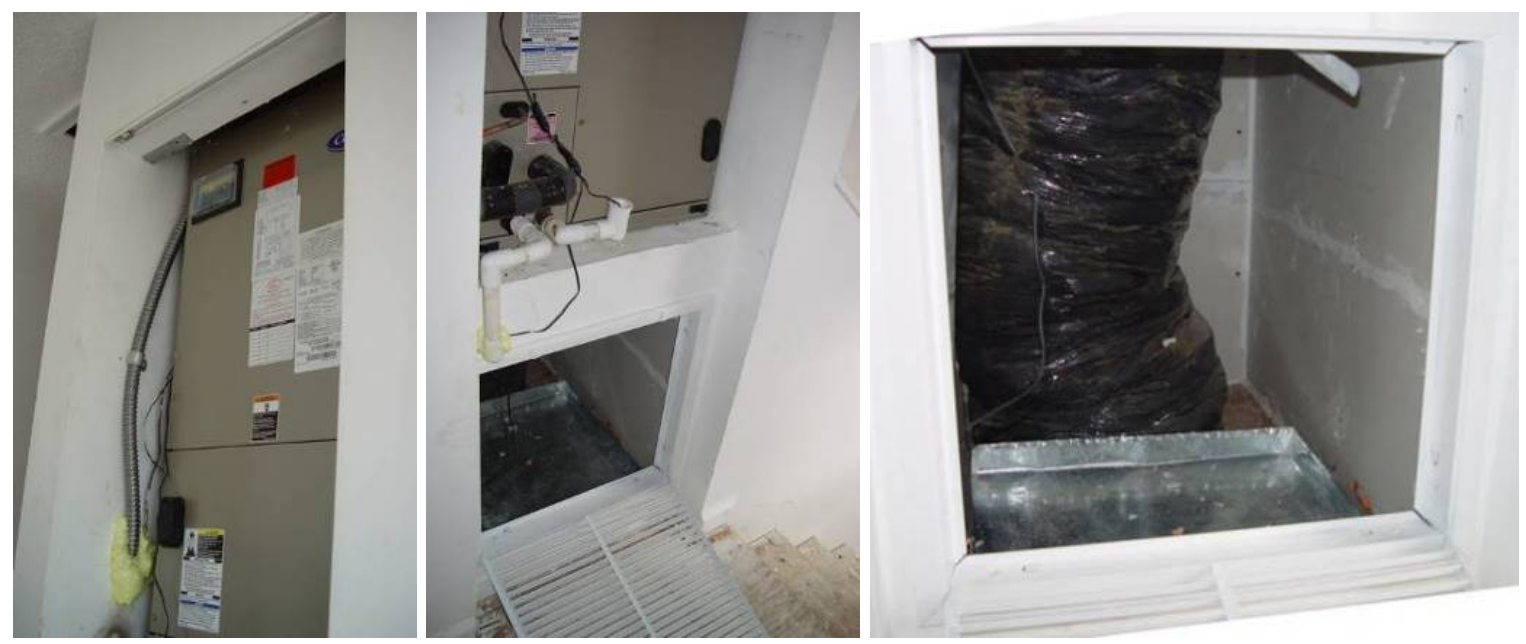

Figure K.31. Retrofit EH-21: Post-Retrofit Air Handler Closet (left), Post-Retrofit Closet (center), and Post-Retrofit Open Return with Airflow-Restricted Louvered Doors (right)

Table K.35. EH-21 Post-Retrofit Pressure Mapping

\begin{tabular}{lc}
\hline \multicolumn{1}{c}{ Location } & Pressure $(\mathrm{Pa})$ \\
\hline House WRT Out & -1.6 \\
Master WRT House & 1.3 \\
Bedroom 2 WRT House & 2.2 \\
Bedroom 3 WRT House & 4.6 \\
\hline
\end{tabular}

In summary, the partner successfully retrofitted this home to accomplish a deep energy retrofit with only a handful of renovation measures. The projected energy cost savings of $39 \%$ was achieved through the installation of an electric hybrid water heater with heat pump, almost exclusive use of efficient lighting, reduction in whole-house infiltration, and installation of a forced air, central air conditioner (SEER 14.5) with integral resistance heat.

There were two issues with this retrofit project:

- The air handler was built into a confined space, and the mechanical contractor failed to patch a large hole leading from mechanical closet ceiling into the attic. Furthermore, a supply trunk running through the return platform and lack of mastic used to seal the plenum seams resulted in some avoidable duct leakage. This lack of quality assurance and central oversight indicated a gap in the retrofit contracting paradigm.

- The design of the closet creates airflow restriction, because the return plenum access is housed behind the louvered doors of the air handler closet.

When the partner provides cost data for the energy-related elements of the renovation, researchers will complete the economic calculations. 



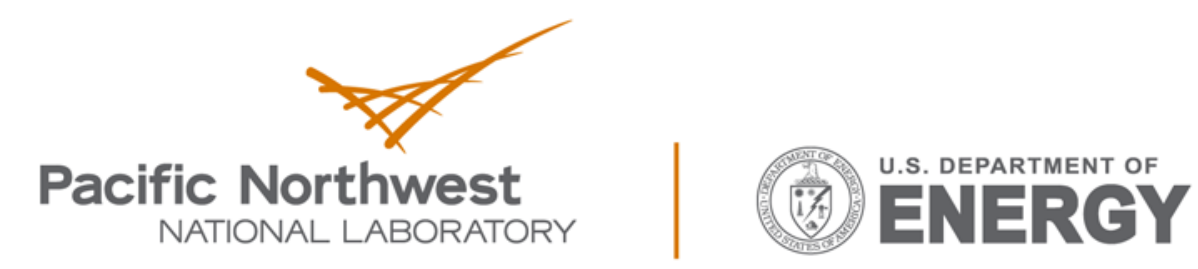

Proudly Operated by Battelle Since 1965

902 Battelle Boulevard

P.O. Box 999

Richland, WA 99352

1-888-375-PNNL (7665)

www.pnnl.gov 